\title{
Humanising Te Papa: Transforming what Te Papa does to the public life of the city
}





\section{Humanising Te Papa:}

\section{Transforming what Te Papa does to the public life of the city}

by

Paige Boyd

A 120-point thesis submitted to the Victoria

University of Wellington in partial fulfilment

of the requirements for the degree of

Master of Landscape Architecture

Victoria University of Wellington

School of Architecture 


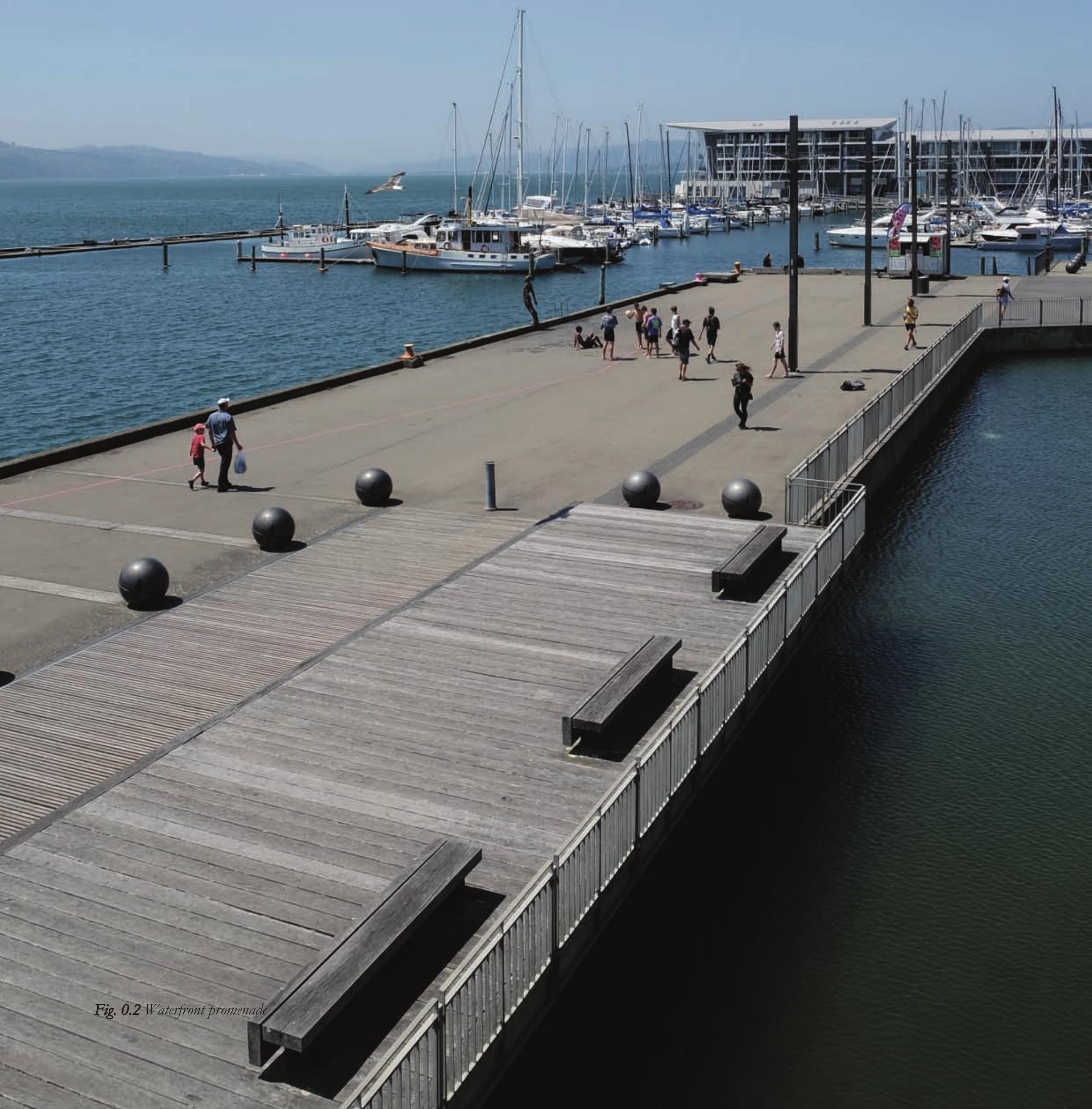


When a large public building is constructed within any landscape it is often found to create adverse affects on the public life surrounding it. This investigation focuses on Te Papa in Wellington, New Zealand. It employs design strategies that emerge from site observation, analysis and exploration of design and behaviour literature. Site observations are undertaken at various scales to determine the behaviours that occur in and around the site, and analysis of this provides an understanding of why such actions can happen and why others cannot. Exploration of the literature is employed to understand past approaches to this design problem and to inform the analysis process. Design testing allows ideas to be played out in hypothetical scenarios and the outcomes of which will be compared to past approaches.

There is a strong focus on pedestrian movement as a catalyst of public life, in relation to the movement itself and the interactions people have with the surrounding environment when influenced by the movement flow. The overall goal of this thesis is to observe and analyse a large building in the public realm that, although is surrounded by movement, limits engagement in ways that results in a decrease of public life. The research leads to the exploration of how flows can be coordinated to generate eddies of interaction and pause and ways to activate and open up particular edges of this building in order to create new opportunities for the public to engage with the landscape. It finally attempts to find ways to not only create new public life, but also intensify the public life in this challenging situation. 


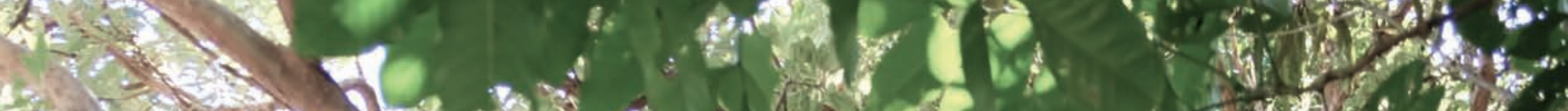

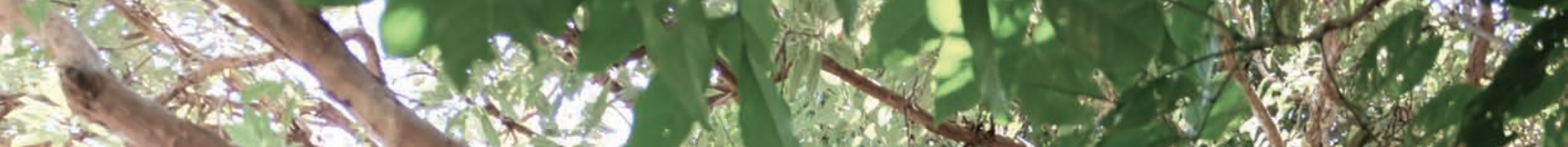

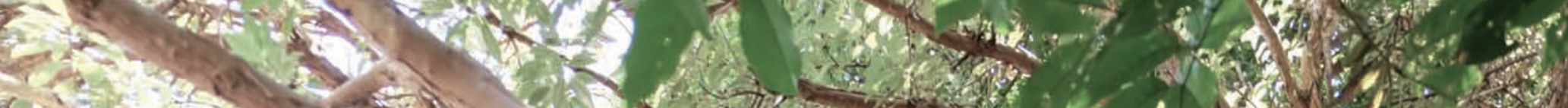

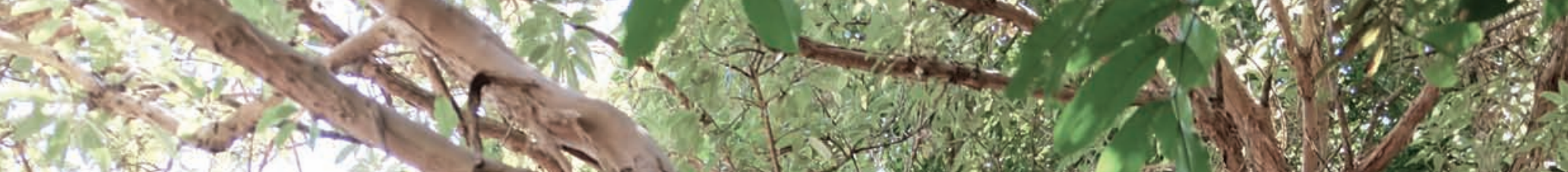

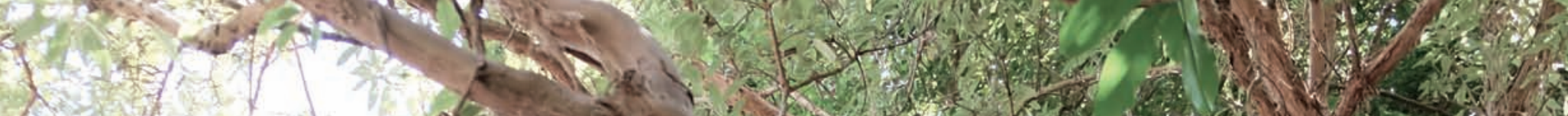

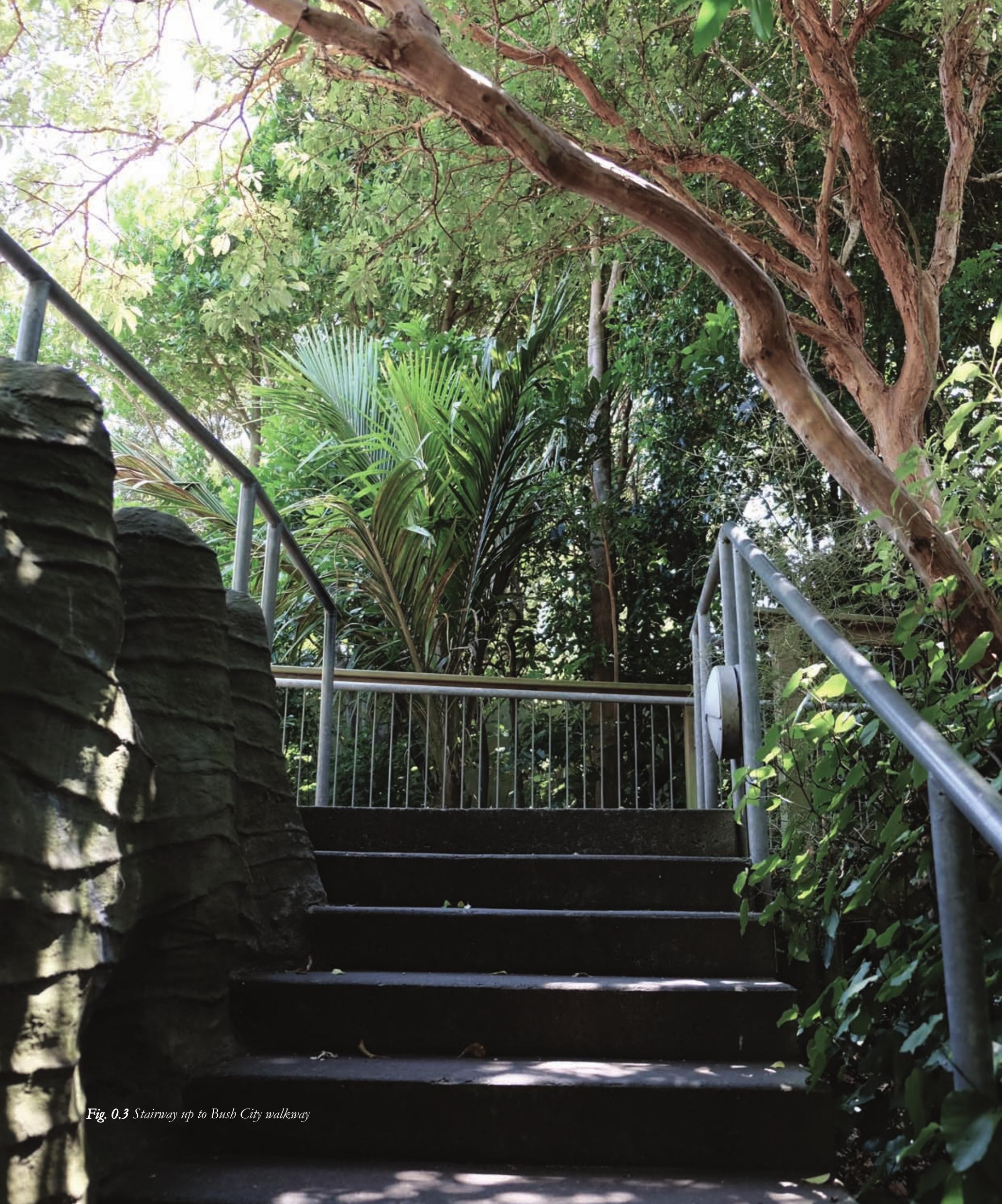




\section{ACKNOWLEDGEMENTS}

Thank you to all those that helped me along the way throughout all my years of study, this has certainly been an adventure.

To my supervisor, Peter Connolly, thank you for helping to define my research and reminding me of the value of my work.

To Positeamitority, thank you for keeping me sane during the long hours, mild freak-outs, and frequent deadlines.

To my family, for all the support you have given me in all shapes and sizes. You have been my rock through all the struggles that came with studying and moving to a new city, and I immensely appreciate all the encouragement you have given me. You helped me to get where I am today, so thank you to the moon and back.

To Jojo, you came in as the workload got tougher and the hours got longer but your endless support and encouragement is something I treasure. Thank you for enduring the various moods that came with the progress of this research. There were times where I would have struggled without you, so thank you for believing in me. 


\section{Abstract}

Chapter 1: Site Analysis

Initial Observation

Waterfront Movement

Relationships

Public Life

Limitations

Te Papa: Physical

Building Affects

Chapter Conclusion

Chapter 2: Background _... 57

Site History

City Goals

Waterfront Development

Te Papa Concepts

Te Papa Development

Aspirations \& Criticism

Chapter Conclusion

Chapter 3: Literature Review $\quad 75$

Life Between Buildings .....__ 77

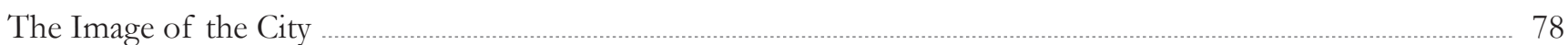

Inside Outside ...

Chapter Conclusion $\ldots+\cdots-1-20$

Chapter 4: Design Direction _._____ 83

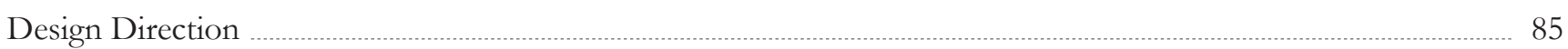

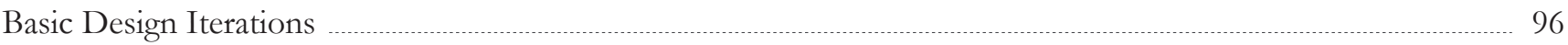

Design through Section $\ldots$

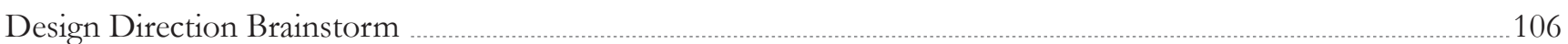

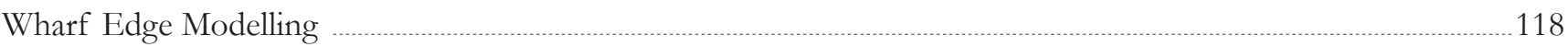

Photograph Iterations _.___._. 120

Chapter Conclusion _... _ _ _ _ 126 
Initial Concept

Relationships $\ldots-134$

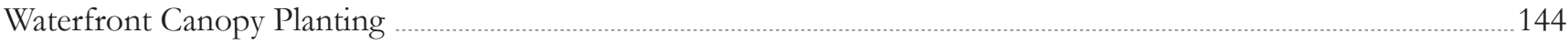

Art Gallery _.__ 158

Shops …

Garden Wall _.._. 162

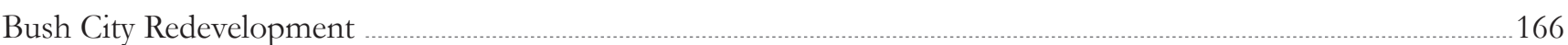

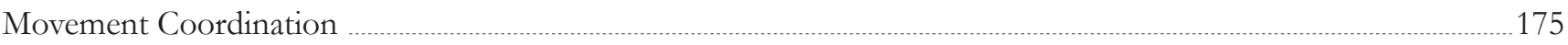

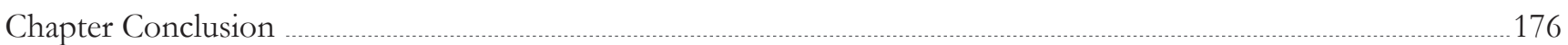

Chapter 6: Design Development

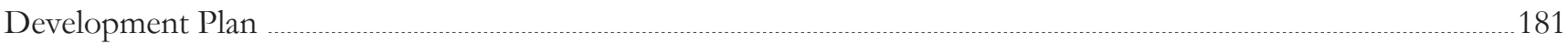

Urban Forest Canopy …__ — _

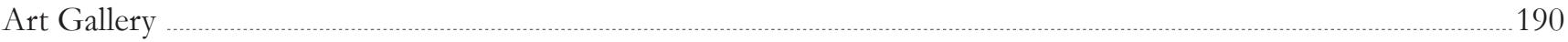

Shops $\ldots$

Bush City _.

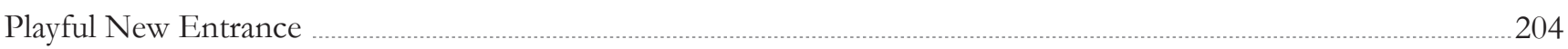

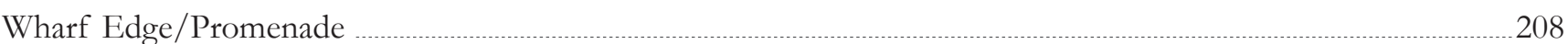

Seating Tests $\ldots \ldots$

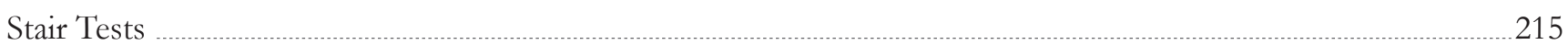

Materiality _... _......

Chapter Conclusion

Chapter 7: Final Design ... 223

Final _.......

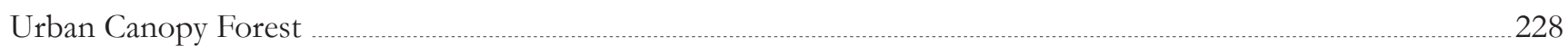

Art Gallery _._ _ - 239

Shops $\quad 2$

Sunlit Bush Enclave _........

Playful Entrance

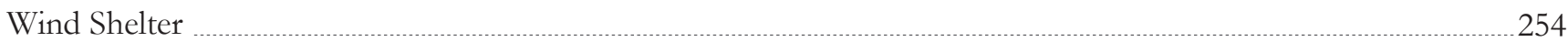

Wharf Edge

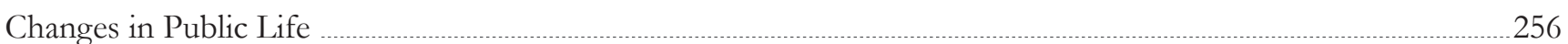

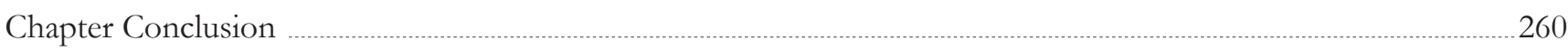

Chapter 8: Conclusion _._. 263

Bibliography ... _ _ . 270

List of Figures 


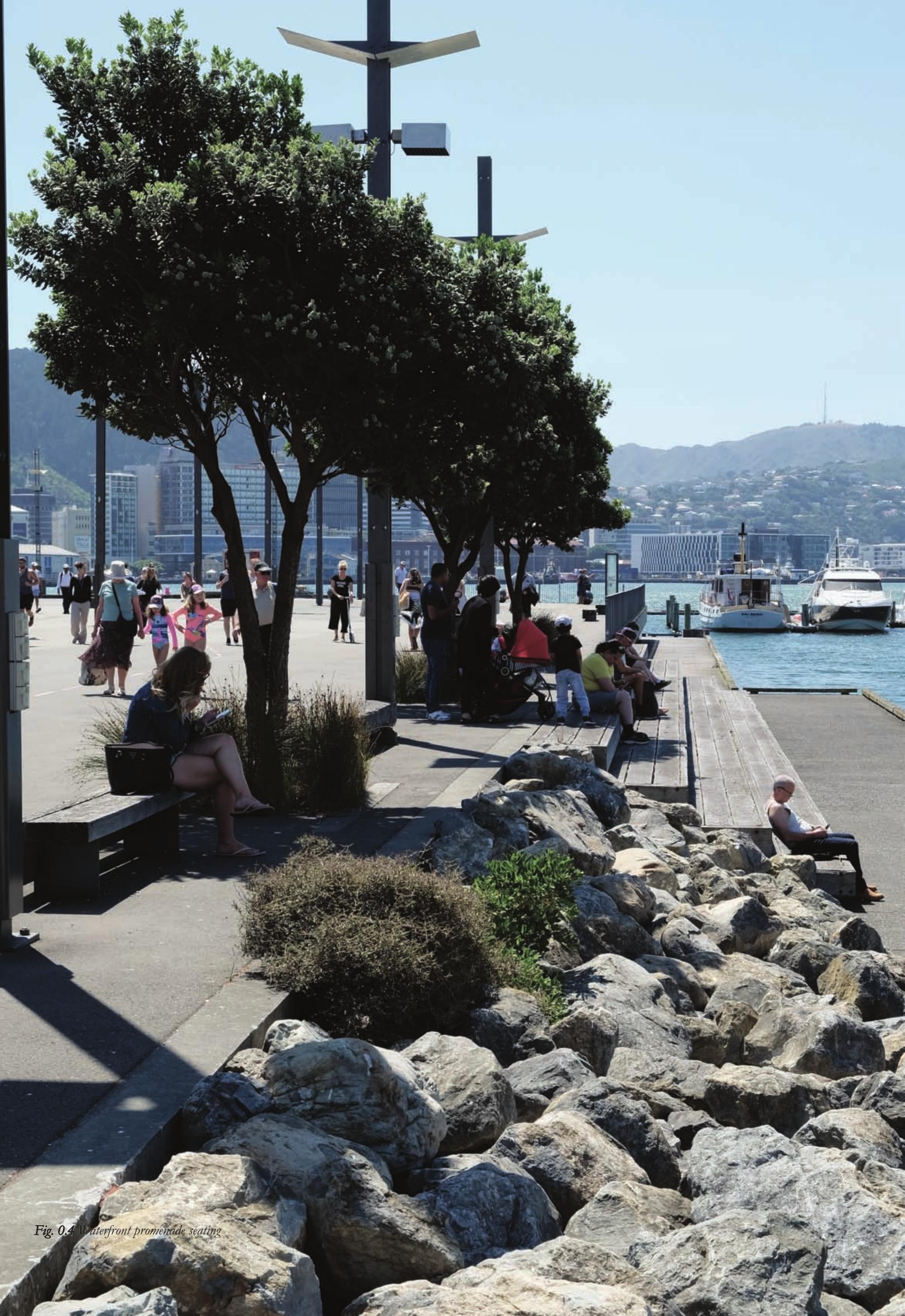


Wellington is a vibrant place and compact city, bordered on the south, west and east by hilly terrain and on the north by the harbour, creating the need to always redevelop what exists within the city in order to keep up with the changes that come with a growing city. Wellington's waterfront is a large public realm where pedestrian movement takes priority and all buildings constructed within this zone should benefit the public life of the space.

Te Papa is one of the most popular buildings in Wellington, bringing in crowds of over 1.5 million people a year (Museum of New Zealand Te Papa Tongarewa, 2017). Te Papa has just celebrated its 20th year since opening. During these two decades, the interior layout and exhibitions have continually changed to intensify its functioning. However, the façade of the building and spaces around Te Papa have not been updated since construction finished, despite the initial issues that arose with how it responded to the city, the waterfront, and the potential public life that a building this size could create. There is an active waterfront promenade to the north and east of Te Papa. The relatively large areas between this promenade and the building tend to have very little public use. The entrance area provides efficient access in and out of the building. The remaining areas around the building are dominated by carparking and deter public life.

There is very limited public interaction with the building apart from the entrance area. This design-led research explores the ways in which the landscape can be designed in order to create a series of new public spaces that allow people to occupy the waterfront in ways that are not currently available. 


\section{Research Question, Aims and Objectives}

This research takes a site-specific approach to understand in a broader sense what landscape architectural design can do to reconstruct spaces that are negatively affected by buildings. The following research question defines to research direction:

\section{How can landscape architecture counter the negative affects a large building has on public life?}

The aim of this research is to:

- Discover ways that landscape architecture can activate building edges and areas around large buildings

- Employ various approaches to invite people to linger and gather in new and existing public spaces

To do this the research has the following objectives:

- Understand how specific movements facilitate public life and how to work with this

- Recognise and understand how a building can both produce and disrupt public life and the city depending on its design and placement in the landscape

- Identify the relevant forms of local public life and what specific environmental factors provide these

- Discover ways to change people's relationship with a large building

- Determine how a space can be designed to create numerous opportunities to generate public life

\section{Design Methods and Process}

Initial site observations were undertaken to understand the ways in which public life existed in such a popular location such as the waterfront, with close attention paid to how people moved around the space. On-site analysis is vital for gaining insight into how the waterfront and Te Papa gets people to tend to do certain things and not do others. Intensive movement mapping led to the discovery of how much the building of Te Papa affects the potential of the public spaces around it, and the lack of engagement with these spaces, which then informed the direction of this research.

Once the focus of the research was determined, an exploration into the literature from key authors was undertaken to learn about how past designers are relevant to this problem which will allow this research investigation to be positioned within the landscape discipline. The key authors analysed for this research are:

- Jan Gehl, for his research on human behaviour in cities

- Kevin Lynch, for his research on how the perception people have of the city affect how they use the space

- Anita Berrizbeitia, for her research on the relationship that exists between spaces and the importance that should be given to the threshold

Precedent studies are also approached in order to learn how designers have engaged with this problem to gain inspiration to design a space that incorporates the relevant discoveries. The design testing phase use a variety of scales because of the range of affects (involuntary actions; what it tends to get people to do) the building creates for the public life. These different analyses open up different ways to perceive the public functioning associated with this building - from its role in the wider city to interactions between individuals and others and objects. 


\section{Focus of Research}

This research aims to gain understanding of how public occupies the areas around this building, and how to work with this understanding to create new opportunities for public life. It aims to explore how new and existing buildings can have a relationship with its surrounding landscape, and how they can be designed together to enhance the experience created in each. This research will produce a final design that is a representation of the design strategies explored in the thesis.

We live in a world where the landscape is often secondary to the building. This almost guarantees the existence of public spaces that suffer from lack of public engagement that comes from many large buildings. This design-led research focuses on one site and the context that it sits within. Like with much of landscape architecture, there are certain types of public life and interaction that happen in only due to its location, culture, surrounding context, etc., making this research singular to Te Papa.

\section{Thesis Structure}

1. Site Analysis (Observation)

2. Site Analysis (Background Research)

3. Literature Review

4. Determination of Design Direction - Precedents, Iterative Design Testing, Exploration through Sketching

5. Preliminary Design/Initial Concept - Variety of Design Testing, Research

6. Developed Design - Variety of Design Testing

7. Final Design - Exploration of Potential Engagement and Occupancy 


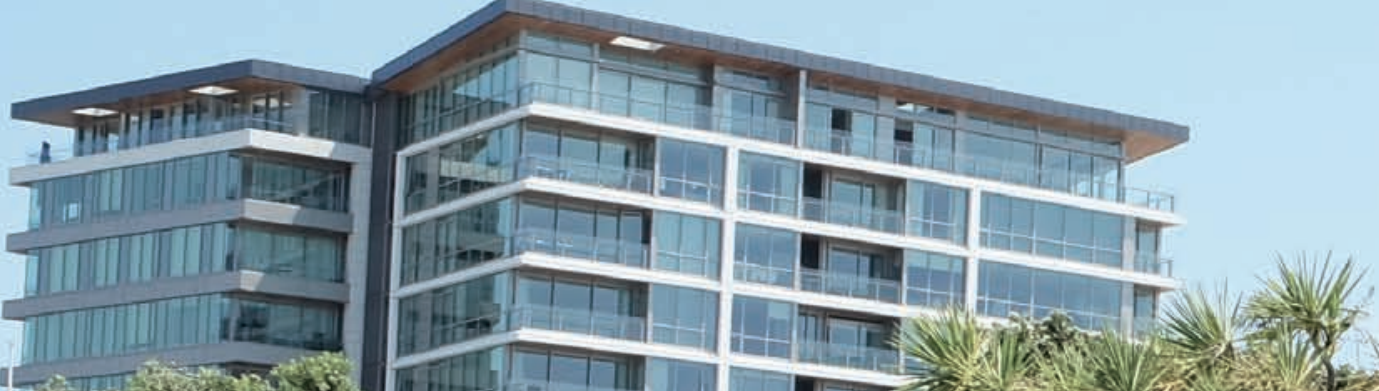

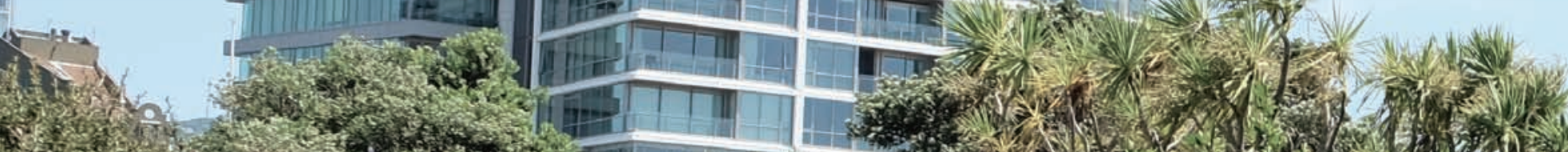
Now

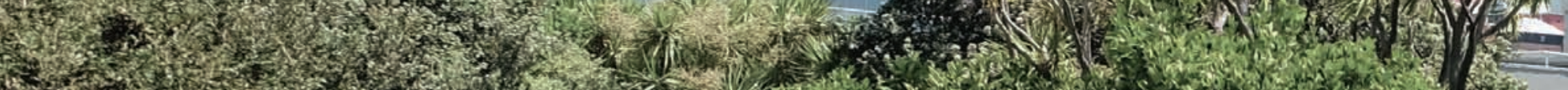

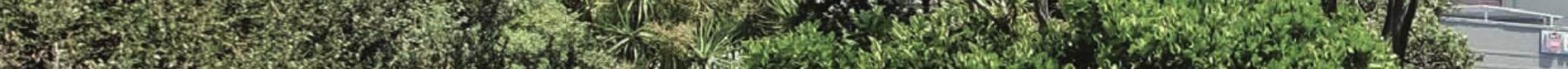

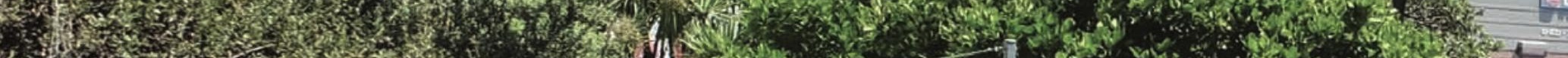

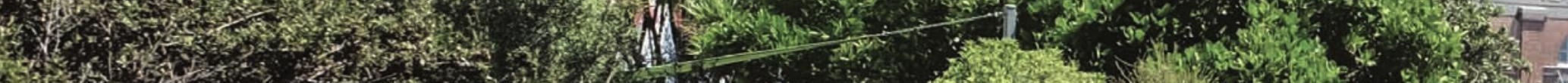

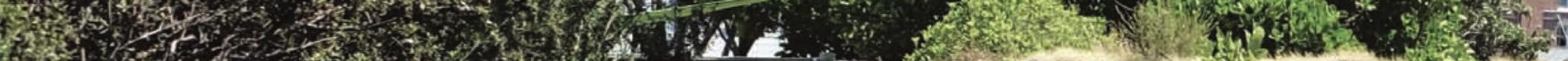

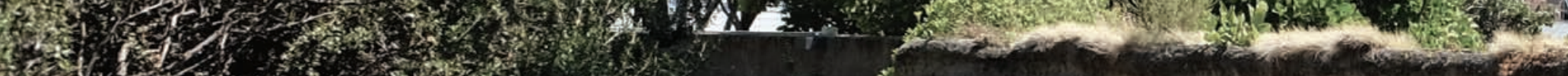
2.5.

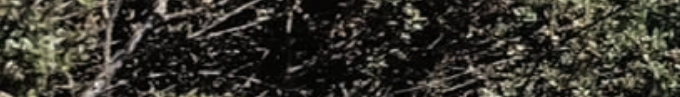

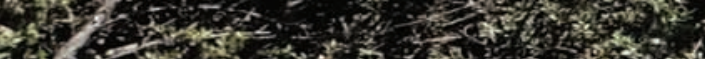

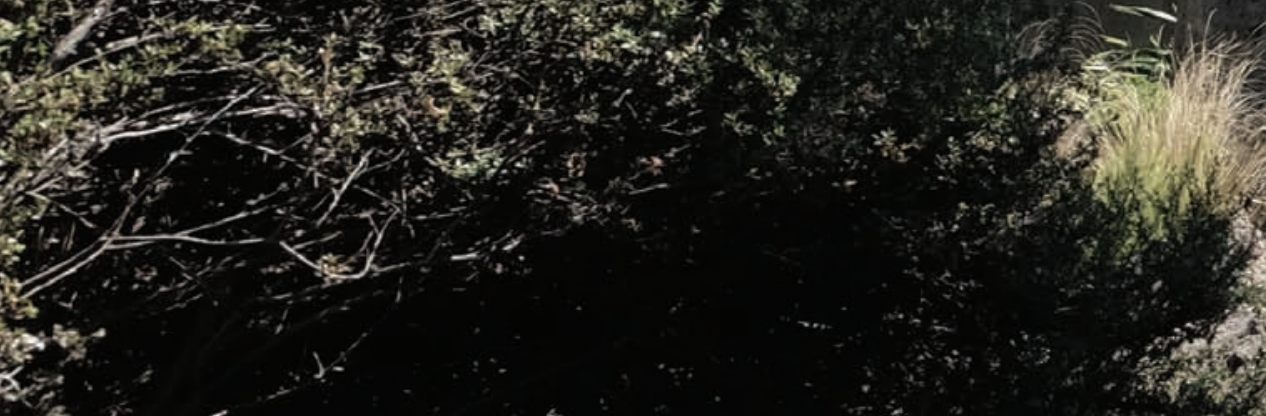

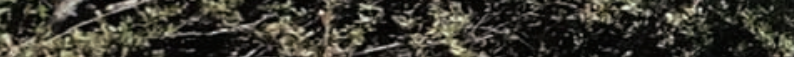

t.

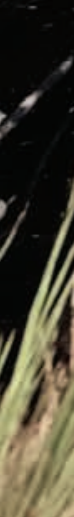

\section{is.}

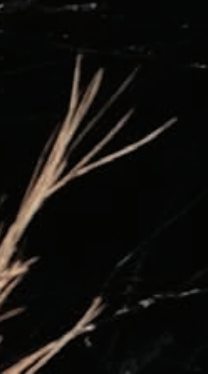






\section{INITIAL OBSERVATION}

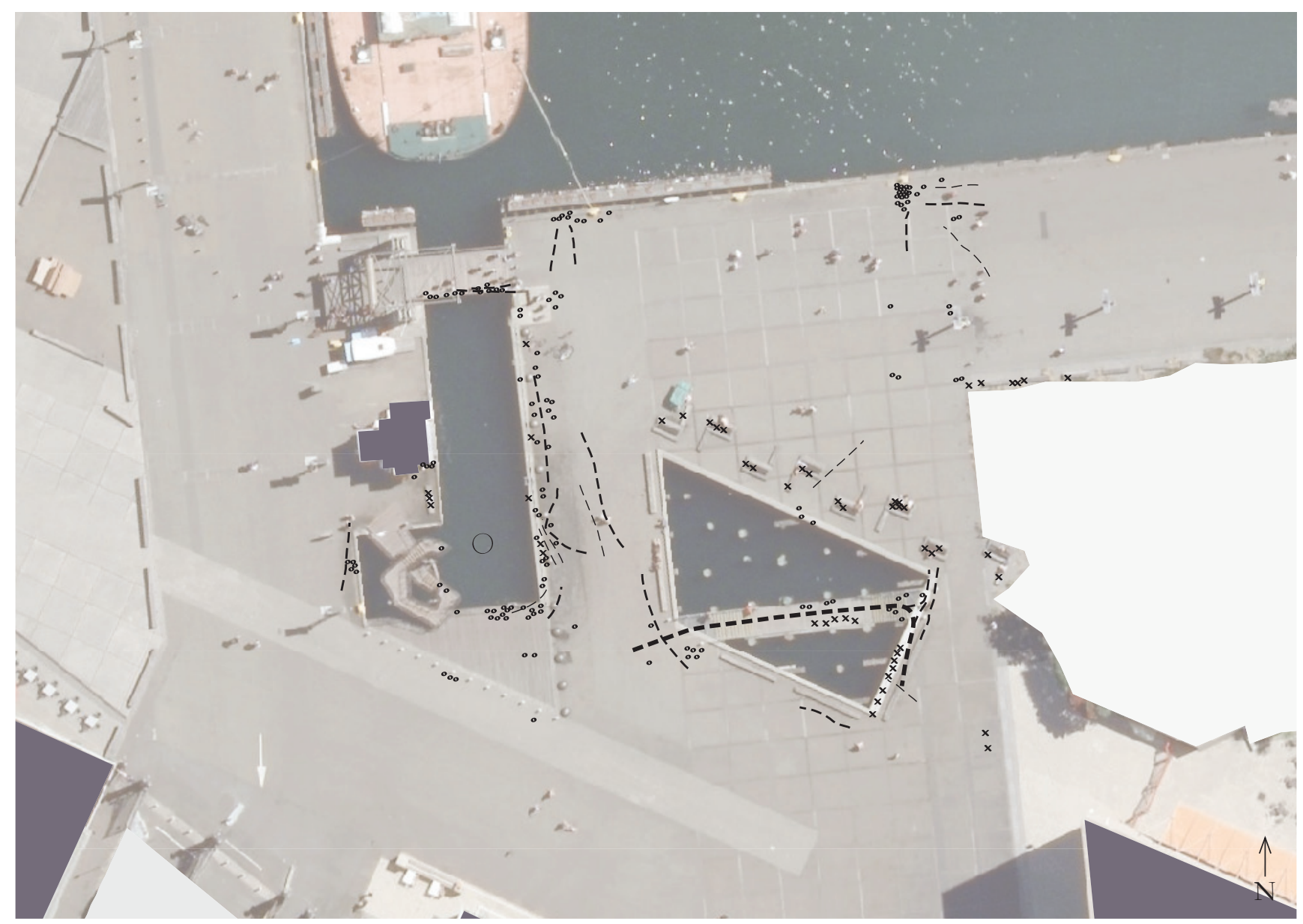

Fig. 1.1 Mapping of lingering that occurred during a 30 minute lunchtime

\section{Key: $\quad$ × Temporary Lingering \\ - Long-lasting Lingering \\ - - Temporary Distraction while Walking}

This design-led research begins with an initial observation of a popular waterfront location near Te Papa, the purpose of which is to observe the tendencies people have when they interact with the physical environment, and social activities that exist within this waterfront location. This study is a small representation of where people linger during a sunny lunchtime period, the result of which is to see what repetitive interactions occur and which were the most significant. 


\section{WATERFRONT MOVEMENT}

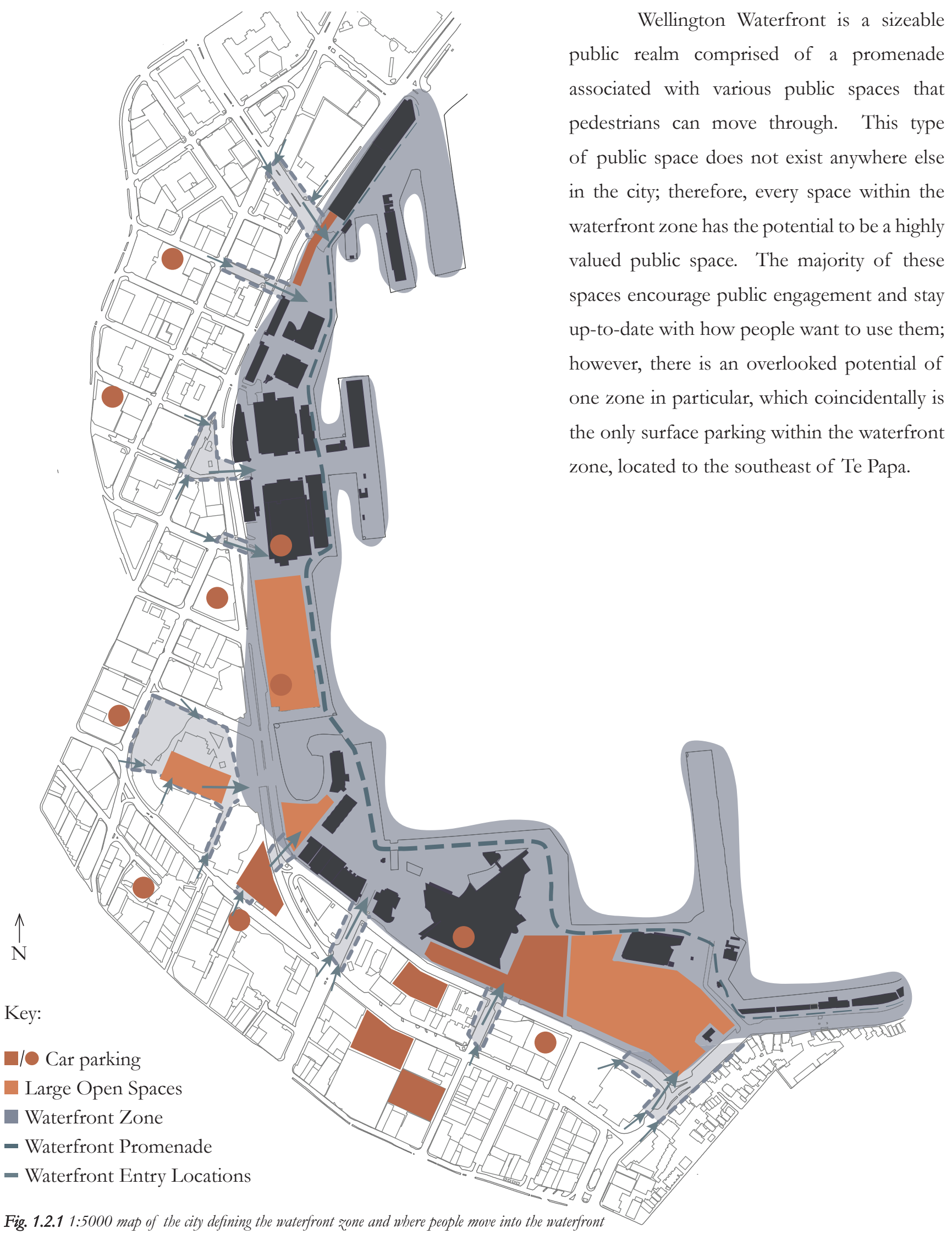


Although the waterfront zone allows people to move freely within it, a busy road hinders the transition between the city and waterfront. The photographs below demonstrate the attention, or lack of, given to the threshold at each area that people can move into the waterfront. The northern end of the waterfront has undergone development over the past several years and have incorporated a small zone to act as a threshold to differentiate and celebrate that entrance. Most of the $2 \mathrm{~km}$ of road which acts as the transition between the rest of the city and the waterfront discourages this transition or makes it very abrupt.
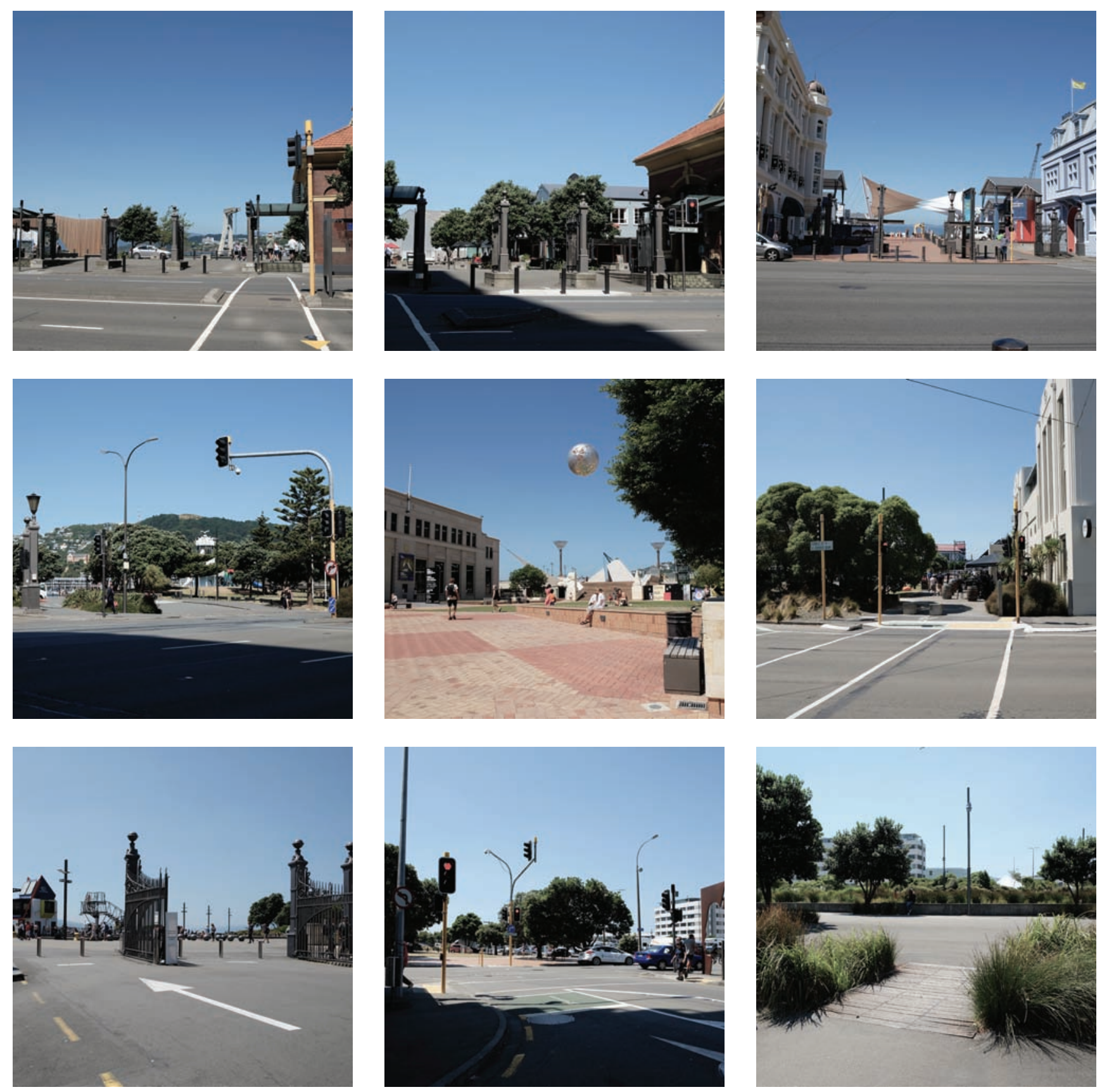

Fig. 1.2.2 A series of images capturing the nine different places people move through into the waterfront (north through to south) 


\section{Who is Moving Through the Waterfront?}

One thing of interest is that the Te Papa area is at the centre of most movement in and around the waterfront and perhaps it is the junctions and the flows within them that cause most activity to happen in this location.

This section of research is about the 'vectors' of this area of the waterfront. It does not assume that all visitors are the same. A vector is a particular orientation or motivation that comes with each visitor. It is associated with where in each flow they have come from, what they may want from the site and where they are going. Separating the various movements with an understanding of where people may have come from and where they may be going allows an investigation of what type of user may take this route. This research of general movement will be the basis of further research into how the site influences activity.

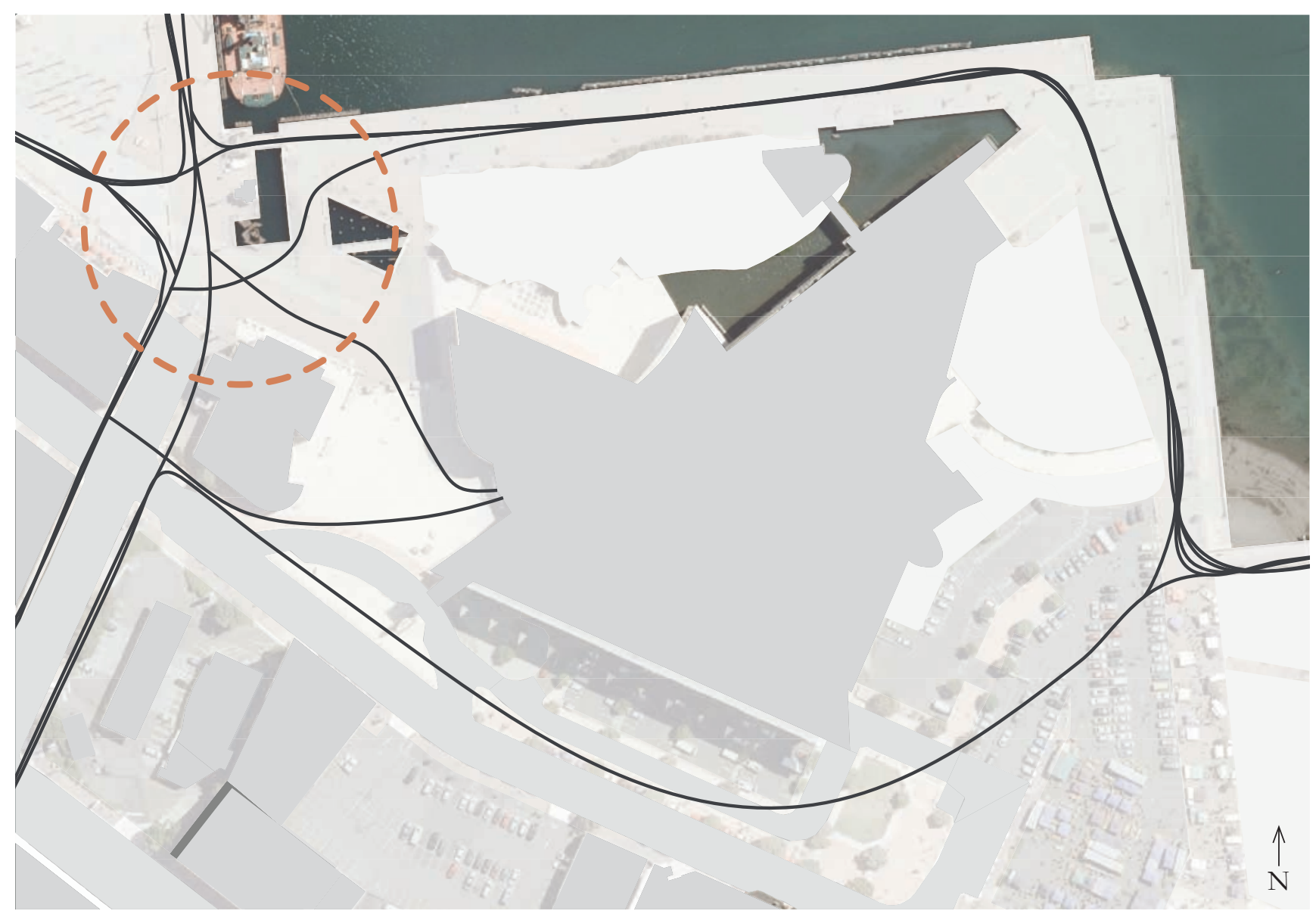

Fig. 1.2.3 Generalised movements around this area of the waterfront create many junctions in one location, as demonstrated in this 1:2000 map of the site

Fig. 1.2.4 (opposite) The generalised movements are separated depending on where they entered the site from, these four 1:4000 mappings give an idea of who is moving through the site and where their decision points are 


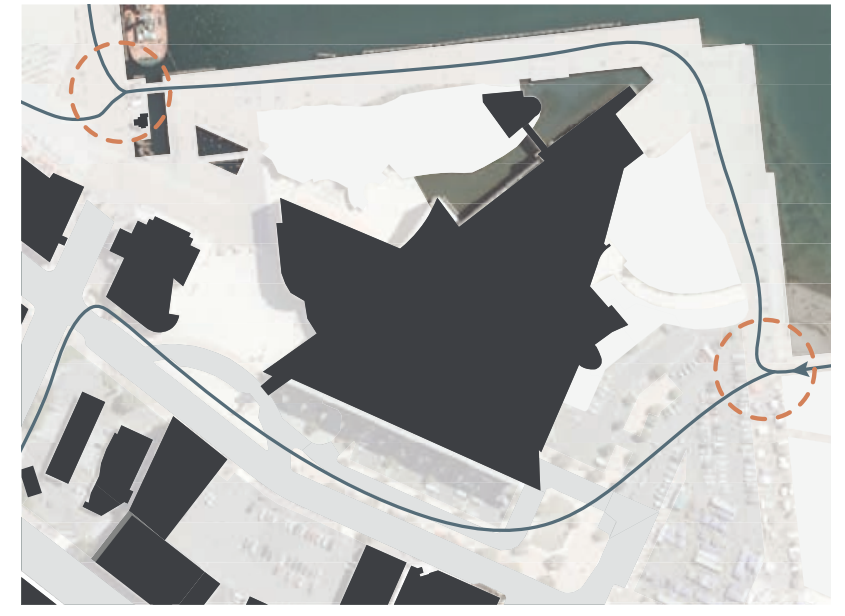

- Runners

- Cyclists

- Workers

- Locals

- Swimmers

- Casual Walkers

- Beach Goers

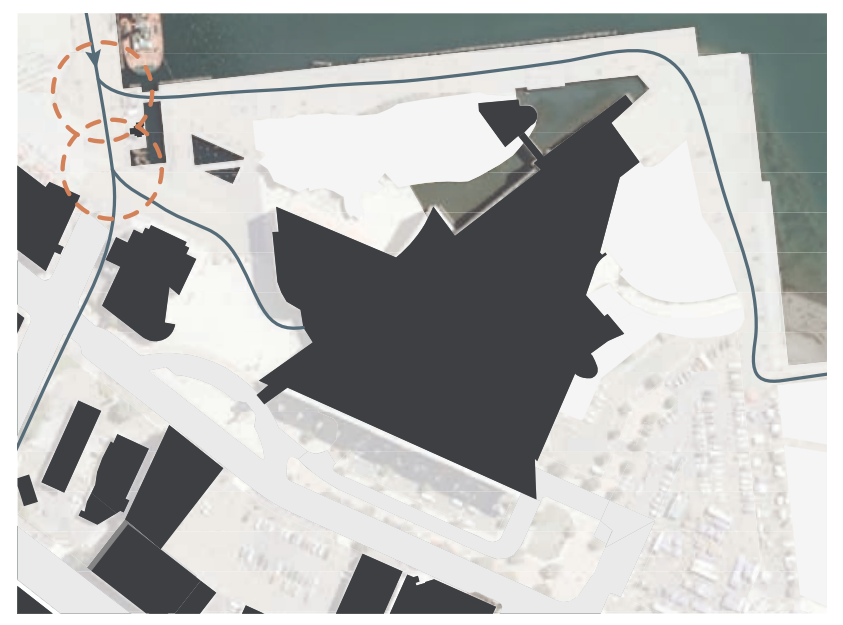

- Runners

- Cyclists

- Explorers

- Tourists

- Workers

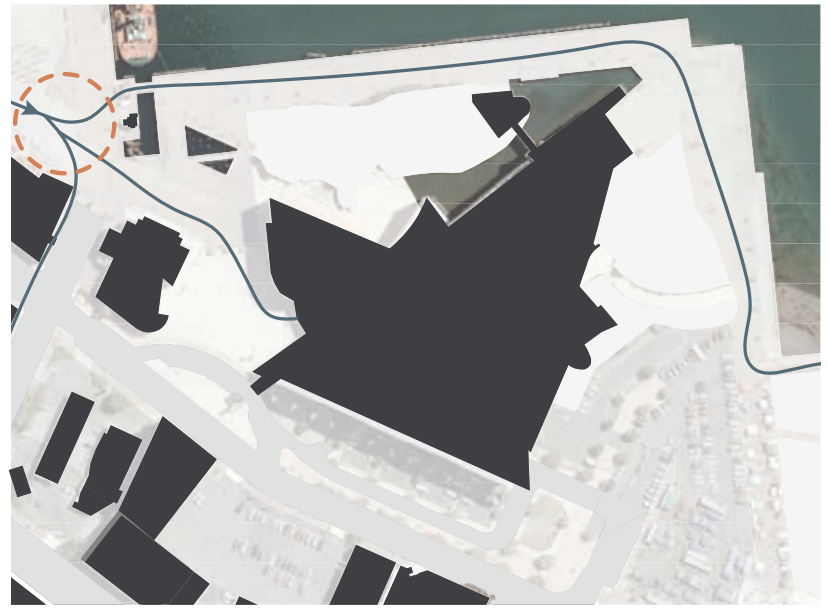

- Walkers

- Runners

- Explorers

- Tourists

- Visitors

- Short cutters

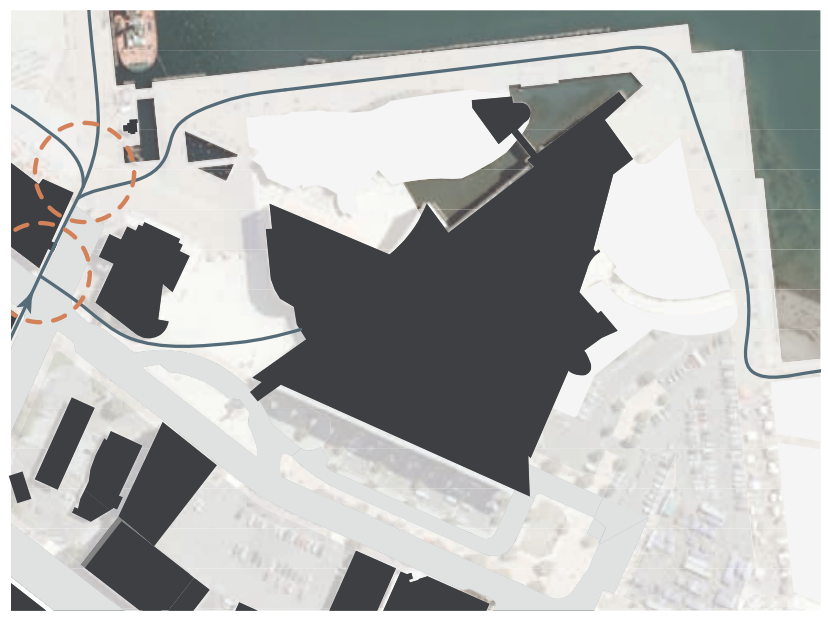

- Workers

- Short cutters

- Tourists

- Explorers

- Train Station Travellers

- Walkers 

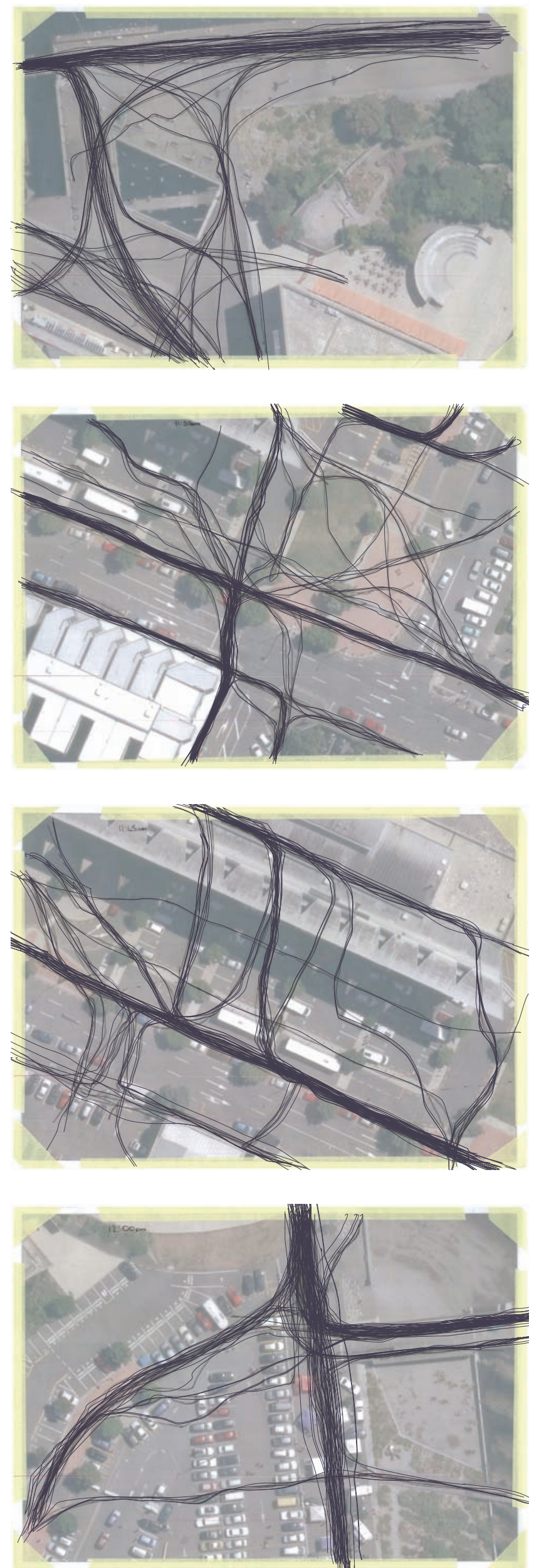
A precise observational study is required to understand specific paths taken and what configurations of space and factors influence people's movements. This observation consists of tracing individual movements for 20 minutes in several locations mapping the main routes, secondary routes and several outlier routes. This section of research enabled depiction of the further movement tendencies around the site. Understanding what these are and what influences them will inform ways to influence these movements. 



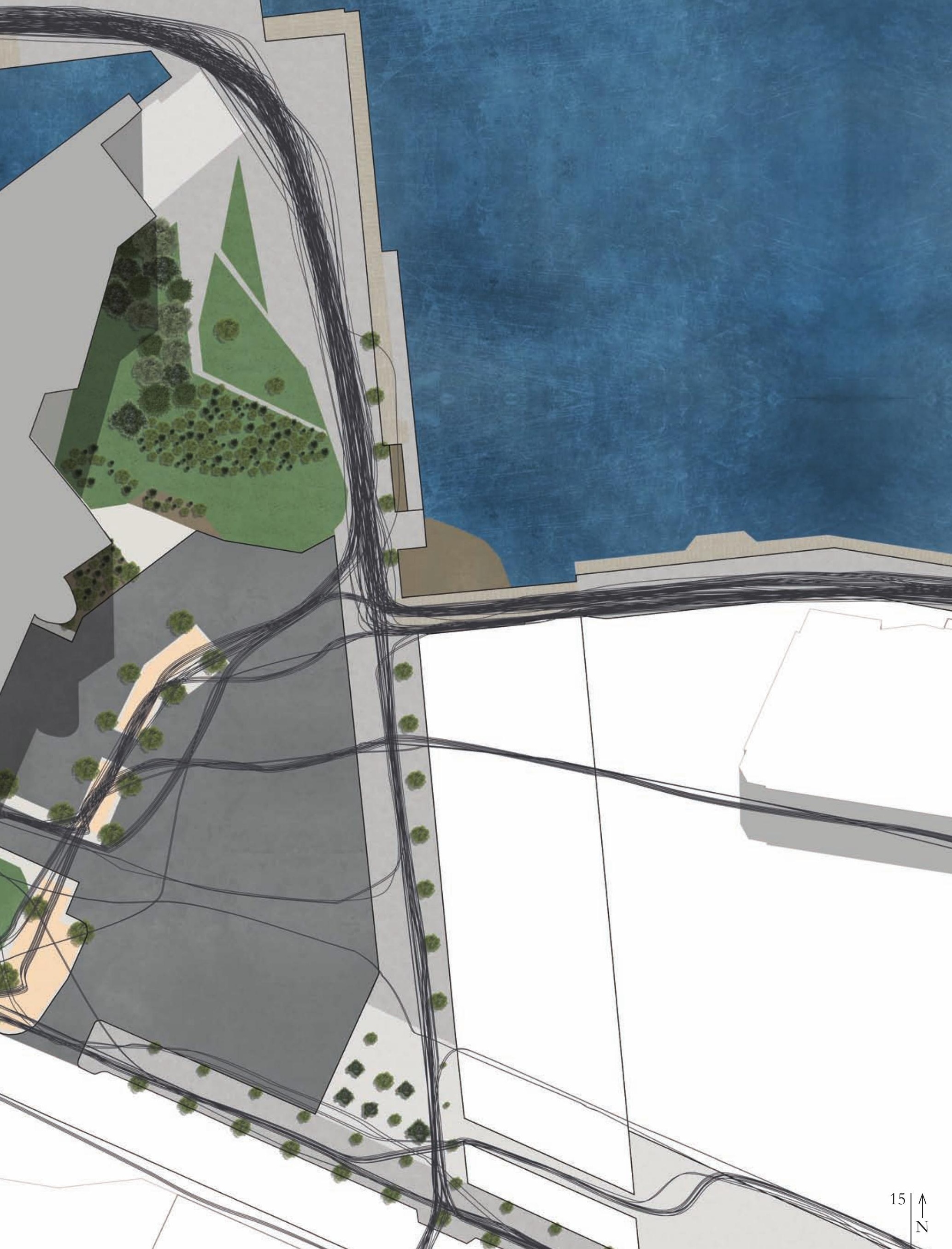




\section{Movement Categorization: Promenade/Taranaki Wharf}

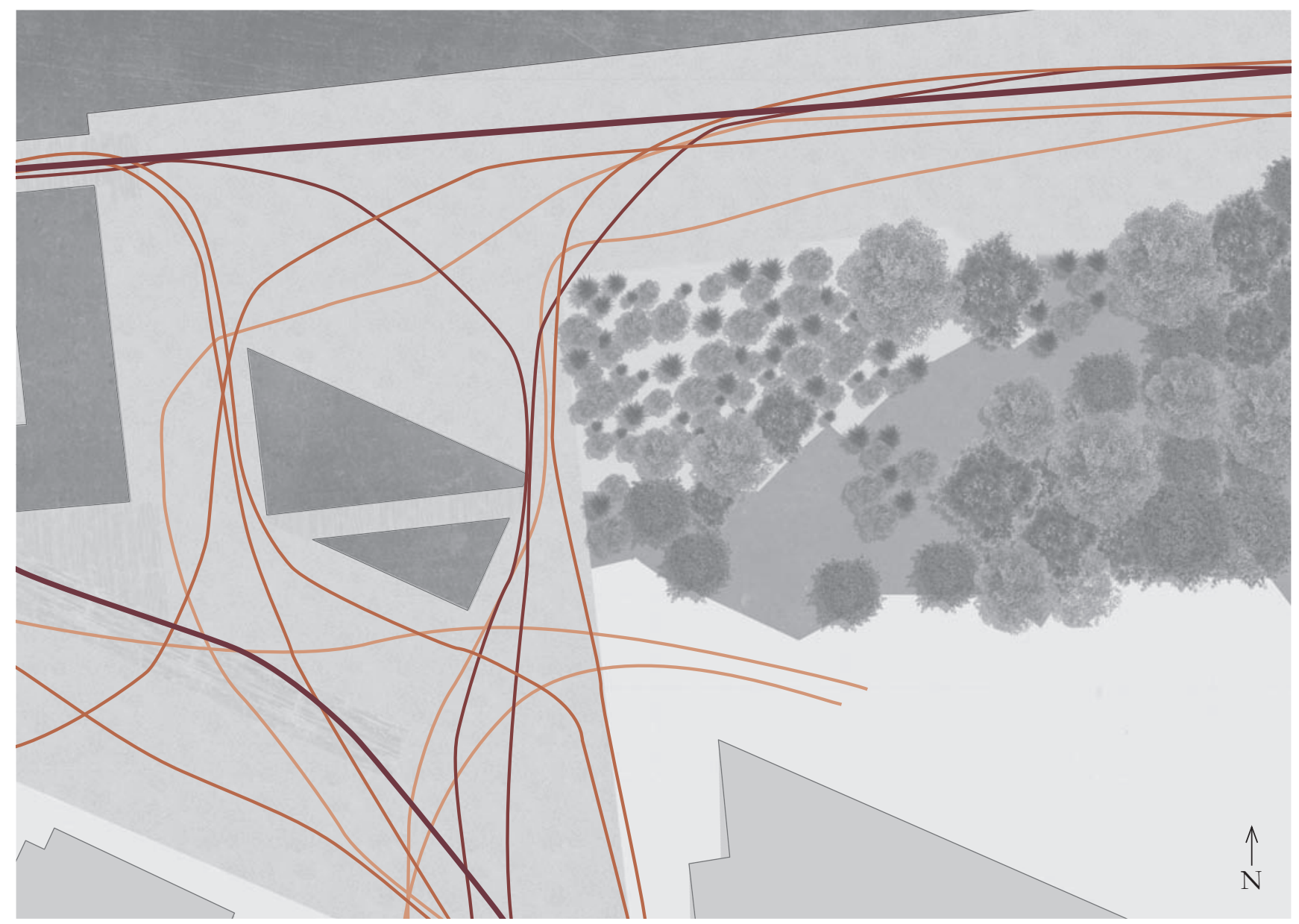

Fig. 1.3.3 Defining the separate movements within intensive mapping 1:600

Dominant

These people are involved in one of two things, the first is visiting Te Papa and the second is utilising the promenade for exercise, leisurely walking, or exploration.

Common

This is made up of people moving from Te Papa to the promenade, or vice versa.

Secondary

These people have the same reasons as the common movement but take a slightly different, more confined movement, perhaps to avoid the crowded areas.

Irregular

People on this movement are visiting the outside bar near Te Papa or wandering around being intrigued with the waterfront, and are quite likely visitors to the city. 

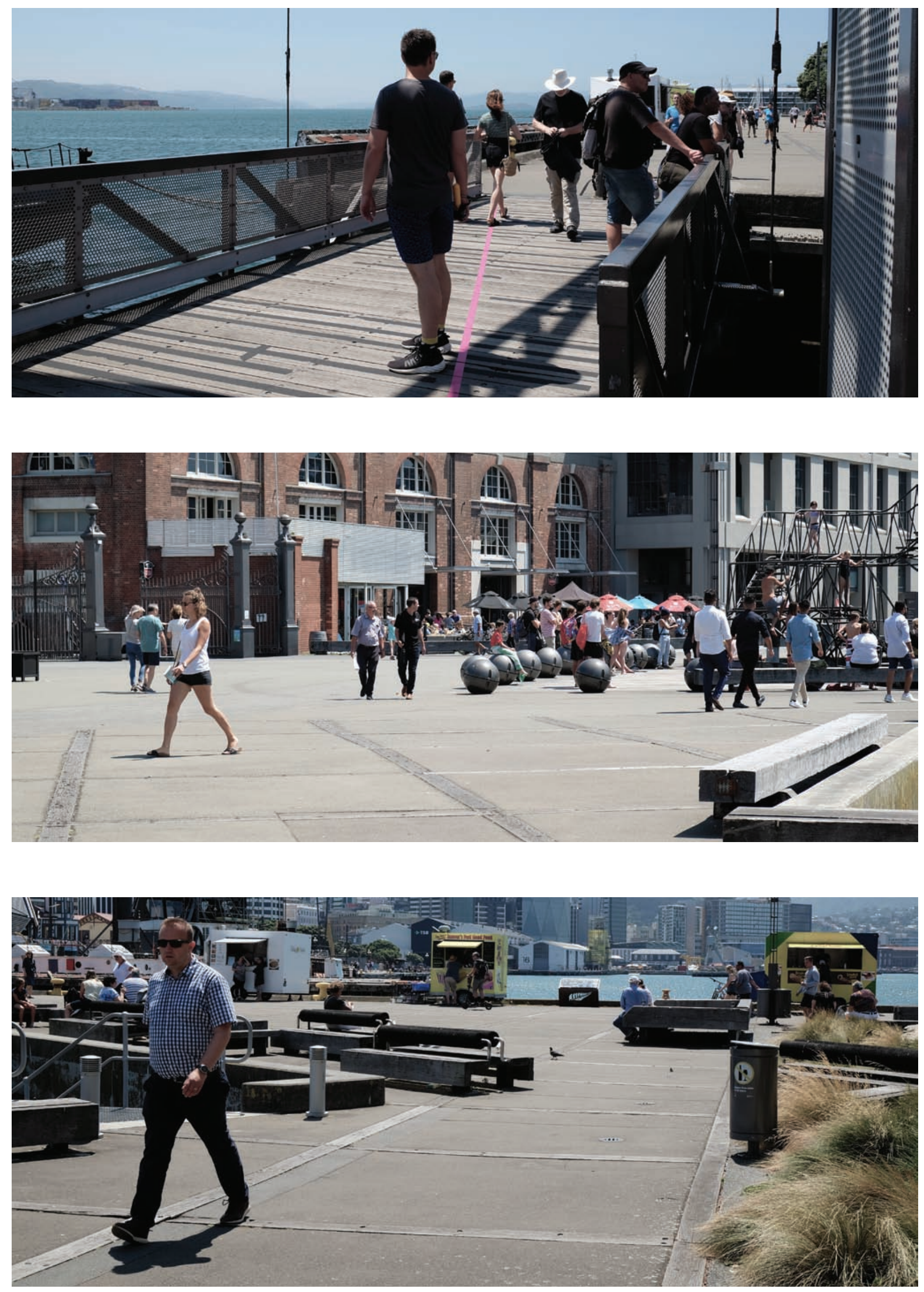

Fig. 1.3.4 Photos taken of movement through the Promenade/Taranaki Wharf site 


\section{Movement Categorization: Tory Street}

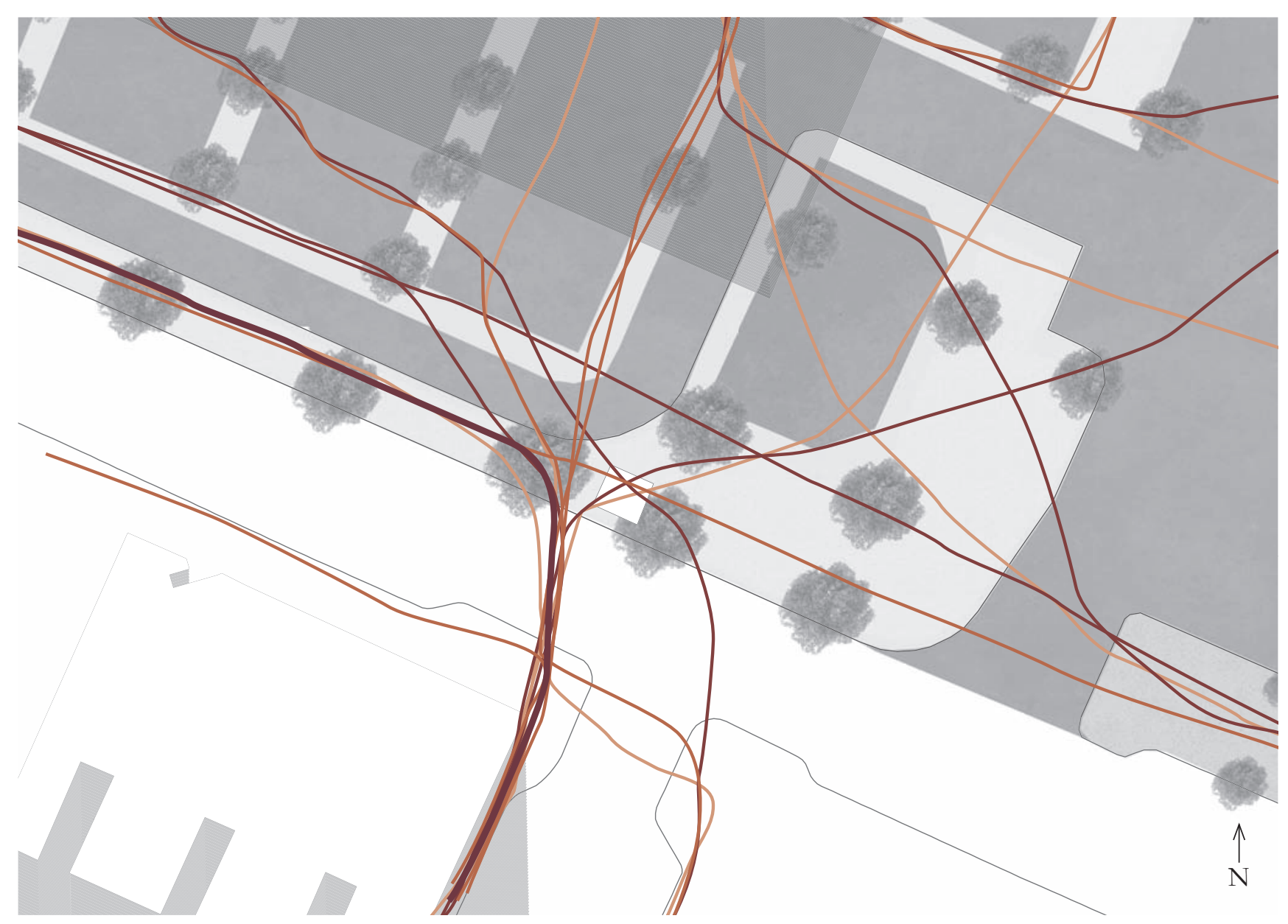

Fig. 1.3.5 Defining the separate movements within intensive mapping 1:600

Dominant

The majority of people choose not to enter the carpark site and instead walk alongside parked cars on a small footpath.

Common

These people also walk along the footpath or through the carpark towards Te Papa's entrance; there is no clear or direct route to Te Papa from here, so there are several ways people chose to get there.

Secondary

These people use the secondary footpath within the site, and journey through the carpark to get to their destinations, these people are more familiar with the area and are comfortable taking the most direct route to get to their destination.

Irregular

These people are still heading to similar places as the other movements, they have just chosen to do it in different ways, or perhaps they are going to a popular location but have come from an isolated area of the city. 

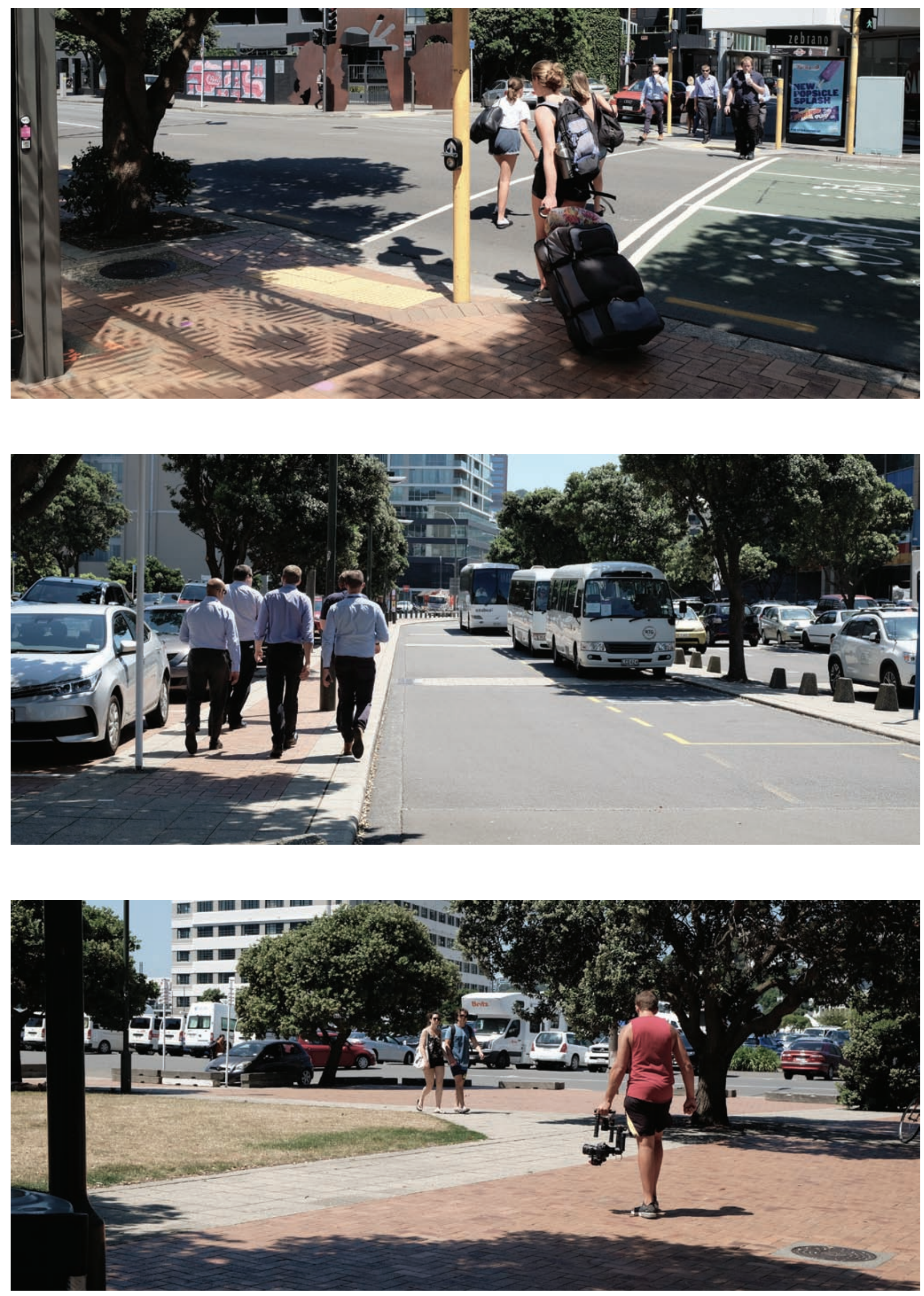

Fig. 1.3.6 Photos taken of movement through the Tory Street site 


\section{Movement Categorization: Te Papa Carpark (Cable Street)}

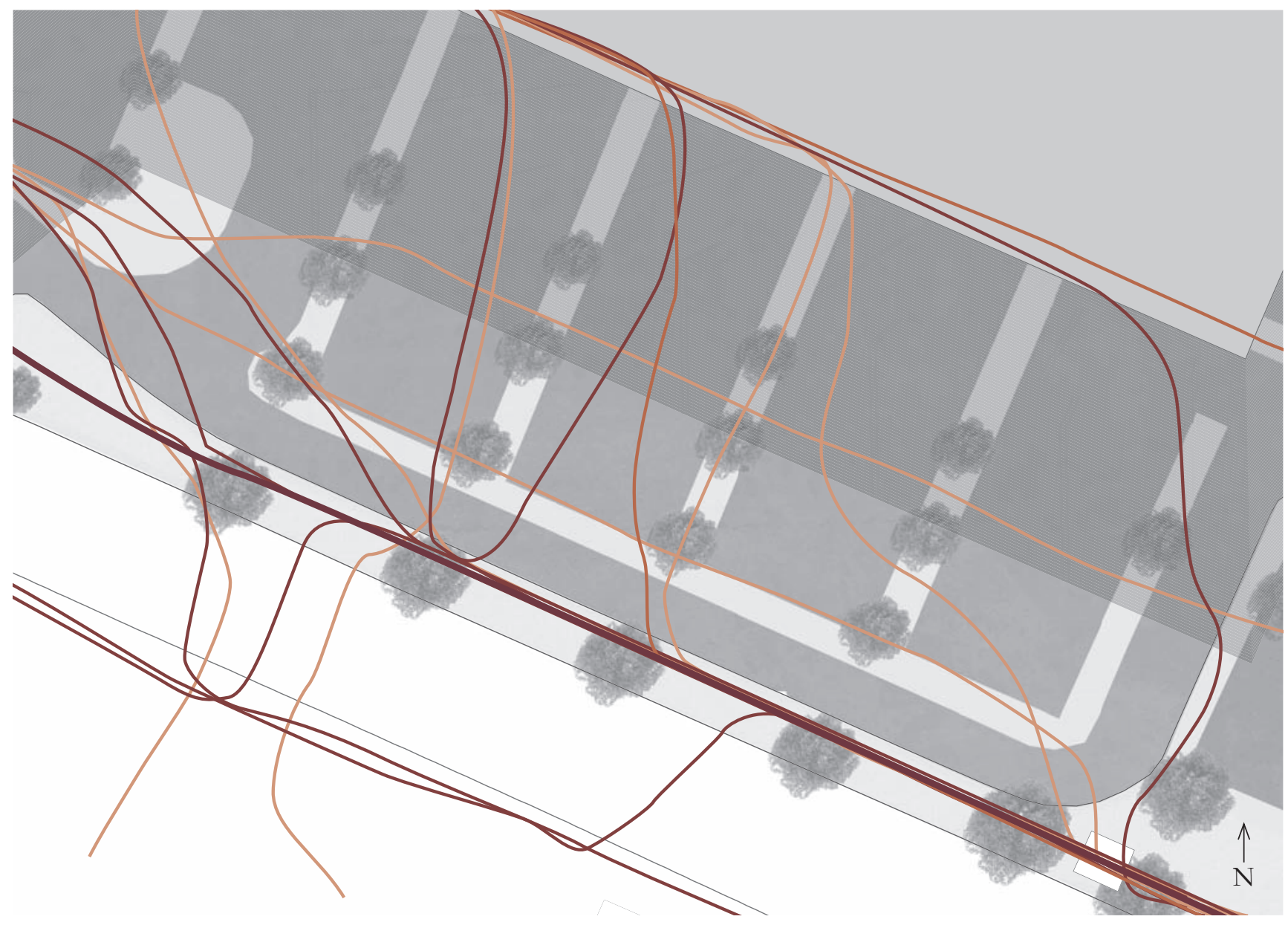

Fig. 1.3.7 Defining the separate movements within intensive mapping 1:600

Dominant

Most people tend not to move through the carpark but rather stay to the footpath until a clear route is obvious.

Common

Secondary

Irregular
Te Papa's entrance determines these people's movement; they have either cut through the carpark at its centre or gone around under the covered walkway to get there.

Similar things determine this movement although they have a series of slightly varied routes to get to the same destinations, perhaps because they are more familiar with the area or saw an opportunity to change their movement sooner than others.

These people cut through the carpark in ways that others do not, perhaps because they have a different destination/origin or have walked through there so often that they see it differently than others. 

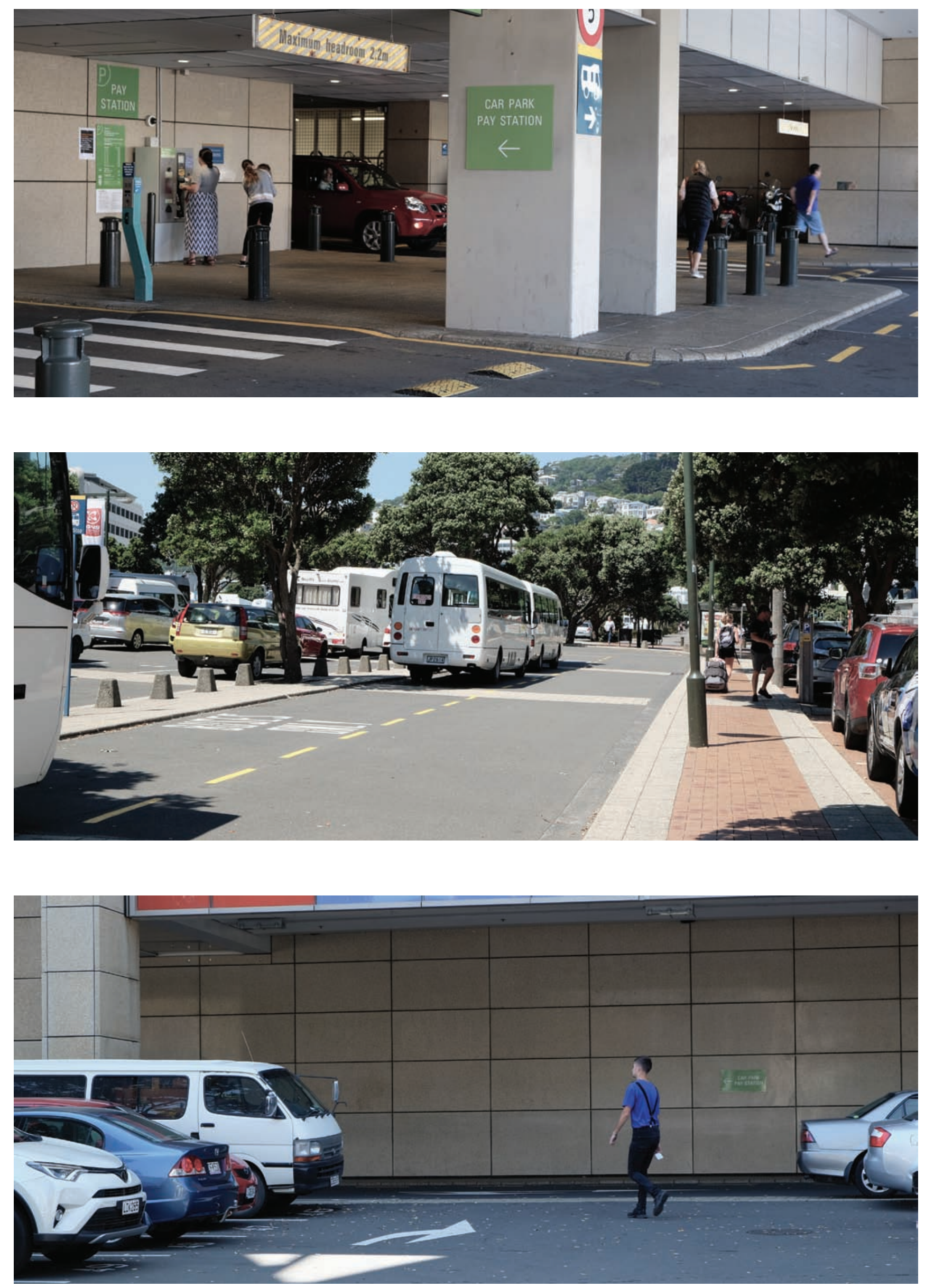

Fig. 1.3.8 Photos taken of movement through the Carpark site 


\section{Movement Categorization: Promenade/Waitangi Park Bridge}

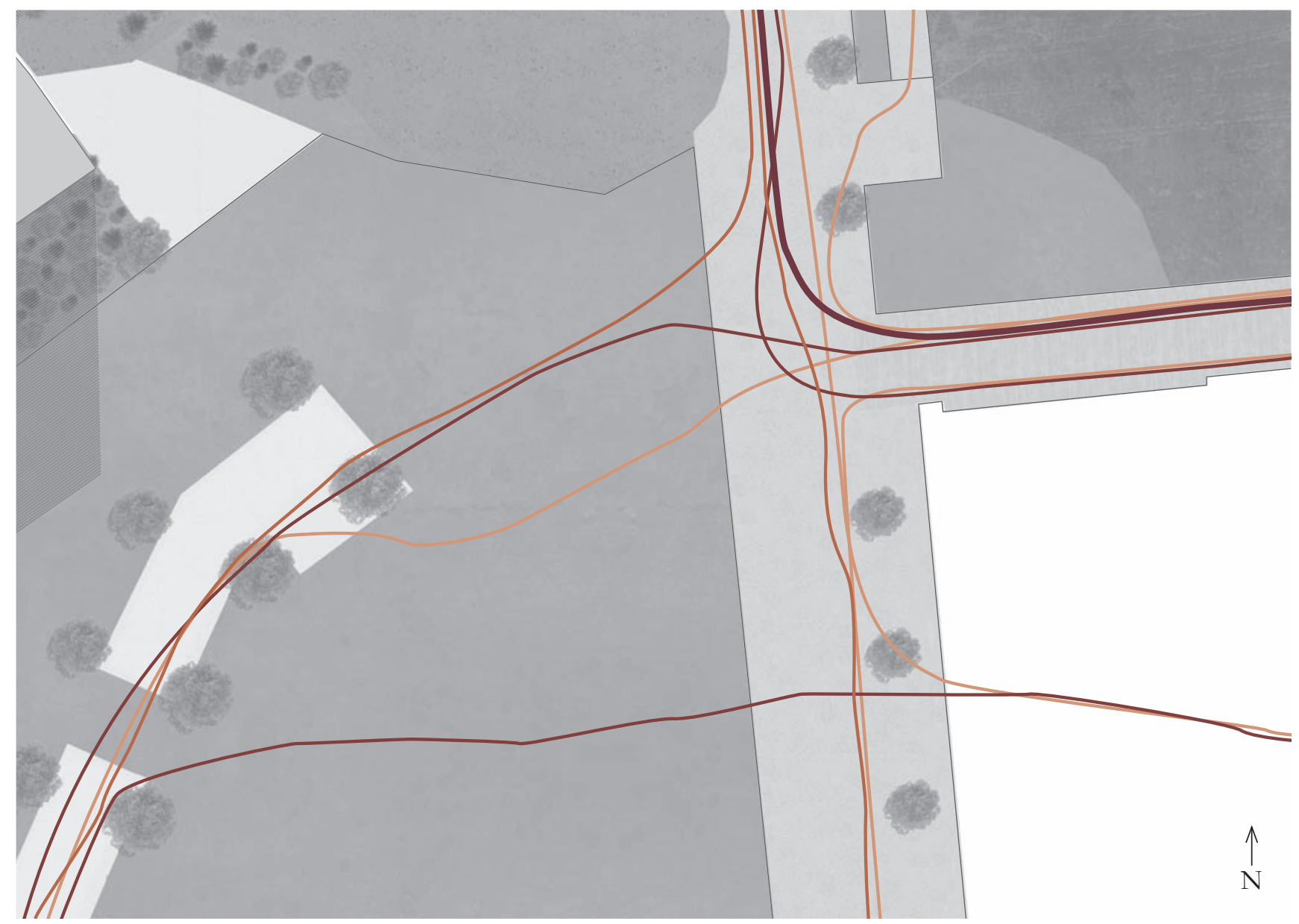

Fig. 1.3.9 Defining the separate movements within intensive mapping 1:600

Dominant

This movement follows the waterfront promenade

Common

The promenade influences this movement but these people have a different destination/origin and divert away along paths set out for that to happen.

Secondary

These people are doing similar things to those above but in slightly different ways, choosing paths that have fewer people on them.

Irregular

These people take in between routes to get to similar places, or some do not have destinations, and so they are wandering around the area in an explorative manner. 

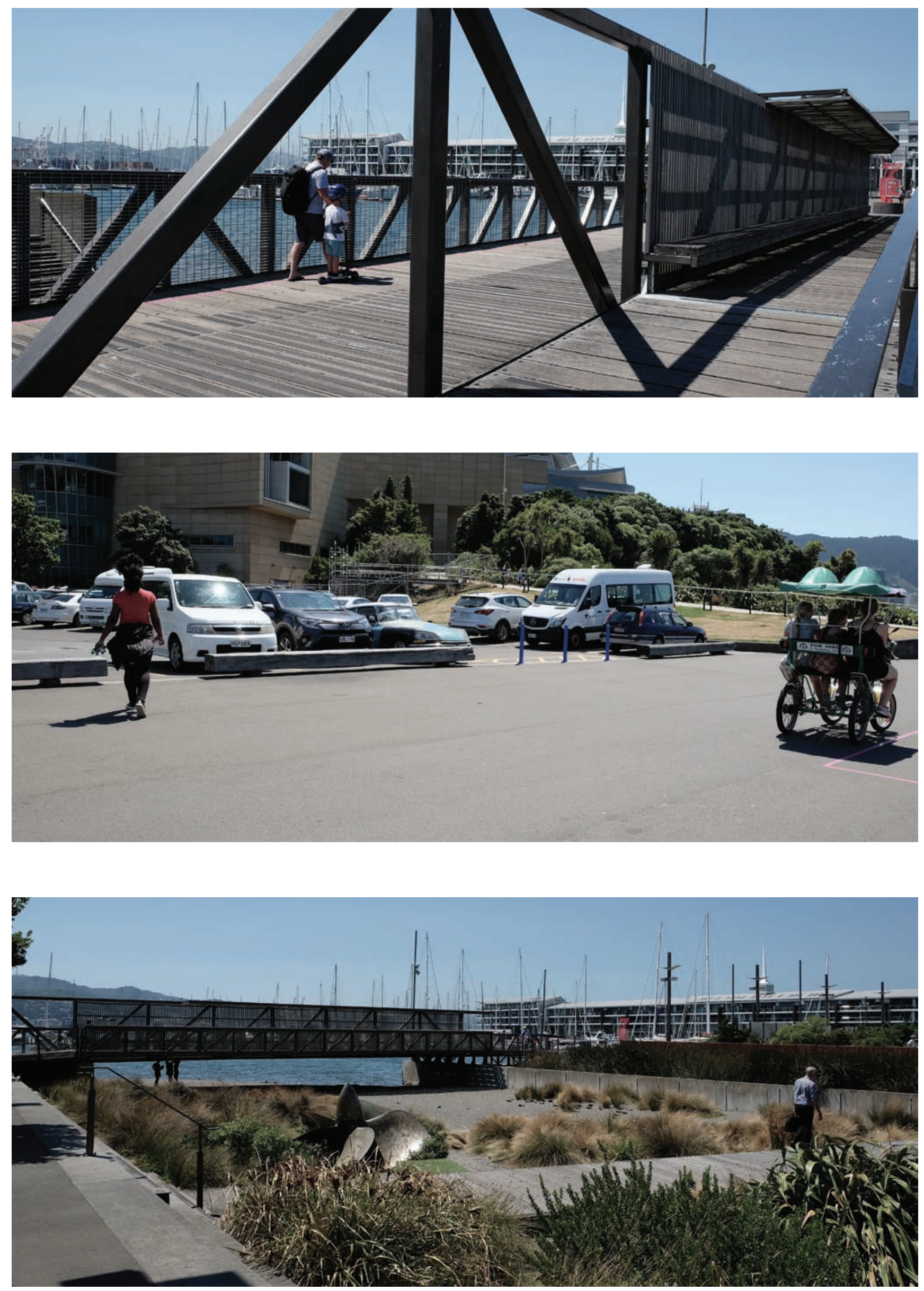

Fig. 1.3.10 Photos taken of movement through the Promenade/Waitangi Bridge site 



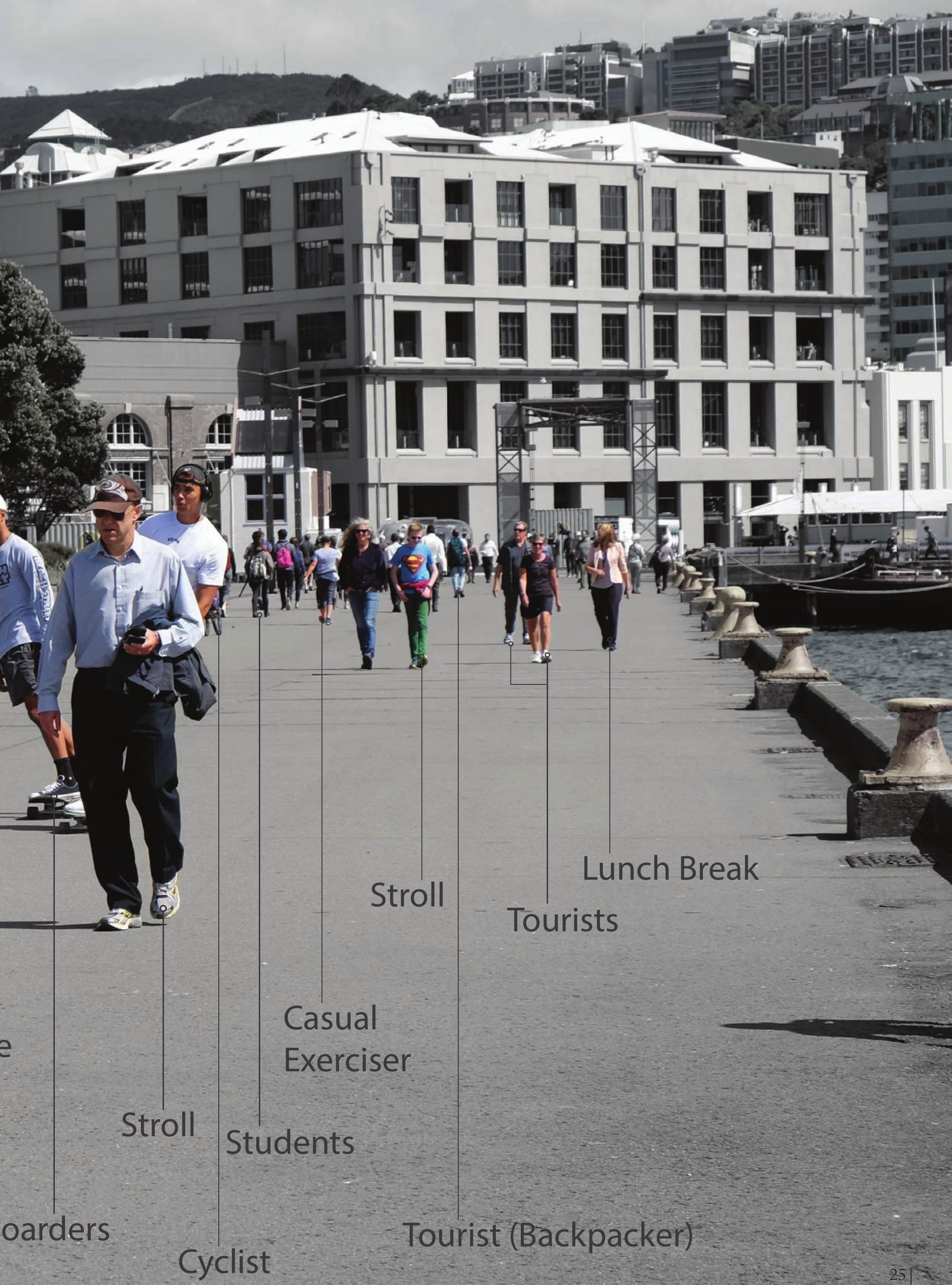


Understanding why lingering occurred seemed important to the public life of the area. There was a close relationship between movement flows and lingering. The aim of this section of research is to investigate the different ways that people are lingering in the space, their relationship to the movement, and the physical element required for that interaction to occur. Different types of lingering are identified and described in a manner which attempts to account for why they each occur, and their relationship to movement, utilising text, diagrams and photos.

Key:

Movement Zone

Physical Edge

Lingering

Movement 


\section{Fly on the Wall}
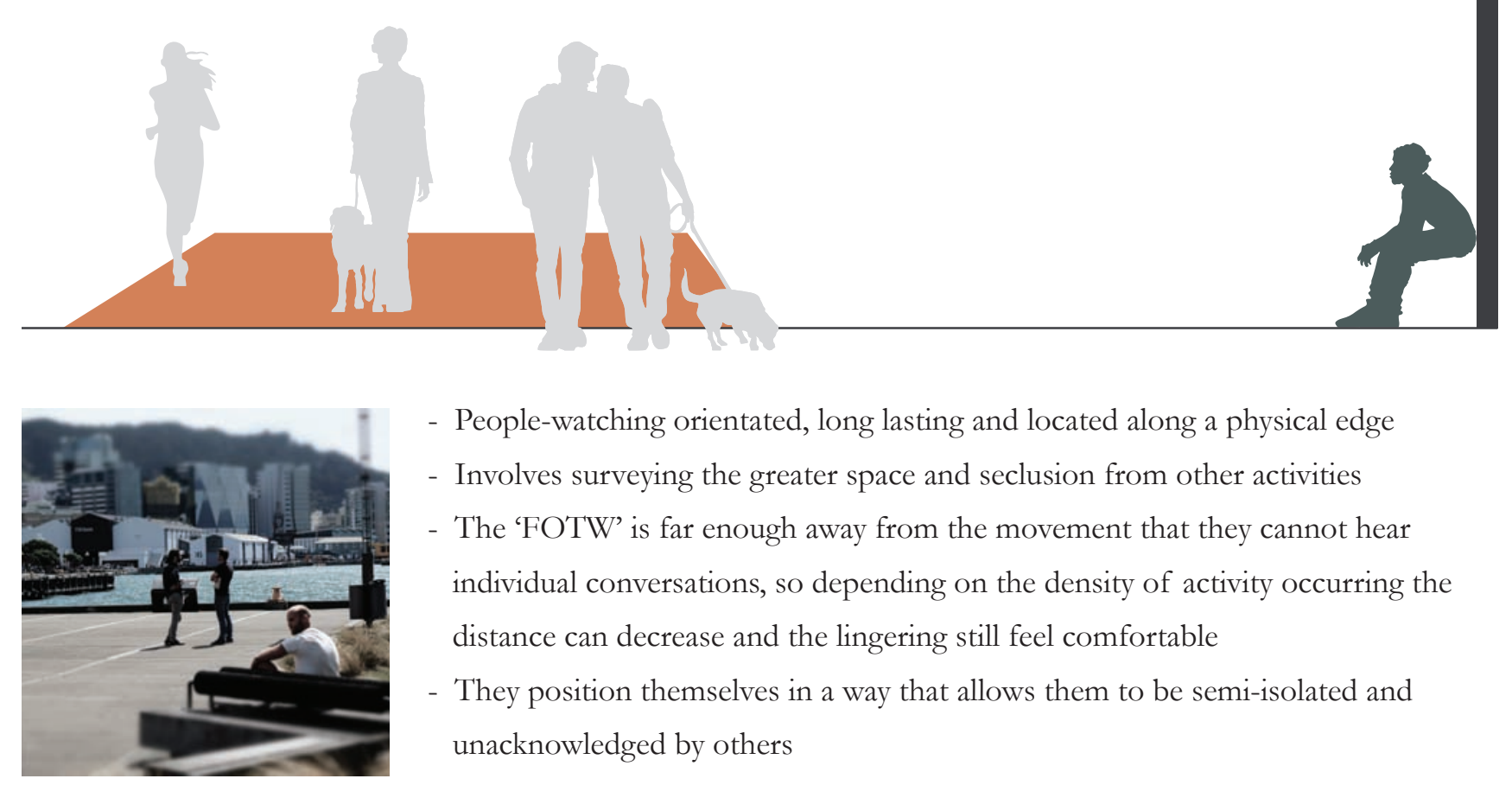

- People-watching orientated, long lasting and located along a physical edge

- Involves surveying the greater space and seclusion from other activities

- The 'FOTW' is far enough away from the movement that they cannot hear individual conversations, so depending on the density of activity occurring the distance can decrease and the lingering still feel comfortable

- They position themselves in a way that allows them to be semi-isolated and unacknowledged by others

\section{Brief Chatting}

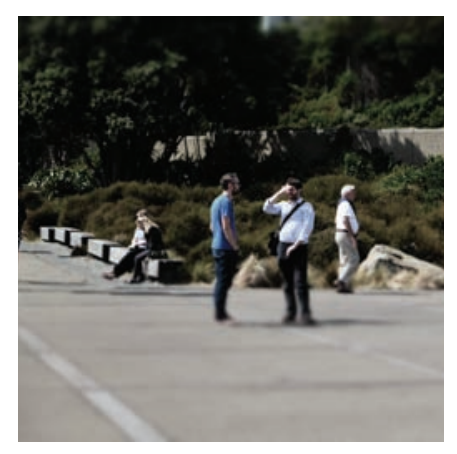

- Spontaneous and temporary

- Often occurs as an unplanned meeting while they are part of a movement and step off to the side to briefly chat

- They are close enough to the movement to continue walking at any moment, which demonstrates the semi-committed manner of this lingering

- Does not require a physical edge but instead a perceived zone 
- They are interested in discovering new things and are open to pausing at anything

- Not people or destination focused; they are just part of the movement until there is something that interests them to stop

- Can stop within the movement to interact with the thing of interest; this causes the movement to go around them temporarily

\section{Long-lasting Central Seating}

- People in groups make up the majority of this lingering interaction that occurs in locations that are amongst existing activity but with ample space between them and the dominant movement

- Their orientation is not reliant on the movement but directed towards each other.

- Groups will sit in ways that ensure there is a barrier between them and other groups (the space required for a barrier will often decrease when the number of people in the space increases) 


\section{Attraction Distraction}
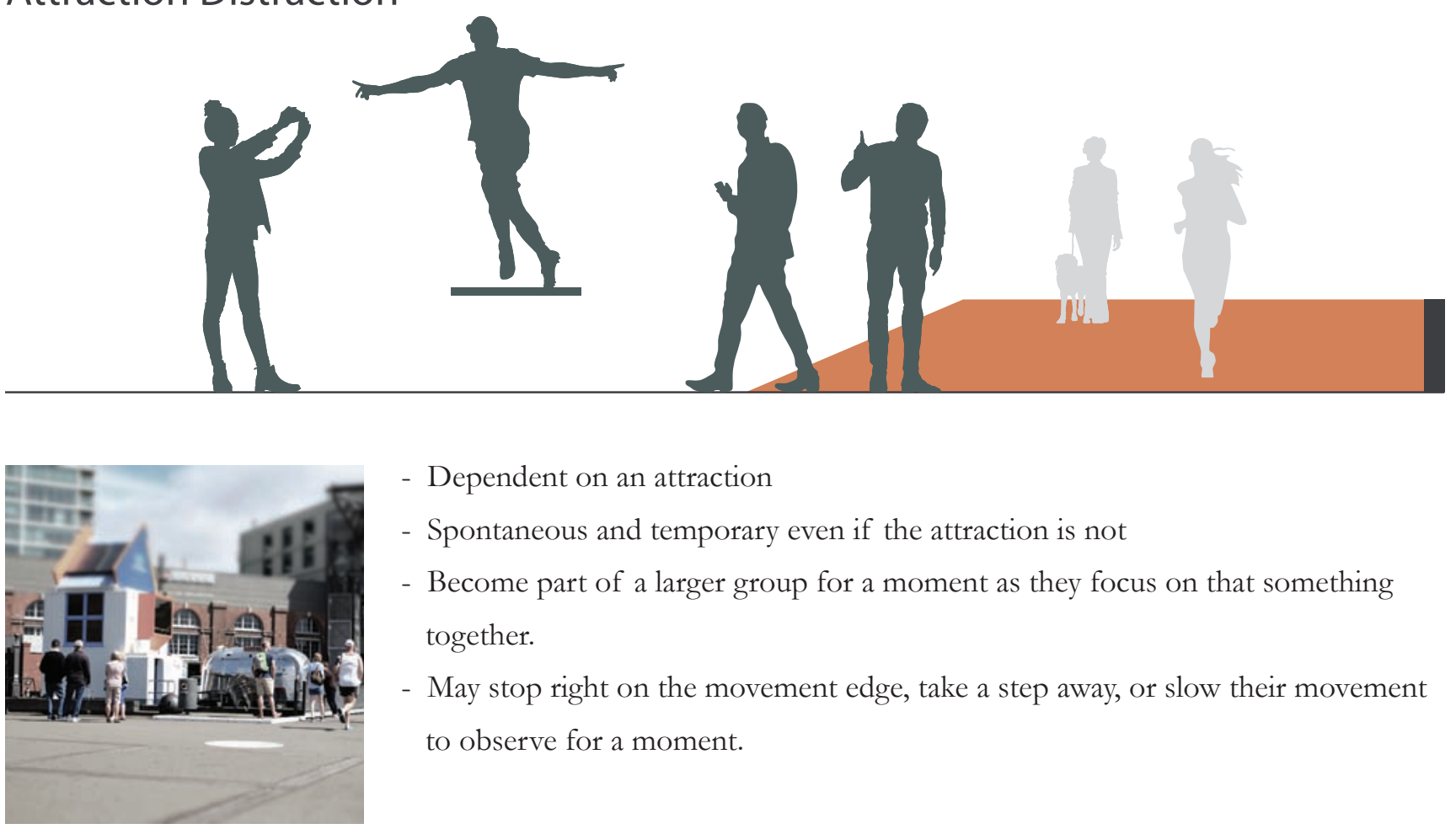

- Dependent on an attraction

- Spontaneous and temporary even if the attraction is not

- Become part of a larger group for a moment as they focus on that something together.

- May stop right on the movement edge, take a step away, or slow their movement to observe for a moment.

\section{Explorers Unfamiliar with the Area}

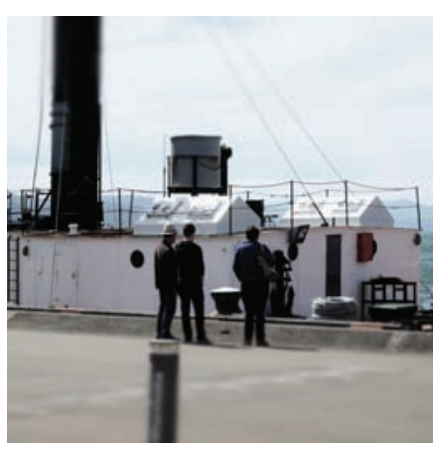

- Either tourists or people from out of town who are passively engaging with the city

- May not acknowledge the movement, sometimes stopping in inconsiderate places that cause people to move around them

- Distracted while attempting to get to their destination or just pausing at places of interest such as harbour views 


\section{Preoccupied User of Space}
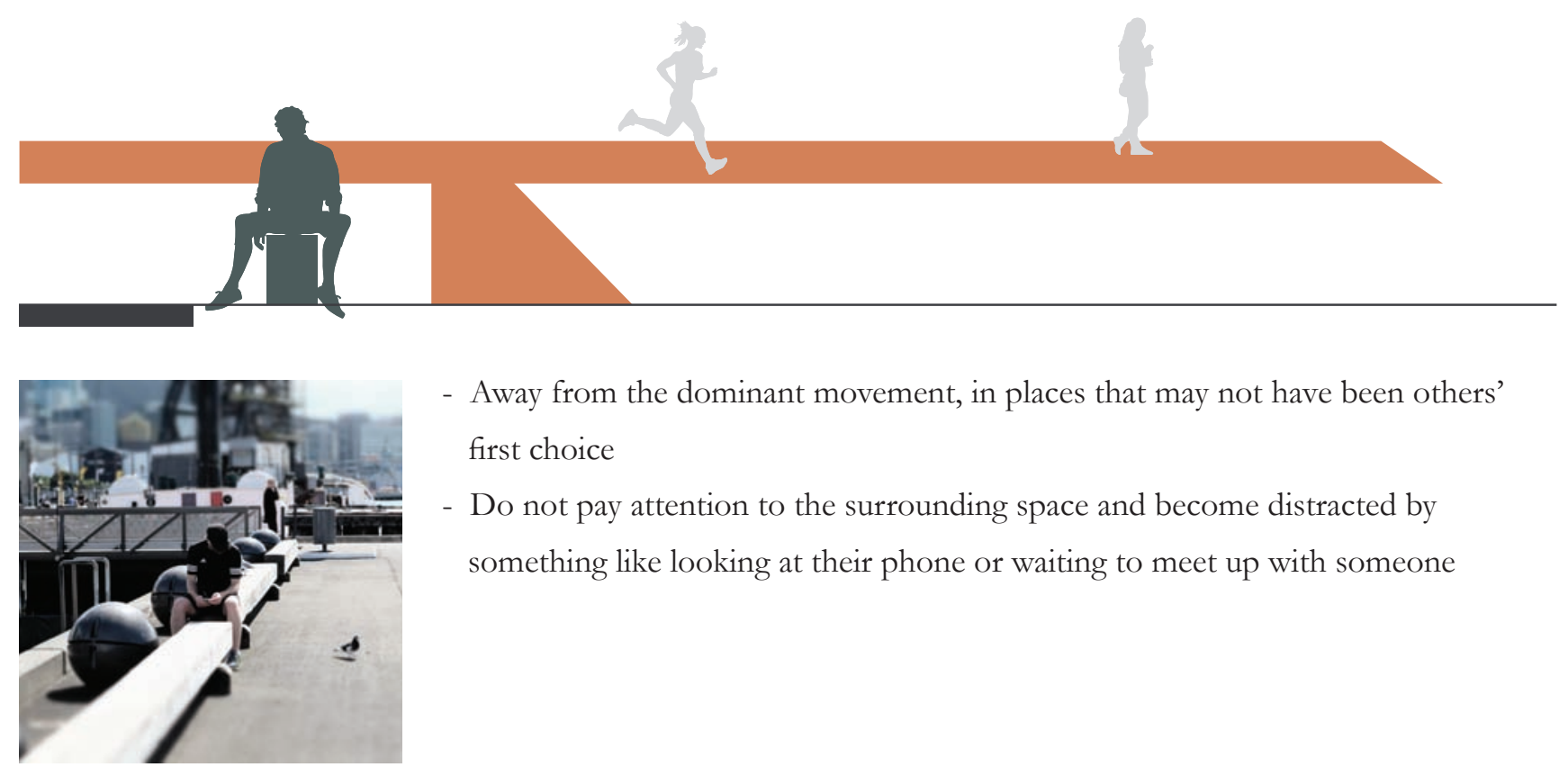

- Away from the dominant movement, in places that may not have been others' first choice

- Do not pay attention to the surrounding space and become distracted by something like looking at their phone or waiting to meet up with someone

\section{Very Temporary Edge Seating}
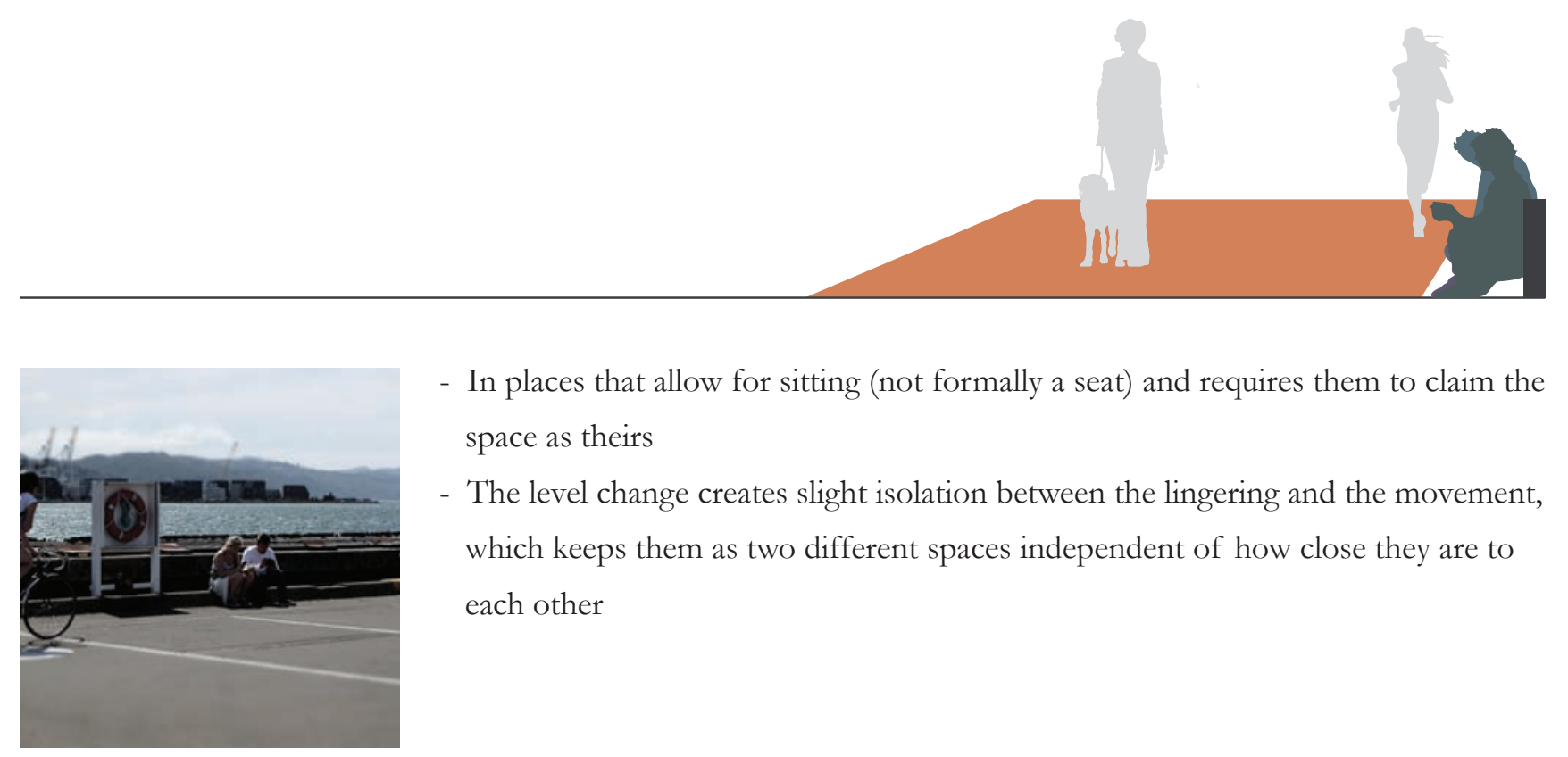

- In places that allow for sitting (not formally a seat) and requires them to claim the space as theirs

- The level change creates slight isolation between the lingering and the movement, which keeps them as two different spaces independent of how close they are to each other 

$x$
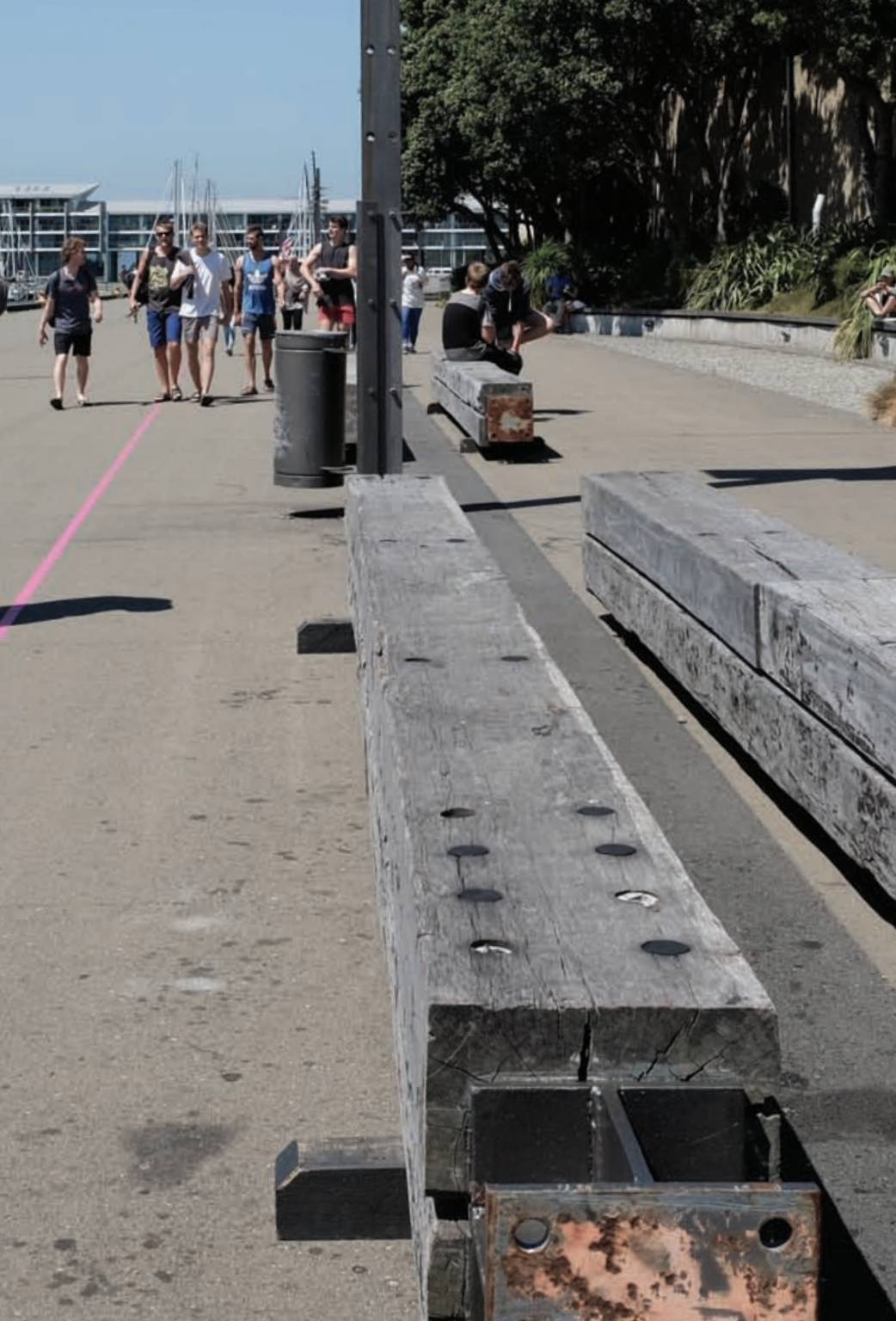

Fig. 1.4 Waterfront promenade alongside Bush City

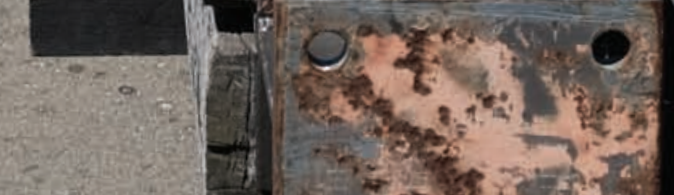
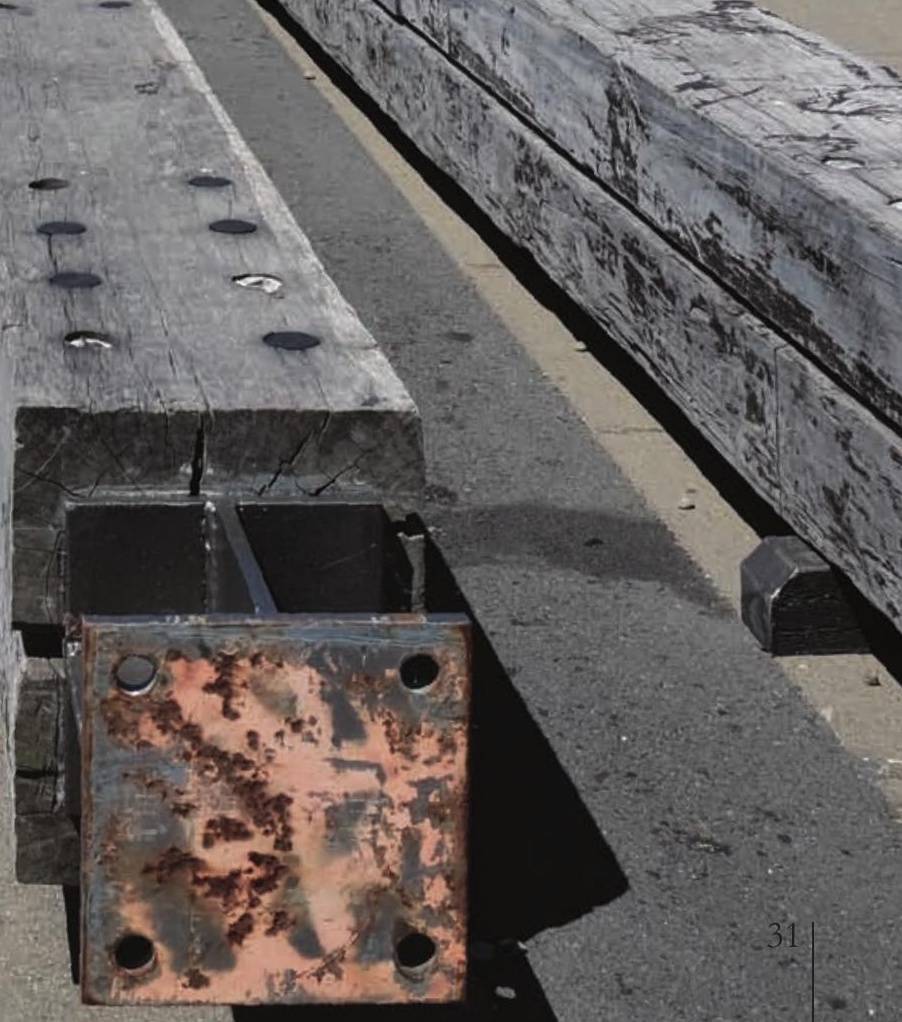


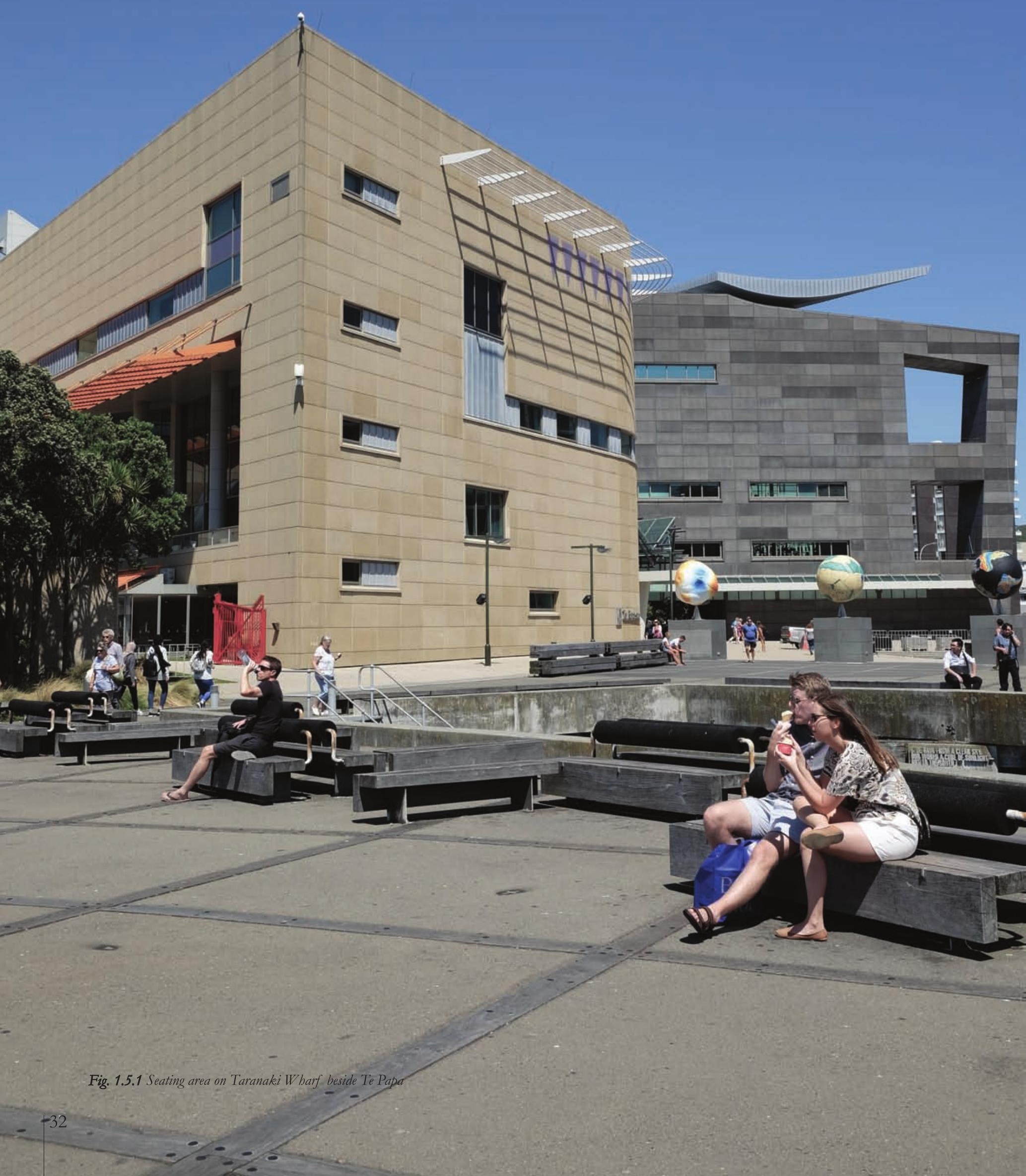


In this research, public life is considered as multiple layers of activity and a space is successful if it allows these multiple layers to occur. Lingering occurs as part of the public life of a space, and in addition to that, it is essential to consider all the layers of movement within the space part of the public life.

Movement is the catalyst for all public life. The movement of the city consists of a variety of activities and people will linger in and around movement to be part of the activity. People will choose to be in spaces that are within a social or public territory of others. A space where people a constantly moving is a perfect location for this. Movement itself is public life; a leisurely walker is out to enjoy leisurely movement itself - a movement open to the world. Destination-orientated walkers will choose to walk a certain way to a destination as a result of many people already walking that way. Being part of the workday movement of the city is an important part of public life. Lingering provides a way to open up to such movements. The non-workday movement tends to involve an openness to the world, others, your own thoughts, to greater things and to details.

Lingering in this research defines an interaction with a space caused by the physical environment provided and what the person required of it. The term gathering will sometimes be used to describe when a group of people have a more specific and permanent interaction with a space, often by choosing to come to this location because of a particular destination or a physical requirement they desire of the space. 
This research has talked about interaction within public space having specific requirements in order for them to occur which are different depending on what they came to the space for, this is the limits of the space. Two things can limit a person:

- Their individual 'vector'

- The external physical conditions

Different people will experience different limitations, for example these limitations allow for certain abilities of action to emerge, a cyclist requires open, connected areas that allow them to be uninterrupted and not interfere with people; while a person interested in people-watching will want to sit against an edge and be able to look out over people, these two physical conditions may occur within the same space. Urban spaces provide an open range of vectors to find conditions that suit or incite their vector.

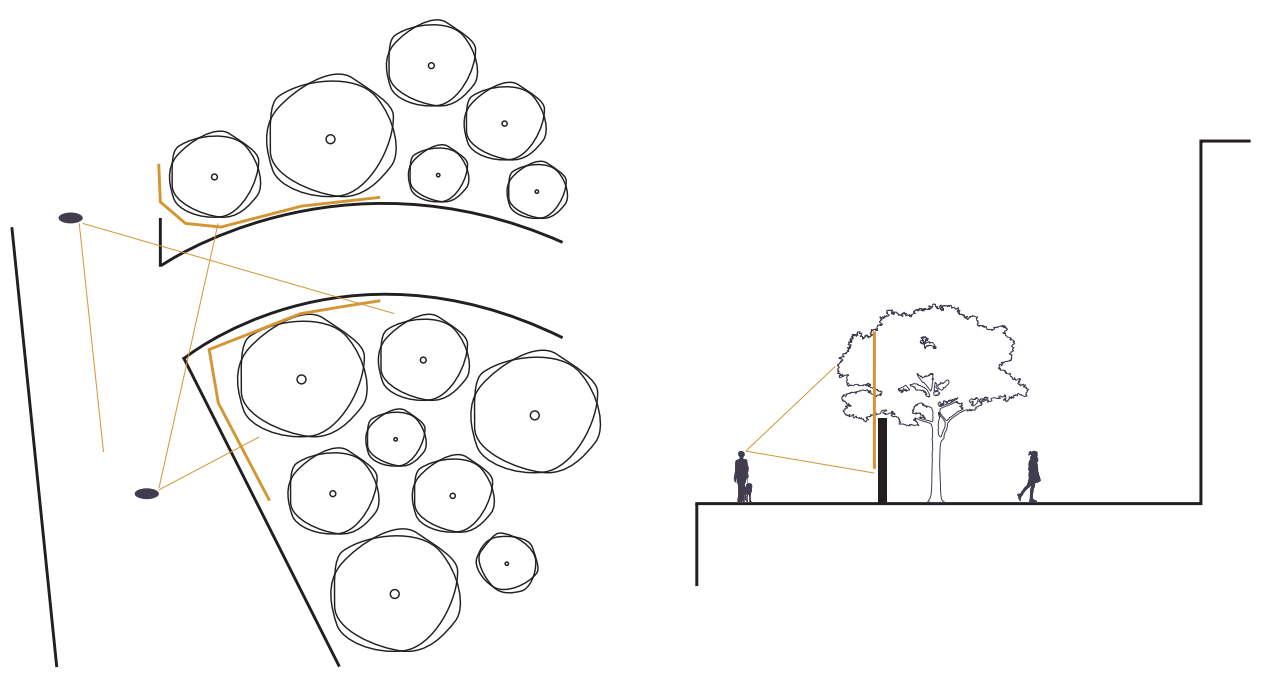

Fig. 1.6.2 Two examples of visual limits that exist on the site

Vision and access is another limitation related to each vector. If a person cannot see into a space, they will not know what is in there or what kind of public life is occurring or has the potential to occur in there. This type of limitation occurs in several places around Te Papa, which causes places to be disregarded and forgotten when they have the potential for public life. 


\section{TE PAPA: PHYSICAL INTERACTIONS}

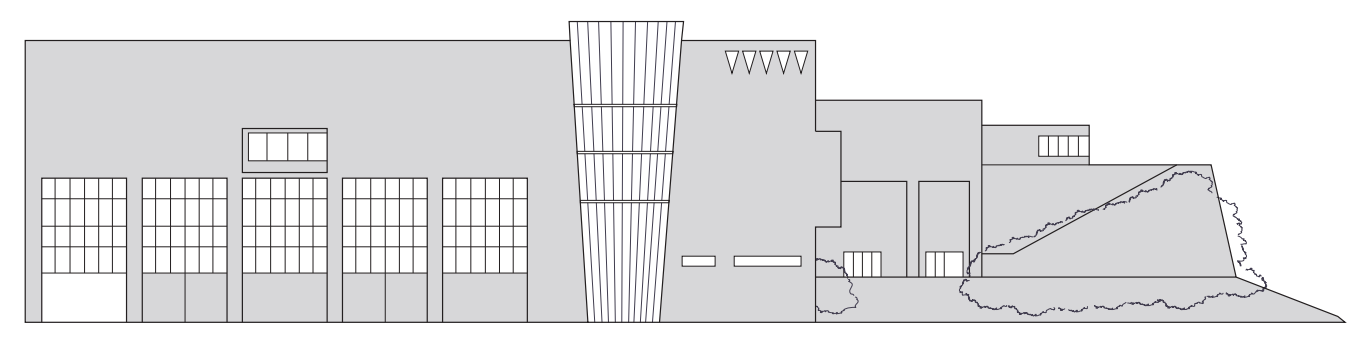

Eastern Facade

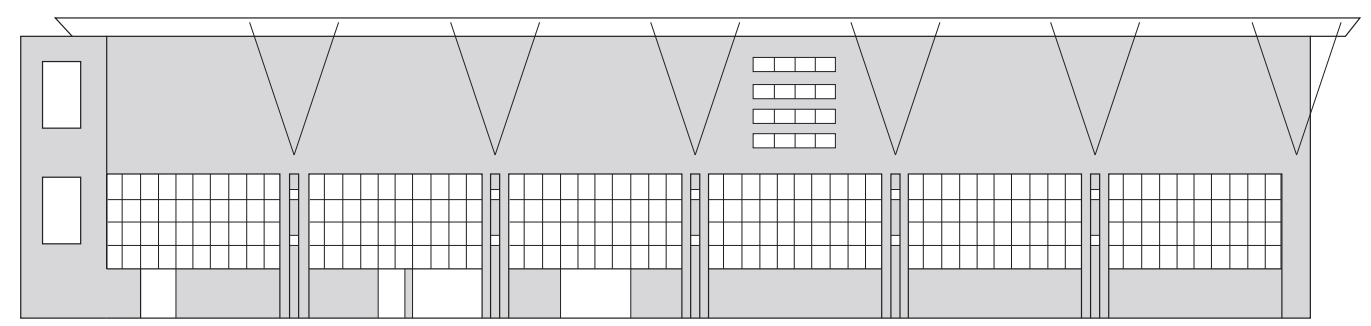

Southern Facade

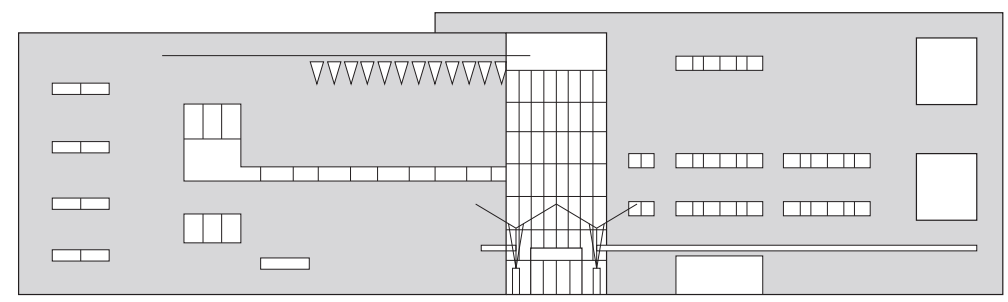

Western Facade

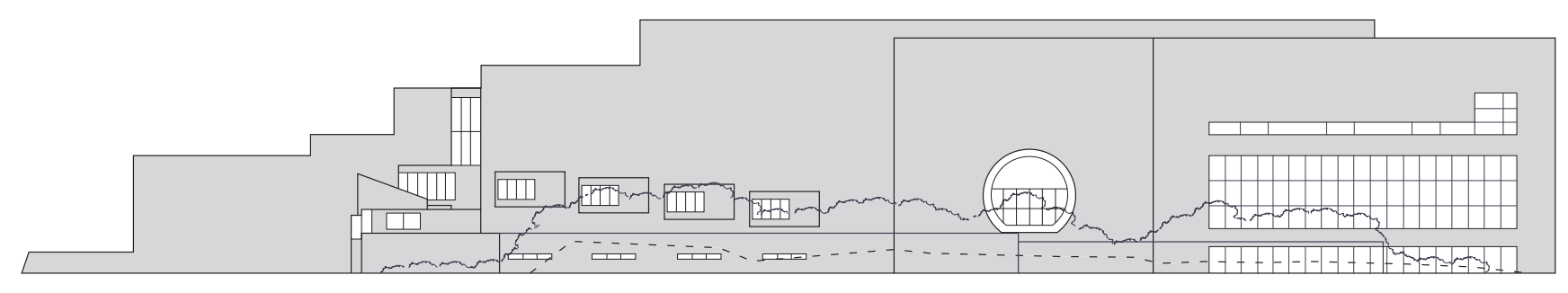


Planting separates people from the façade but does have a small gap up to the building (however there is no public building access). It then has an opening into a covered area of the outside carpark that has a small footpath running alongside it.

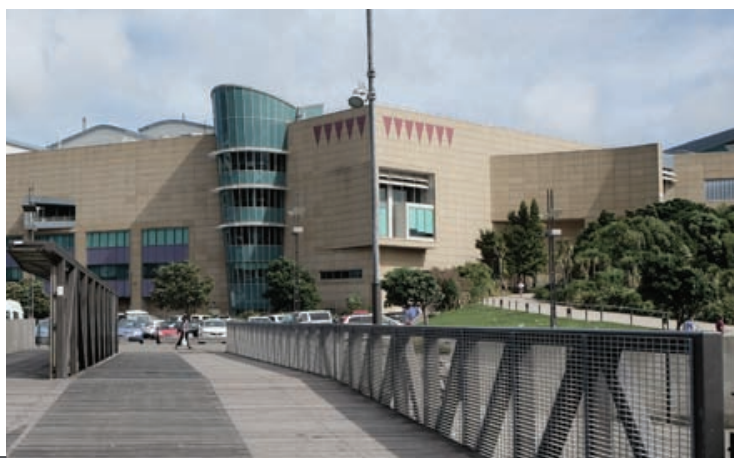

Very little interaction with the façade because the car park keeps people confined to under the covered area or out on the footpath where buses and trees limit the interaction people can have.

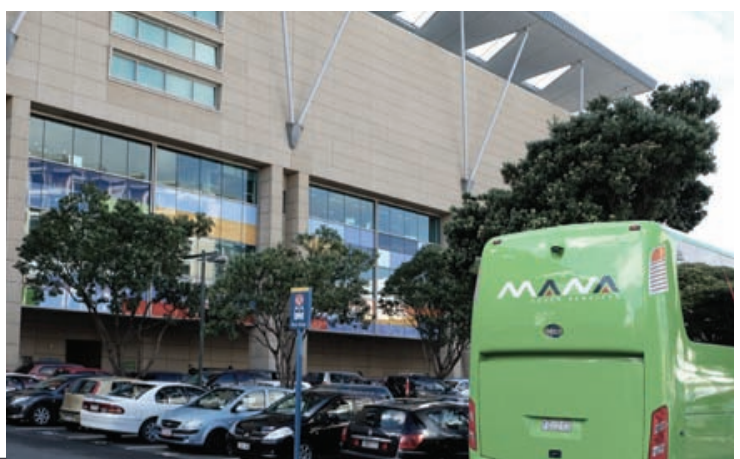

The entrance is located here that provides interaction with the ground floor, and there is an opening that connects through to the covered footpath.

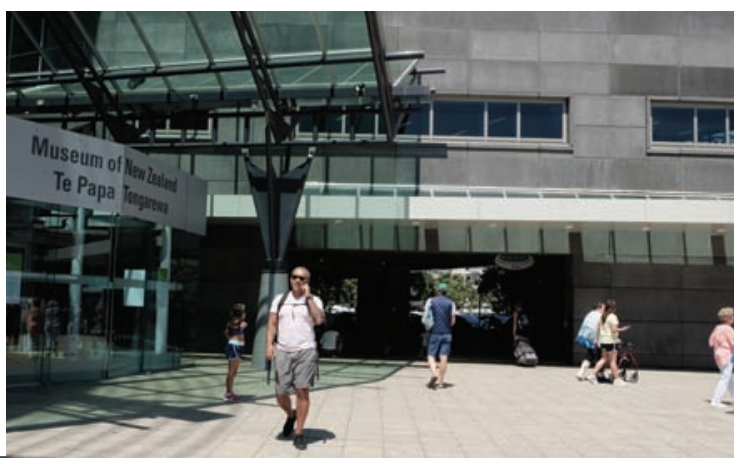

Bush City and a large wall blocks off the space with a large wall; a pond stops people from interacting with the façade. People are able to enter into that blocked off area, and enter the building via the café.

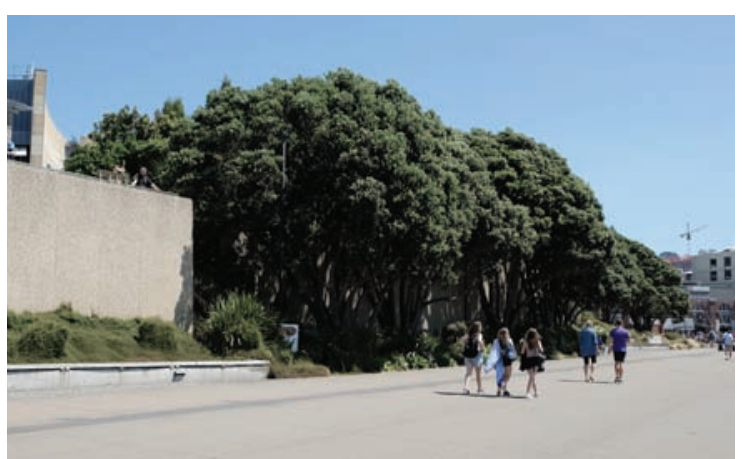




\section{Model}

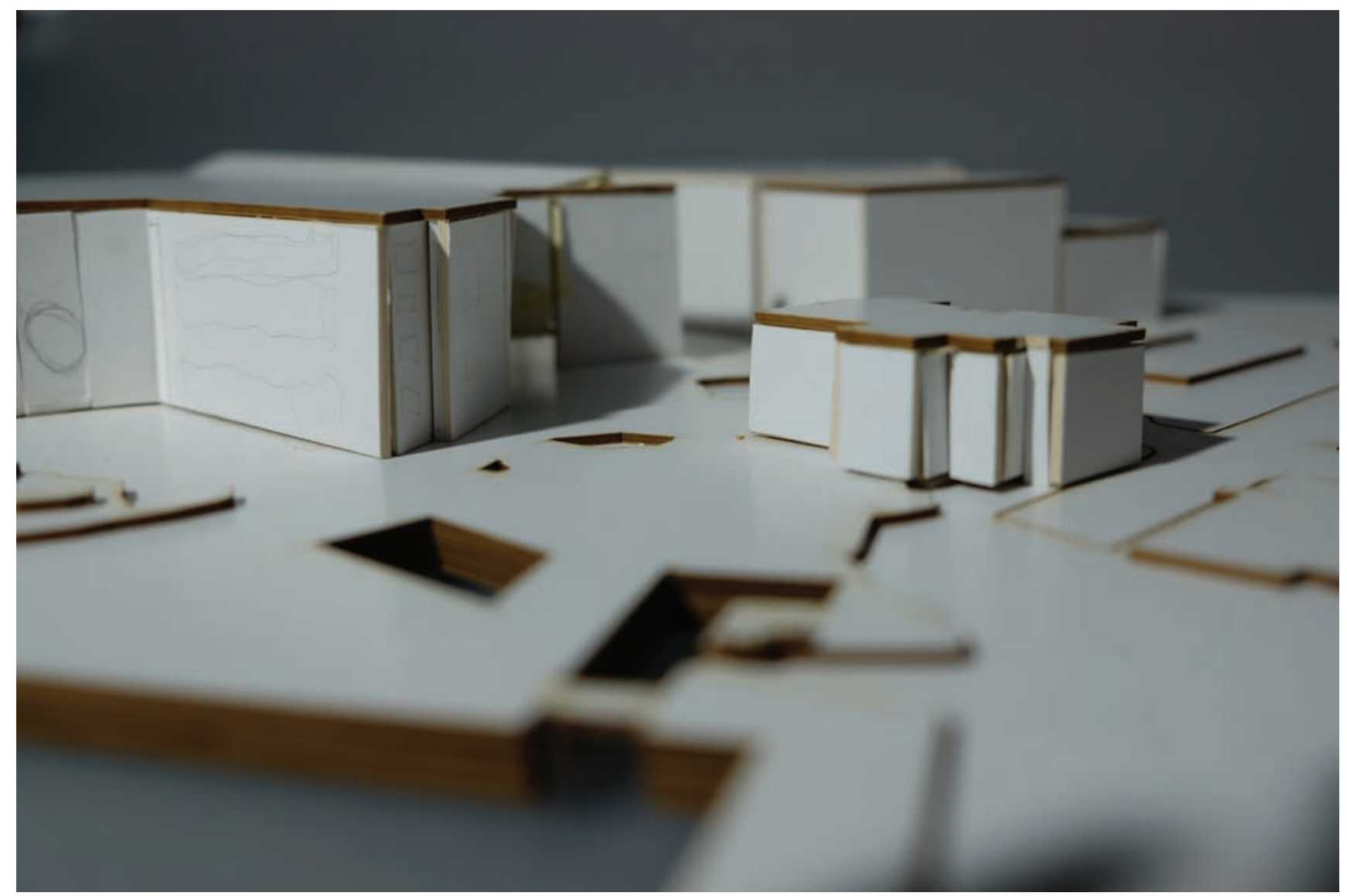

Fig. 1.7.2 Documentation of the sketch model, showing contours and windows

It was vital to have something to refer to when imagining the spaces around Te Papa and the openings in its façade during all stages of research. The creation of this model helped visualise the relationship Te Papa has with the rest of the site, and how certain designs would respond to that. 

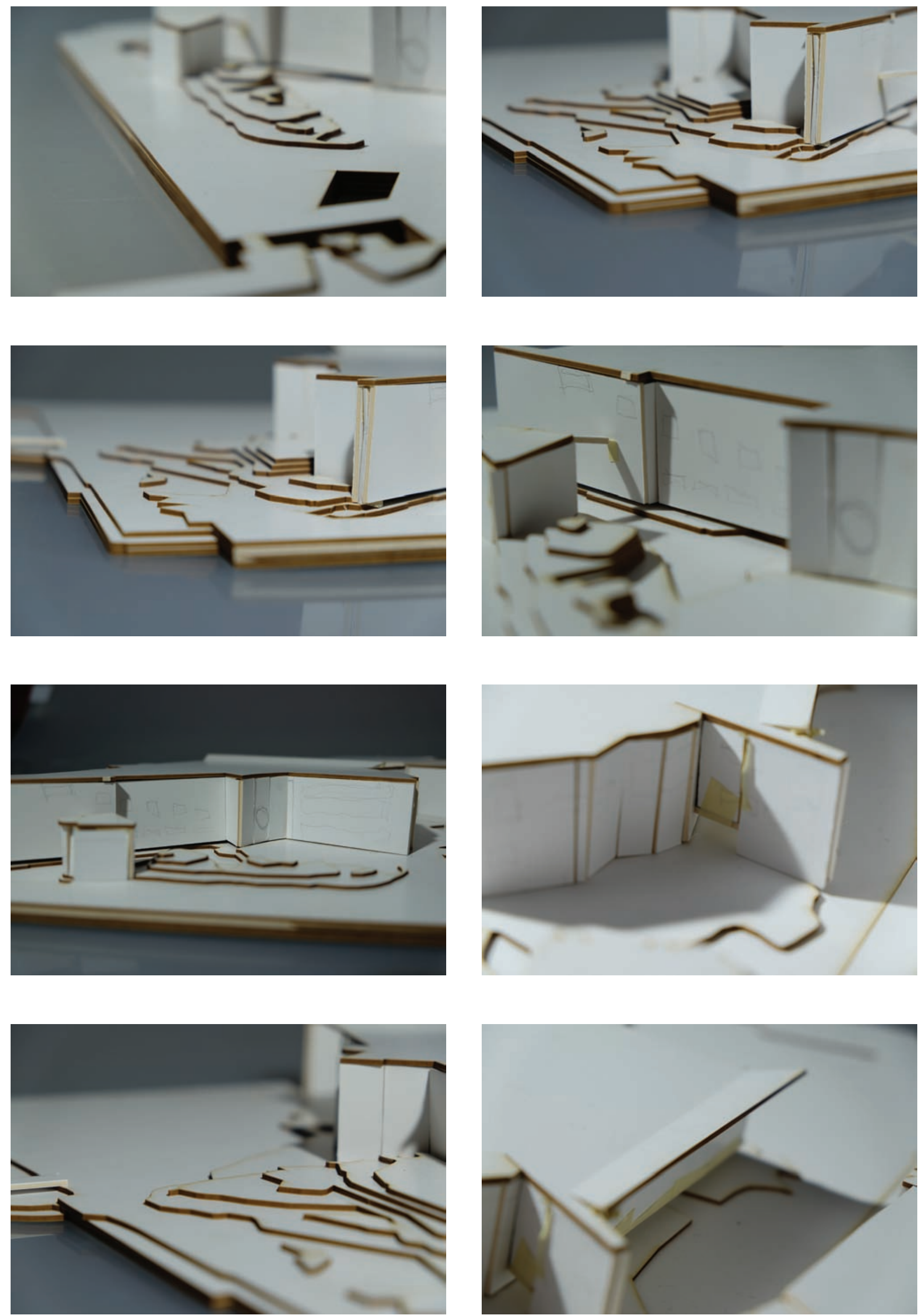


\section{Internal Access and Connection to Outside: Ground Level}

As mentioned previously, the only connections to outside on the ground floor are the entrance and the café. The public access on the ground floor consists of the atrium, Te Papa shop and café.

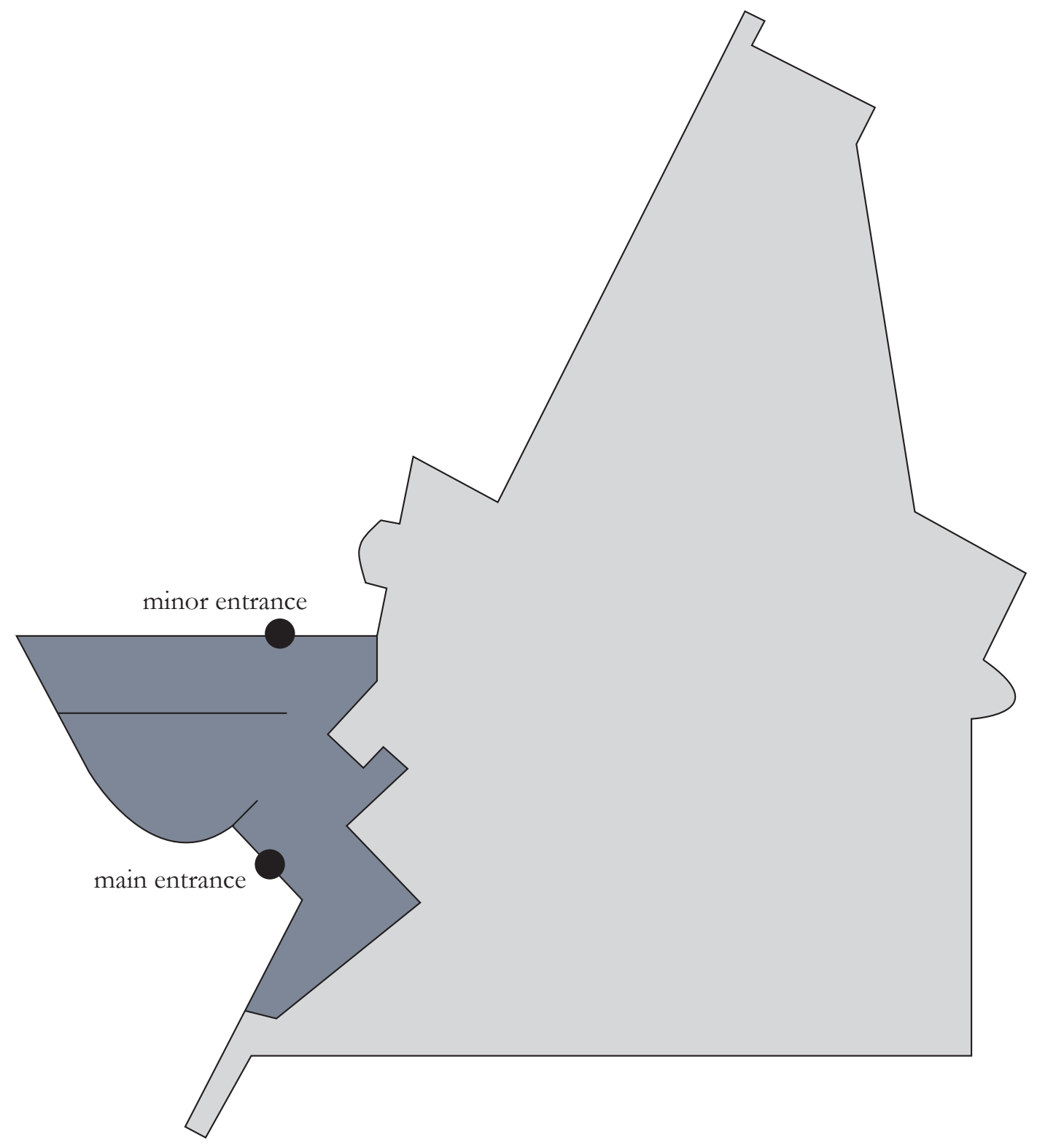

Key:

Public Access

Back-of-House/Admin Areas

Fig. 1.7.3 Areas that the public can move around in on the ground floor (blue) 

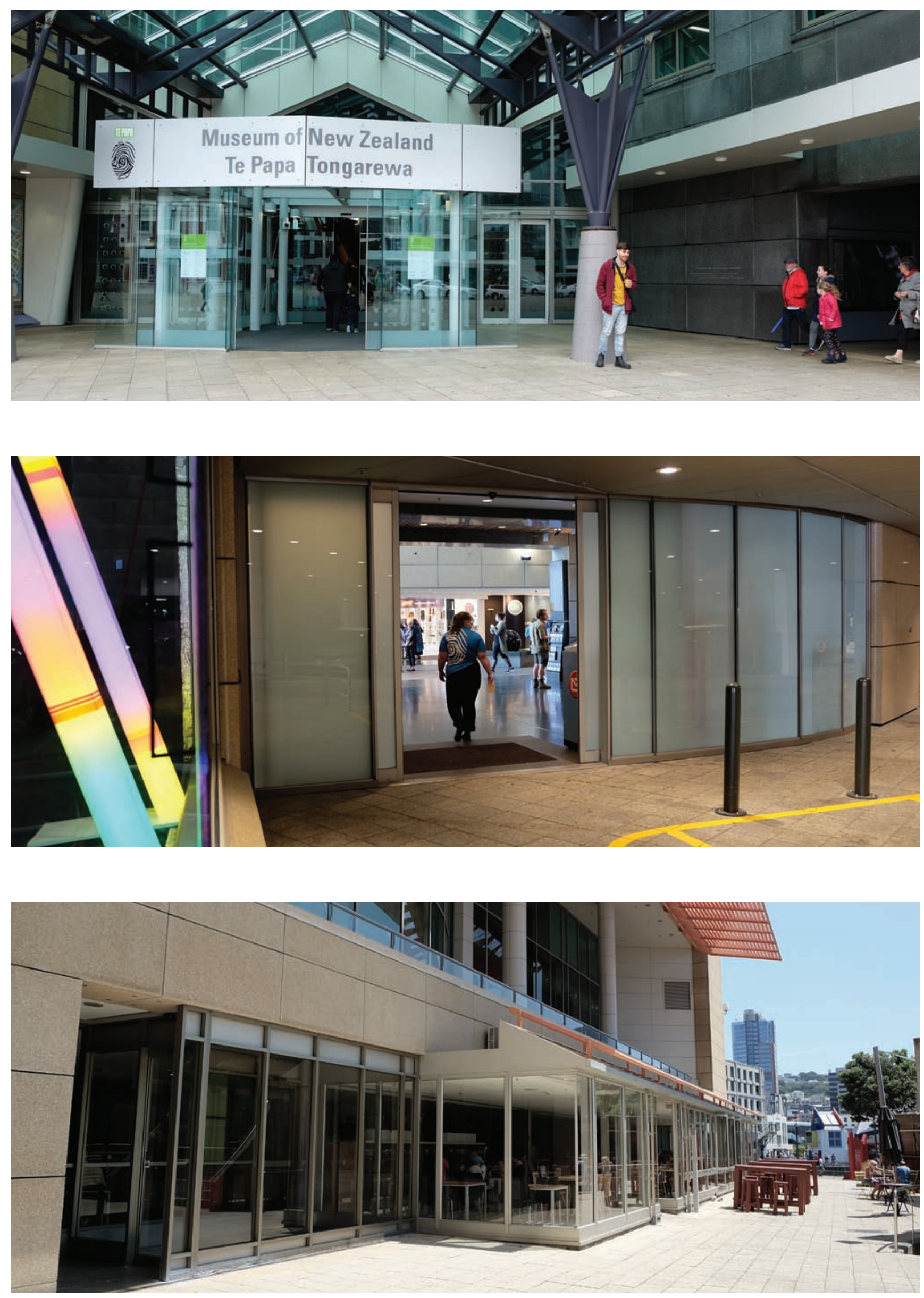


\section{Internal Access and Connection to Outside: Level 2}

Level 2 begins with another atrium space where the information desk and seating are located; this is where the museum begins. This atrium space has two large windows; one looks west to the city and the other looks north out to the harbour. A function room, theatre and several exhibition spaces flow off this atrium, including a kid's zone, which has a window and permanently locked door to the outside that connects to the marae entrance.

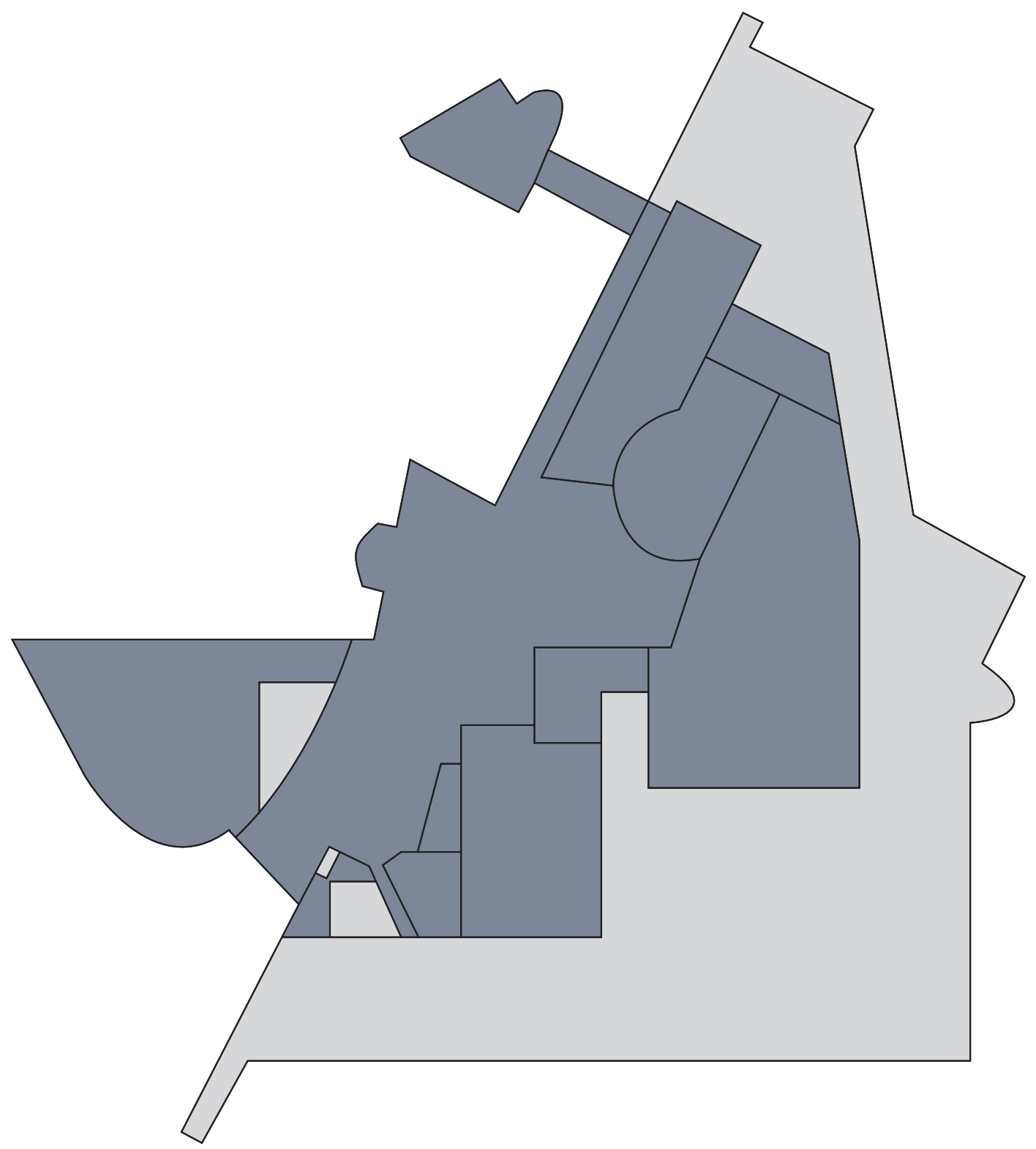

Key:

Public Access

Back-of-House/Admin Areas

Fig. 1.7.5 Areas that the public can move around in on the second floor (blue) 

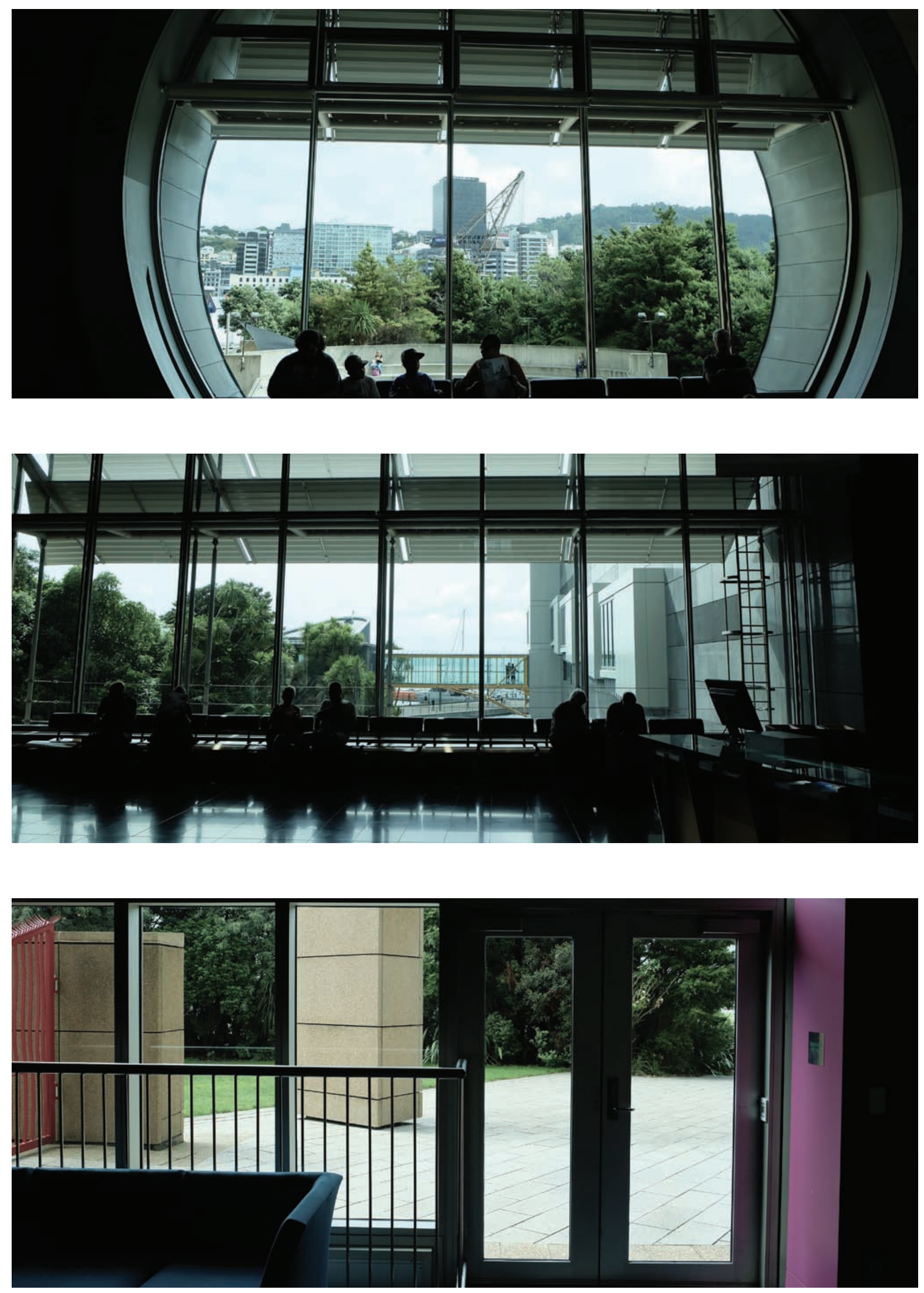


\section{Internal Access and Connection to Outside: Level 4}

Level 4 consists of several exhibition spaces and a café; it also has several areas where windows open up to the outside. One window provides a lookout that is wider than $180^{\circ}$, however, while this window looks out to the harbour and Waitangi Park, the carpark dominates the view.

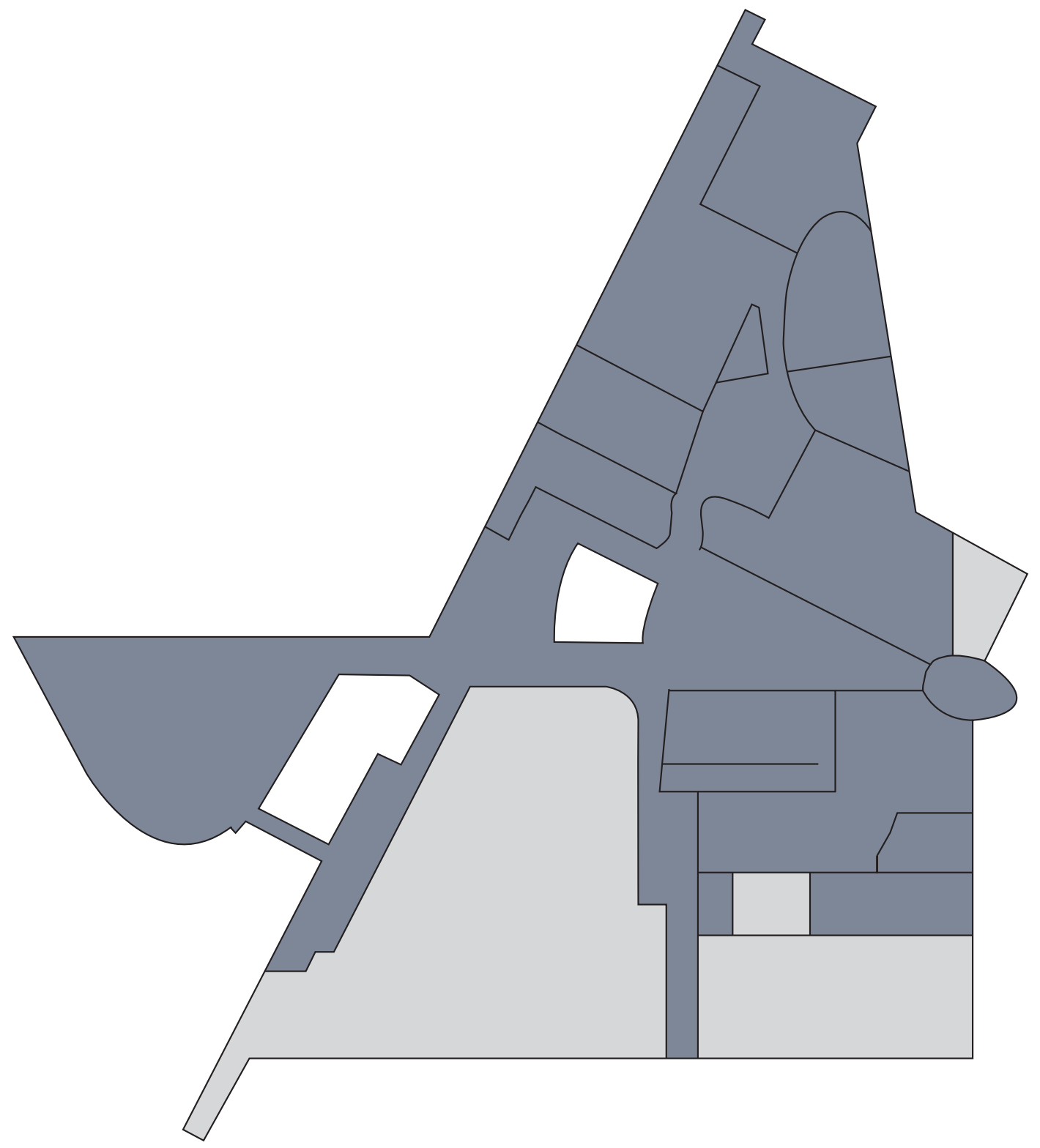

Key:

Public Access

Back-of-House/Admin Areas

Fig. 1.7.7 Areas that the public can move around in on the fourth floor (blue) 

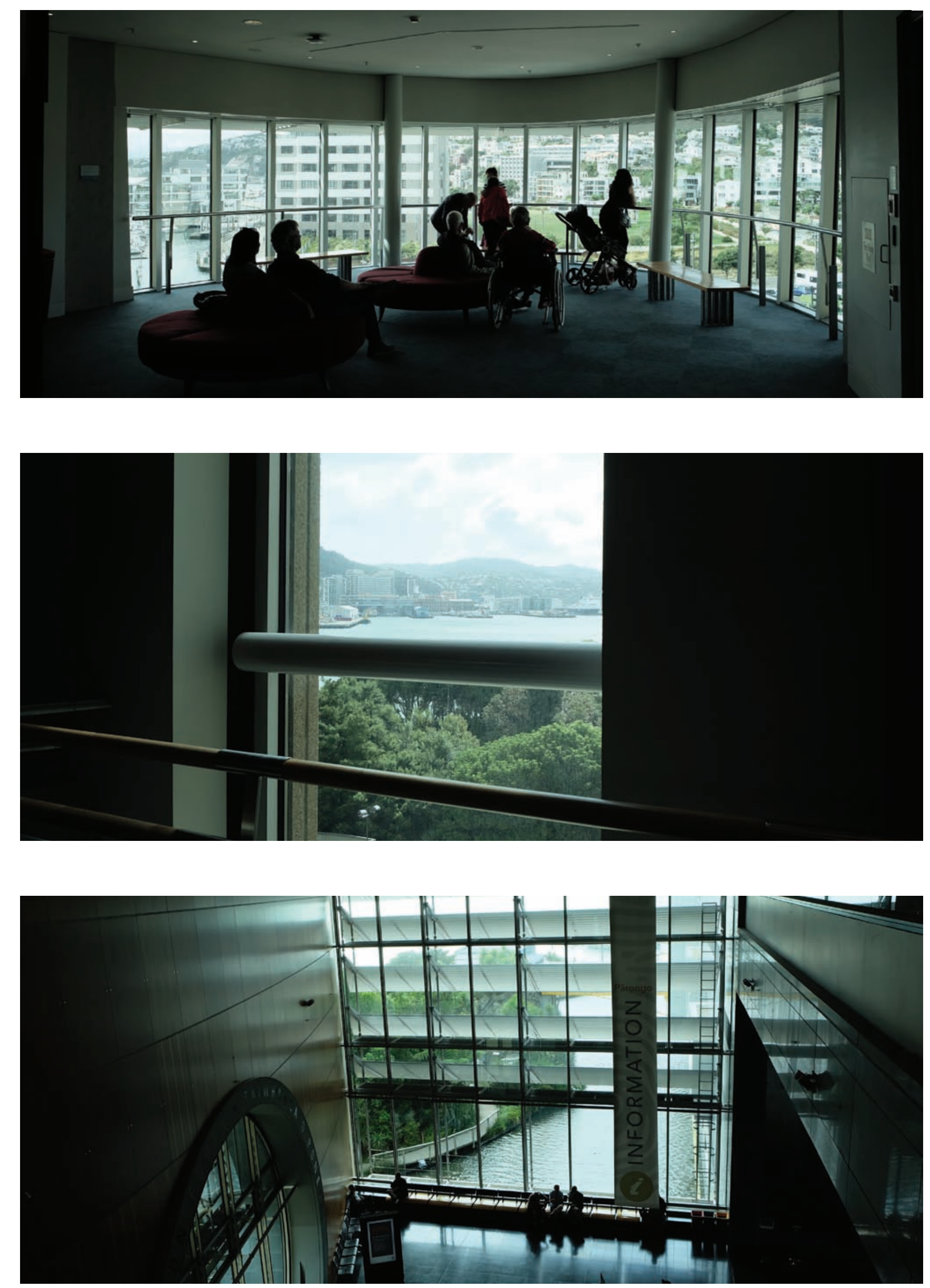


\section{Barnett Street Carpark Usage}

The Barnett Street Carpark is next to Te Papa and is used by Te Papa employees, contractors, caravans, those visiting the waterfront, and on Sunday mornings a weekly fruit and vege market is held in the south east corner of the carpark. This carpark is one of two surface carparks right on the waterfront, which is contrary to what was recommended by WCC in 2001 when a waterfront framework was created: 'ideally, surface parking should be progressively removed as development takes place' (Wellington City Council, 2001).
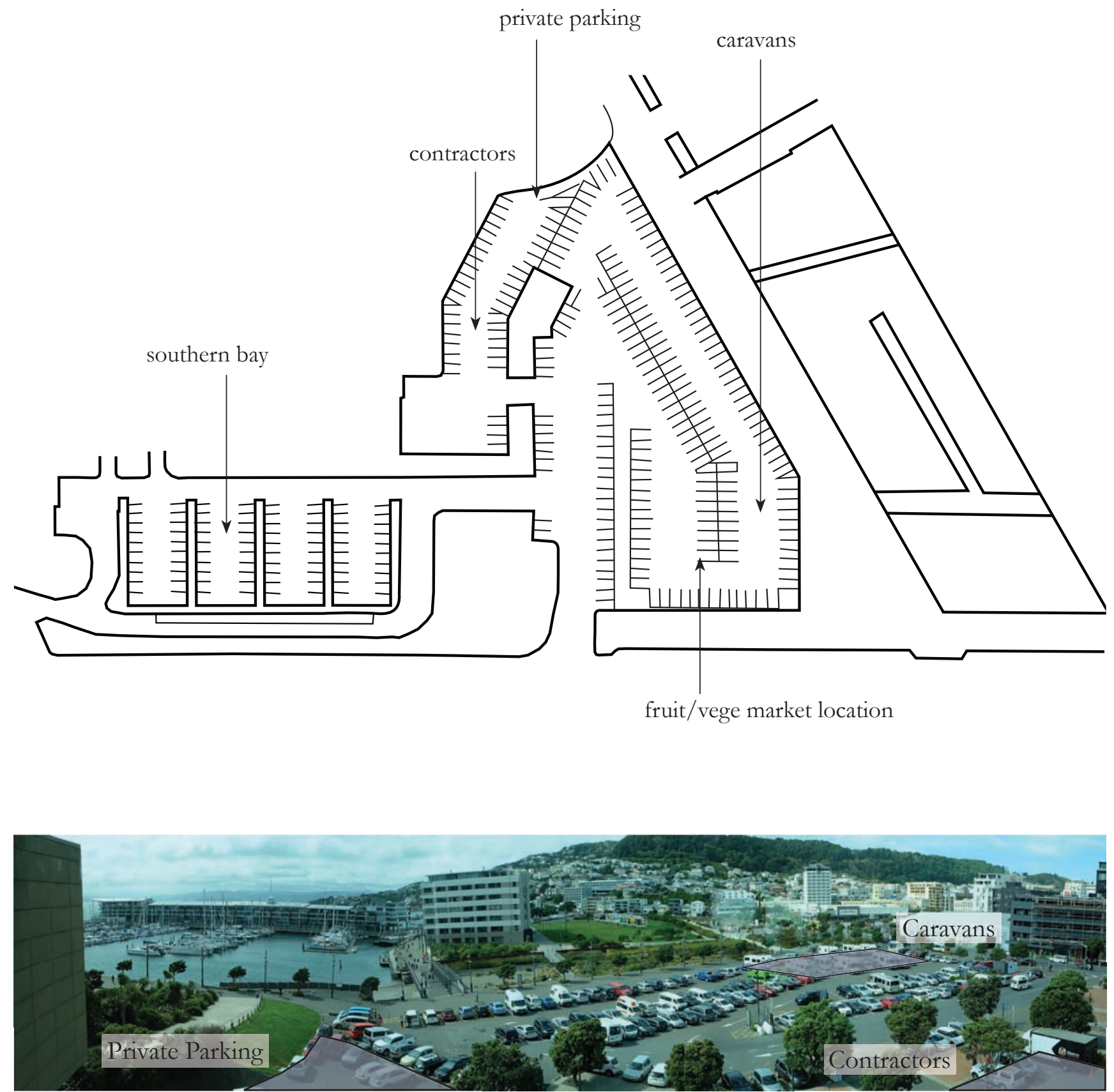

Fig. 1.7.9 Layout of the carpark

Fig. 1.7.10 Carpark with the more valuable landscapes surrounding it, highlighting the type of parking available

Fig. 1.7.11 (opposite) Sunday morning market located in the carpark 

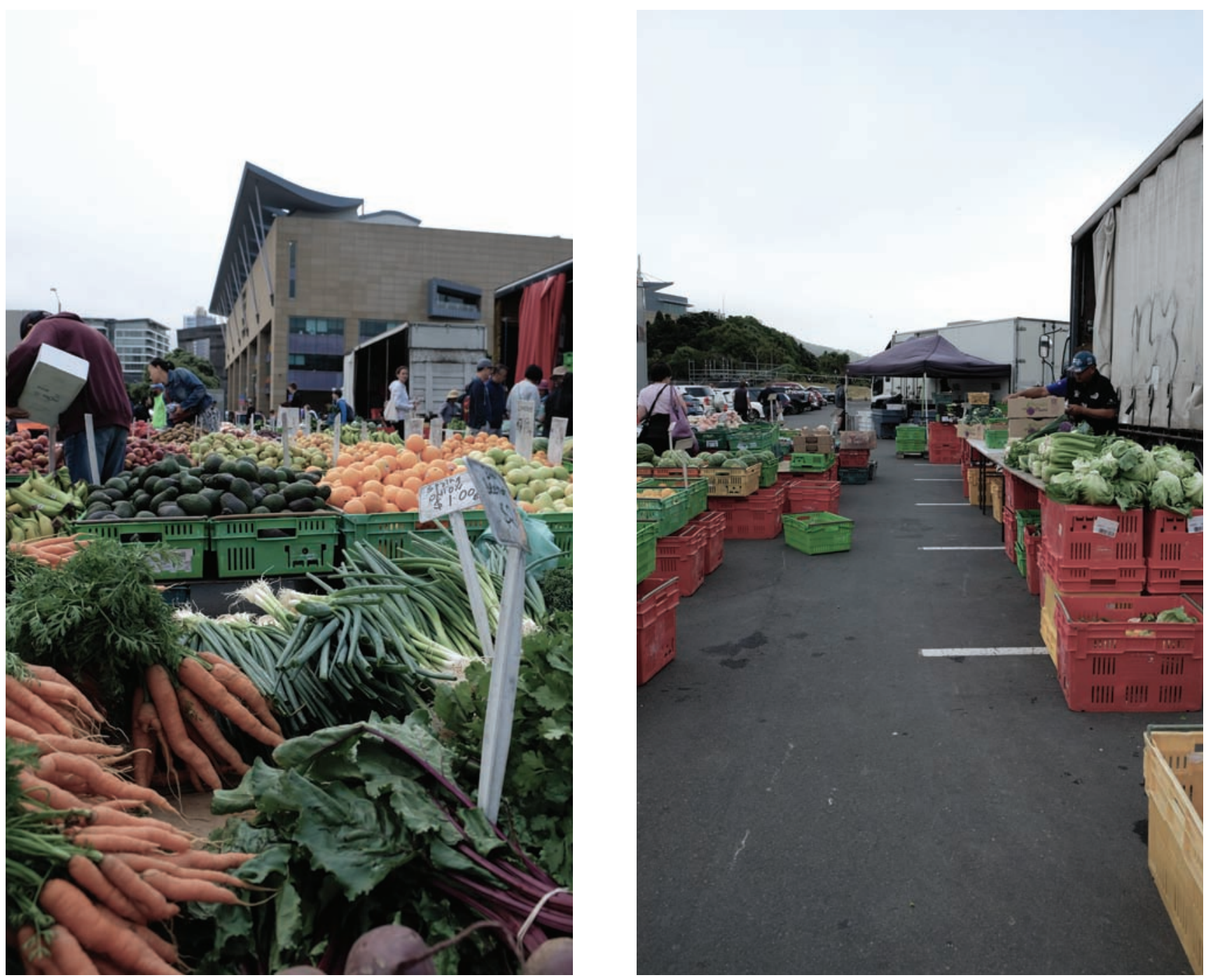

Every Sunday there is a fruit and vegetable market in the southeast corner of the carpark, which brings with it lots of food trucks and people. The potential of this waterfront location is evident with the creation of this temporary destination, it is such a valuable piece of the waterfront and has such a vast potential to be so much more than a carpark. The design outcome of this investigation will consider the re-location of this market to a nearby carpark that keeps it as part of the waterfront realm. 
Shade Created by Te Papa

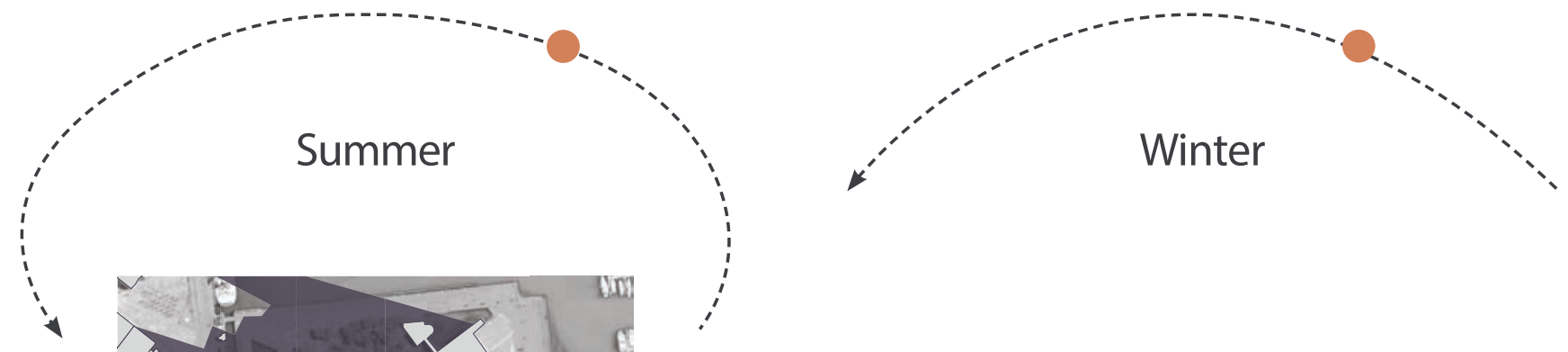

6am

9am
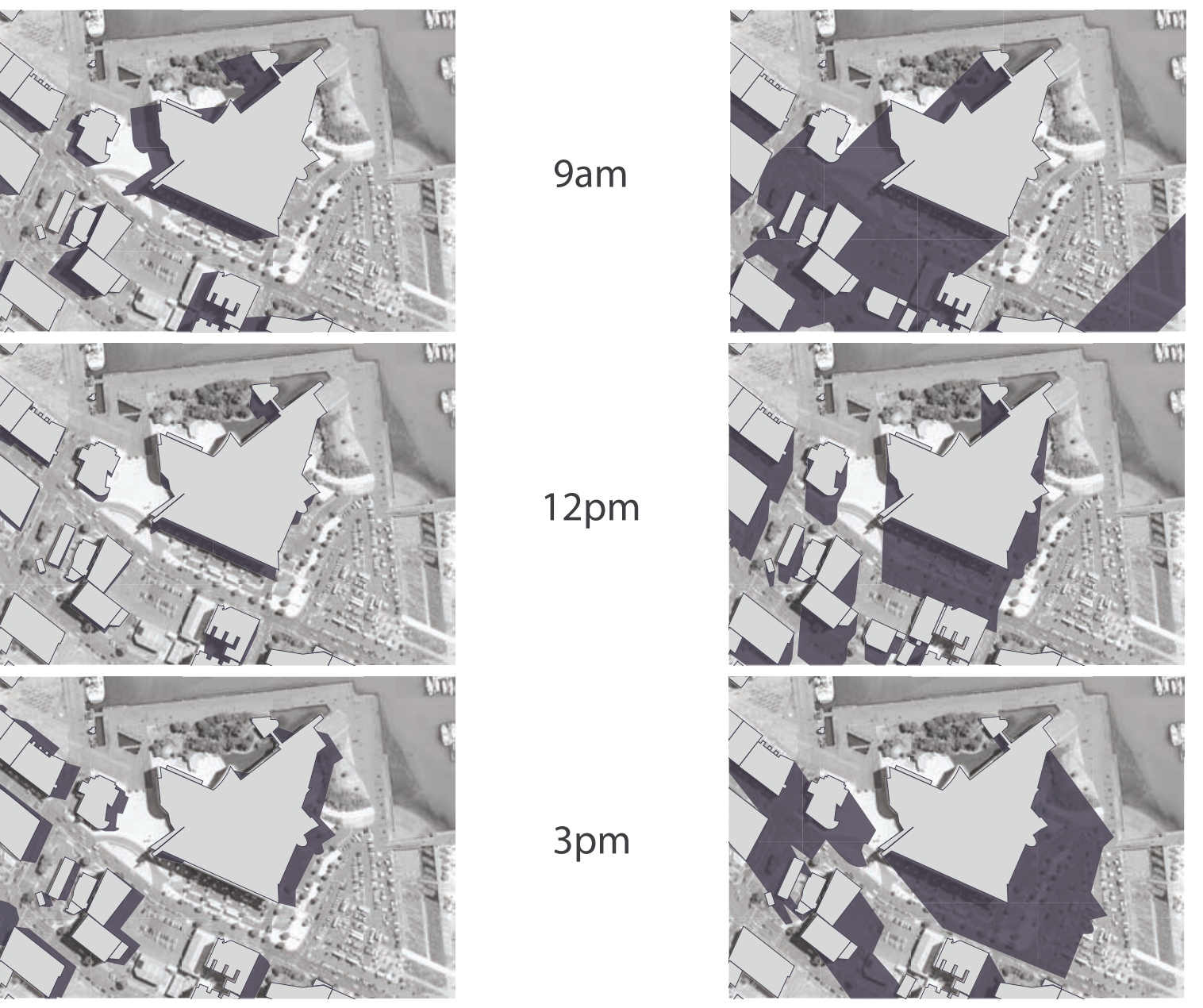

6pm 

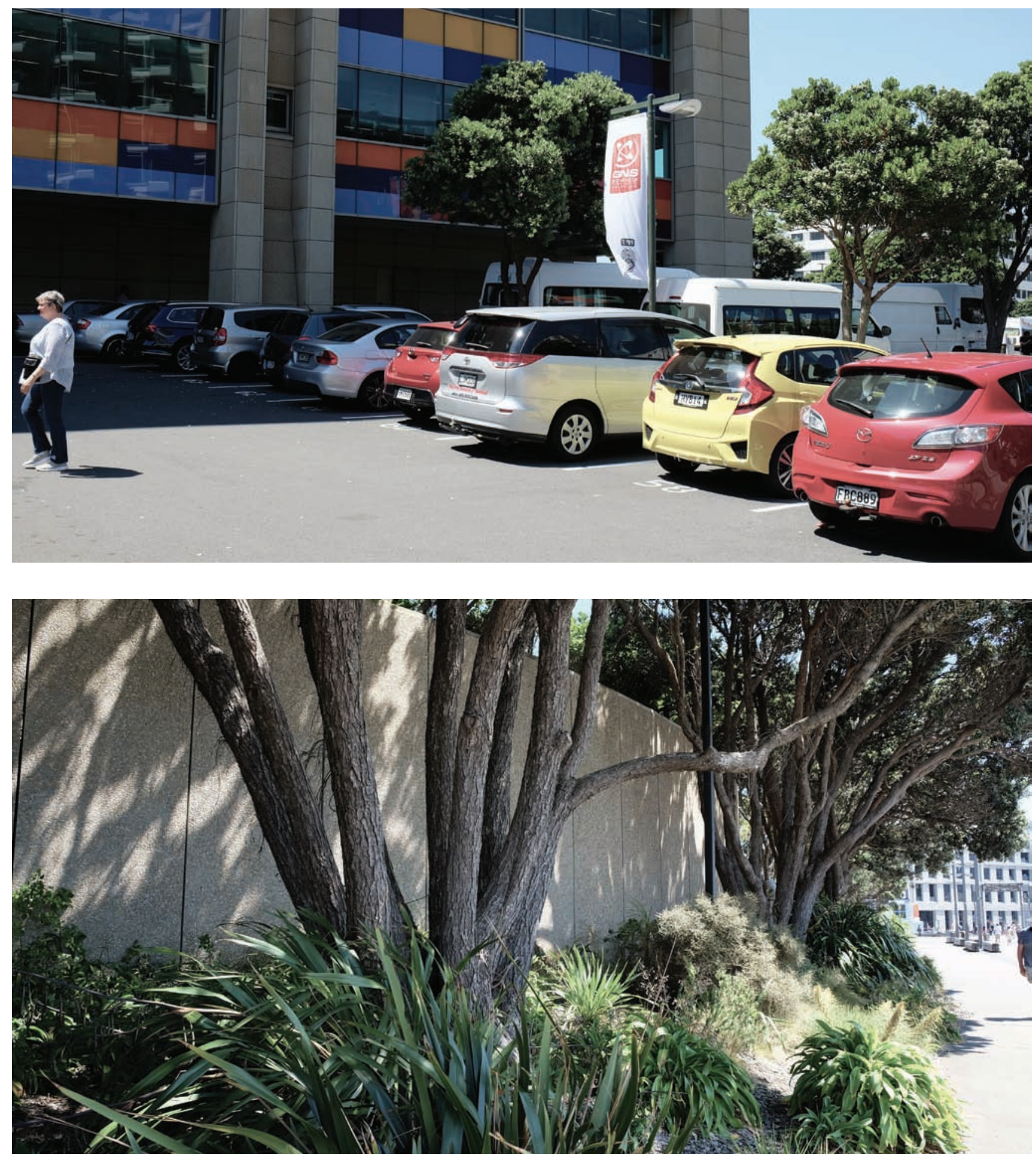

The southern area of the site is usually covered in shadow, the size of which changes throughout the day, while the northern areas are usually sunlit spaces that people enjoy to spend time, which is also the direction of the harbour view. The photographs above demonstrate the harshness of the shadow when it comes from the large building compared to a softer shadow created by planting.

Fig. 1.7.12 (opposite) Sun study of site during winter and summer, to determine what areas a significantly affected by the sun and shade the building creates

Fig. 1.7.13 Two locations where shade is created 


\section{BUILDING AFFECTS}

This research has looked into how the facades and edges around Te Papa affects the interaction people had with the areas around the building. The following section takes a step back and looks at the site from above to understand the tendencies of the movement around the edges of the building. This draws attention to the impact that such a large building mass has on the flows in this particular peninsular-like part of the waterfront. The first thing is how the movement is often pushed right out away from the building, this occurs because of the physical form of those spaces, and consequently prevents any engagement with the building to occur other than at the single entrance. Understanding how the building effects movement and how the current movement promotes certain types of lingering and restricts others provides the focus of a redesign that will coordinate the movement in a manner that increases the spaces for public life.

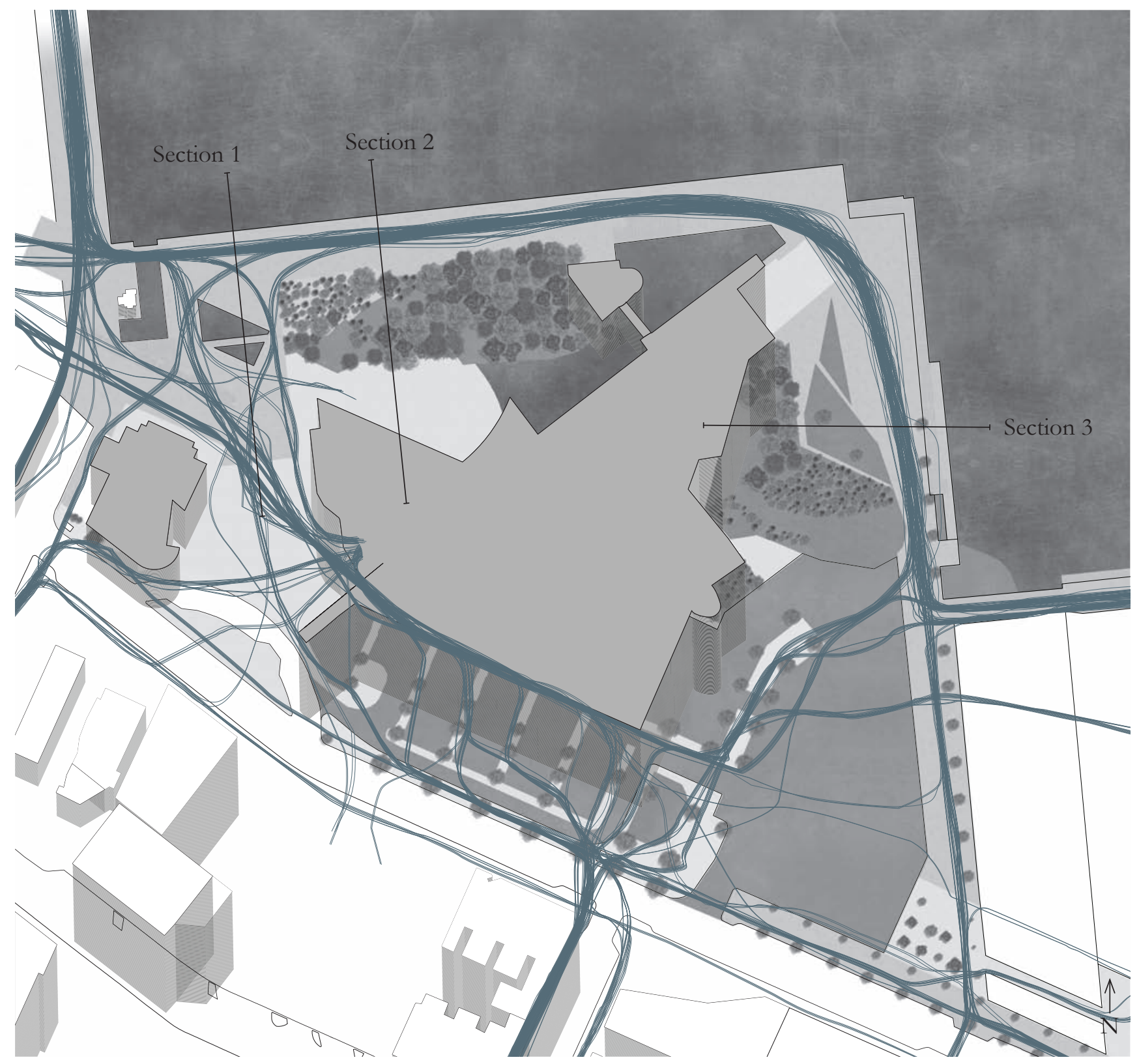

Fig. 1.8.1 1:5000 mapping of movement around building demonstrates how far away from the edge of building some movement is 


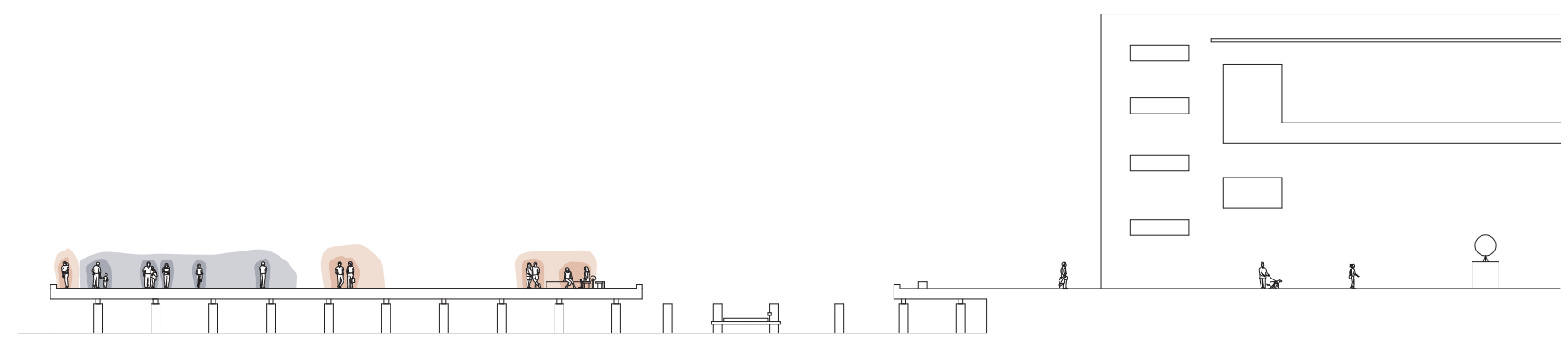

Entry

Fig. 1.8.2 Section 1 shows the density of activity that occurs near the waterfront perpendicular to Te Papa's entrance, although it also shows there is a limited amount of activity that occurs away from that location alongside Te Papa 1:600

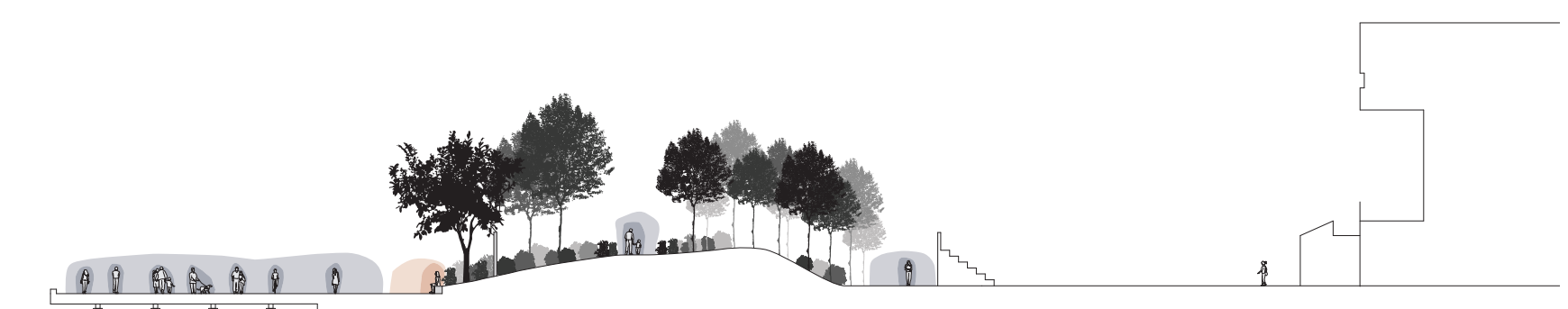

Front

Fig. 1.8.3 Section 2 shows how Bush City creates a huge divide in the site. Lingering occurs on the edge of the main movement along side Bush City, but very little activity occurs within the enclosed space even if the size creates a buge potential 1:600

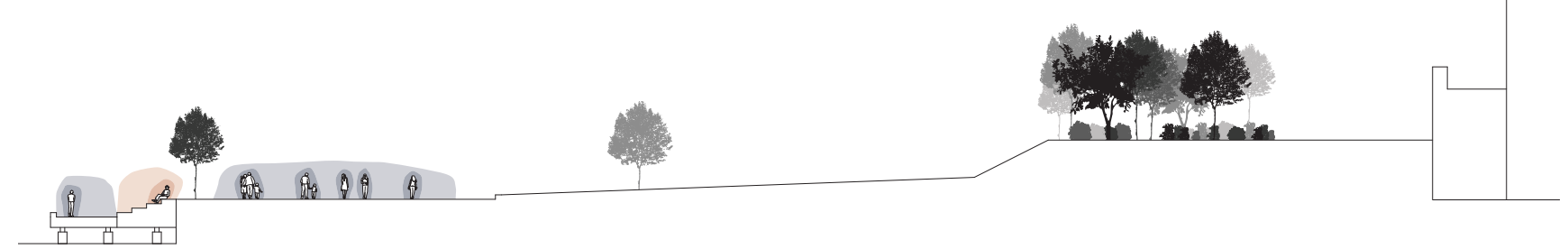

Side

Key:
Movement Zone
- Movement User
Lingering Zone
Lingering User

Fig. 1.8.4 Section 3 shows the vast distance between the movement and the building edge, the two movement flows and the one place that people lingering even though there is a wide open space to the right of the main movement 1:600 
Urban Scale Affects: Territory Creation

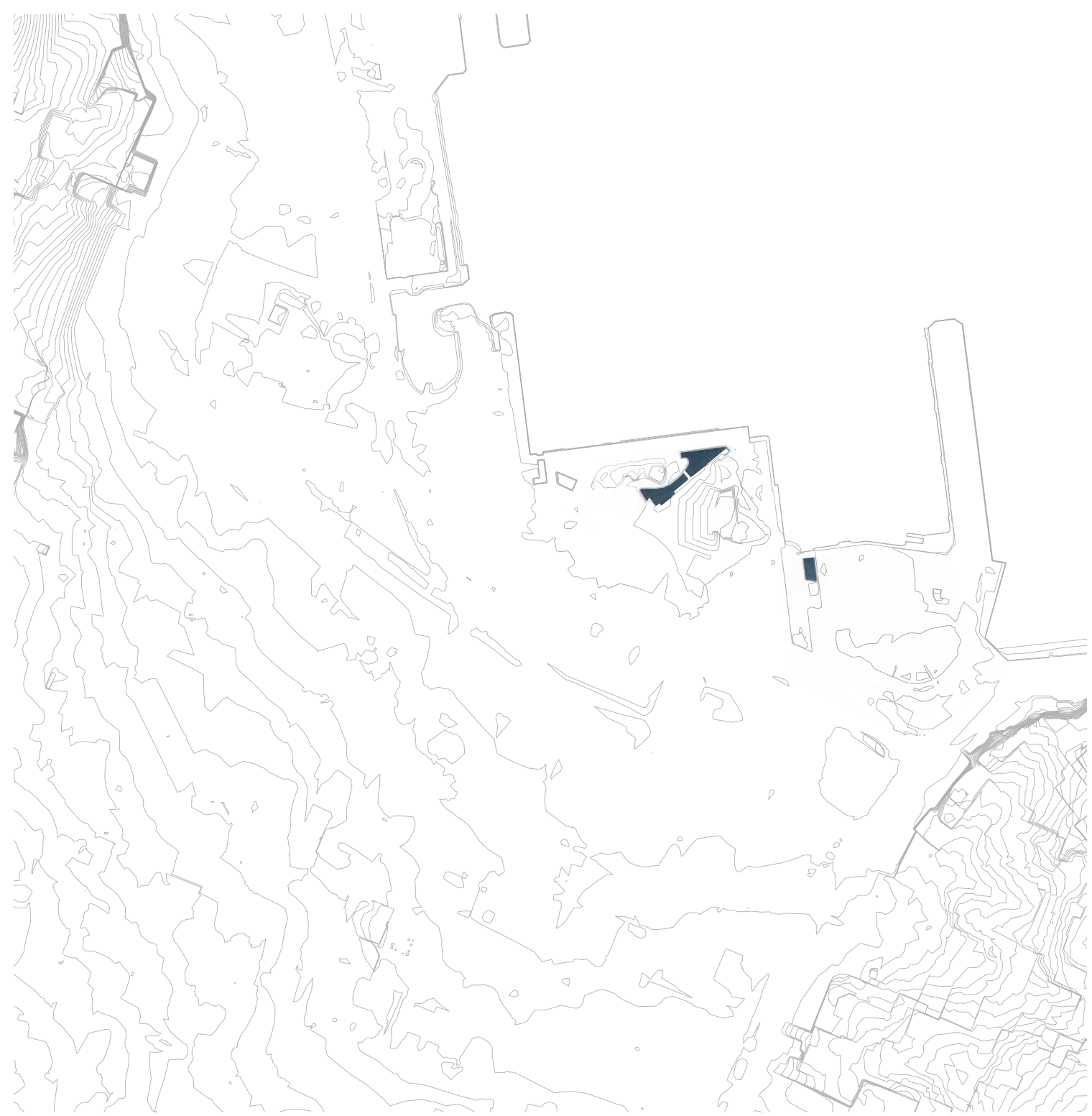




\section{Popular Gathering Space}

This area of the waterfront is one of the most popular. It allows for a variety of types of diverse activities. This space is an existing gathering space, so has the potential for the people using this space to spill out into newly designed spaces.

\section{Te Papa's Plaza}

This is a large, open public space that has the potential to hold various activities however is usually only used as a $\mathrm{n}$ entry and exit area for Te Papa or a temporary waiting location, a taxi stand cuts it off from the city. A change in materiality and sculpture displays marks a divide between this space and the waterfront.

\section{Waterfront Promenade}

The promenade is a moving public space or flow, its potential lies in the fact that it currently directs people around the building. There is always people using this space so enhancing the other spaces around it will invite people to engage with them as well.

\section{Sunlit Bush Enclave}

Bush City has created a massive divide between the waterfront public space and its internal courtyard, because of the inability to access it due to a large wall and steep terrain. It has a huge potential to give the users of the waterfront a new experience; nowhere else can people find themselves within a sheltered bush environment on the waterfront or central city. The large courtyard and pond area is an extremely sunny area, although its positive aspects are under appreciated because the restricted access hinders people from occupying this space.

\section{Raised Quay Lookout}

Te Papa offers non-public access to the building on the second floor that requires a level change of 4 metres. This creates a raised lookout point with a view of the marina and harbour, though it is not utilised. The level change also creates the opportunity for a new type of edge engagement that is not in other areas around the building. The promenade currently pulls people away from these potential interactions.

\section{Generous Public Space Potential}

This is a considerable area of valuable waterfront land, however, the existing carpark prevents any public engagement to happen in this area. It remains undeveloped since it was first constructed and does little to enhance Te Papa or Wellington's waterfront. Other waterfront locations continue to upgrade as their uses change, but this area has not changed to fit the way public use of the waterfront has changed.

\section{Shaded Bay}

This more narrow yet large space located between the dominant building of Te Papa and a busy inner city road, along with the existing carpark, creates the perception that this space cannot be an inviting public space. The building itself separates this space from the potentially popular plaza. The southern wind hits the south face of the building and pushes it down into this space. The shade created by the building onto the space creates the opportunity to install wind shelter elements without worrying about the shade they will create, which could lead to a new public space that although is shaded would be sheltered from most of the harsh Wellington winds. 


\section{CHAPTER ONE CONCLUSION}

This chapter helped establish an understanding of how Te Papa influences the movement of people, including an exploration of the people that are involved in this movement and those that engage in other activities within the site. This understanding of public life will inform how the new design will be occupied and how to design a space that reflects the needs of the people using it. This research has begun to recognise and understand how a building can both produce and disrupt public life and the city because of its design and placement in the landscape. Furthermore, this chapter worked to gain a clear idea of how the interior of Te Papa functions and the possible connections that could be made or enhanced between the interior and the landscape.

The research undertaken in this chapter provides a platform from which to evaluate future design testing. The movement mapping and observational studies ensure the future design analysis mappings will be precise and specific in relation to how the local public life would respond. 
$a^{2}=\therefore a^{2}$

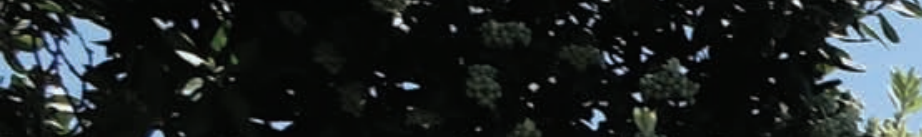

A $\quad \therefore \therefore \sqrt{2}=\sqrt{3}$

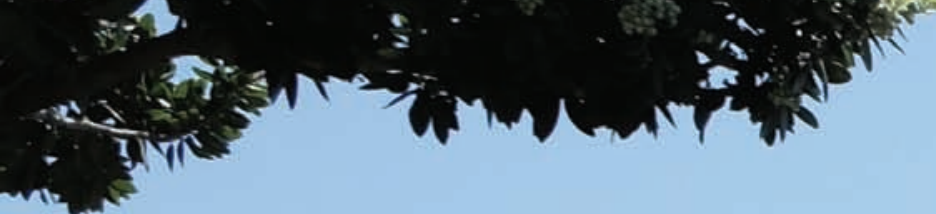

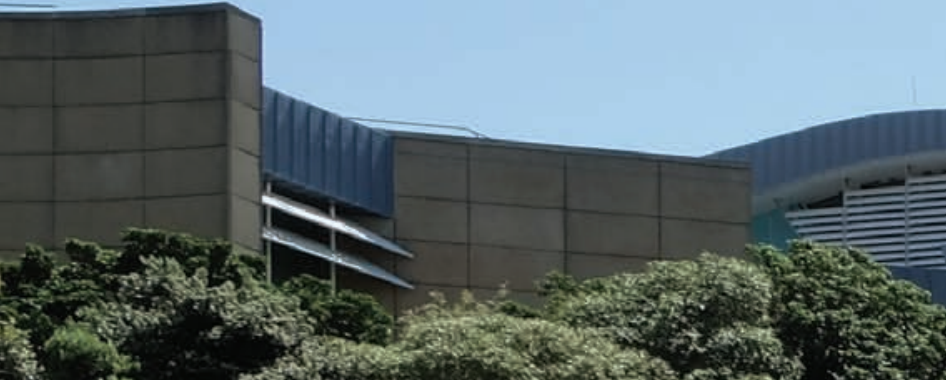

15: th S.1.

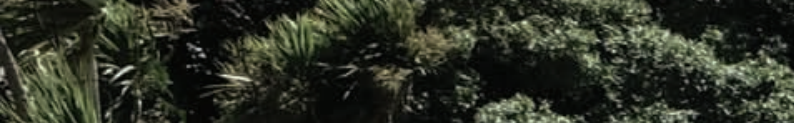

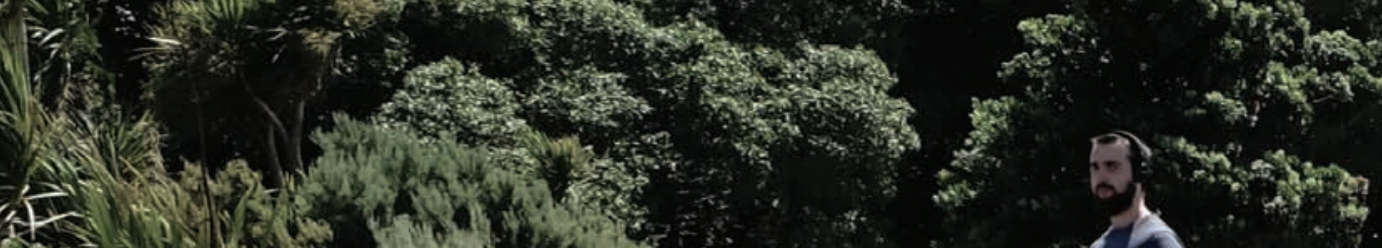

(a) 1 (1)

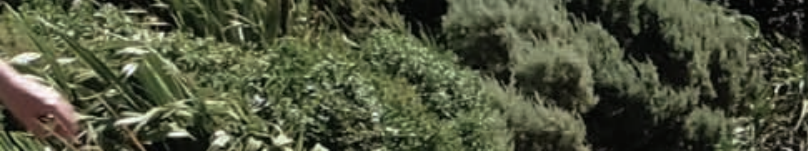

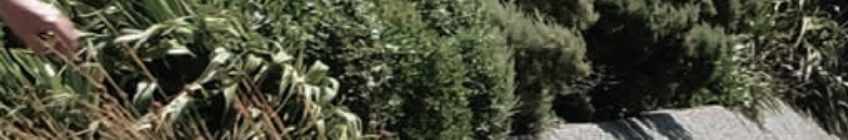

3.

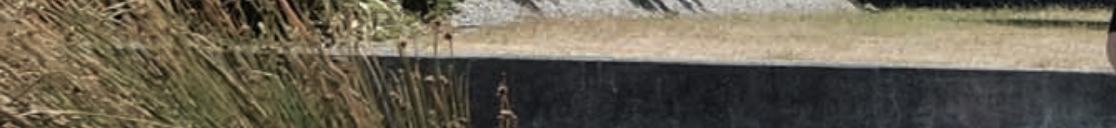

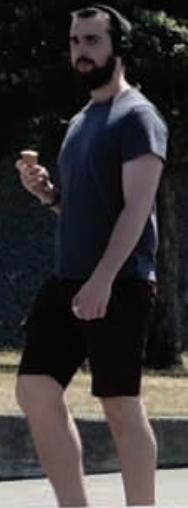

Hor 300 and

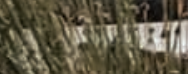

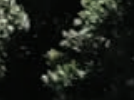


Site History

City Goals

WaterfrontDevelopment

Te Papa Concepts

Te Papa Development

Aspirations \& Criticism

Chapter Conclusion

\section{BACKGROUND
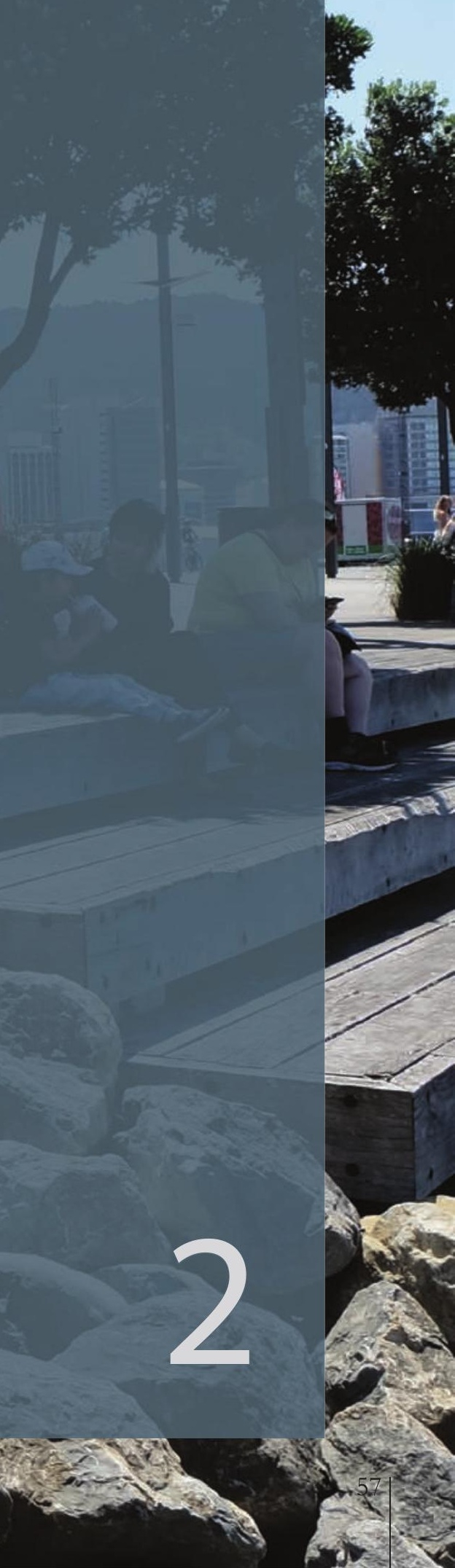
'Public spaces should change with the changing goals of the city' (Carr, Francis, Rivlin, \& Stone, 2009)

This chapter explores how the waterfront has developed over time and how the city has changed since the construction of Te Papa. The research also examines the concept stage of Te Papa's design, how that changed before the final construction of the building, and the future development forecasted by the architects at the time of construction and which has not been realised. Understanding these two different perspectives on opportunities for this waterfront location will be of significance when reflecting on what the final design strategy could mean for Wellington and its ever-changing public realm. 


\section{CITY GOALS}

1998

It is essential to understand that at the time of the designing of Te Papa the majority of the waterfront was not the vibrant public space that we see it as now. However, in 1998, the council did create plans to 'develop the waterfront as a major open space with frequent connections to the city, significant green areas and continuous public access along the water's edge' (Yska, 2006). Around the time Te Papa opened, approximately only 5,000 people lived in the city centre (ID Community, n.d.). This was just the beginning of the increase of Wellington's population density and with it the demand for open public spaces and increasing desires for those in the inner city to connect with the natural environment and the waterfront area. Goals for the development of the waterfront included:

- encourage people to experience the natural environment while living in this vibrant capital city

- use and enhance sustainable recreation and leisure environments

- to provide a wide range of opportunities for people to use and enjoy the city's open spaces

- give people the choice of mixing and matching their recreational activities through recreational networks and corridors

- enhance the features that make Wellington unique

- interweave and complement the built and natural environments

- develop the waterfront as a major open space with frequent connections to the city, significant green areas and continuous public access along the water's edge (Yska, 2006)

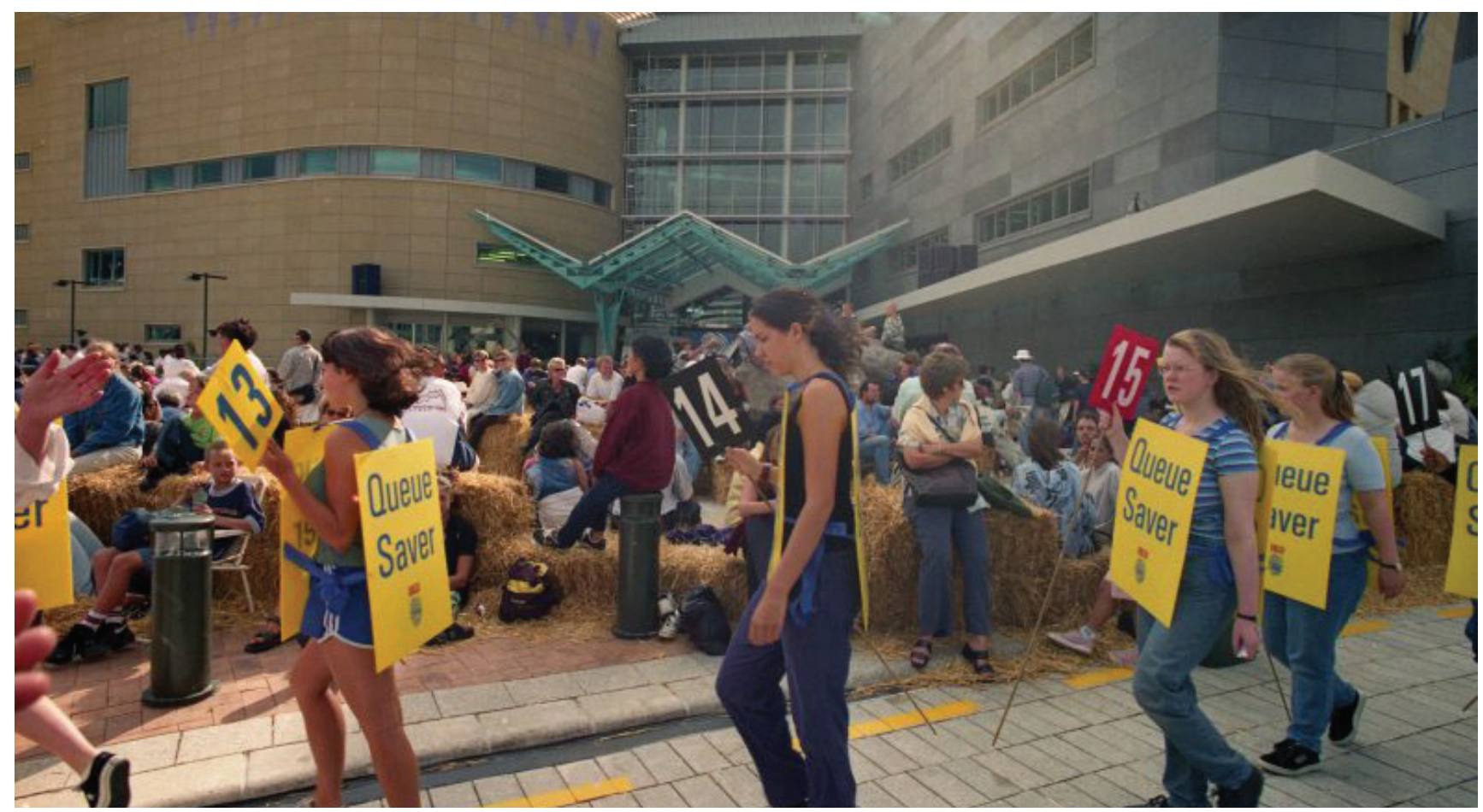

Fig. 2.1.1 Opening day of Te Papa 1998 


\section{8}

With an approximate population of 16,500 and an estimation for this to double by 2040 (ID Community, n.d.), it is essential to continue to create and develop public spaces within the city to ensure that everyone living in the city has the opportunity to interact with the unique physical landscape. With limited spaces available within the compact city, the city constantly requires a review and redevelopment of current spaces to keep up to date with the population increase and their needs. Several other goals of the city at this time were:

- enable people to feel connected to each other and their communities

- find a way (as a smaller city) to stand out and position ourselves

- provide activities that help people feel connected to one another and to their city

- Wellington needs a city that can support and integrate a diversity of people, not just attract them

- actively plan for population growth

- give physical expression to the city's identity in new buildings, public spaces and integration with the natural environment

- ensure that inner-city urban development is adaptive with the ability to change over time

- continue to support and grow mixed use in the city

- clearly define waterfront areas and make their link to the city more explicit (Wellington City Council, 2011)

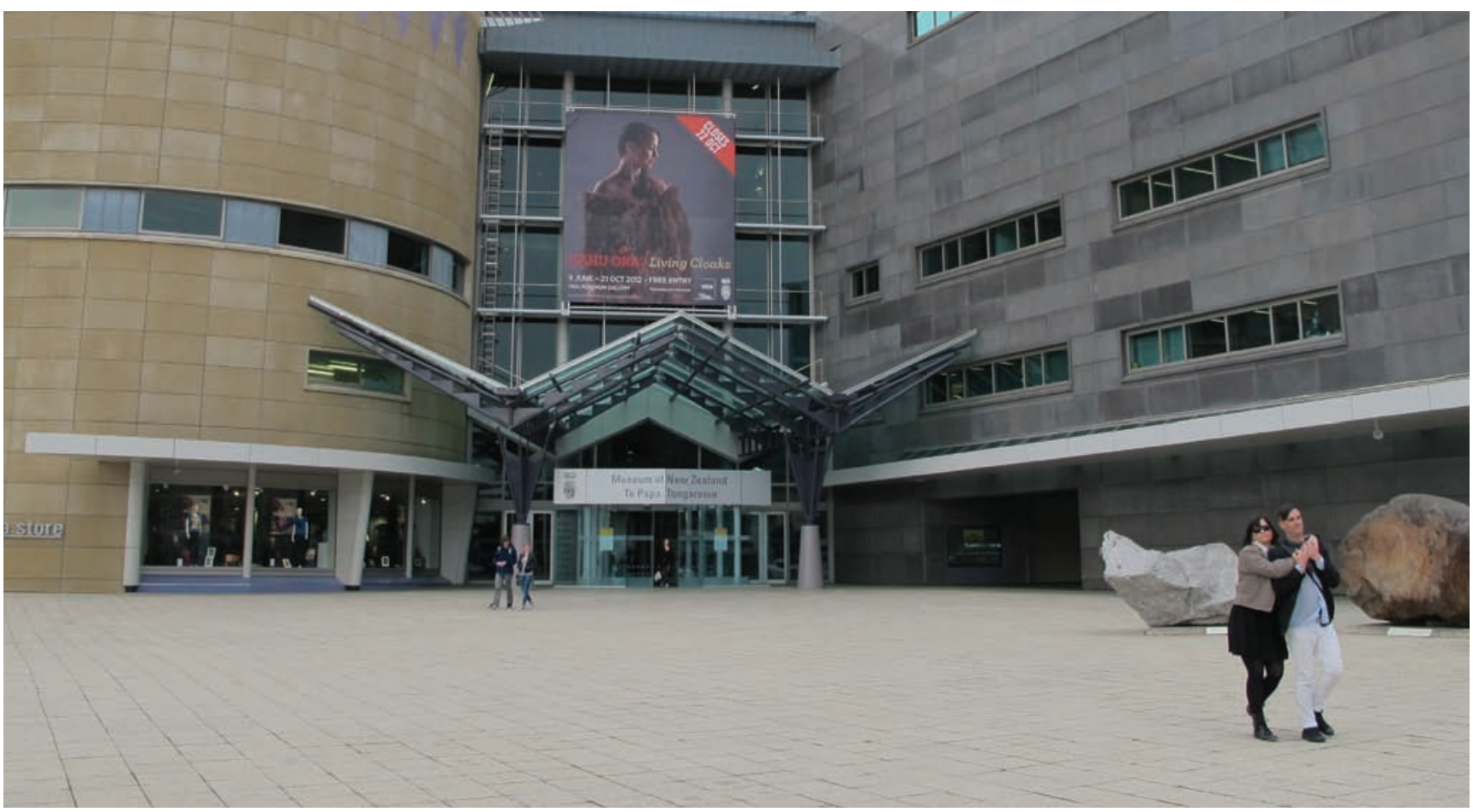

Fig. 2.1.2 Te Papa's large often empty plaza now 


\section{WATERFRONT DEVELOPMENT}

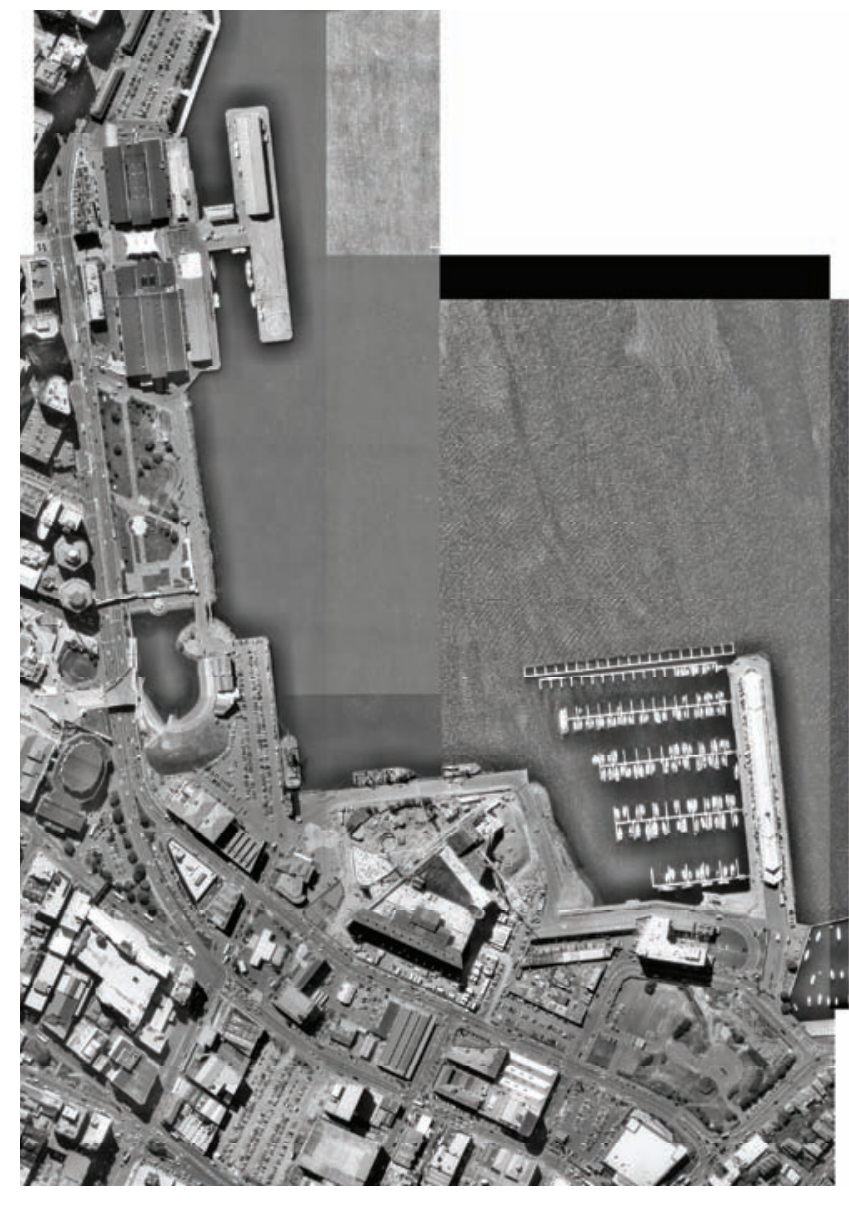

1996

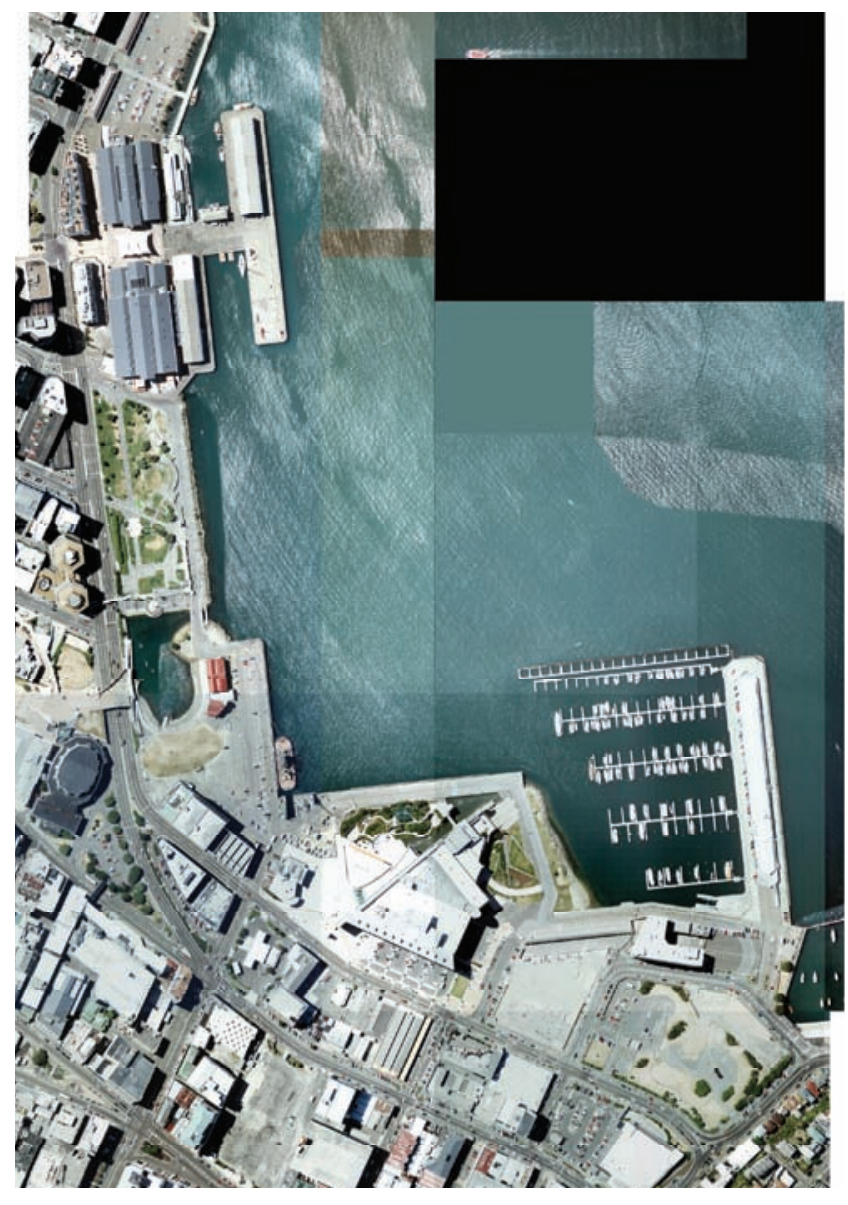

1999

Te Papa was under construction at this point and the majority of the waterfront was car parking. An annual streetcar race that looped around the waterfront influenced the design of Frank Kitts Park (tz17's Motorsport Videos, 2014)(Eventfinda, n.d.). Because the start of the race occurred on the strip of concrete between the park and the water, the edge of Frank Kitts Park was raised several metres to ensure public safety and act as a lookout for the beginning of the race, disconnecting the park from the waterfront. 


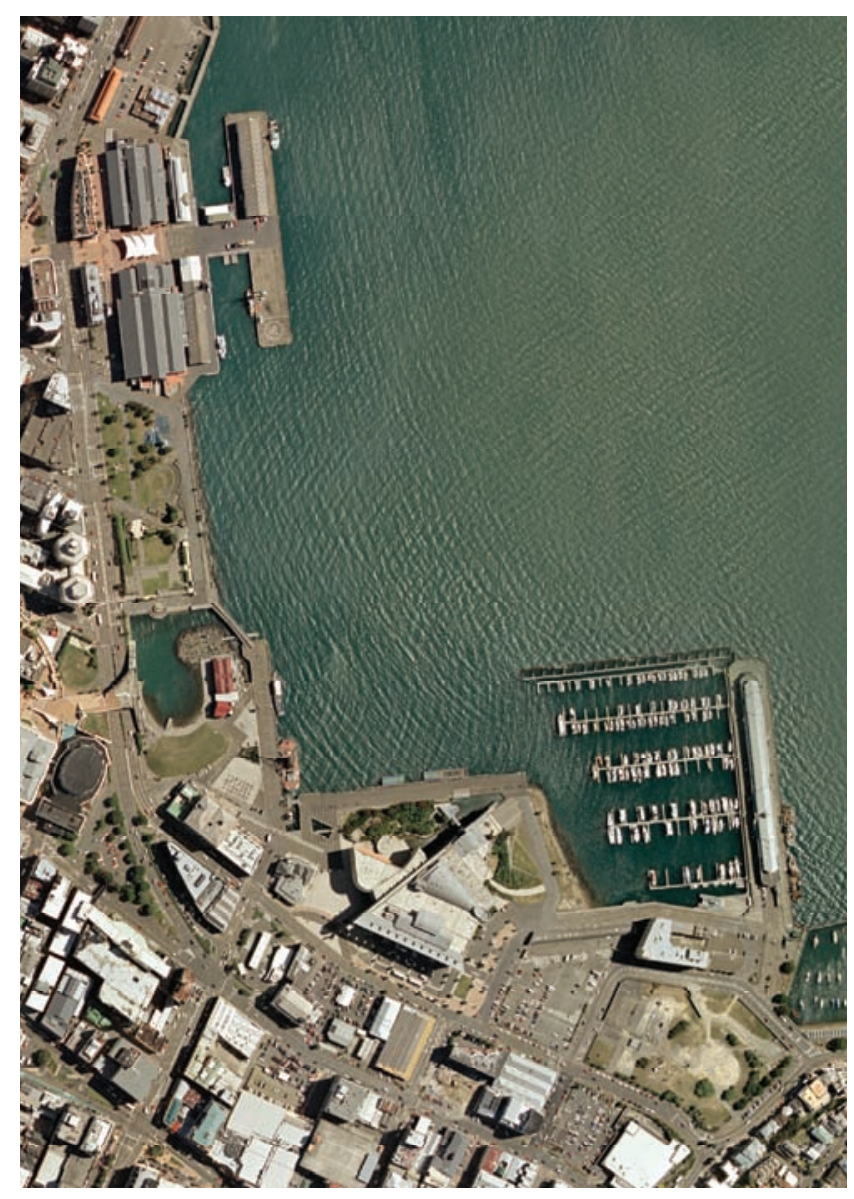

2004

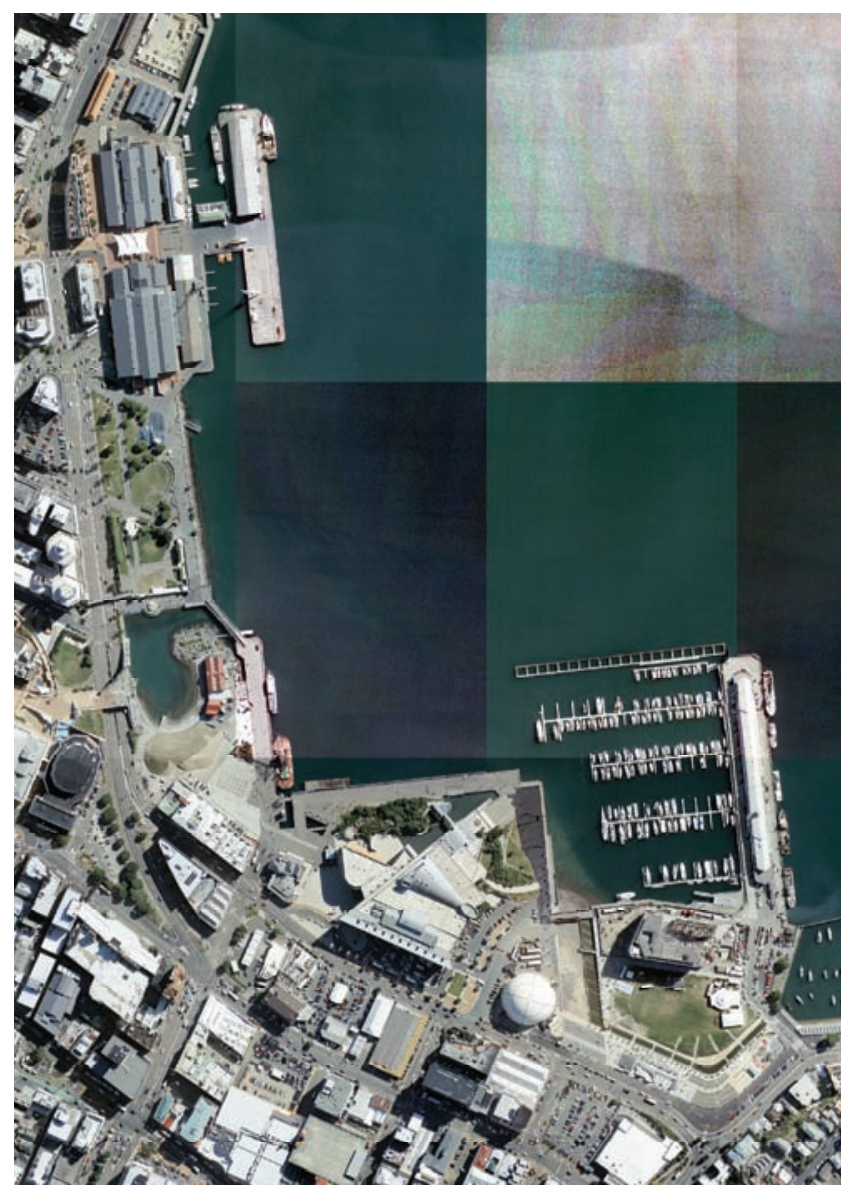

2006

Early 2000s saw a shift in the occupancy of the waterfront, with several new areas that allowed public engagement. A pedestrian bridge replaced the old Dunlop Bridge which invited the beginning of a waterfront promenade. Odlin's Plaza and a grassy hill created a brand new public space on the waterfront where people could enjoy the sun and harbour views. In 2006, Wraight + Associates were involved in the redevelopment of the park space now called Waitangi Park, which involved streamlining the promenade, extending the wharf edge right over the water. However, this left a triangular leftover space between the park and Te Papa that has since just become a carpark, even though Wraight + Associates considered how this would alternatively work as a connection zone from city to sea (Landezine, 2016). 


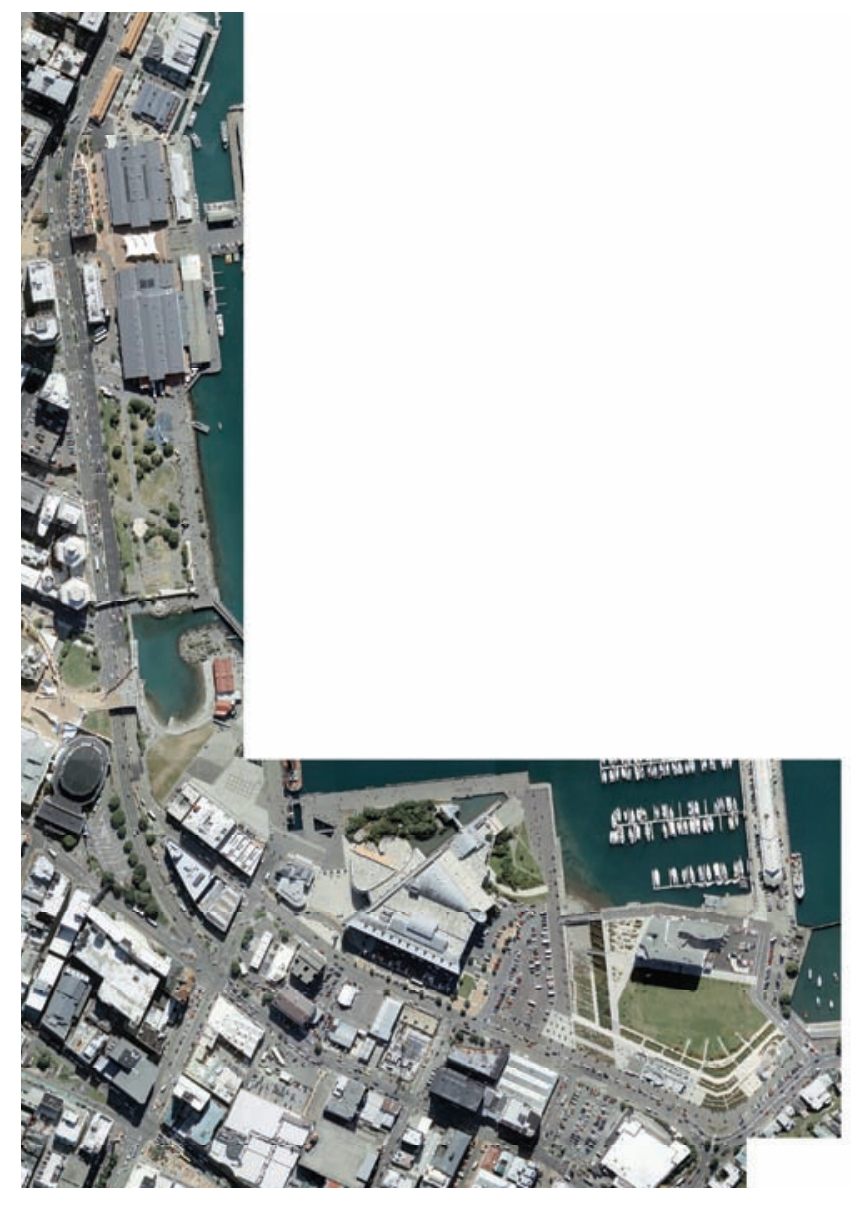

2008

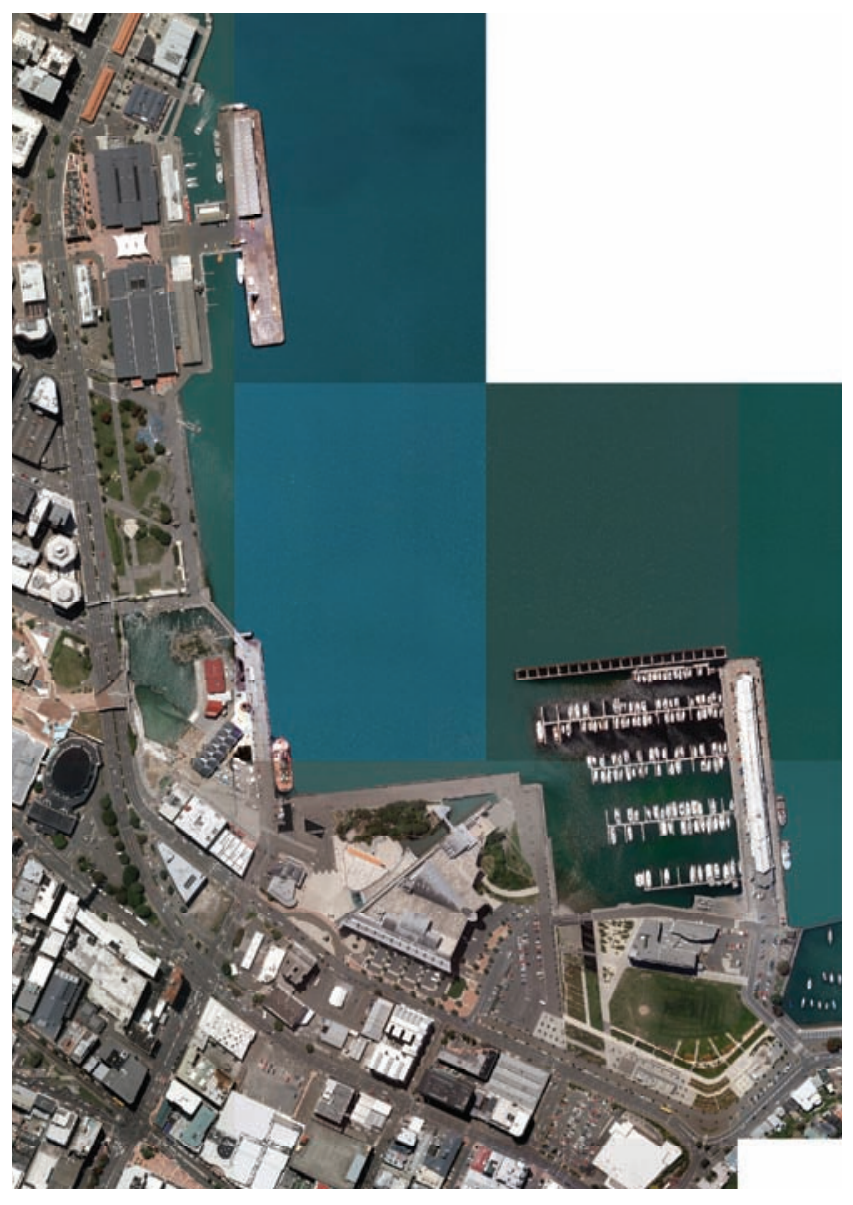

2011

Te Wharewaka o Poneke and public spaces around the lagoon were created in this period. This provided further connections with the water. 


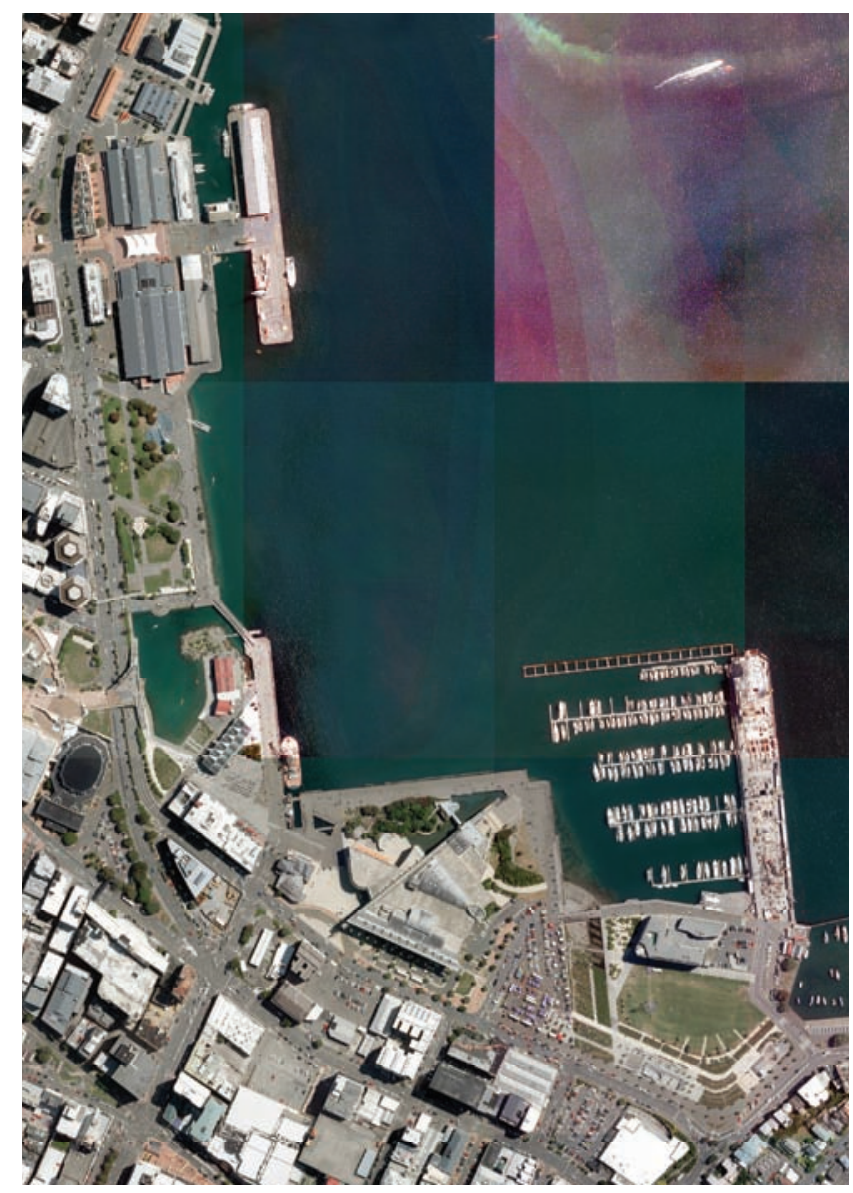

2012

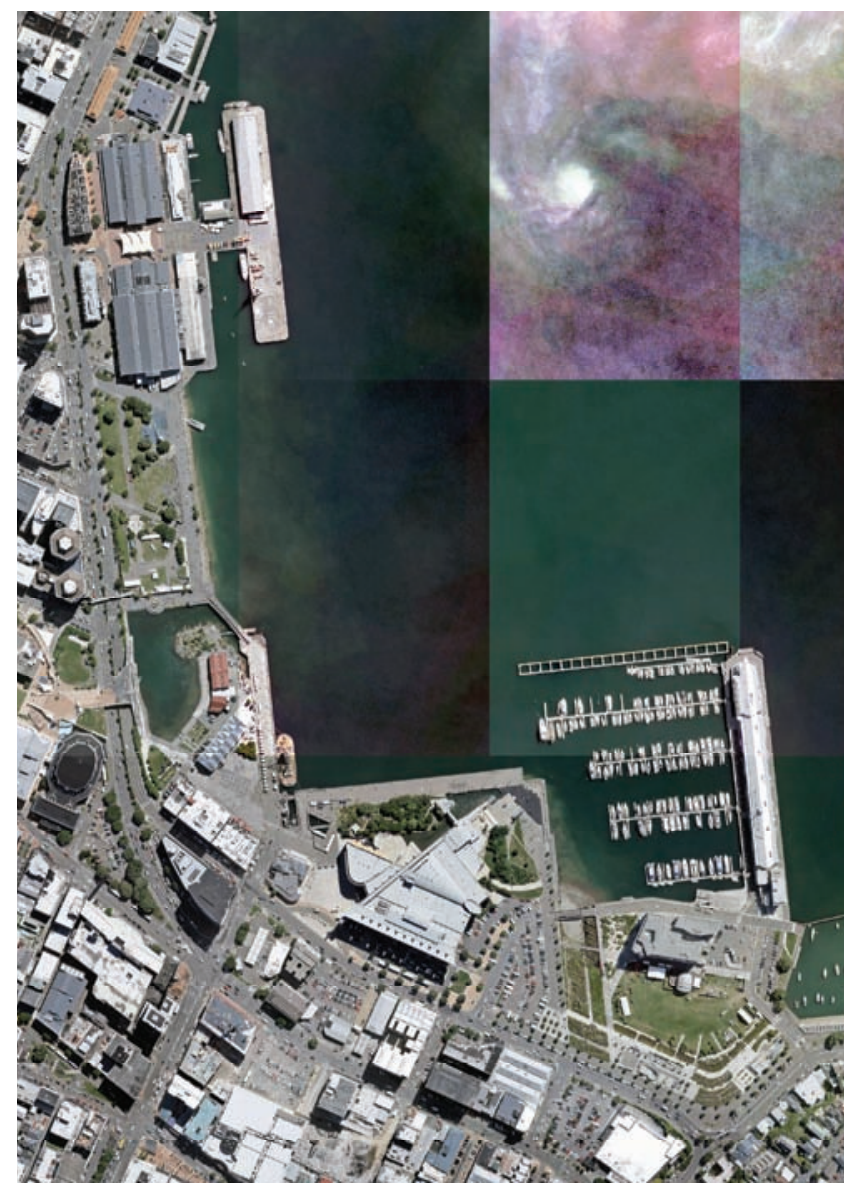

2017

Clyde Quay Wharf was redeveloped as high-end apartments in 2015, and since then there has been very little new development of the southern end of the waterfront. 


\section{Un-constructed Plans for Waterfront Development}

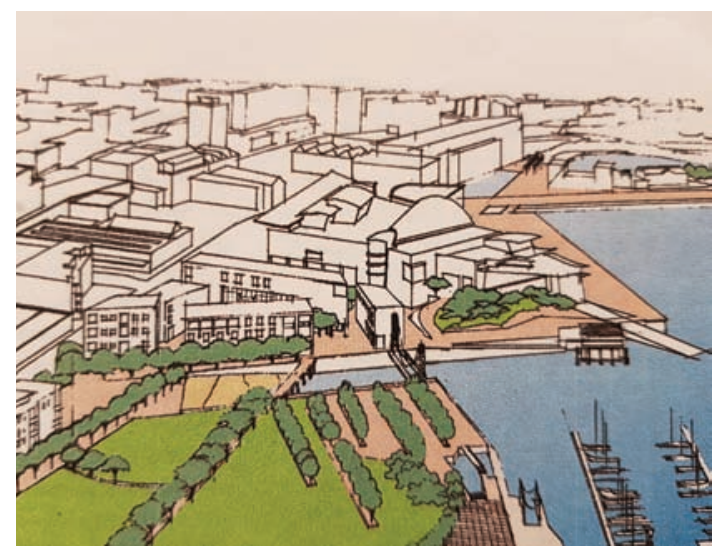

\section{High DensityWaterfront Apartments}

\section{Cancelled}

A collection of apartment buildings were proposed for the site to the east of Te Papa to ensure that the giant form of the building did not stand alone and look out of place with such a flat landscape. This, however, was just an architectural concept and not something picked up by the council (Niven, 1998).

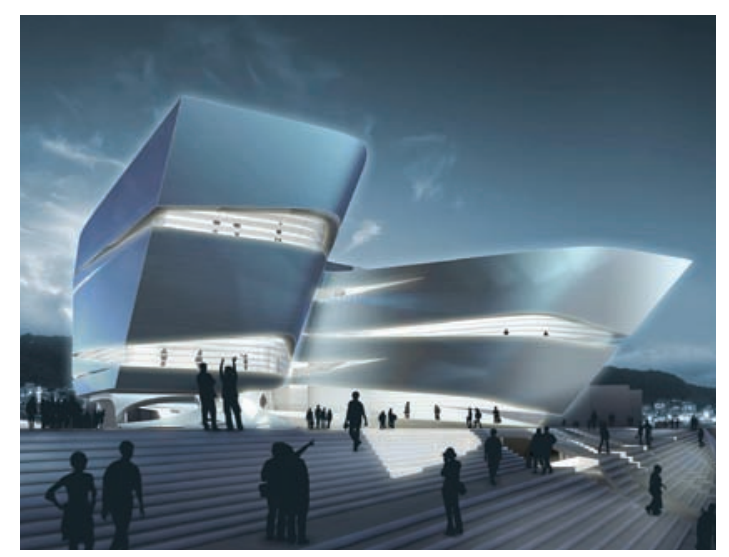

\section{Waterfront Art Gallery}

\section{Cancelled}

This concept won a 2015 design competition to extend Te Papa's art collection to a stand-alone building, once again in the site east of Te Papa. However, it never proceeded further than a design competition concept (UN Studio, 2015).

\section{Frank Kitts Park}

\section{Under Development}

A redesign of Frank Kitts Park has been under development for several years, with the Environment Court finally granting the project its resource consent in 2018. This redesign orientates the park towards the harbour in to order to achieve the connection with the neglected water's edge (Wraight + Associates, 2007).

Fig. 2.2.9 Artist's sketch of high-density apartment concept

Fig. 2.2.10 Render for art gallery concept by UN Studio

Fig. 2.2.11 Render for Frank. Kitts Park redevelopment by Wraight and Associates

Fig. 2.2.12 Render for Convention Centre by Studio Pacific Architecture

Fig. 2.2.13 (opposite) Location for the proposed convention centre

Fig. 2.2.14 (opposite) Article reporting that the initial proposal was discarded 


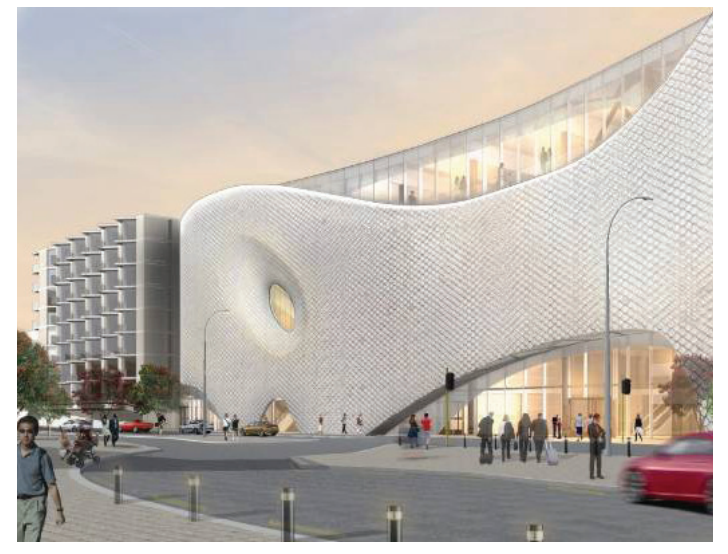

\section{Convention Centre/Movie Museum}

\section{Under Development/Replanning}

A concept for a convention centre and movie museum proposal opposite Te Papa with shared ownership between WCC and Peter Jackson. However, budget and contract issues have resulted in the two partners going different directions, leading the site to be solely a convention centre, which requires a redesign before it can continue. (Newshub, 2018).

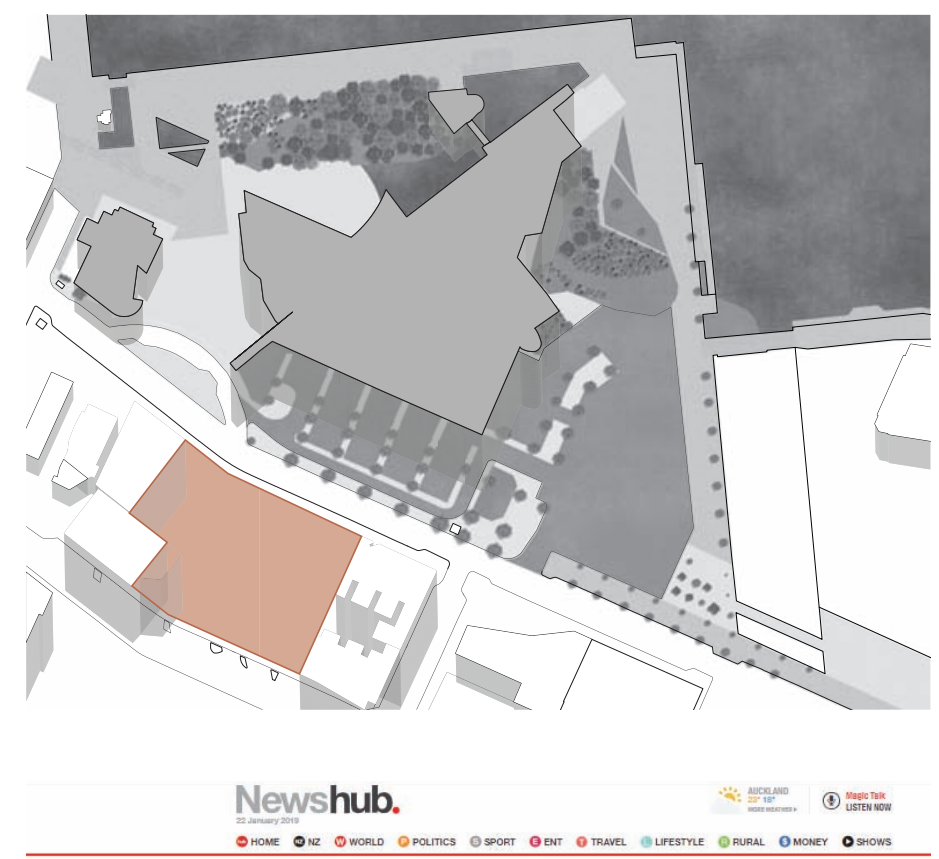

Peter Jackson's Wellington movie museum plans scrapped

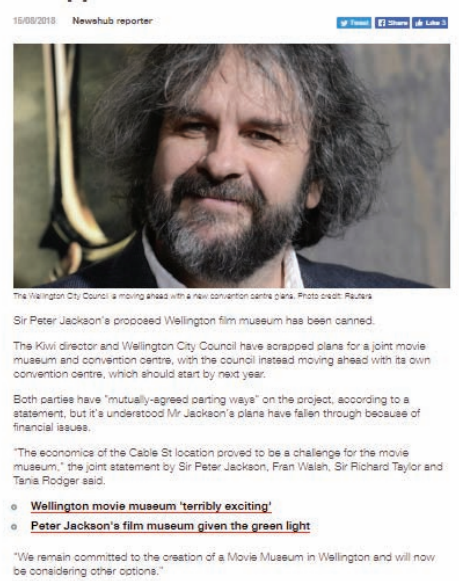




\section{TE PAPA: CONCEPTS}

The competition brief for Te Papa's design requested a concept that expressed the bicultural nature of the country, explored and preserved the heritage of culture and knowledge, and respond to its waterfront location in the capital city. The following five concepts were short listed following the initial stage of the competition (Architecture New Zealand, 1990).
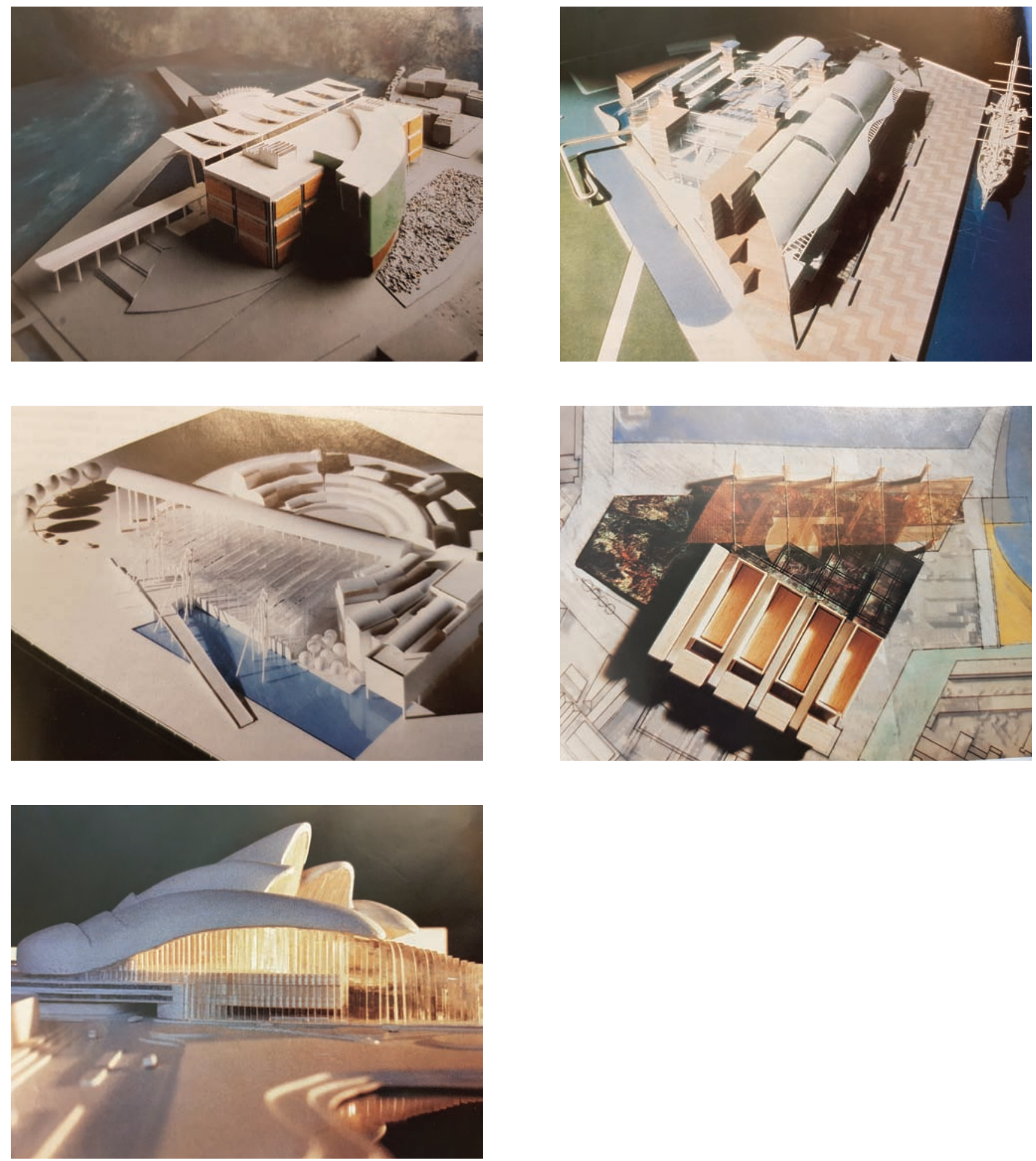


\section{TE PAPA: DEVELOPMENT}

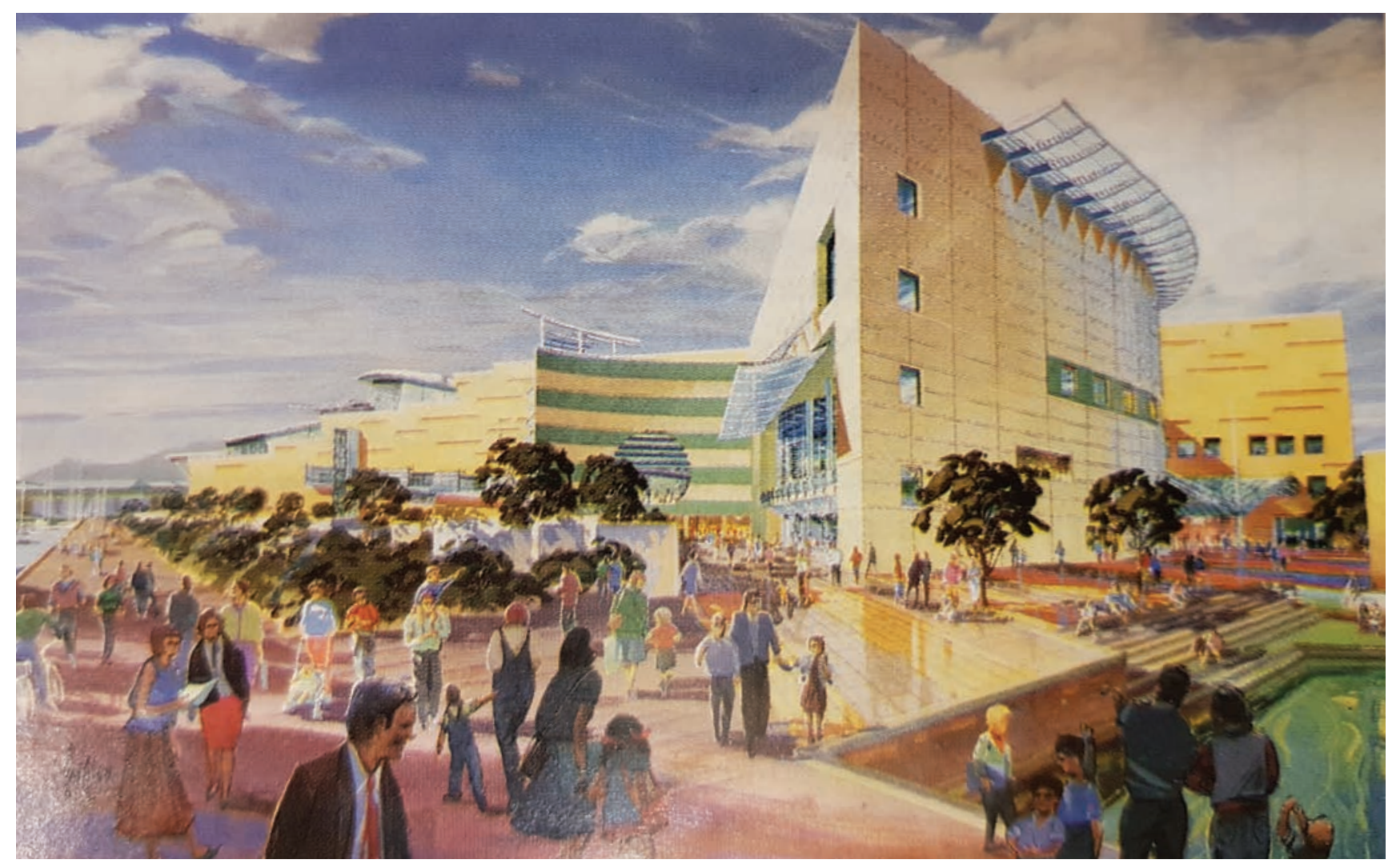

One strong theme that the architects wanted to continue through the design was 'encounter', which resulted in an isolated world of discovery that required the design to be fully internalised and lose most connections the original concept had created with the environment around it (Reid, 1998). A major thing lost in the development stage was the connection with both the city and the waterfront that the initial concept strived to create (Niven, 1992) (Niven, 1998). 


\section{ASPIRATIONS \& CRITICISM}

The original design of Te Papa aspired to be a national icon that celebrates an encounter of cultures, more specifically bringing together the identities that make up New Zealand's bicultural nature. The architecture of the building would respond to its context, and create connections to the city, Civic Square and the harbour, by the use of a large wall that represented an axis of the North Island and reflected Te Papa's placement within the city. This axis wall would extend from the edge of the city right up to and over the water's edge, lowering itself down to the harbour and inviting people to engage with the water and the built form of Te Papa. The wall would also act as the centre of all cultural aspects of the internal makeup of the museum. Likewise, it would be the physical place of 'encounter' and pull both cultural halves of the museum together (Reid, 1992). Te Papa was going to be the centrepiece of the city and create a new vibrancy within Wellington.

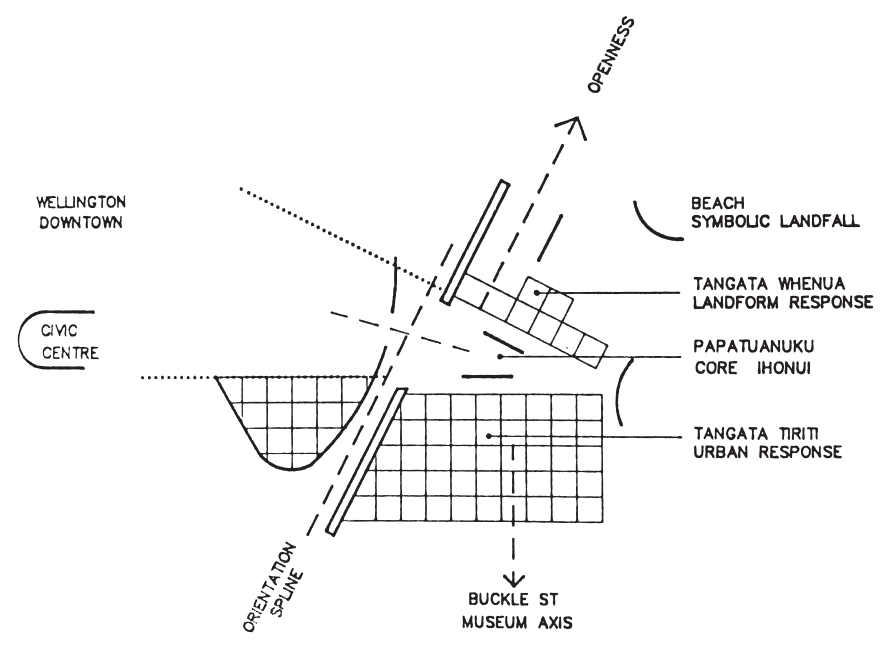

Fig. 2.5.1 Concept diagram by Jasmax

These aspirations for a significant public space both inside and outside were unfortunately not followed through and the building that was designed did not reach the level of interaction that concept implied, as both a museum space and as a significant effector of public life in the city. During the design revision stage, there were many people dictating the direction of the project; consequently, this resulted in a building that was significantly altered from the concept.

The first major change that occurred was to pull Te Papa away from the edge of the water and have a wide path between it and the harbour, this decision was made primarily to allow the car race to continue around the waterfront. The introduction of Bush City further reduced any chance Te Papa had to create a connection with the water. Bush City was created as a museum exhibition and is a place that showcases many native plants and allows people to interact with a 'natural' landscape. In a 1992 interview, the principal architects stated that the introduction of the concept for Bush City did indeed remove any chance of fulfilling Te Papa's original concept of a strong connection with the water, but that it made sense looking at the space from a 'museological point of view' (Reid, 1992). They attempted to rectify this with the introduction of a pond that ran alongside the axis wall, however, this remained partially hidden from the public so people did not engage with it as the architects had desired. 


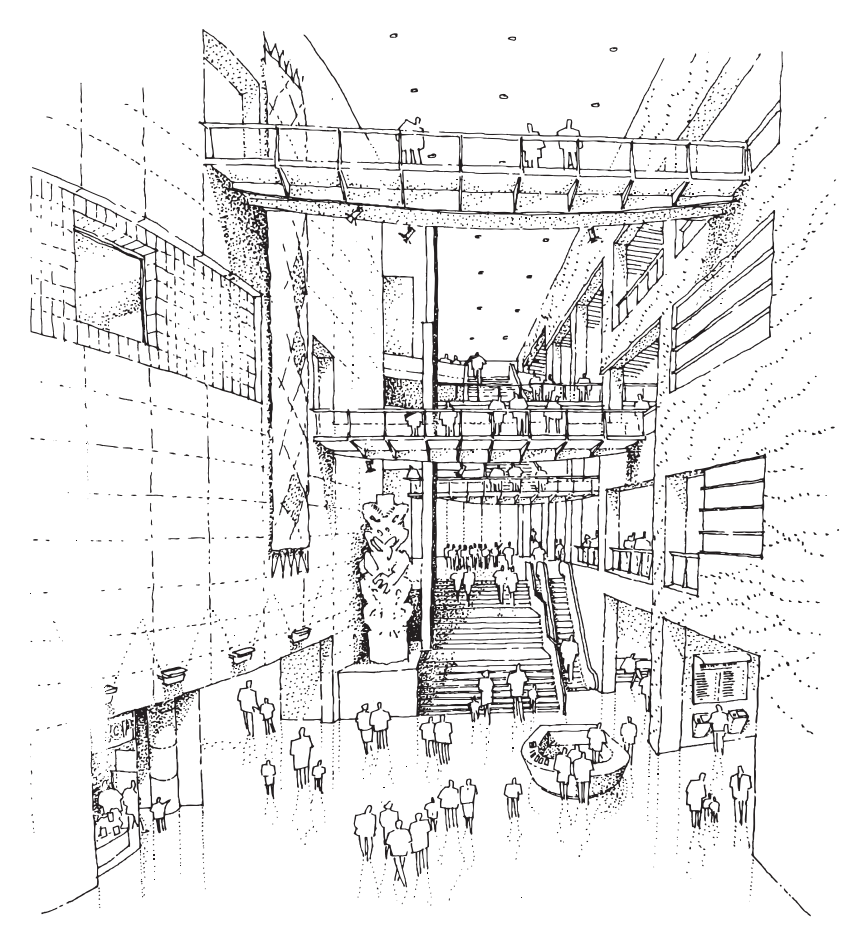

Fig. 2.5.2 Concept sketch of atrium space by Jasmax

The 'axis wall' was meant to be a connecting feature of the building, for both internal and external elements, however it completely disrupts what could be a potentially powerful introduction to Te Papa and strong connection to the city. The wall cuts through the landscape, defining the edge of the plaza and directing people in towards the entrance, which could be seen as a positive by itself, however, it completely cuts off the southern side from the plaza, which leaves a space that had the potential to be a large civic space that celebrated Te Papa's connection with the city to be neglected and considered back-of-house.

An article written before the opening of Te Papa describes the final built form as a 'building externally remote from central Wellington' (Reid, 1992) and discusses the failures of the Council to design and plan with the foresight of potential development of the site in regards to public life and movement around the city. The configuration of the waterfront and the lack of public life within the waterfront realm at the time of Te Papa's design resulted in the architecture not responding to the possibility of this changing and the result is a building that removes any possibility for new public life unless drastic changes are made to the built form. In 1998, those familiar with landscape architecture/urban design were already aware of several simple things that could have improved the landscape and public engagement with the site around the building. In particular, Niven creates a list of four initial changes that would 'repair some of the dysfunctional aspects of its setting'. These involve:

- 'Physical support for the museum's peninsular form'

- 'A re-assessment of the space between the south face of the museum and the city'

- 'A modification of the walled edge between [Bush City] and the waterfront'

- 'The ability to determine a complementary scale of the buildings to the east and west of the museum'

(Niven, 1998)

This research will work to develop some of these and provide new proposals for the site based on the current movement within the city and waterfront, as well as a consideration of future development and population increase that will occur. 


\section{CHAPTERTWO CONCLUSION}

This chapter helped establish a clear history of the site and the influencers in play during the design and construction of Te Papa. Past writing and opinions on the issue at hand provides support and further knowledge that will inform the design phases. Also, being aware of the original aspirations that the initial concept for $\mathrm{Te}$ Papa is important when determining the direction the design might take, as they can be reincorporated into the design.

Reflecting back on the development of the waterfront makes clear the lack of attention given to this location since its construction, and the lack of spaces that are redeveloped in order to keep up with the changes occurring in the city, both physically and socially.

Moving forward, this chapter fuels the need for a redesign of this space because a changing city deserves a changing public realm that responds to their needs as a collective, and as individuals. The clear criticism that came about before Te Papa had even opened its doors, also backs up the research and justifies the need for it. 
13. 


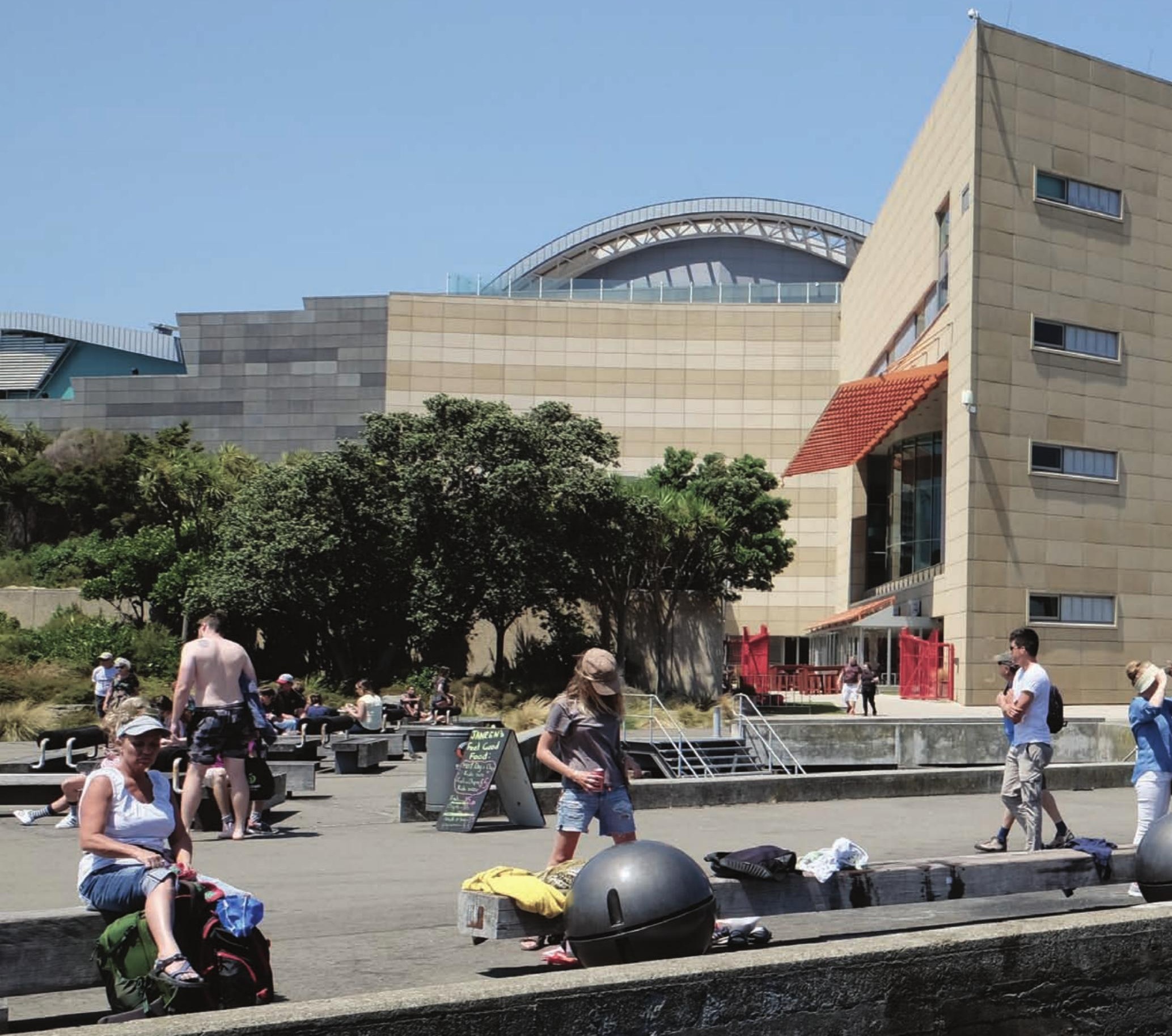





\section{LIFE BETWEEN BUILDINGS}

\section{Jan Gehl 1971}

Jan Gehl proposed that people's perception of public spaces will determine the quality of it, their perception being influenced by their walking experience. Gehl's research looks into many different aspects of public life, he also discusses the idea that walking in public space is not just about movement, but it is about being present and having the opportunity to be a part of new activities. People make their own decisions about where they want to walk, and what designers can do is create routes that make the walking experience enjoyable and as easy as possible, which is going to increase the perceived quality for the person using the space.

Gehl discusses three different types of activities that cause people to use public space, and defines them as necessary activities, optional activities and social activities. Necessary activities are those that must be done. These will happen independent of the weather and things that are happening outside, including going to work or running errands. Optional activities occur when the weather and space allow for it and invite them to do so, for example taking a walk or going to the park. Social activities are spontaneous and are a result of current activities. (Gehl, 1971)

The distribution of these activities on the waterfront is slightly different from public space within the city because of the strong harbour winds and that it is not a direct route to most places in the city. The only necessary activity that occurs on Wellington's waterfront is the people that use it for exercise regardless of the weather. Many optional activities occur on the waterfront, these include eating lunch, looking at the view, strolling, visiting cafes and even more. The waterfront allows for many social activities when other activities are in abundance and the weather is inviting, these include people watching, an increase in walkers and patting dogs. It is a popular way to walk from one part of the city to another, but because it is not a direct route and does not provide shelter, people will use it when the weather is appropriate and inviting. People use the waterfront because it is a pleasant space to be in aesthetically and environmentally, and because they go there by choice, it is vital to design spaces that invite people to engage in optional and social activities. 


\section{Kevin Lynch 1960}

Kevin Lynch talks about 'the legibility of the city image' and the role it plays in the quality of the environment. A clear and coherent image of the city gives people freedom of movement. An important thing that Lynch discusses is that 'we must consider not just the city as a thing in itself, but the city being perceived by its inhabitants', often quality is about how people perceive the space rather than how the space is. The perception people have of a space determines their possibilities for movement.

We should not see public space as it is, but we need to look at through how people perceive it. Everyone has their image of a space, which can change over time as they use the space more or if they experience it under the direction of someone else who has a different image of the space. It is interesting that movement can determine the quality of the space and its image, and the quality of the space and the image that people hold of it can determine movement. (Lynch, 1960)

The conclusions taken from this text put forward the idea that public space is perceived differently based on how someone wants to use the space and any design produced for a public space must consider a variety of possible activities that could occur that invites a diverse amount of people into the space. This understanding relates to the idea of limitationsdiscussed in Chapter One. Ppeople will see and use a public space depending on their vector and how the space may allow them to engage in the way required for them. 


\section{Anita Berrizbeitia, Linda Pollak 2003}

The threshold between two spaces is where they are differentiate but also relate to each other, and it holds the potential to become an important space on its own that celebrates both sides of the threshold. The edges of these thresholds are where new activities can spontaneously pop up, where different users can interact with each other, and the potential of the space is introduced. This was very suggestive for the area around Te Papa, rich with multiple thresholds.

Another focus of this text is the disruption a building creates when placed in the landscape, and what opportunities that offers to both building and landscape. This disruption leads to a potential for the building to respond to the landscape in a way that physically reconstructs the landscape to create new spaces for public engagement, it also offers an opportunity for the building to create conceptual connections. In addition to reconstructing the landscape, a well-designed building will respond to the landscape through the thresholds between inside and outside, the interior can become part of the surrounding area and represents the landscape it is placed in. (Berrizbeita \& Pollak, 2003) 


\section{CHAPTER THREE CONCLUSION}

This Literature Review helped establish how other authors have considered public life in the city and what they believe are key factors in the functioning and enjoyment of public spaces. It also explored the relationship that can be created between interior spaces and landscape spaces.

The knowledge gained from the authors that discuss public life has been considered in relation to the research being undertaken in this thesis and helps position the research within the landscape architecture discipline. 


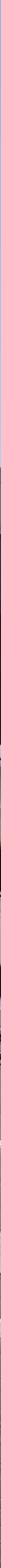





\section{DESIGN DIRECTION}

This chapter will explore the possible directions that the design could take through precedent studies and concept iteration. The previous chapters are the basis for this stage of the design-led research and informed three basic ideas for the exploration:

\section{Co-ordination of Movement}

\section{Opening/Activating Edges}

\section{Destination Creation}

The goal of this stage in the research is to start understanding how the site could be re-configured to facilitate public life. This stage looks at many different scales to ensure that both the overall movement of the site and how a single person can engage with the building are considered. It also is about trying to understand what people want to experience/achieve when they come to this site and elements in the physical environment that can allow for those things. 


\section{Co-ordinate Movement}

This section looks at three precedents that coordinate movement flows to create lingering opportunities.

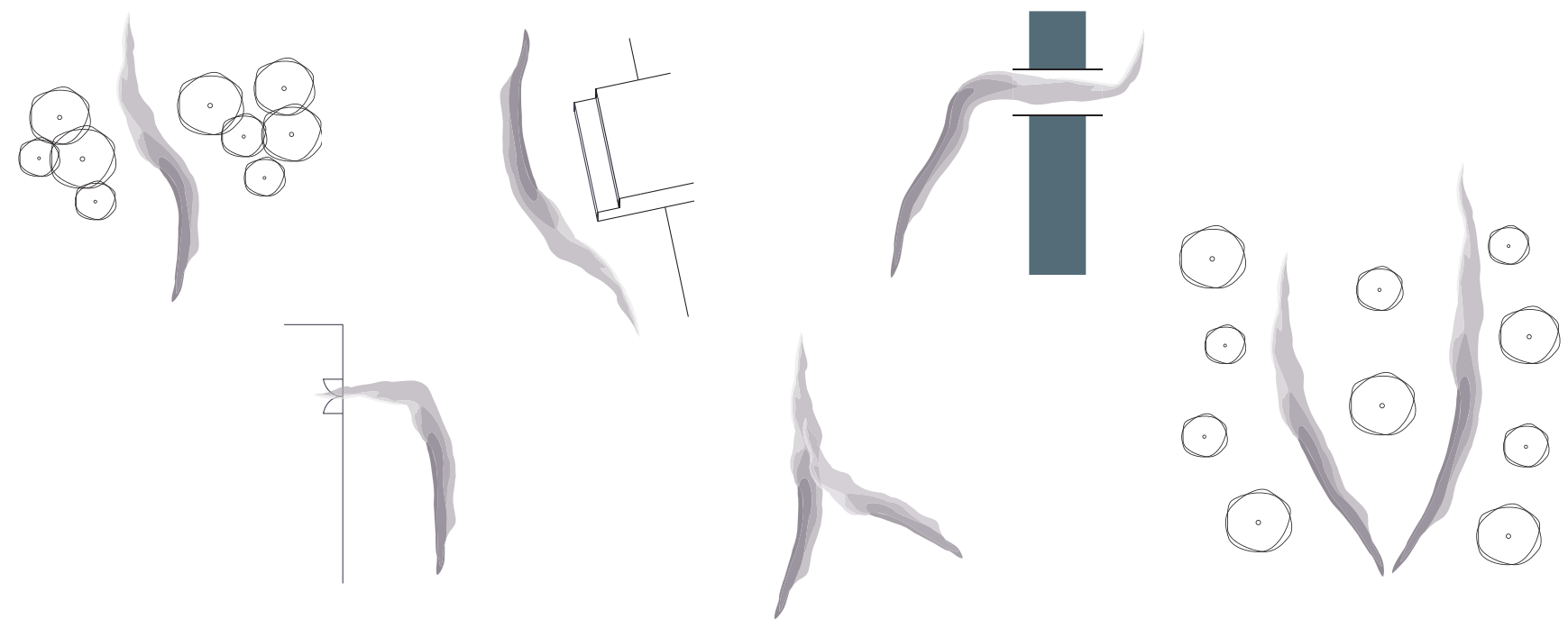

Fig. 4.1.1 Representation of how movement can be co-ordinated by physical elements in the landscape

\section{Chicago Riverwalk - Sasaki/Ross Barney Architects}
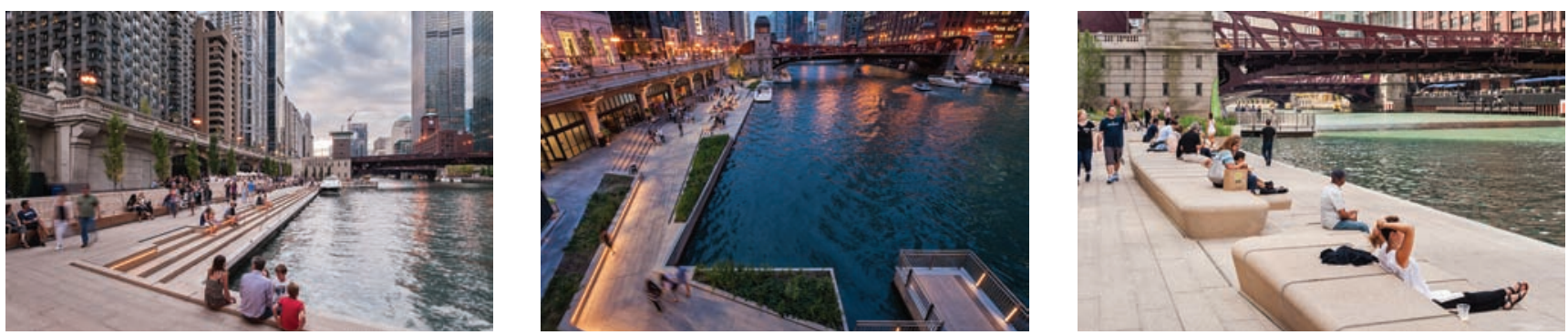

Fig. 4.1.2.1-3 Three photographs taken of the Chicago Riverwalk

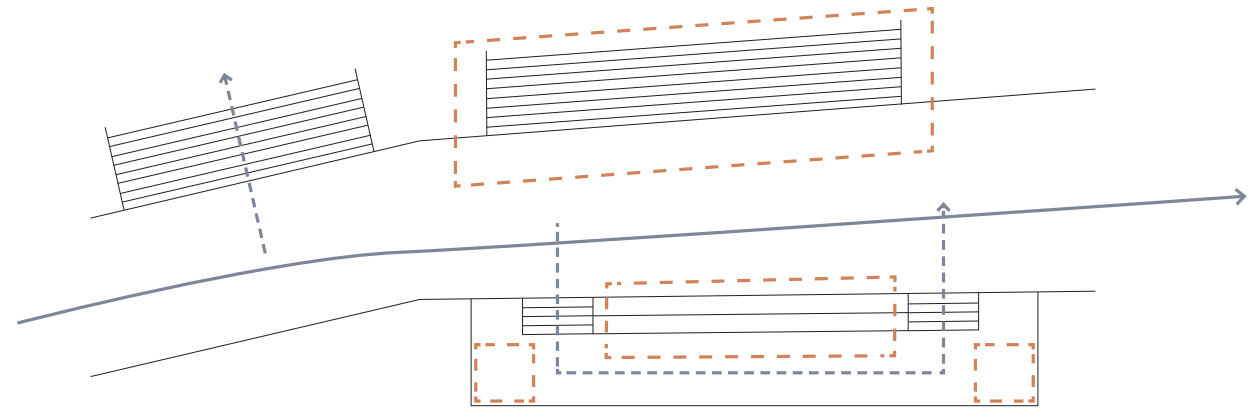

This design uses occupiable level changes on the edges of the movement that invite people to sit and enjoy the landscape allowing them to be part of the activity. whilst being out of the way of the movement 


\section{The High Line - James Corner Field Operations/ Diller Scofidio + Renfro}
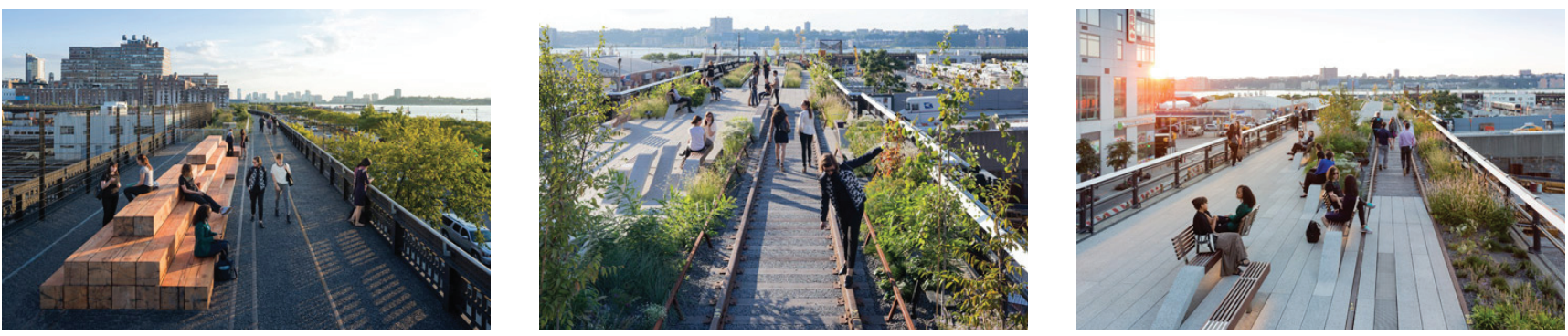

Fig. 4.1.3.1-3 Three photographs taken of The High Line

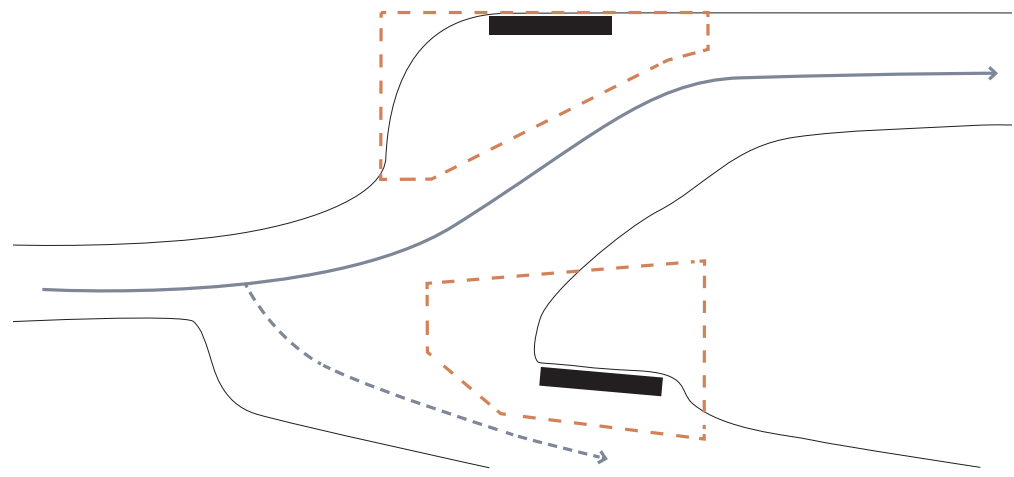

At various locations along this walkway the movement splits into two different flows, the way the physical environment coordinates the movement allows small eddies to form in which this design has purposely placed seats.

University of Los Andes Public Space - Daniel Bonilla Arquitectos
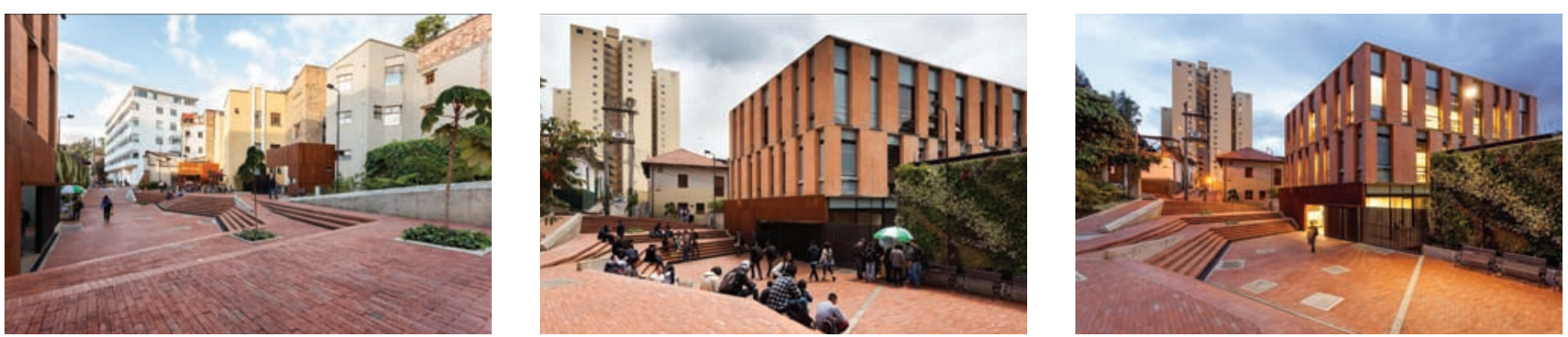

Fig. 4.1.4.1-3 Three photographs taken of the public space at the University of Los Andes

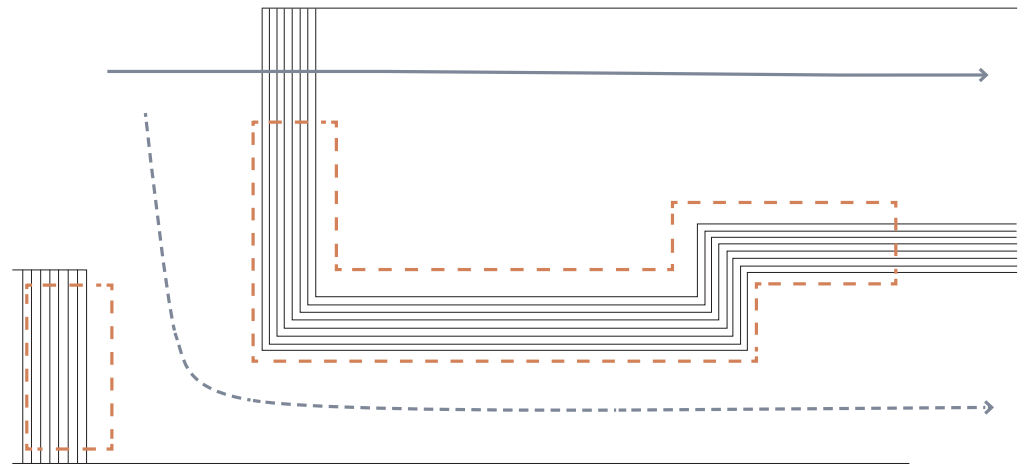

This uses level changes in a slightly different configuration, in an open space the movement is coordinated in one of two ways, which leaves the space in between to be occupied and lingered in. 


\section{Open/Activate Edges}

Opening up ground floor edges for pedestrians to engage further allows connection with the building and ensures a human scale within the architecture. Other types of edges in the landscape can prevent engagement to occur. This section looks at existing buildings that have created connections between the pedestrians outside and the internal life of the building. Although it does not look at ways to open existing edges, it is still helpful to look at successful designs and extract basic principles to use.

\section{Chile Pavilion - Undurraga Devés Arquitectos}
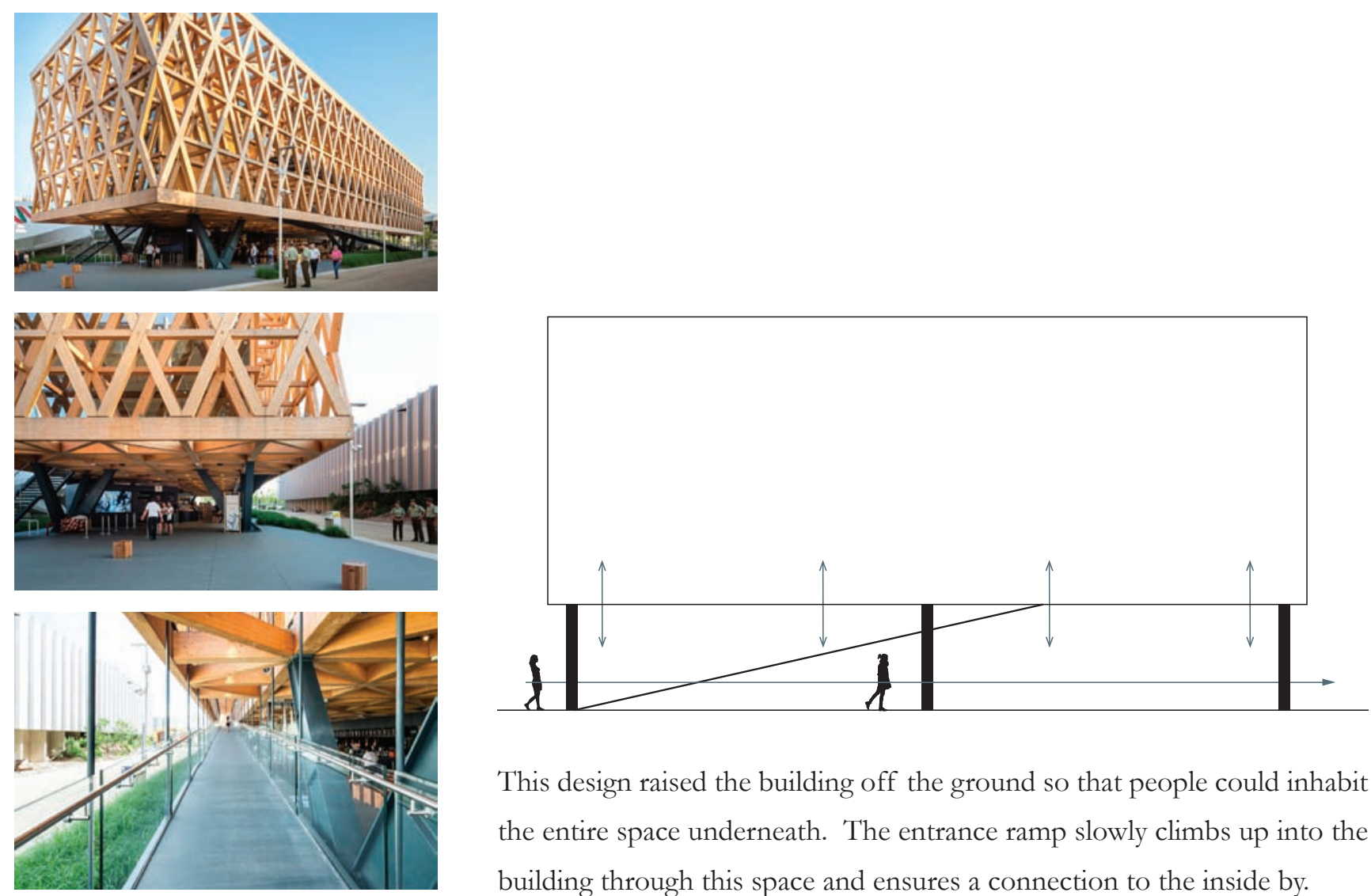

This design raised the building off the ground so that people could inhabit the entire space underneath. The entrance ramp slowly climbs up into the building through this space and ensures a connection to the inside by.

Fig. 4.1.5.1-3 Three photographs taken of the Chile Pavilion 


\section{State Library of Queensland - Donovan Hill + Peddle Thorp Architects}
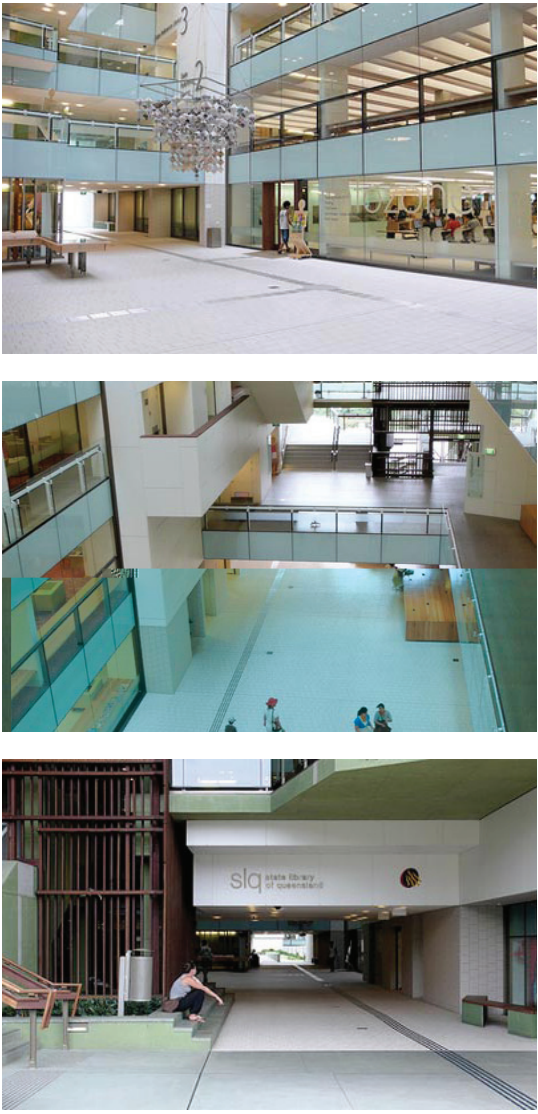

Fig. 4.1.6.1-3 Three photographs taken of the Queensland State Librar
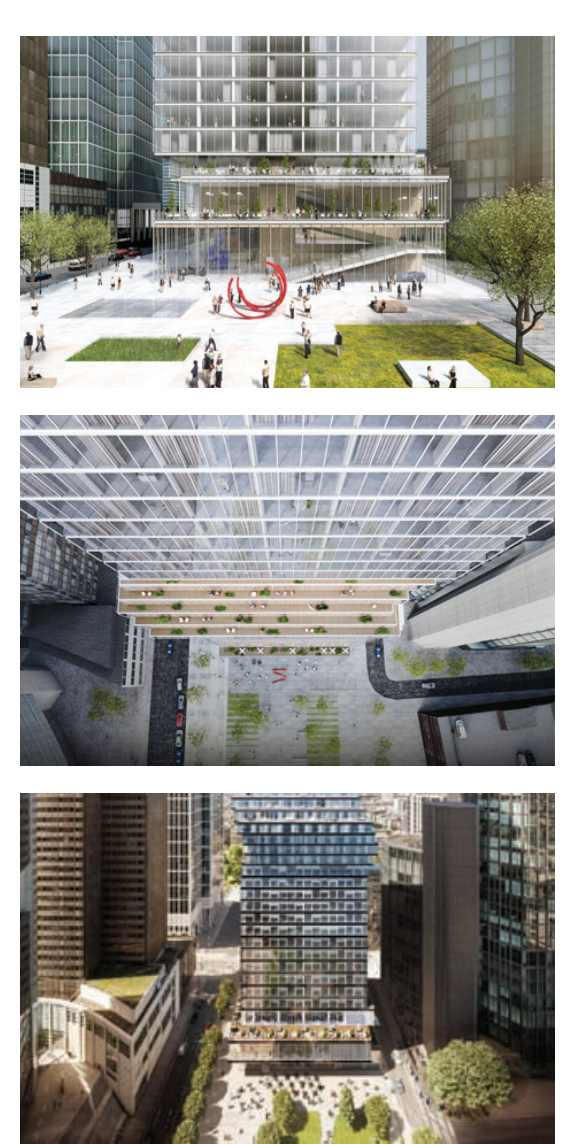

\section{Omniturm - BIG}

Fig. 4.1.7.1-3 Three renders of the Omniturm proposal

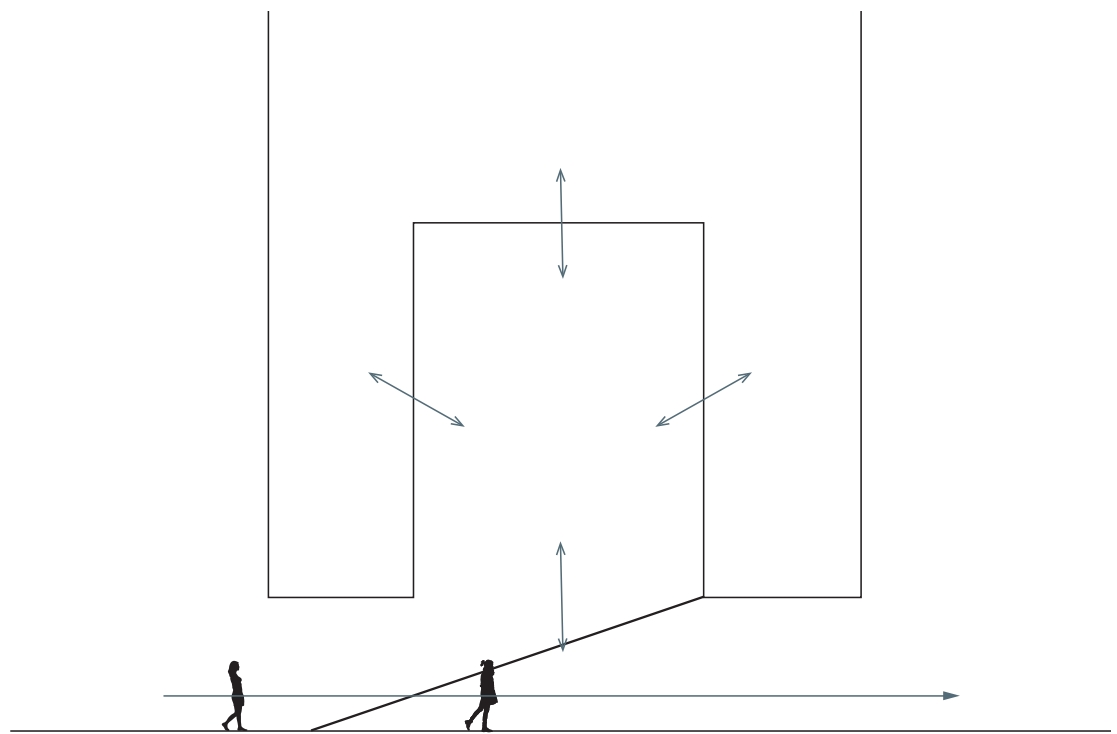

This design creates transparency and connection to the nature around the site while maintaining a sheltered microclimate within the envelope of the building. There is 24 hour access through the ground floor, which creates walkable links and connections to the waterfront.

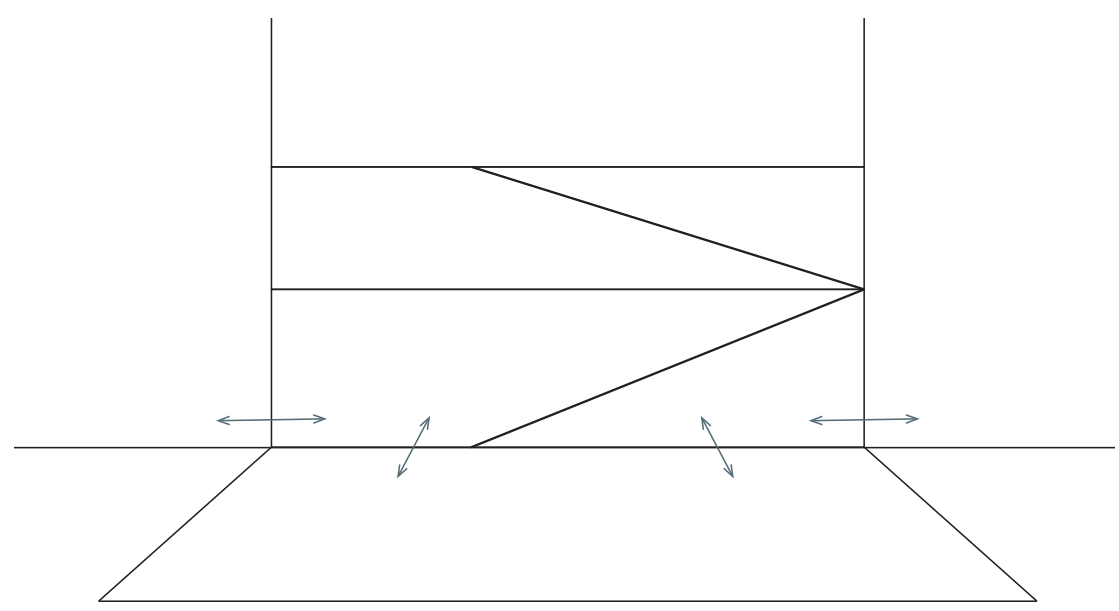

This high-rise building maintains a human scale because of how its first two floors interact with the rest of the city. A large public space in front of the buildings matches its size, and loops around the building to create a public realm that connects the exterior and interior seamlessly. 


\section{Destination Creation}

People need to have a reason to be and stay in a particular space. A new space stimulates people into new habits, provides new paths to and from, and creates new places to pause. This section looks at different ways to create destinations within the public realm.

\section{Hasle Harbour Bath - White}
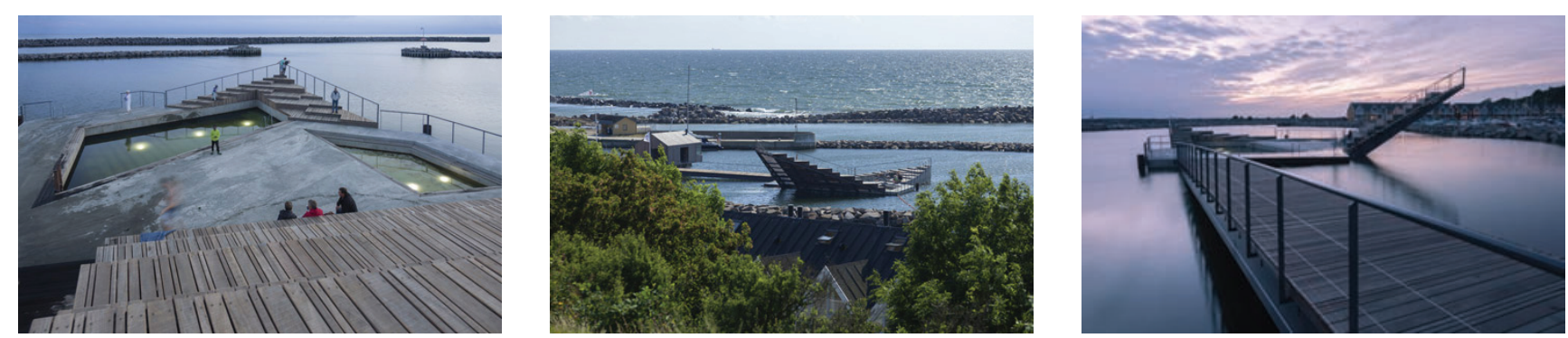

Fig. 4.1.8.1-3 Three images taken of the Hasle Harbour Bath

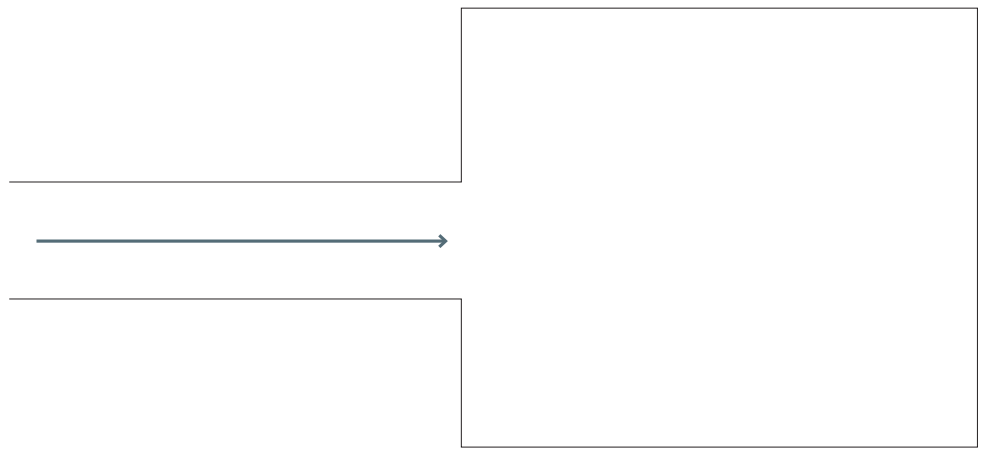

This is a destination in and of itself. People come here just for this and the activities that occur here. 


\section{The Goods Line - ASPECT Studios}
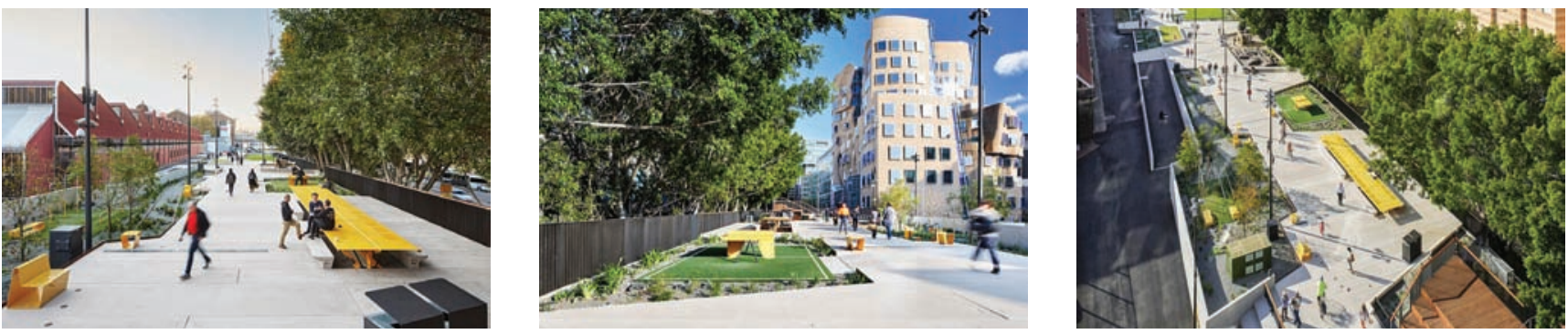

Fig. 4.1.9.1-3 Three images taken of The Goods Line

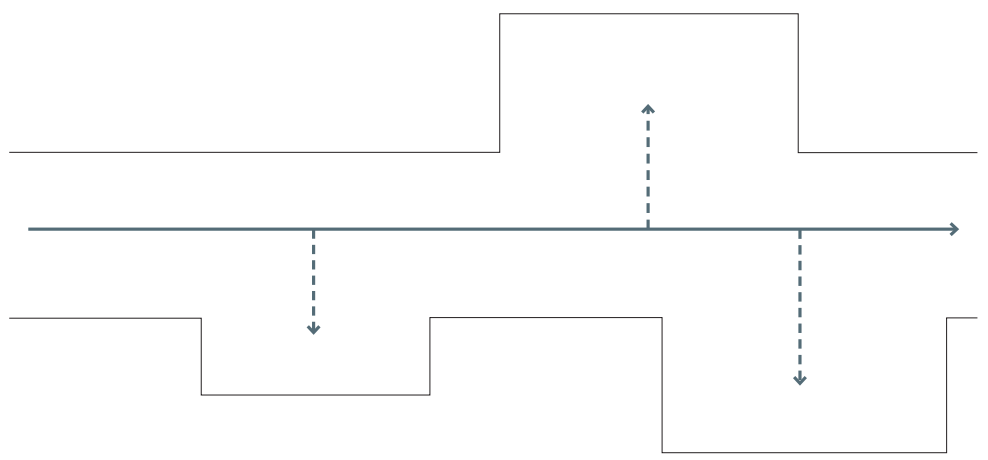

This makes use of small destinations along a path. This invites people already in the space to stop and interact with something, these small things allow for the creation of multiple layers of activities to exist with the one space.

\section{Netanya City Hall - Zarhy Architects}
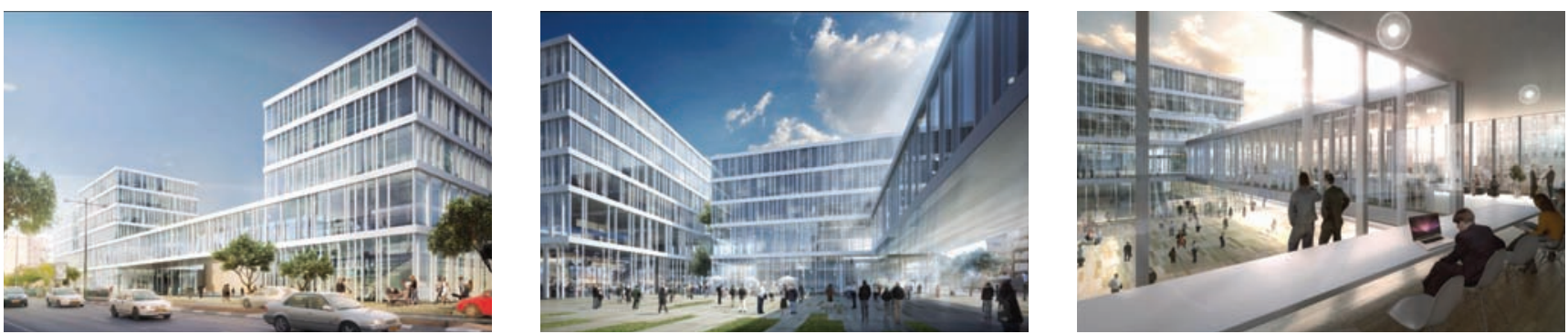

Fig. 4.1.10.1-3 Three renders of the Netanya City Hall proposal

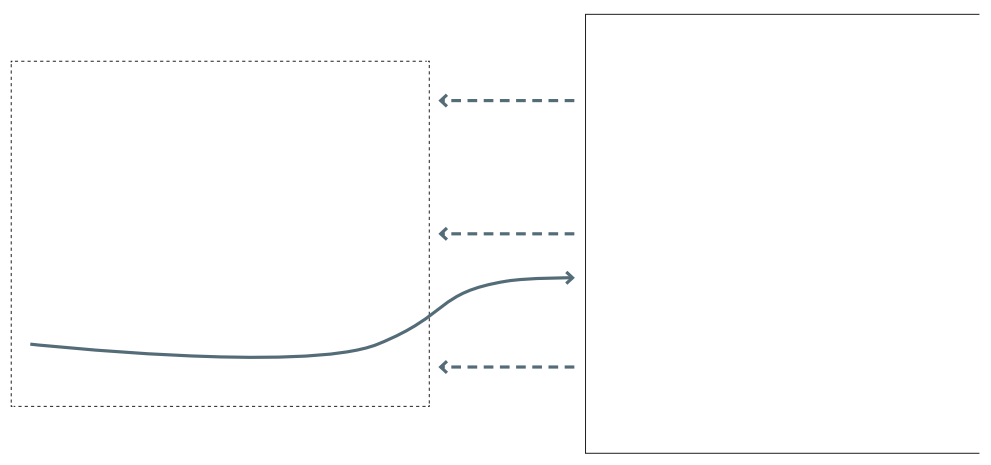

This is about creating areas where destinations can spill out to create a new public space. These function only with the help of an existing popular destination that invites people to stay longer. 


\section{Initial Experimentation of Design Direction}

This redesign experiment takes those three design drivers and creates a new configuration of the existing spaces around Te Papa that would allow more engagement with the landscape. This analysis of the movement assumes that the waterfront promenade will remain the dominant movement of the site, but by opening some planted edges and allowing various entrances into Te Papa, it has allowed new movement to occur which would create new eddies and ideally result in an increase in public life.

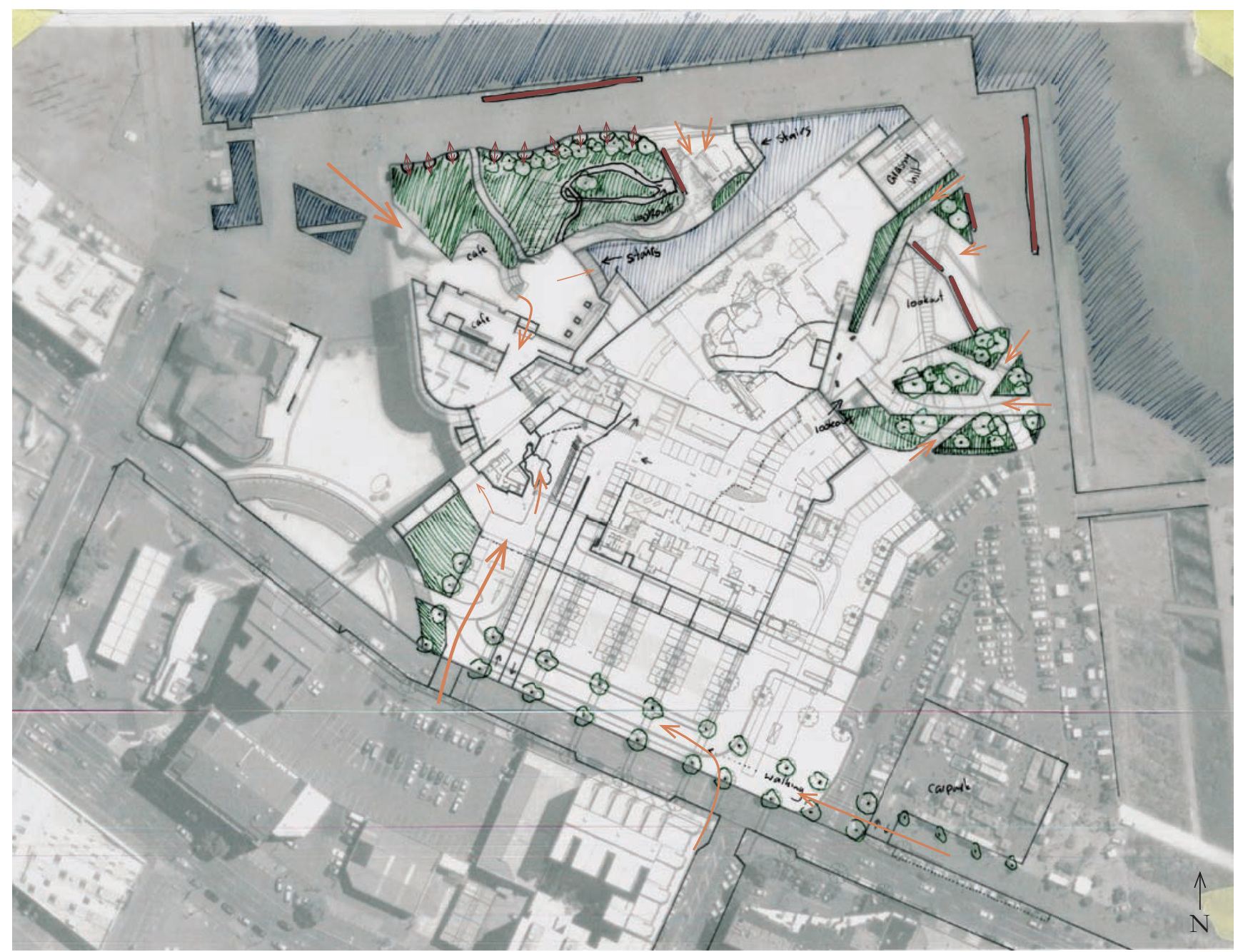

Fig. 4.1.11 Scan of sketch concept 1:1750 with arrows to demonstrate areas that will pull movement 


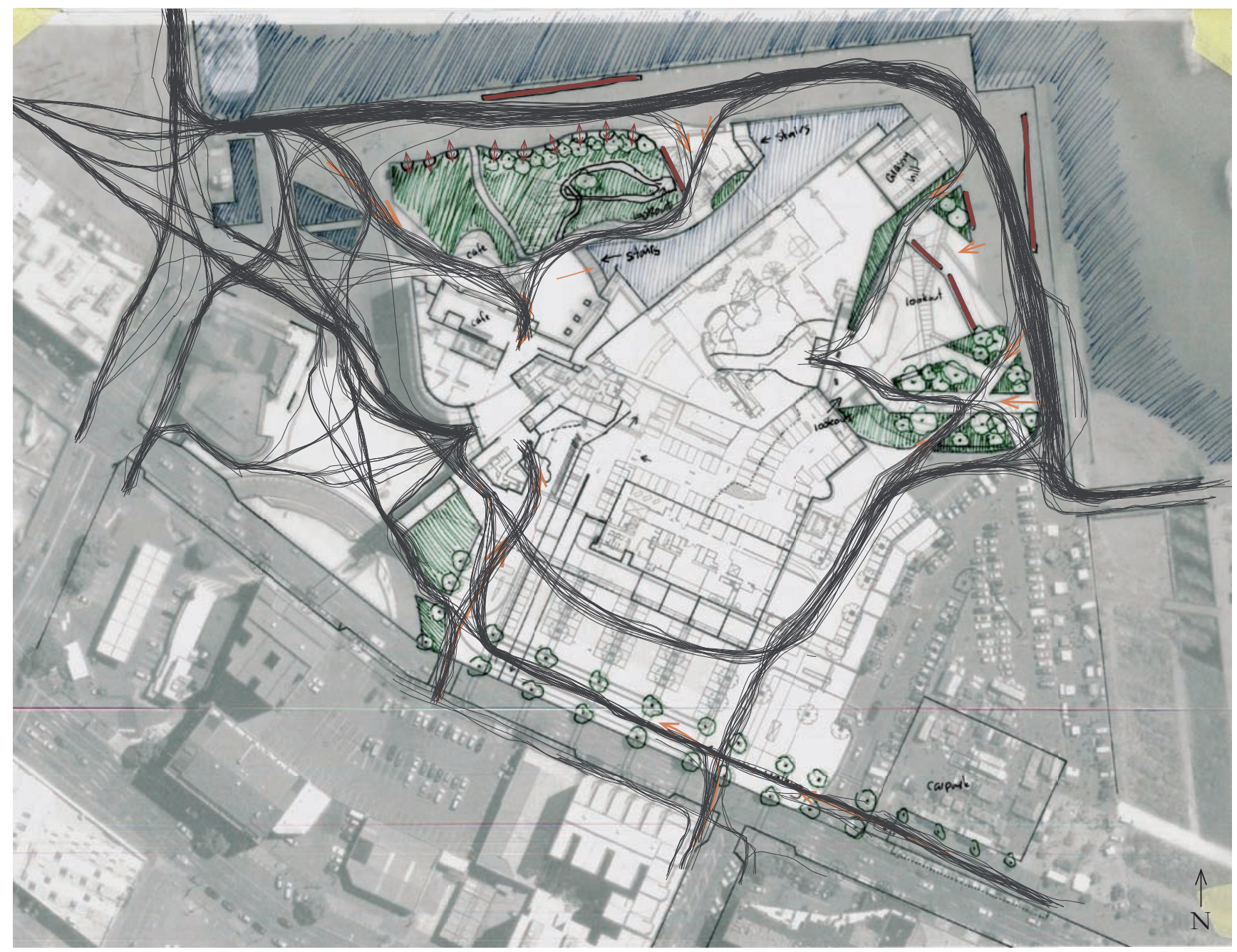

Fig. 4.1.12 Scan of sketch concept 1:1750 with potential movement flows 

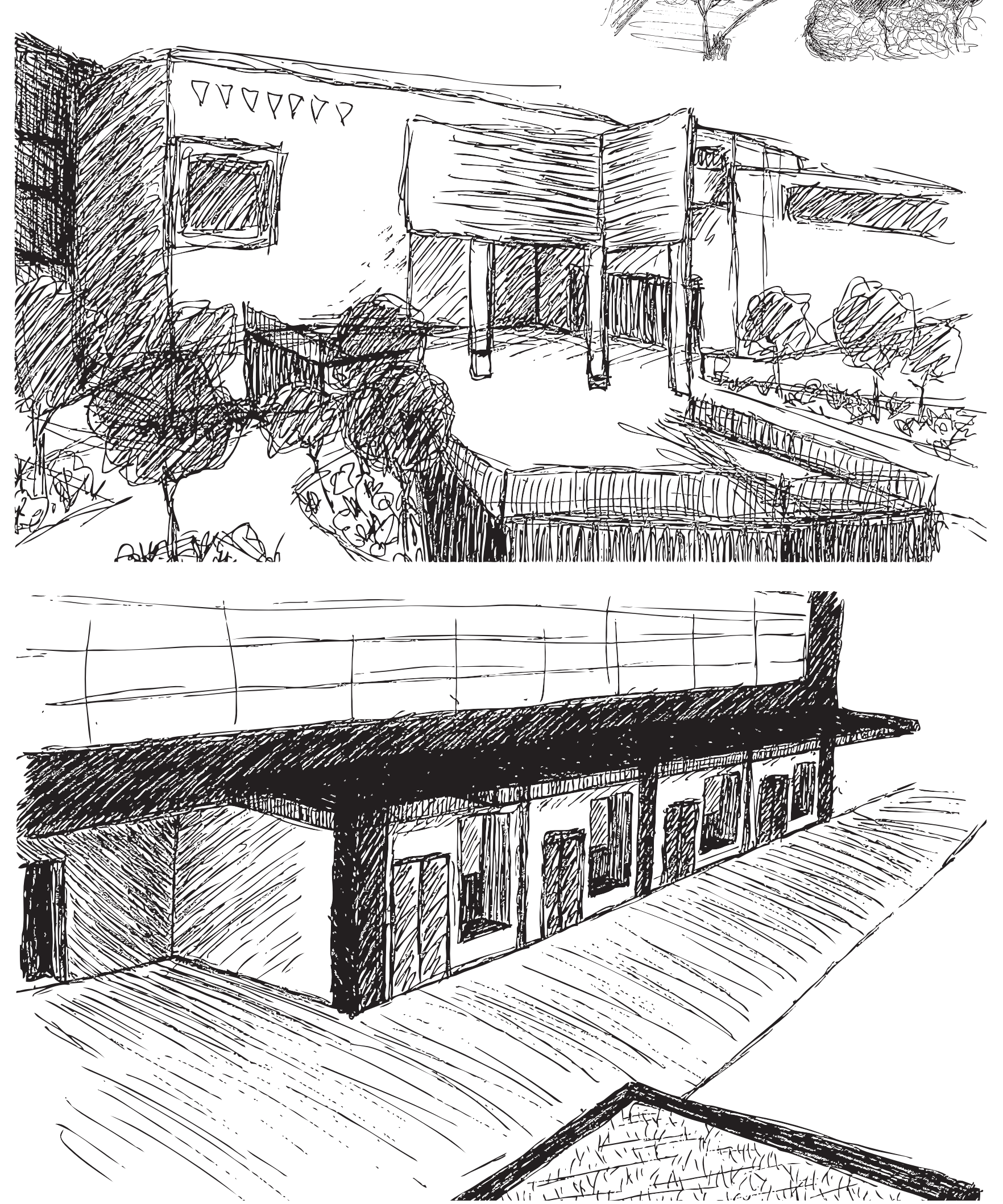

Fig. 4.1.13 Sketches that explore individual locations of the previous concept plan, which shows areas where the edges of Te Papa have been opened for pedestrian movement or activated in other ways to invite engagement. These sketches were useful to play around with edge activation as sketching allowed for more detail to be constantly added or covered up 


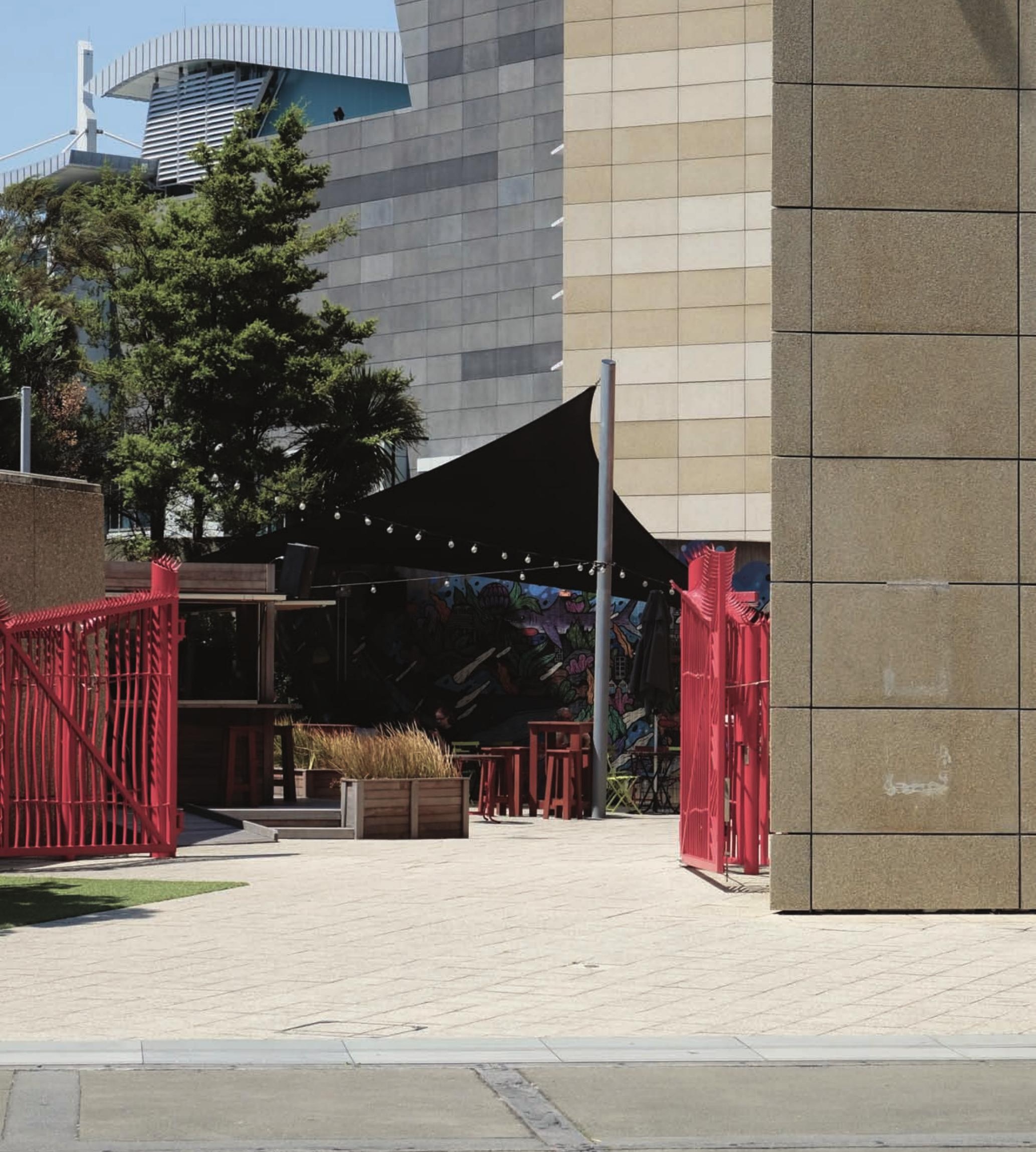

Fig. 4.1.14 Entrance into Red Gates, an outdoor bar within Te Papa's Bush City courtyard, and the Te Papa Cafe 


\section{BASIC DESIGN ITERATIONS}

Building from the previous redesign experiment, this interactive concept study involves six design changes for each of the four spaces. These sketched concepts aimed to be quick and able to layer on top of each other to explore how the movement changes in a variety of scenarios. The resulting designs were not the focus of this stage of research but instead a precise understanding of how existing waterfront movement would likely react in a range of different design scenarios. The cross-sections taken from these designs suggests that attention now needs to be paid to the human scale.
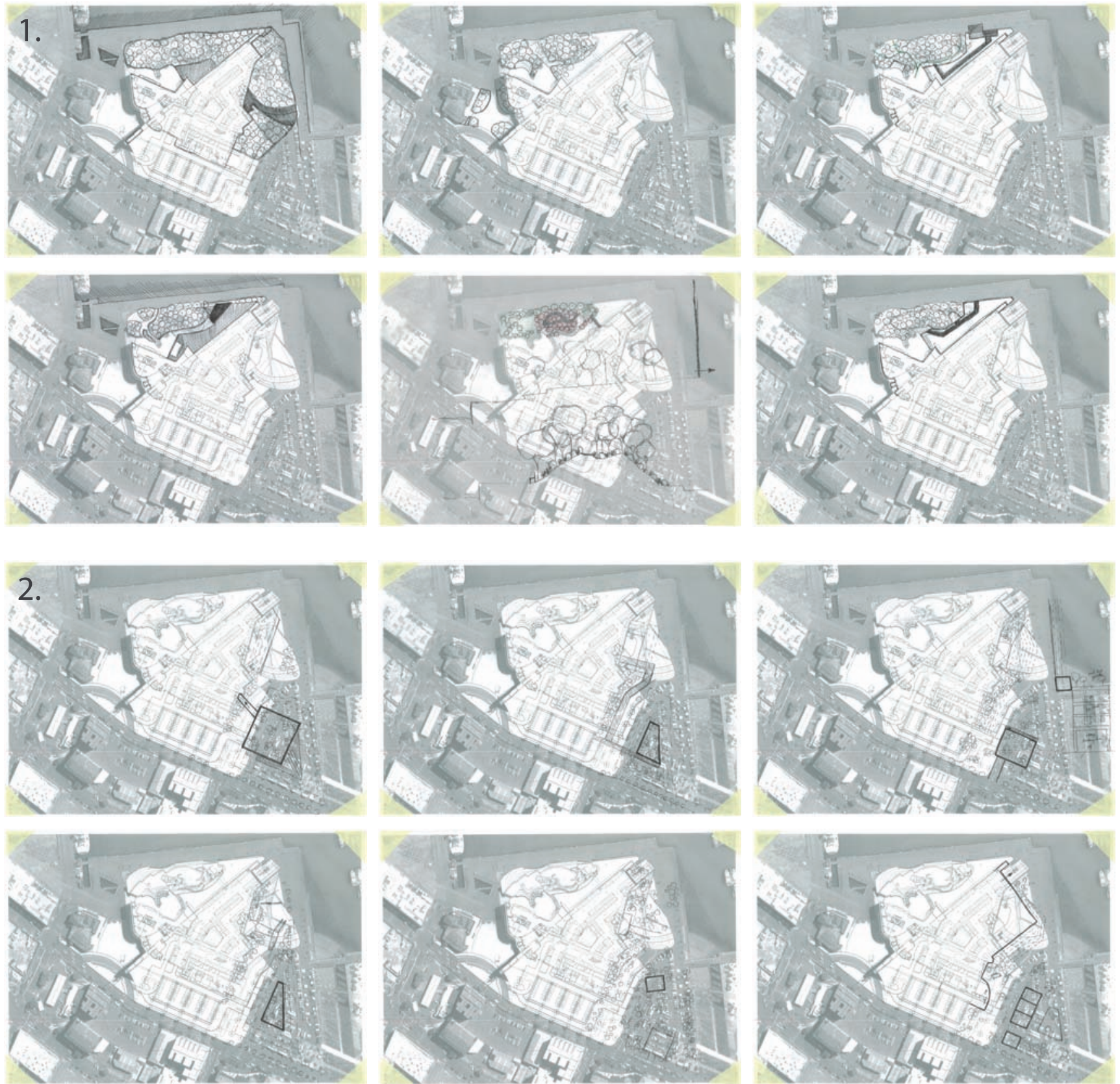
Fig. 4.2.1 Scans of the quick sketch iterations done for the combination exercise (4 groups of 6 iterations). Scanned directly from the tracing paper before they were layered on top of each other to make different arrangements of the site. Each one explored adding destinations to draw people into the spaces, adding planting to co-ordinate the movement, opening up edges around the site to enhance the engagement with the building, and re-configured elements the exist on the site to create more interest and opportunities for public life engagement
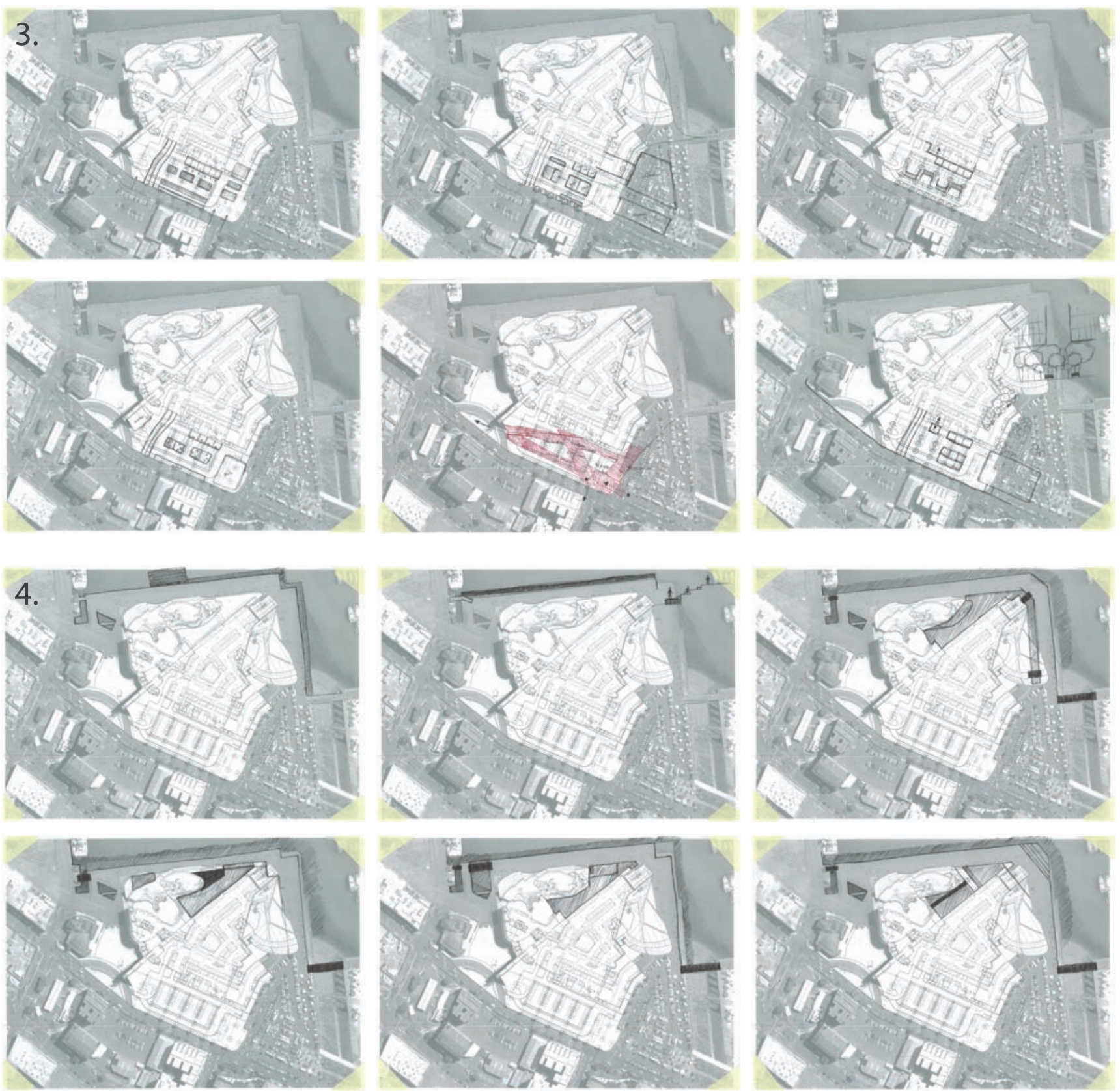


\section{Iteration Combination 1}

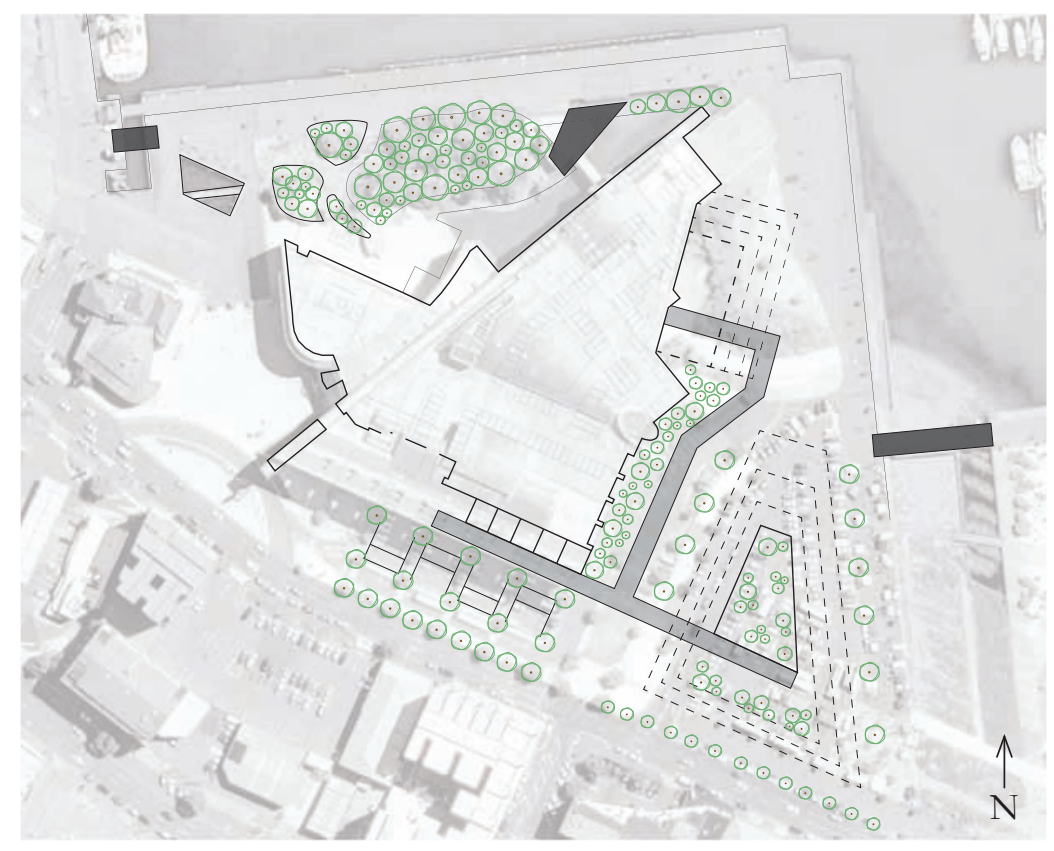

Fig. 4.2.2 A combination plan 1:5000 and associated potential movement mapping. A building with a rooftop garden is added to the south-east corner and is raised by a series of platforms. The new building is connected to a new Te Papa entrance and addition of shops by a covered walkway that would provide shelter in such a large public space. The wharf has been slimmed and Bush City opened via a wide bridge along the pond and paths created where the terrain would allow it. The corresponding sections 1:1250 demonstrate the size of these spaces with the placement of a silhouette

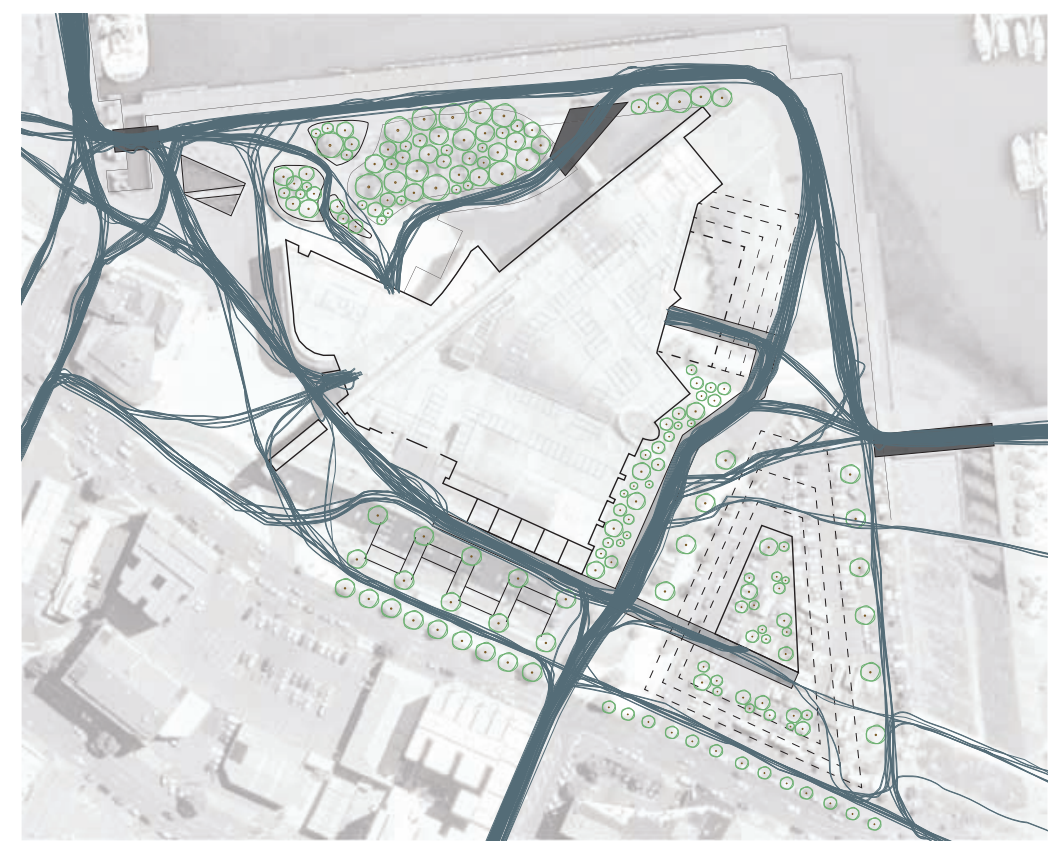

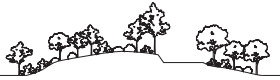
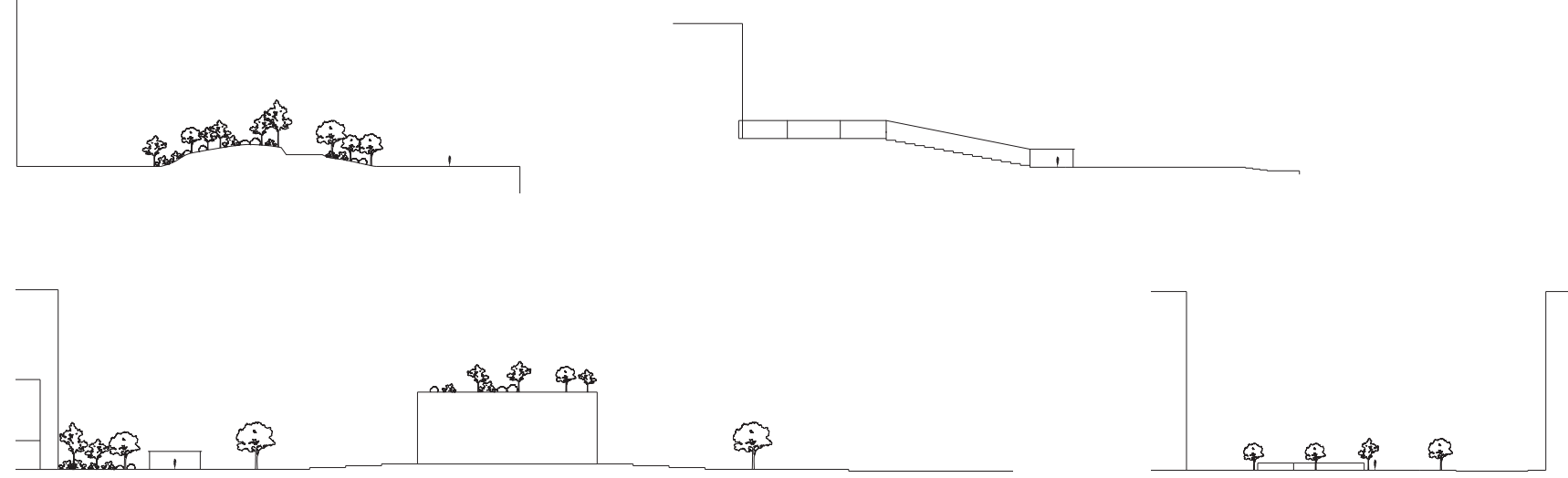


\section{Iteration Combination 2}

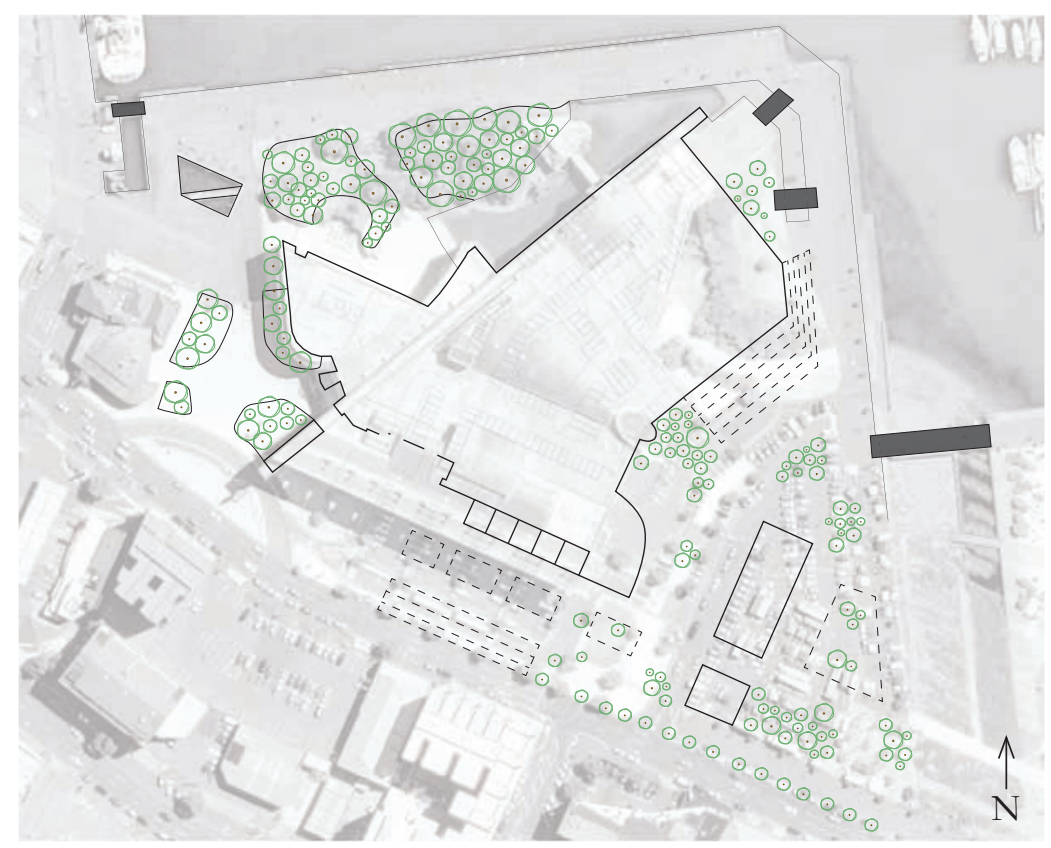

Fig. 4.2.3 A combination plan 1:5000 and associated potential movement mapping. Two buildings are added to the southeast corner with planting and a raised grassy area nearby. This connects through to the addition of shops and raised areas to the left as well as extensions to Te Papa that create sheltered public spaces. New planting within the plaza defines the edges of the space and reduces its vast size. Finally Bush City is opened up with one main path cutting through the middle, and the pond is extended around the building to connect to the areas on that side and improve the coherency of the public space as a whole. The corresponding sections 1:1250 demonstrate the size of these spaces with the placement of a silhouette

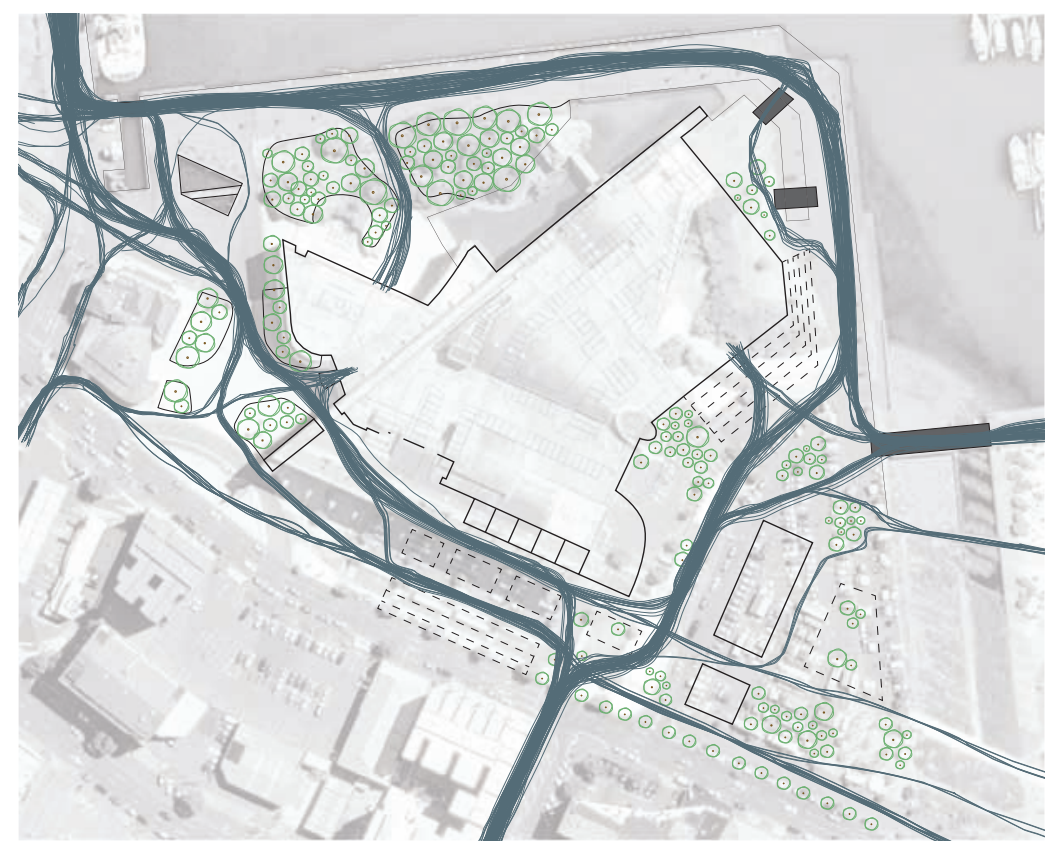

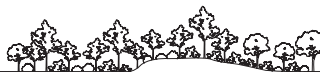
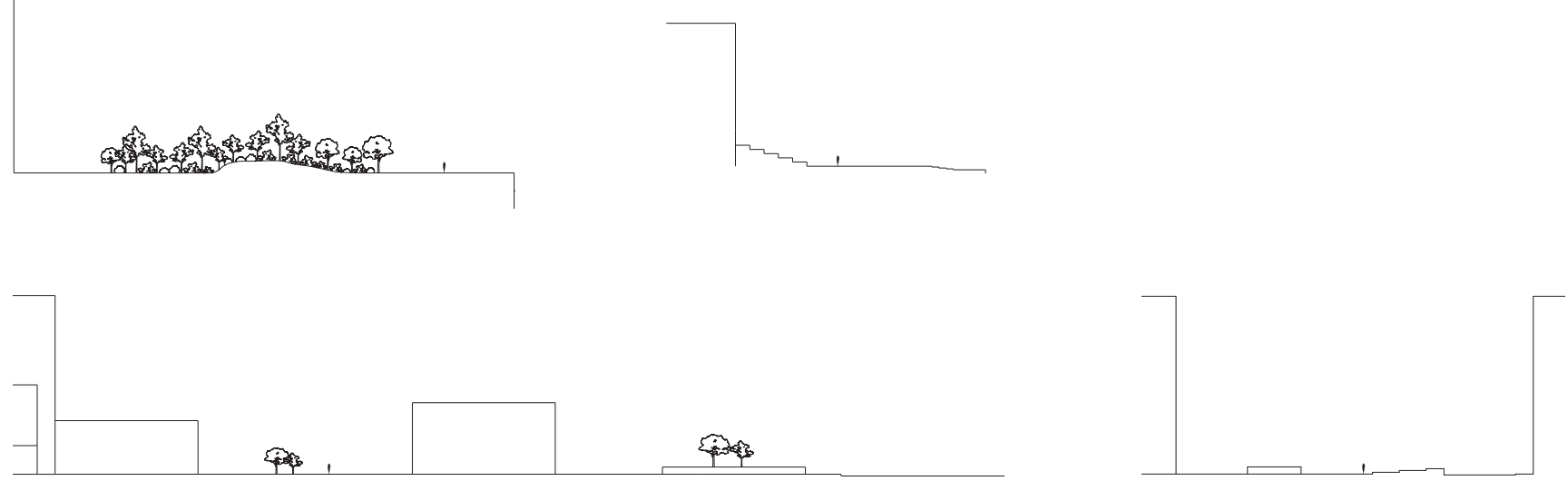


\section{Iteration Combination 3}

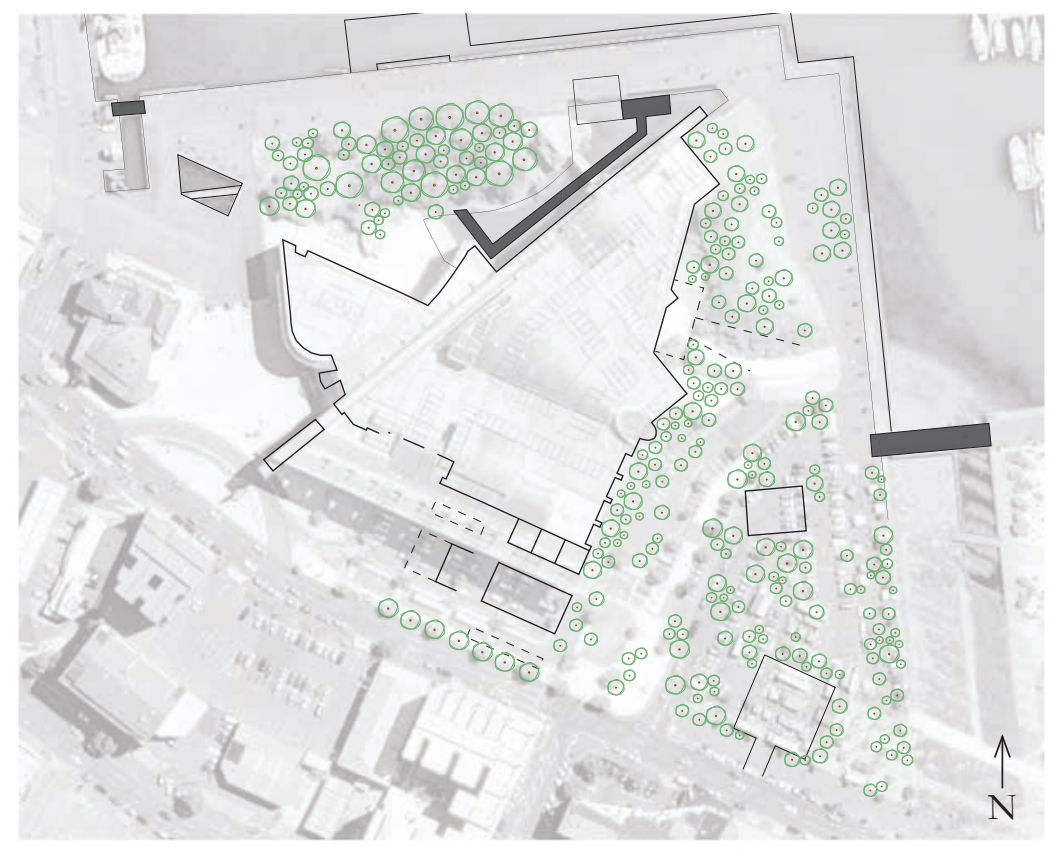

Fig. 4.2.4 A combination plan 1:5000 and associated potential movement mapping. The south-east side is transformed into a large planted area with a small building placed within it, which will create a series of small sheltered public spaces for people to enjoy. The addition of shops, the new entrance, and planting along Te Papa's edge improves the interacting people can have with the building because of the shift in scale. Platforms have been created along the wharf edge, on both the harbour side and pond side. The platform on the pond side connects through to Bush City via a bridge, and the rest of Bush City is opened up by the removal of a small wing of Te Papa and the large wall. The corresponding sections 1:1250 demonstrate the size of these spaces with the placement of a silhouette

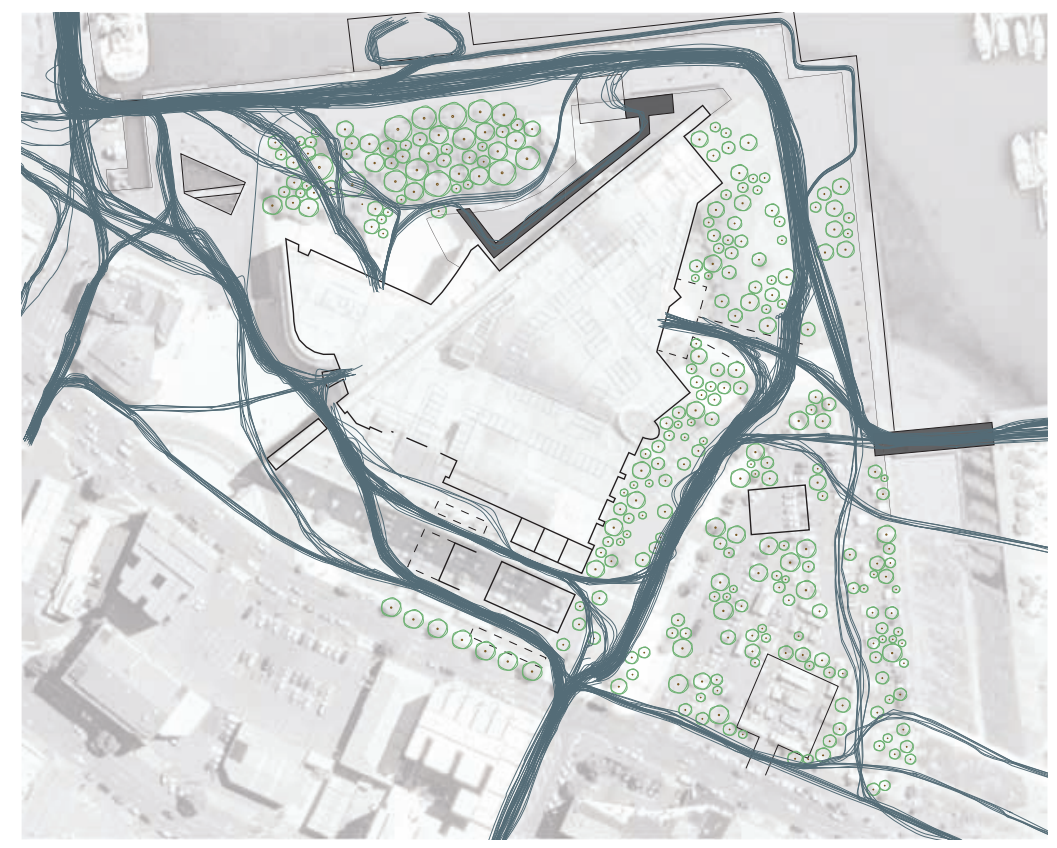

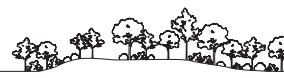




\section{Iteration Combination 4}

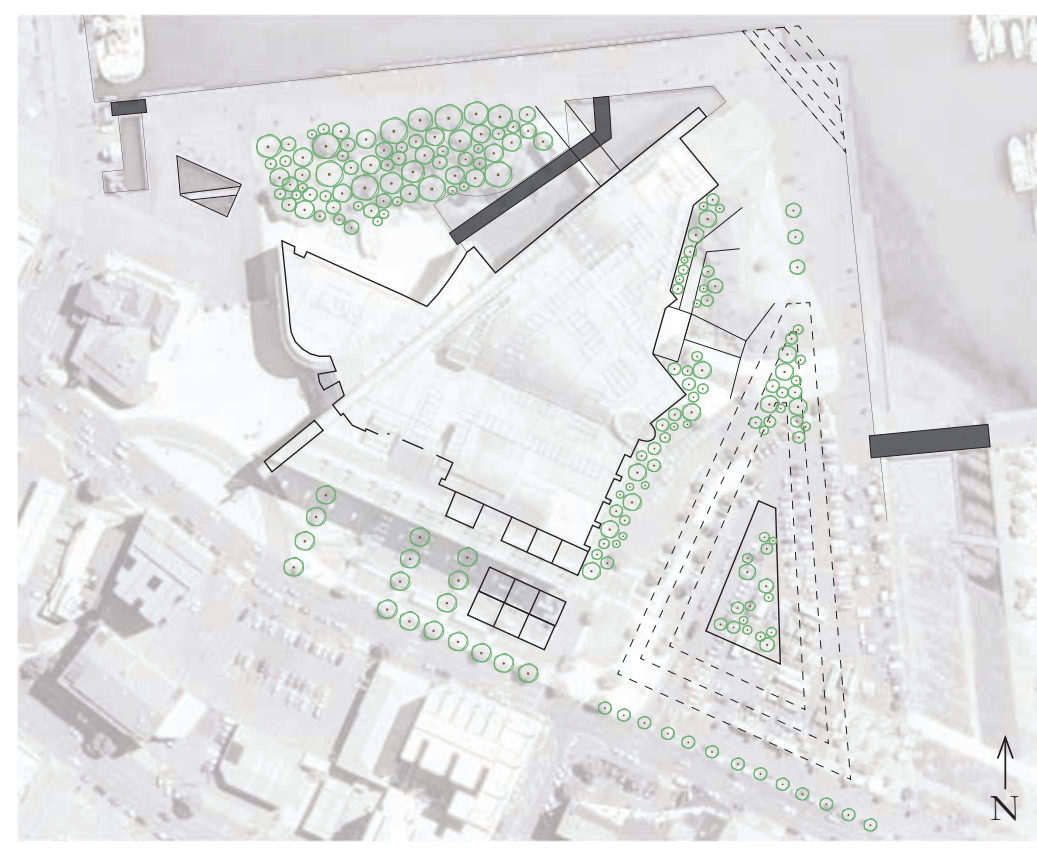

Fig. 4.2.5 A combination plan 1:5000 and associated potential movement mapping. A large building with rooftop garden is part of this concept also. The new entrance to Te Papa is connected via a ramp and an overhead pedestrian bridge that creates a new interaction people within the site can have with each other. A series of platforms are added to the north-east corner of the wharf to invite people down to the water's edge. Planting has been used to define the spaces and bring something of buman scale into this area of the site. Bush City remains fairly closed off except for the addition of a bridge across the pond and small platform that allows people to touch the building's facade. The corresponding sections 1:1250 demonstrate the size of these spaces with the placement of a silhouette

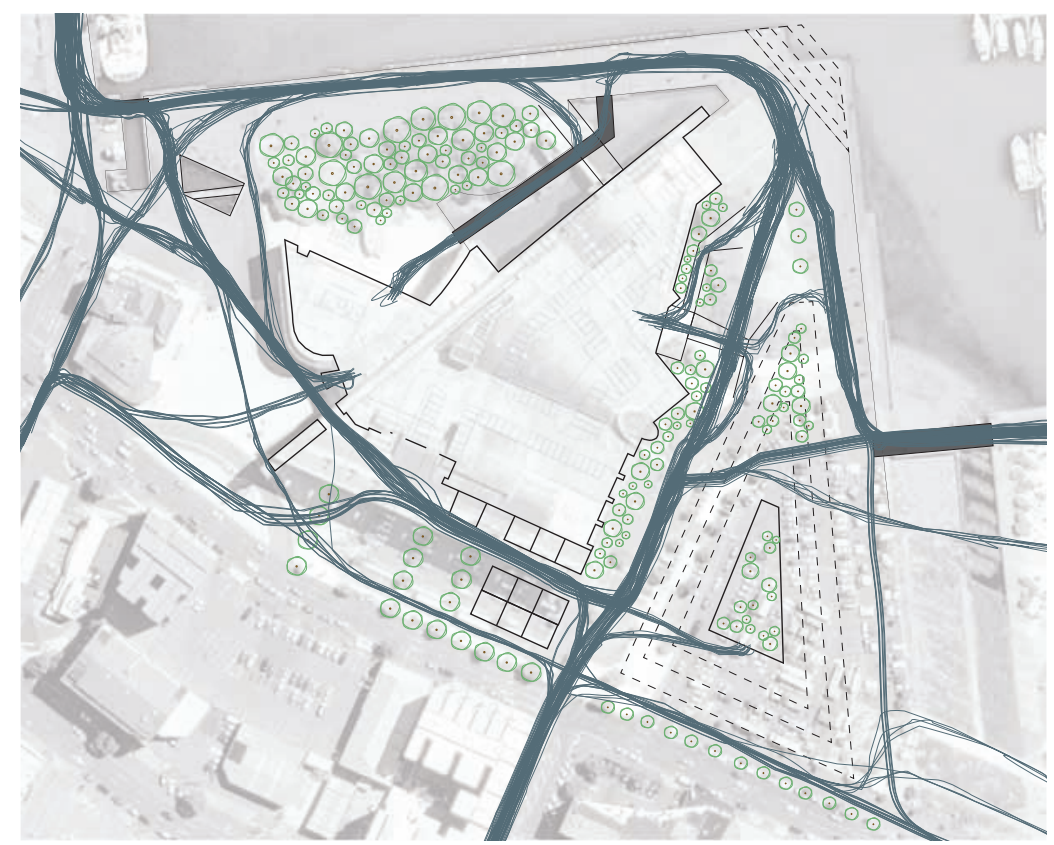

की

s
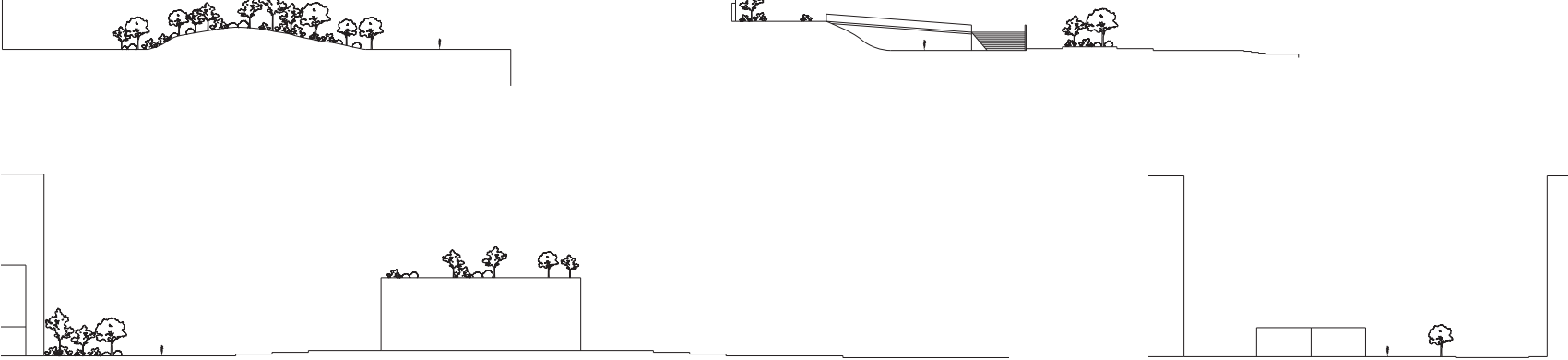


\section{DESIGN THROUGH SECTION}

This area of the design research takes two sections through the site and creates design iteration based around human silhouettes in order to explore how physical elements can define spaces within a large site. Different silhouettes are included to consider how different user groups would use the space and to arrange the section based on what they require from a public space.

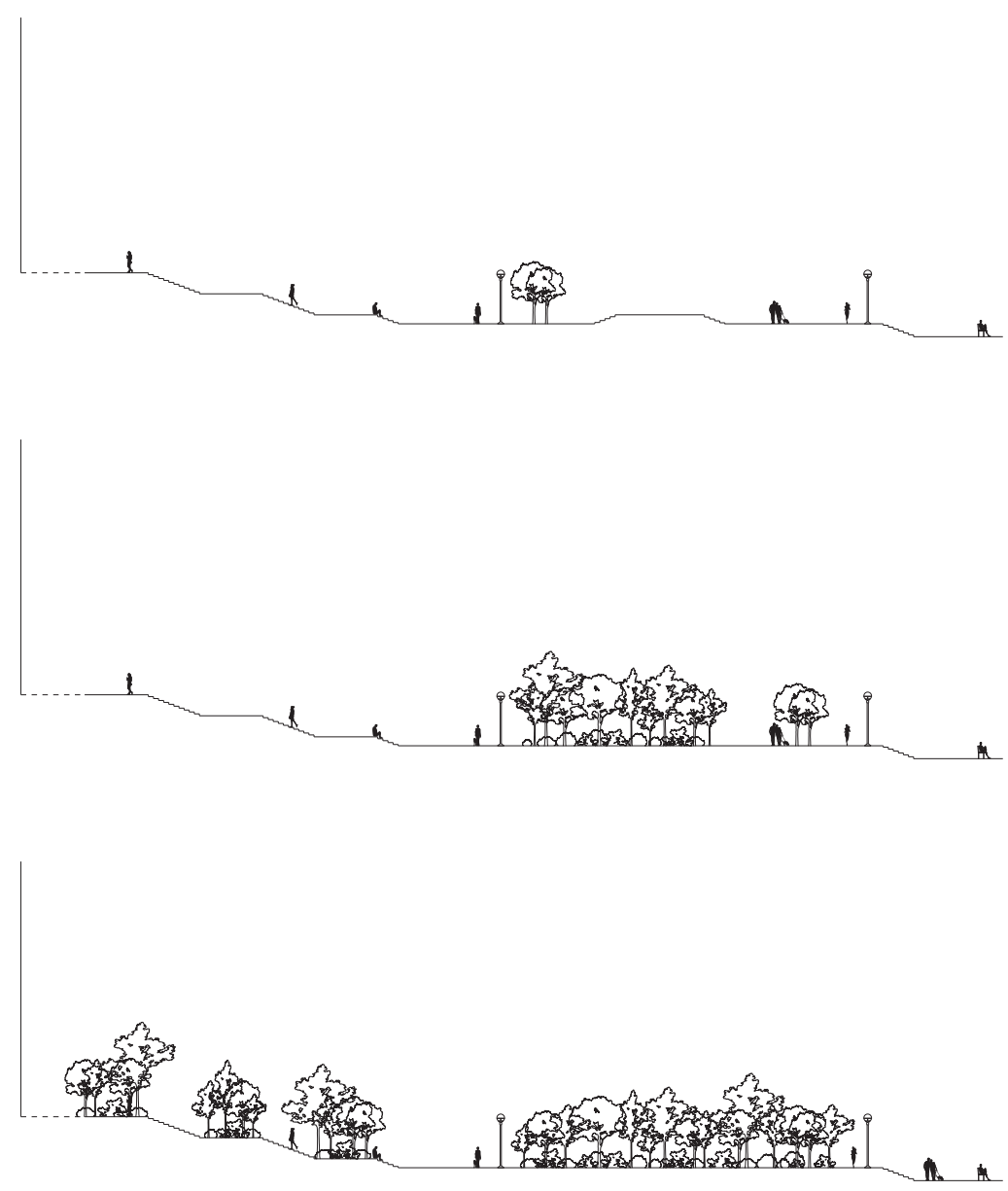

Fig. 4.3.1 Section iterations 1:600 of potential new entrance explore how configuration of planting and level changes can define spaces and how people would interact with each other and the site 

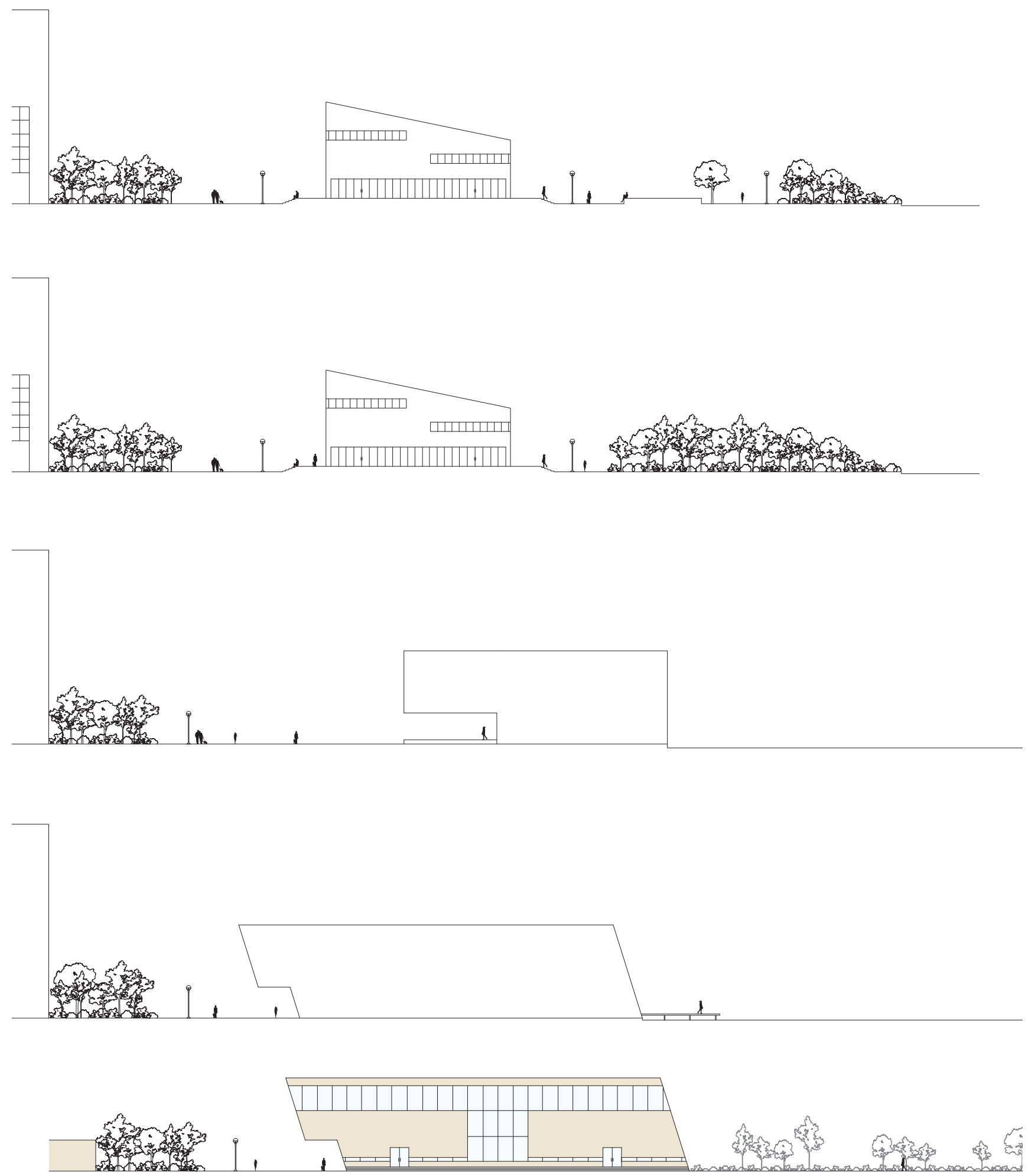

Fig. 4.3.2 Section iterations 1:600 of problematic south-east corner explore bow configuration of planting and level changes can define spaces and how people would interact with each other and the site 


\section{Entrance Stair Section Testing}

These tests are to create a staircase that has to rise 4 metres in a non-dominating way that can encourage lingering and be inviting to walk up. The second page builds on the initial sections deciding that a staircase with several landings is the best way to ensure it does not become overly dominant, and consider four different users: a person walking past at the bottom, a person sitting on the stairs, a person walking up the stairs, and a person on the top level.
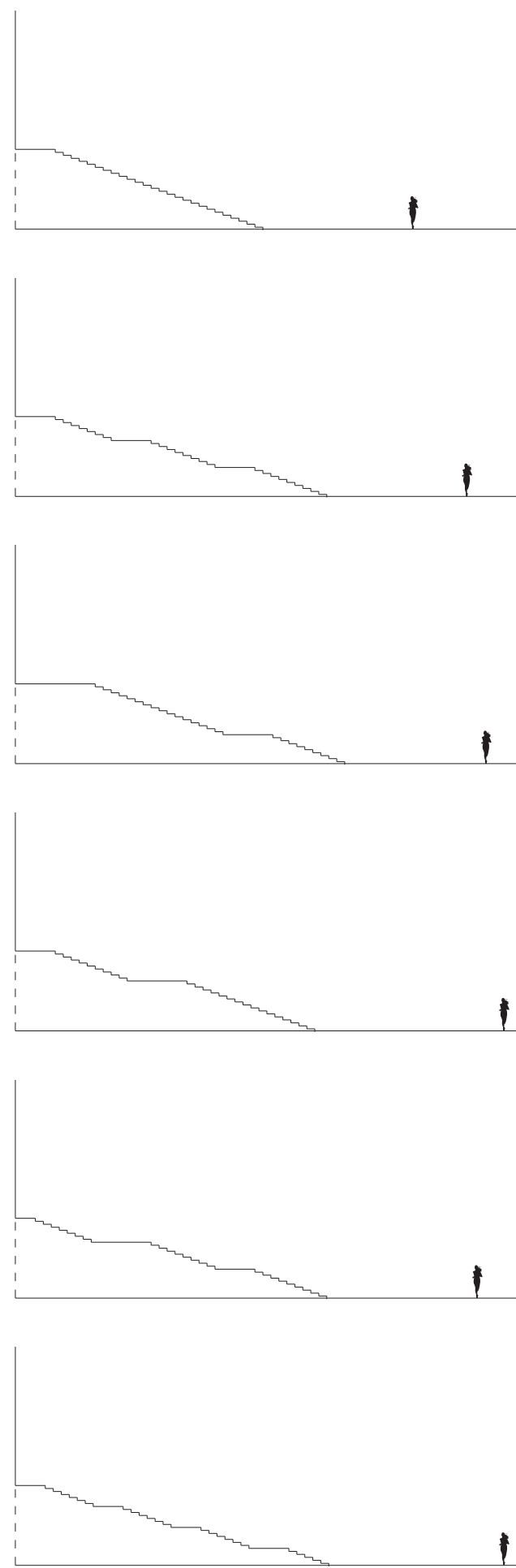

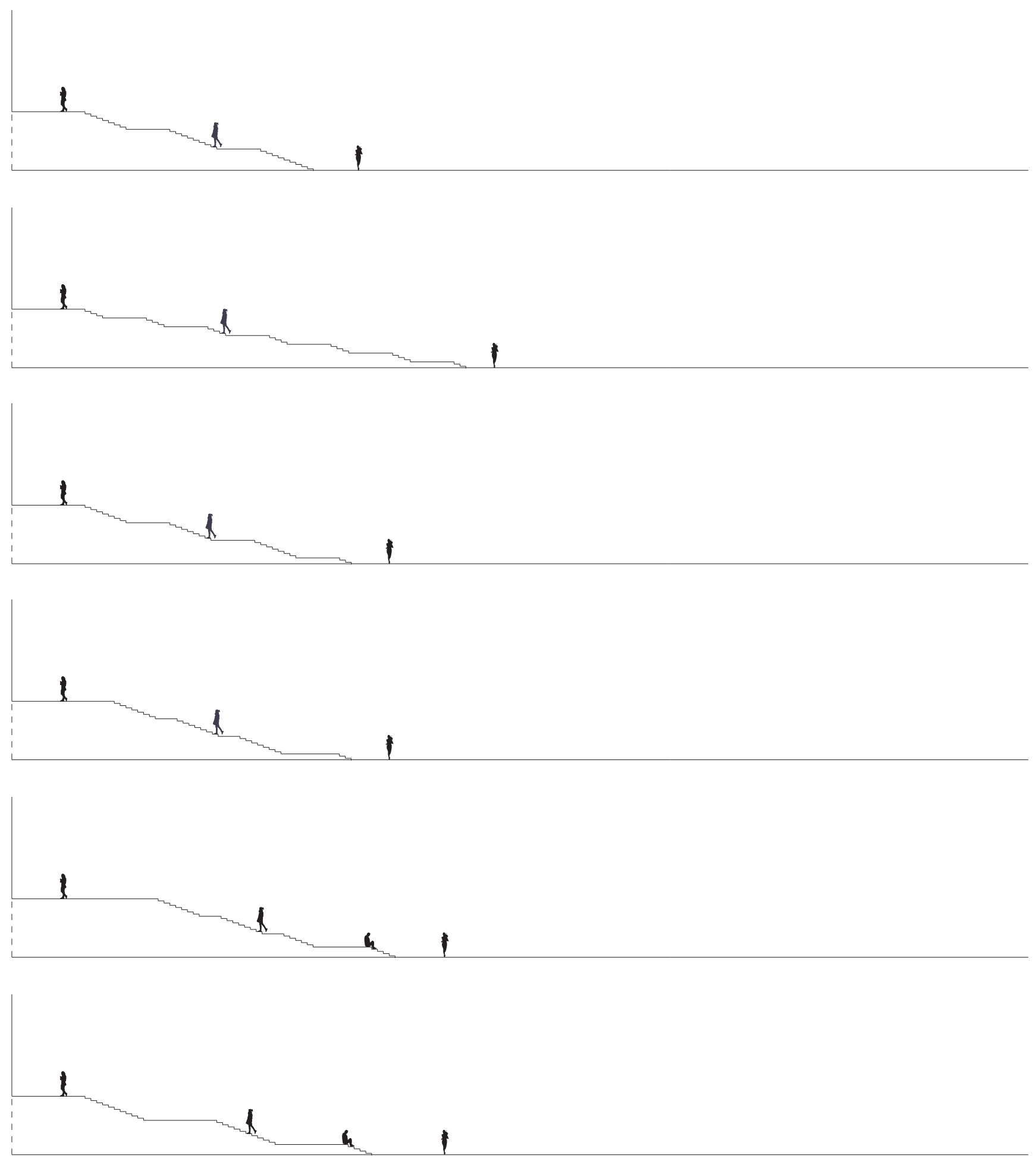

Fig. 4.3.3 Section iterations 1:400 of new entrance explore how the configuration of the staircase can be inviting opposed to overly dominant because of its size

105 


\section{DESIGN DIRECTION}

This precedent and sketch investigation explores the potential of different areas around Te Papa. Each area has a name, a selection of photos exploring aesthetic design choices, and a series of iterative sketches that explore design possibilities. This brainstorm-style research explores various designs independent of other spaces, which ensures each area responds to its characteristics and potential. This area of research came about because of the vastness of some of the spaces and breaking them down like this and naming them helps to identify the individual elements of each. Identifying these individual spaces moves the research forward to explore the type of public space that would be best for each of them and what that might look like. A series of investigations inspired by precedents that explore the type of public life that would be produced because of it follows.

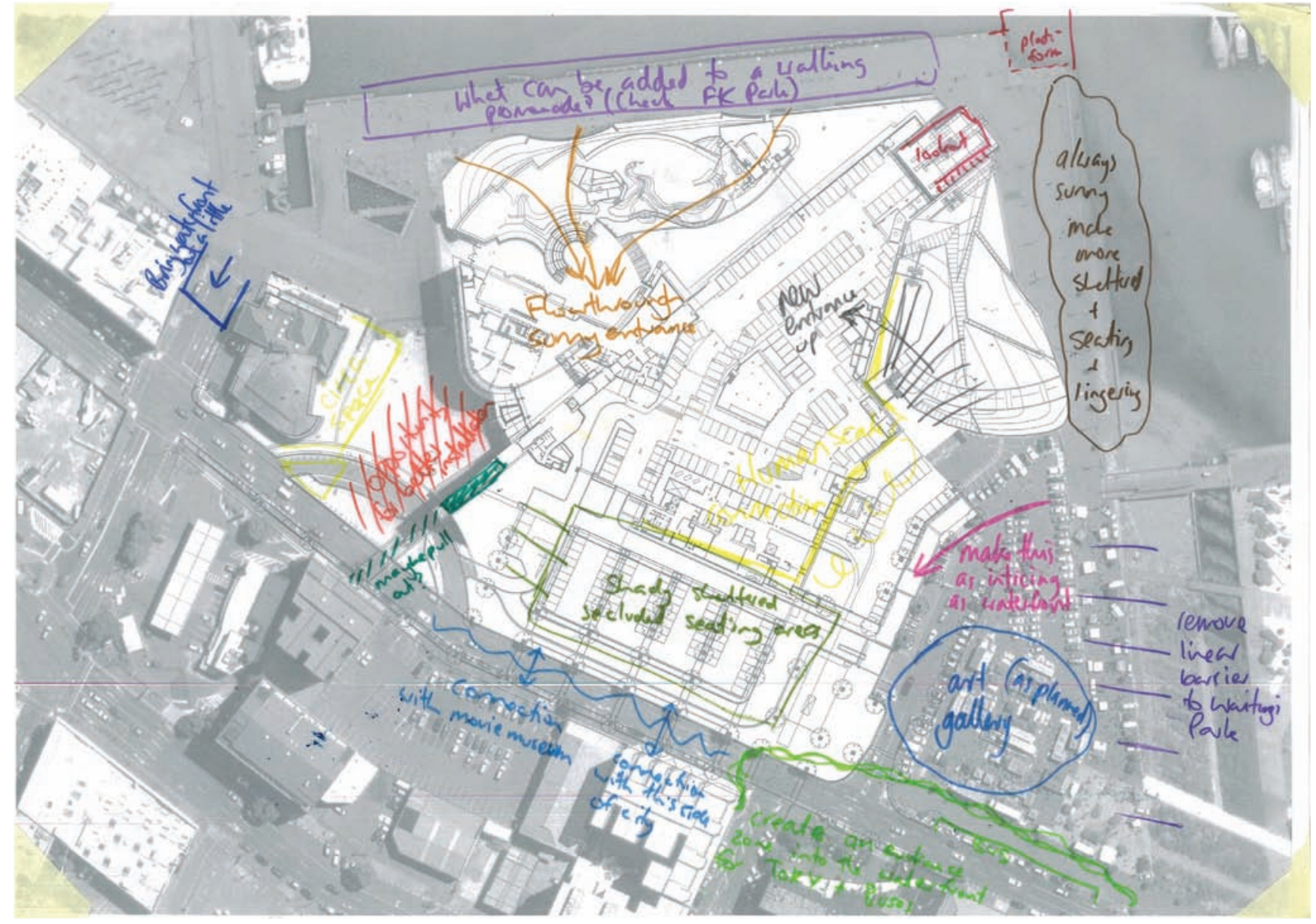

Fig. 4.4.1 Scan of quick separation of spaces around Te Papa in relation to their physical barriers, location, limitation, or potential and each is named accordingly 


\section{Flow Through Sunny Entrance}

Fig. 4.4.2.1 Pathway through a dense garden setting

Fig. 4.4.2.2 Level changes in a pathway through a garden

Fig. 4.4.2.3 A large conservatory space that allows sun to stream in and incorporates planting elements within the interior

Fig. 4.4.2.4 Several public spaces exist due to a level change between the planted area and the building's entrance

Fig. 4.4.2.5 The entrance is extended out into the space due to the awnings from the building, which draw people in

Fig. 4.4.2.6 A winding pathway through a bush setting

Fig. 4.4.2.7 The courtyard in front of a building responds proportionally to the size of the entrance and additional areas are redefined as new public spaces

Fig. 4.4.3 Sketches explore the transitions through the bush and from bush to building
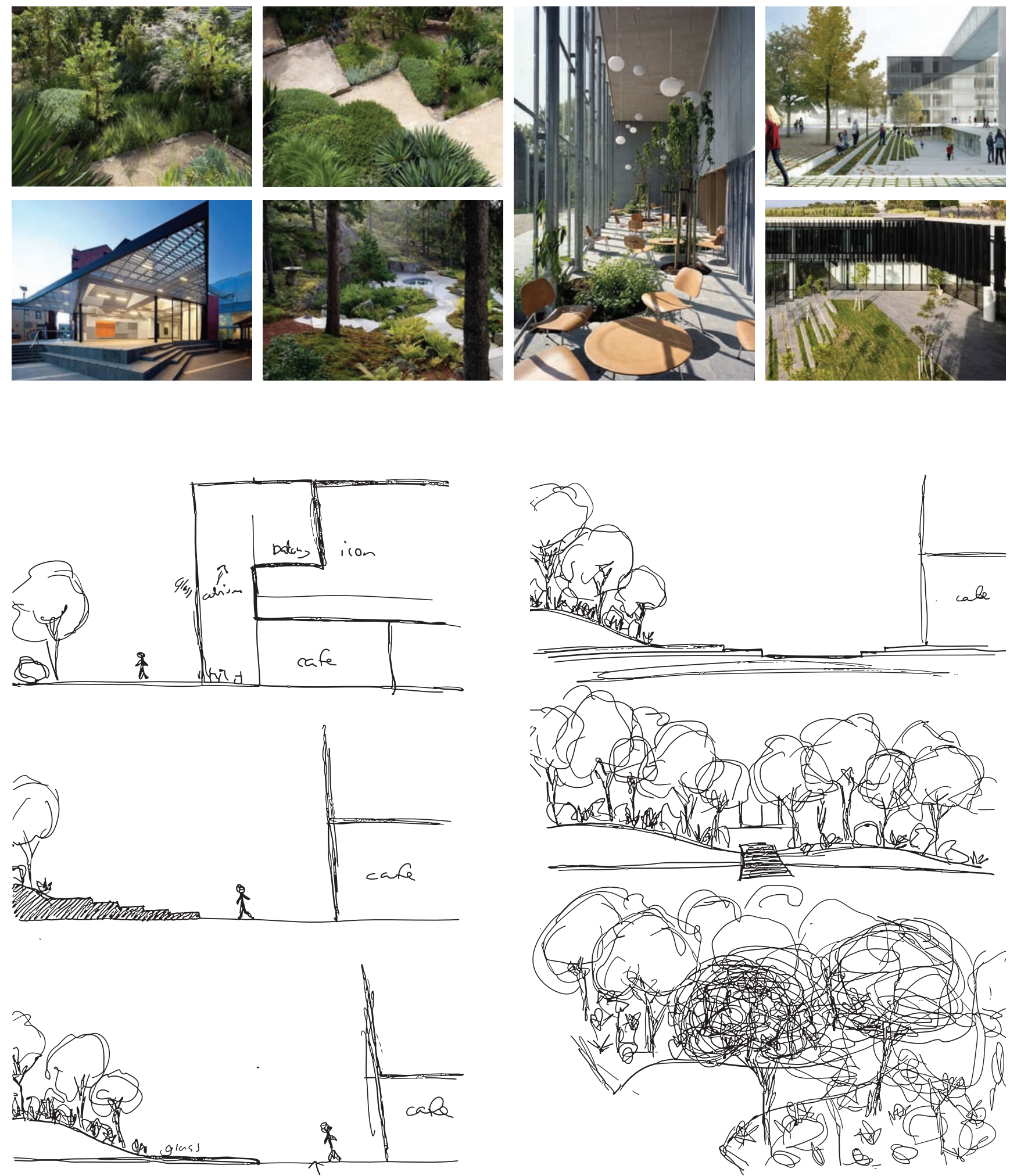


\section{Walking Promenade Addition}

Fig. 4.4.4.1 Seating is provided along the water's edge

Fig. 4.4.4.2 A platform is separated from the walking area by level changes

Fig. 4.4.4.3 Another area on Wellington's waterfront creates a wide edge near the water that people can sit on

Fig. 4.4.4.4 A change in materiality defines this area of the wharf

Fig. 4.4.4.5 Seating separates a lingering area near the water's edge from the walking area

Fig. 4.4.5 Sketches explore edge options for the promenade
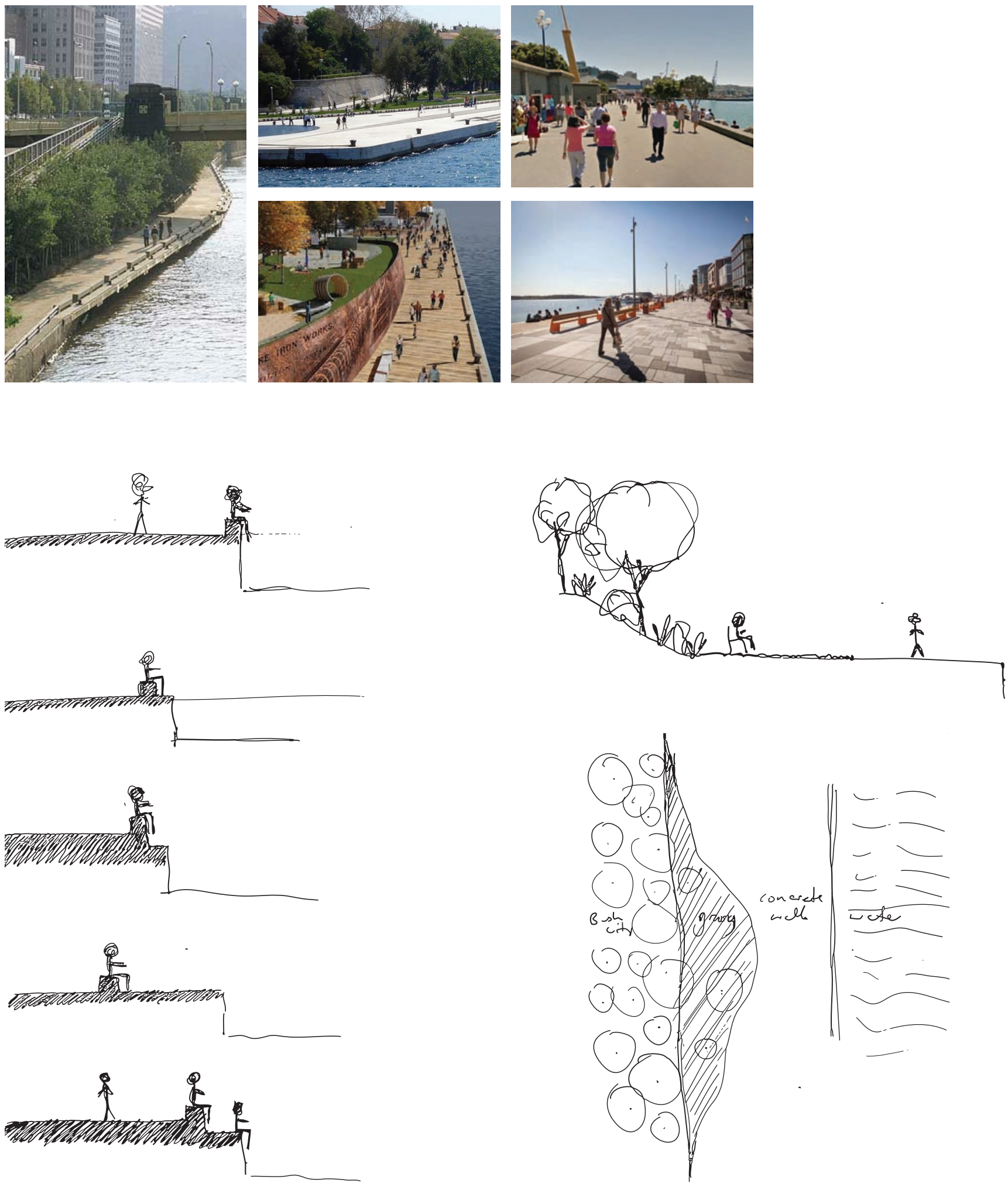
Lookout Against Building
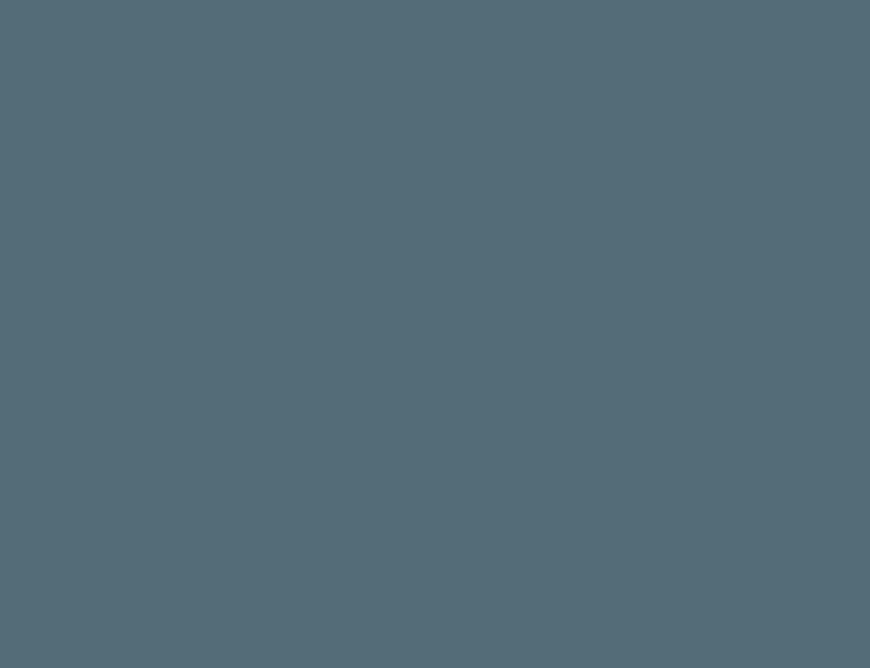


\section{Waterfront Transition}

Fig. 4.4.8.1 Progression through threshold is created through the use of lighting strips through the site

Fig. 4.4.8.2 Materiality and seating define the threshold between two spaces

Fig. 4.4.8.3 Materiality and unusual shape of the design highlight this as a new and different area

Fig. 4.4.8.4 Raised edges for planted areas define the two different spaces

Fig. 4.4.8.5 The transition here is highlighted by the compression and reopening of the space

Fig. 4.4.9 Sketches explore ways to transition from one space into another
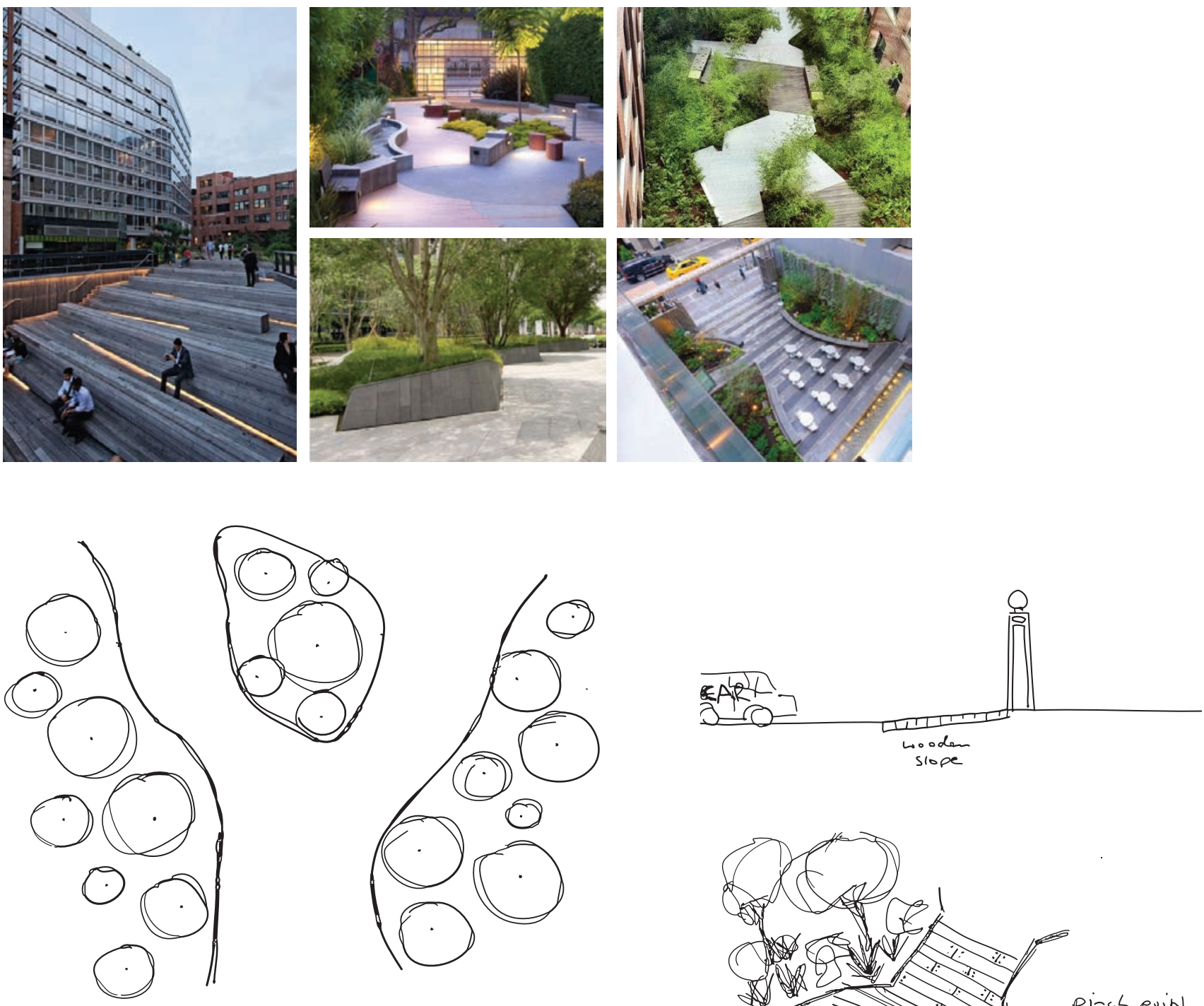

a pincl point 'gate'
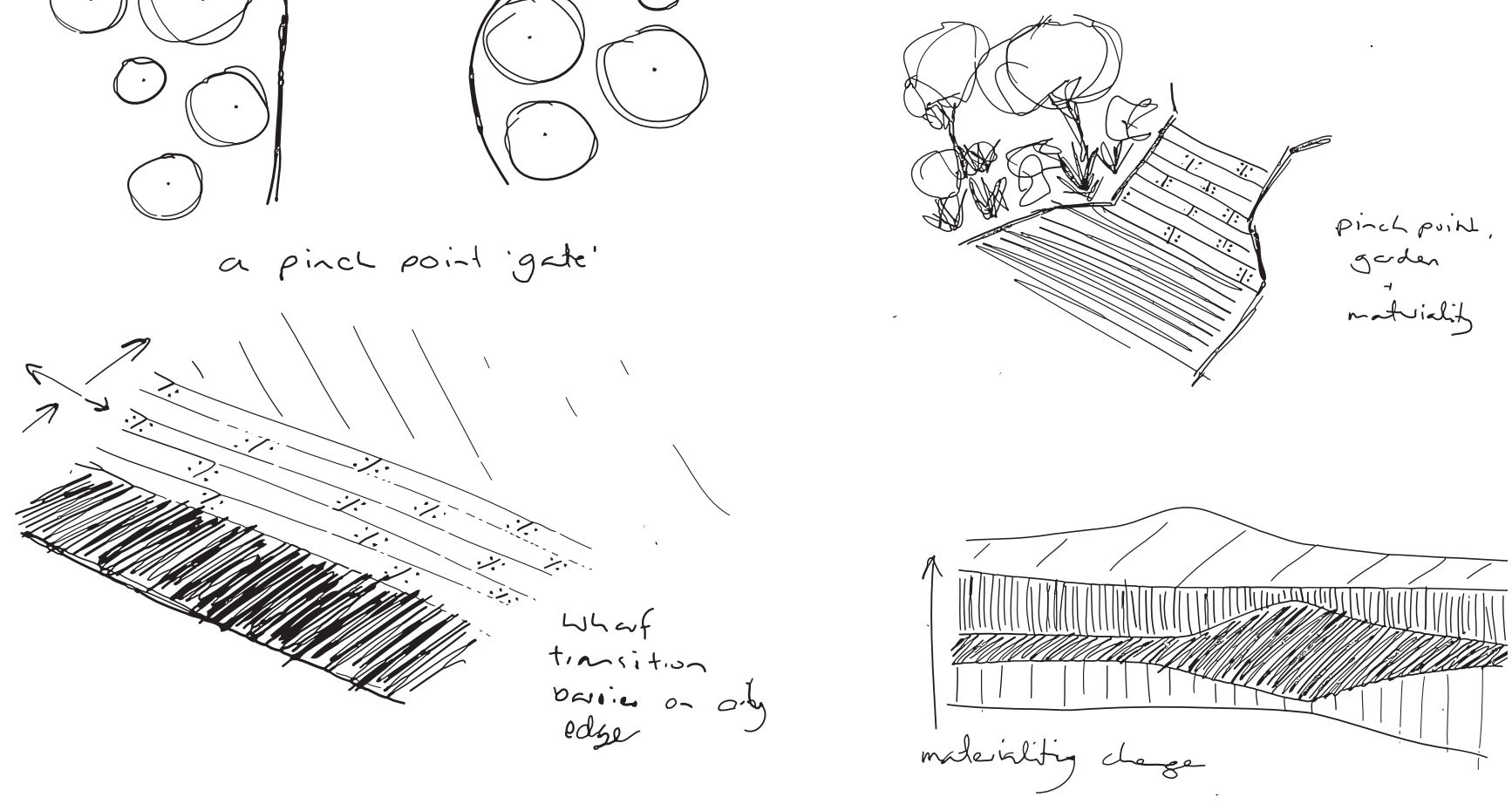


\section{Platform}

Fig. 4.4.10.1 Materiality and level changes are used to define different areas of this waterfront

Fig. 4.4.10.2 Multiple platforms are extended out from the main walking area seen in the background

Fig. 4.4.11 Sketches explore how changing the wharf edge can improve connections with the water
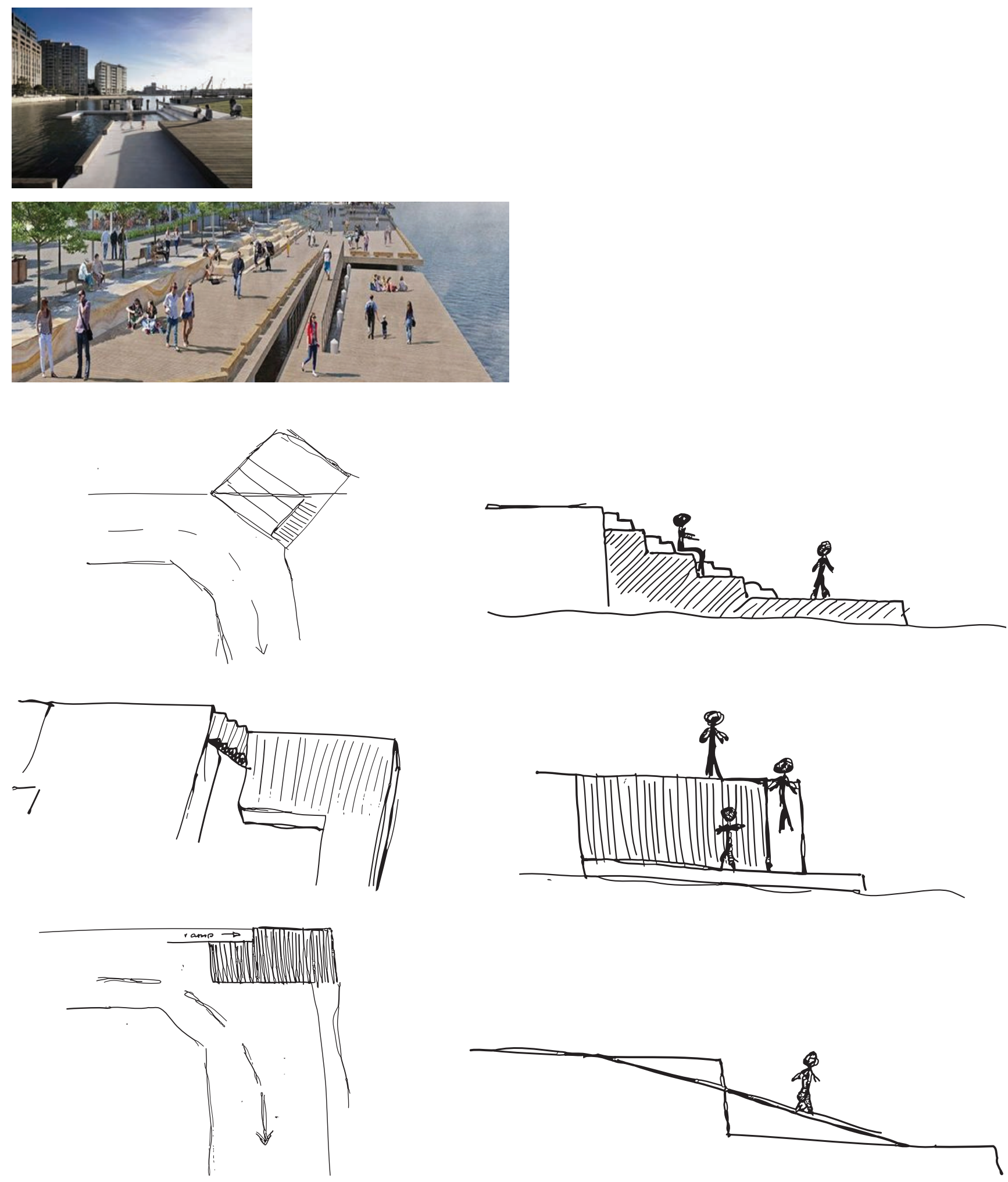


\section{Museum Exhibition Installation}

Fig. 4.4.12.1 A pavilion can be used to break up the vast plaza space

Fig. 4.4.12.2 A sculpture element can define the edges of spaces and rise up to envelope part of it

Fig. 4.4.12.3 Materiality and planting can break up a large space to define smaller spaces within it

Fig. 4.4.12.4 This pavilion allows people to sit beneath it

Fig. 4.4.12.5 This pavilion moves up and down, which allows many different engagements

Fig. 4.4.13 Sketches explore how a pavilion may sit within the plaza
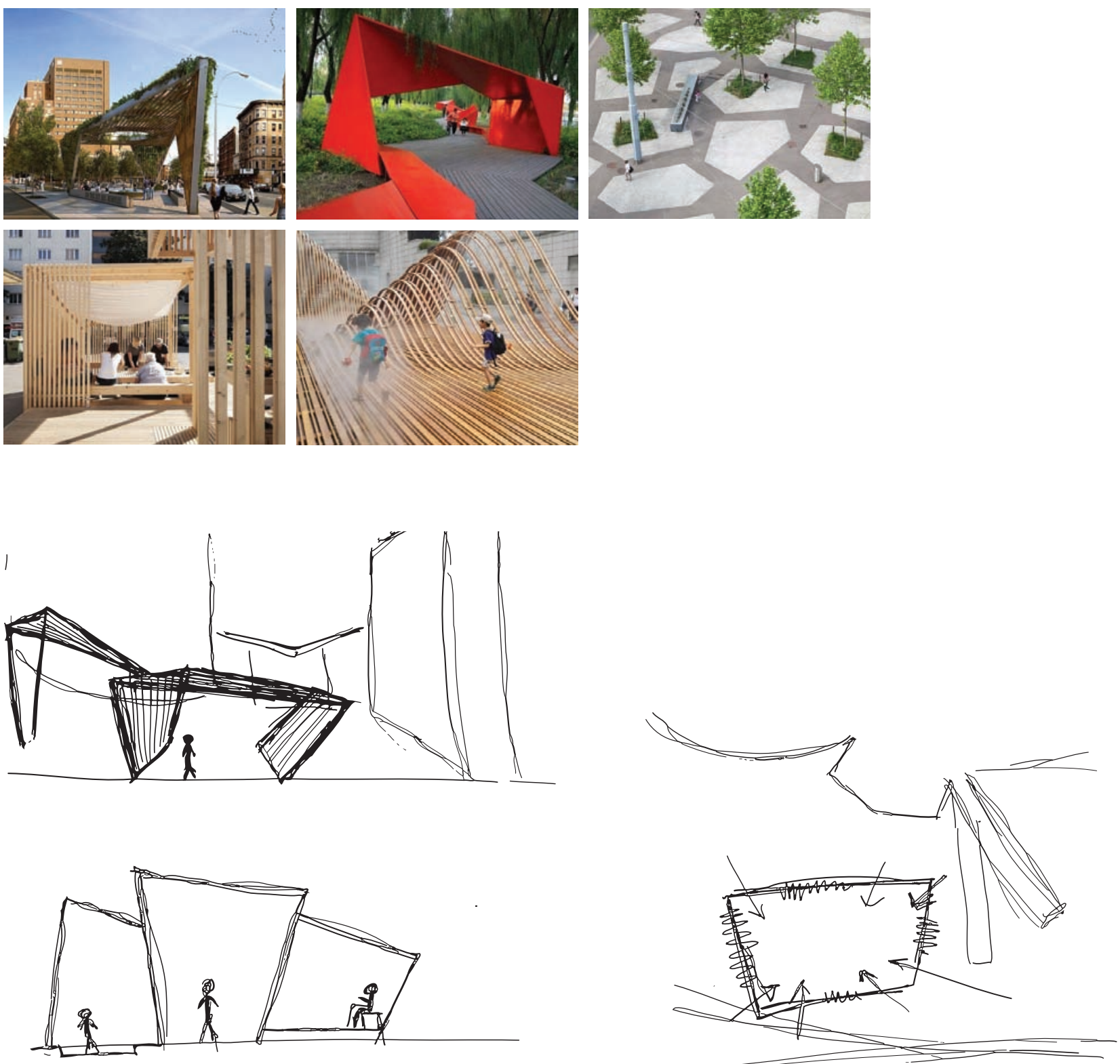

an evtrance

$$
\begin{gathered}
\text { What does it mean? } \\
\text { What is its purpose? } \\
\text { cold be bcad } \\
\text { of the arch te durs } \\
\text { photo sthdy. }
\end{gathered}
$$

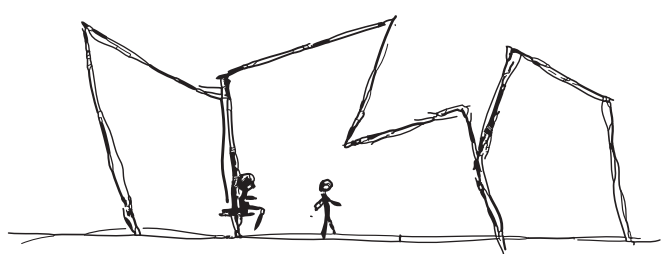




\section{Connection Across Road}

Fig. 4.4.14.1 Two sides of the road are defined as one space due materiality

Fig. 4.4.14.2 A large island between road lanes can become a new public space

Fig. 4.4.14.3 A unique crossing defines the movement people tend to take across the road anyway

Fig. 4.4.15 Sketches explore bow to create connections across the busy road that separates Te Papa from the city
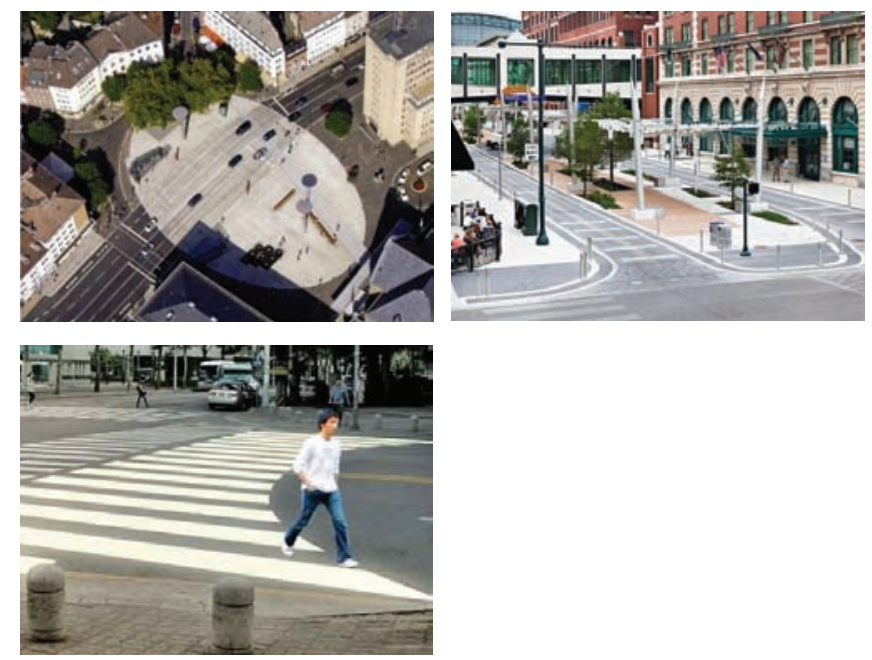

cyclists are a huge part of the waterfont site so finding precise ways to design fo
them is important to
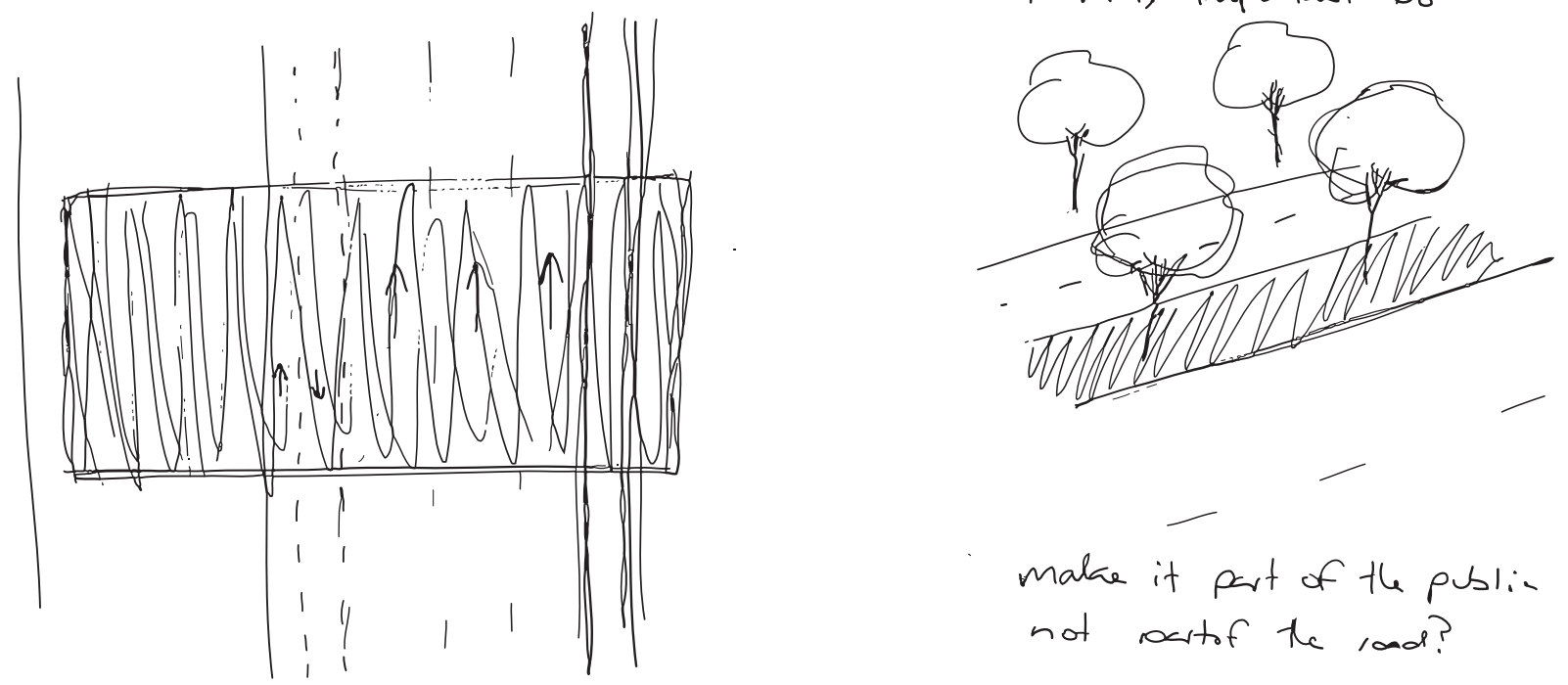

entire materiality chargewhich flows ito public spaces.

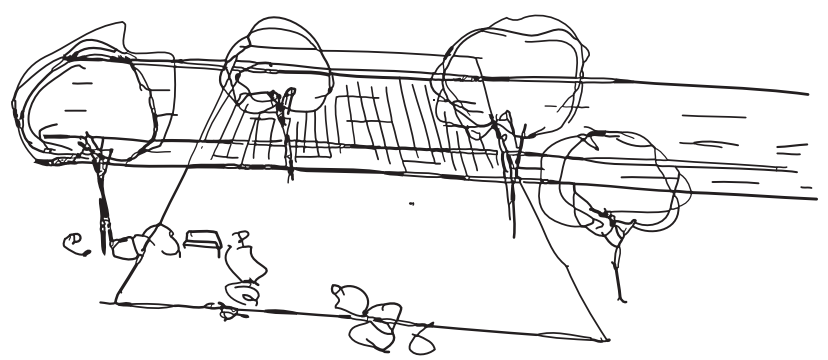

make it part of the puslie spece not rocrtof the land?
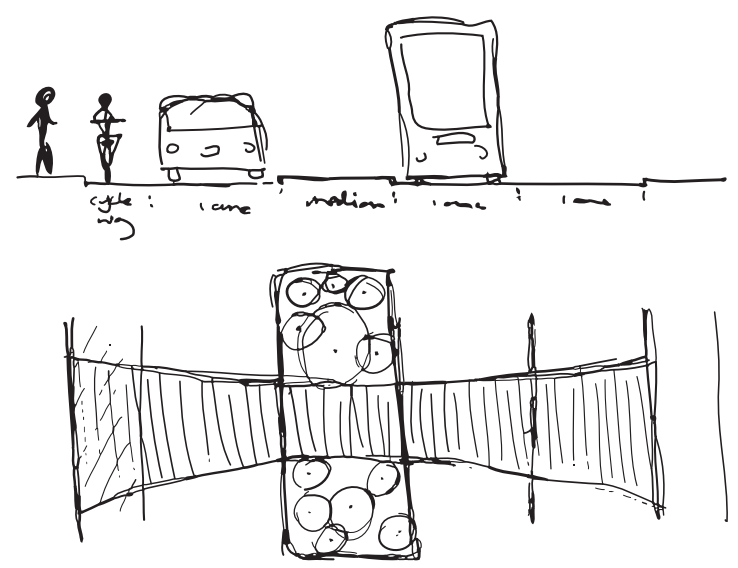


\section{Shady Sheltered Secluded Seating Areas}

Fig. 4.4.16.1 Structures also provide an element of shelter

Fig. 4.4.16.2 Structures can also define spaces within a larger space

Fig. 4.4.16.3 Defining a lot of smaller intimate spaces invite people to linger in them

Fig. 4.4.16.4 A dropped down public space is surrounded by planting to provide additional wind shelter

Fig. 4.4.17 Sketches explore shelter elements for the design of this space
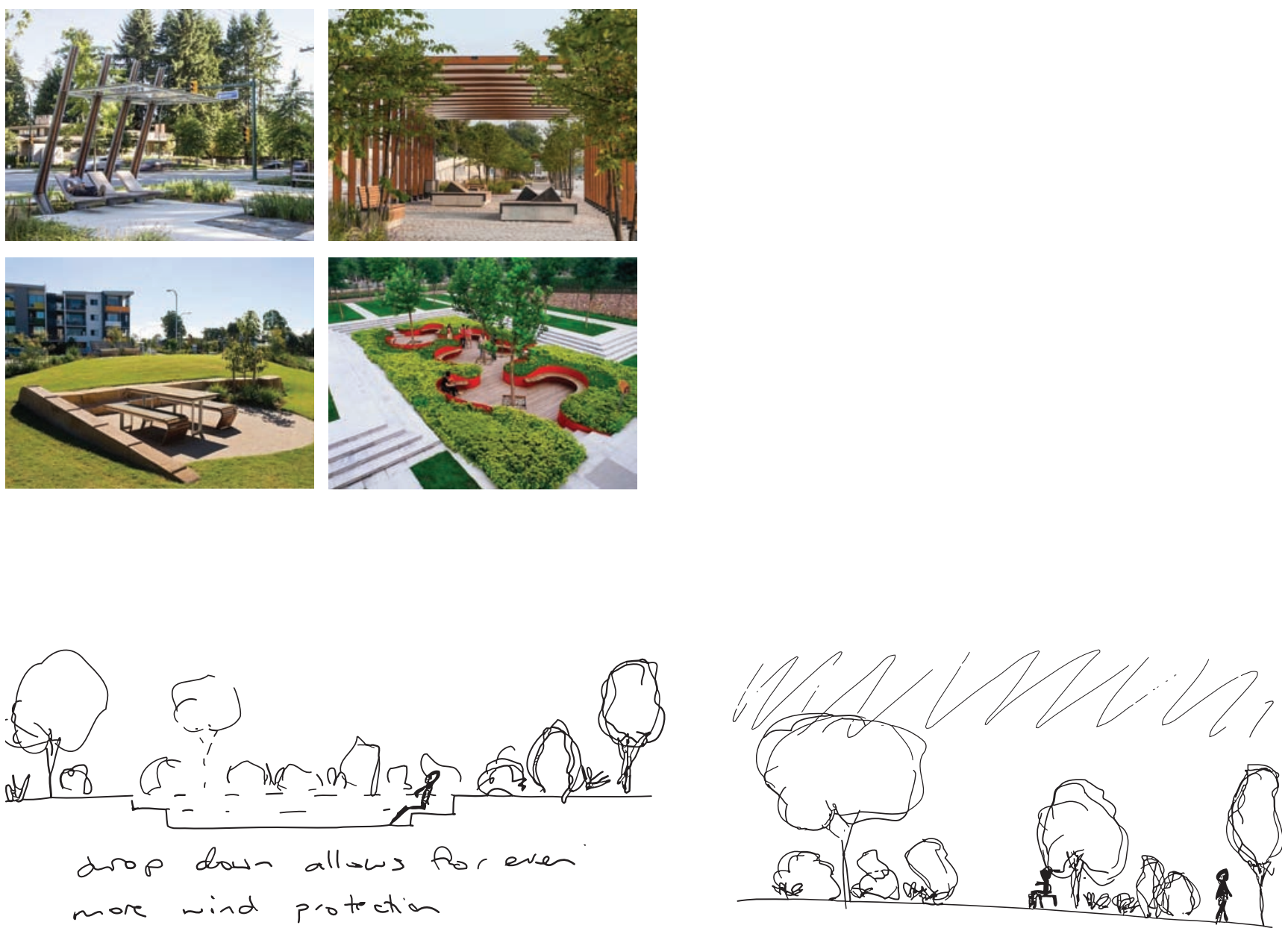

$$
\begin{aligned}
& \text { already shaded so } \\
& \text { use shating and staltering } \\
& \text { elemarts to eleninate the } \\
& \text { wird to reduce the hasthnos } \\
& \text { of the sheded space. } \\
& \text { Use thi space as a vade } \\
& \text { vith shelteres socluded spaces. } \\
& \text { For indiriduals + groups. } \\
& \text { Where is Wellingtin is the } \\
& \text { are gaden publi: space thet } \\
& \text { ya cen walk thuy? }
\end{aligned}
$$




\section{Art Gallery}

Fig. 4.4.18.1 Connections are created through the space by raised buildings and continuation of materiality

Fig. 4.4.18.2 Large windows increase the connection people can have with the building and its interior

Fig. 4.4.18.3 A stairway on the edge of the building creates a new relationship between the people walking up it and the landscape

Fig. 4.4.18.4 The entrance pulls people up into and is inviting

Fig. 4.4.18.5 The large glass facade and overhang with the continuation of material from inside connects both inside and outside seamlessly

Fig. 4.4.18.6 The building is raised and the material of that is continued through the building making it one flowing public space

Fig. 4.4.18.7 The bottom edge of the glass facade is defined by the terrain of the landscape and makes it look as though they formed each other

Fig. 4.4.19 Sketches explore ideas for an art gallery building form
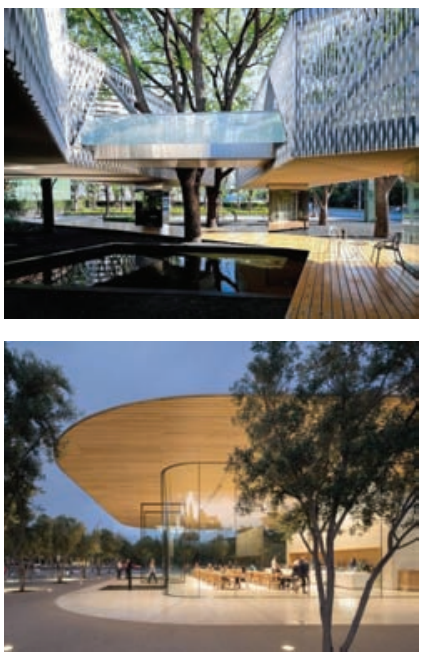
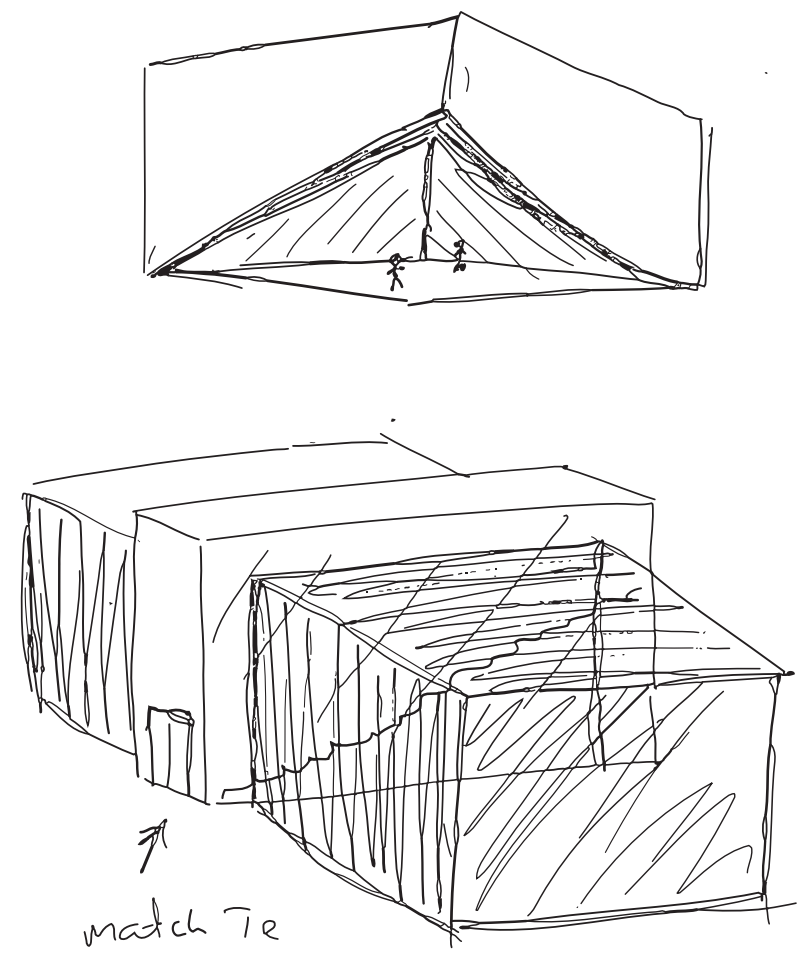

Papas avis chunk bot maler this one fromglos and it J atrium + sthir care. = Veu Museun-Berlin
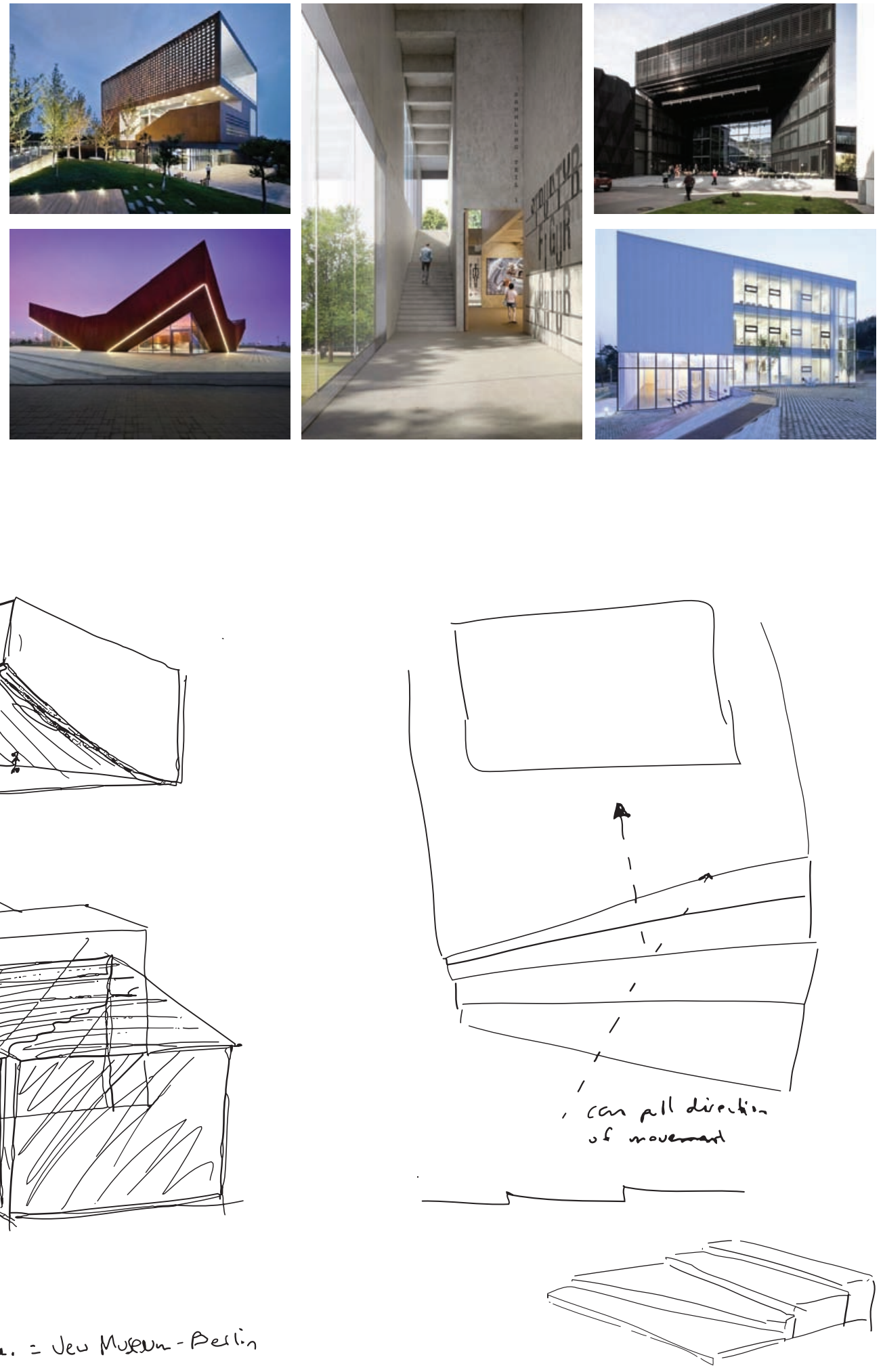


\section{New Raised Entrance}

Fig. 4.4.20.1 A staggered staircase increases the sense of exploration

Fig. 4.4.20.2 A pathway moves up into the building while the building extends out over it

Fig. 4.4.20.3 The building form start before the entrance which invites people to engage with it before they even enter the building

Fig. 4.4.20.4 This type of stairway looks like it is gently placed on top of the landscape

Fig. 4.4.20.5 A range of stair heights creates walking areas and sitting areas with the same stairway

Fig. 4.4.20.6 Cutting the stairway through a raised area can pull people into it

Fig. 4.4.20.7 This stairway appears to cut through the landscape

Fig. 4.4.21 Sketches explore stairway ideas and architecture for the entrance
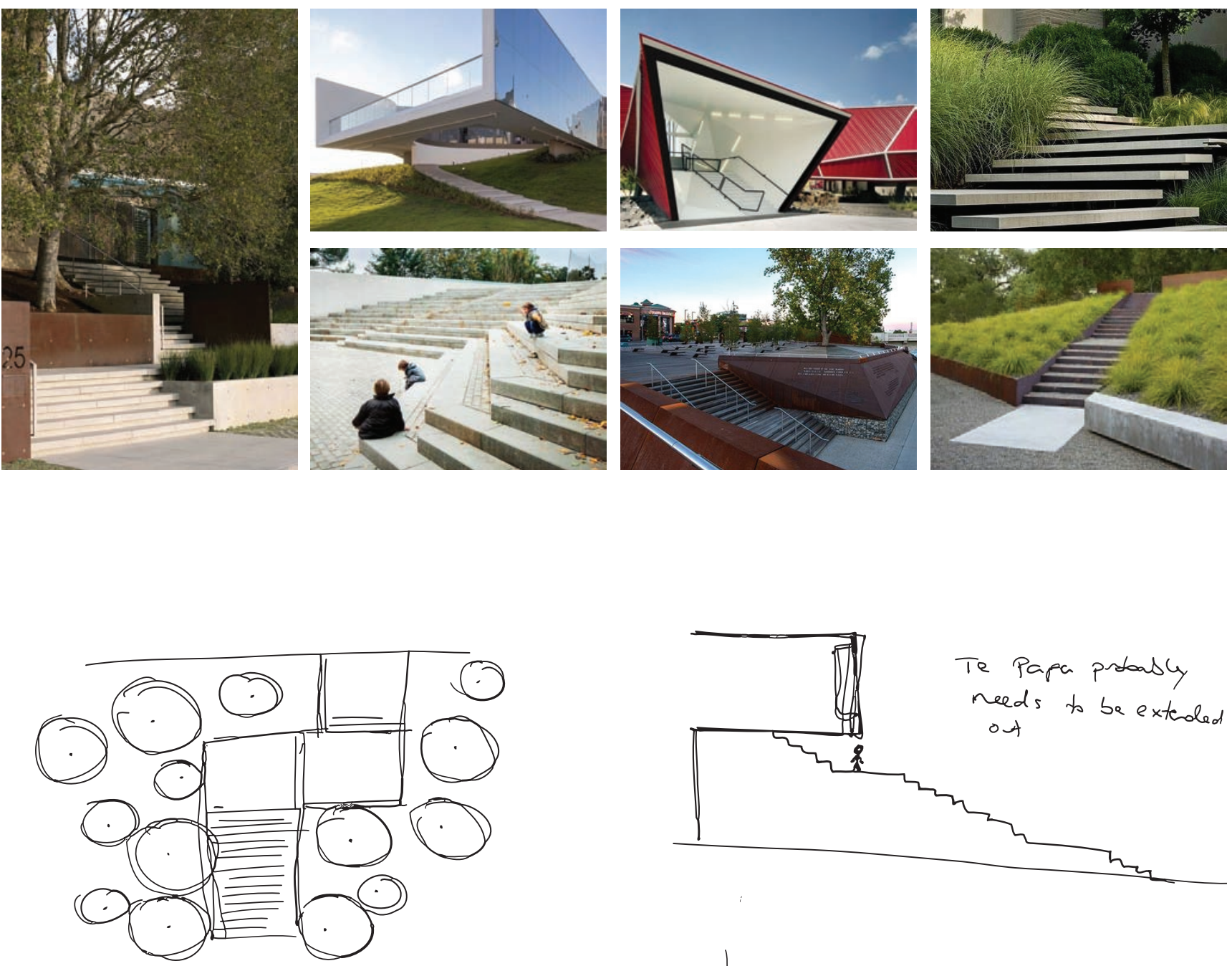

zigzag garder entrance
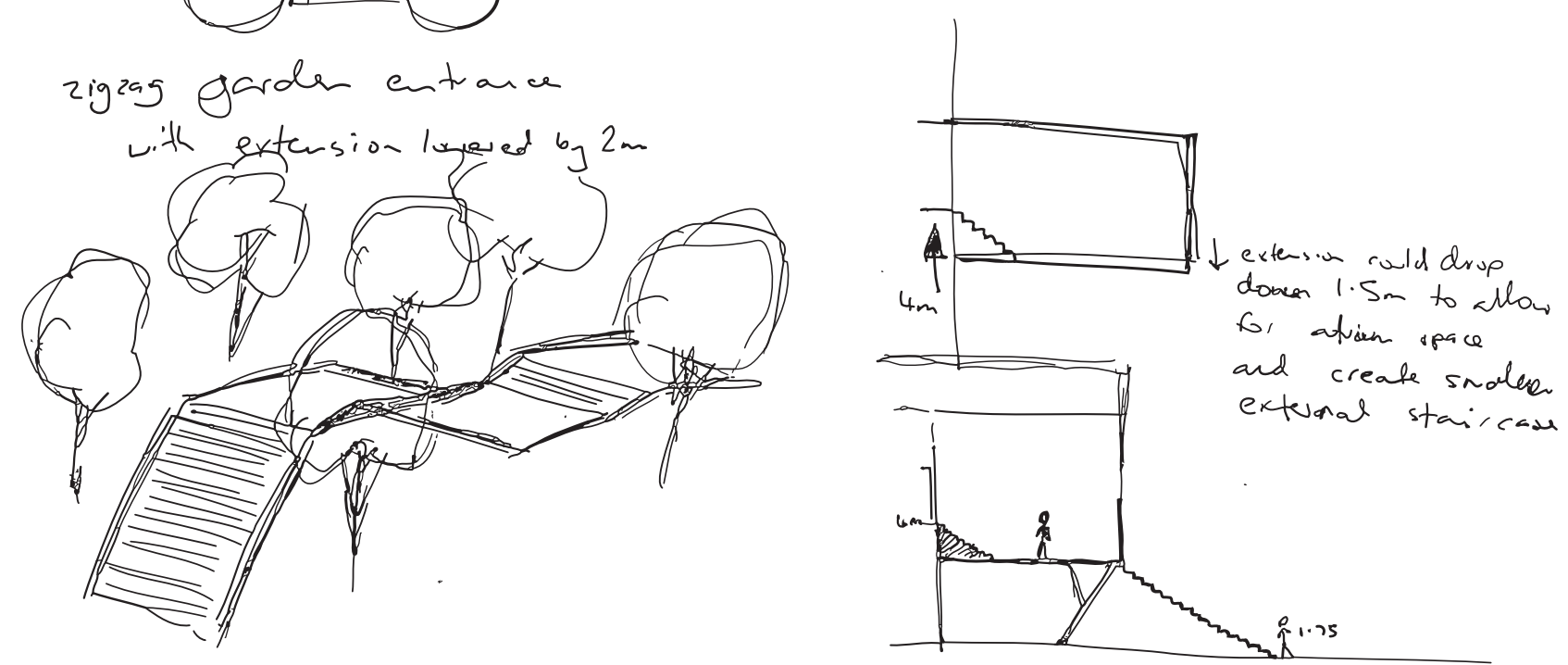


\section{Removal of Waitangi Park Linear Barrier}

Fig. 4.4.22.1 A staggered pathway moves people back and forth between the space

Fig. 4.4.22.2 Small areas of seating can be found off the main path in this design

Fig. 4.4.22.3 A pathway of grass is defined by planting and people are invited to seating areas set back into the planting

Fig. 4.4.22.4 Change of materiality defines the edge of this pathway that weaves through this garden

Fig. 4.4.23 Sketches explore how materiality and paving configuration can define a path
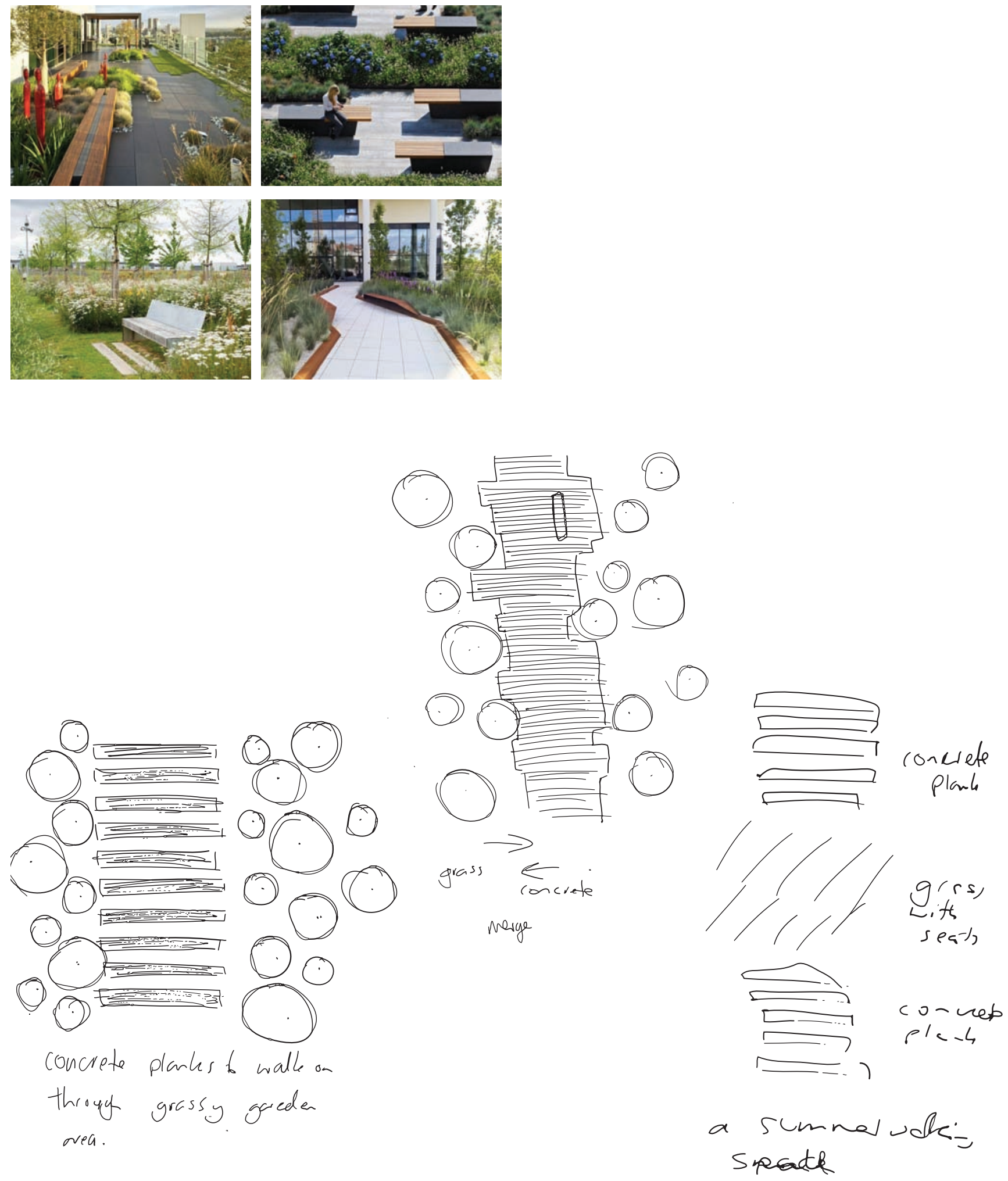

concrete planks to walle on

through grassy gaceden

ovea. 


\section{WHARF EDGE MODELLING}

These iterative physical models explore how changes to the wharf edge make this area more inviting and ways to create a connection with the water.
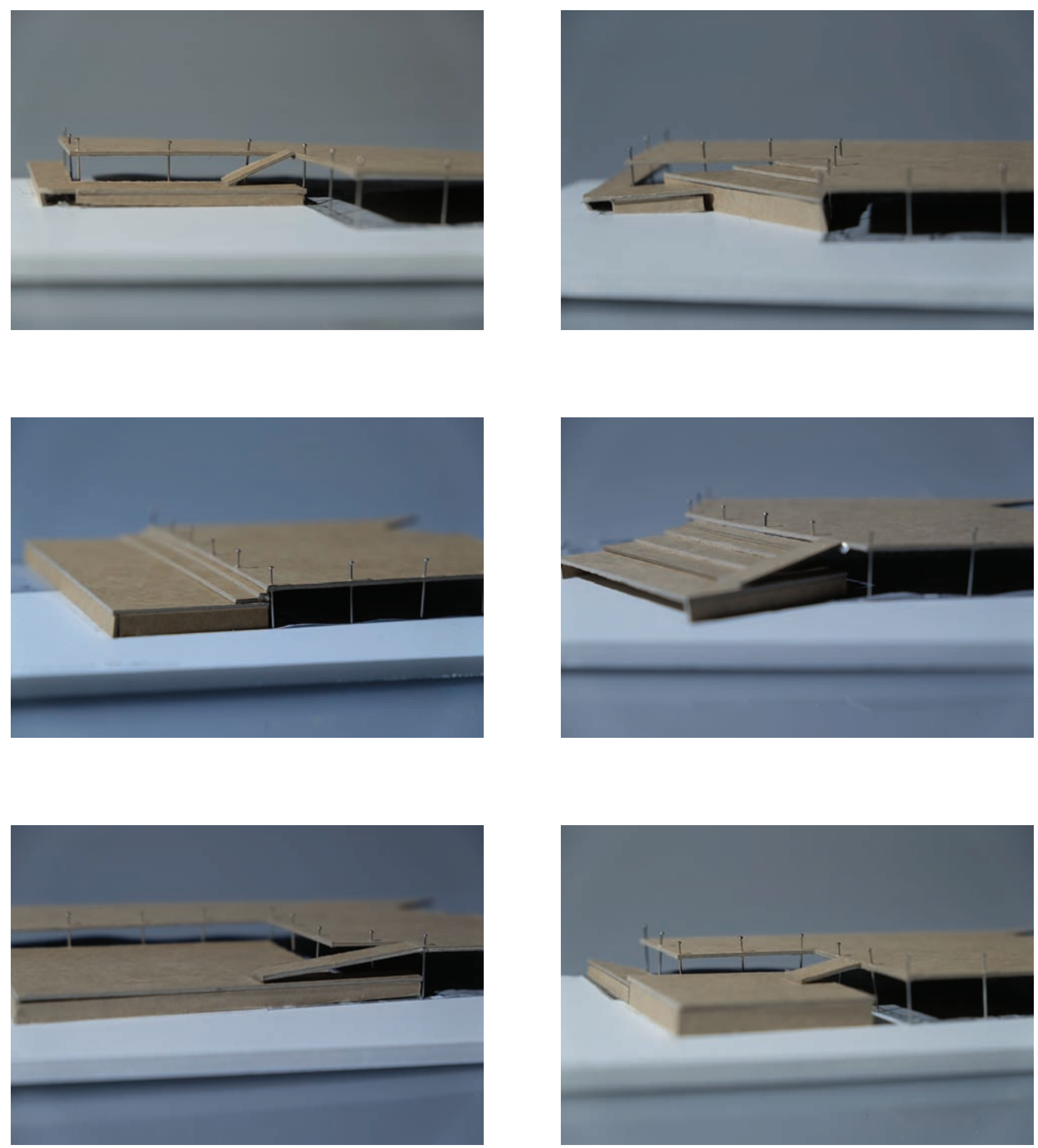

Fig. 4.5.1 A series of sketch models to explore possible changes to the wharf edge 


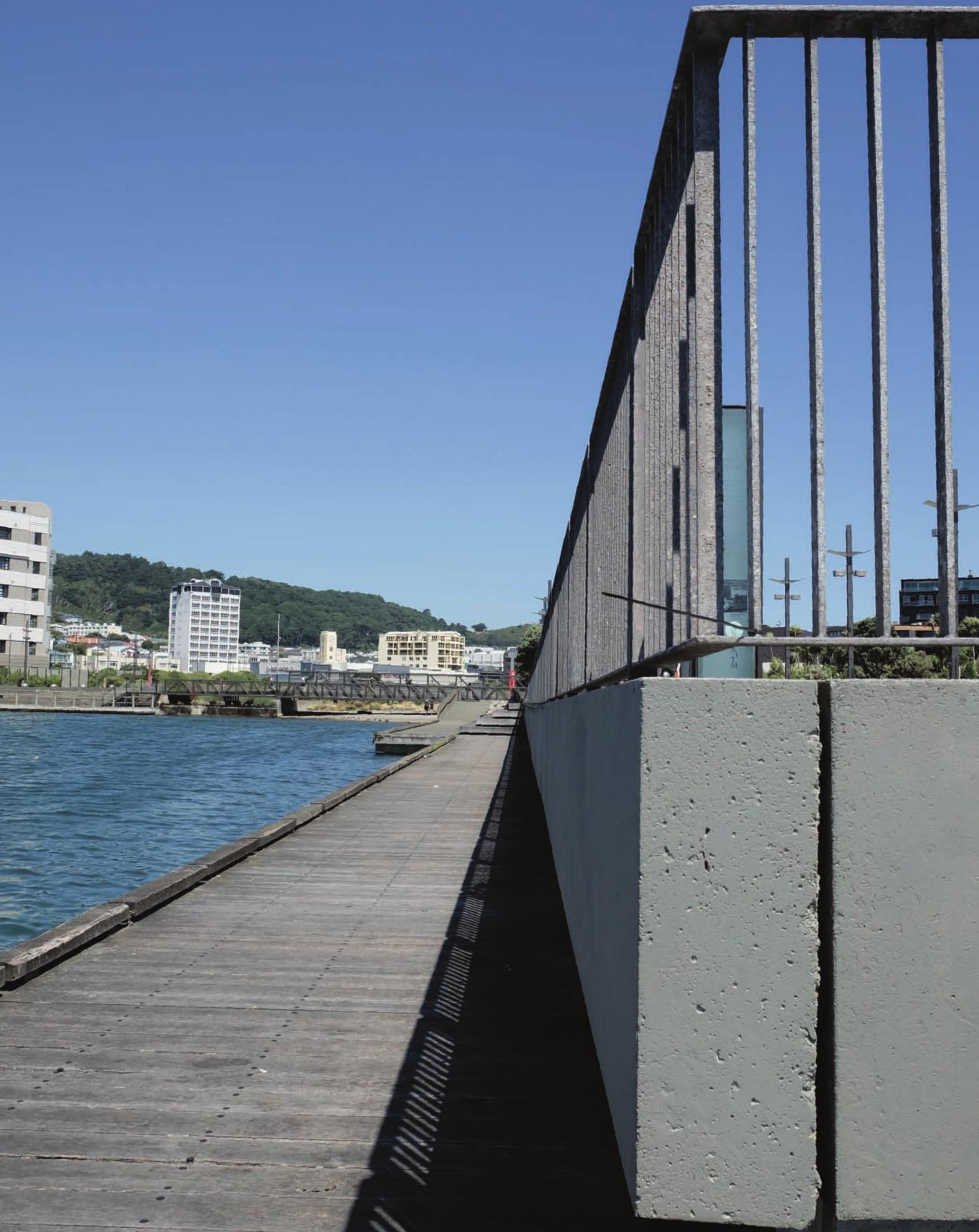




\section{PHOTOGRAPH ITERATIONS}

This study is about how to change edges or facades to create a new interaction for people to have around it. All of these small studies have a before/after comparison that include silhouettes to demonstrate various ways to engage with the new concepts. This quick investigation ensures future consideration of the close scale human interactions that occur when designing spaces.

Fig. 4.6.1 A series of perspective collages on photographs taken around site to explore changes that could be made in order to enbance public interaction with the edges created by Te Papa
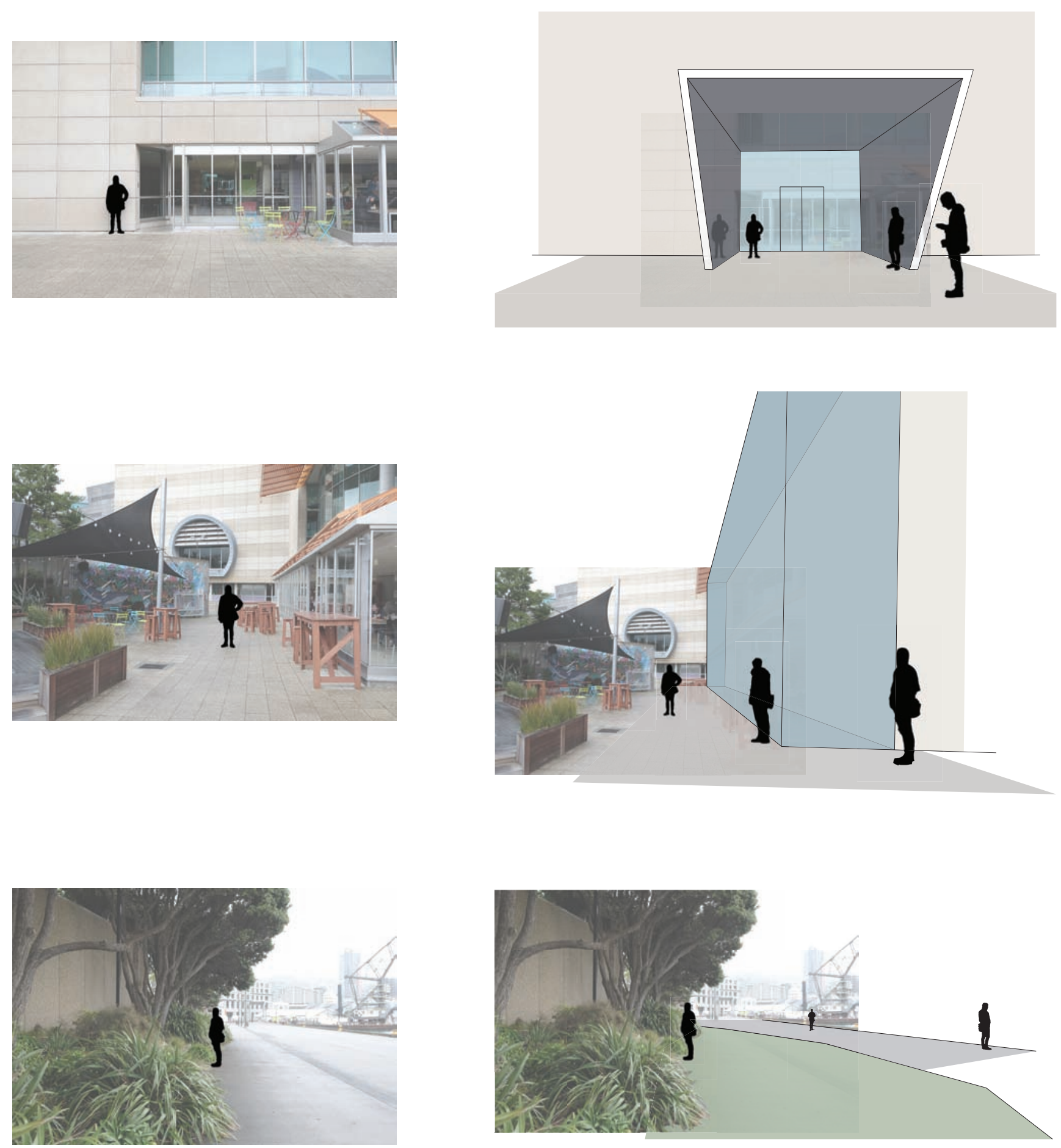

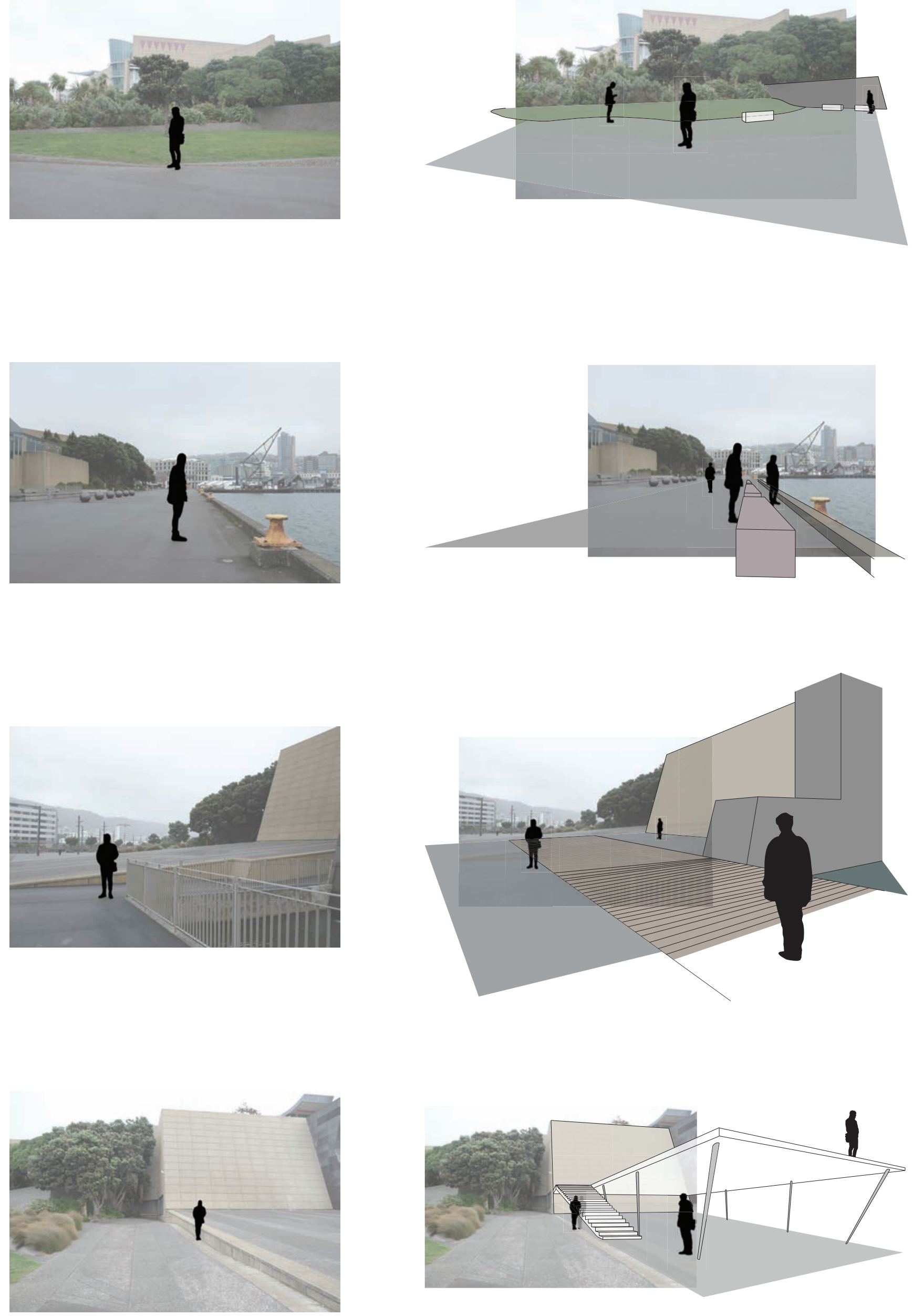

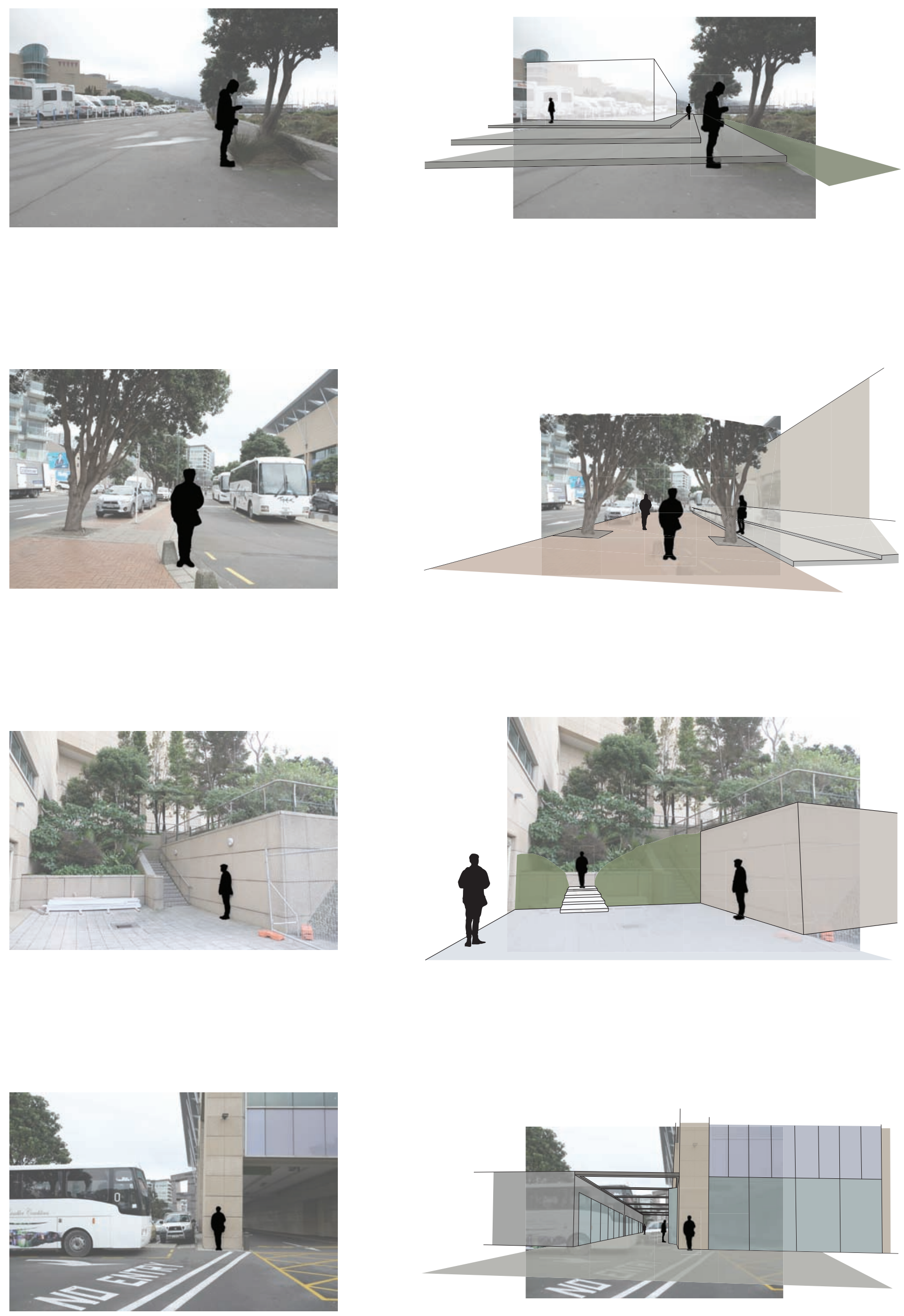

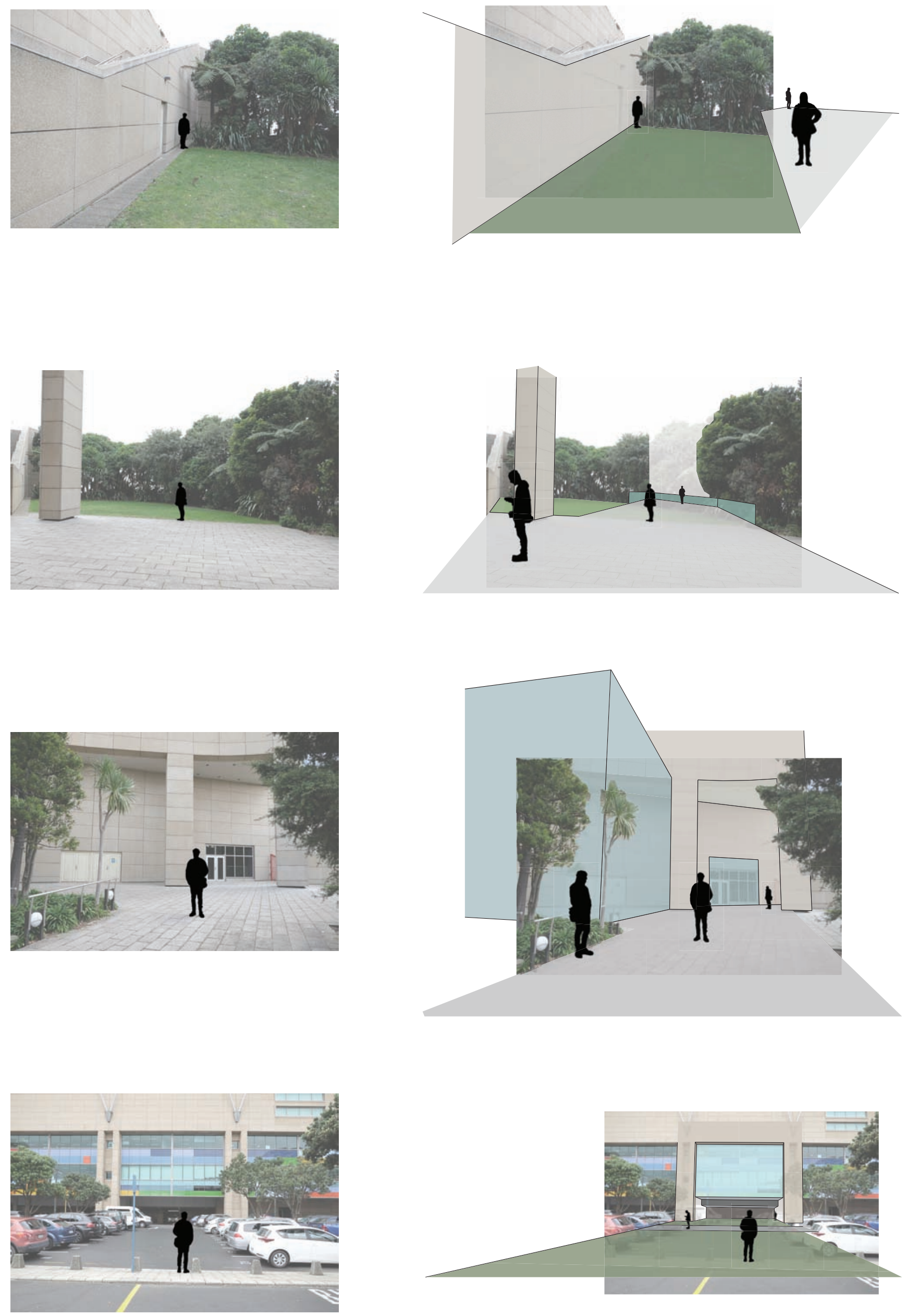

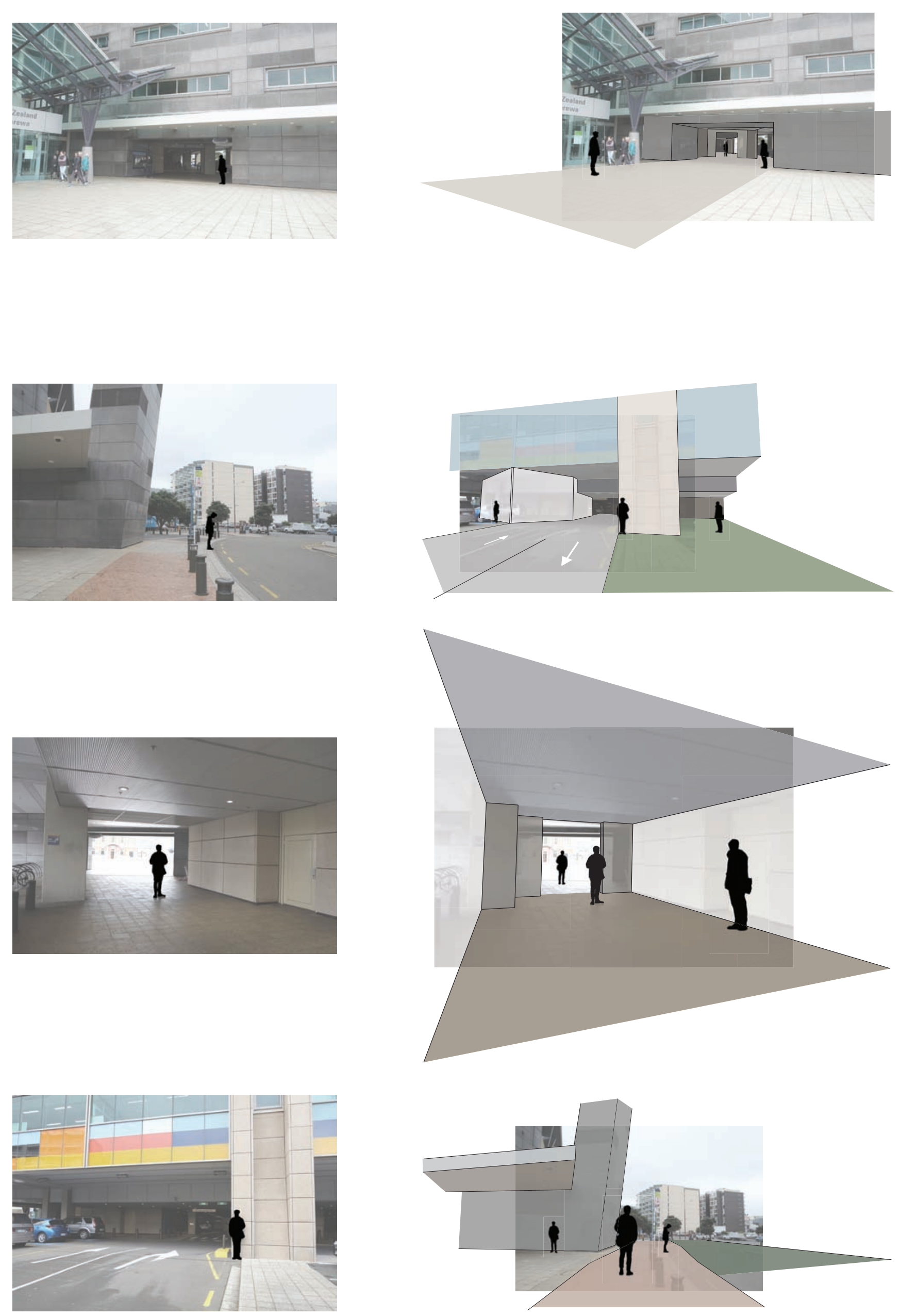


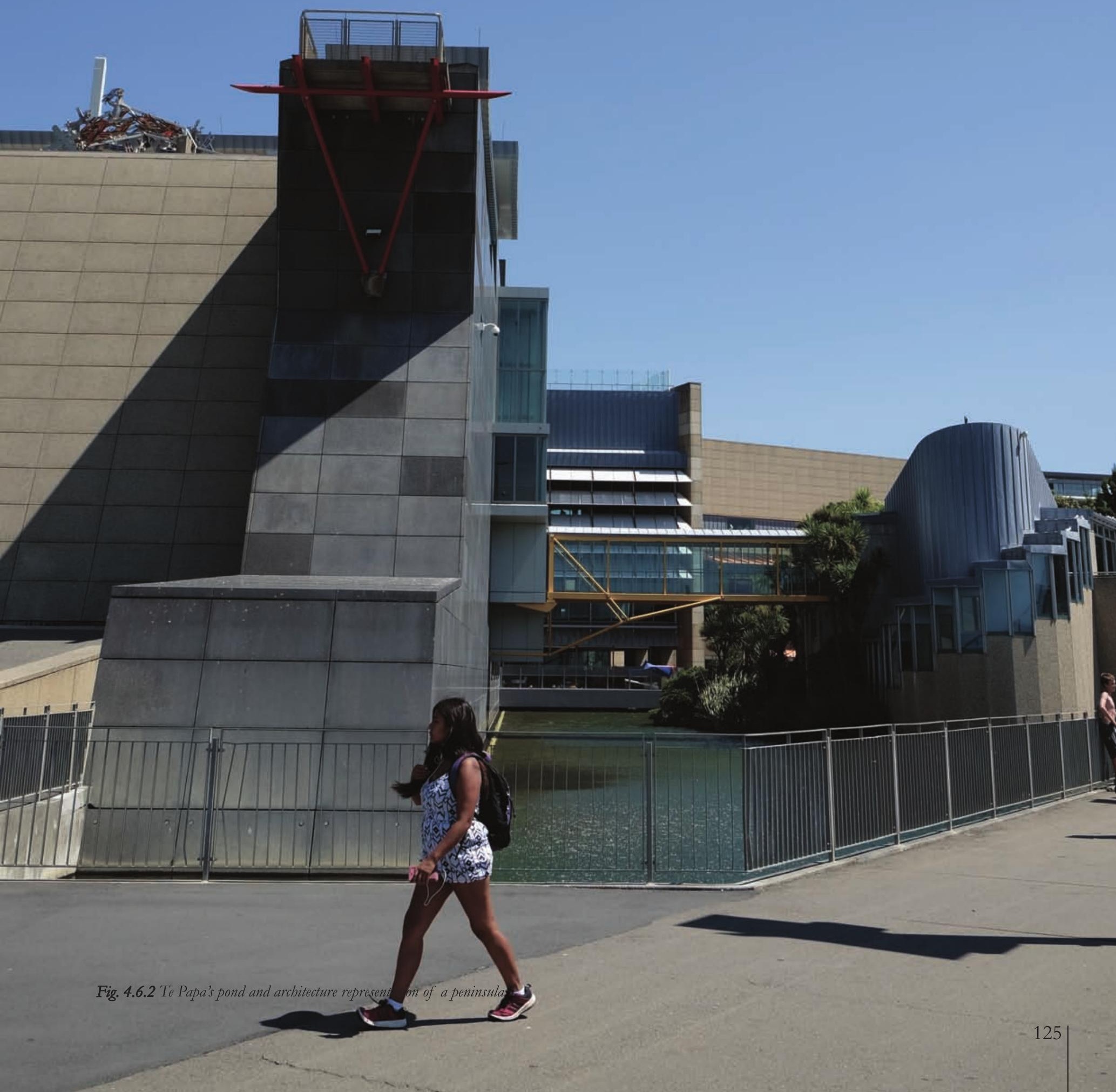




\section{CHAPTER FOUR CONCLUSION}

This chapter helped establish the direction that this design-led research will take by the introduction of three key drivers to consider in the design stages. The first, the understanding and use of Movement Co-ordination leads to designing spaces that respond to how specific movement facilitates different public life and working with that to create further opportunities. Second, employing design approaches that Open/Activate Edges will change people's relationships with a building and can be used to create a multitude of activity opportunities for new public life. Third, Destination Creation is important in the design of all new (and redesign of existing) public spaces and has the opportunity to create numerous opportunities to generate public life.

Moving between site scale and human scale ensured each was considered within each other and granted a fuller understanding of how the public might respond to these design changes. The iteration process and wide range of research in this chapter helps fulfil one of the aims which is to employ various approaches to invite people to linger and gather in new and existing public spaces. 
\$

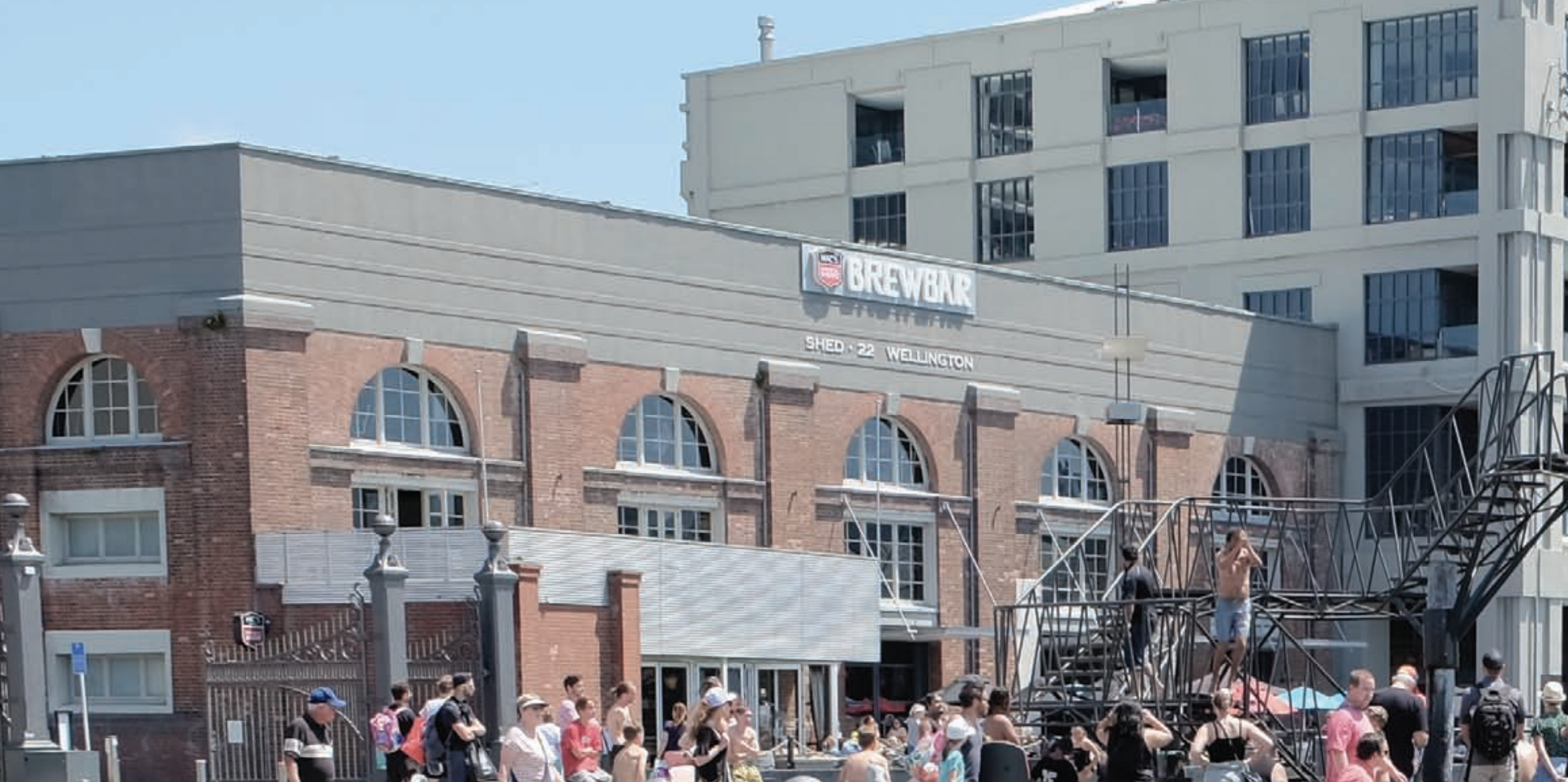

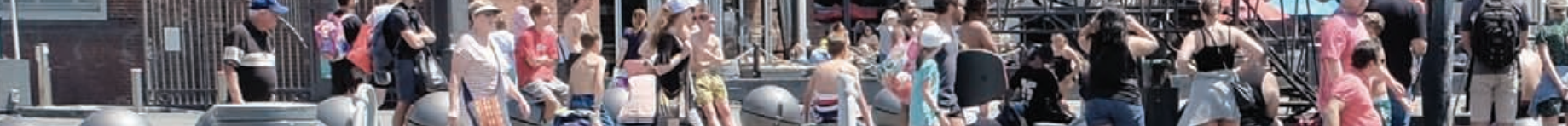

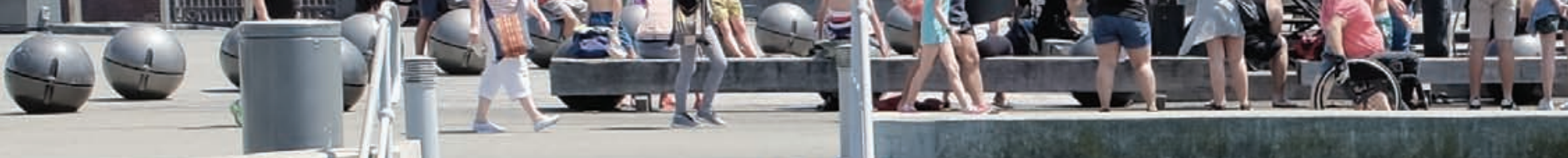

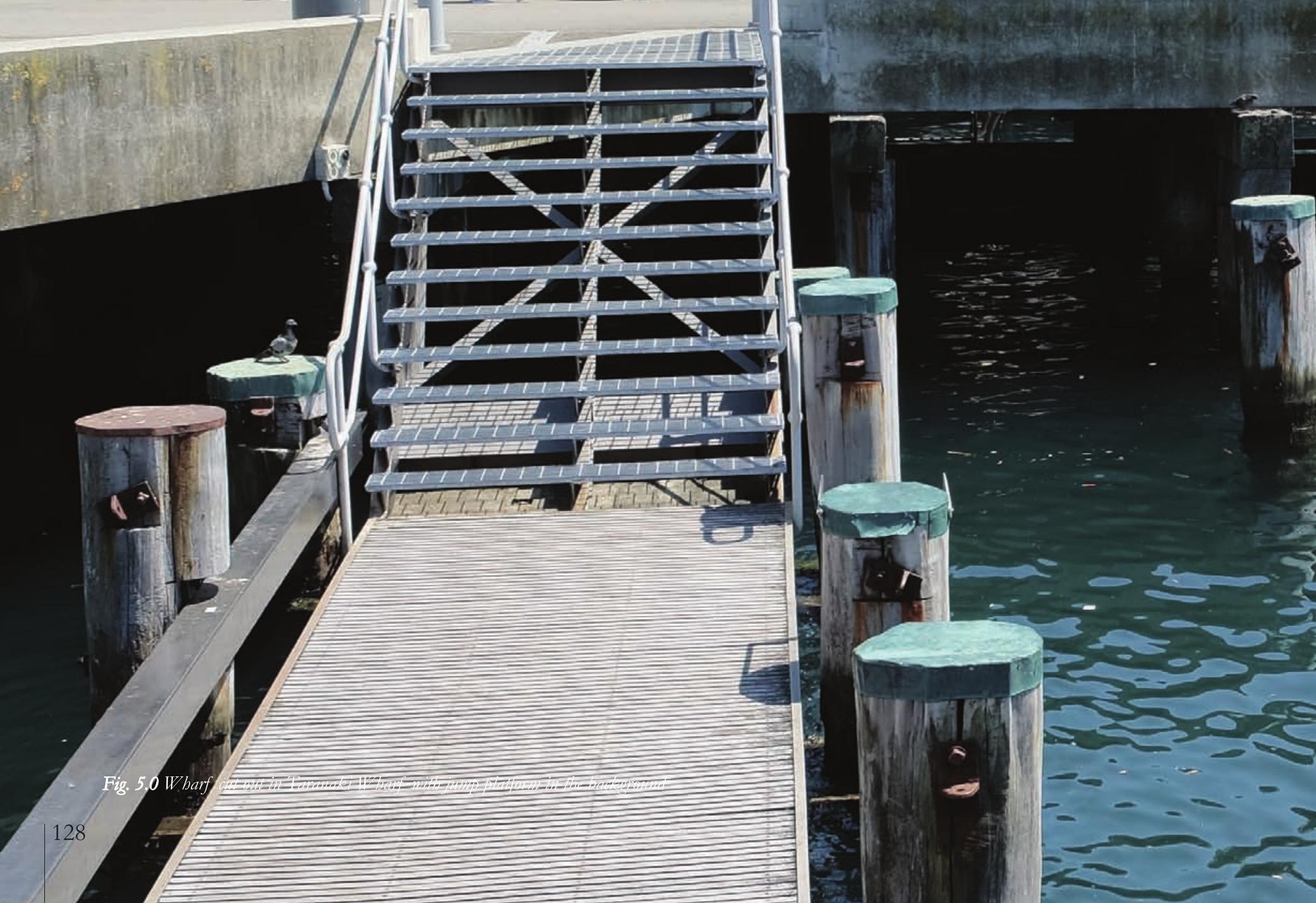





\section{INITIAL CONCEPT}

The formation of an initial concept allows testing of the design methods.

This is the concept of enclosure; it creates a varied microclimate that protects from the wind in many places.

Three main criteria for the creation of this concept are:

- Create connections and interactions with the water

- Explore ways in which Te Papa can be opened up

- Make Te Papa less dominant and reintegrate it as part of the waterfront and city

The design-led research finds ways to enhance the positive interactions and activities happening in the site and remove areas that negatively affect the potential for the public to exist.
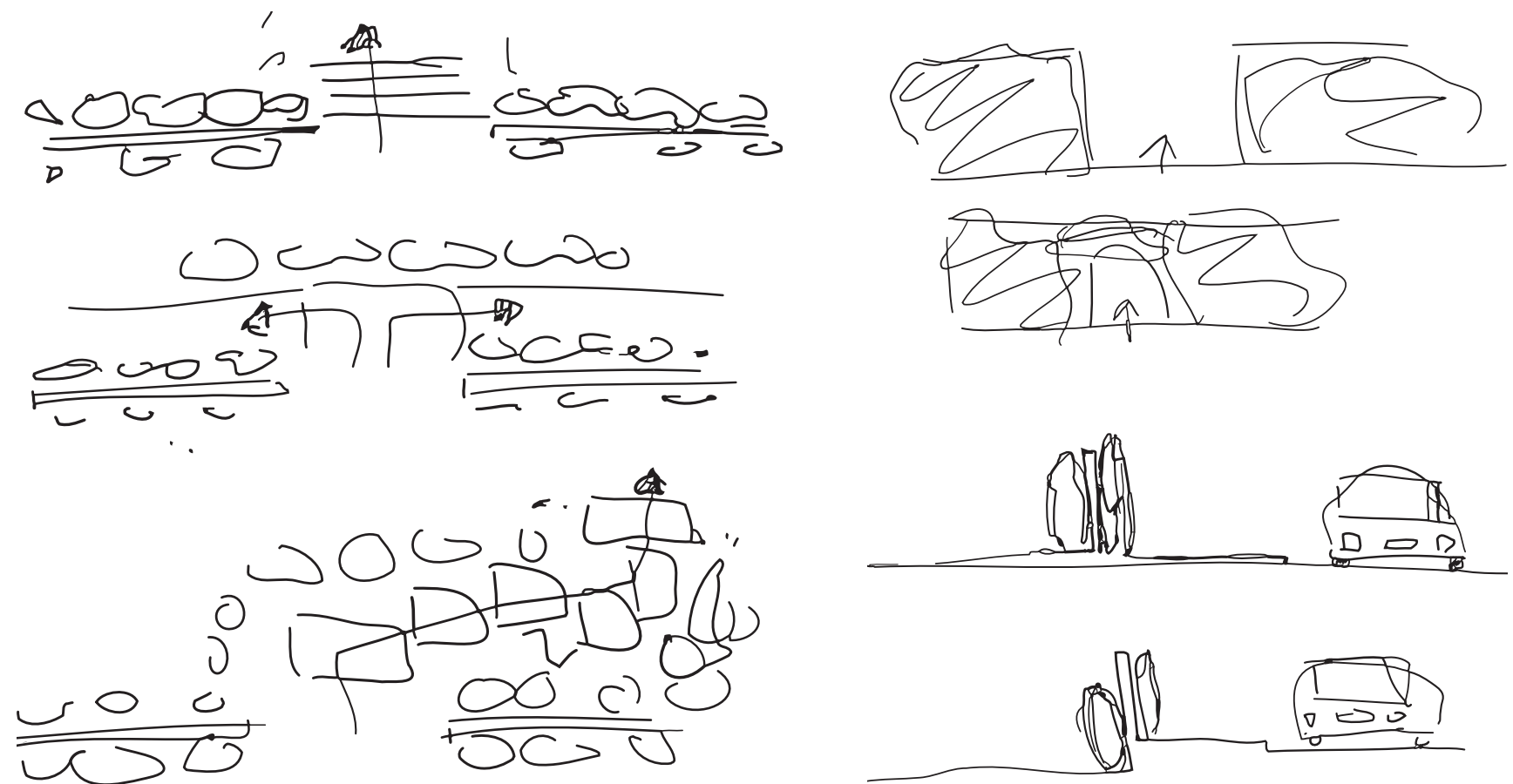

Fig. 5.1.1 Sketches scanned from book that document the initial thinking behind bow an enclosed space would work within a greater public space 


\section{Conceptual Masterplan}

This initial masterplan focuses on the southern and eastern sides of Te Papa; it pieces together different ideas that came about in the previous chapters in a way that will have the potential to increase public life and create a public space that builds off from Te Papa's edge rather than pull away from it. The following research will help ensure the threshold between these public spaces are inviting to people.

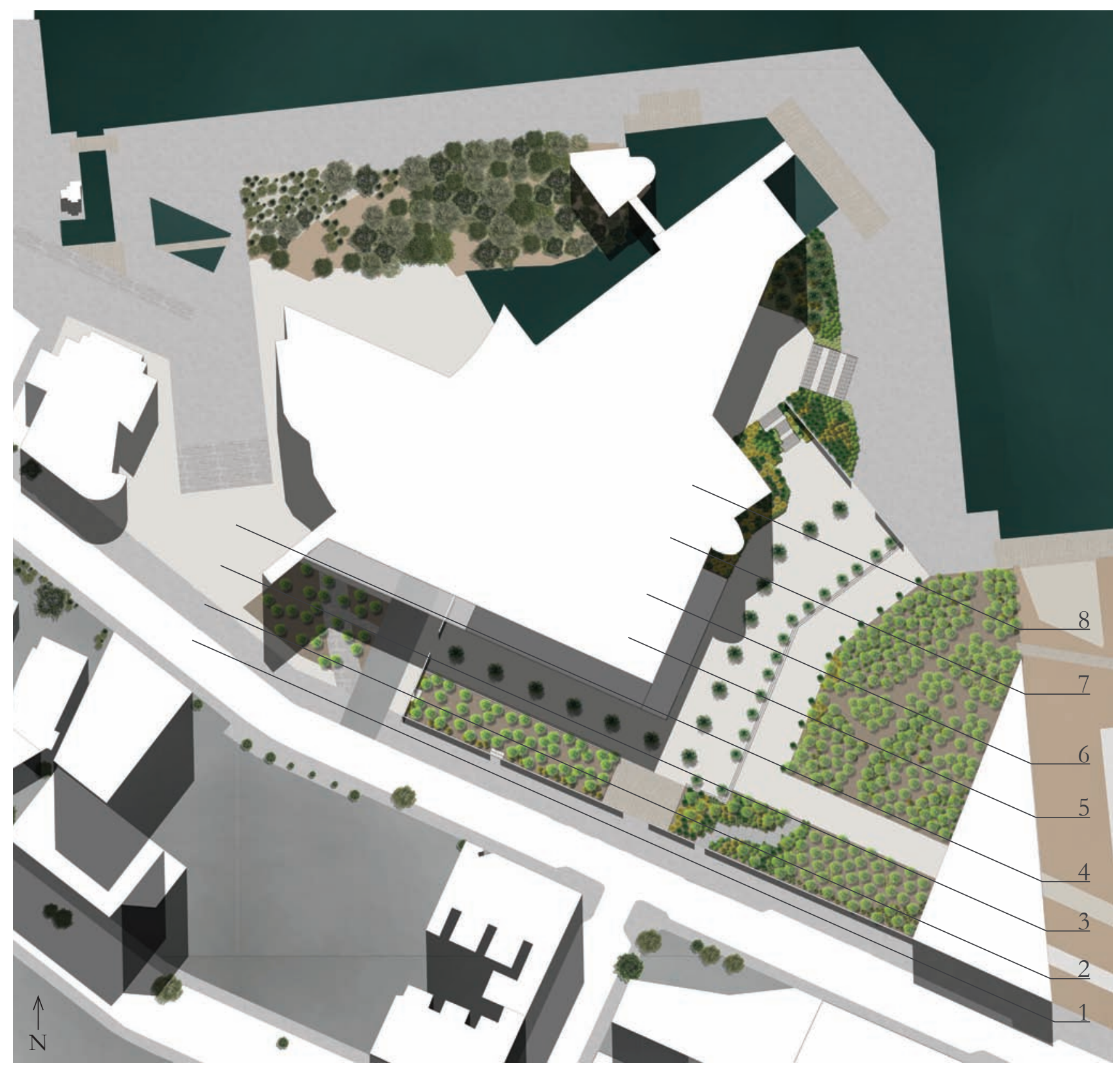

Fig. 5.1.2 Masterplan for initial concept 1:1250 
Imagining A Canopy and Civic Space

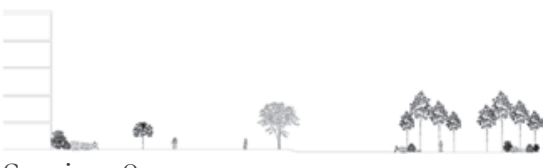

Section 8

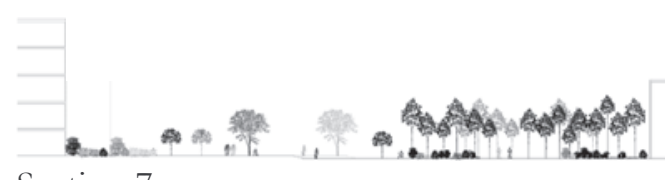

Section 7
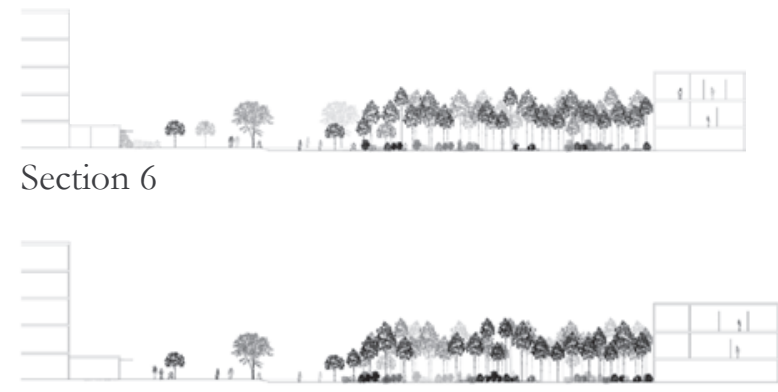

Section 5
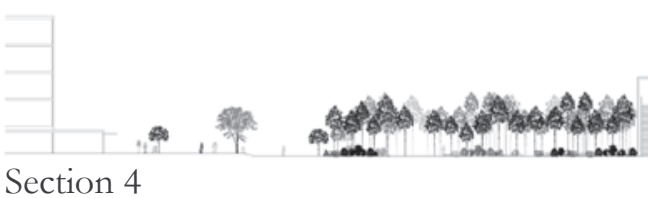

Section 4

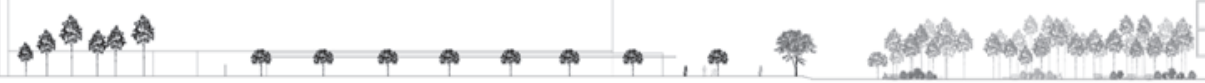

Section 3

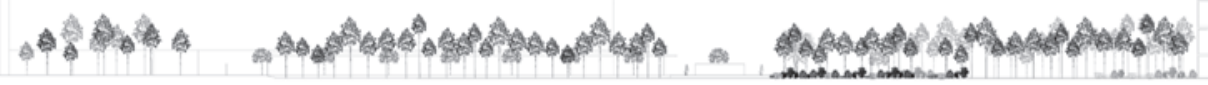

Section 2

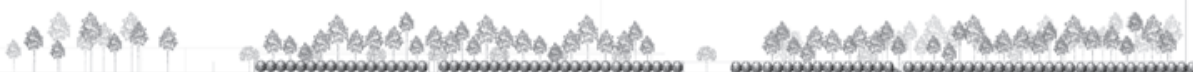

Section 1

Fig. 5.1.3 Sections taken through the initial concept masterplan 1:1250 
This section investigates how user groups that exist in the area may find new interactions with this concept, as well as the movement and public life it may create. These sketches explore how the form of the physical environment and its configuration may affect the limitations or conditions for each relationship and their ability to engage fully in the site. 


\section{Attraction Distraction}

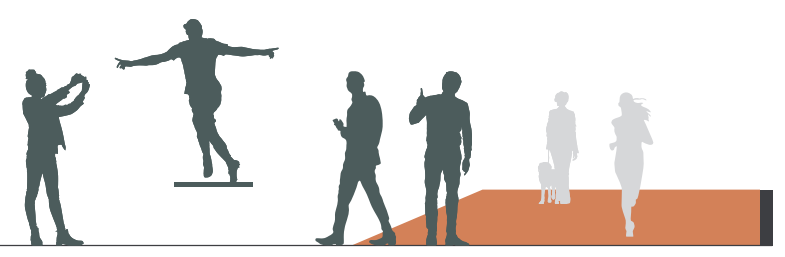

For this to occur sight lines need to exist between the movement and places where an attraction might occur.
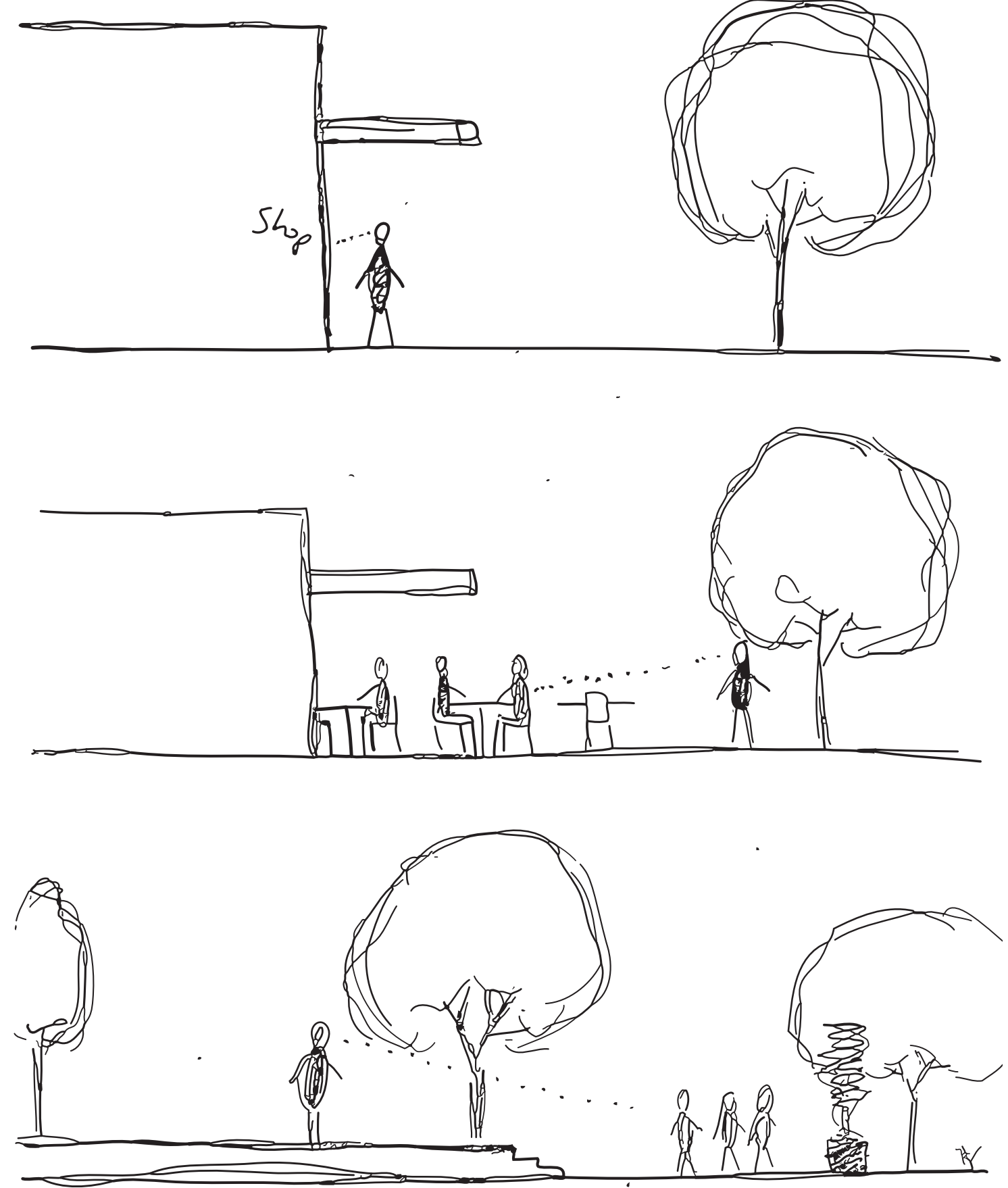

Fig. 5.2.1 Sketches scanned from notebook relating to relationship interaction 


\section{Explorers Unfamiliar with the Area}
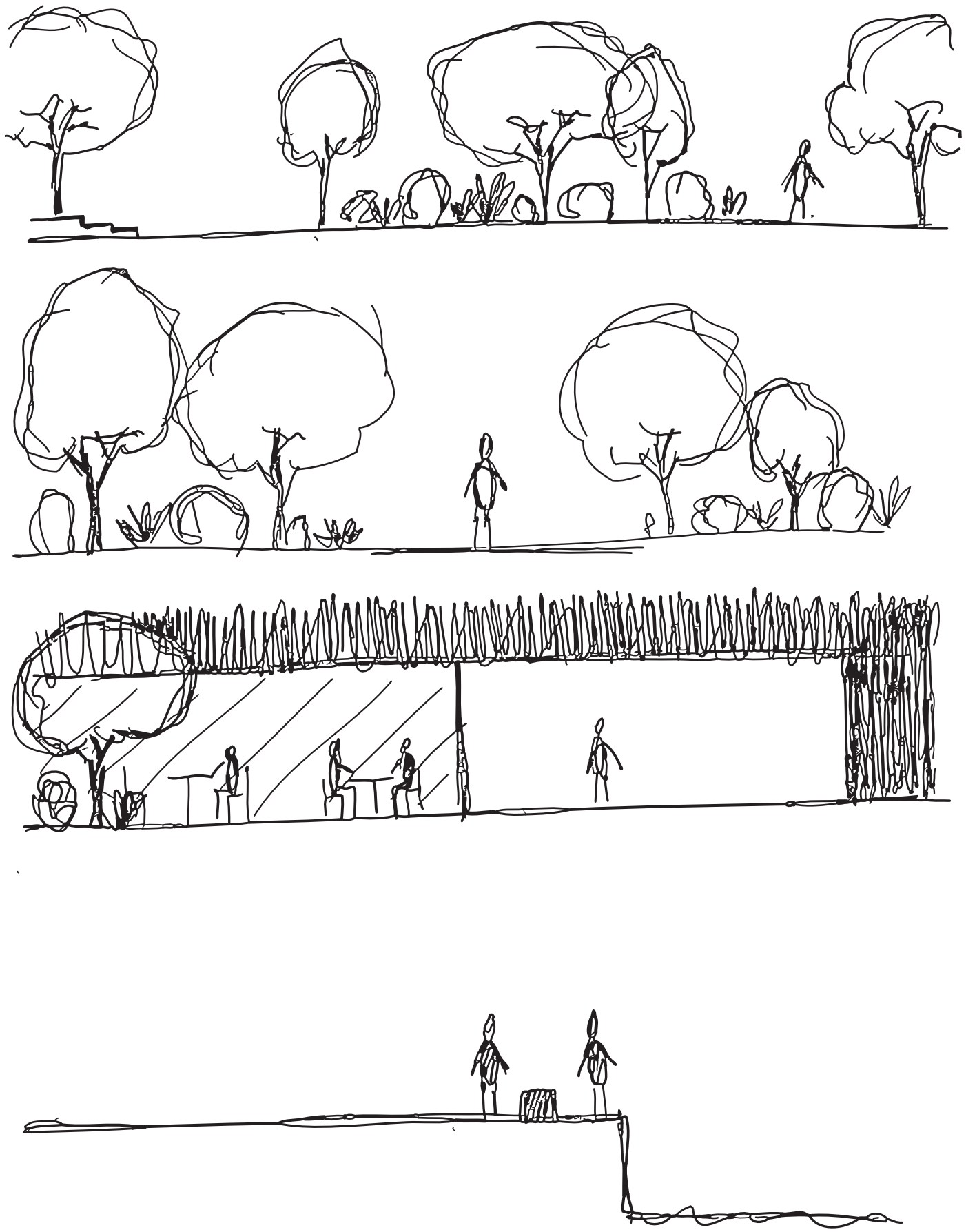

Fig. 5.2.2 Sketches scanned from notebook relating to relationship interaction 
Invested Explorer
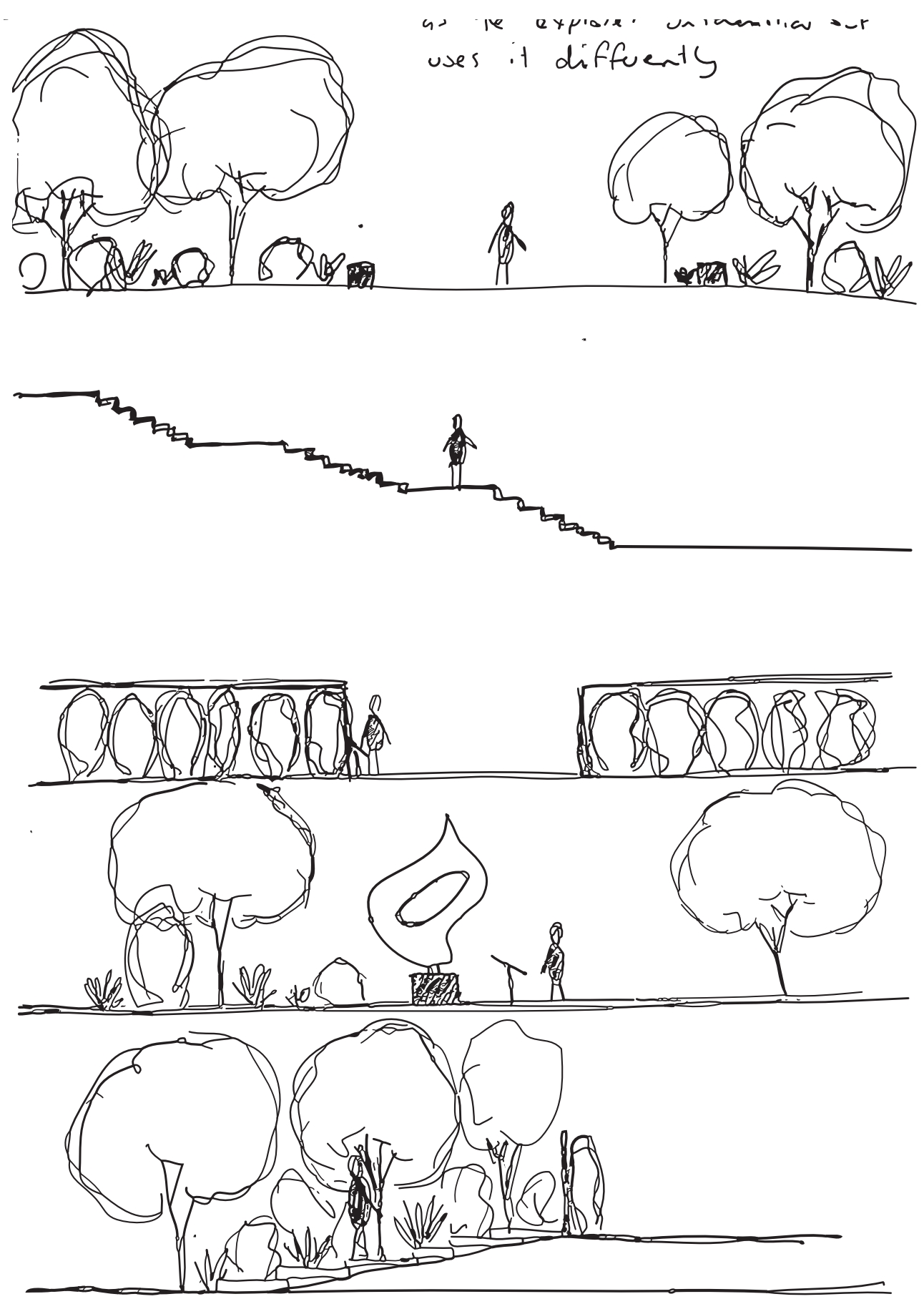

Fig. 5.2.3 Sketches scanned from notebook, relating to relationship interaction 
Brief Chatting

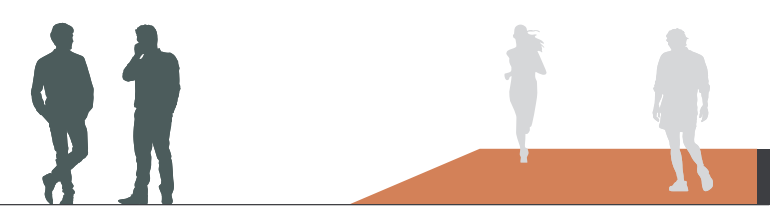

This requires areas where the movement is coordinated in ways that allow eddies to occur, formed by redefining the edge of the movement with planting or level changes.
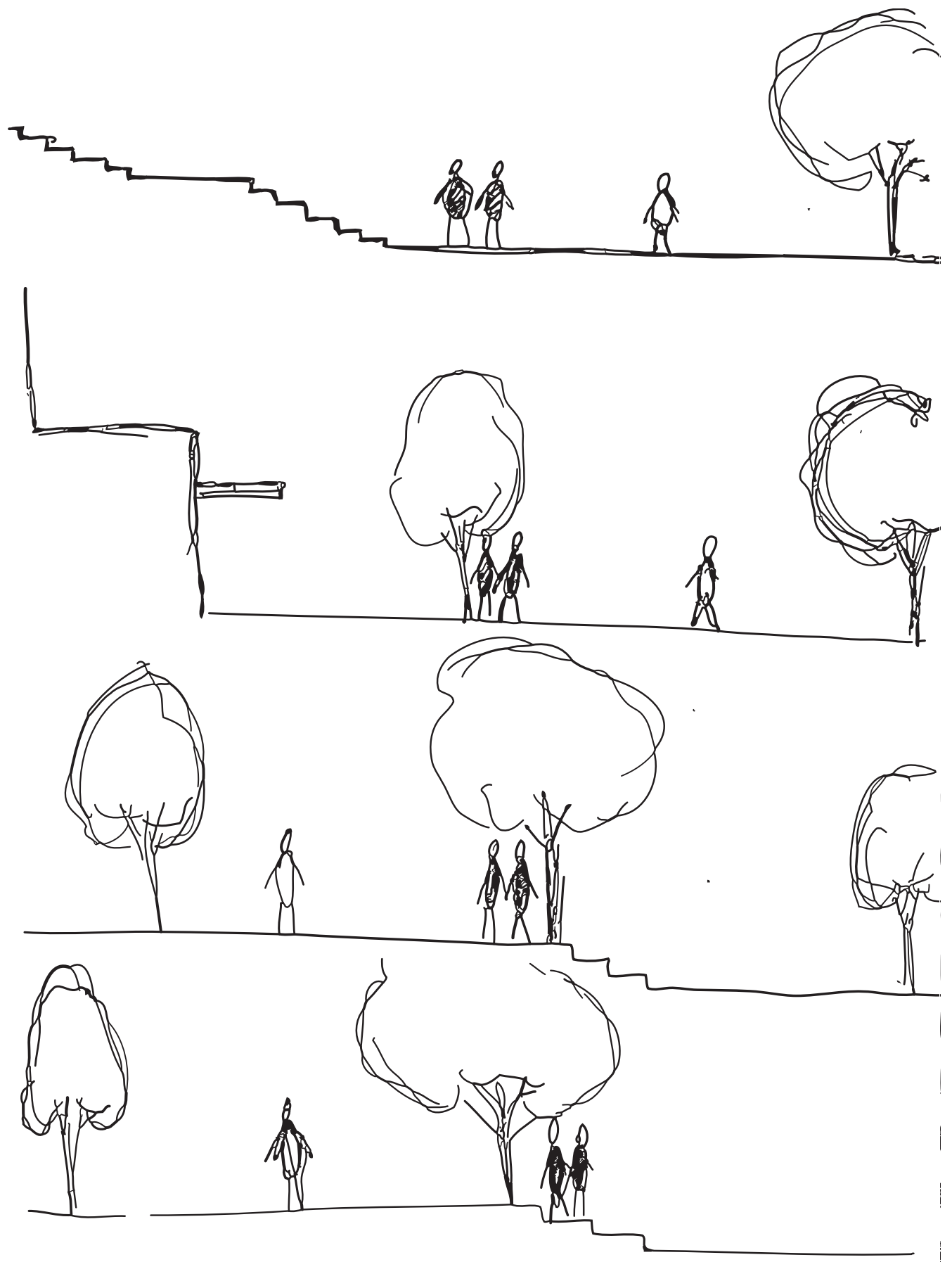

Fig. 5.2.4 Sketches scanned from notebook, relating to relationship interaction 


\section{Preoccupied User of Space}

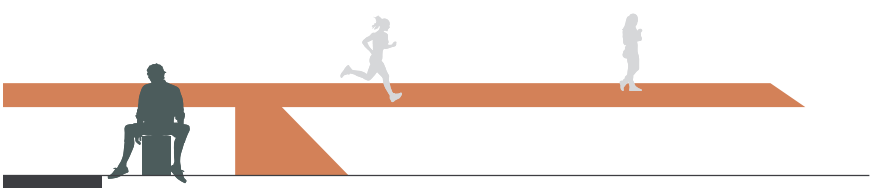

This user requires seating that is away from the movement slightly and does not engage in places with dense activity, so the areas suitable for this user will change depending on the amount of activity.
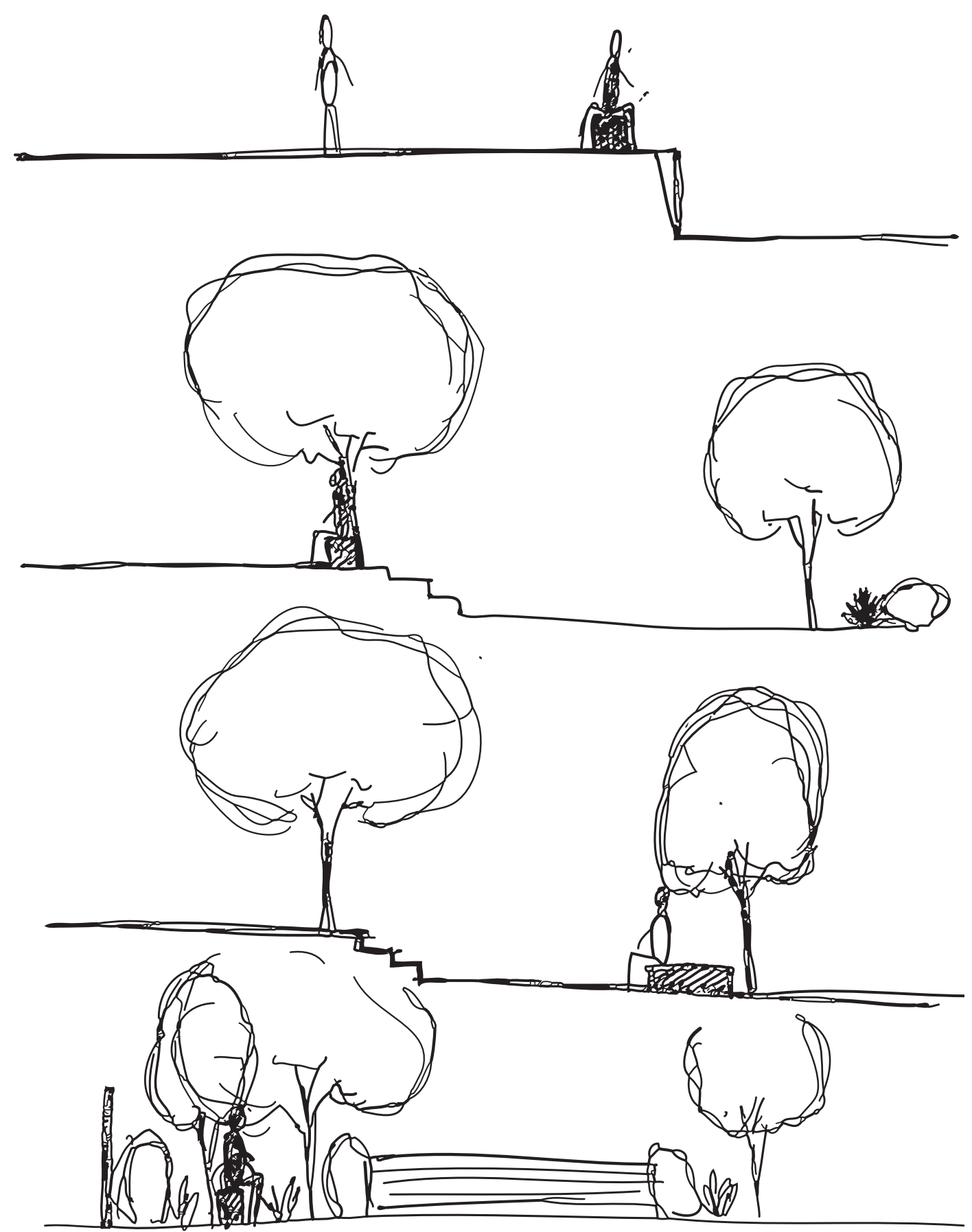

Fig. 5.2.5 Sketches scanned from notebook relating to relationship interaction 
Fly on the Wall

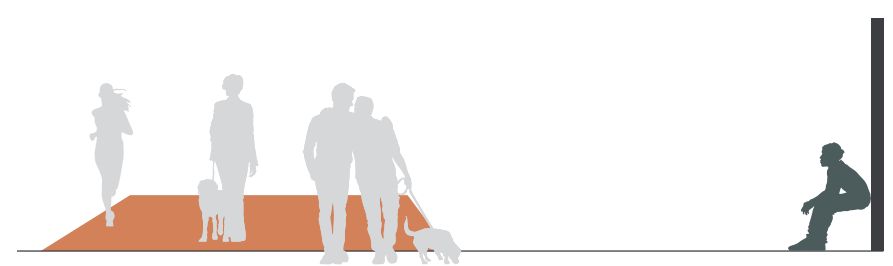

This requires seating on the edges of movement flows that are placed in non-intimidating locations in order to watch people
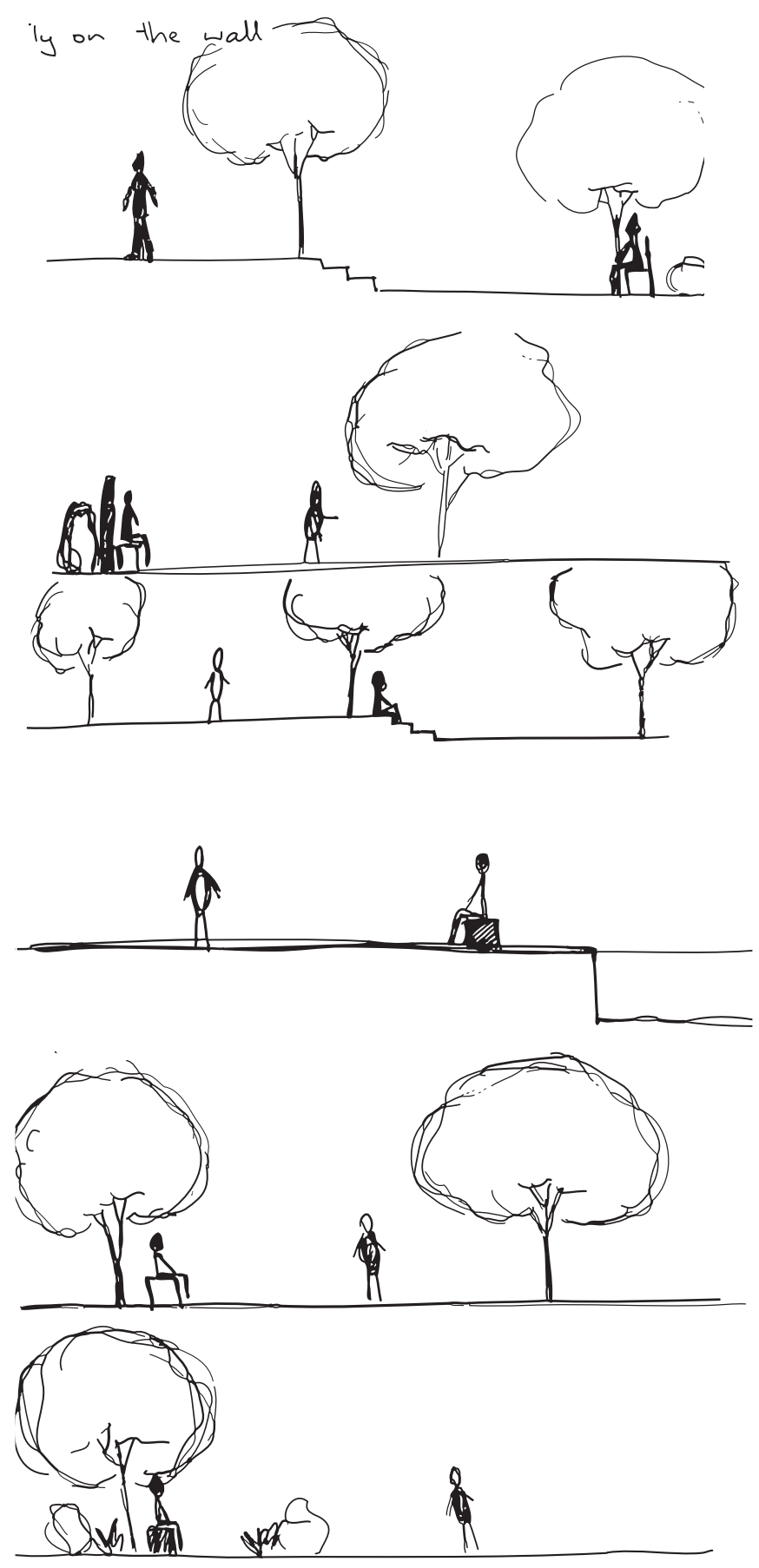

Fig. 5.2.6 Sketches scanned from notebook relating to relationship interaction 


\section{Very Temporary Edge Sitting}

A variety of edges created with walls and level changes along movement flows will invite this user group to engage with and linger in the site.
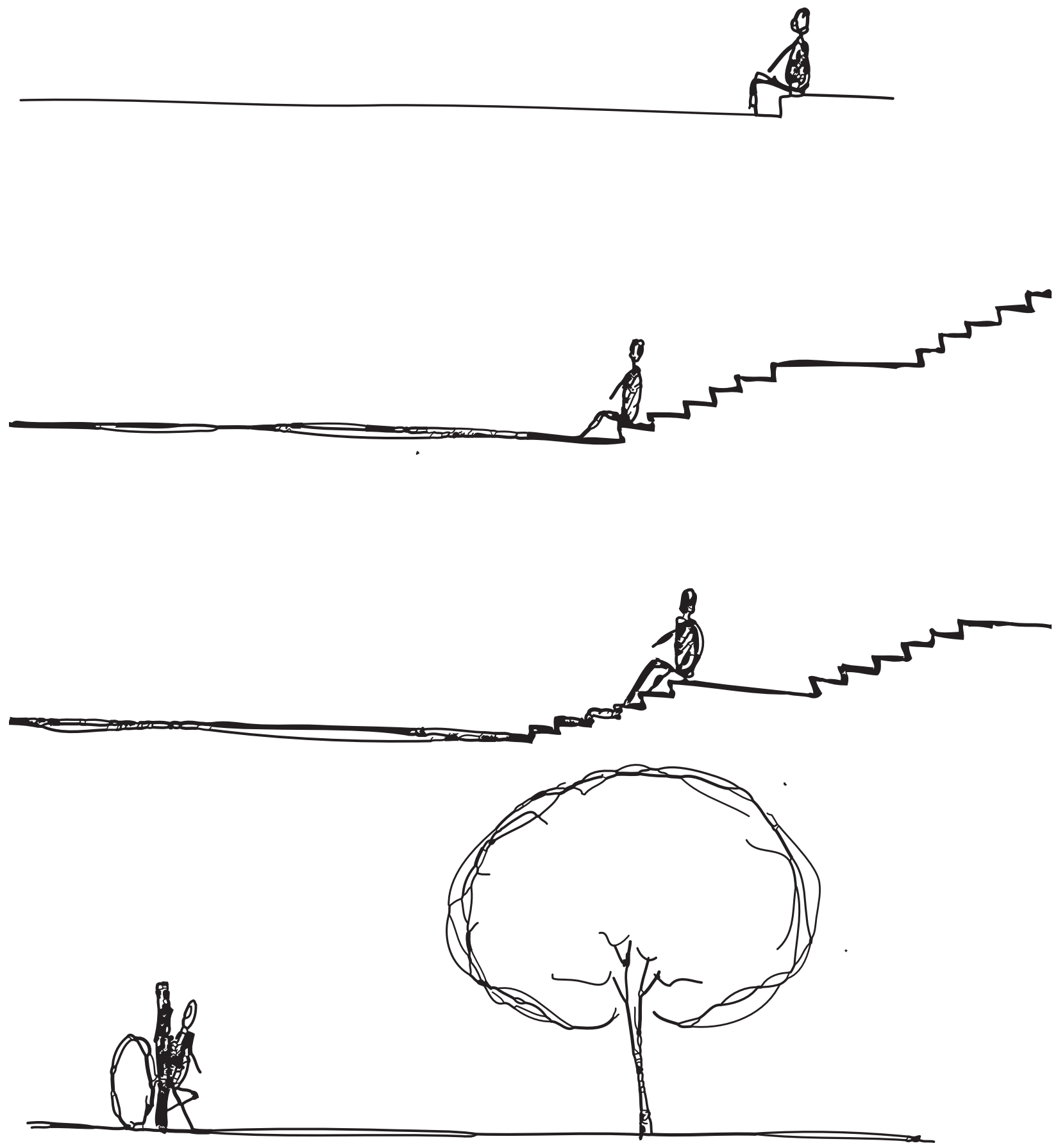

Fig. 5.2.7 Sketches scanned from notebook relating to relationship interaction 


\section{Long-lasting Central Seating Amongst Activity}

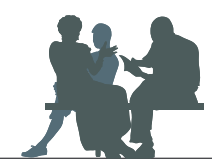

These users will engage with seating that is for groups and creates a claimed zone when they are sitting there. The seats will be located in areas that put them within the centre of activities happening in the site.
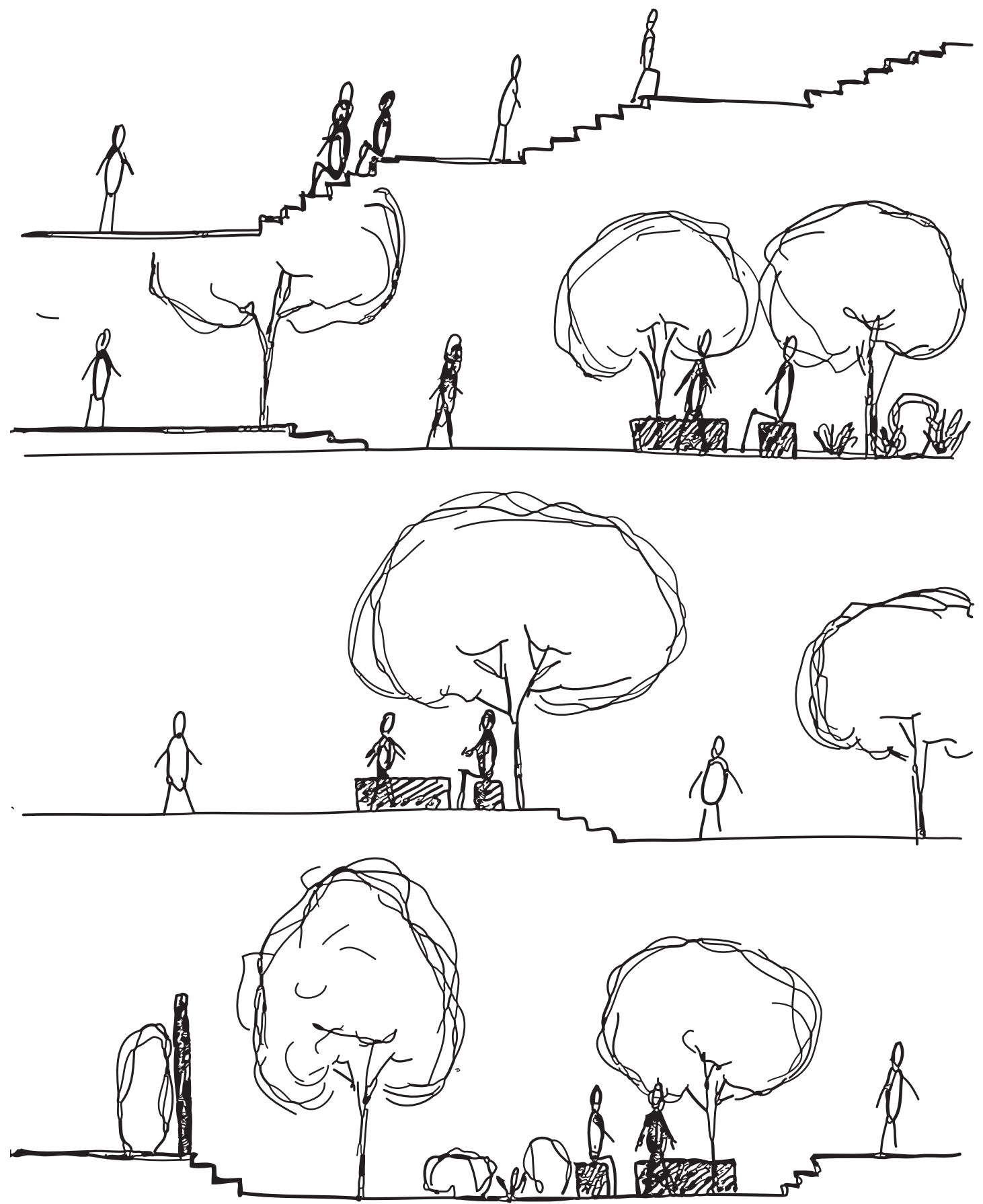

Fig. 5.2.8 Sketches scanned from notebook, relating to relationship interaction 


\section{Visualising Habitation}
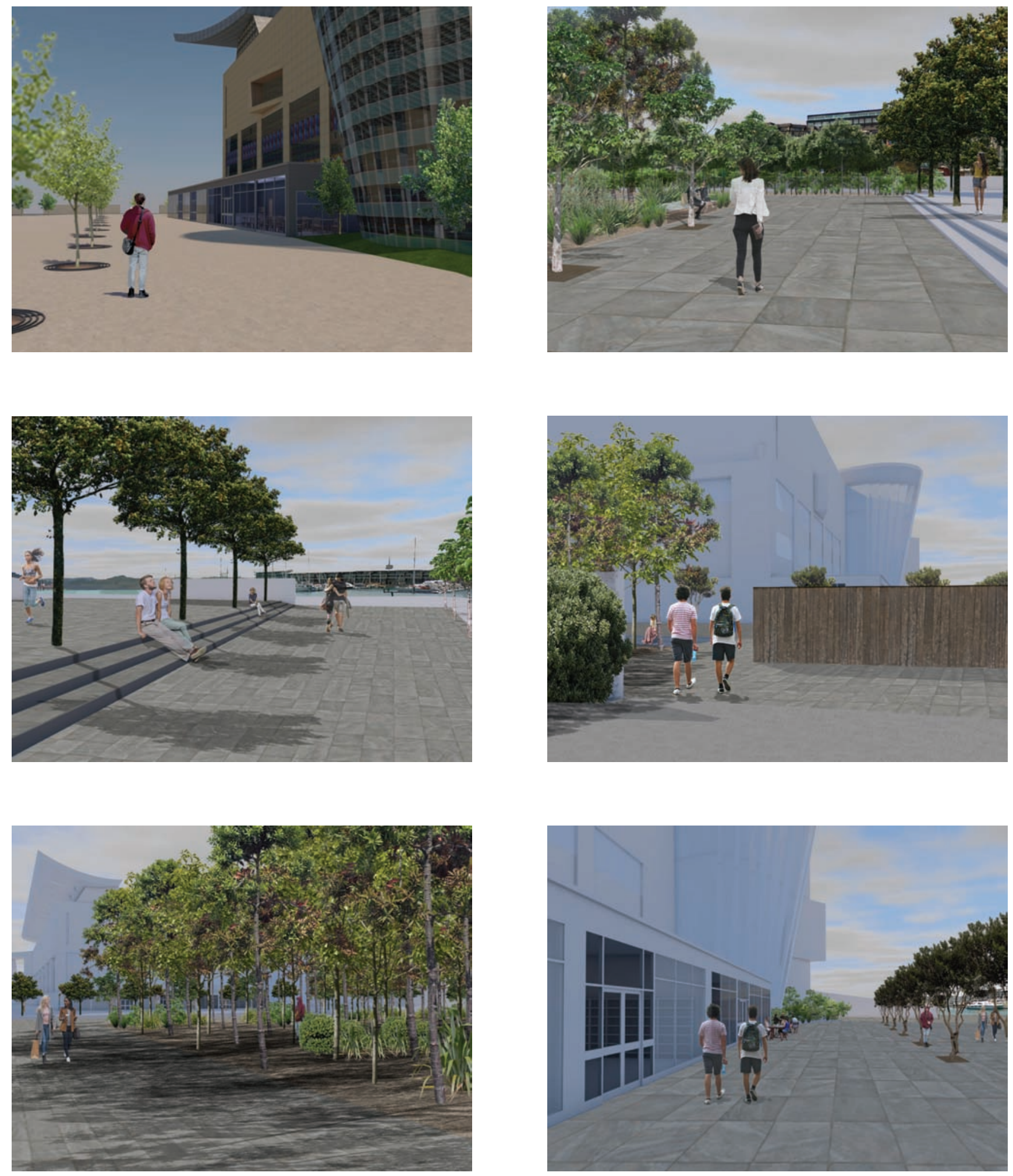

This stage required the creation of a 3D digital model in order to visualise how several users could engage with the site. Rendering in 3D demonstrates layers of foreground and background activities, with reference to the surrounding landscape, something that is not available in section sketches alone. 


\section{WATERFRONT CANOPY PLANTING}

Wellington Waterfront is a coastal environment that requires hardy trees that can stand up to the wind. The human size comparison section explore how a person may walk/look under, through or over different types of plants, the spaces they create and how that may feel to walk alongside. This research will also determine an appropriate canopy tree that responds to the site. (Te Motu Kairangi, n.d.)

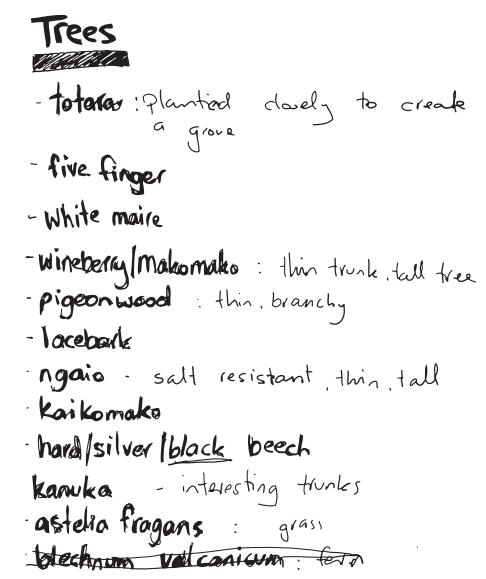

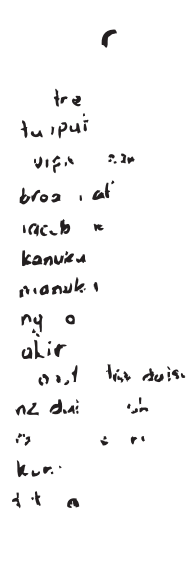

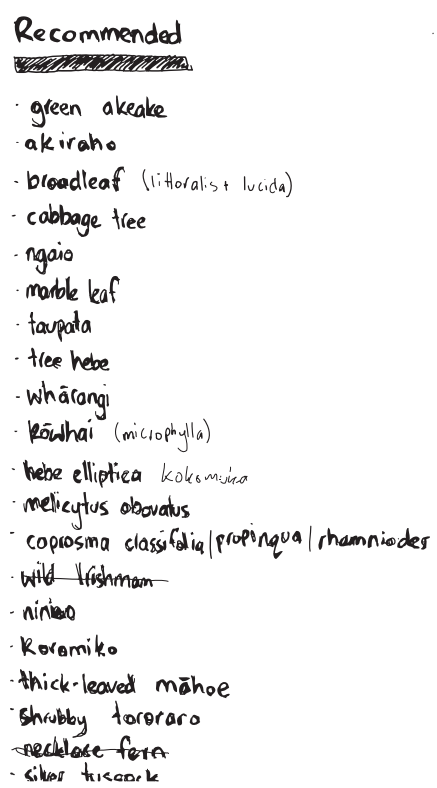


Human Body Size Comparison
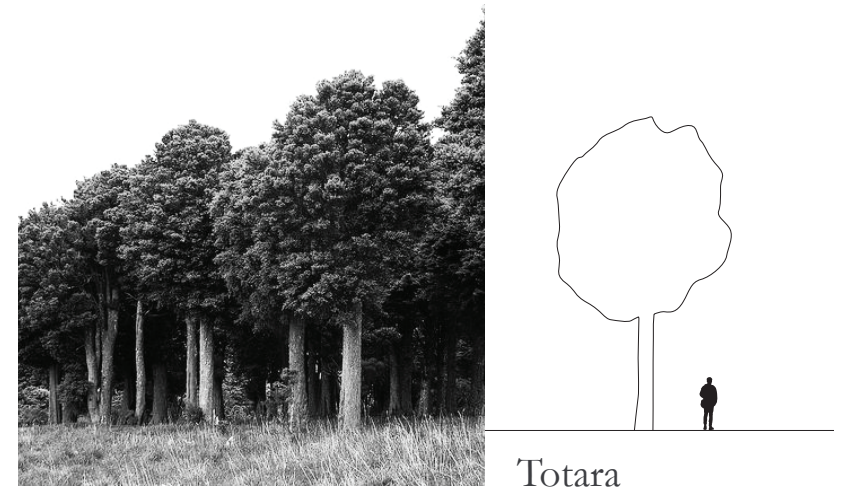

\section{Totara}
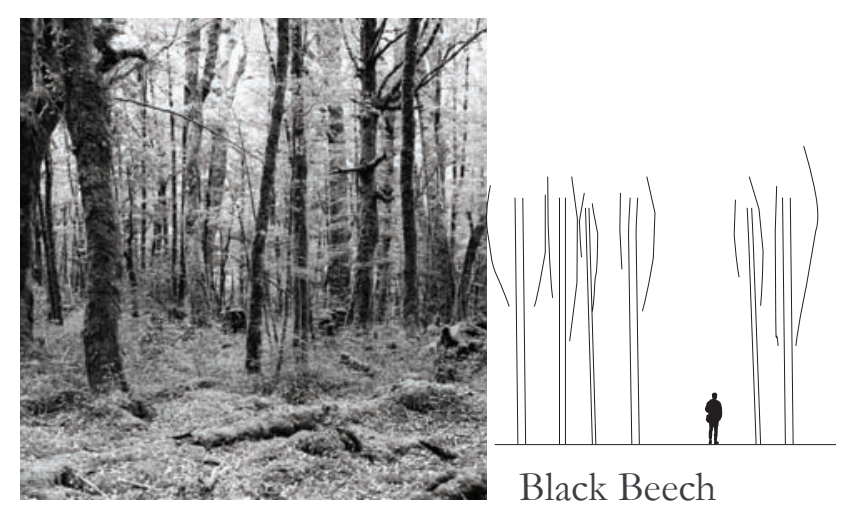

Black Beech

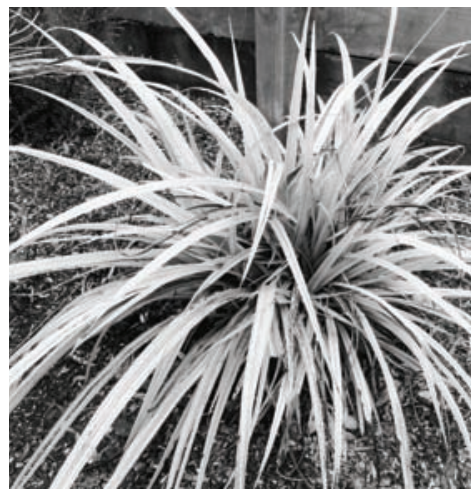

Astelia Fragans
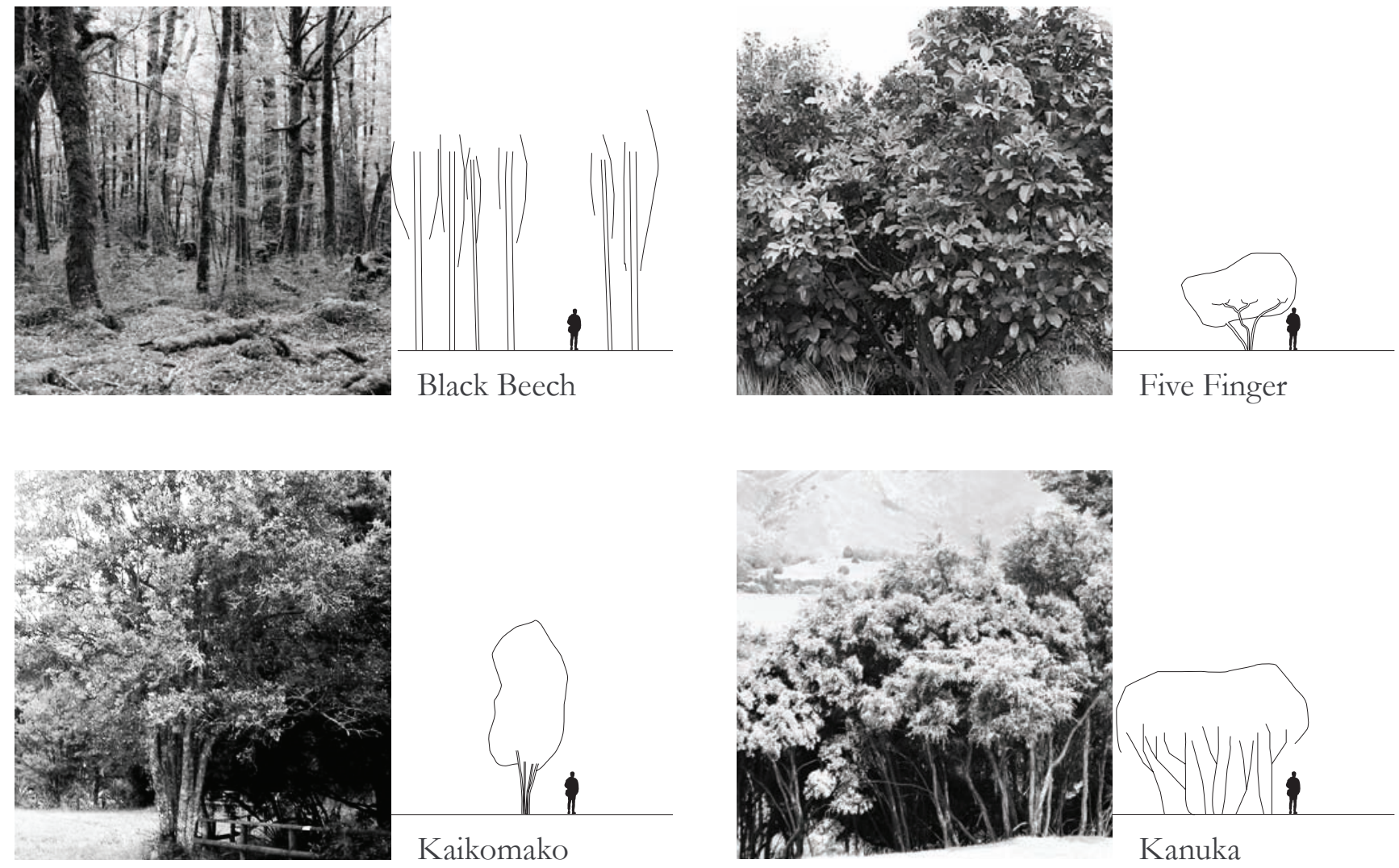

Kanuka
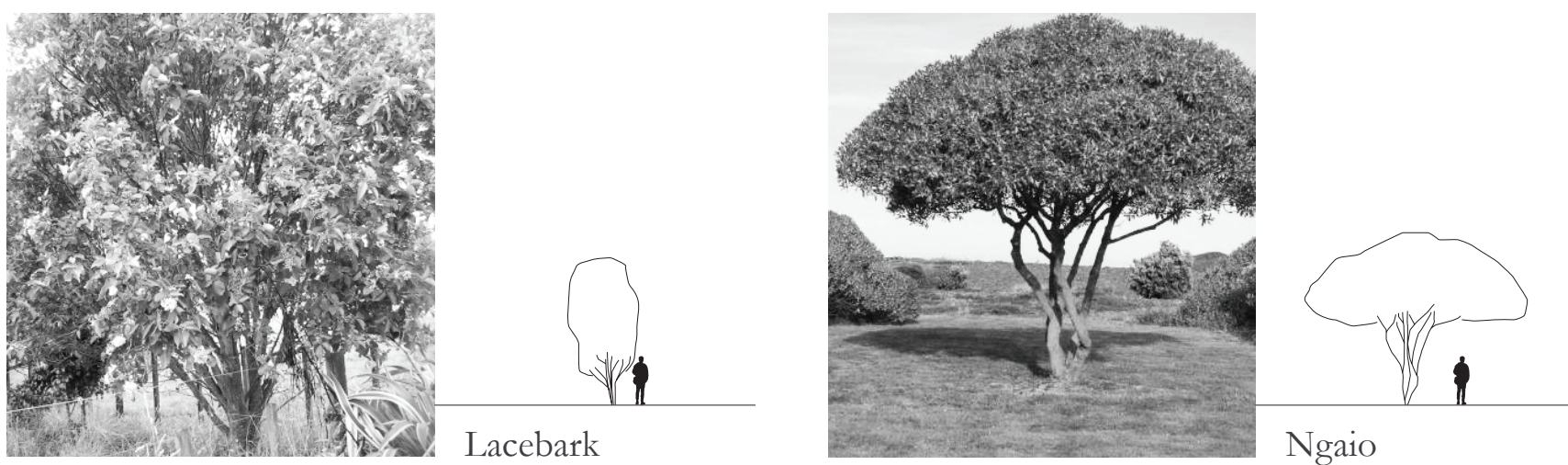

Lacebark

Ngaio

Fig. 5.3.1 (opposite) Scan from notebook listing plants of interest to research

Fig. 5.3.2.1-24 Plant height studies with corresponding photograph of plant 

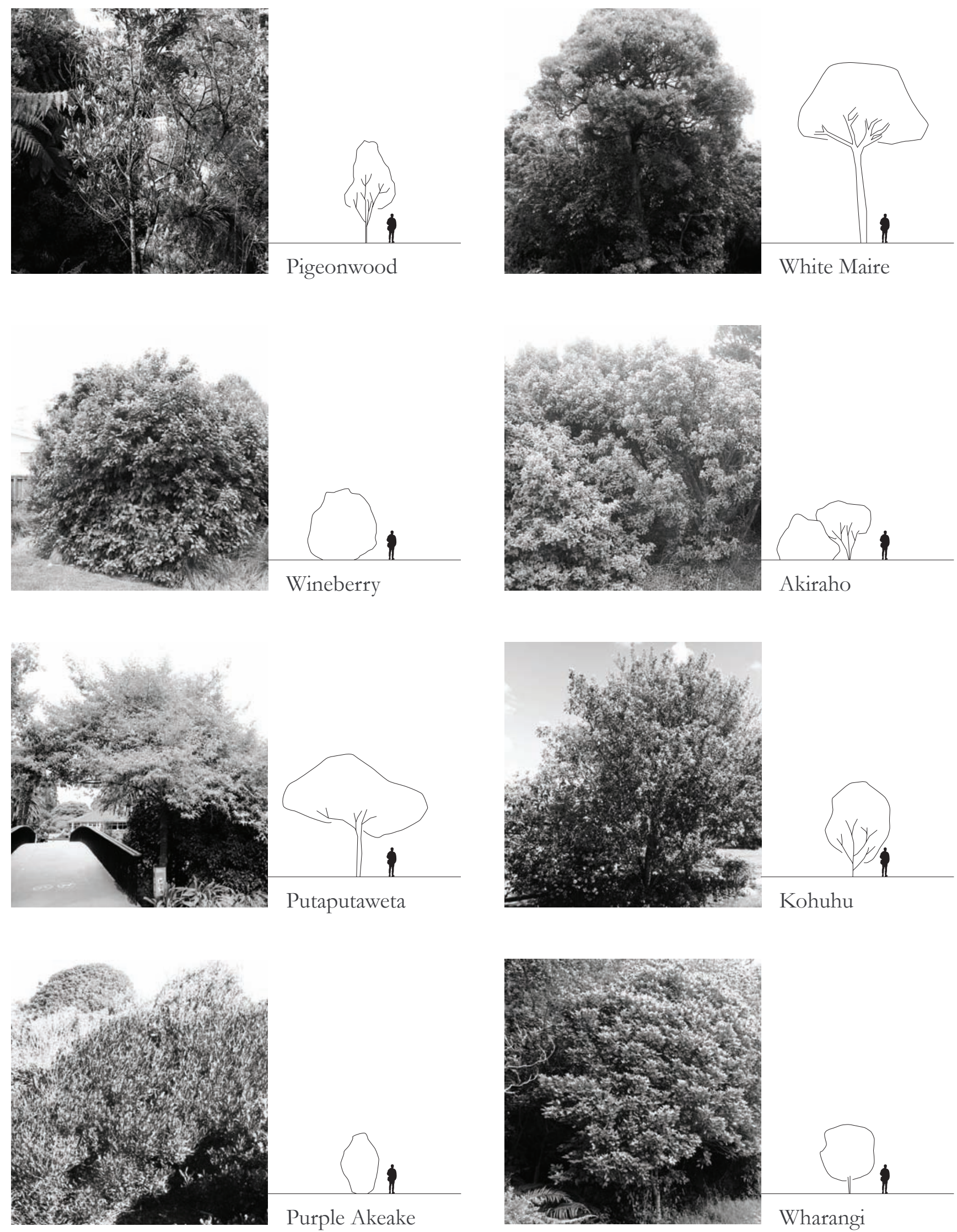

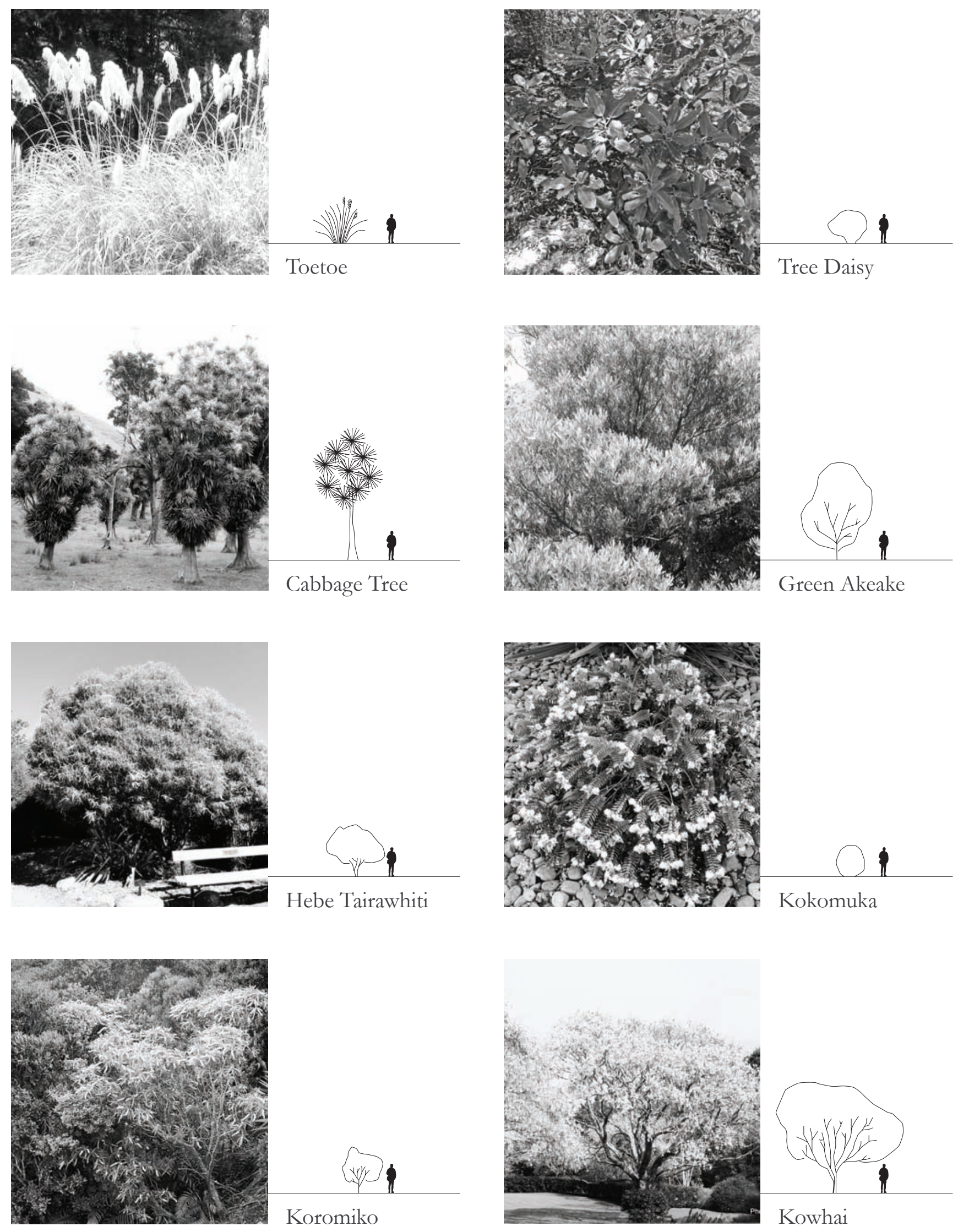


\section{Sight Lines and Path Creation Through Planting}

This sketch investigation identifies how the configuration of planting can enclose spaces, create pathways and keep connections between separate spaces. Choosing a range of plant species will enable the creation of a variety of spaces within the site. The outcome of this research is a list of characteristics, in which the chosen plant species must fit:

- Tall tree - can see past

- Dense small tree - stops vision

- Porous small tree - can see through

- Dense large shrub - stops vision

- Porous large shrub - can see through

- Medium shrub - can just see over

- Small shrub/grasses - can see past
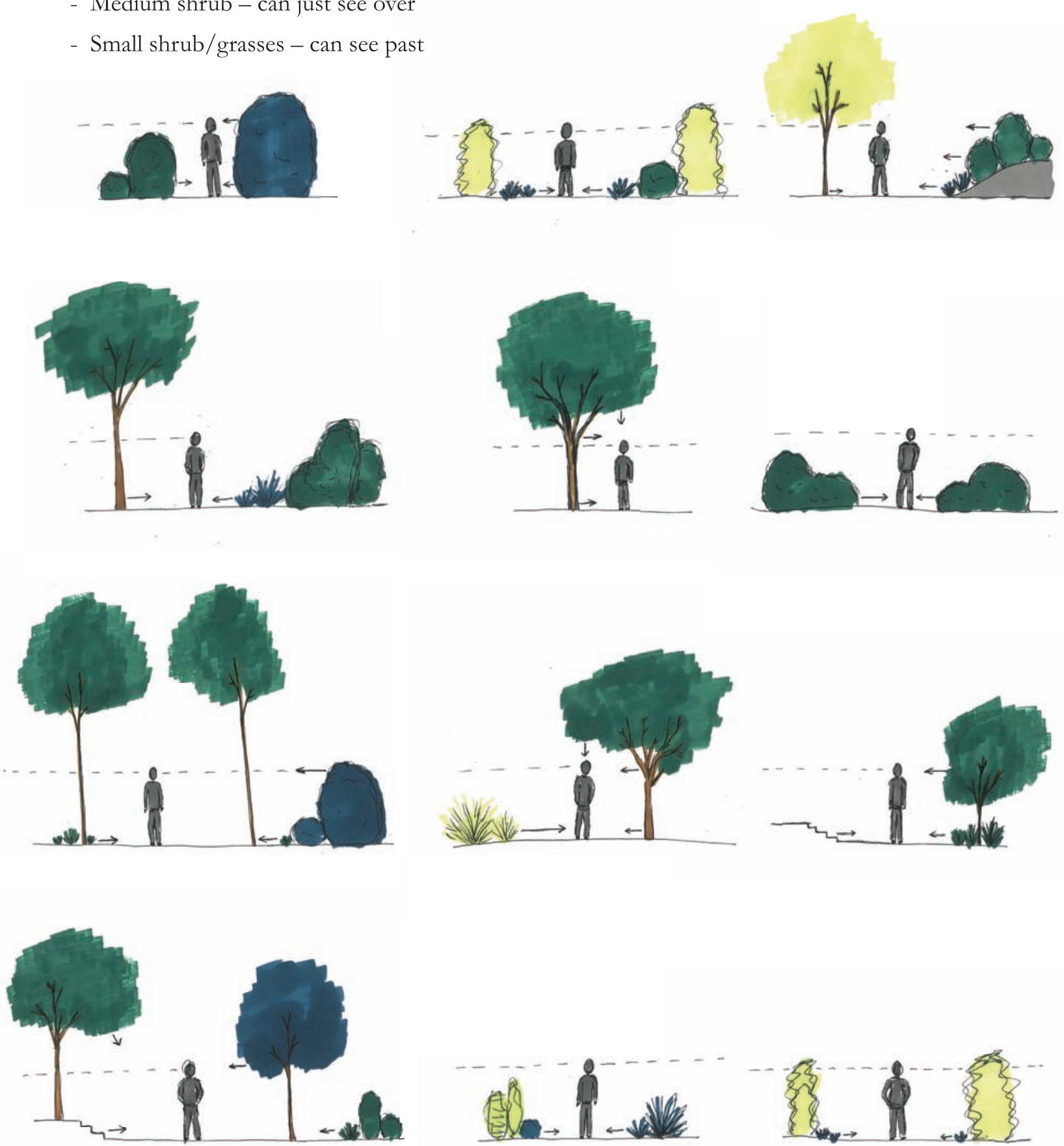

Fig. 5.3.3 Scan of sketches that explore different configurations of planting and what that means for the person walking there 


\section{Sight Lines and Path Creation Through Planting}

Different canopies and trunk width will determine a different space beneath them. Through a series of sketches, a list of parameters is set for the canopy tree that will create a sheltered space to explore in various ways.
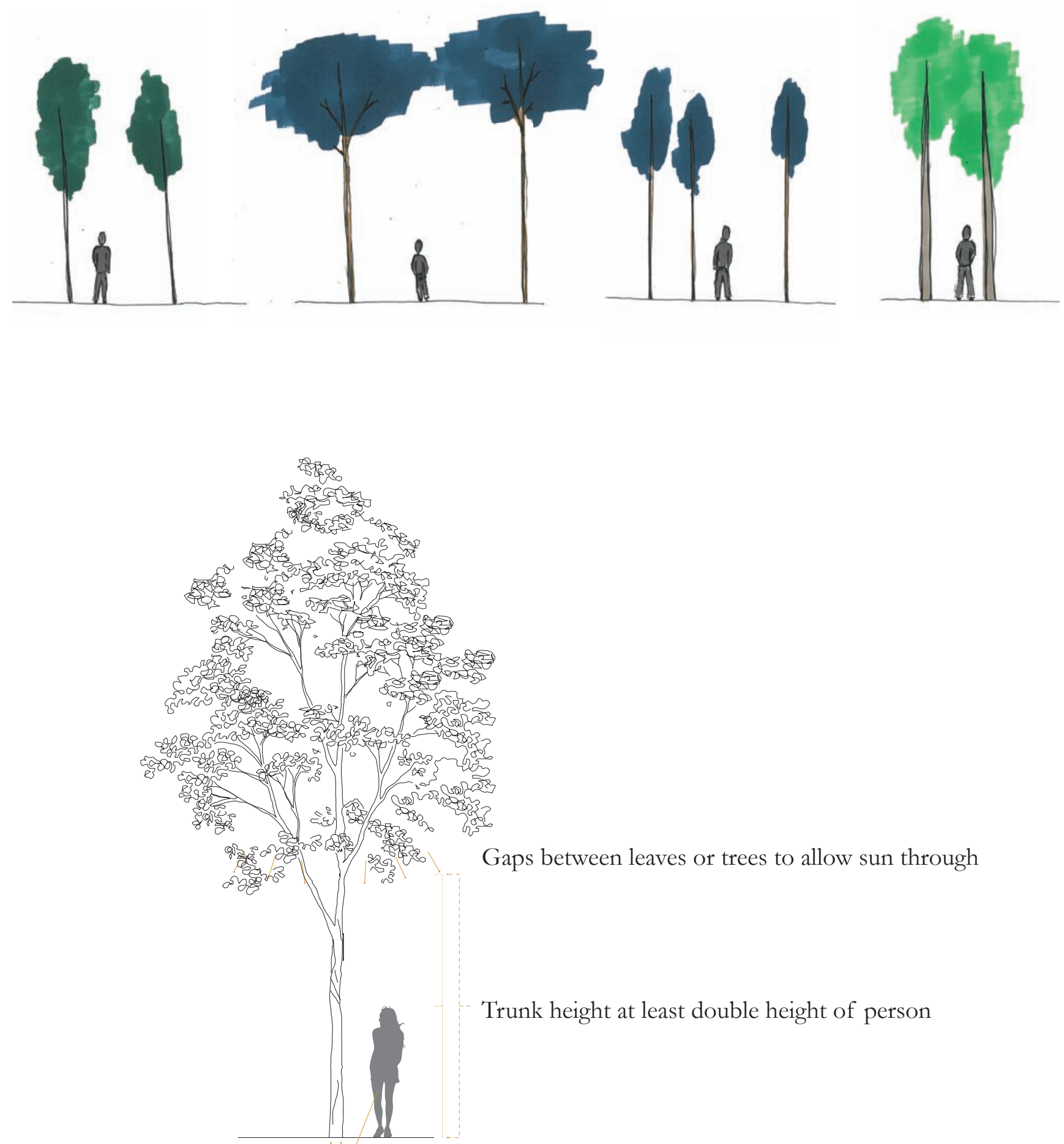

Trunk height at least double height of person

Trunk width smaller than human

Fig. 5.3.4 Scan of sketches that explore spacing and height of canopy trees

Fig. 5.3.5 Diagram breaking down the elements that make up the desired canopy tree for this site 


\section{Characteristics of Existing Canopies}

This investigation analyses existing canopy planting that has a relationship with public use to identify the characteristics of them and what they achieve.

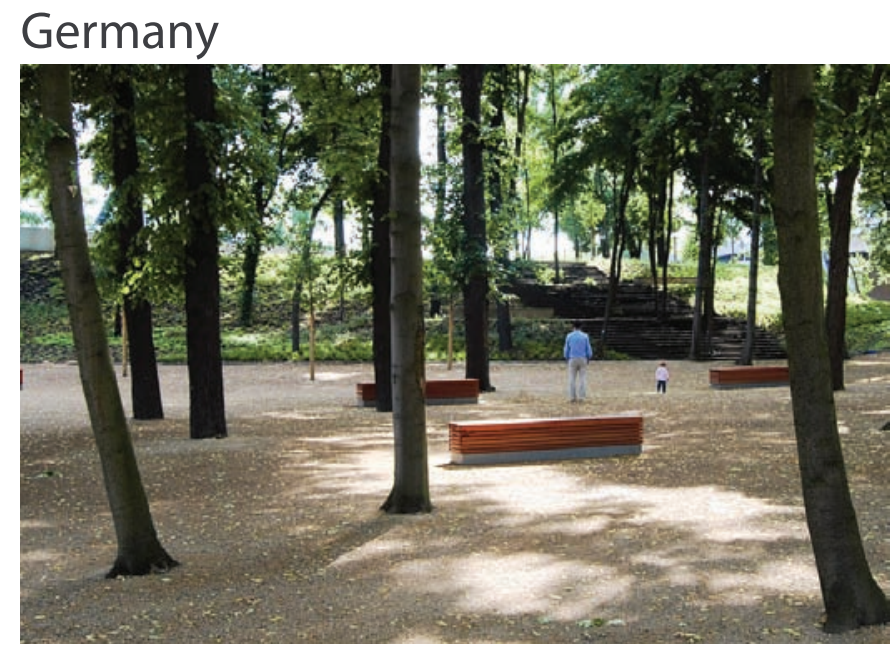

New Zealand

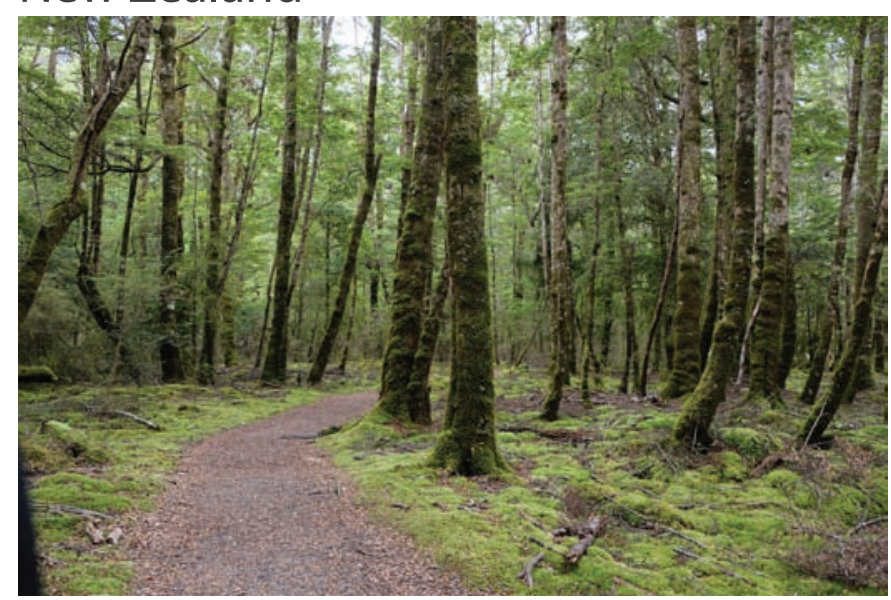

\section{Belgium}

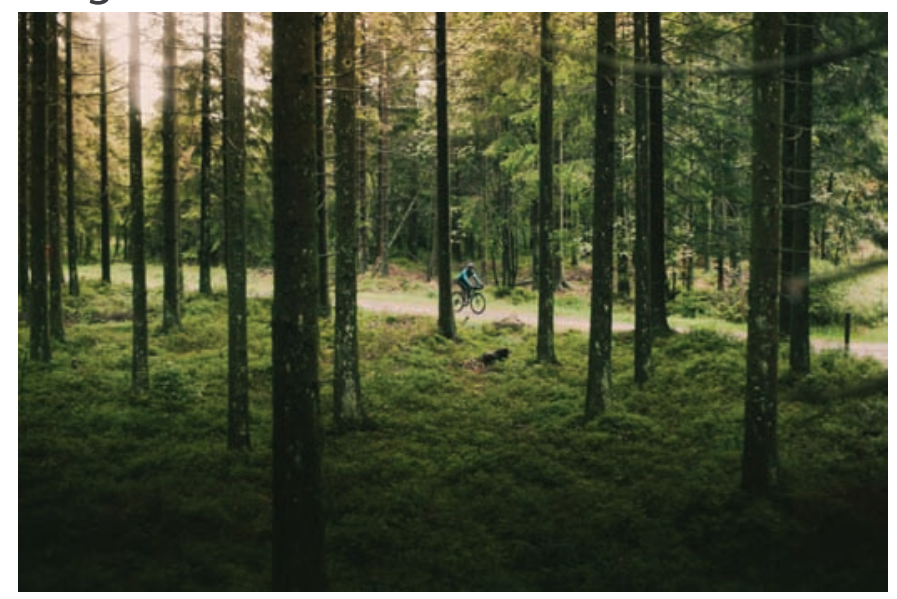

Fig. 5.3.6.1 ULAP-Platr, Berlin, Germany

Fig. 5.3.6.2 Forest, lower South Island, New Zealand

Fig. 5.3.6.3 Hautes Fagnes bike track, Liege, Belgium
Wide spacings between trunks and high canopies, along with the hill in the background, define this public area as one large room-like space.

The dense canopy trees define the space directly around the pathway, it does not allow movement else where within this space. The planting density does not let people to see through to the other areas, and this limited visual connections is made just by the trunks alone.

This large canopy space is adjacent to a pathway, which doesn't define the occupancy of the space and allows people to move through it freely if they choose to enter this space. 
New Zealand

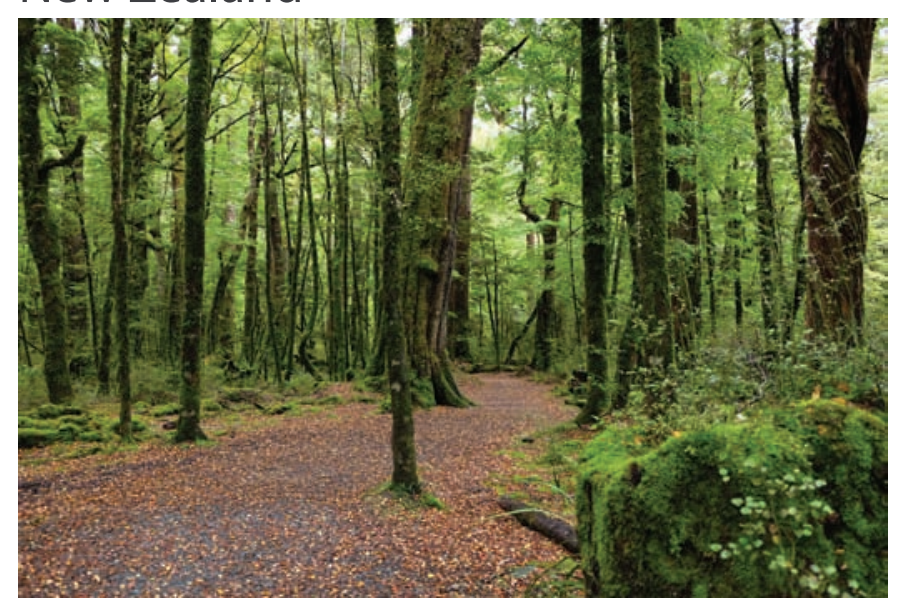

\section{Sweden}

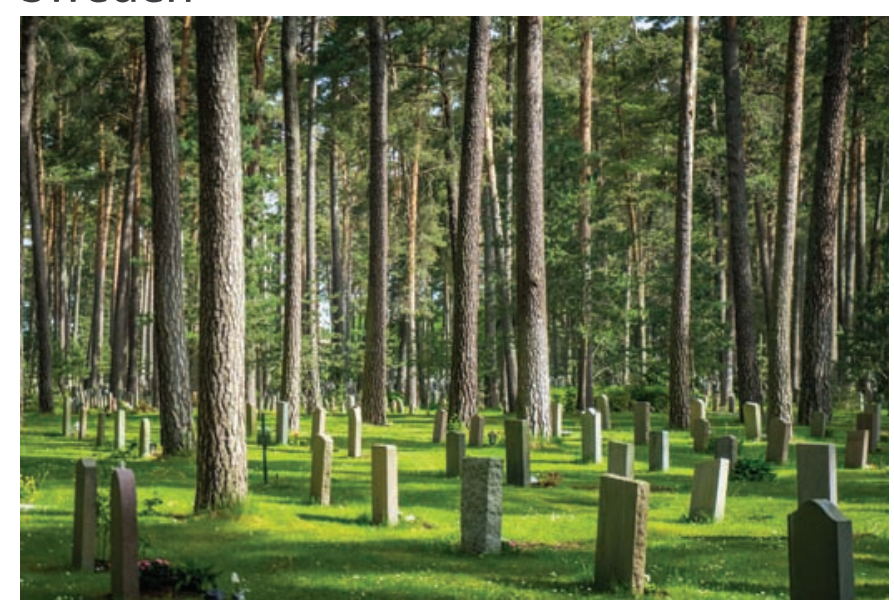

The Netherlands

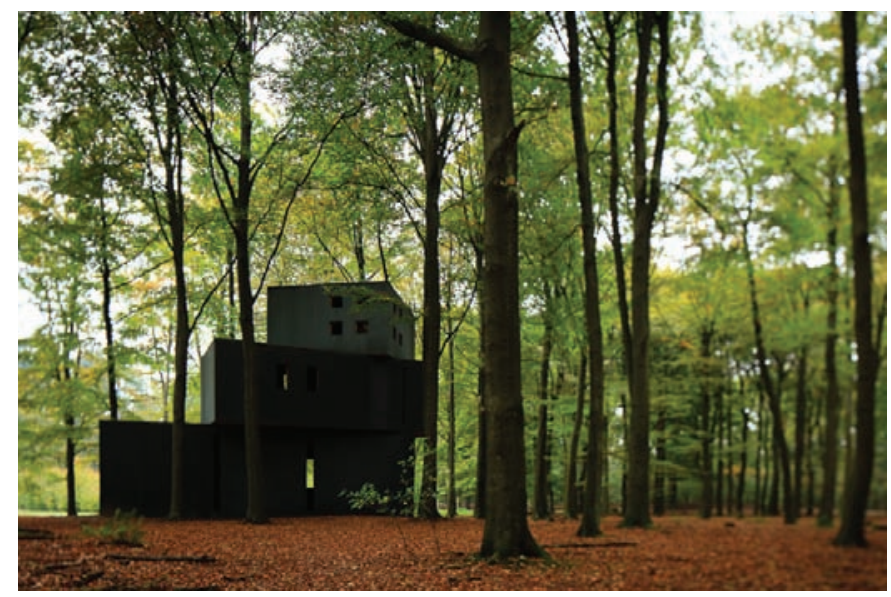

Fig. 5.3.6.4 Forest, lower South Island, New Zealand

Fig. 5.3.6.5 Skogskyrkogairden Cemetery, Stockholm, Sweden

Fig. 5.3.6.6 Kroller-Muller Sculpture Garden, The Netherlands
The canopy and light understory are built up to define the edges of the space, but at moments people can see through them because of their porosity.

The canopy is used in this public space as a way to define the area, as once the person moves out of here they have left the environment and atmosphere that was present within it.

The canopy provides are really unique background for a sculpture garden, it allows scale to be played with in an environment that will always relate to human scale. 


\section{Trees Around Wellington City}

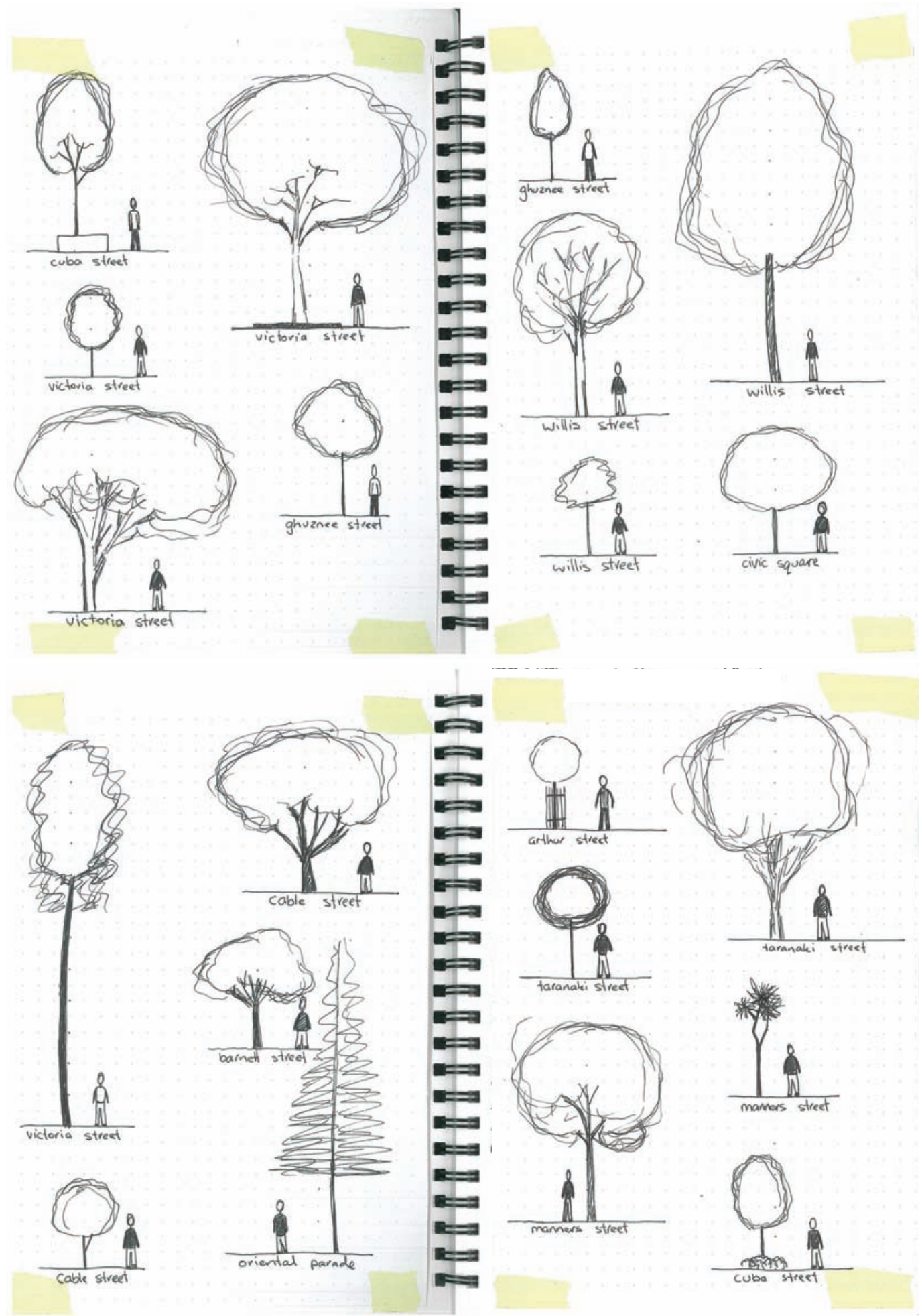

Part of the planting research looks at trees in an urban context around Wellington and documents their relationship with a passer-by. The outcome of this is the discovery of another canopy tree that exists within the city, which blends so well into its urban environment that people walk beneath it without acknowledging what it does for the public space. In this location, the tree responds to the vast height of the buildings around it and creates a close interaction with the natural environment to be had by pedestrians, sub-conscious or not. 

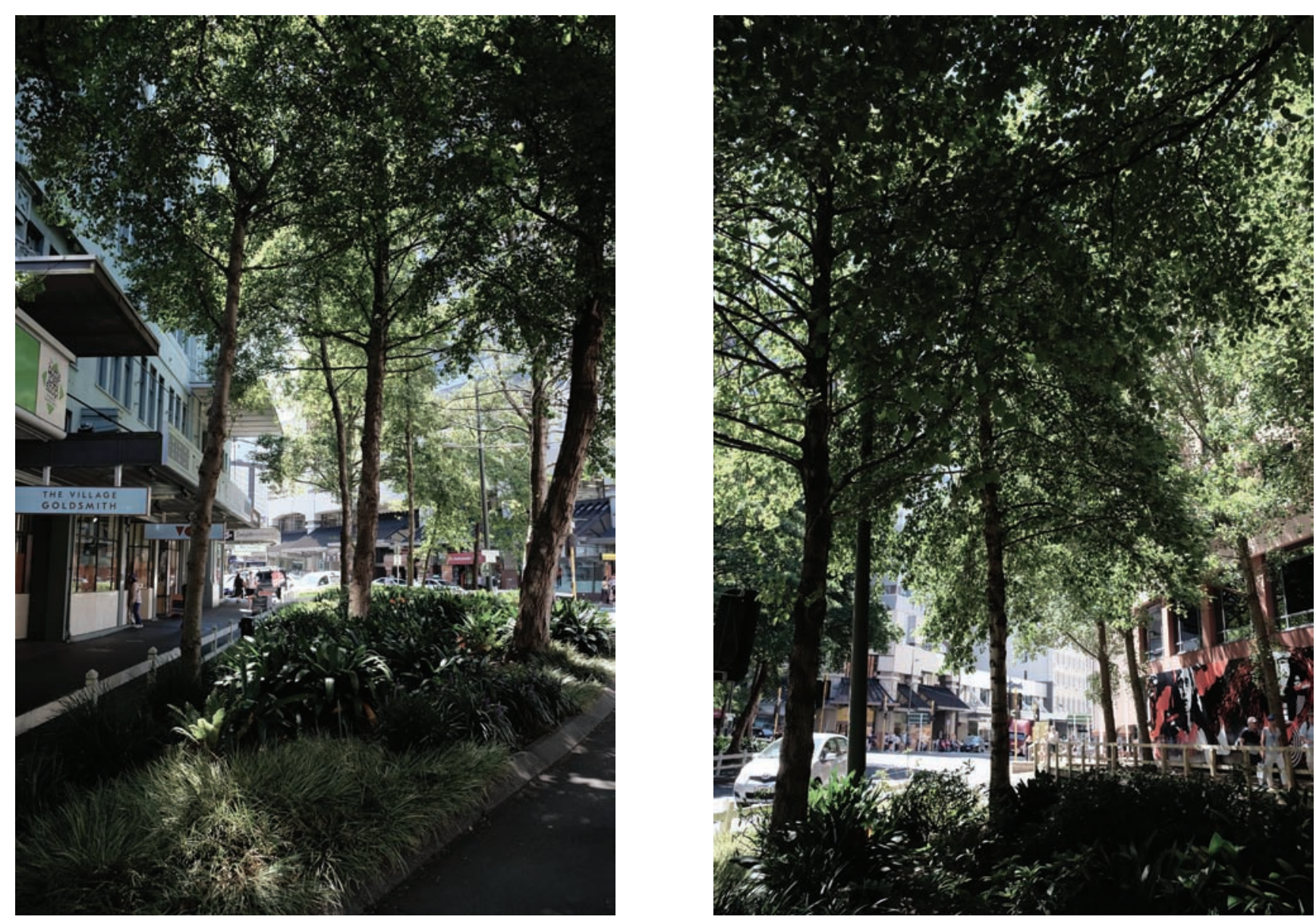

Fig. 5.3.7 (opposite) Scan of sketches done on site around Wellington City

Fig. 5.3.8 Canopy trees found on Victoria Street 


\section{Trees Around Wellington City}

The result of the preceding research is a set of plants that fit into the categories previously decided upon with it. The arrangement of the plants form paths and enclosed public spaces, demonstrated in the following planting plan.
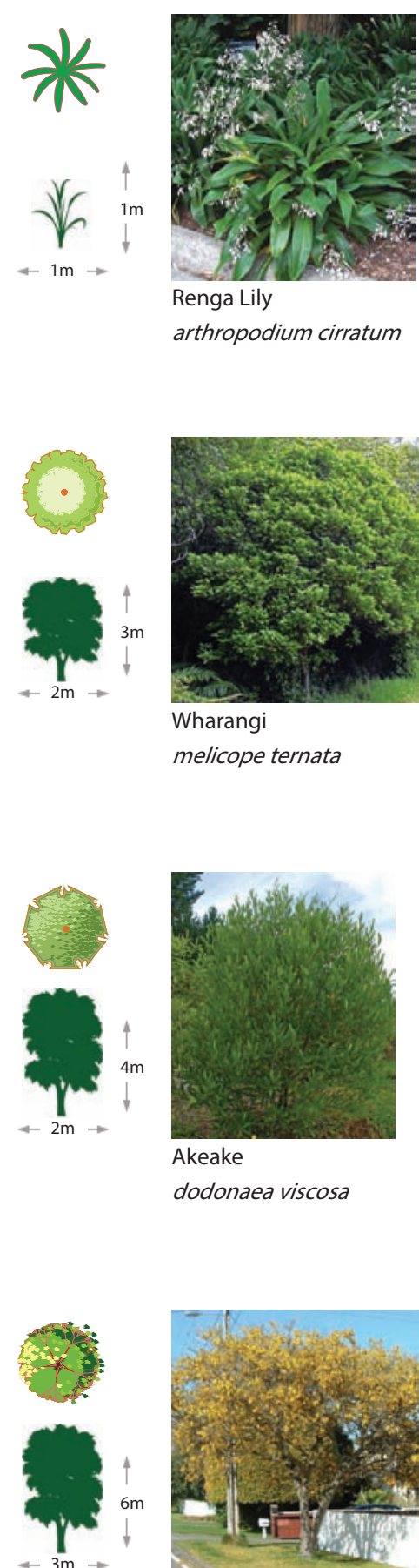

Akeake

dodonaea viscosa

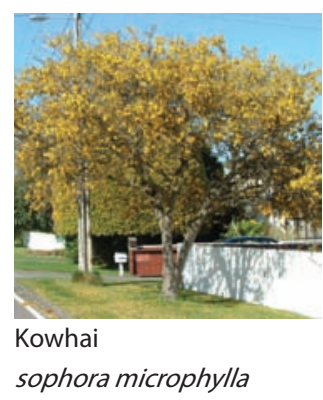

Wharangi

melicope ternata
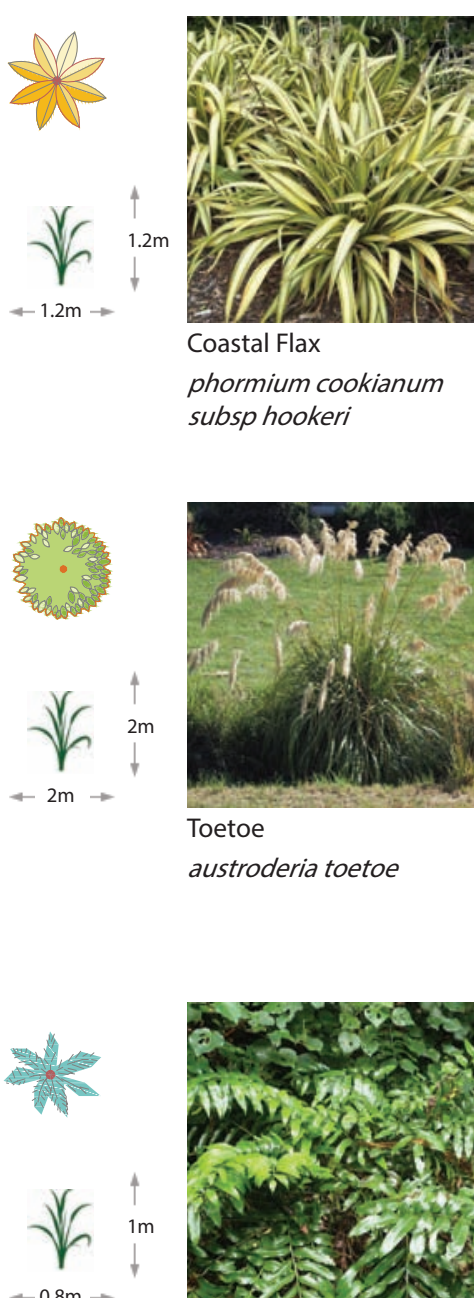

$\leftarrow 0.8 \mathrm{~m} \rightarrow$

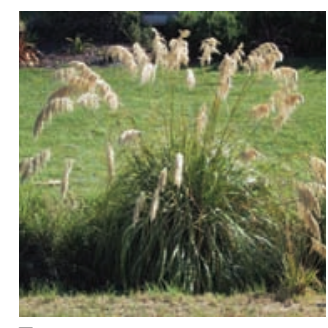

Toetoe

austroderia toetoe

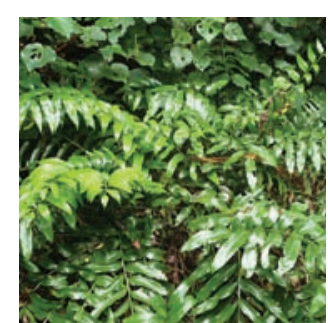

Shining Spleenwort

asplenium oblongifolium

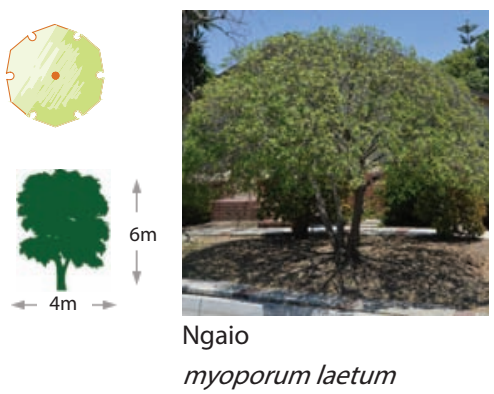

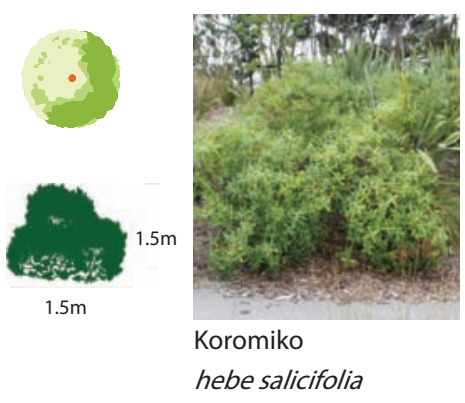
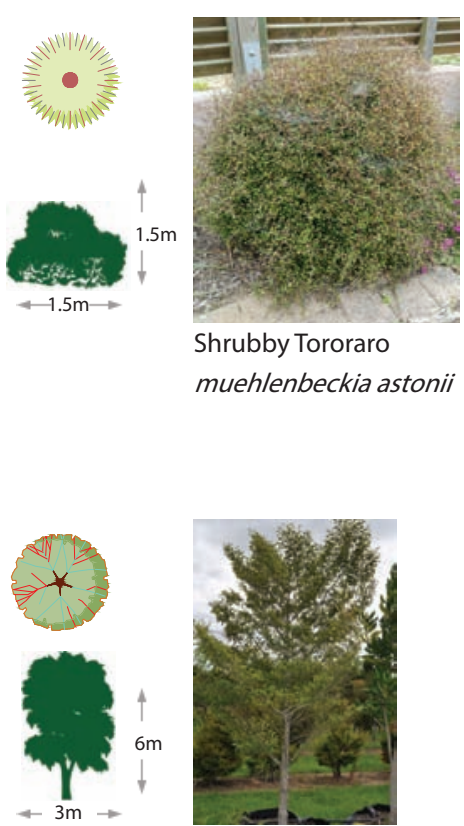

Putaputaweta carpodetus serratus 


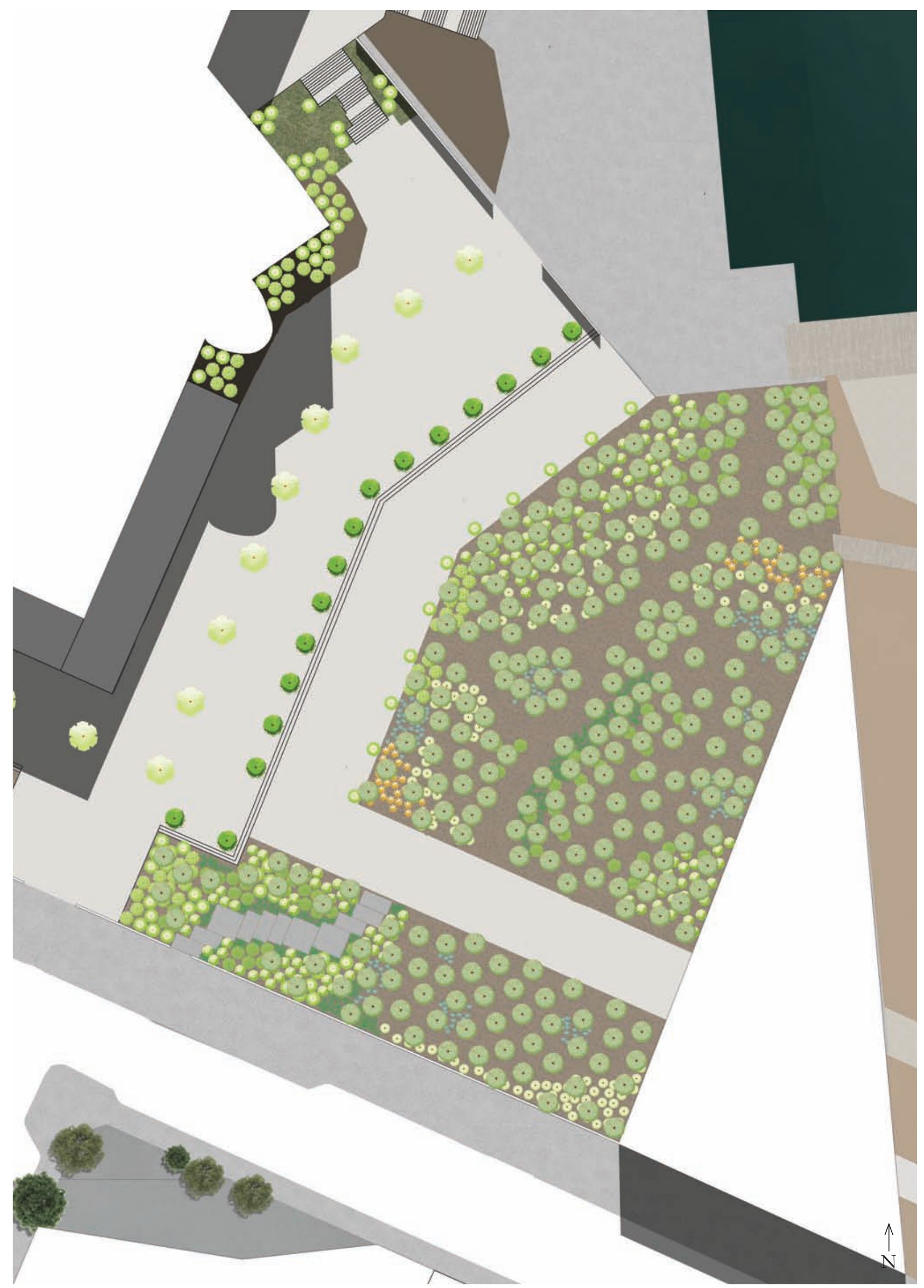

Fig. 5.3.9.1-11 (opposite) Photographs of potential plants, used in planting plan

Fig. 5.3.10 Planting plan 1:500 


\section{Understanding Spatiality Through Render}

3D photo collage allows visualisation of how movement through the forest may feel and the potential interactions had with the surrounding spaces. This is an important step to begin the research into exploring the sociability of these understory spaces.
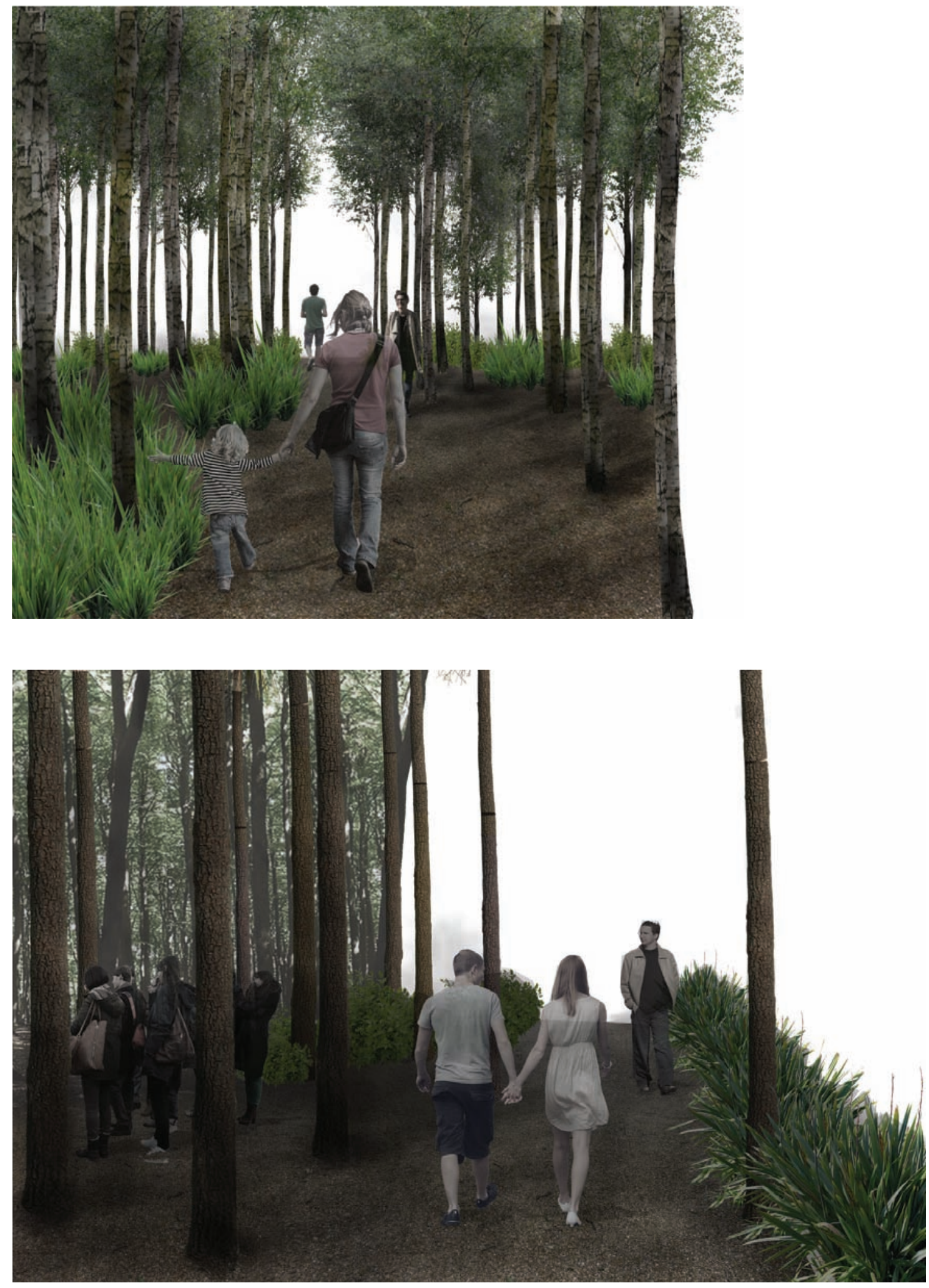

Fig. 5.3.11 Renders explore what the experience of walking through the canopy may be like 


\section{ART GALLERY (DESTINATION)}

The placement of an art gallery is in relation to the most recent plans for the site, and the desire to create a building that responds to the scale of Te Papa and relates to the city/waterfront location. Redefining the edge of the potential public space will allow it to be uniform and remove the impact the small corner would have on the occupation of the site. The three main features in this initial design were:

- the ability to walk under the building on the ground floor to ensure it maintained connections between the new site and surrounding landscape

- the building void that connected the ground floor thoroughfare up into an atrium space.

- circulation will occur on a staircase on the internal edge of the art gallery which will create a backdrop for those in the canopy forest and allow those in the gallery to climb up through the canopy

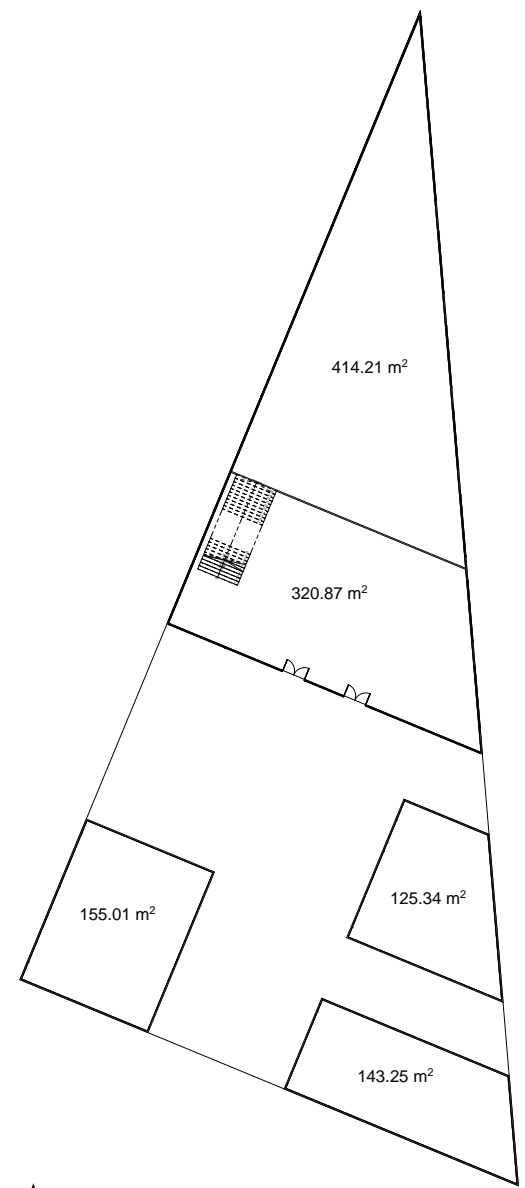

$\uparrow \quad$ Ground Floor

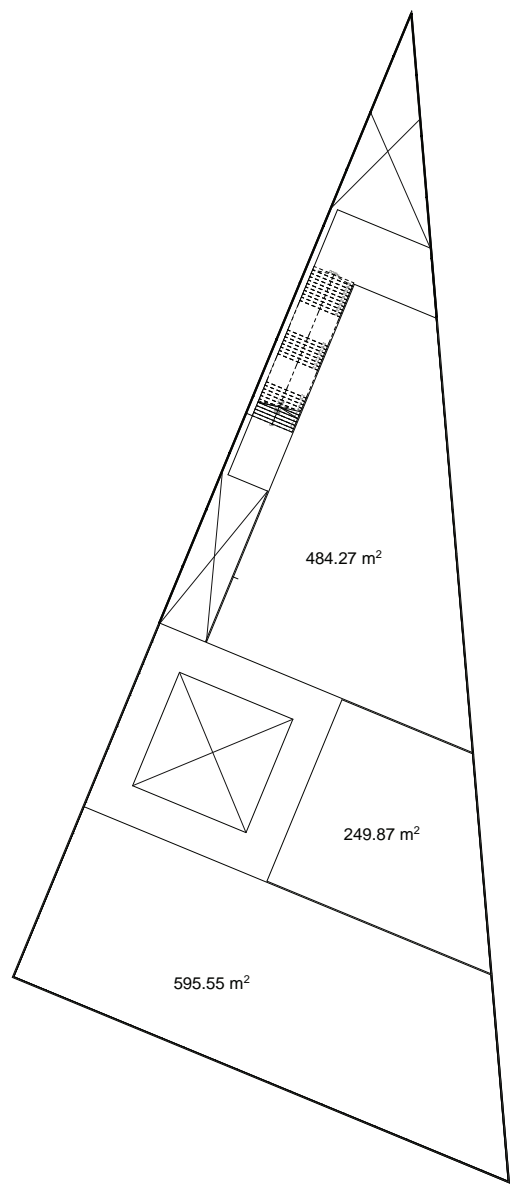

First Floor

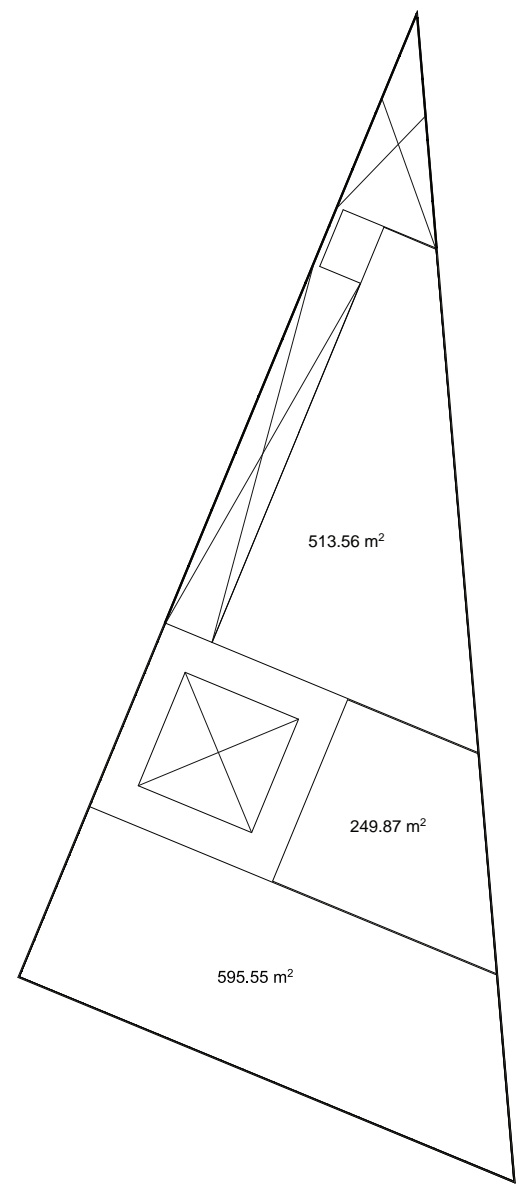

Second Floor

Fig. 5.4.1 Basic floor plan layout of the initial concept for the art gallery 

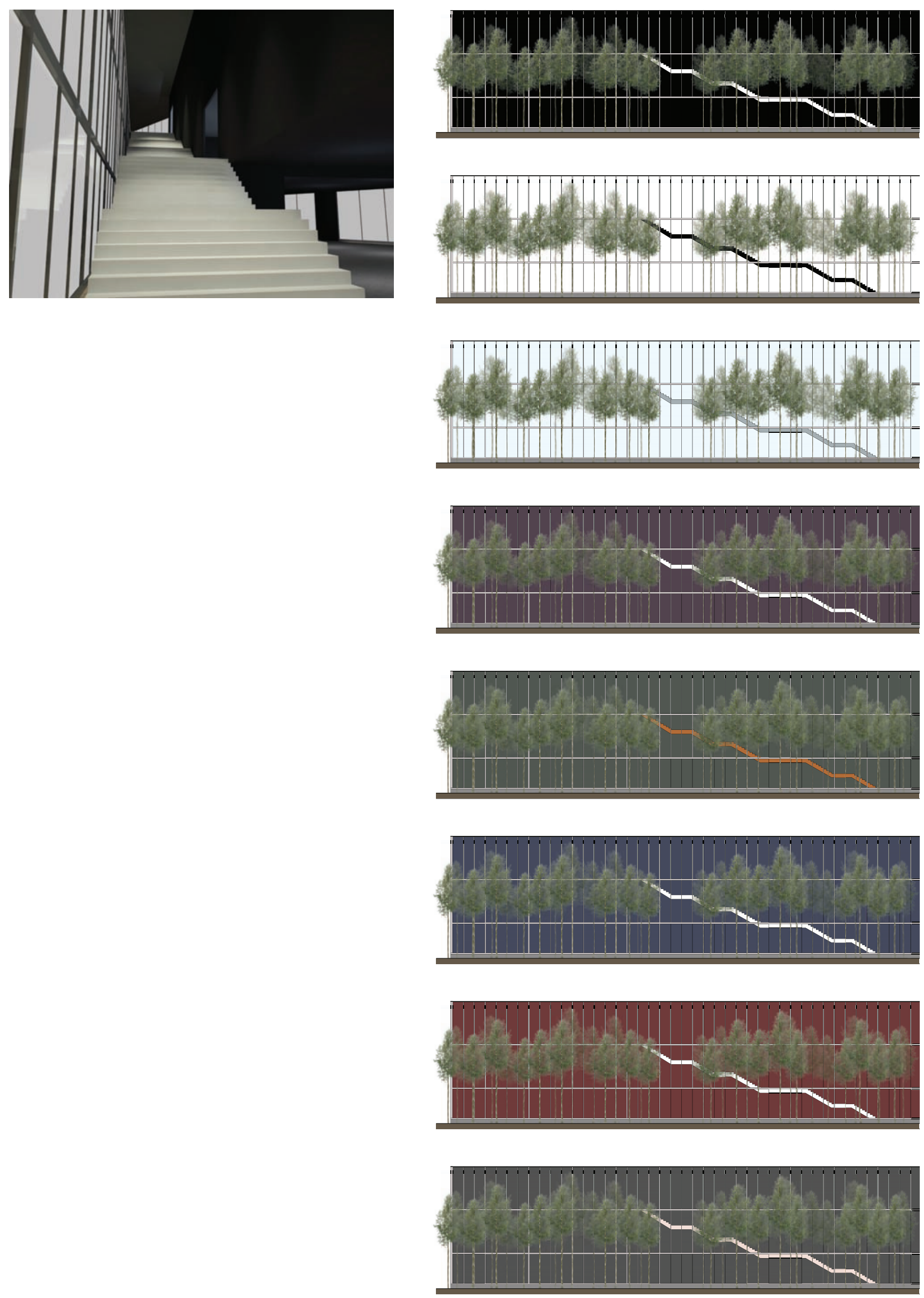

Fig. 5.4.2 Render of the stairway that is a major feature of both the interior of the gallery and the landscape surrounding it

Fig. 5.4.3 Elevations 1:500 explore colour potential of staimway and internal wall in regards to viewing it from outside 


\section{SHOPS (DESTINATION)}

The concept aims to create a new destination against the east façade of Te Papa to draw more people to this area. The three retail choices were simple: a café, a bookstore, and small gallery space that can be hired to display local artists' work. These types of shops would respond well to their museum/waterfront location; however, in this design the form and placement of this building block does not attempt to connect with its surroundings, including Te Papa's edge. These sketches studies start to explore simple ways to connect physically with the surrounding context but do remain a linear formation.
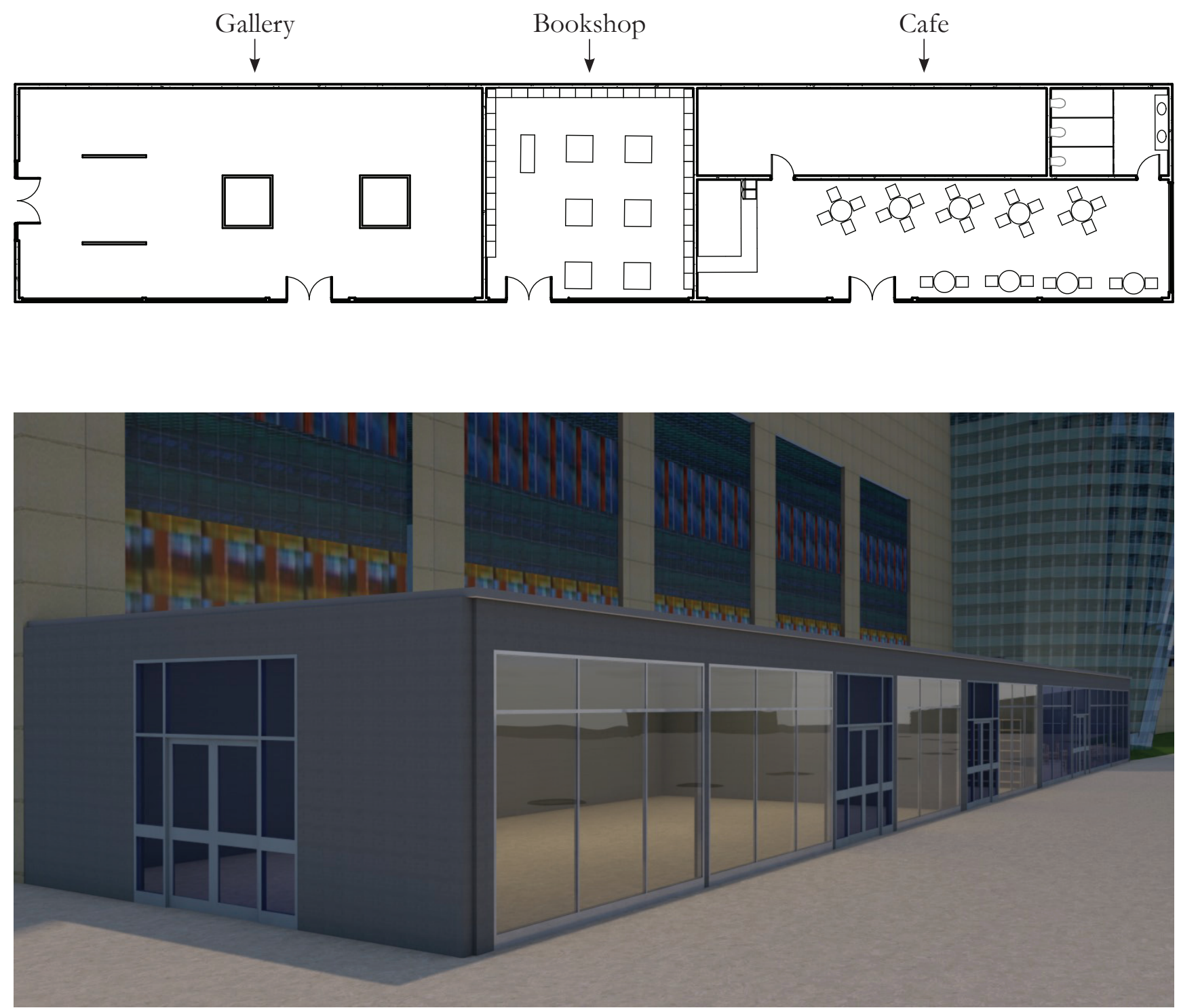

Fig. 5.5.1 Basic floor 1:250 plan layout of the initial concept for shops

Fig. 5.5.2 Render to show placement on site 

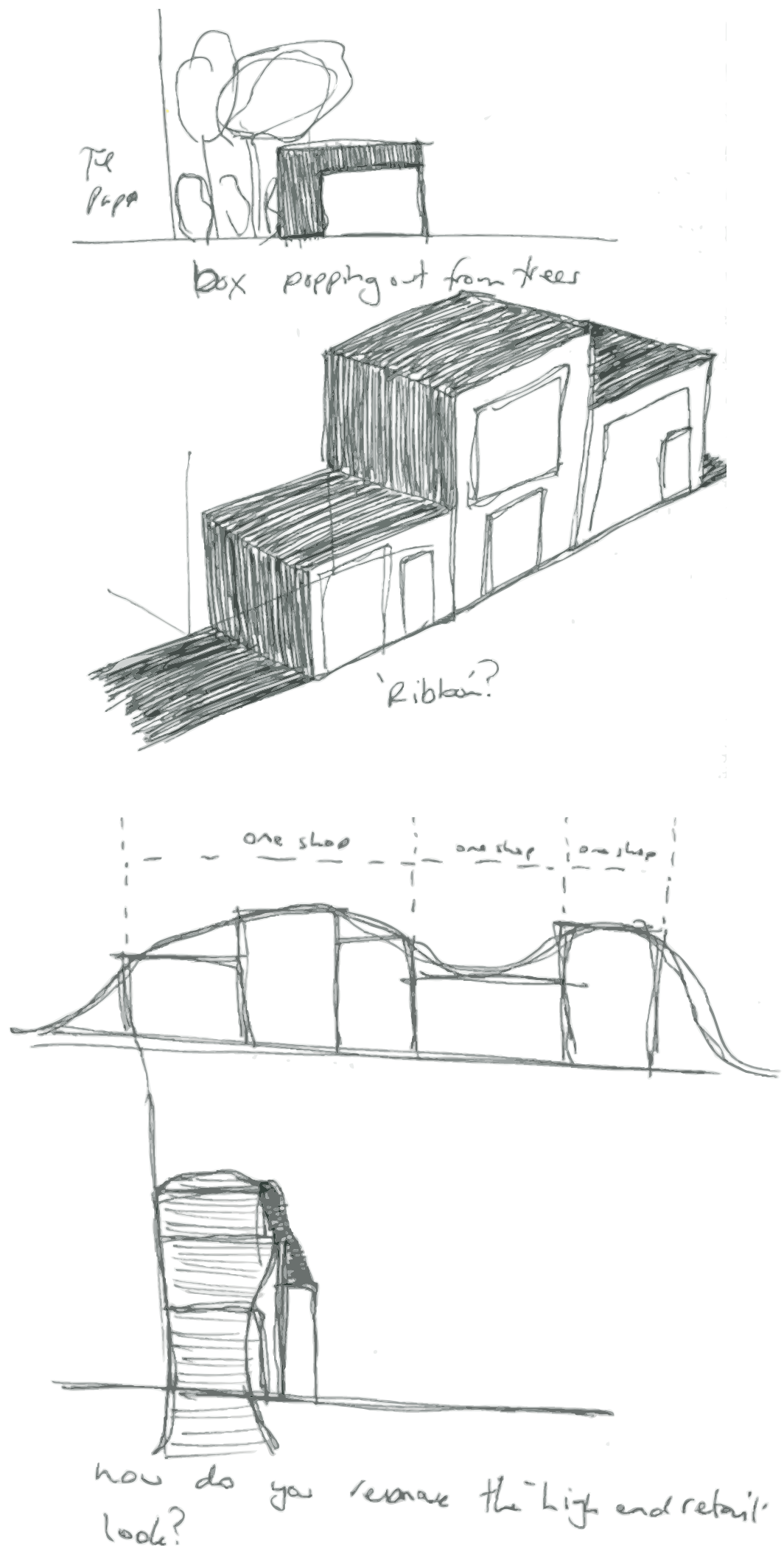
look?

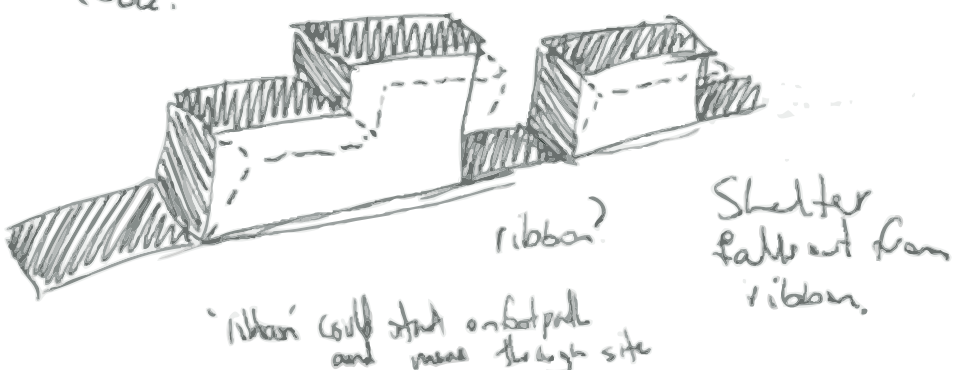

Fig. 5.5.3 Scan of sketches from notebook exploring changes that could be made to the building form

161 


\section{'GARDEN'WALL}

Enclosing the space within a wall is one of the few ways to reduce the effects of wind. This section of research explores ways to ensure a large wall does not hinder people's ability to engage with the site and context. The first study diagrams how the wind will interact with different types of barriers, and further research will inform ways to deal with a potentially dominant wind wall (Wellington City Council, 2000).
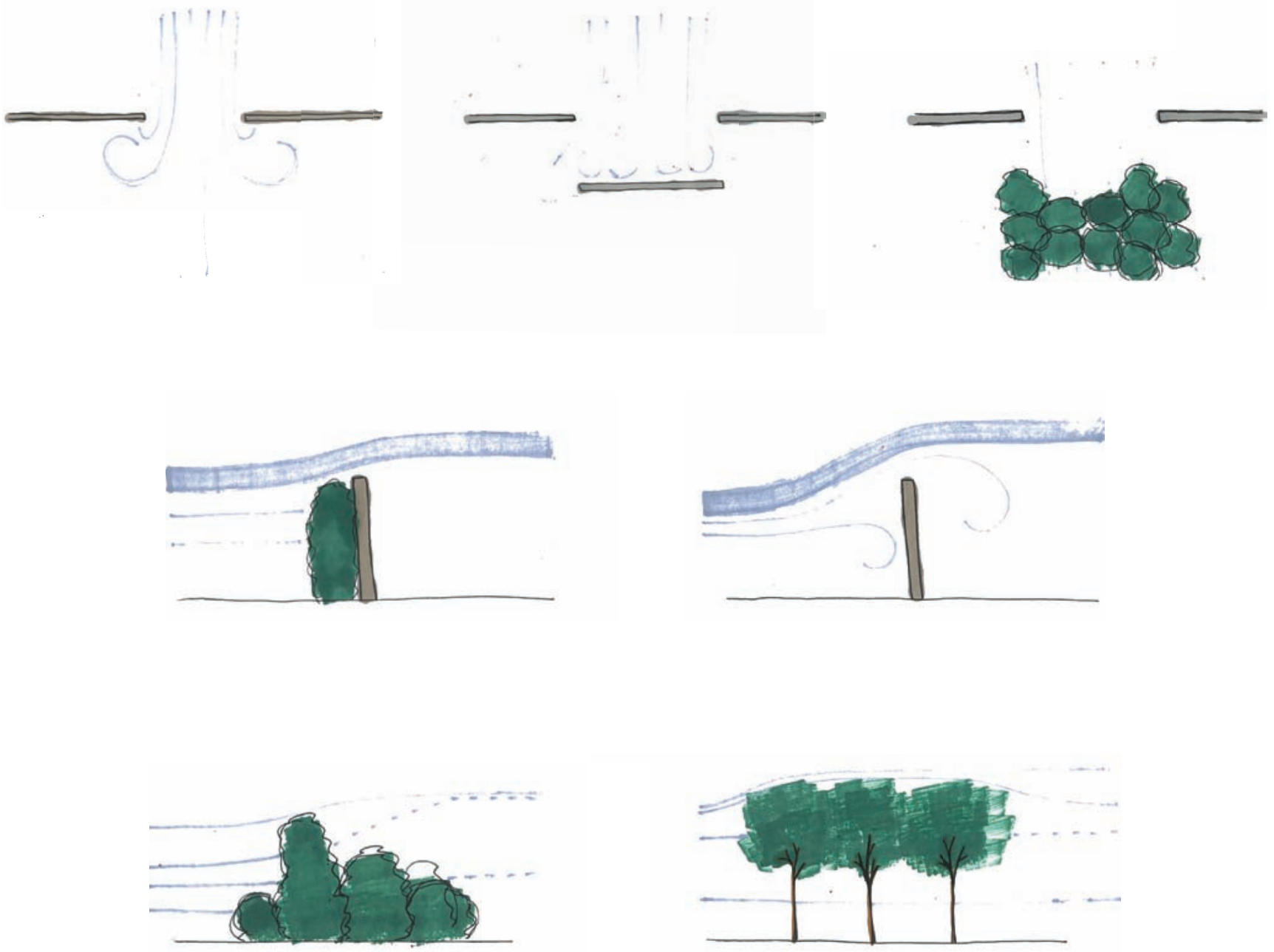


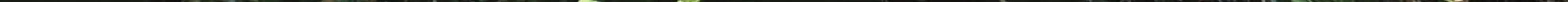




\section{Wall Height and Configuration Testing}
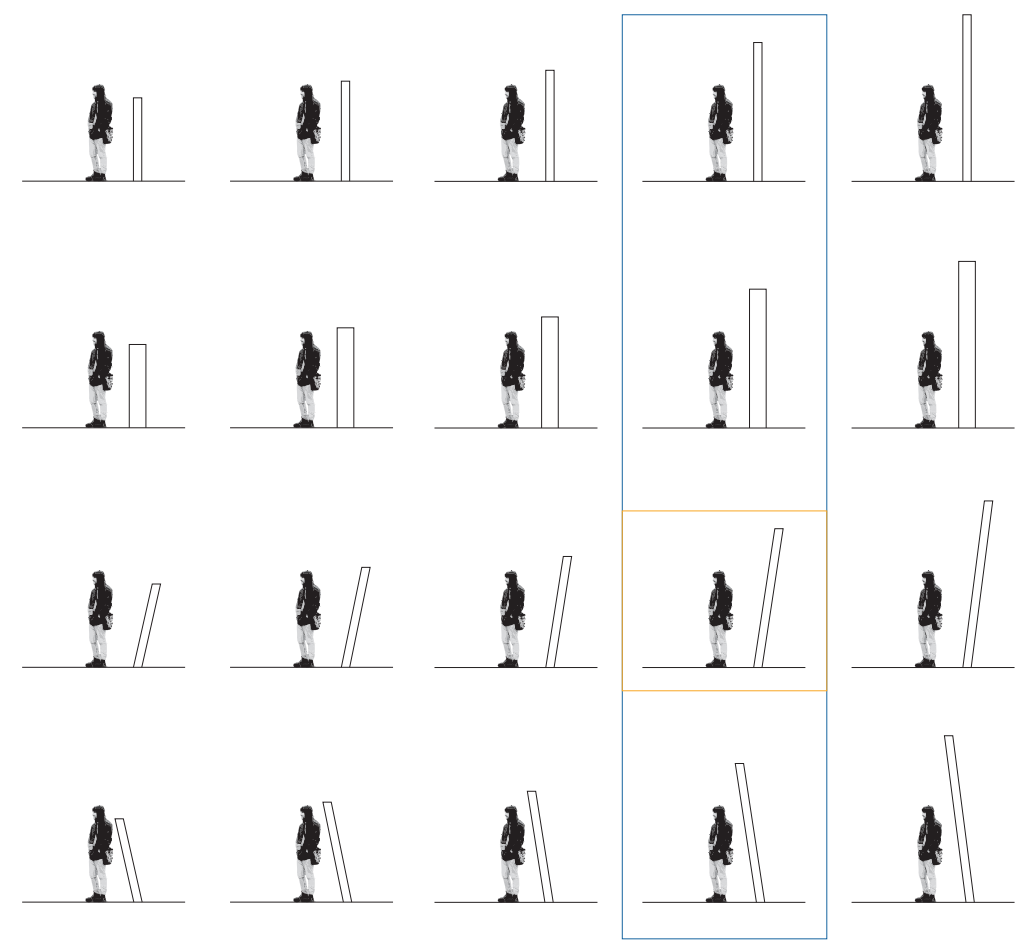

This intensive study of wall heights, widths and design details explores the potential relationship created between the wall and a person walking beside it. The outcome of which is to find the maximum size of the wall before it negatively affects life on the footpath. If someone can see through the wall at places, it might reduce the dominance and invite them into the space using visual connections.
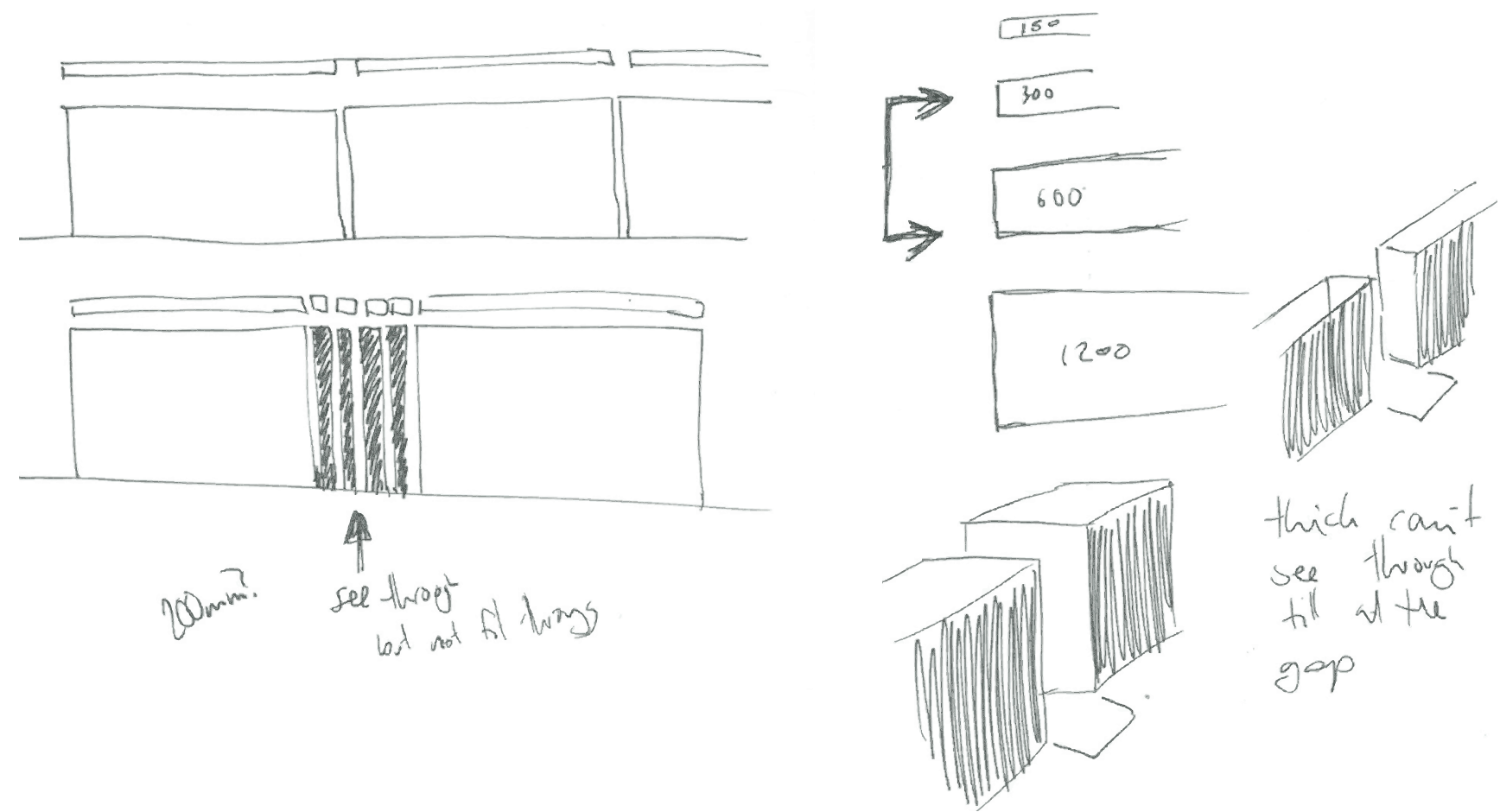

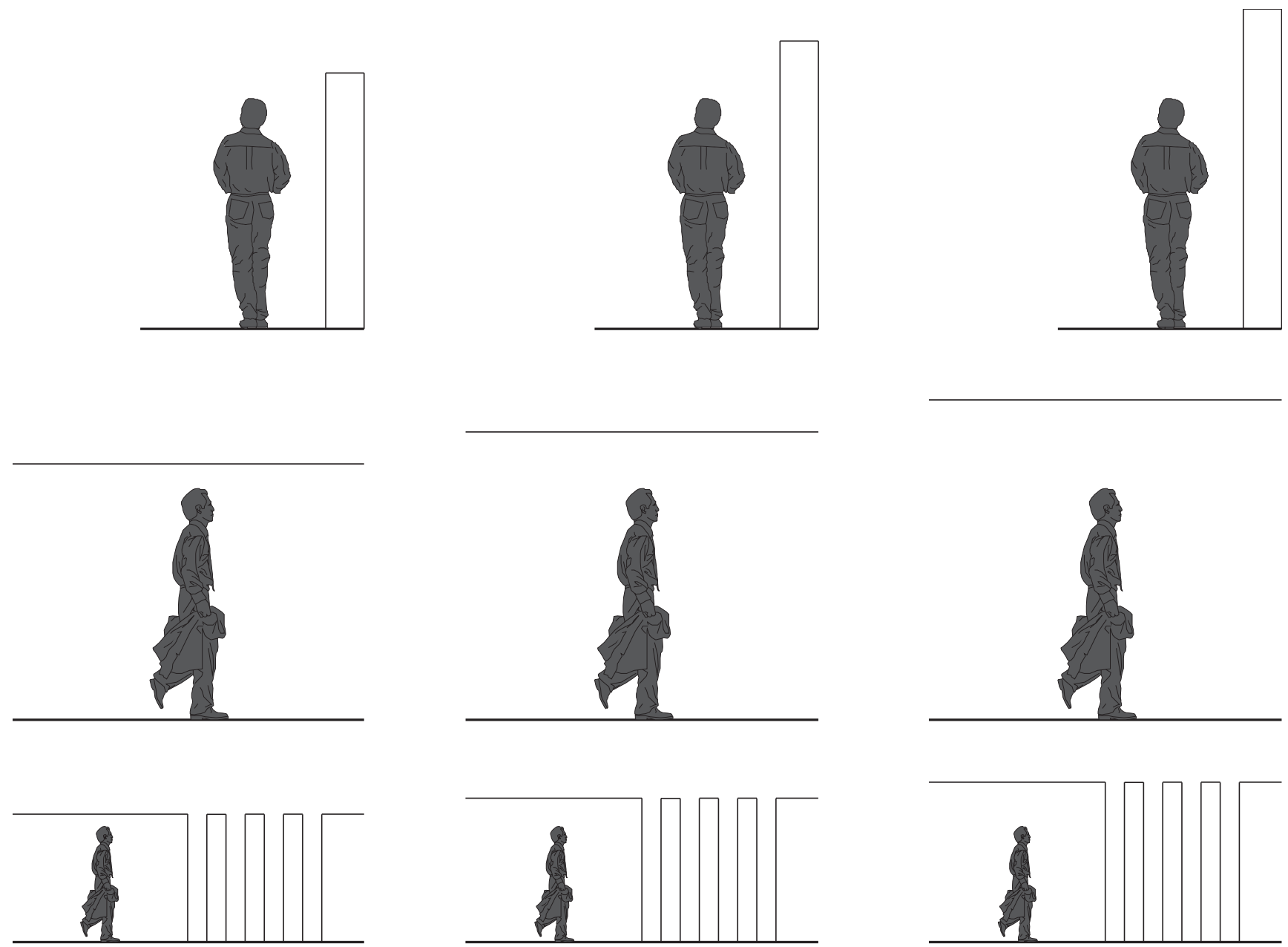

walking beside/through wall

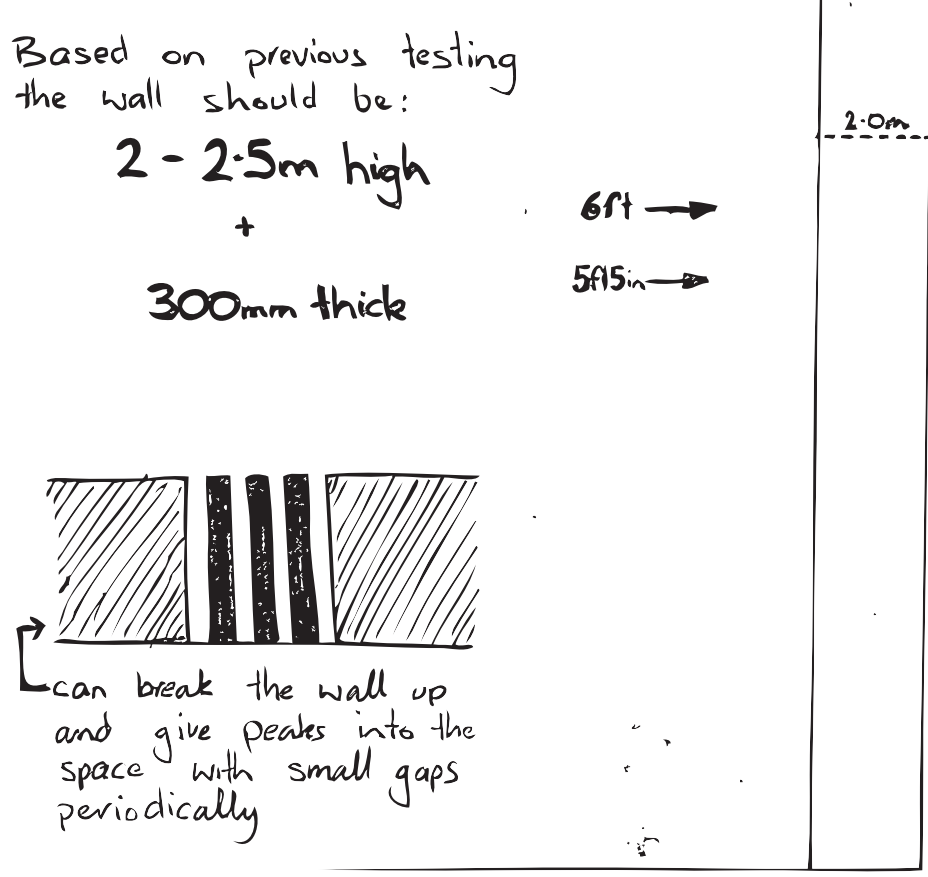

Fig. 5.6.3 Scans of sketches and digital exploration of potential sizes and configuration of a wind wall that would provide shelter for the enclosed public space 


\section{BUSH CITY REDEVELOPMENT}

The original concept planned for Bush City is achieved in the existing site, which is the creation of an enclosed space that highlights native trees and other landscape elements. However, one thing it fails to do is engage with the context and public life of both the waterfront and Te Papa. The northern and western edges push all possible public interaction away, leaving what could be one of the unique waterfront experiences incredibly under utilised.

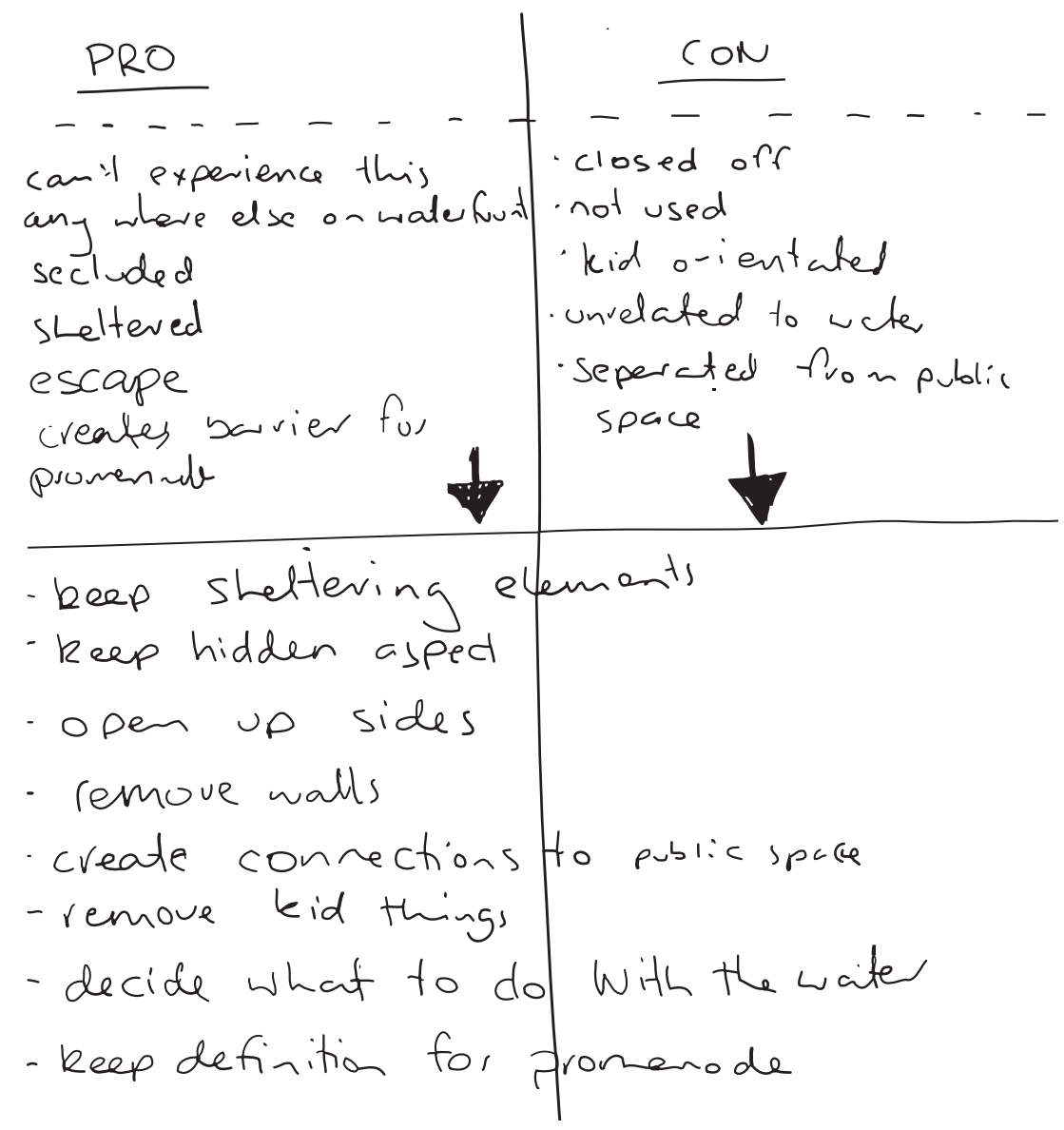




\section{Opening Bush City}

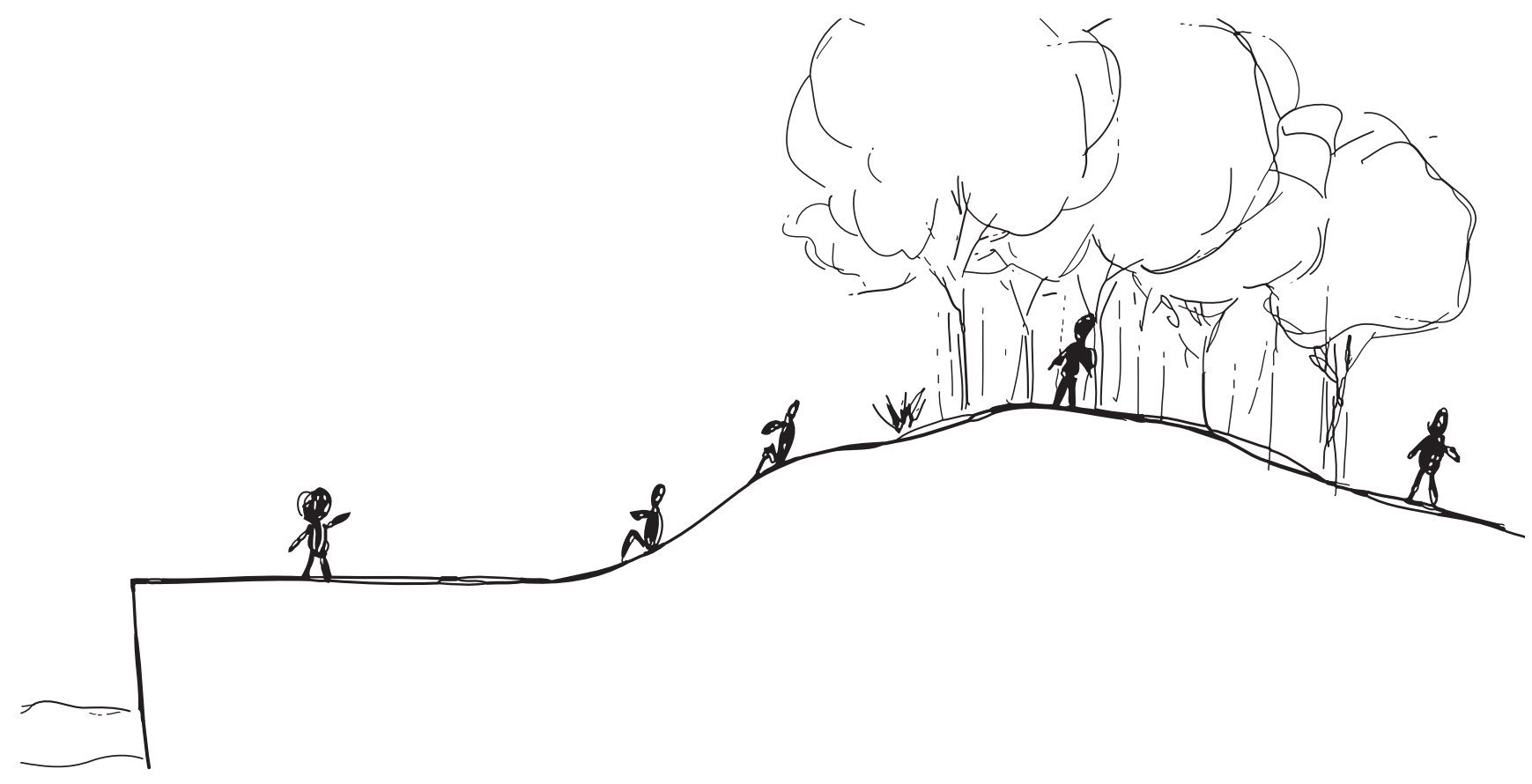

This initial concept for re-configuring the space is to open the edges up in order to improve its connection to the surrounding landscape. This research will explore the best ways to open the space while keeping the main aspects of shelter, use of native plants and an edge to observe the harbour.

\section{Walleable slope}

$15-12 \%$

- lic against

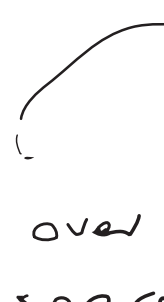

- casily 'climb' over

- sce suar to spaca

- Reep sonefspal seclided

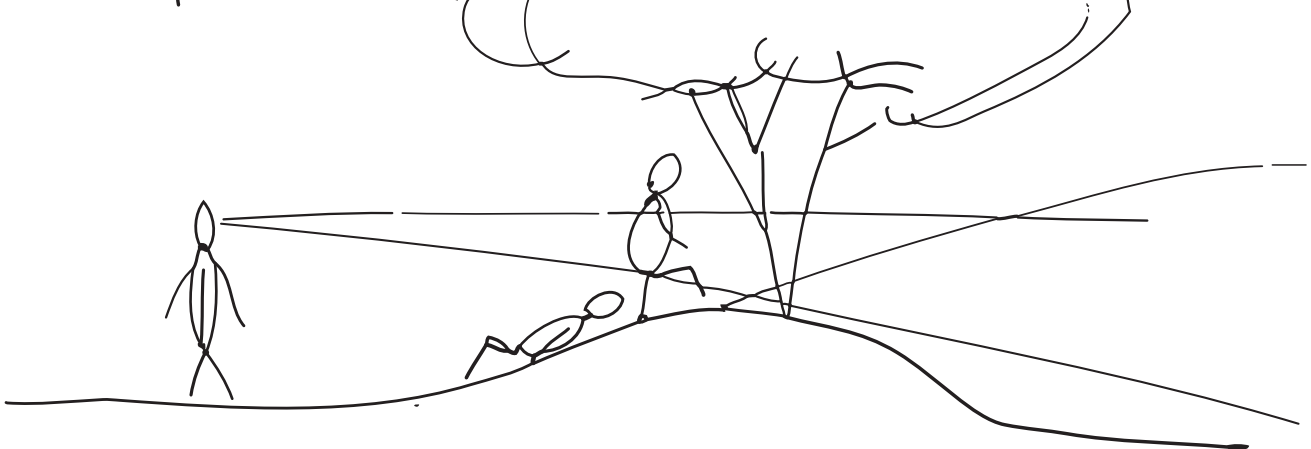

Fig. 5.7.2 Scan of sketches that document the initial concept for changing Bush City 


\section{Creating a Crater in the Existing Site}
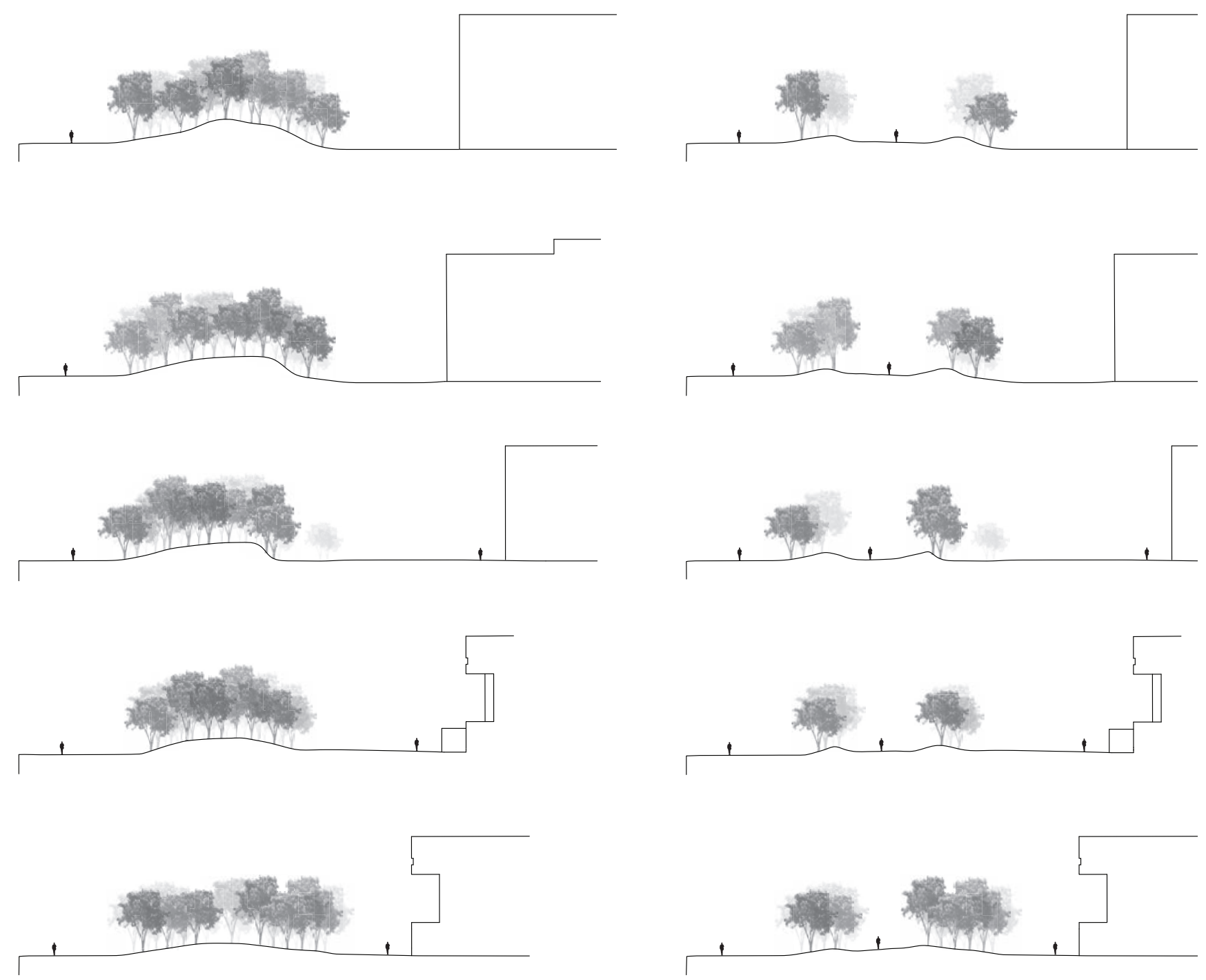

The crater with edge planting concept allows those significant elements of Bush City to remain in positive ways. The planting and the lowering of the inner terrain will keep the wind reduced and ensure the enclosed area remain a sunny, sheltered public space. Breaking down the barriers also drastically increases the connection people can have between Te Papa and the water. 
Testing Slope Sizes
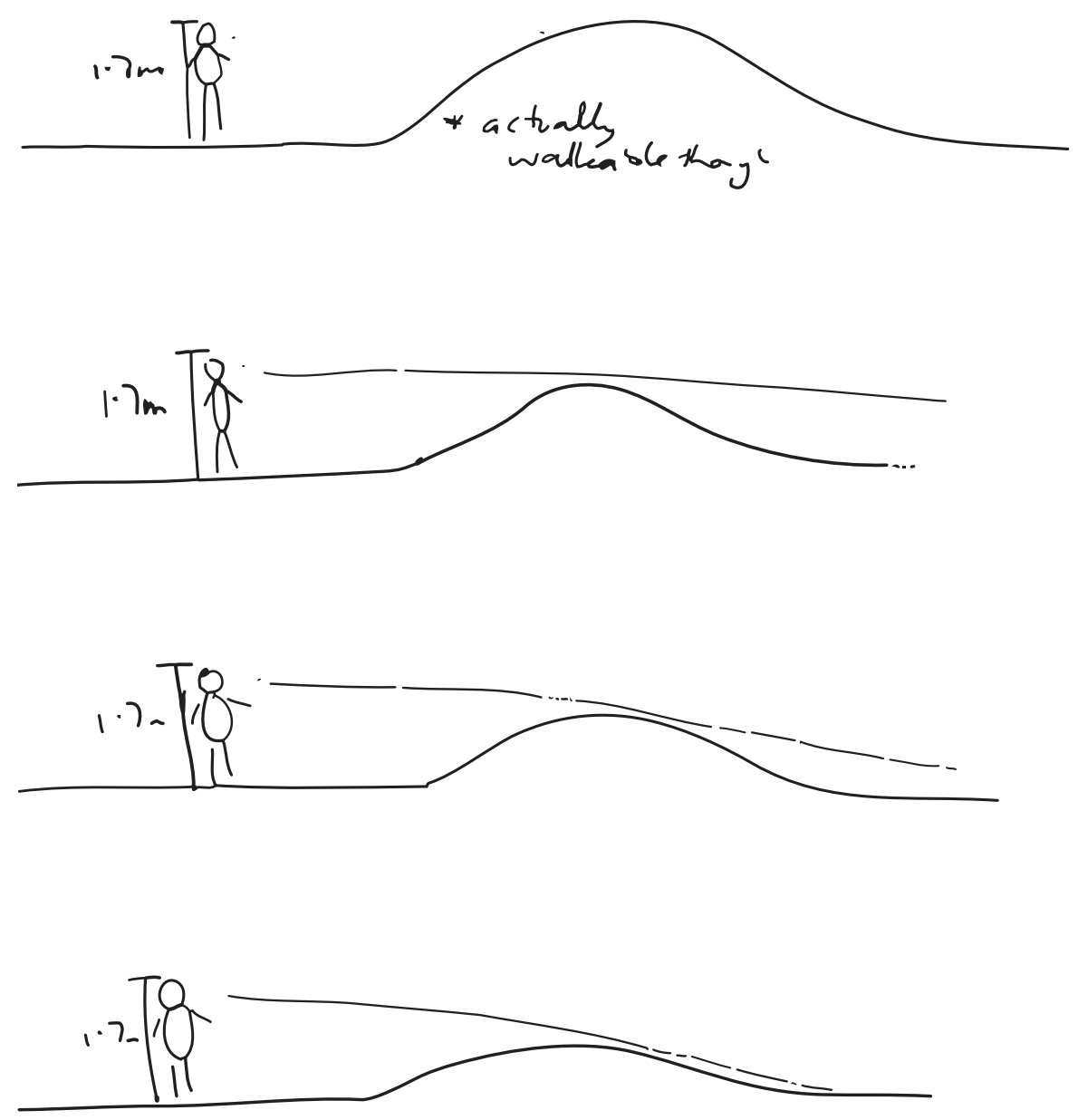

$32 \mathrm{~m}$
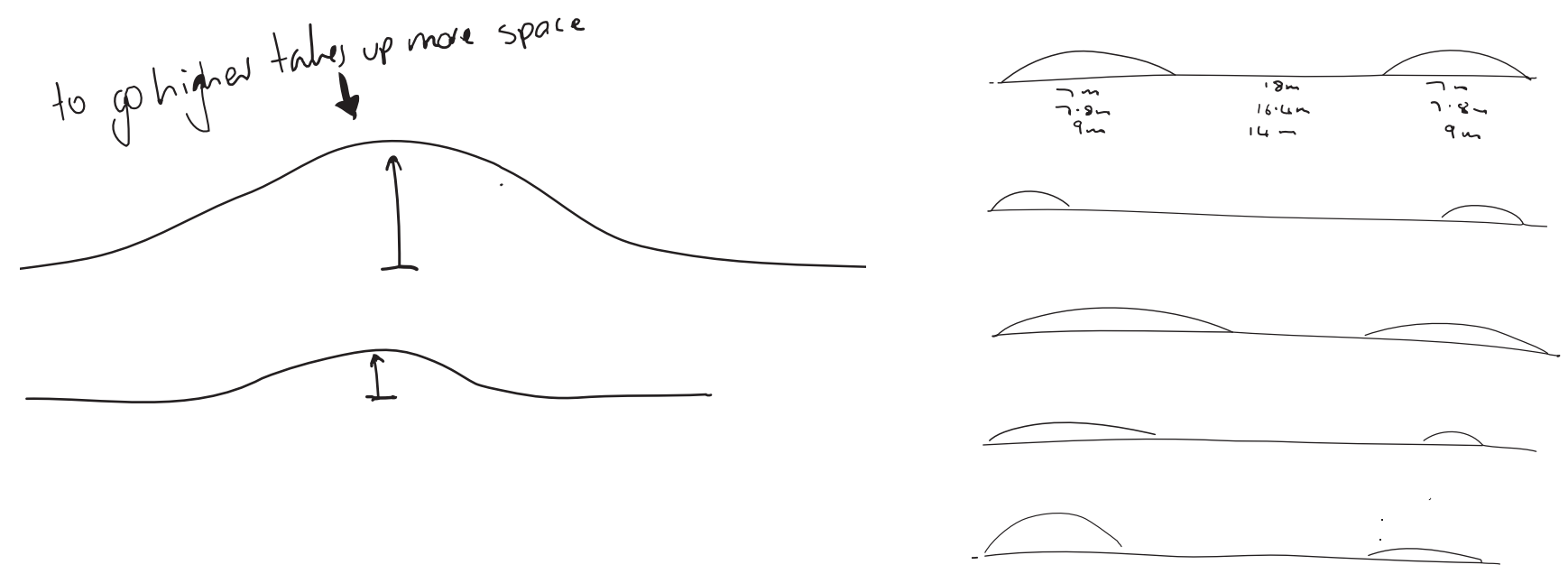

Fig. 5.7.4 Scan of sketches that explore heights and widths of a bill that separates the promenade from the internal space 


\section{Testing Slope Gradient and Height}
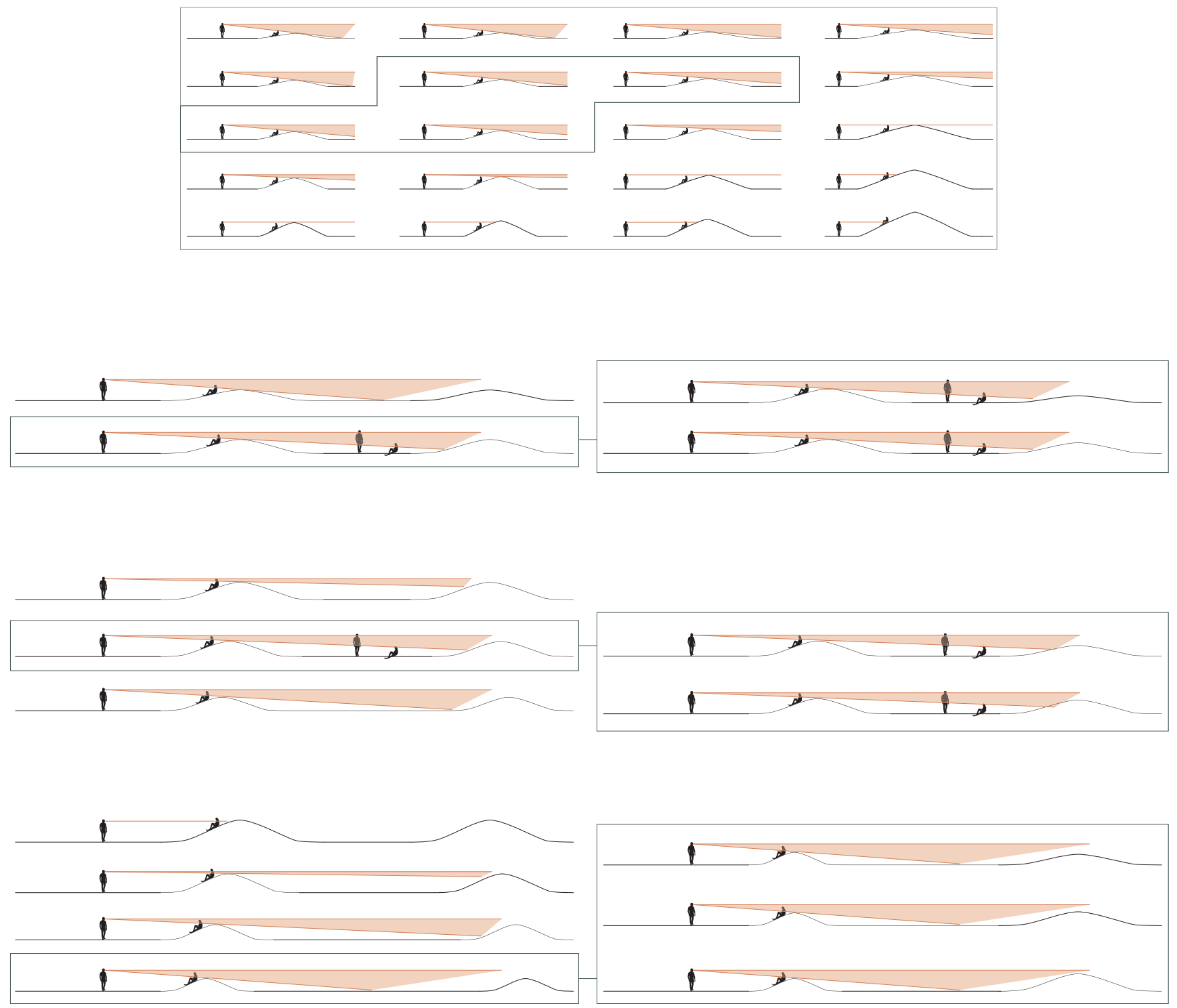
15\% Slopes

$20 \%$ Slopes
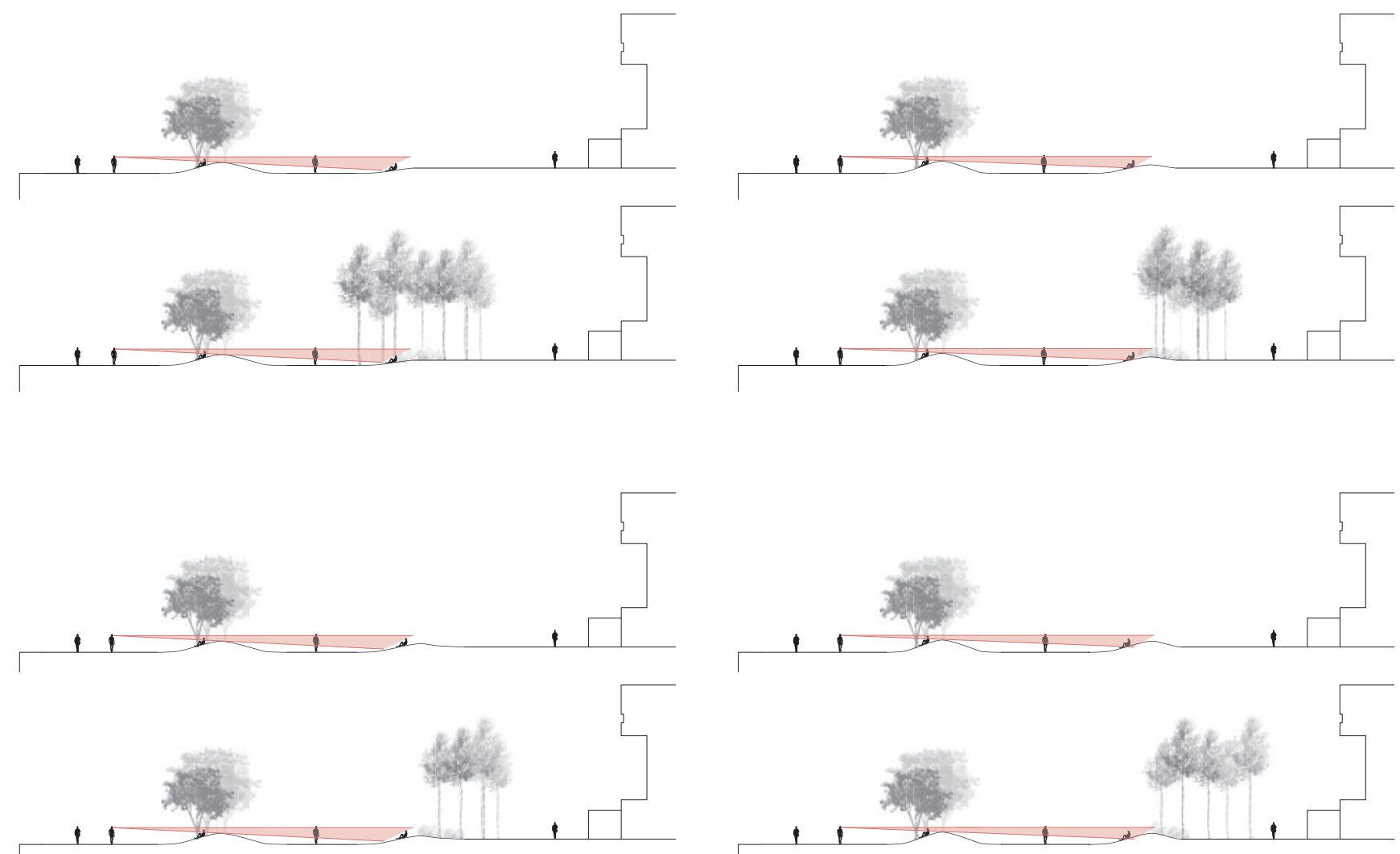

\section{$25 \%$ Slopes}
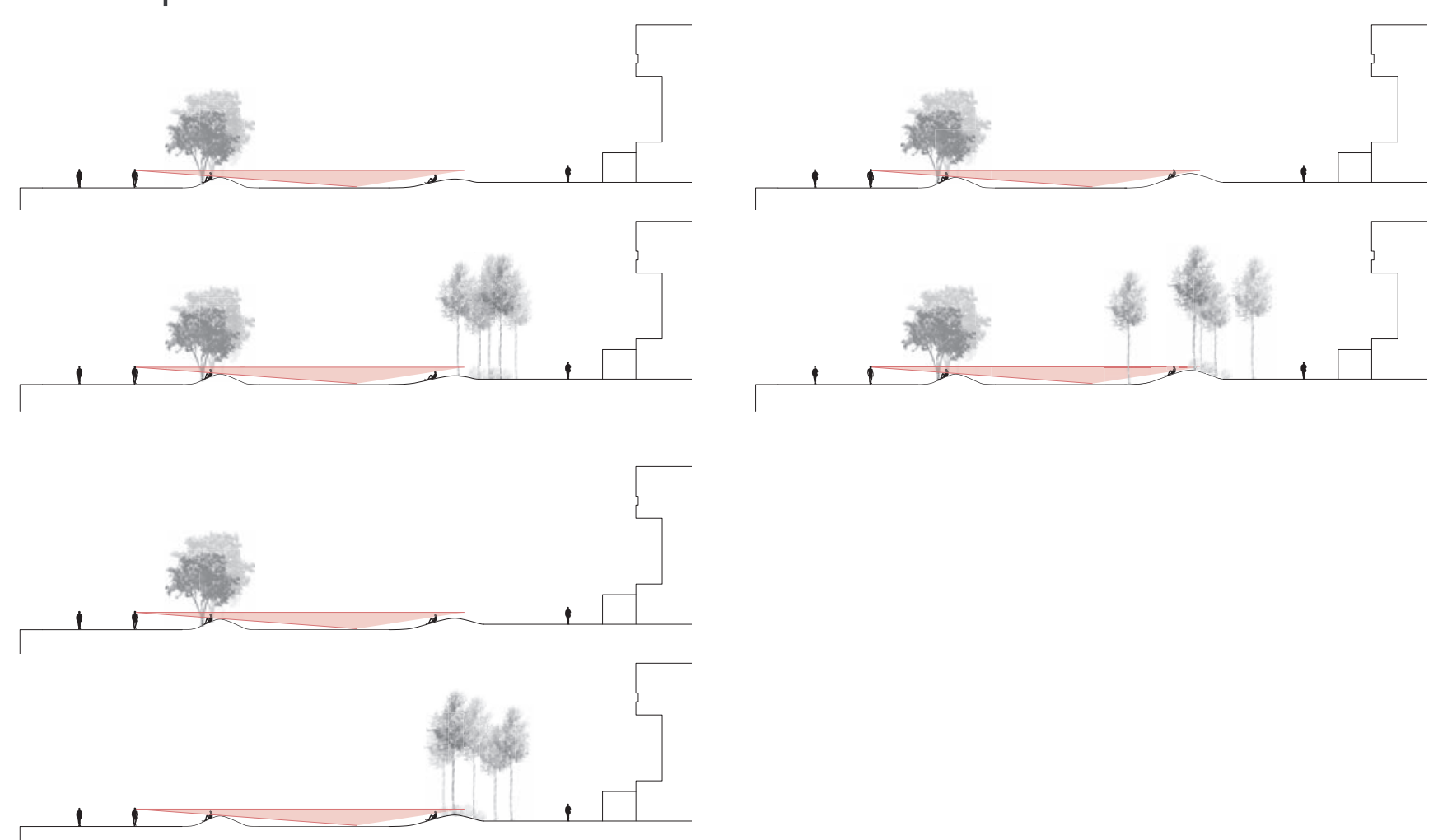

Fig. 5.7.6 Continuation of previous study with the addition of planting, testing the slope gradients and widths that stood out from the previous study 

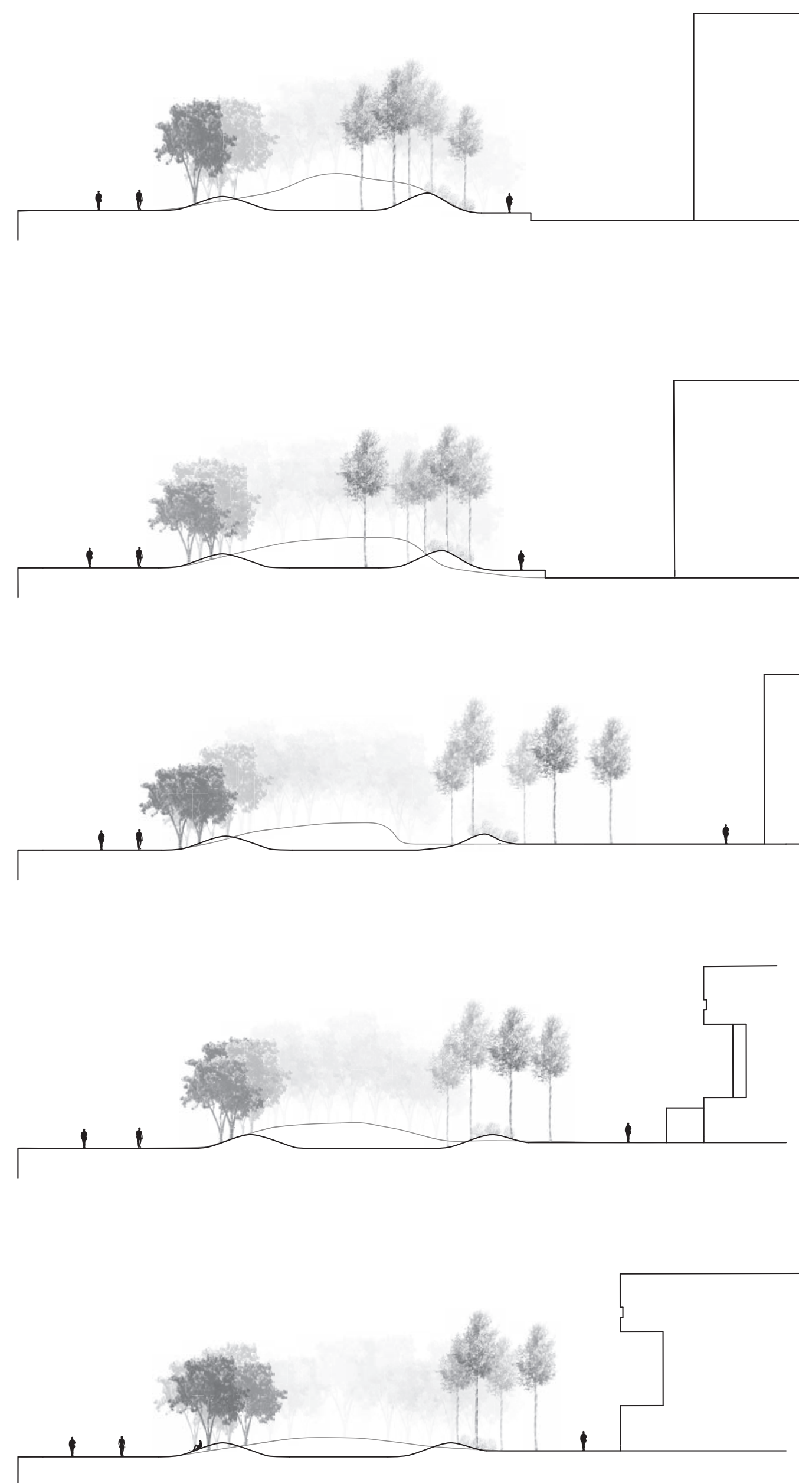


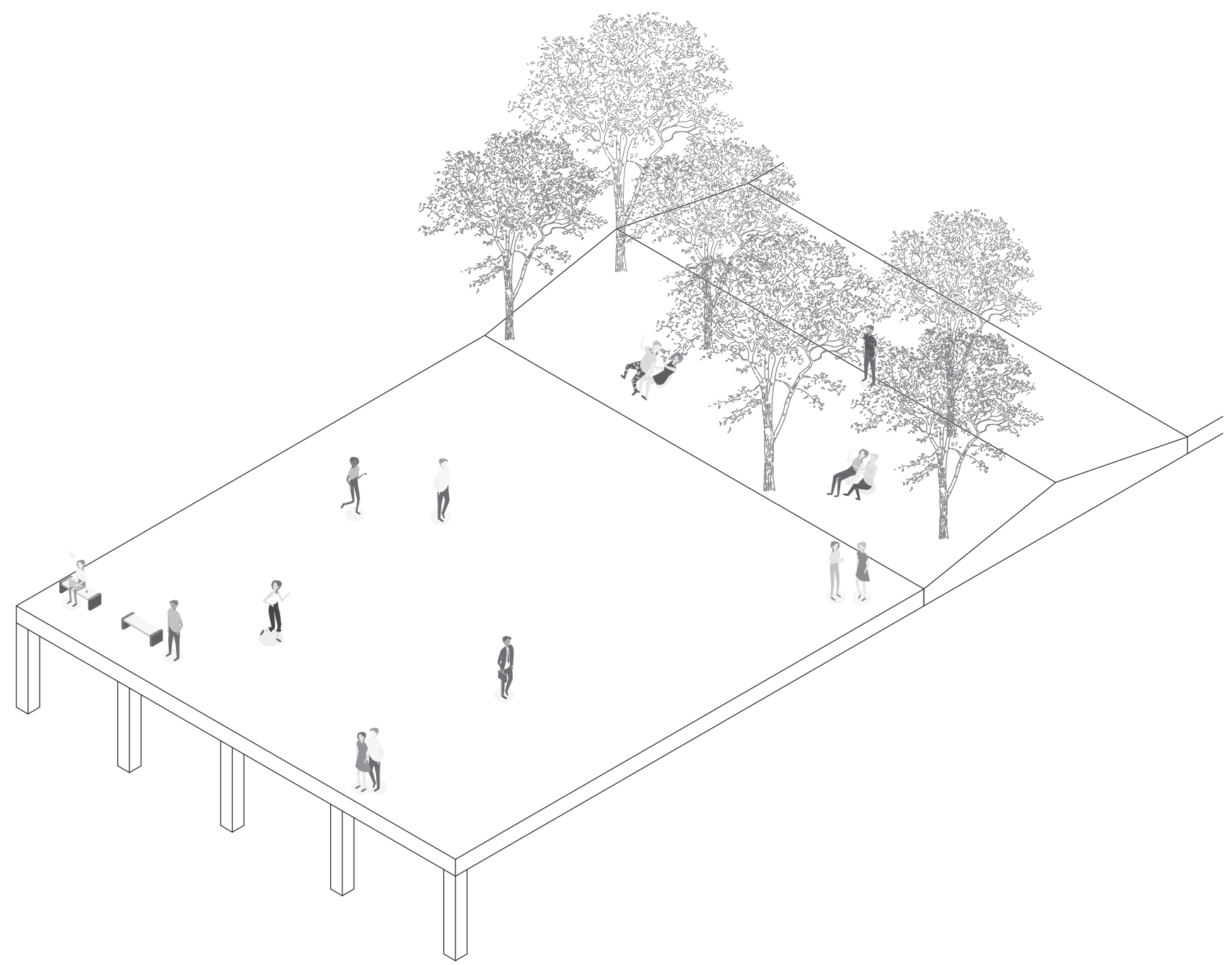

Fig. 5.7.7 (opposite) Comparison of existing terrain with the new crater concept with chosen slope size

Fig. 5.7.8 Isometric of waterfront promenade and connection to crater concept 



\section{MOVEMENT CO-ORDINATION}

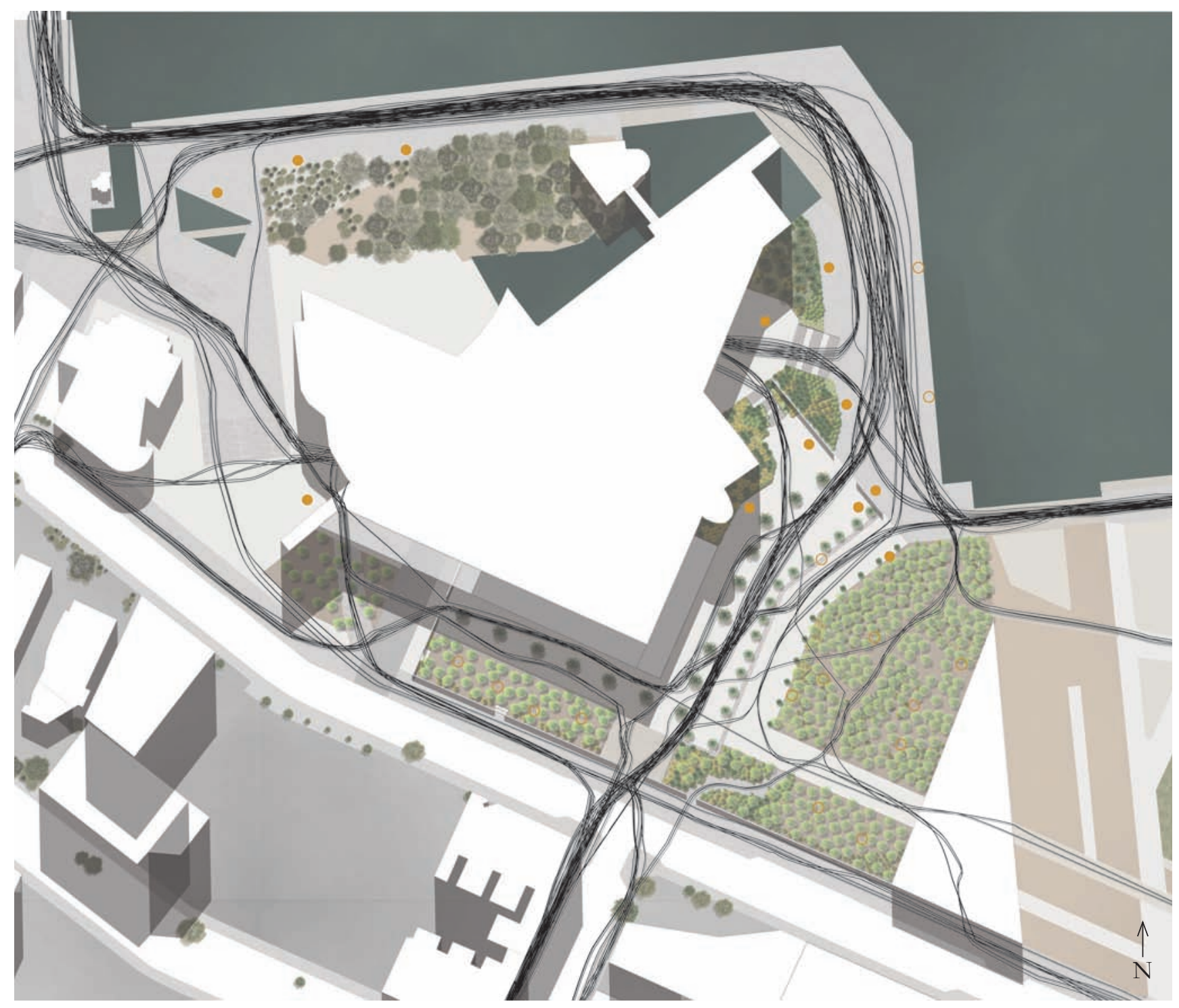

Fig. 5.8.1 Movement mapping of initial concept 1:2000, it also highlights areas where lingering may occur

The final stage of the initial concept is to analyse its potential movement, to observe areas where it may perform well and other areas that may require further design to coordinate it in ways that are more successful. Successful movement allows the relationship discussed in Chapter 1 to occur along the edges in relation to the movement. There is a movement in this design where it will not enhance the public life, which is on the top right side of the site, due to the multiple entrances into this small space, causing the area of coordinated movement to be quite broad and not focused. 


\section{CHAPTER FIVE CONCLUSION}

As stated in the chapter introduction, the formation of an initial concept allows testing of the design methods that are the focus of this chapter. This chapter explores scenarios within the site where designs could be tested and their performance analysed in order to progress with the research.

Sketching as a medium for design played a significant role in the exploration of this concept, in particular the relationship studies that were undertaken. These studies related back to the discussion in chapter one about what different users of the waterfront required in order to engage with the site and the mutual relationship that was created with other users in the site and the movement.

The intensive plant study establishes the focus of research has on in regards to the experience design elements create for the users of the space. The planting was considered first for its durability and suitability for a windy urban waterfront location, and then with regards to the relationship it has to the human body and the types of canopies and spaces that can be created by different types of planting.

This idea of testing all designs based on the relationship that will be created with individual people will ensure that even the smallest of details will enhance the experience had by the public life in the space. 


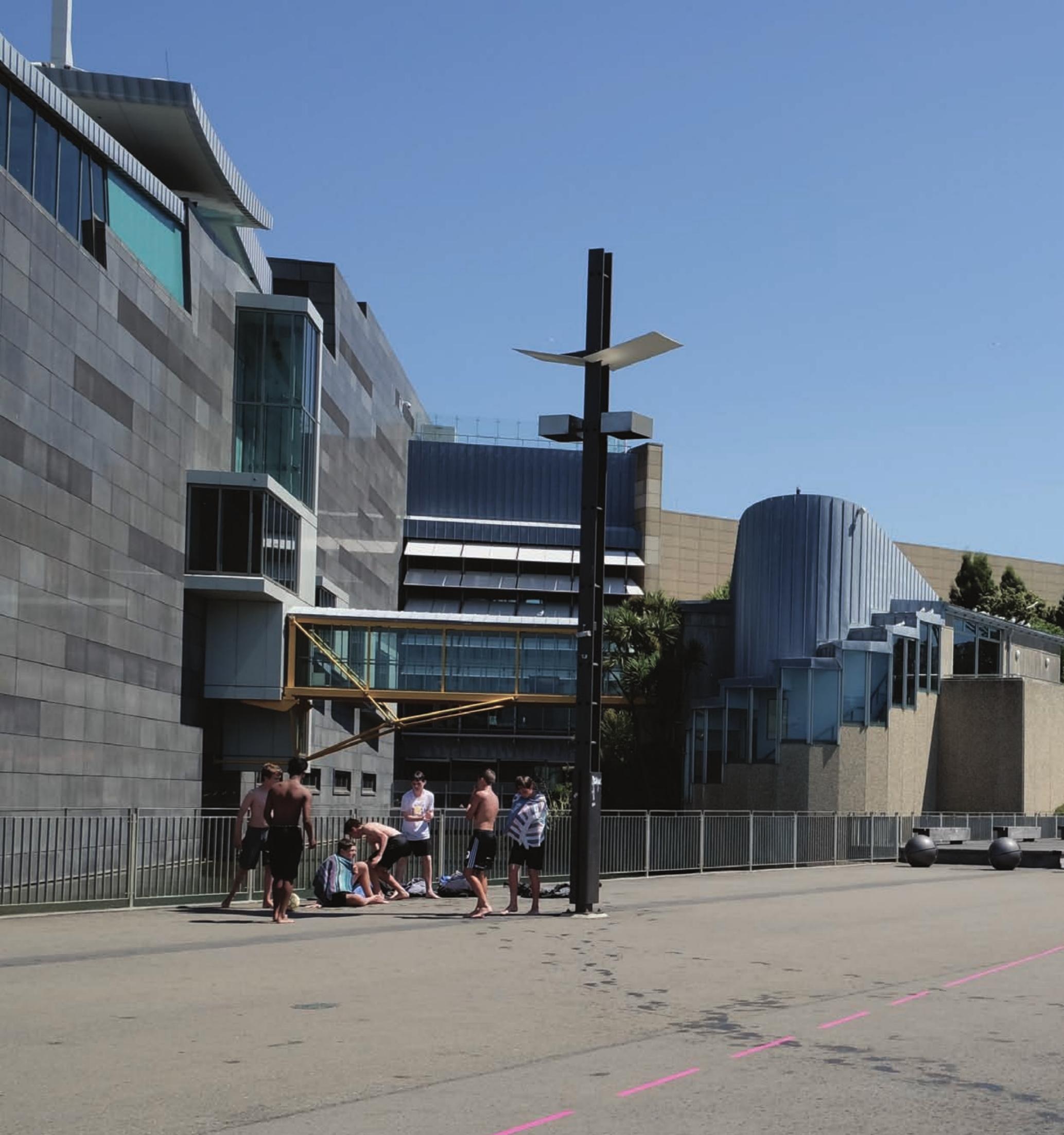

Fig. 6.0 Waterfront promenade 
Development Plan Urban Forest Canopy Art Gallery Shops Bush City Playful New Entrance Wharf Edge/Promenade Seating Tests Stair Tests Materiality Chapter Conclusion DESIGN DEVELOPMENT

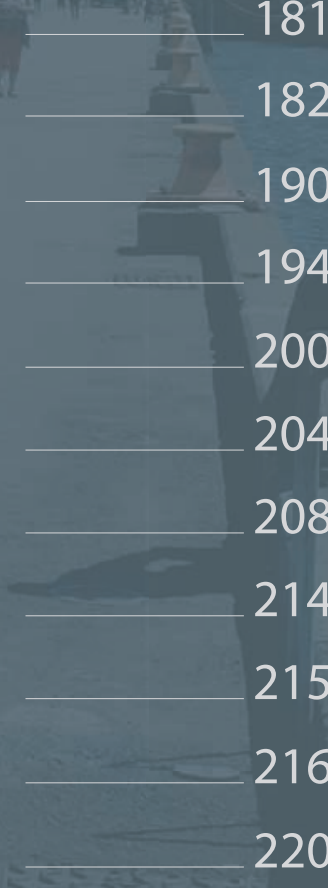

220 


\section{DESIGN DEVELOPMENT}

This section of research takes the ideas generated in the initial concept stage and develop them further, responding to the reflections of the previous chapter. The site has seven different zones based on the concept stage; development will focus on each zone individually and in relation to the surrounding environment in which it is located.

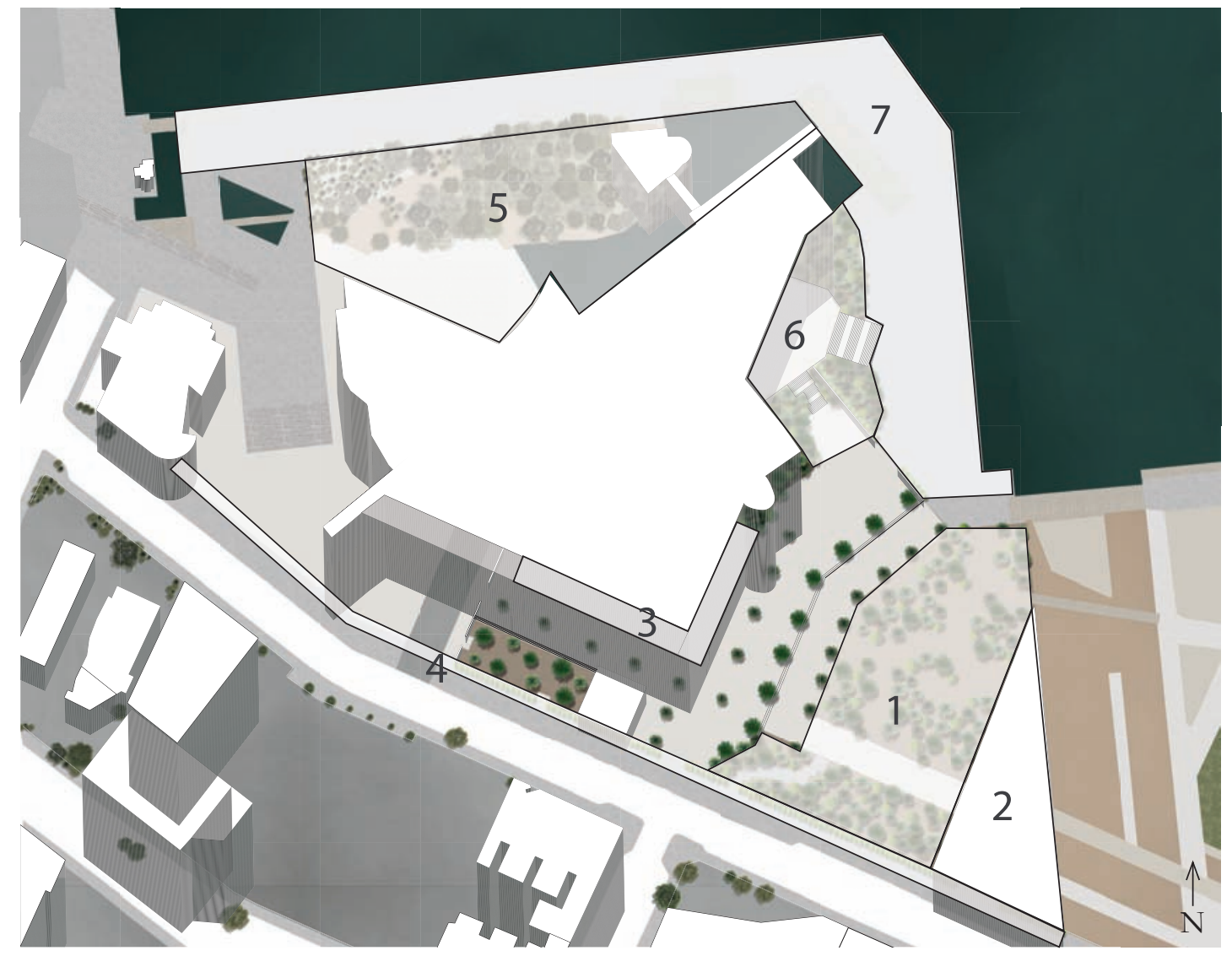

1_ Urban Canopy Forest

2 _ Art Gallery

3_ Shops

4_ Wind Wall/Shelter

5_ Sunlit Bush Enclave

6__ Playful New Entrance

7 _ Wharf Edge

Fig. 6.1 Development plan for this chapter 1:2500 
URBAN CANOPY FOREST

This research aims to develop the public space opportunities that can exist beneath the canopy and how understory plating can potentially create spaces with various relationships to the planting, the extended landscape, and other people within the canopy.

openers with enclosure

large spaces tall canopy see through... walkable defining edges secluded spares pockets between forest - like different scale of interaction
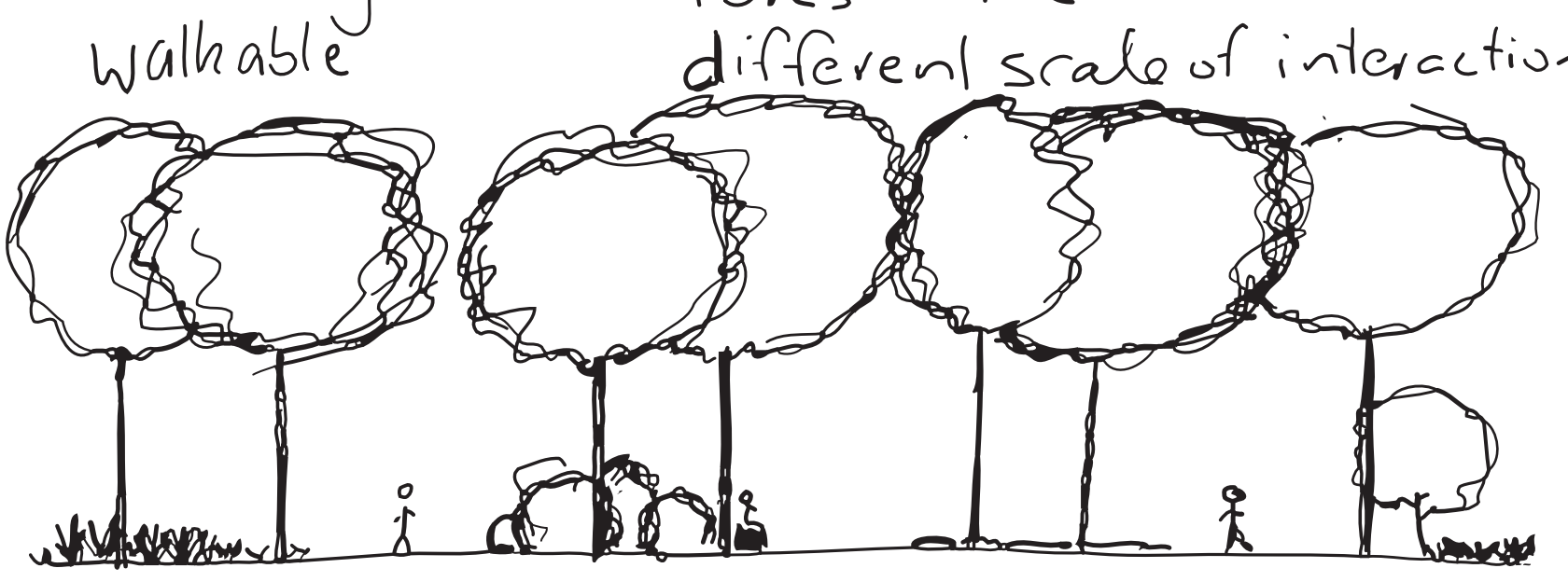

analyse each based on:

1. personal zone

2. Movable zone

primary

secondary

3. seeable zone

extra sight lines

What people activity need what kind of zone?

Fig. 6.2.1 Scan from notebook showing beginning of understory public space exploration

182 
Defining Spaces With Planting

Canopy Trees Only

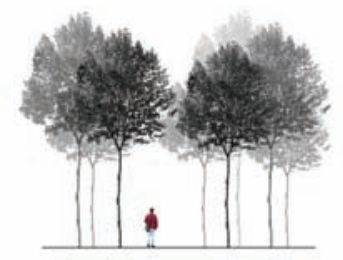

Low Ground Cover
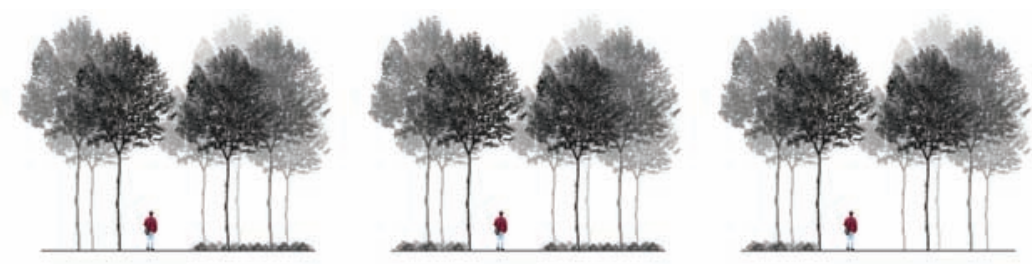

$1 \mathrm{~m}$ Tall Dense Herbaceous
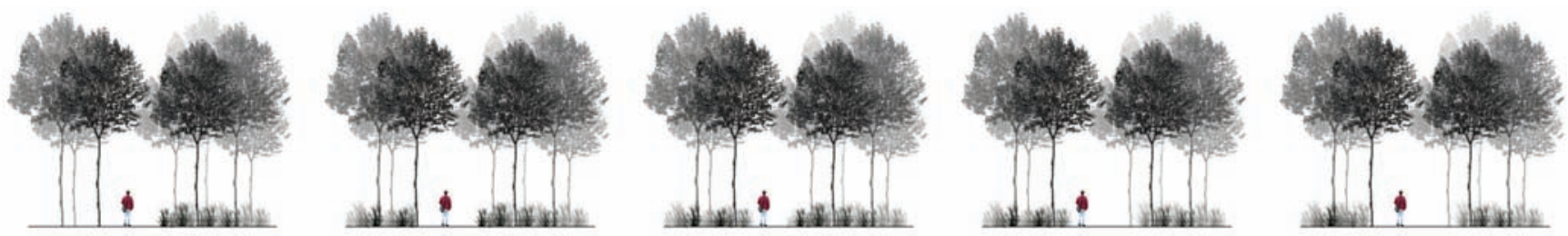

Shrubs
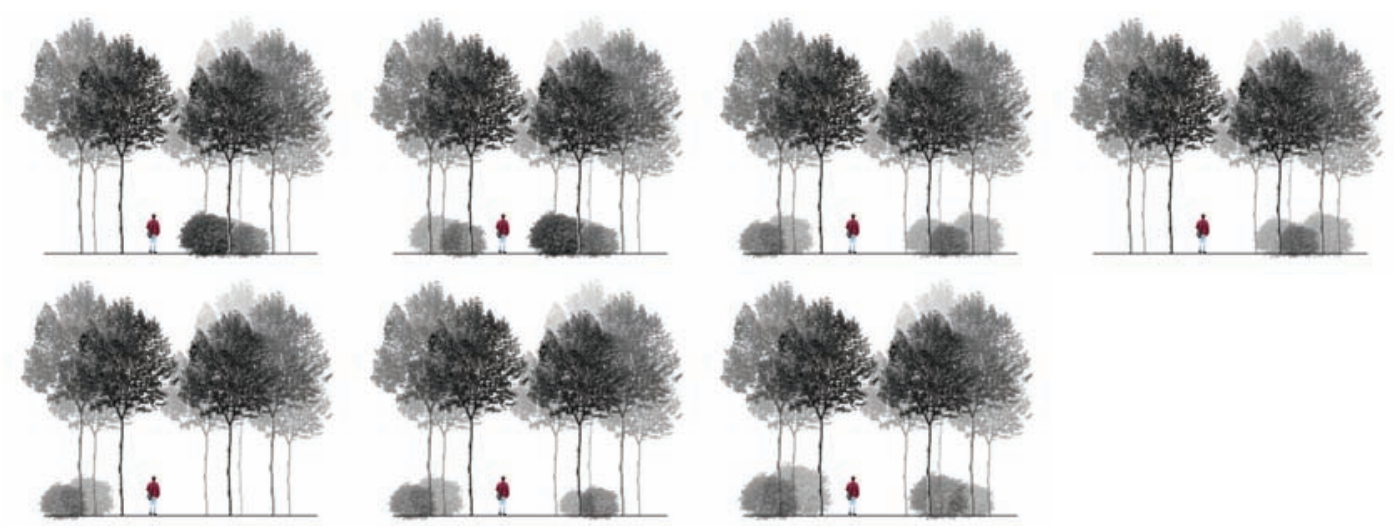

Small Trees
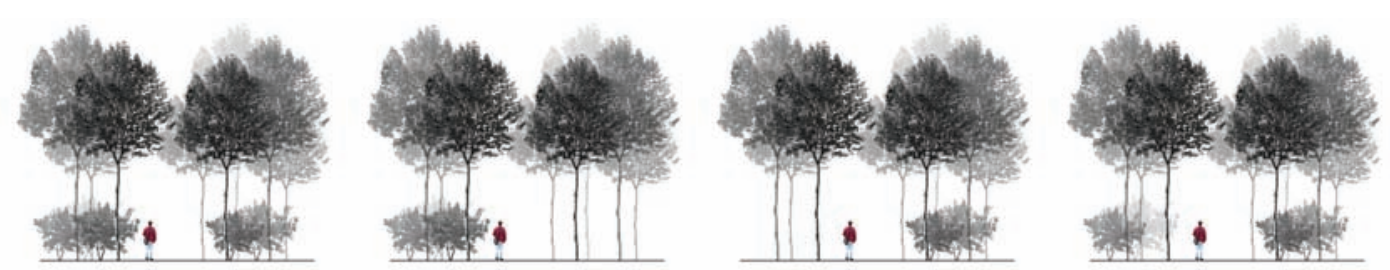

Fig. 6.2.2 Testing of plant heights and pathway creation through sections 


\section{Understory Arrangement Tests: Scenario 1}

Walking/Sitting/Walking
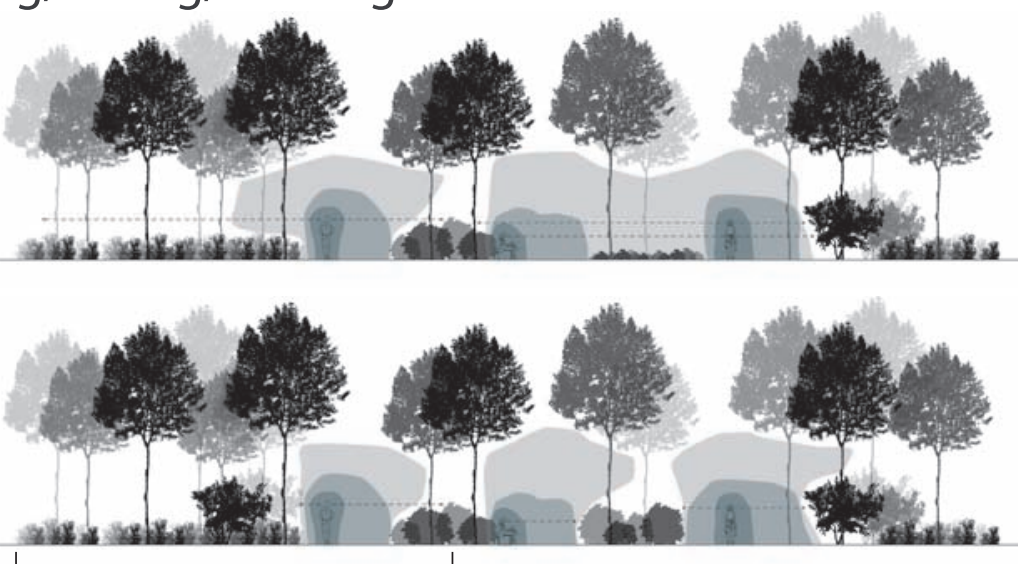

cozy/adventurous walking track
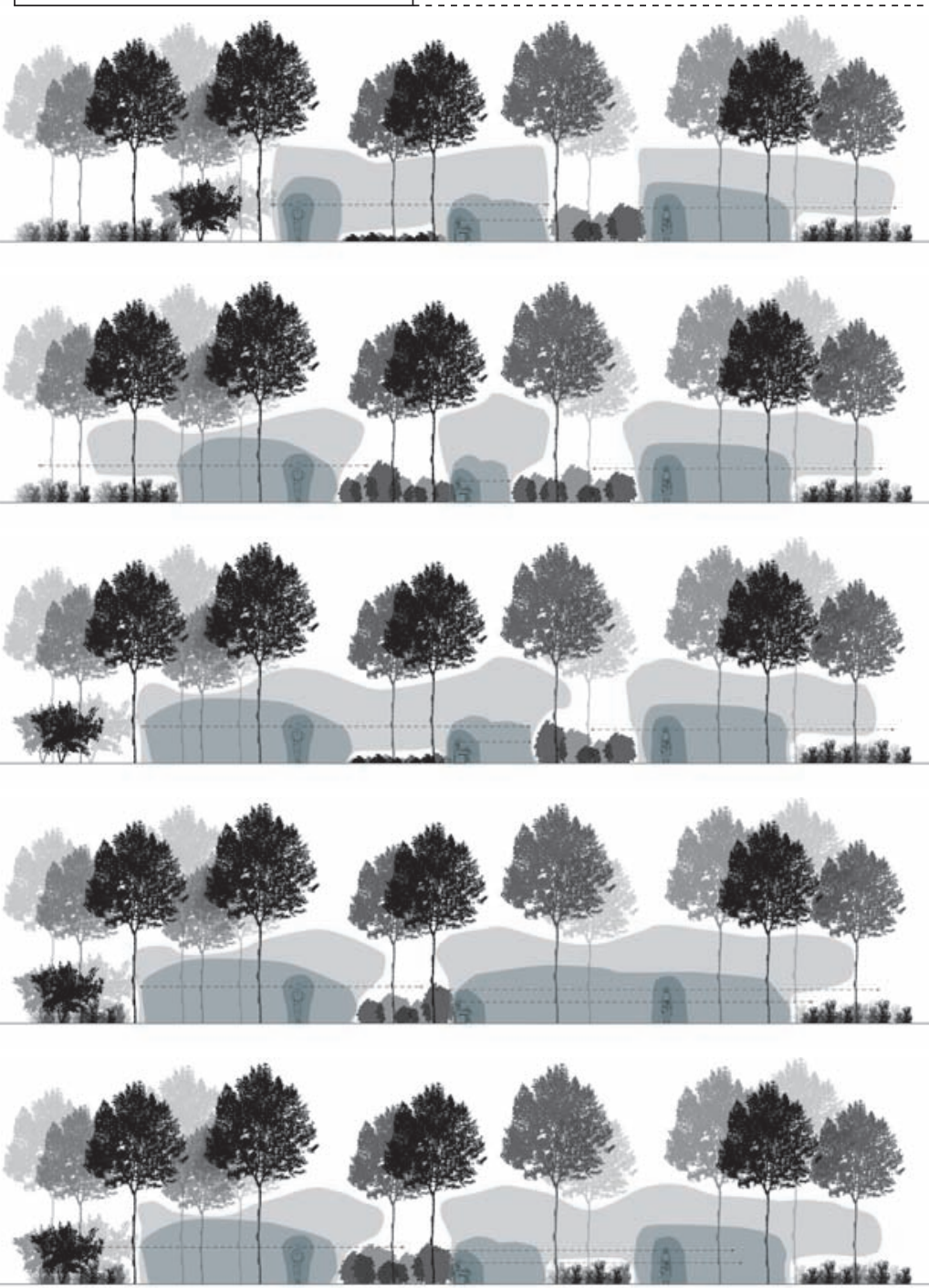

people watching but doesn't let walker feel trapped, givers
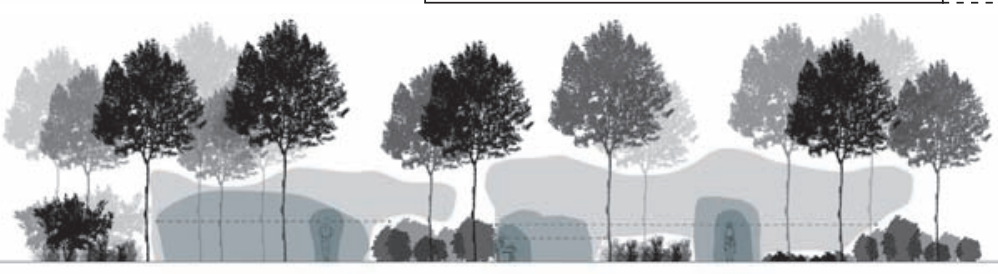
backing for sitter

Fig. 6.2.3 Understory scenarios demonstrate the type of spaces that can be created within the vast forest area, they are analysed for sight lines and creation of zones 


\section{Understory Arrangement Tests: Scenario 2}
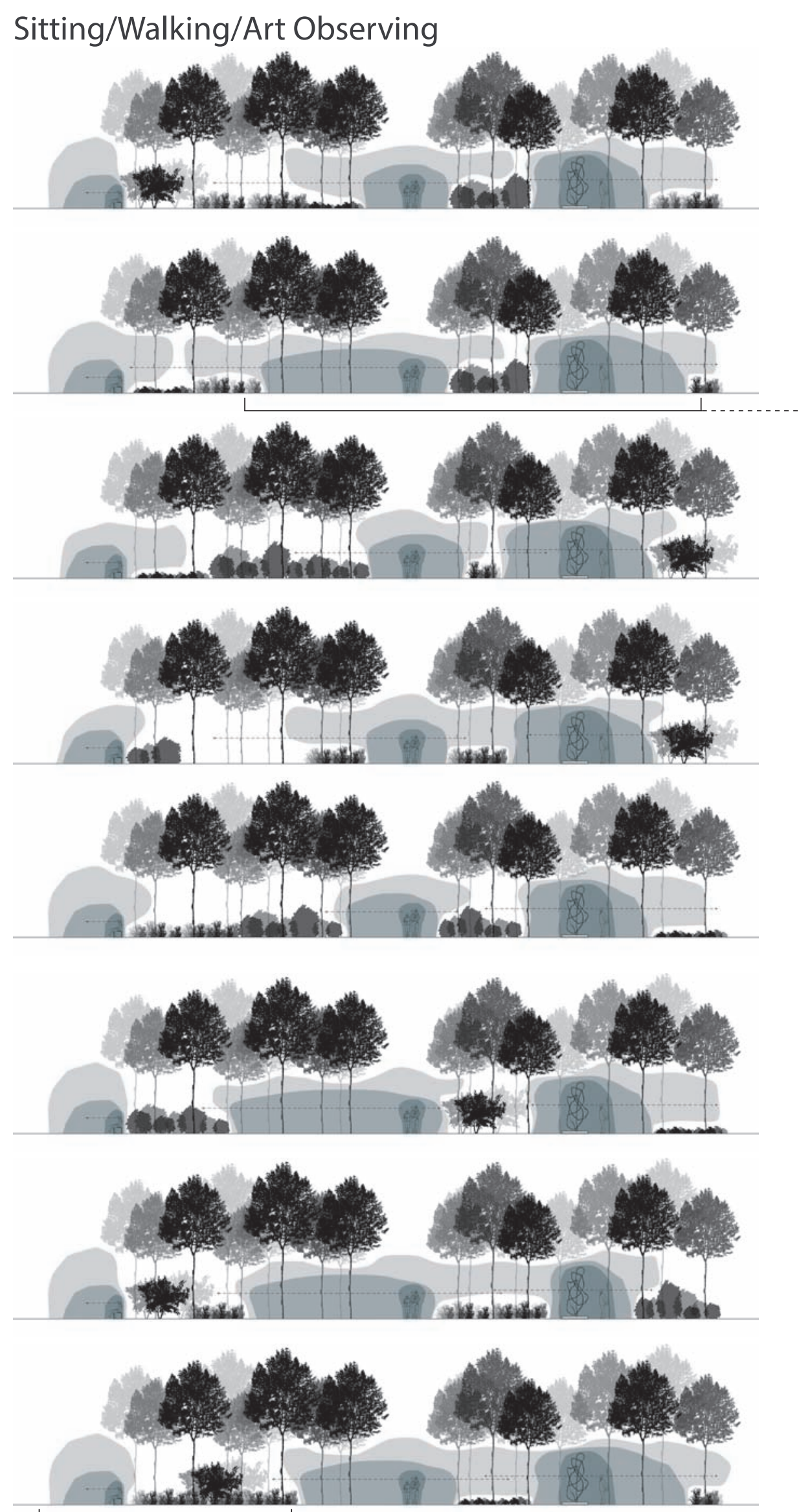

has backing but allows sitter's large walkable space allows for playful interaction; sculpture can be seen from walkers but cannot be directly accessed, nor can see what the space is; openness between art gallery and sculpture/forest is important

Fig. 6.2.4 Understory scenarios demonstrate the type of spaces that can be created within the vast forest area, they are analysed for sight lines and creation of zones 


\section{Understory Arrangement Tests: Scenario 3}

\section{Sitting/Sitting/Walking}

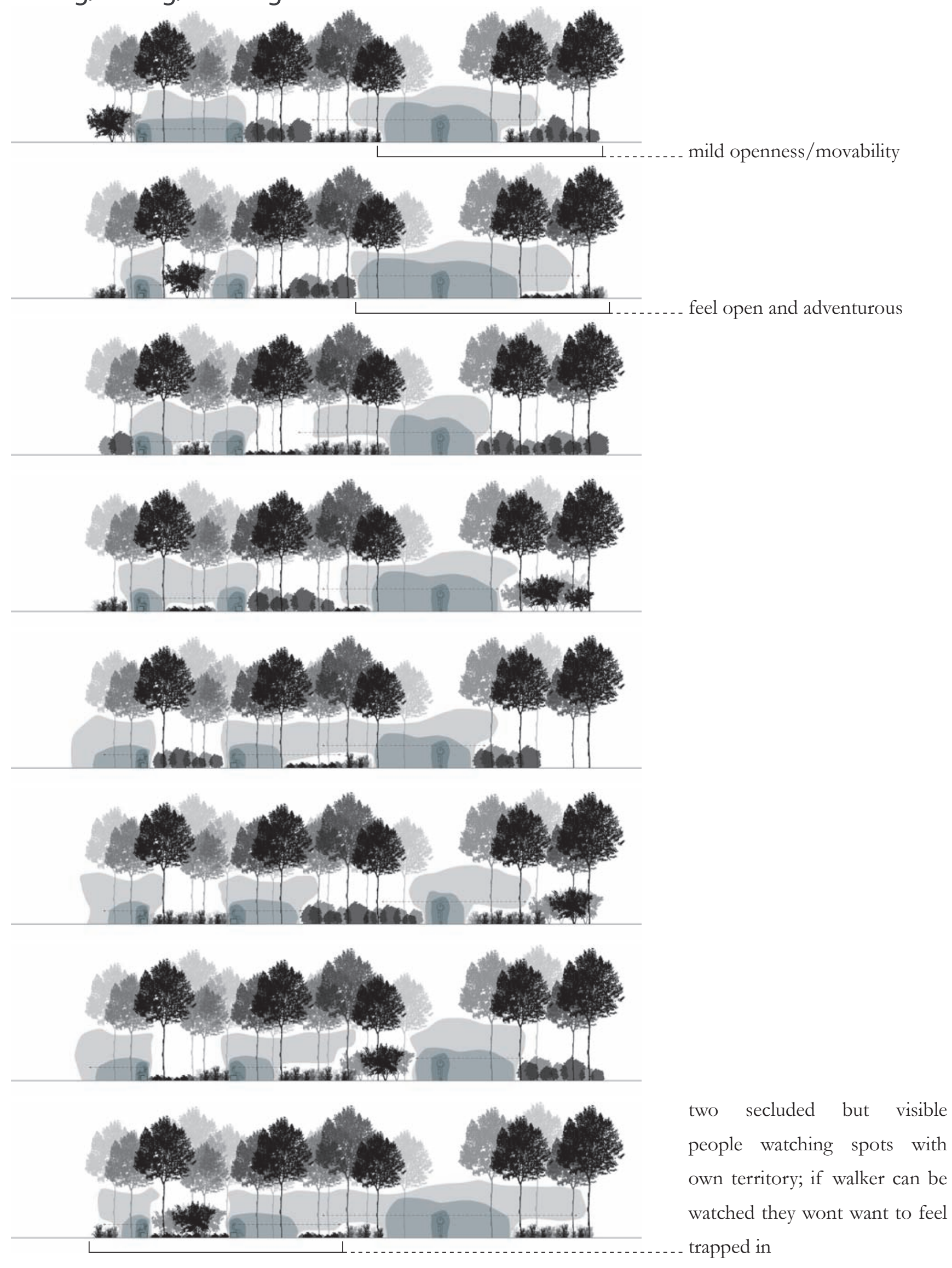

Fig. 6.2.5 Understory scenarios demonstrate the type of spaces that can be created within the vast forest area, they are analysed for sight lines and creation of zones 


\section{Understory Arrangement Tests: Scenario 4}
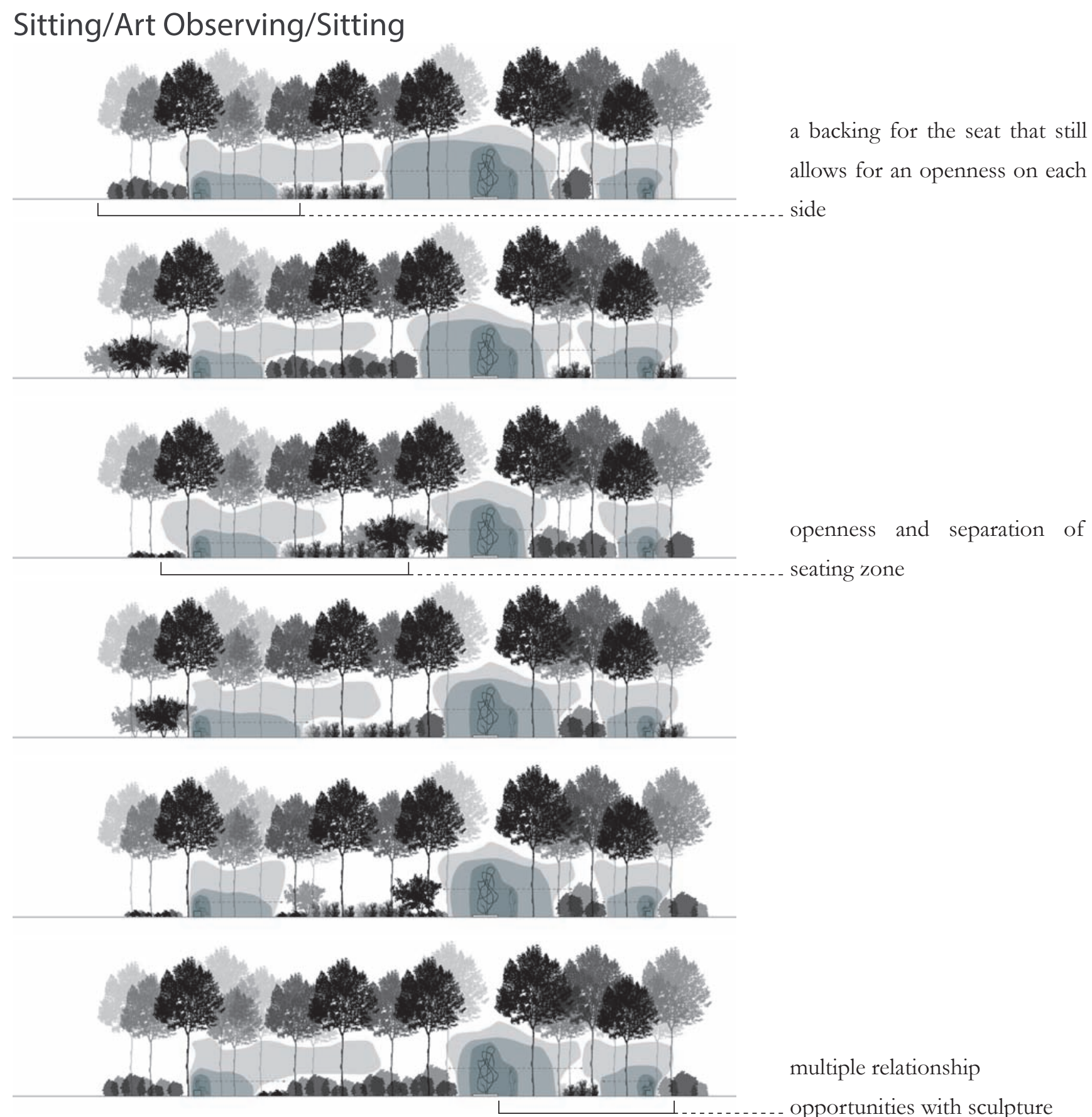

multiple relationship

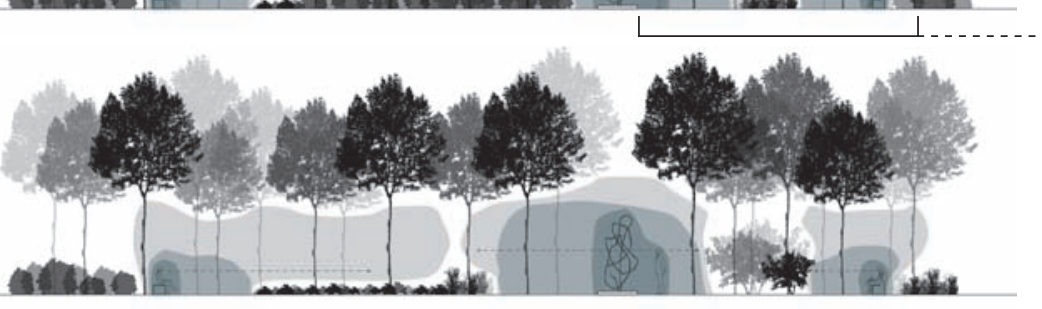

opportunities with sculpture

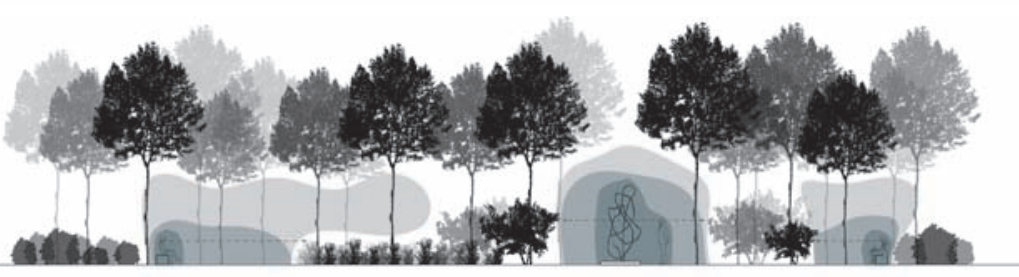

Fig. 6.2.6 Understory scenarios demonstrate the type of spaces that can be created within the vast forest area, they are analysed for sight lines and creation of zones 
Plants for Canopy Forest

F. 1.. 1. Y

$:$ :

$\therefore$

$\cdot .+$.

COASTAL FLAX

H: $0.5 \mathrm{~m}$

$W: 0.5 \mathrm{~m}$

- Evergreen

- Hardy

$8_{\text {expext }}$ 


\section{Canopy Tree: Putaputaweta}

\section{PUTAPUTAIAIETA}
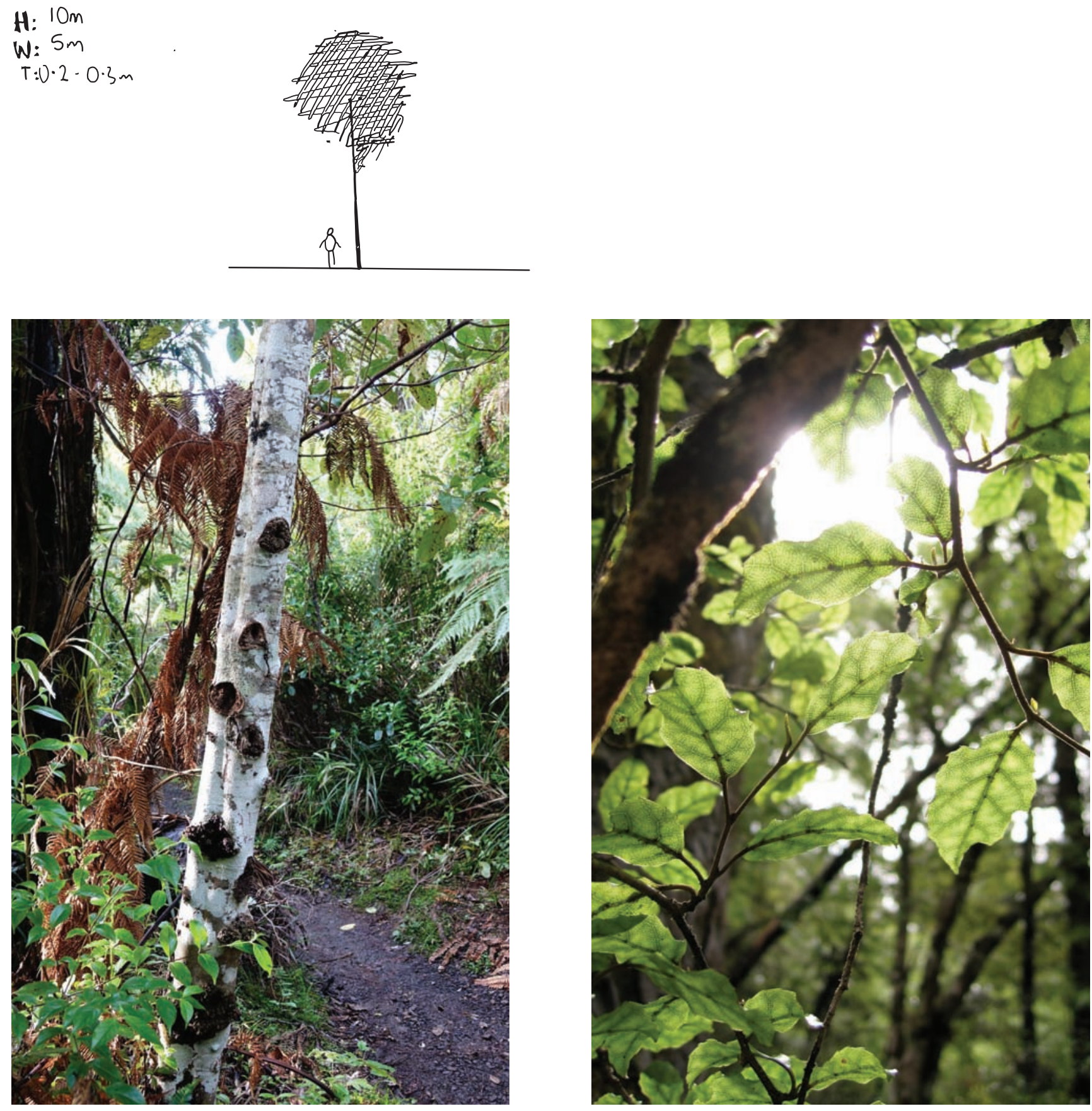

The putaputaweta was chosen as the most suitable for the canopy because of its slender trunk and height/ width of the canopy, it does not often have the chance to be the canopy tree in forests because larger trees outgrow it, however it has the potential to be a beautifully unique canopy tree in this waterfront setting. The tree's estimated full height of 10 metres ensures that it will remain an appropriate size for the urban context and will extend up past the art gallery. It will provide a unique microclimate that is limited to this public space creating a world of its own when people enter into it (T.E.R:R.A.I.N, n.d.). It has a slender and vertical trunk and fine variegated leaves that would provide a richly variegated play of light and shadow under its canopy. 
The design of the art gallery needs to reflect the landscape-focused nature of the research, and create/preserve connections with public space and the physical environment of the surrounding landscape.

2 knildings
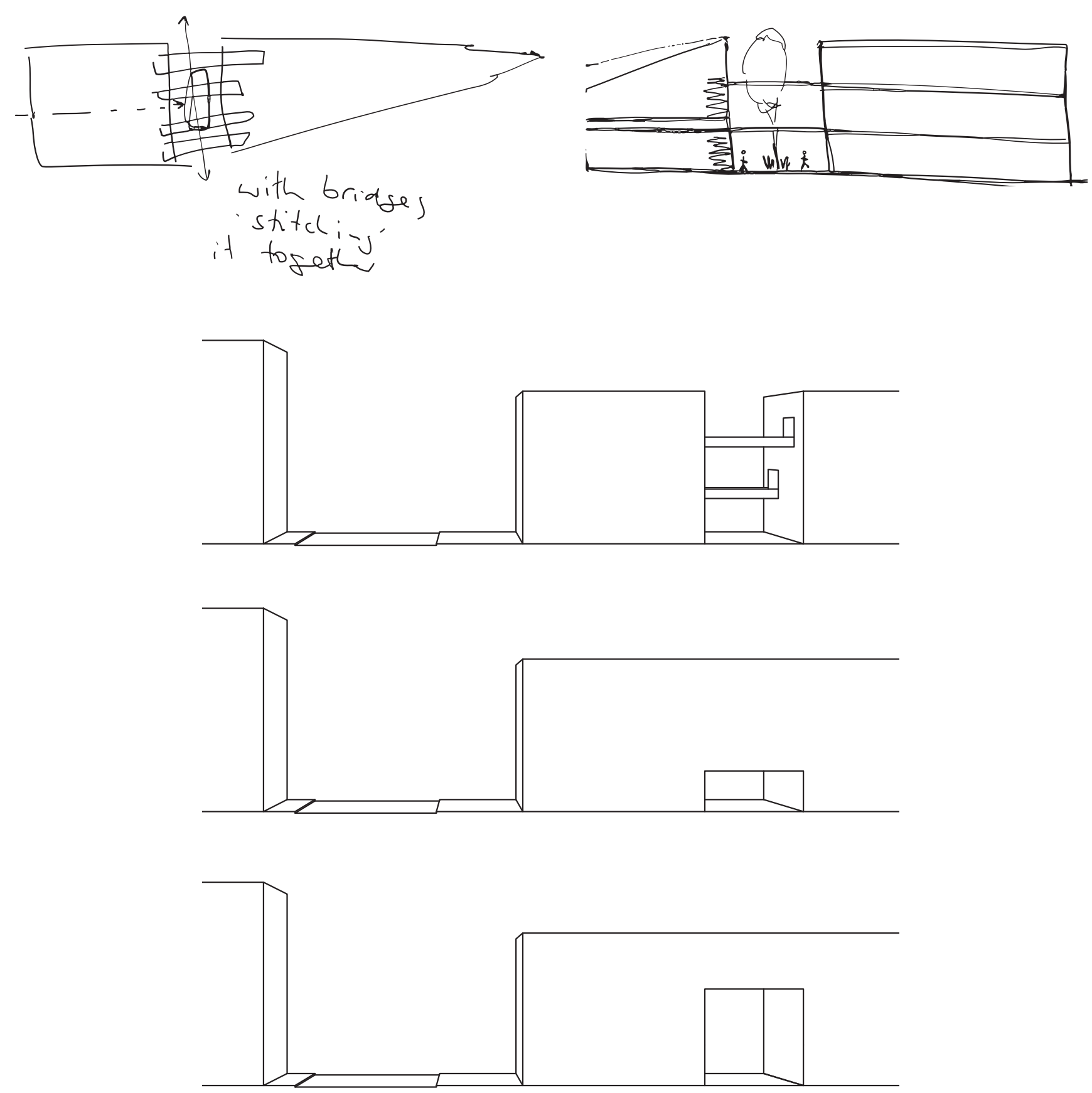

Fig. 6.3.1 Exploration of building form and internal arrangement of the art gallery, through sketches and digital means 

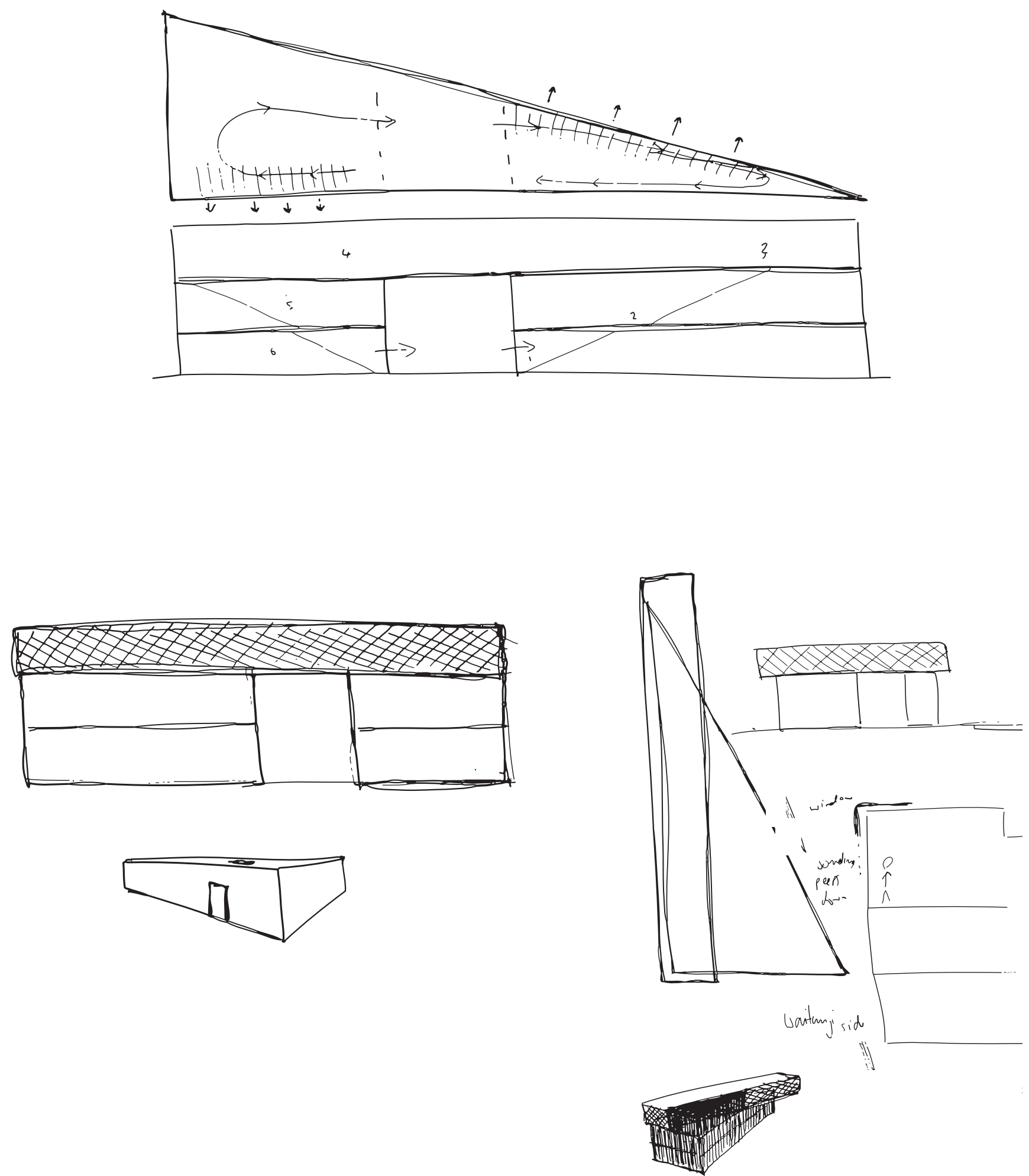


\section{Internal Layout}

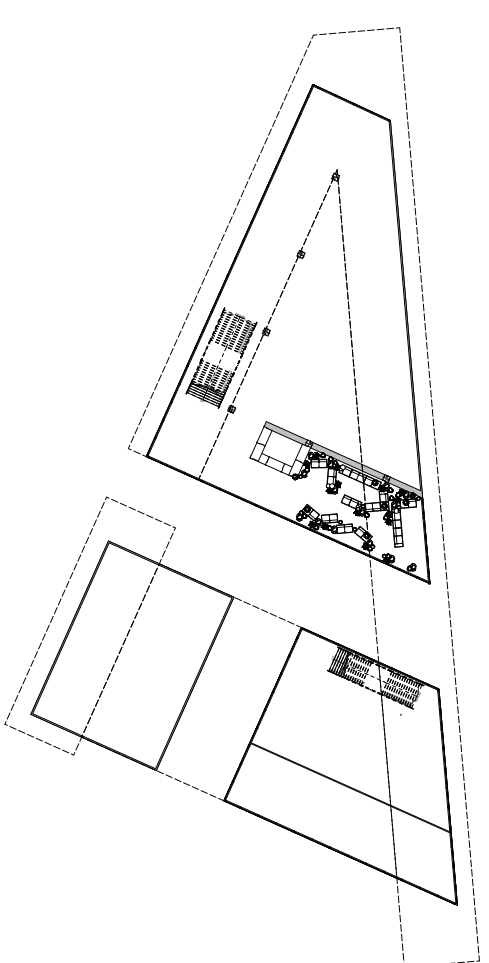

Ground Floor

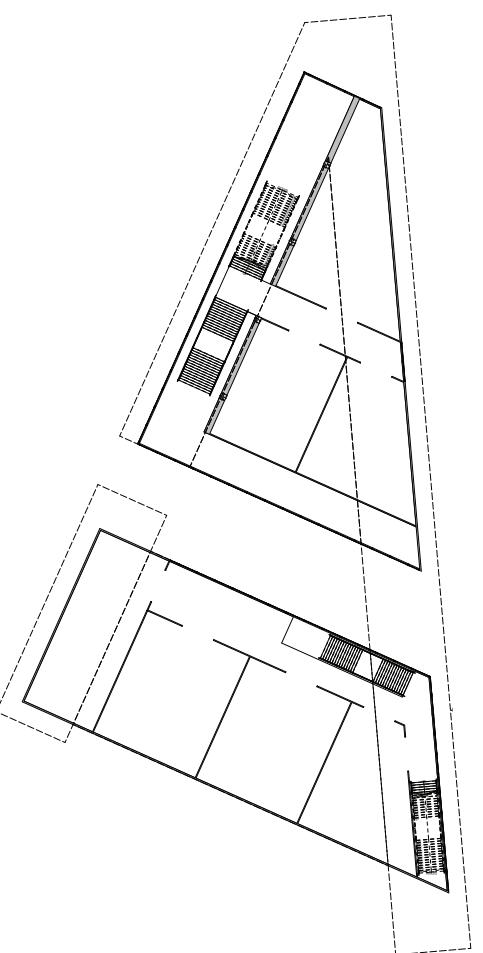

First Floor

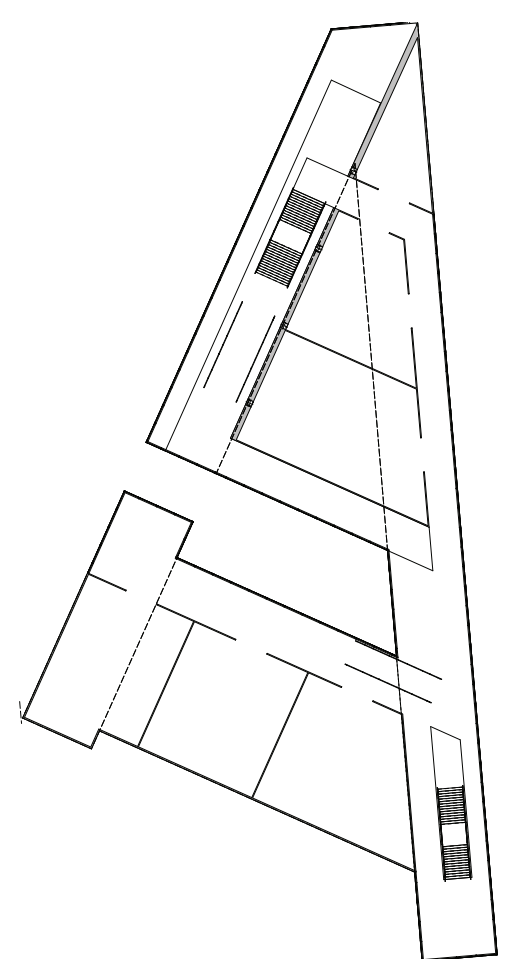

Second Floor
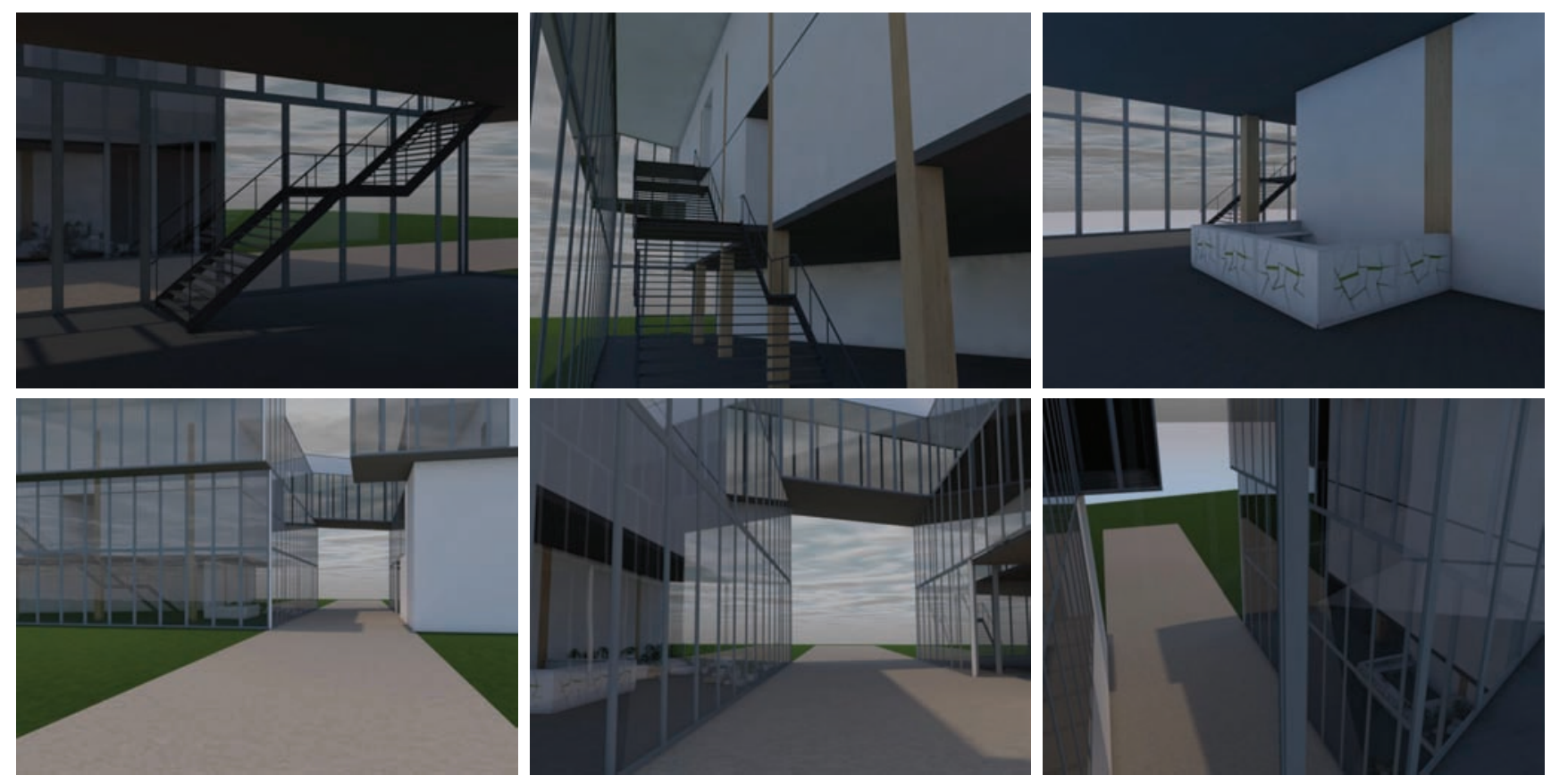

Fig. 6.3.2 Refined floor plan 1:1000 for the art gallery

Fig. 6.3.3 Renders taken from a digital model of the art gallery, which was used to configure the spaces within it and ensure sizes are correct 


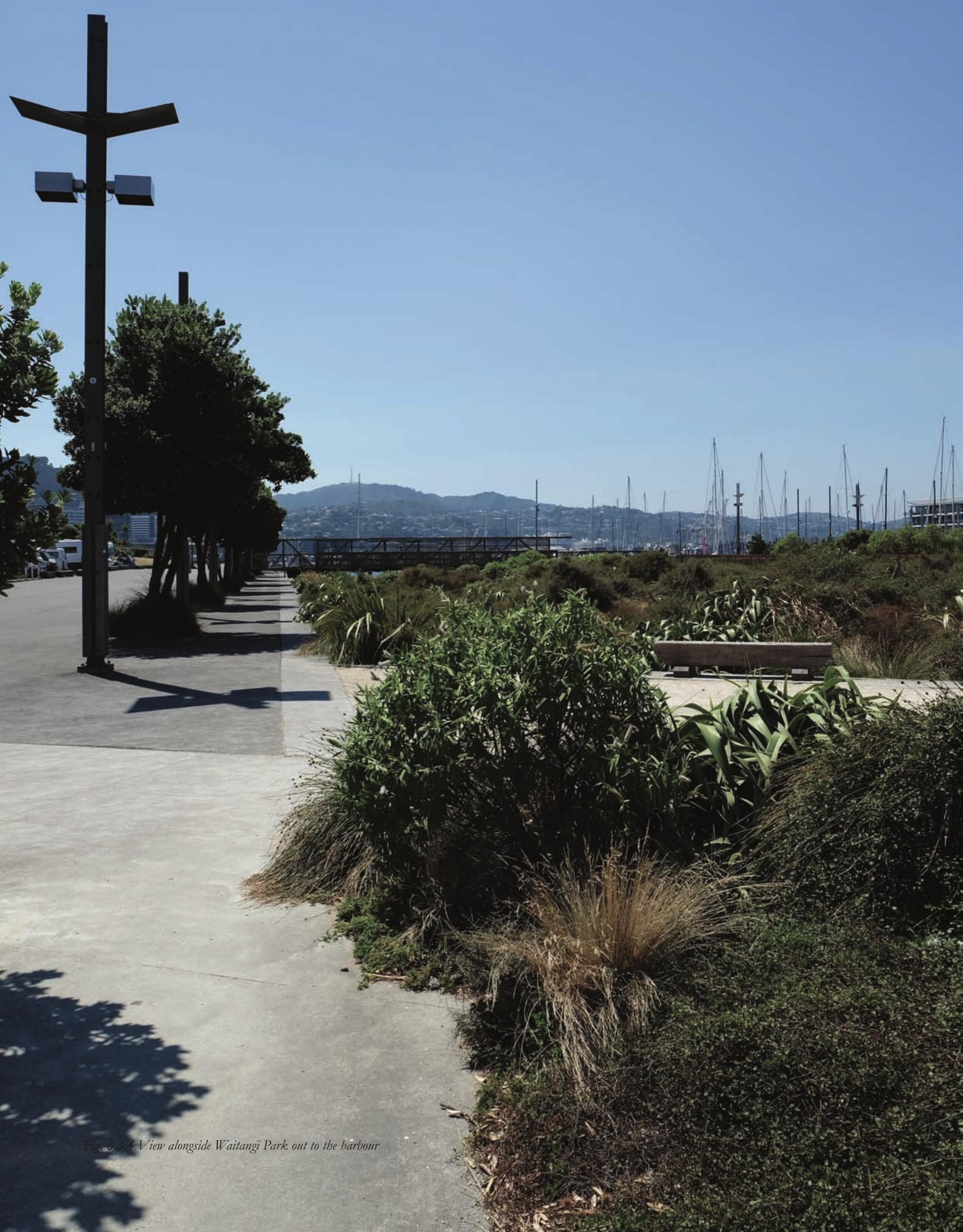




\section{SHOPS}

The aim when developing the shops is to create a design that engages with Te Papa's building edge, responds to the surrounding environment, and invites people to interact with Te Papa in ways that are not possible in the existing site.
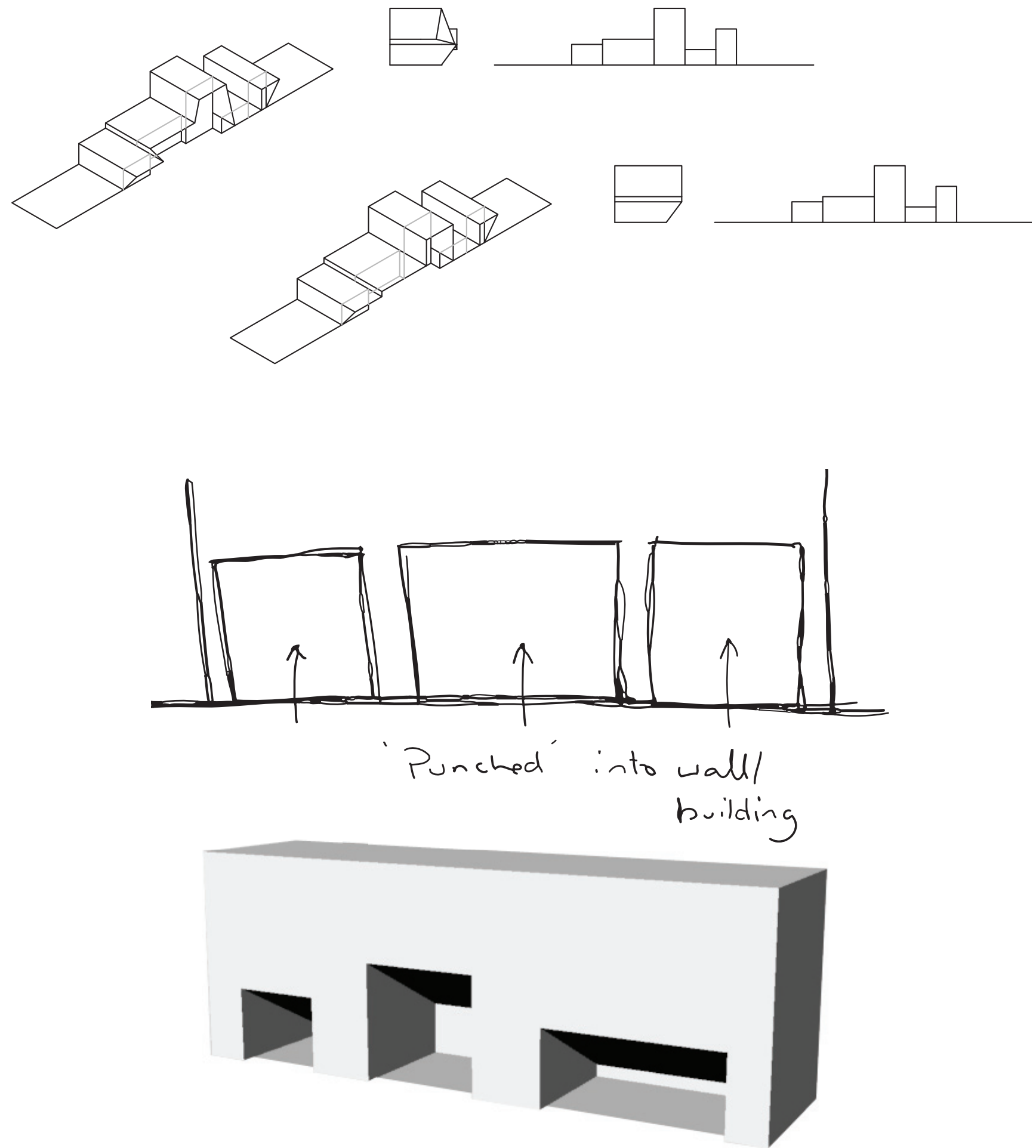

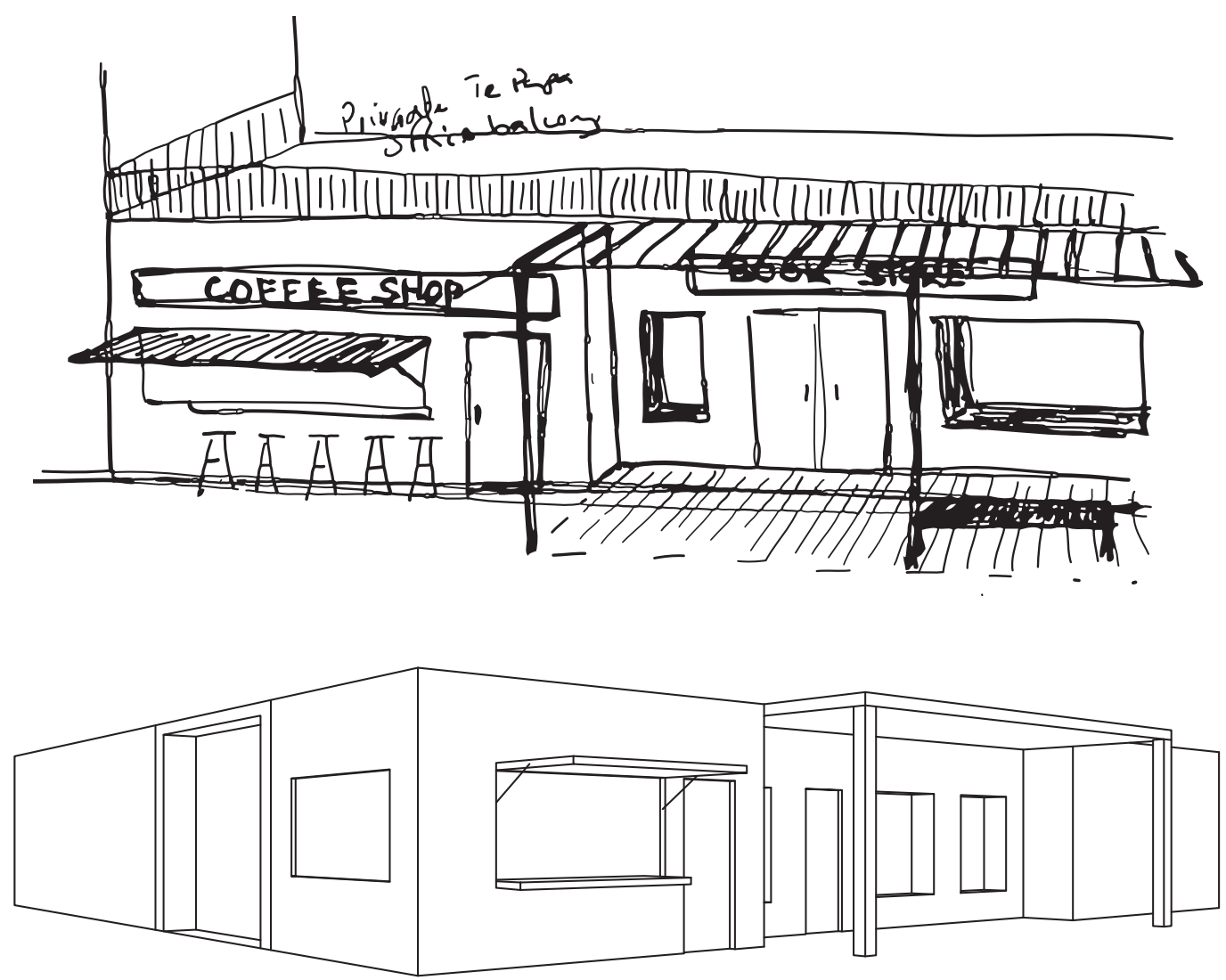
Design Type 1: Pop Up Influenced
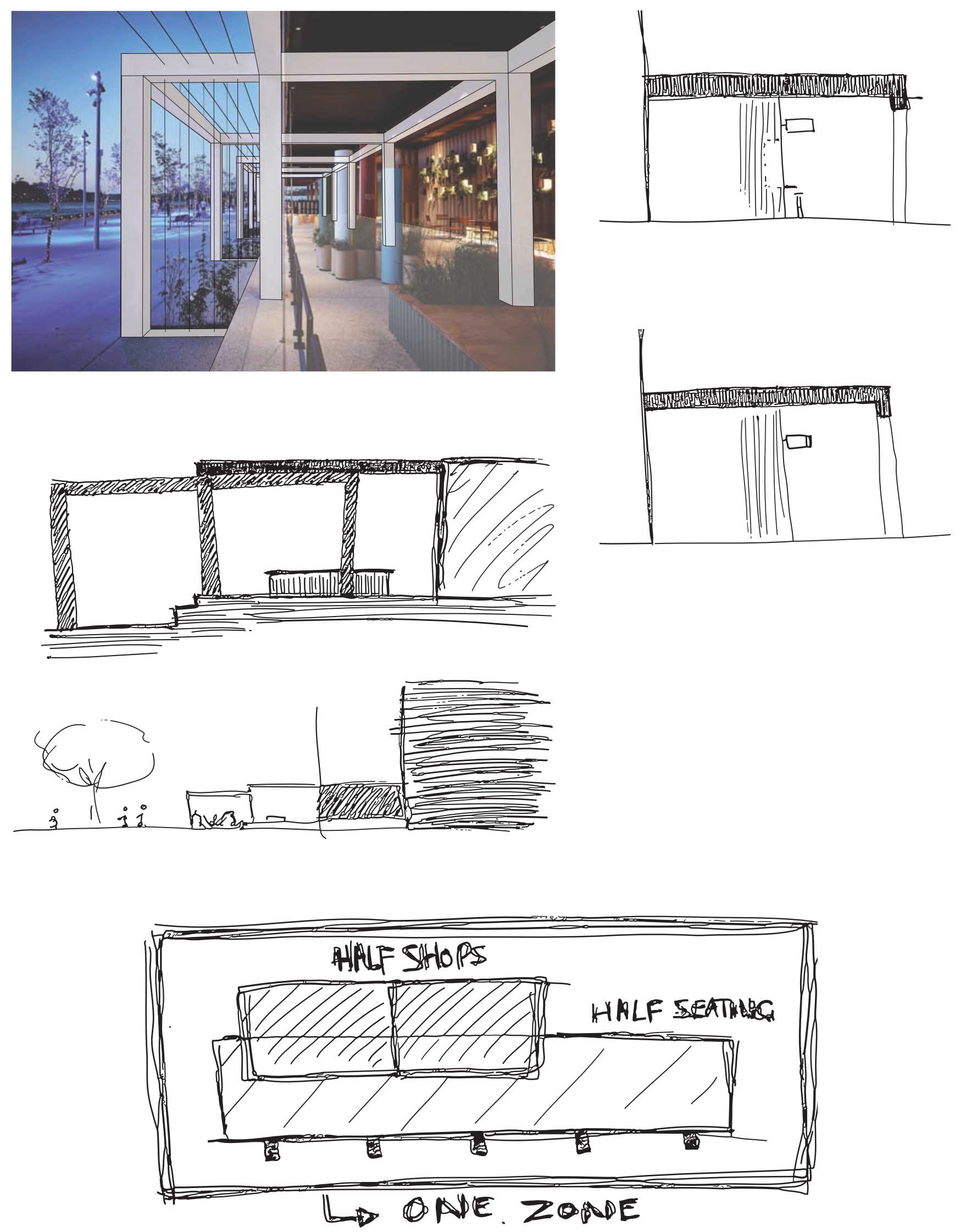

Fig. 6.4.2 Traced image of a popup public space that inspired one approach to the design of the shops

Fig. 6.4.3 Scan of sketches analysing the popup public space, and the final sketch documents what is taken from the study 


\section{Design Type 2: Integrated into Building Edge}

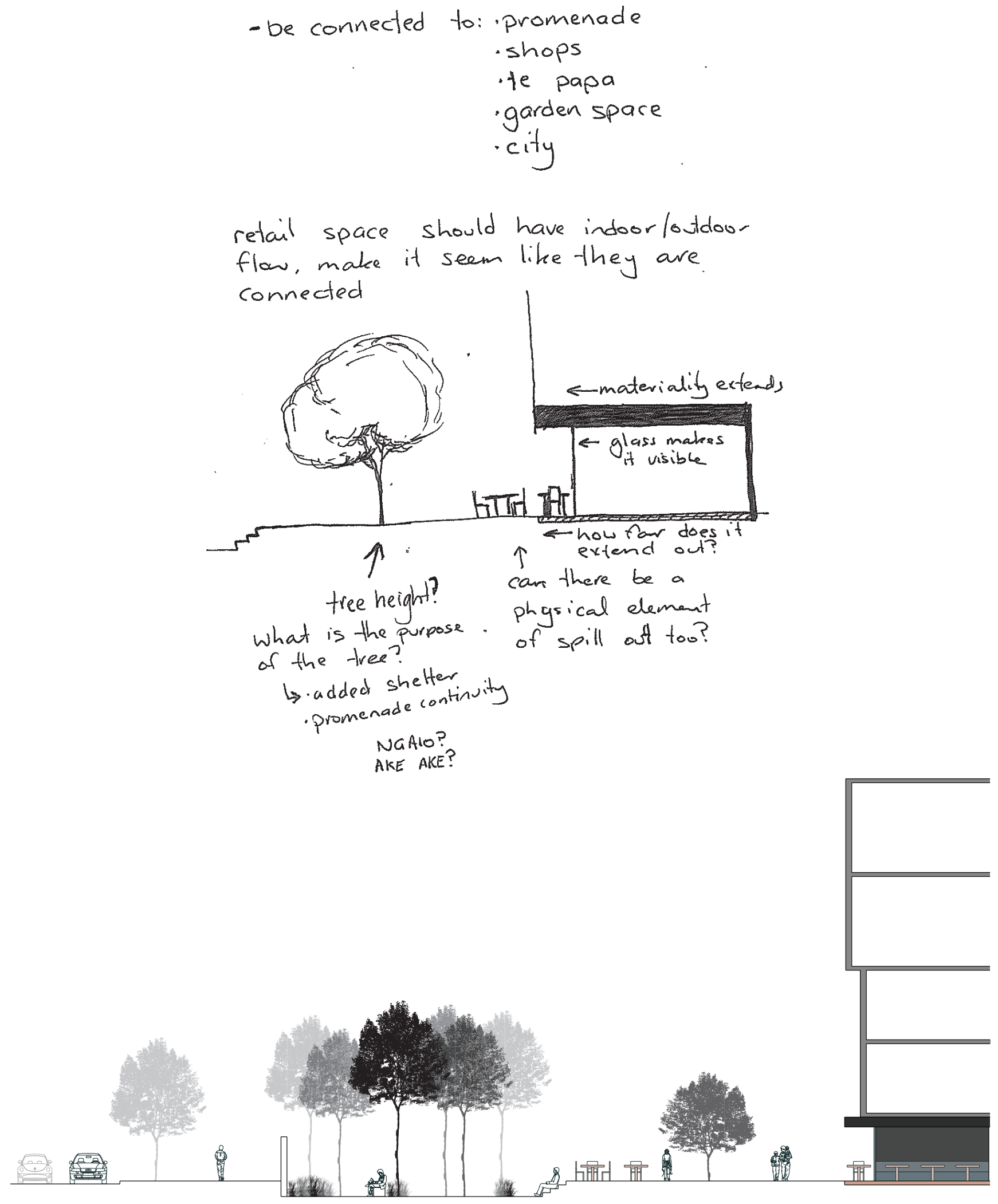

Fig. 6.4.4 Exploration of a second type of shop design, this one is built in the edge of the building and is meant to spill out into the rest of the public space 


\section{WIND SHELTER}

This stage of the research is about understanding how wind behaves around buildings and the few ways, relevant to this design, that the affect of it can be reduced. The previously tests $2-3 \mathrm{~m}$ high wall will be inadequate, instead a wall at least $5 \mathrm{~m}$ high should be considered (Wellington City Council, 2000).
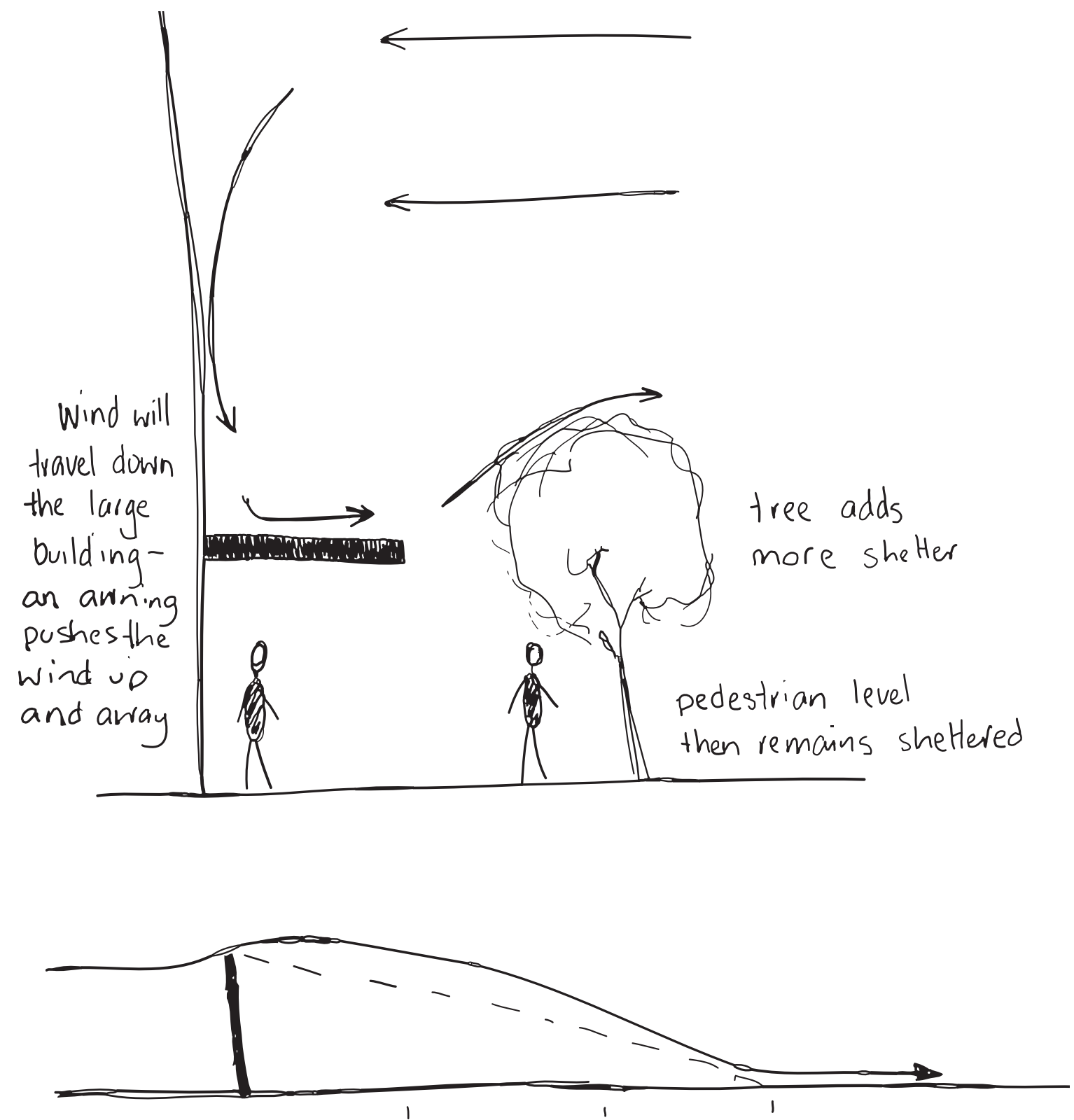

shetter is $3 \times$ the height of the wall

$$
\begin{aligned}
& 2.5 \mathrm{~m} \text { wall : } 7.5 \mathrm{~m} \text { sheller } \\
& 5 \mathrm{~m} \text { wall }=15 \mathrm{~m} \text { shelter }
\end{aligned}
$$




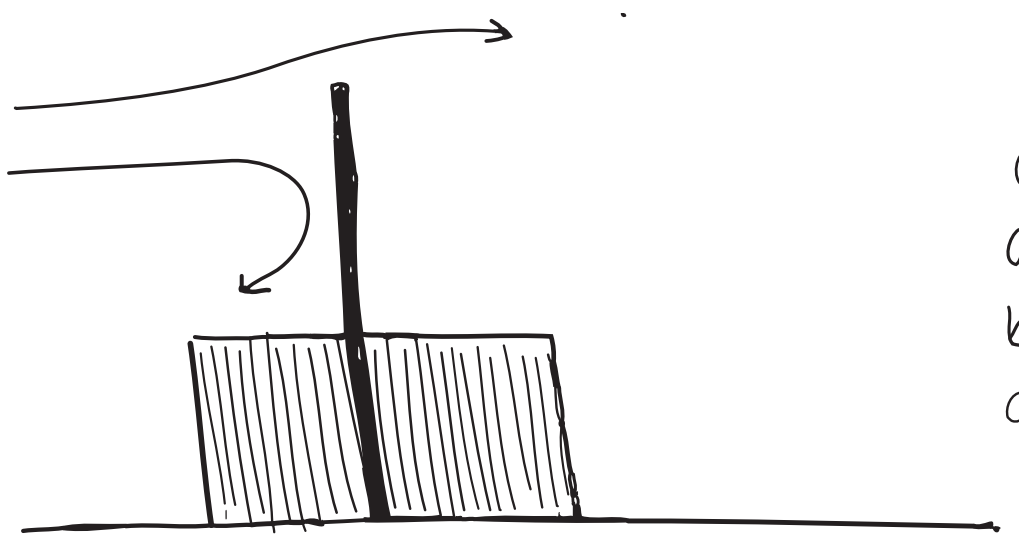

a wind wall with

a wind gate combines both the awning shelter and wall shelter.
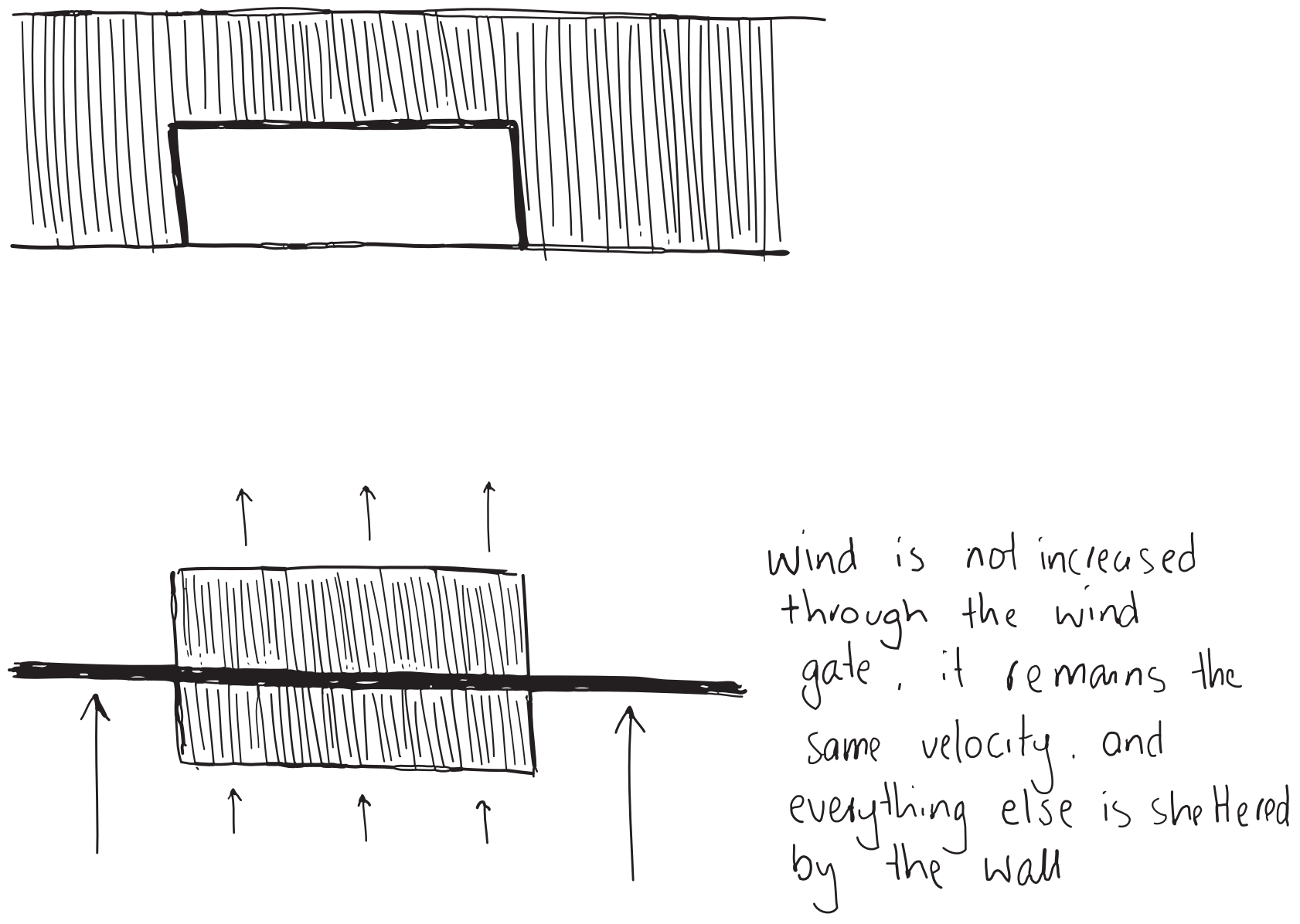

Fig. 6.5.1 Scan of sketches documenting how the affects of wind can be reduced by physical elements 


\section{SUNLIT BUSH ENCLAVE}
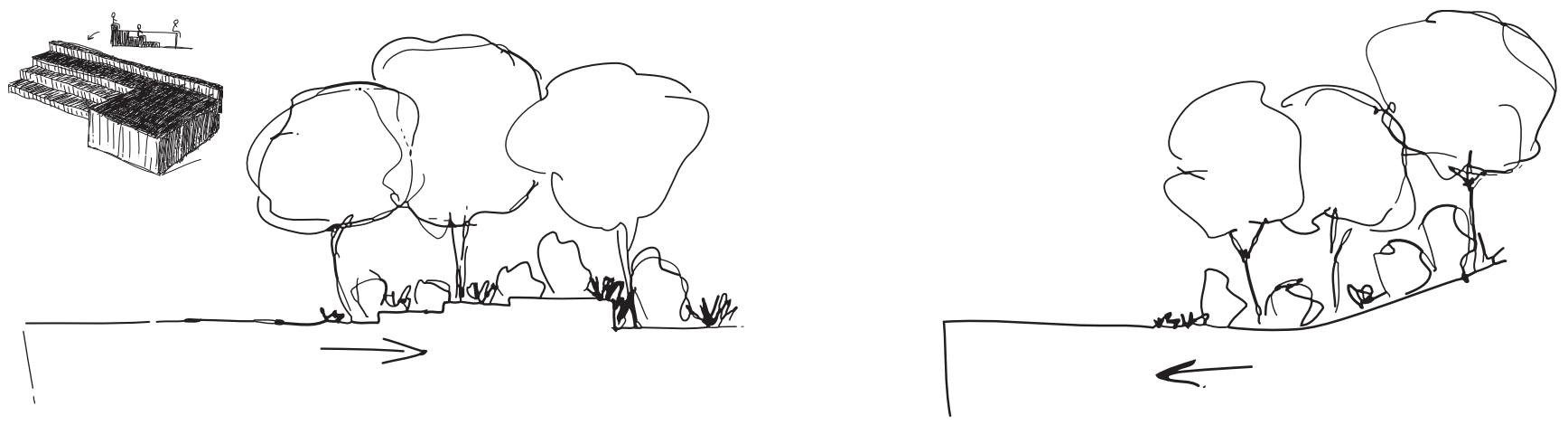

The design concept for Bush City works to break down the northern barrier in order to create a connection with the water and the existing public life of the promenade. It aims to pull people into Bush City and to pull the natural elements of Bush City into the concrete promenade. Creating two different paths through the new space into Te Papa increases the number of opportunities for interaction and engagement in this area.

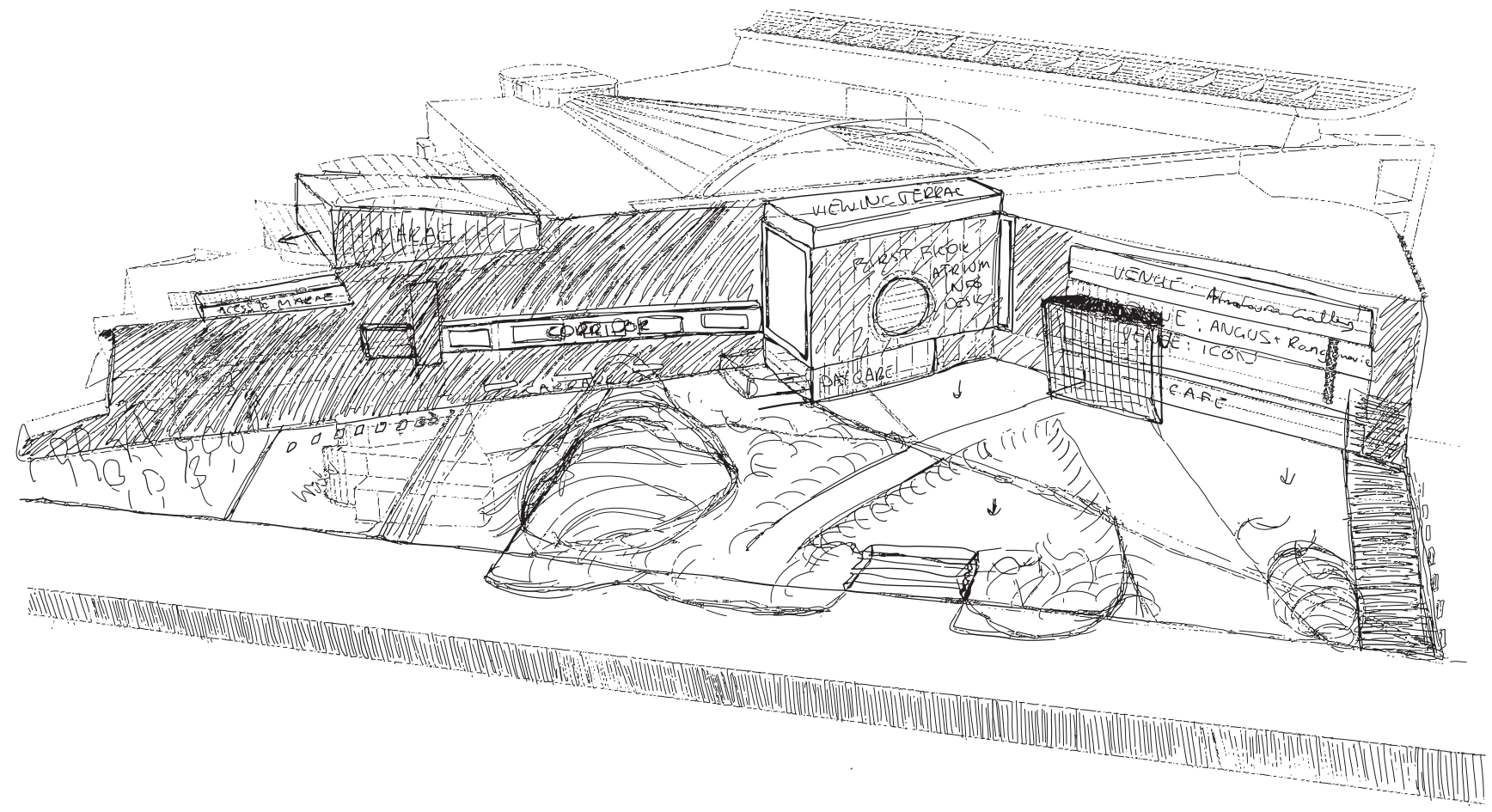

Fig. 6.6.1 Scan of sketches demonstrating what a push/pull concept for Bush City would look. like 


\section{bush city pallhs}

\section{2}
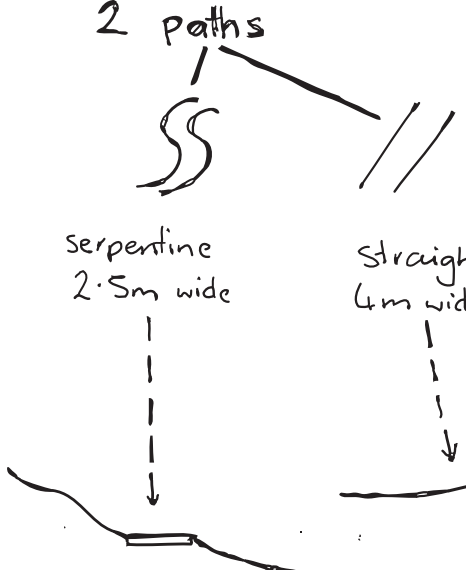

srimary vector:

-experience

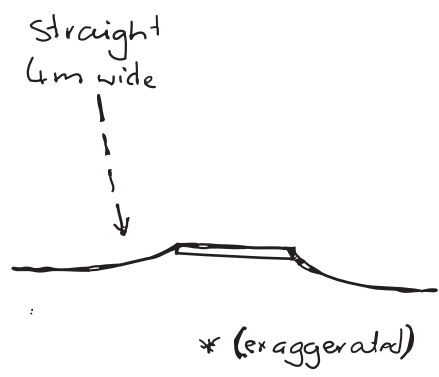

- to te papa

can you leave the path al any stage or is there planting that

whot angles work well?

how does the height of surounding land

affect the experience of the path?
Dush city ditches/hills

7 angles?

$\rightarrow$ planting?

- Whal activities should be allowed for?

- is these a museum attraction?

what can be seen?

- North orientated space = sunny

\section{SHELTER}

these ditches are all about finding

shetter on the waterfront, So views

come spcondary to shetter. but

connection must be maintained and enhanced.

the hills are all about sunny views, creating different plocest styles of seating to look at on several different elements of the water front

After testing this concept in the 3D digital model, it became apparent that the paths were not wide enough to match the scale of the context. People will move from the busy promenade into this space; therefore consideration for allowing for a large number of people to move along the main path into the site and its threshold is essential.

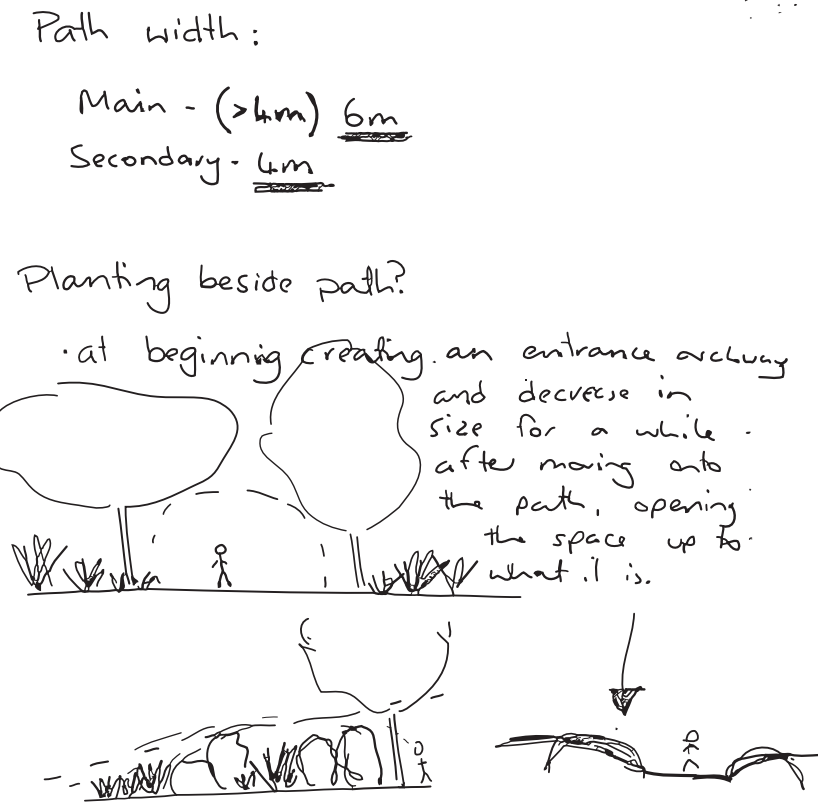

Fig. 6.6.2 Scan from notebook exploration of the concept 


\section{Paths and Slope Gradients}

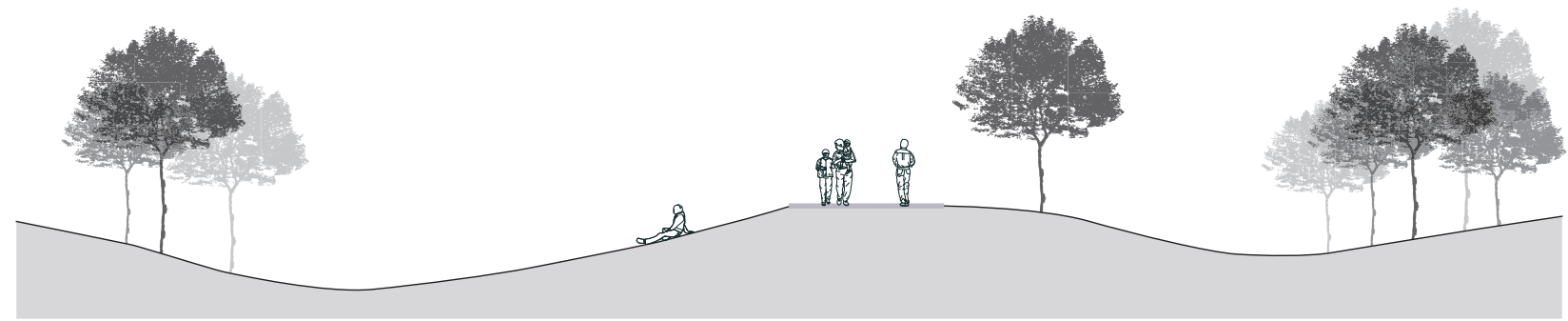

Path 1

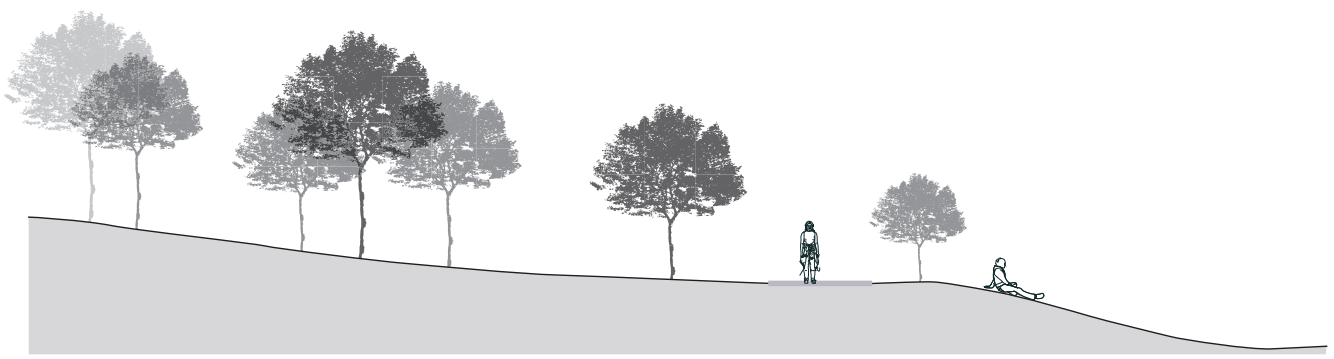

Path 2

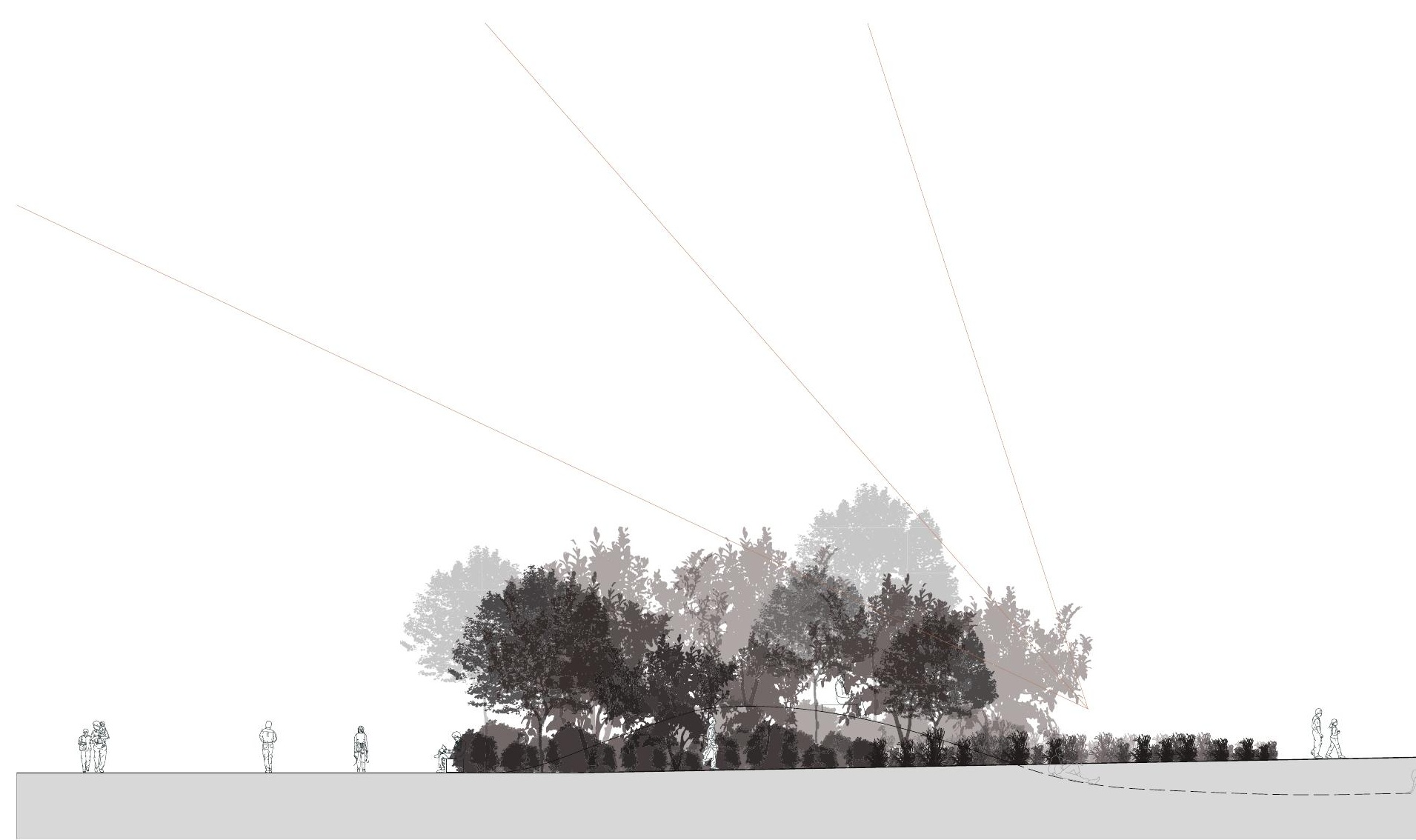

Path 1 (Length)

Fig. 6.6.3 Sections 1:250 explore the relationship between the paths through this space and the surrounding area 


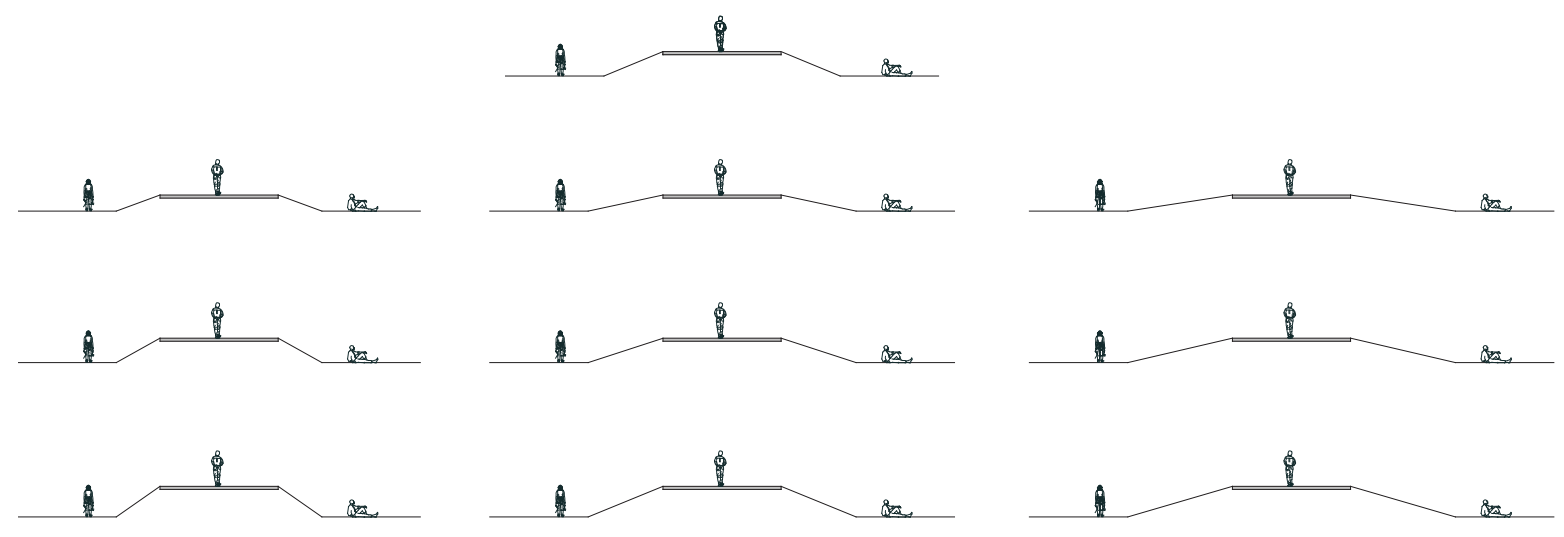

Fig. 6.6.4 Sections explore the size of the raised path in regards to the person walking on it and within the lowered spaces

This study explores the relationship between people in the different zones through a series of changes in slope gradient and width. The purpose of this experiment is to find a balance between differentiation of space, the people in it and the potential opportunity to move from one zone to the other. 


\section{PLAYFUL NEW ENTRANCE}

\section{2 waye op}
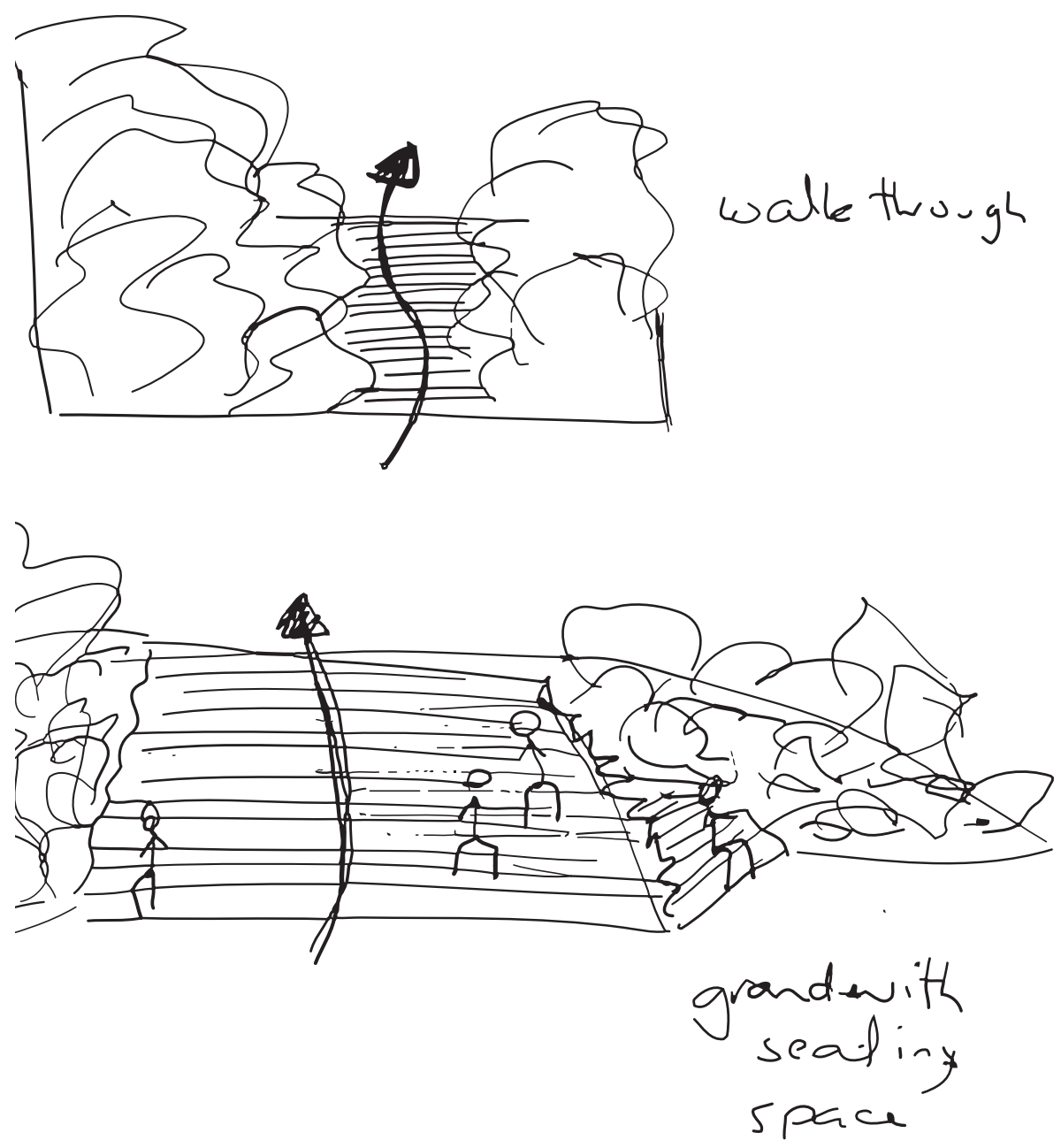

This eastern area of Te Papa can become a new entrance into the museum and provide a lookout over the harbour. With the addition of this new design, Te Papa will have three entrances; the existing entrance is formal and structured with the large open plaza in front, the bush enclave entrance is secondary to the public space created in front of it and creates informal engagement due to the various interaction possibilities. This additional third entrance will provide a different experience by bringing elements of play into the design of this entrance including the threshold into the building. 


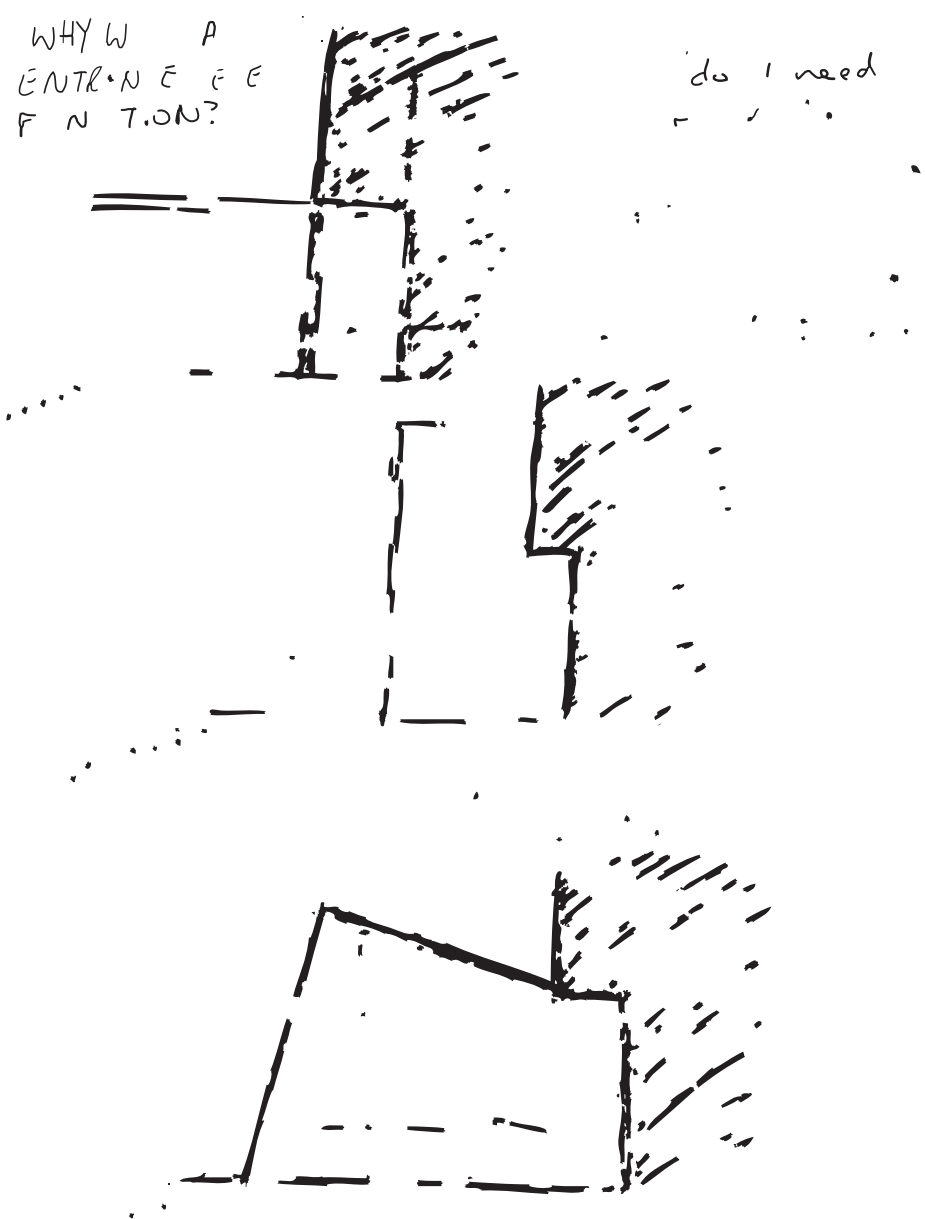


Platform Occupation
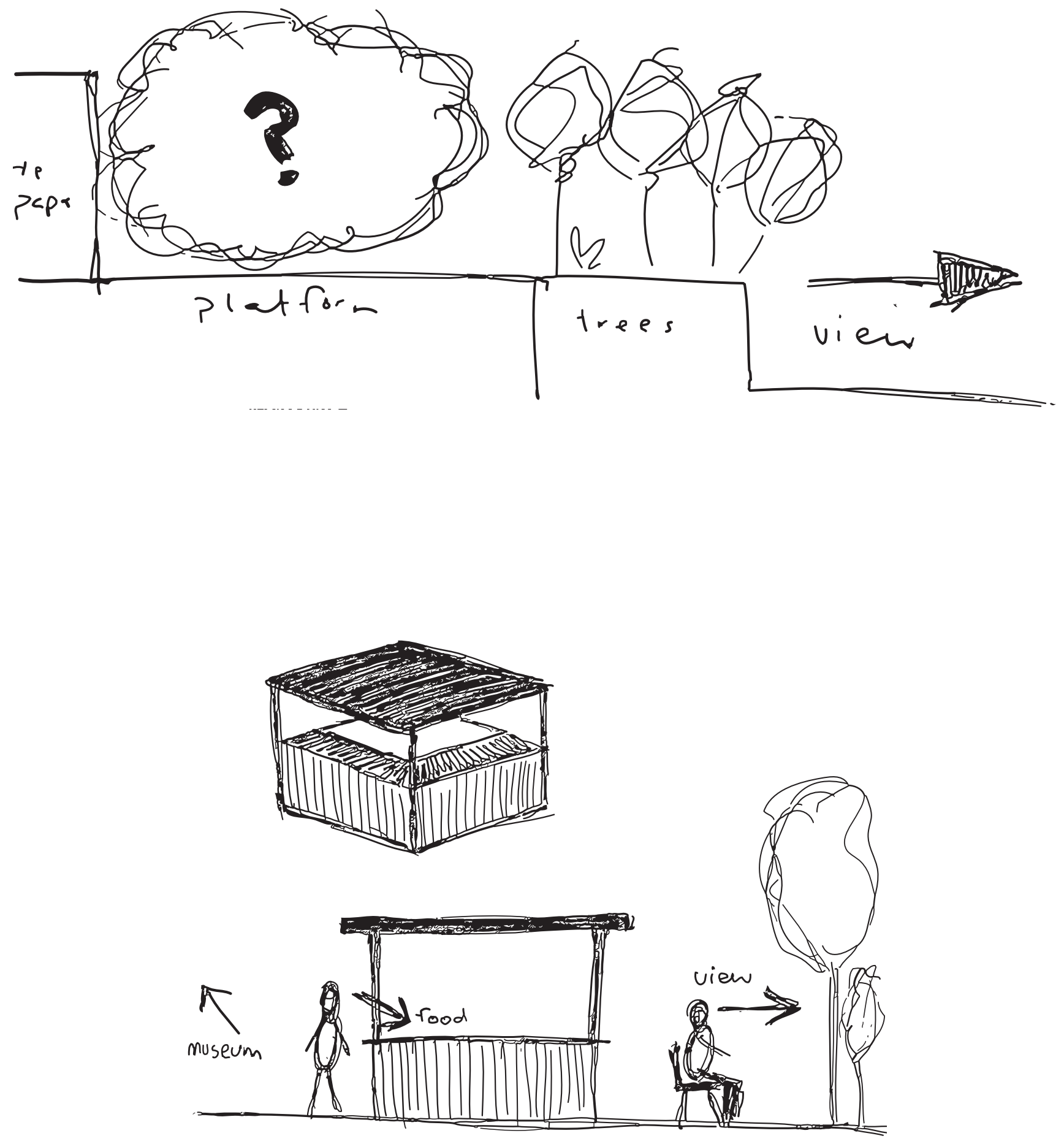

$$
\begin{aligned}
& \text { Pop up FOOD STALLS SIMILAK } \\
& 70 \text { moore wissons? } \\
& \text { Seatiog available behing } \\
& \text { tho-gh to see the view }
\end{aligned}
$$




\section{Playful Design}

Playfulness often relates to children, so this concept located at the new entrance, provides a slide and climbable lookout platforms that invites children to have a unique engagement created especially for them and their families. A meandering path through the planting behind this zone also brings in elements of play through the opening and hiding of the view that creates the experience of exploration as they move along this path.

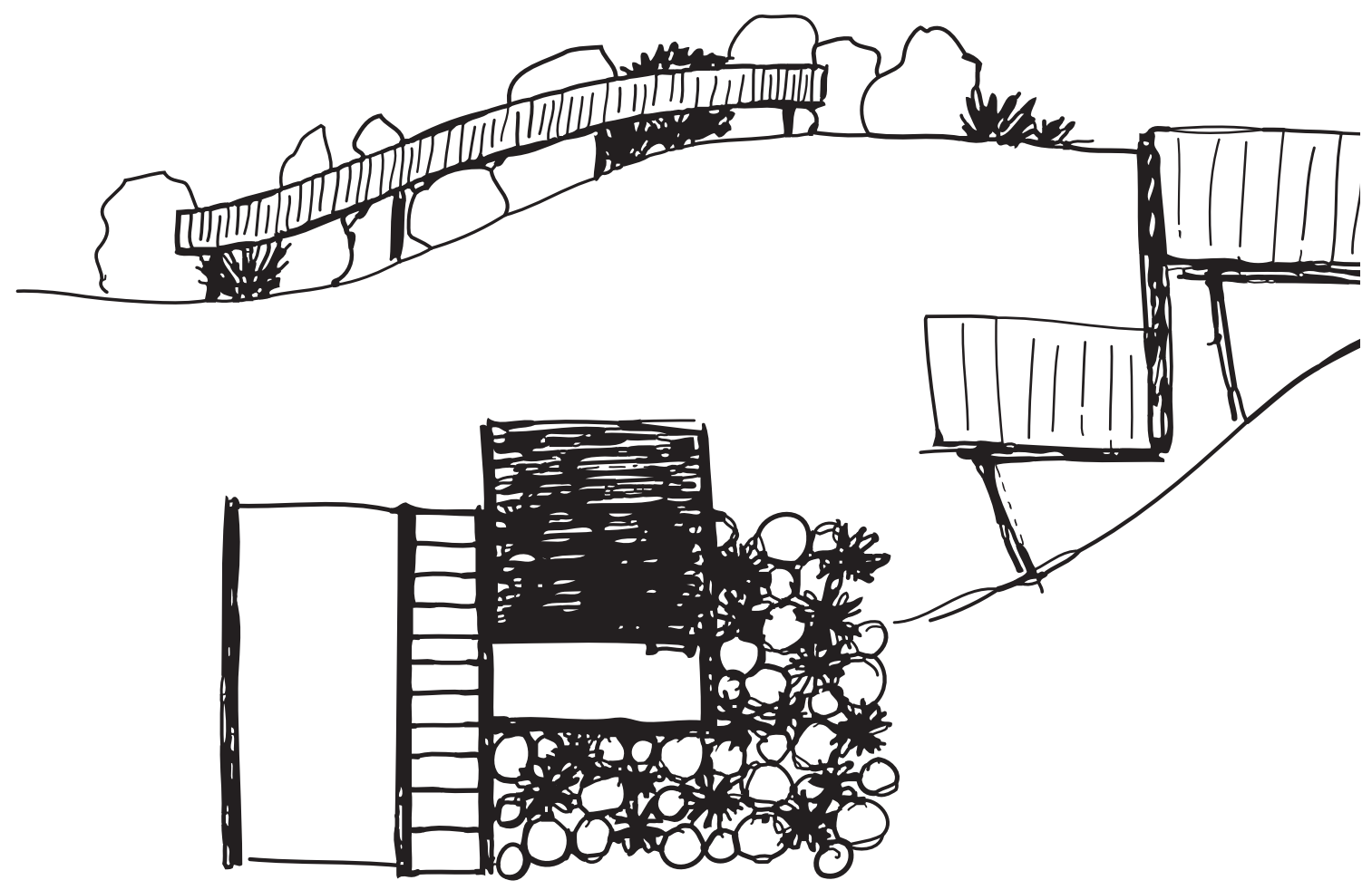

create a zonelterritory al either end of slide to keep it all part of kireds space $\longrightarrow$ Hou do you do that?

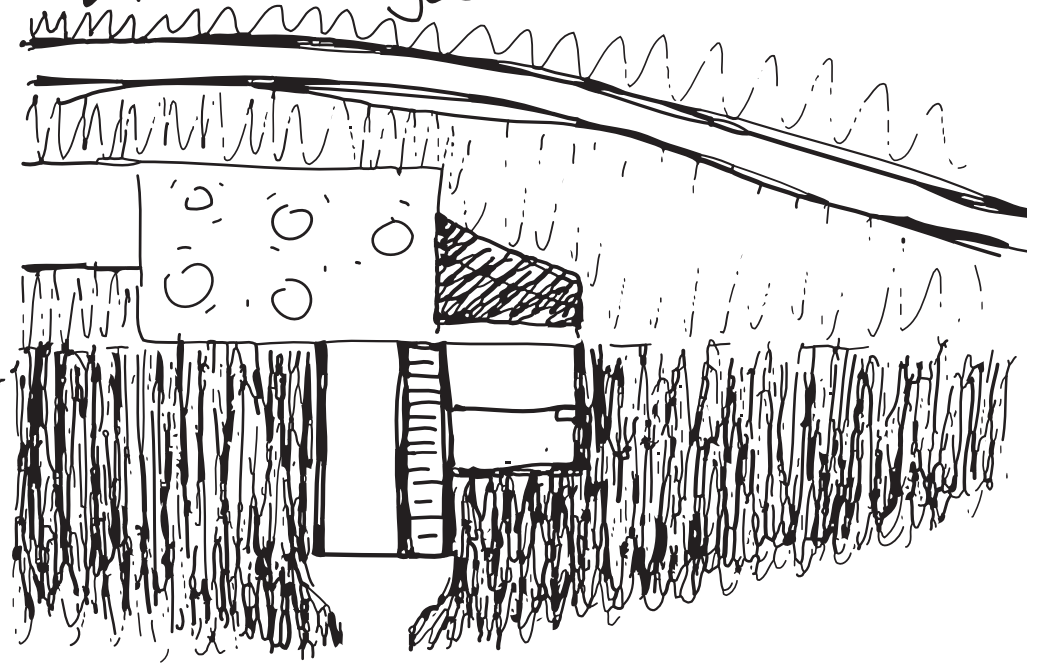

Fig. 6.7.3 Scan of sketches exploring the possibilities for playful aspect of the new entrance 


\section{WHARF EDGE/PROMENADE}

The following sections are taken from similar intervals around the waterfront promenade in order to view and compare the variety of edges in the new design. The sections show where the occupiable space extends out from the wharf and moves down towards the water, which will become one of the few places in Wellington where this is possible.
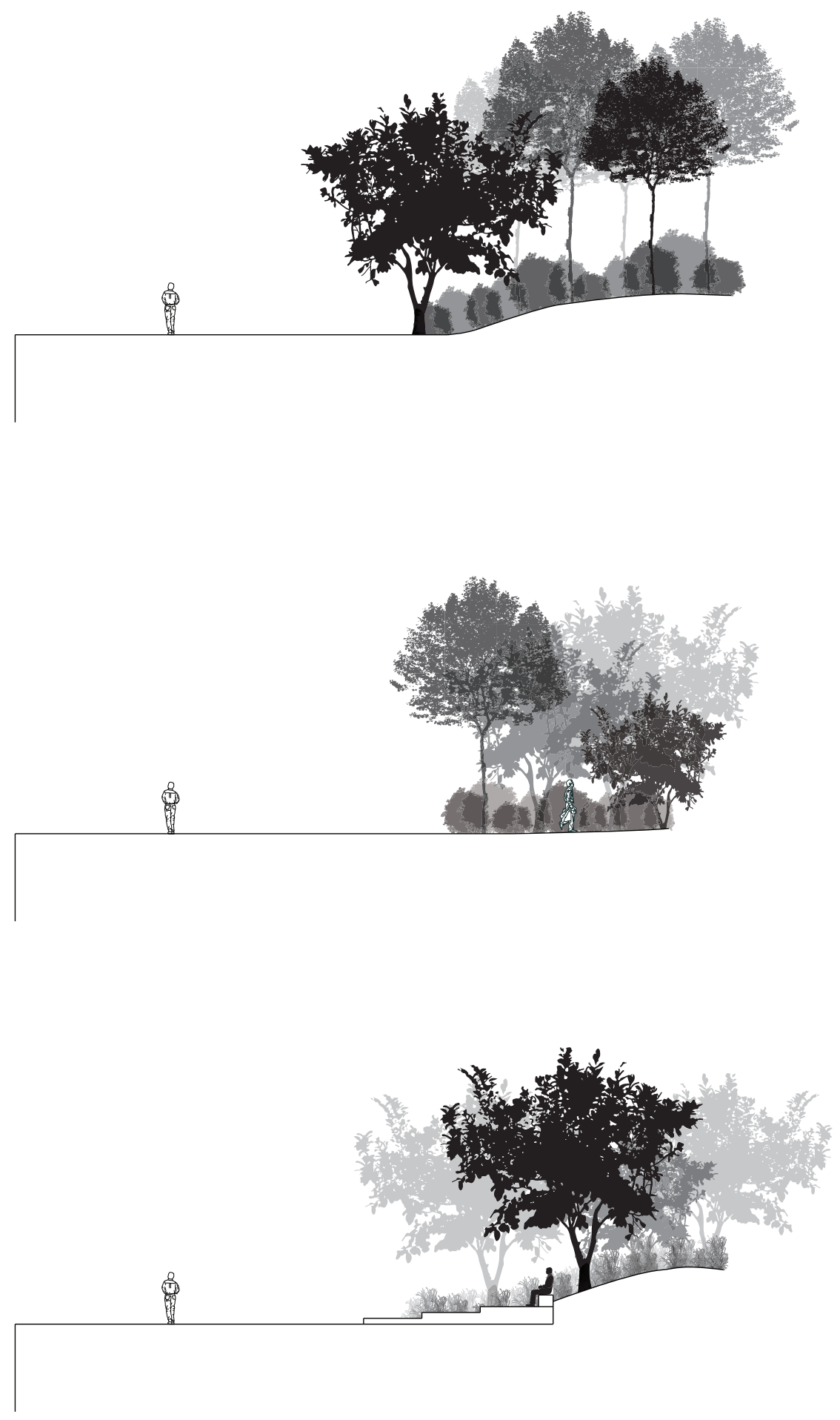

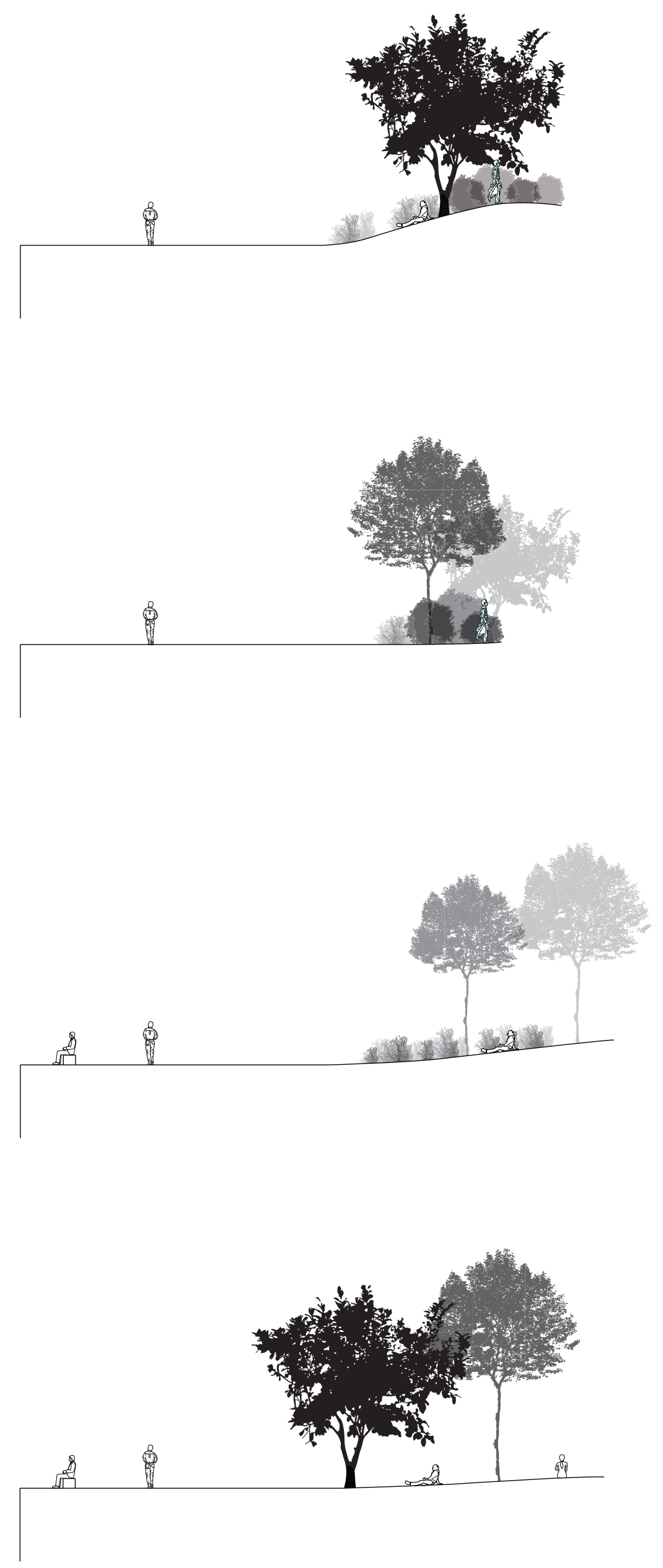


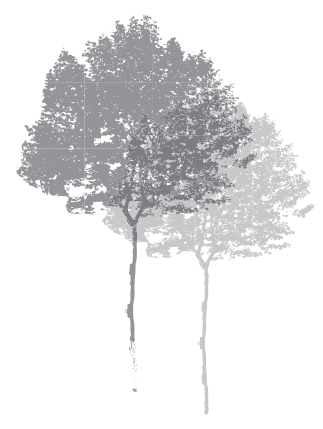



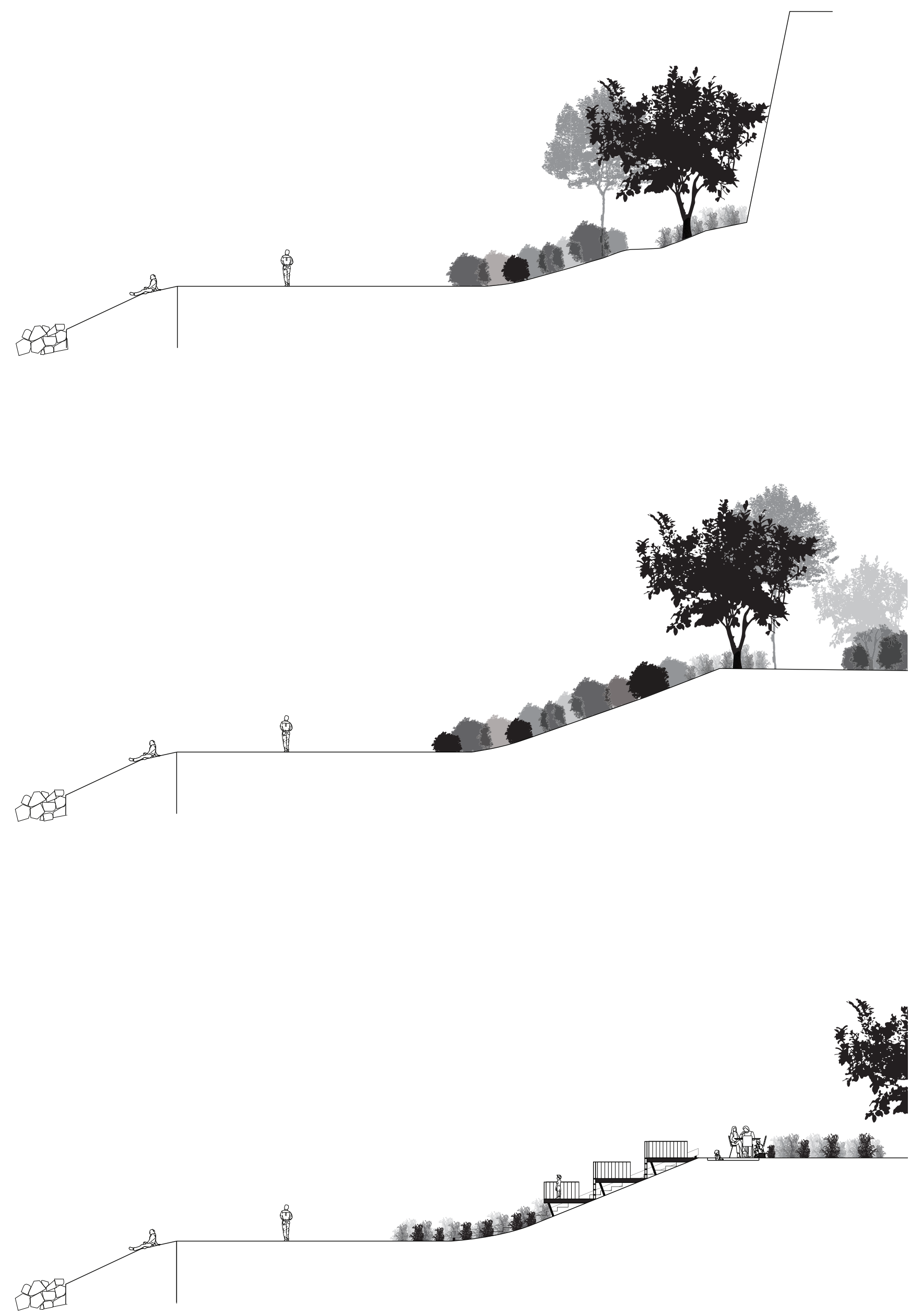

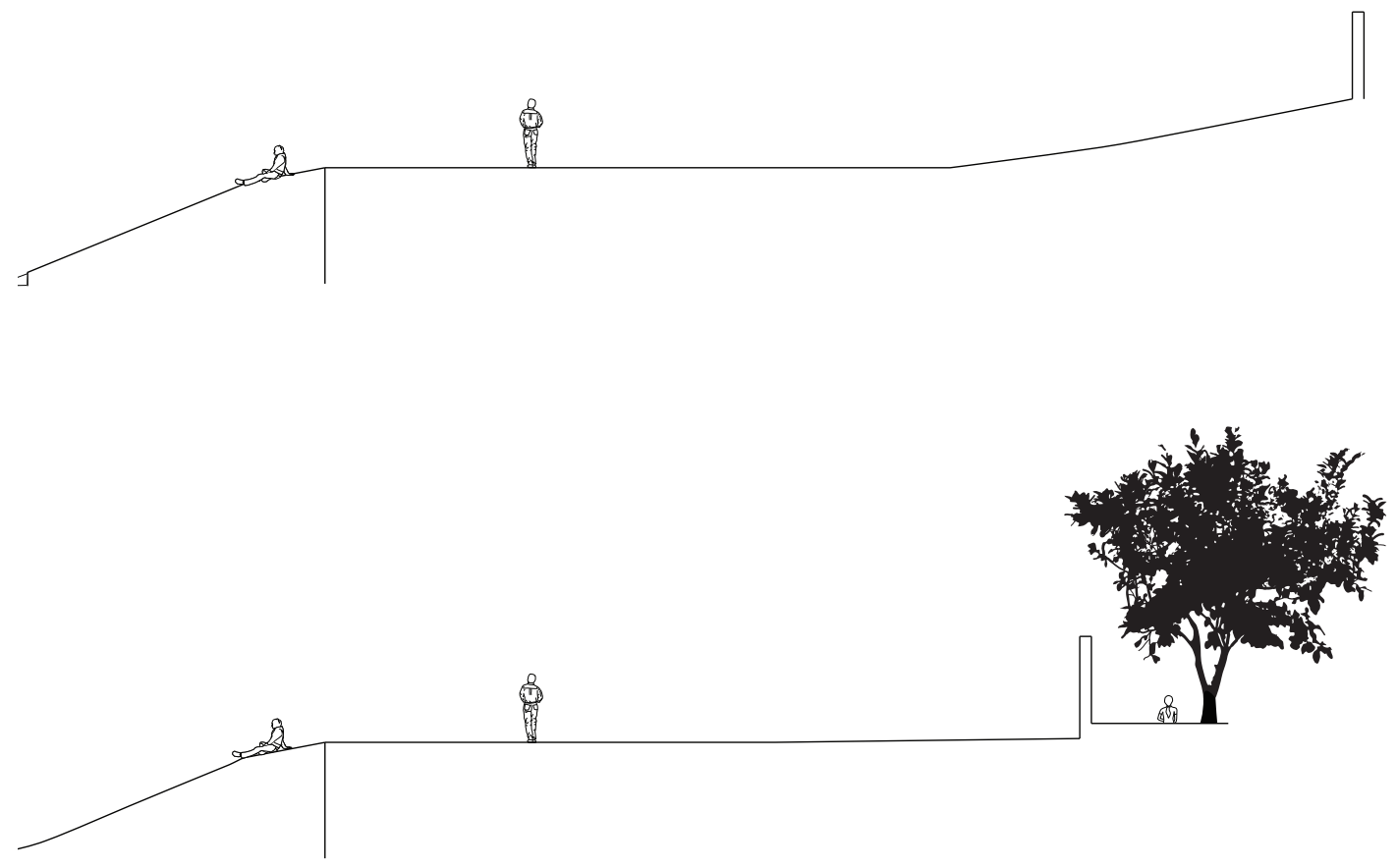

Fig. 6.8.1 Sections 1:250 documenting the experience of walking along the promenade in the new design 


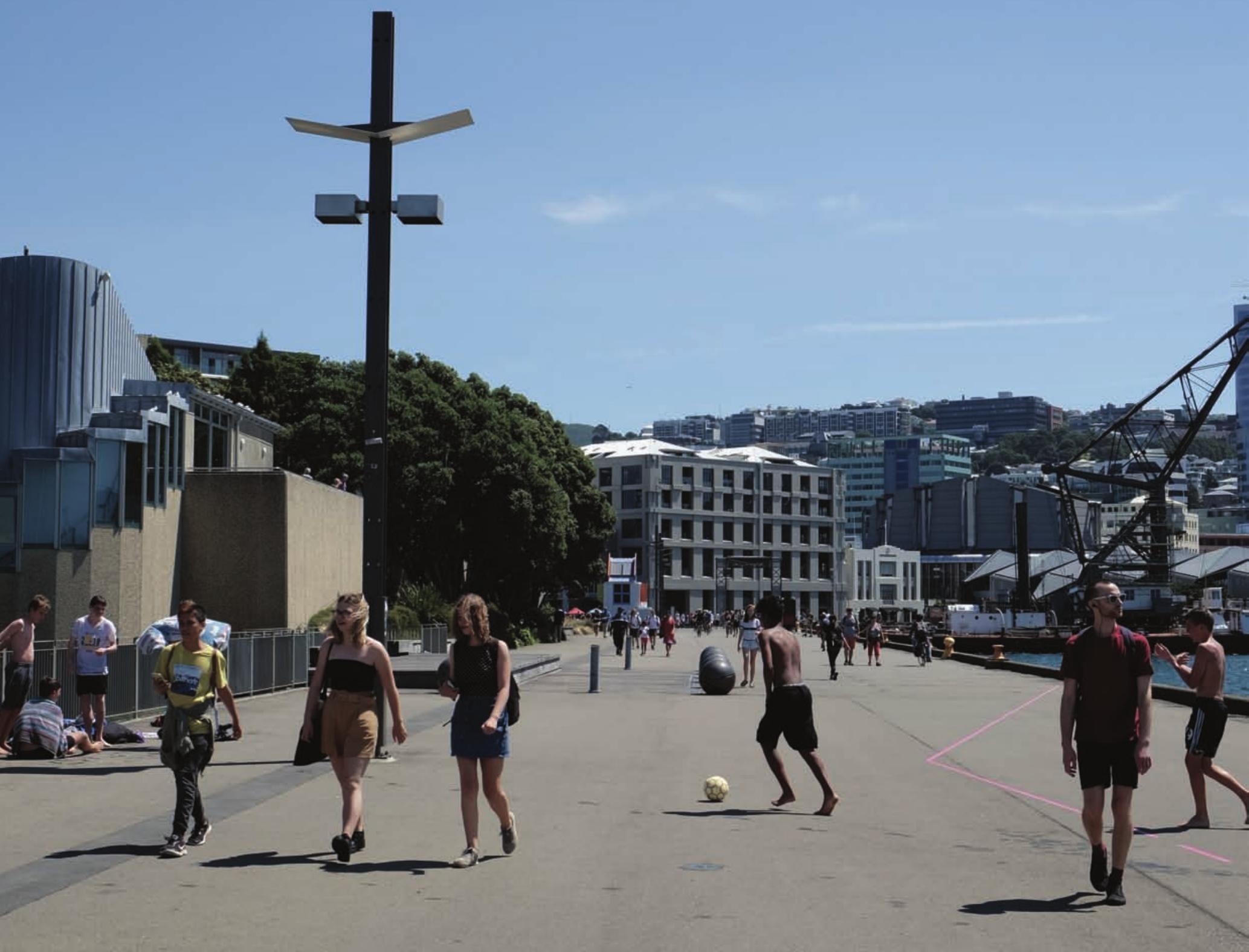




\section{SEATING TESTS}

A quick iterative study explores possible seating options, and how people would use them.
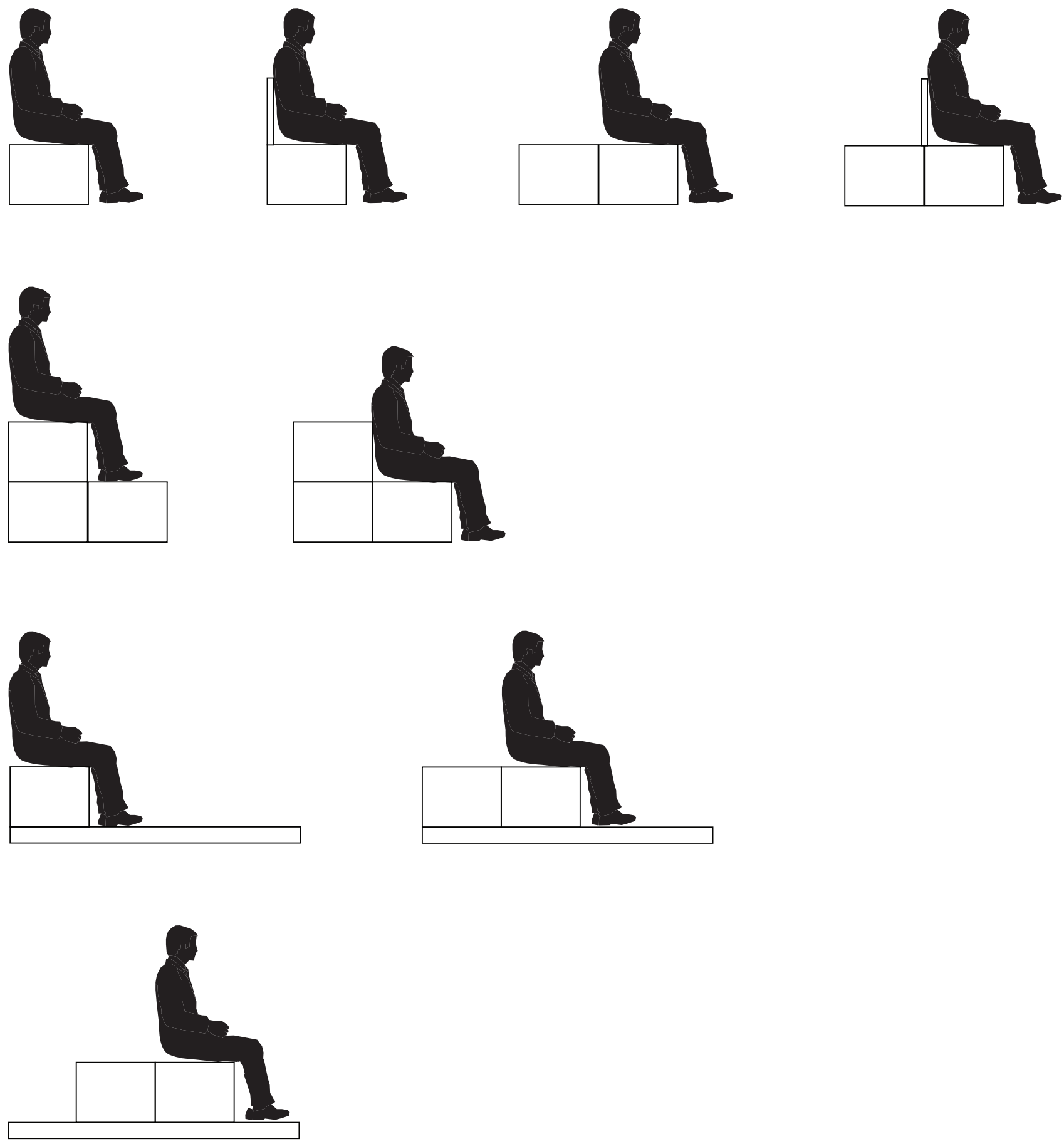

Fig. 6.9.1 Sections exploring how different types of seating might be interacted with 


\section{STAIRTESTS}

This experiment aims to understand which riser/tread sizes work best for both sitting and walking. A taller riser is desired for sitting against, but the optimum riser size for walking is no higher than $190 \mathrm{~mm}$. These diagrams test different heights based on a person sitting against it and their interaction with someone walking by, and someone walking up them.
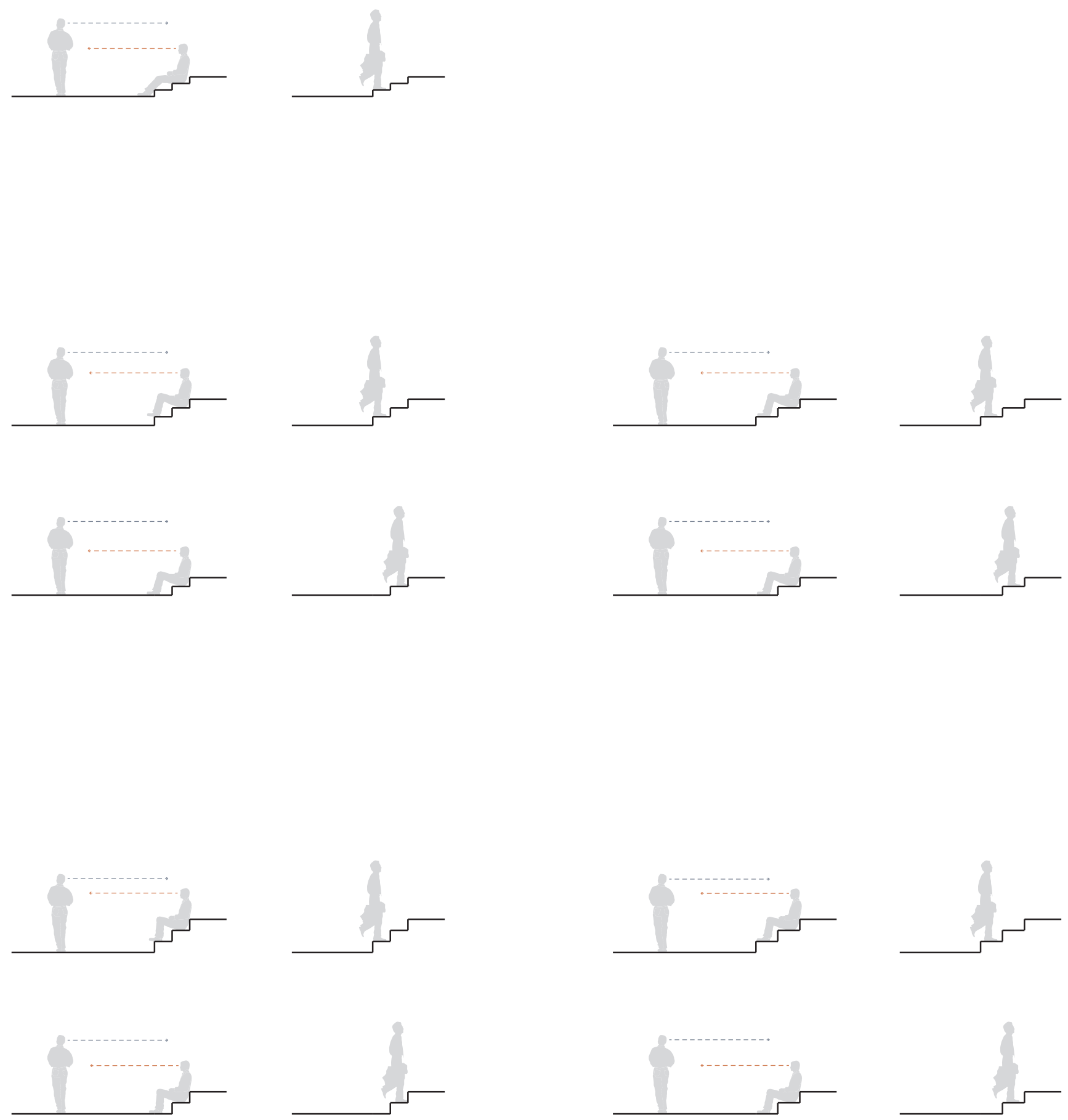

Fig. 6.10.1 Sections exploring different riser height, in regards to walkability, comfort of seating, and relationship between the sitter and someone walking past 


\section{MATERIALITY}

The choice of materials needs to respond to several aspects of the site, the first is the civic nature of much of the enclosed public space; second, it must provide for drainage; third, it must not hinder any movement; and finally, it must relate to the existing structures in the site (i.e. Te Papa). This paver set up creates a differentiation of space, and the porosity allows water to drain through them.
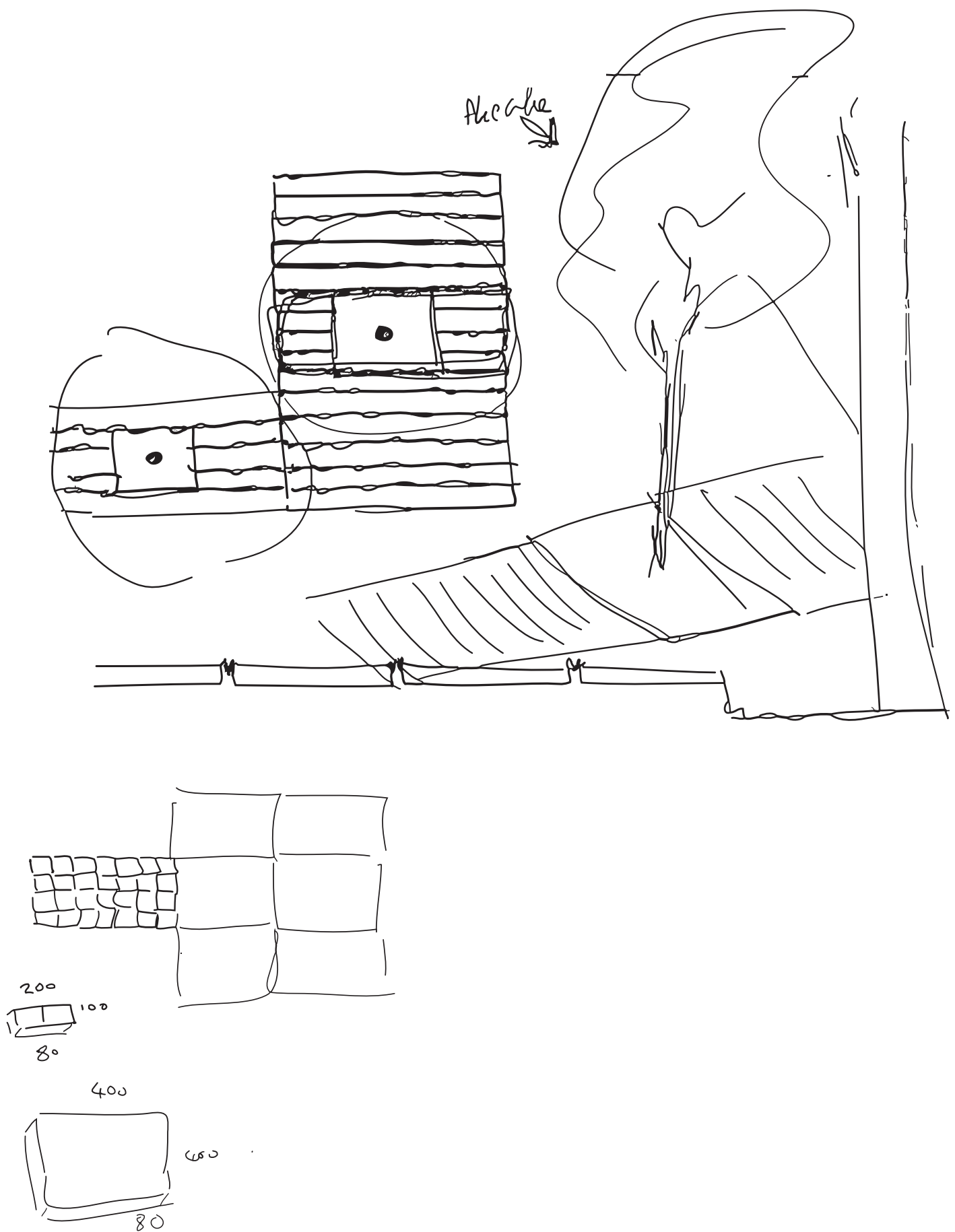

Fig. 6.11.1 Scan of sketches documenting the initial exploration of paving configuration 


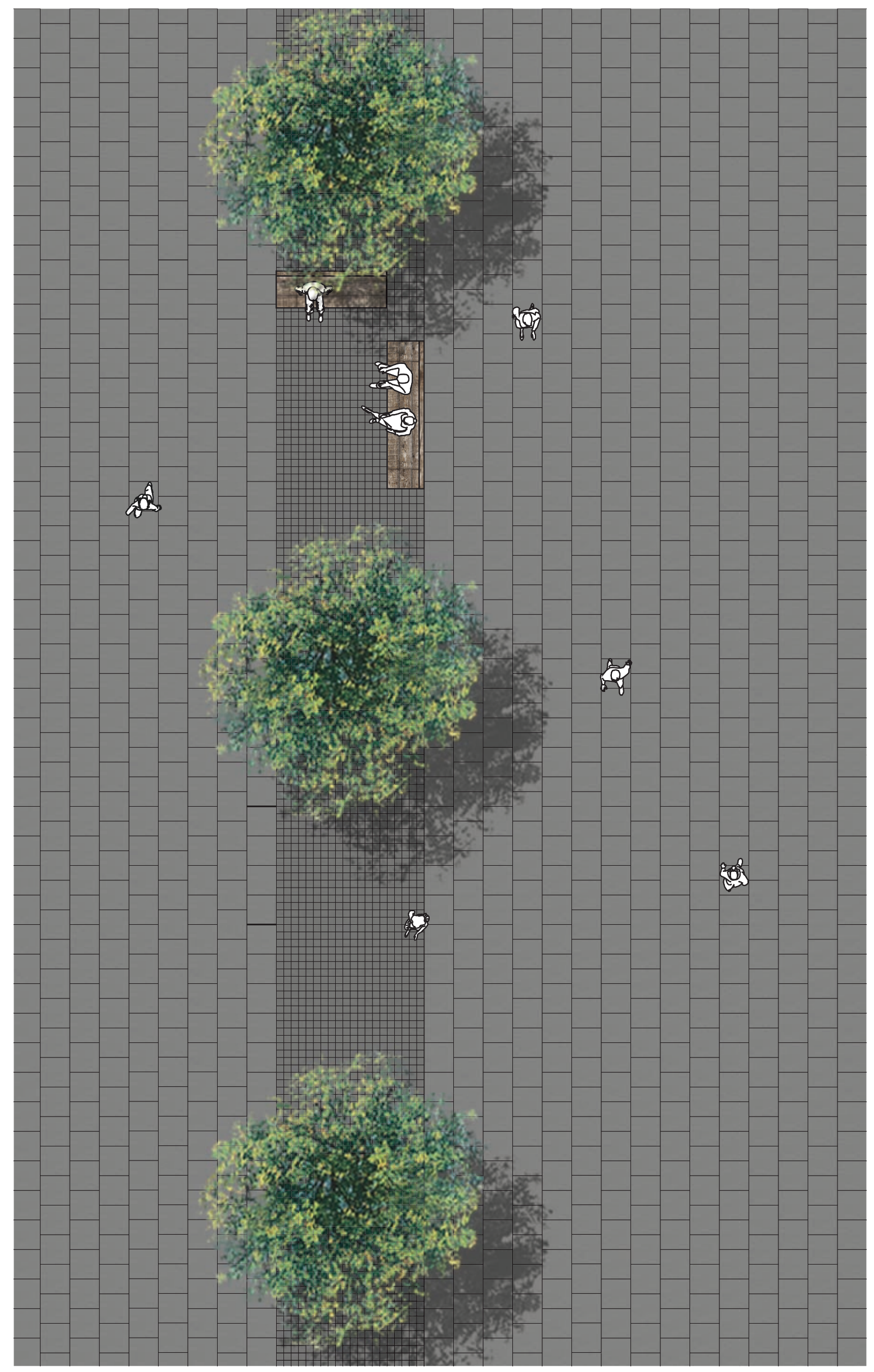

Fig. 6.11.2 Further research lead to this layout of paving, which creates edges within a larger public space to create various lingering opportunities 
Urban Forest Materials

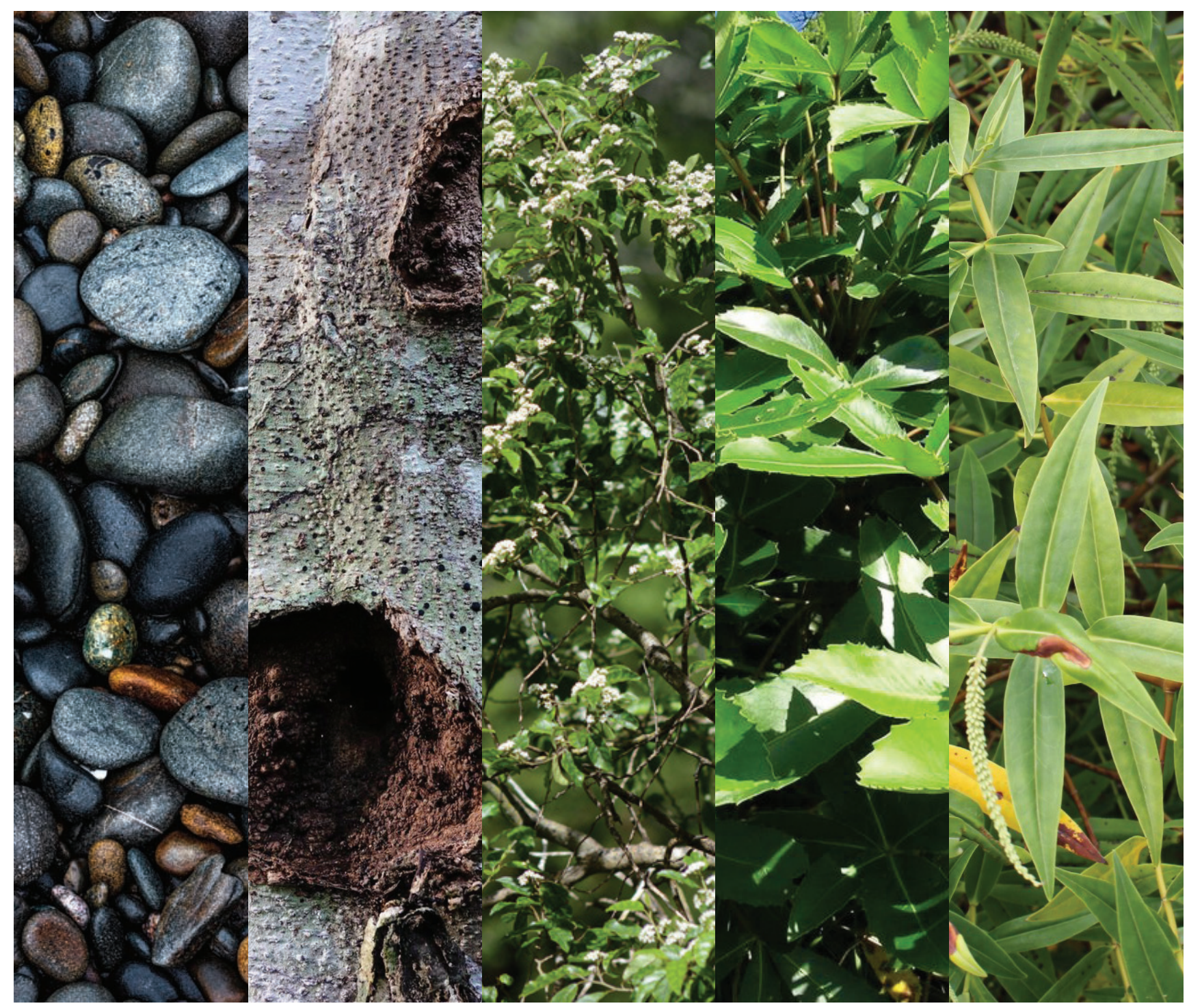

Fig. 6.11.3.1-5 Representation of materials within the forest 


\section{Shops/Art Gallery Materials}

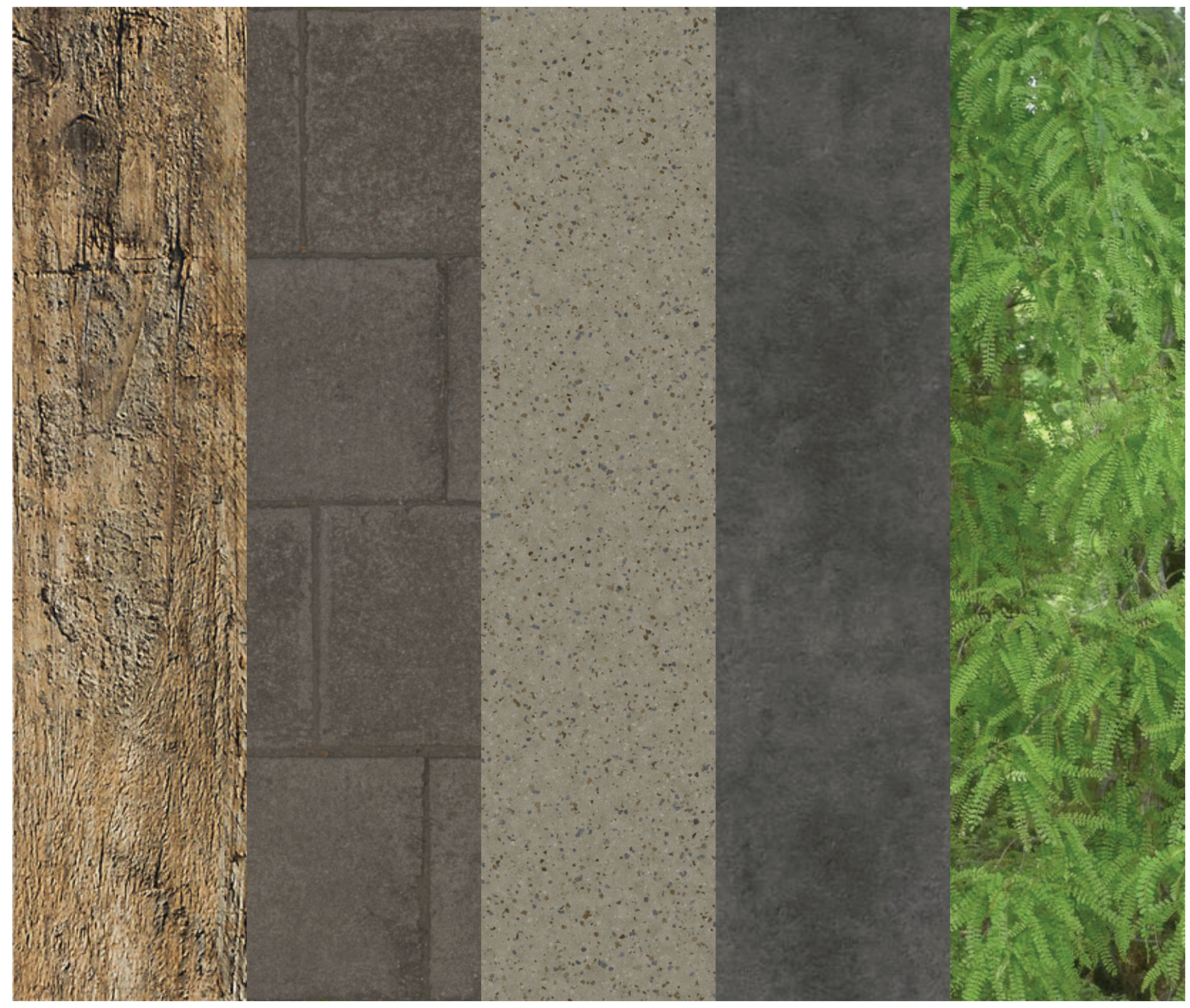

Fig. 6.11.4.1-5 Representation of the material within the civic spaces 
Each section of this chapter establishes the character and environment of the individual spaces and gives consideration into how they might work together as one public realm, as seen in the promenade sections. Determining the 'movable zones' and shared 'perceived zones' between spaces within the canopy forest relates back to the significance of the relationship between movement and lingering found in the previous research. These scenario tests establish a design approach that can be implemented in the final design to ensure a wide range of spaces and opportunity to interact with other people.

The development of the art gallery was informed by the precedent studies in chapter four that analysed how new buildings were well integrated within the landscape and provide further opportunities rather than disrupt the space. With this landscape approach to the architecture of the building, there is a clear connection between the interior and the exterior so that one can engage with the other. The creation of the art gallery was done using a digital model, ensuring that the architectural elements were well considered and appropriate, and the visualisation of the design from different locations and angles helped inform how public life will be generated by the opportunities presented within it.

Reflection on issues that arose from the last chapter led to the design research that was undertaken in this chapter, which explored the potential form of the shops and established two different design approaches for the shops to move forward with. Sketching was a useful tool during these design tests as it was quick and shows the thinking as the drawing progressed.

The research in this chapter was explored at a smaller scale, as it was about the opportunities that could be provided for engagement, and ensure that each space had a character and environment that was unique to it. 

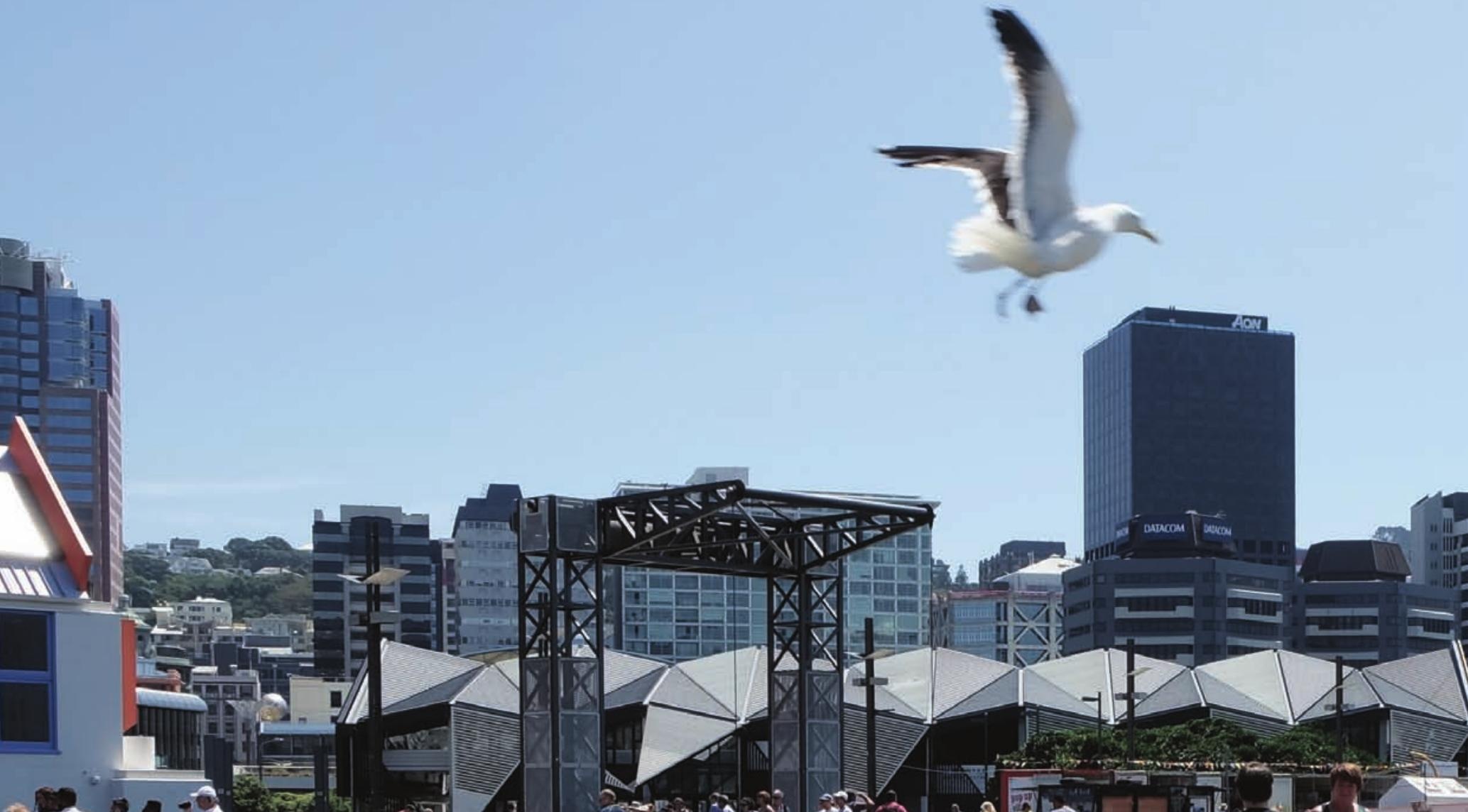
1. 1. $-1-1-12-12$ 


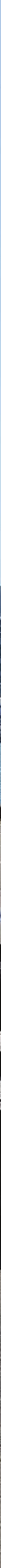


224 


\section{FINAL DESIGN}

This final design chooses to work with existing disruptions to design a series of public spaces that people can occupy singularly or move through as part of a more extensive journey. The design of each space responds to the potential found within it and the actions of user groups in the site. The edges of each space are determined by how Te Papa affects the physical environment. This chapter will discuss how the design of these public spaces would enhance Te Papa and Wellington's waterfront and what they bring to the city and its people.

The design works hard, in a very challenging situation, to facilitate occupation when this large, public building has combined with the wind and various things, like parking, to make a surrounding area that tends to only be moved through. 


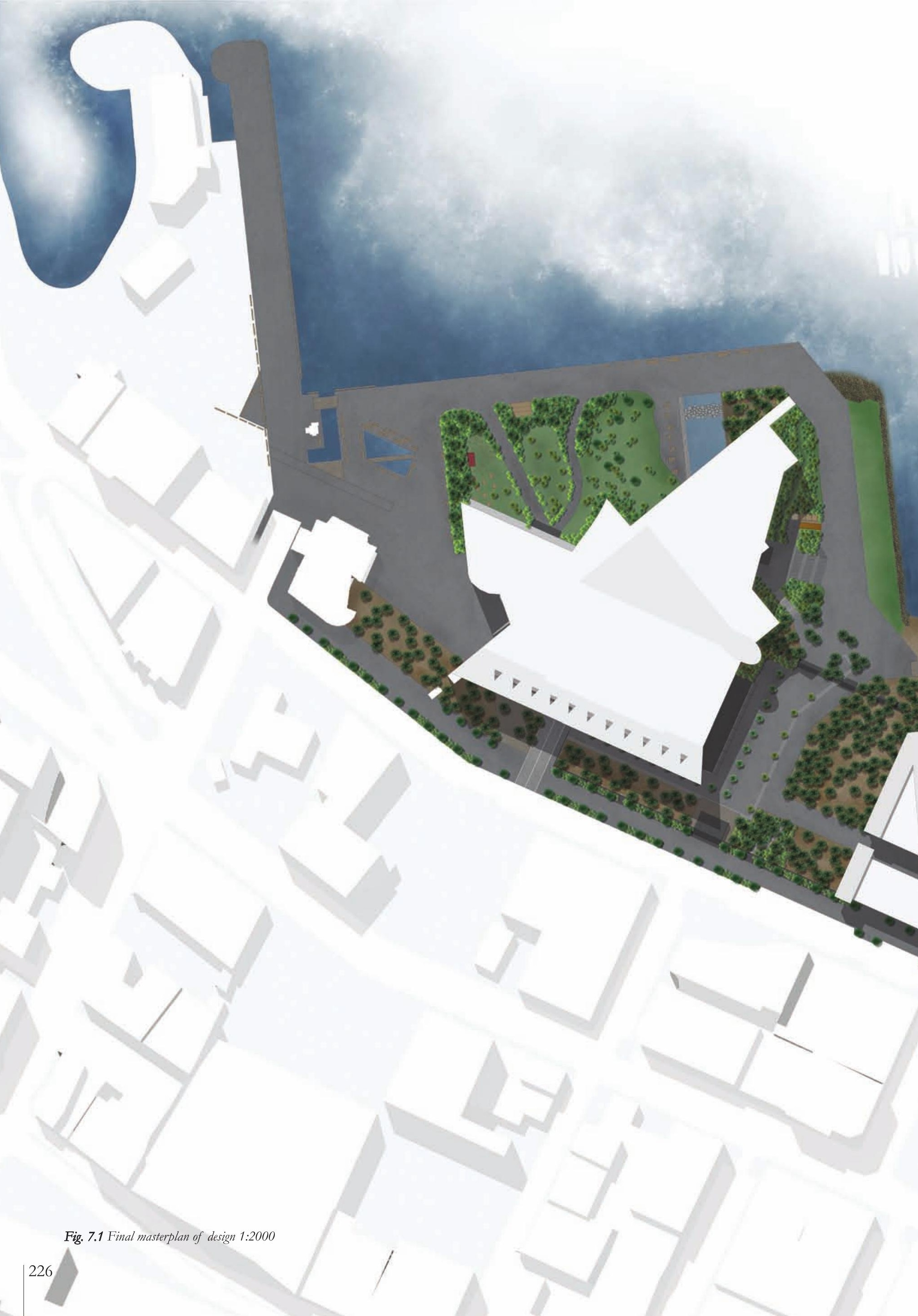




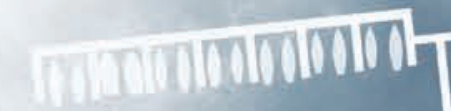

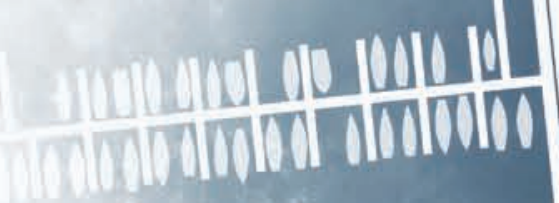

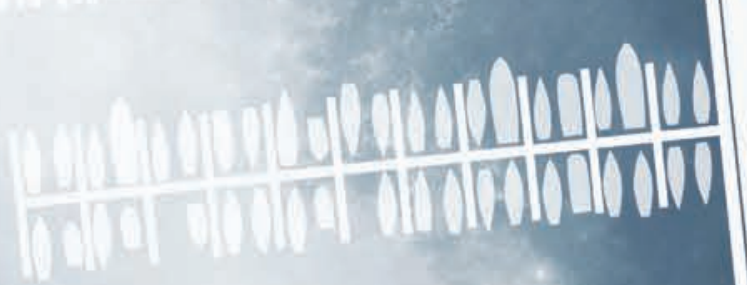

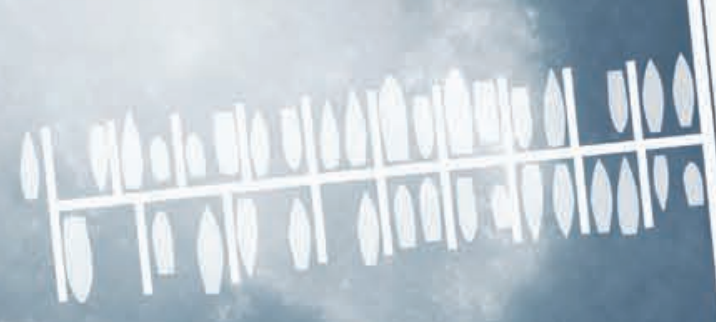

Hencon an

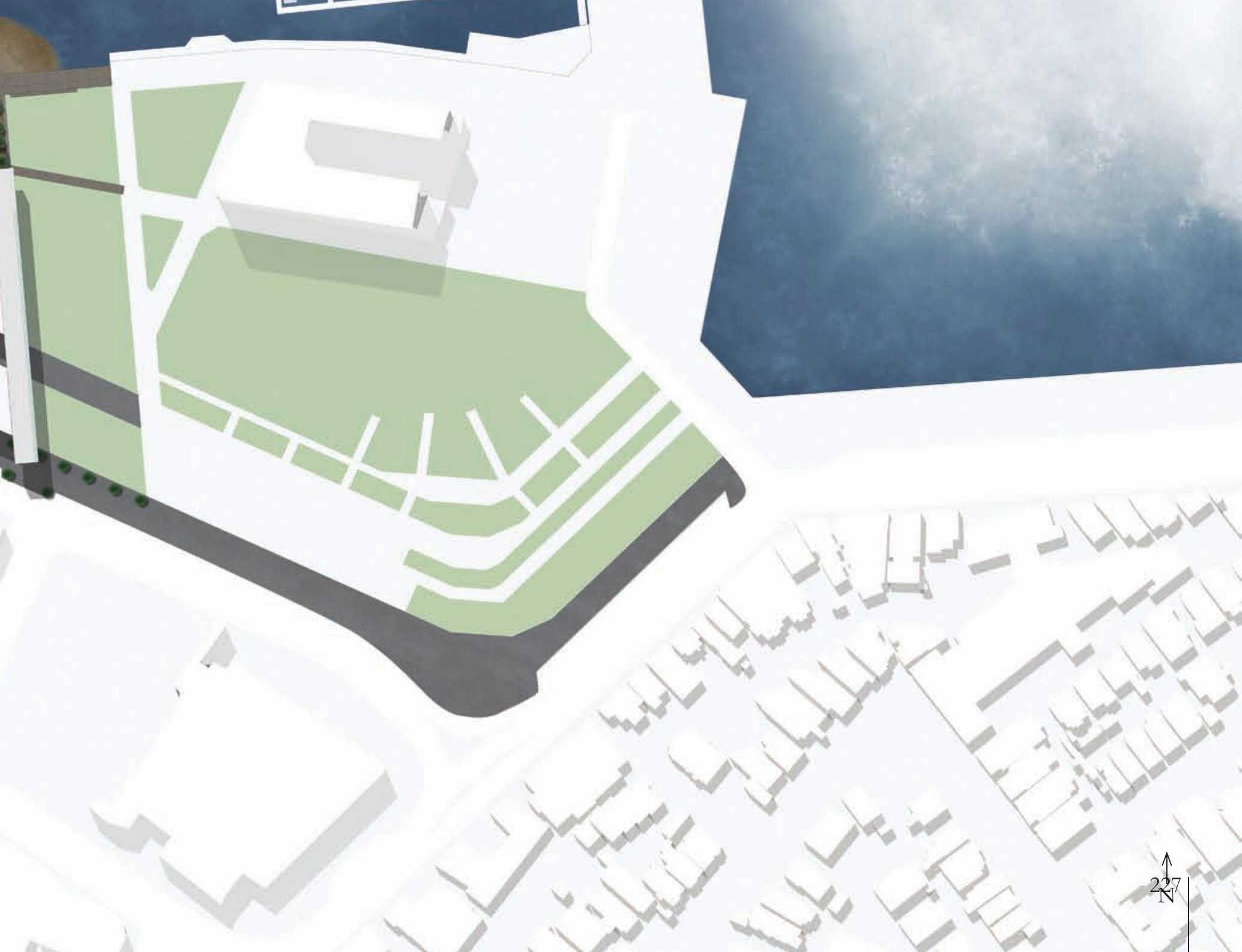




\section{EASTERN URBAN CANOPY FOREST}

In a waterfront primarily made up of concrete and limited grass spaces, this canopy forest would create a rare space that provides shelter and unique public spaces. The understory planting creates a variety of opportunities for people to interact with the landscape and each other; including areas of seclusion, group sitting and a sculpture garden that spills out from the art gallery. The continuation of native species chosen to highlight planting of New Zealand, as seen in the original Bush City and Waitangi Park, invites people to enjoy one aspect of our natural environment. This forest has the potential to become an interesting destination once it grows to full size and will be seen from around the waterfront and certain areas of the city.

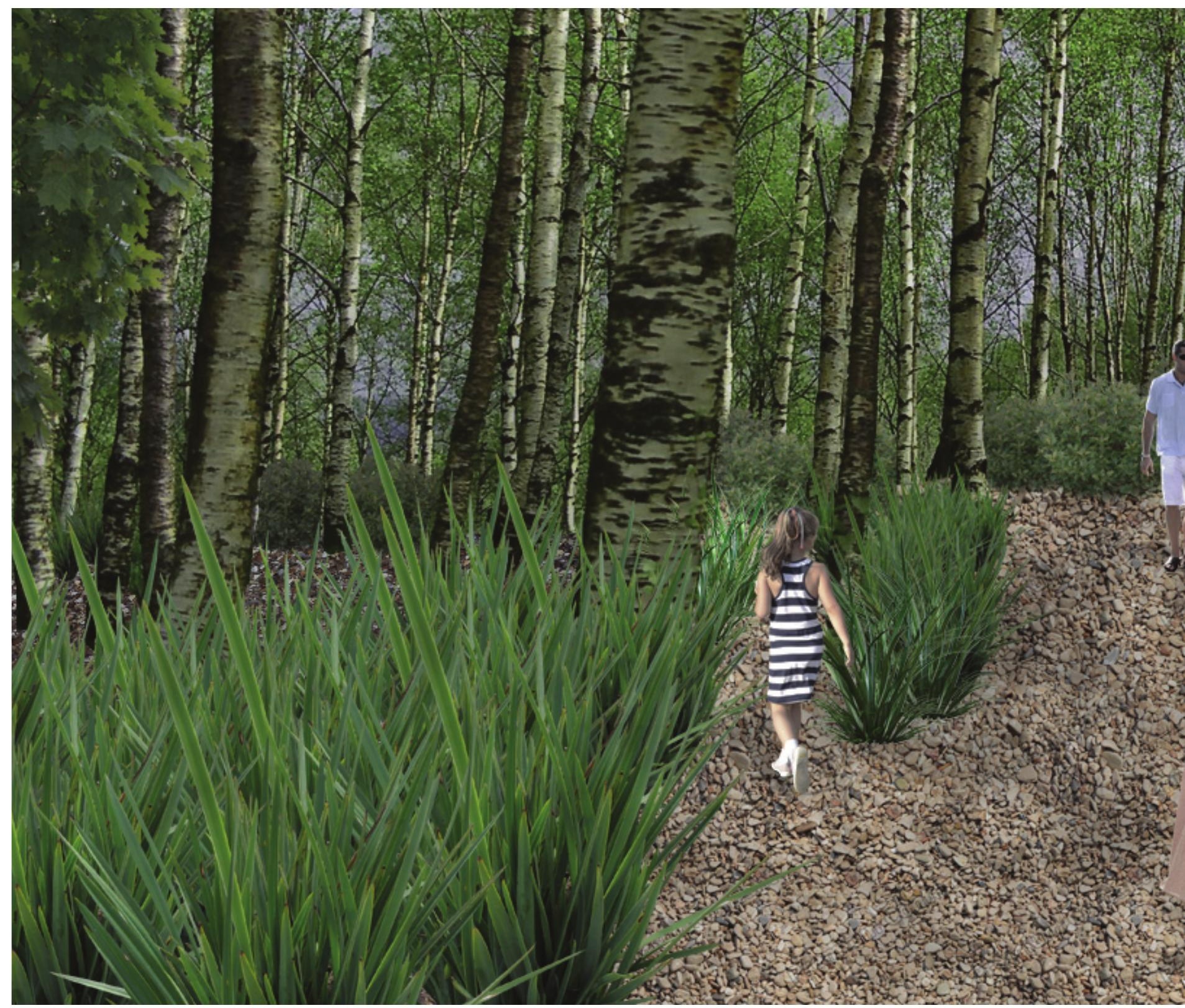


Fig. 7.2.1 Render demonstrating the type of public spaces that exist within the canopy forest

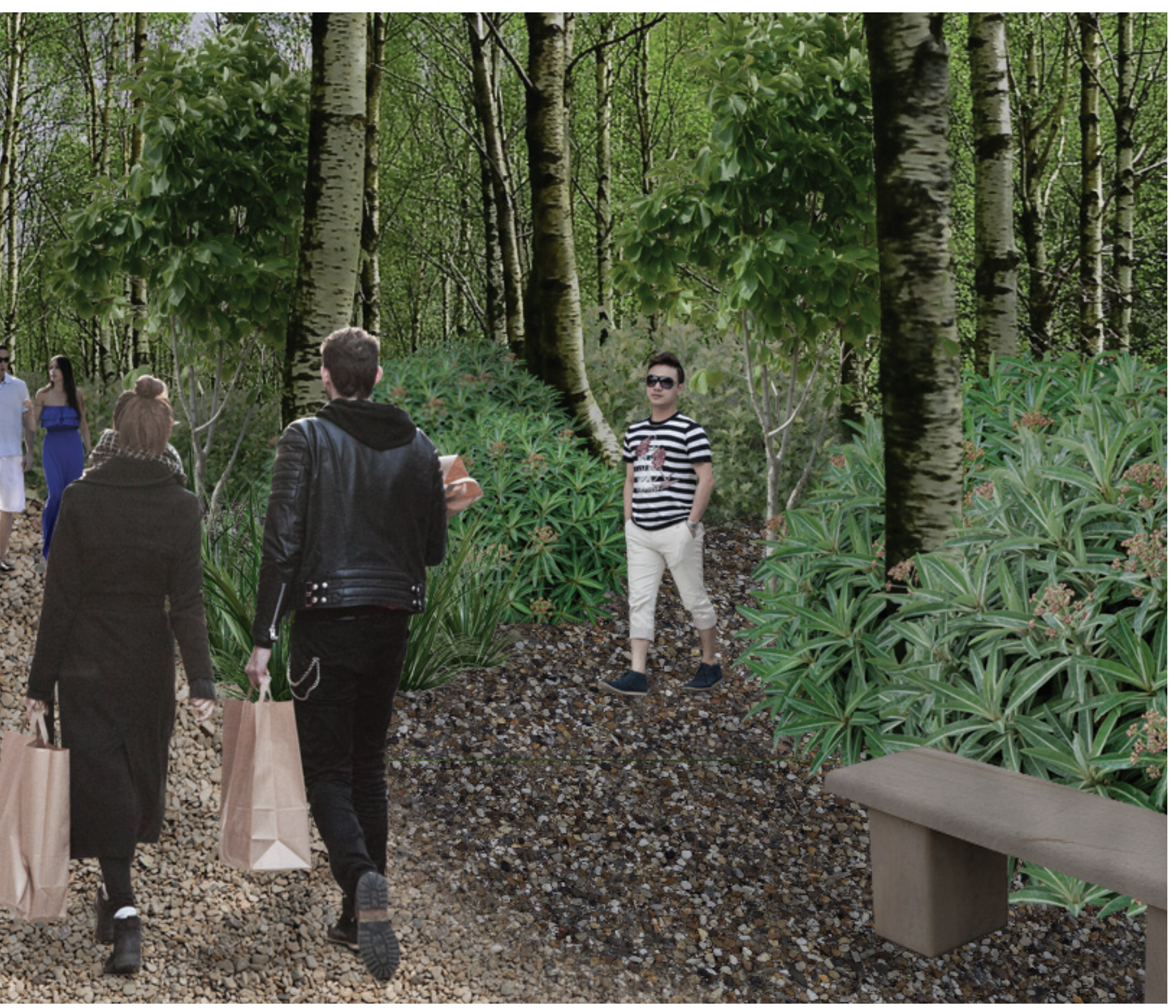




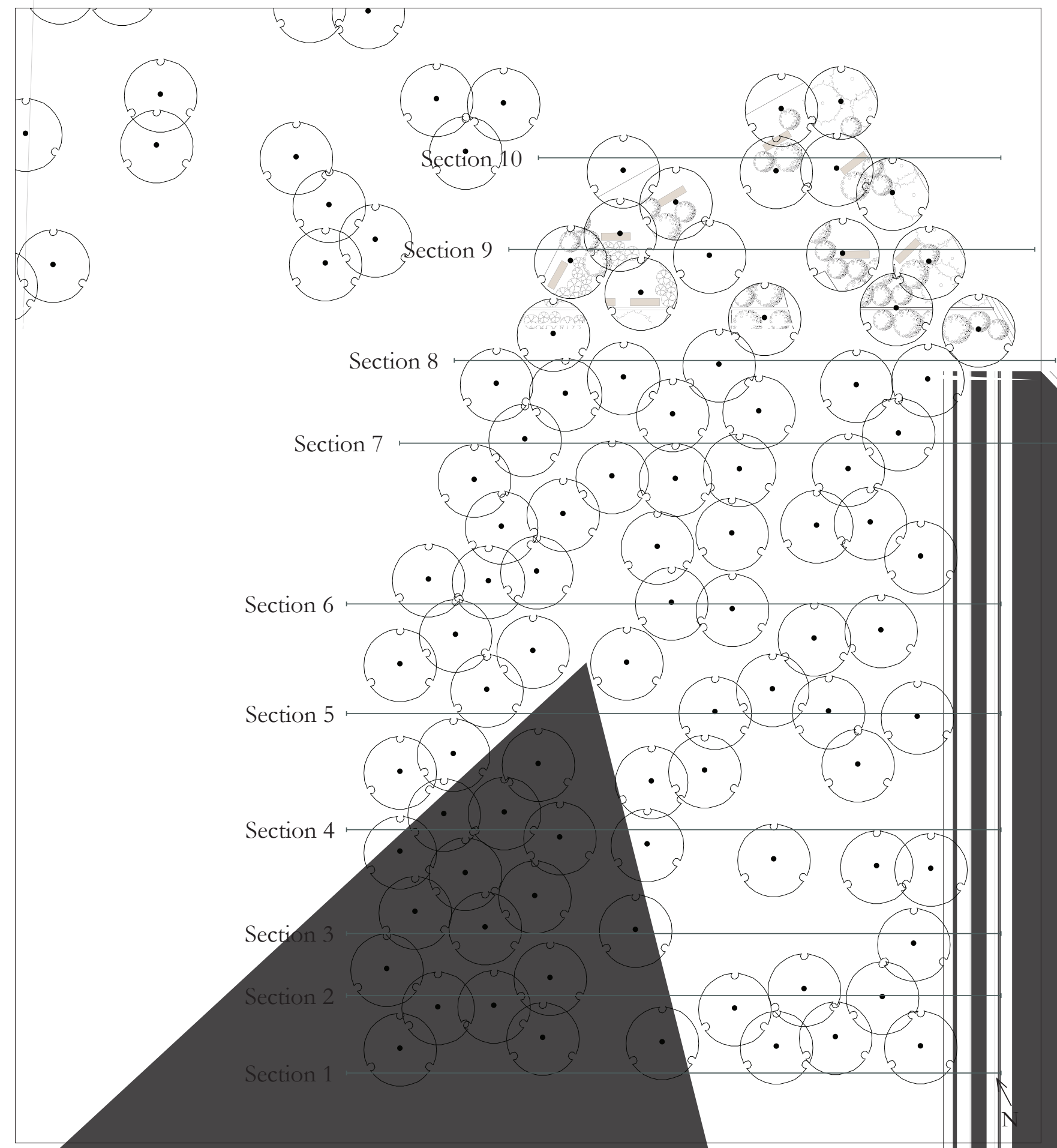




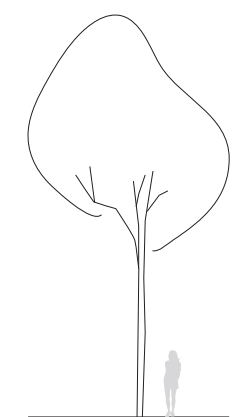

O

Putaputaweta

$\mathrm{H}: 10 \mathrm{~m}$

carpodetus serratus

W: $5 \mathrm{~m}$

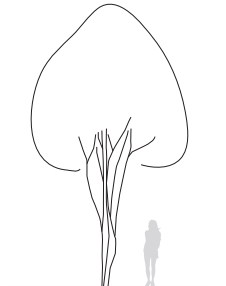

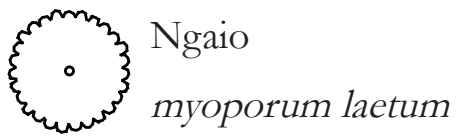

$\mathrm{H}: 7 \mathrm{~m}$

W: $4 \mathrm{~m}$

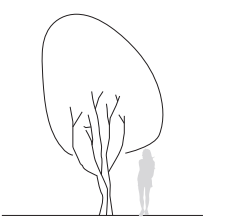

$\left\{\begin{array}{l}\text { Kowhai } \\ 0\end{array}\right.$

H: $5 \mathrm{~m}$

$\mathrm{W}: 3 \mathrm{~m}$

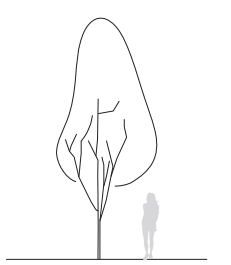

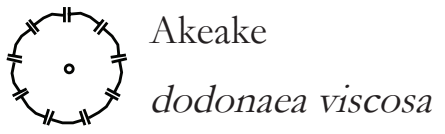

H: $6 \mathrm{~m}$

$\mathrm{W}: 2.5 \mathrm{~m}$

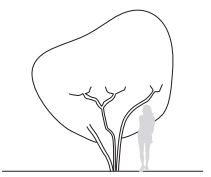<smiles>C1CCCCCCCCCCC1</smiles>

Five Finger pseudopanax arboreus

H: $4 \mathrm{~m}$

W: $3.5 \mathrm{~m}$
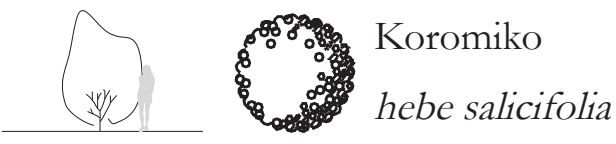

$\mathrm{H}: 3 \mathrm{~m}$

$\mathrm{W}: 2 \mathrm{~m}$

$\mathrm{H}: 0.8 \mathrm{~m}$

$\mathrm{W}: 1 \mathrm{~m}$

arthropodium cirratum

$\times \frac{\text { Dwarf Flax }}{2}$

H: $0.5 \mathrm{~m}$

W: $0.5 \mathrm{~m}$ 


\section{Sections}

The sections demonstrate how three different zones are defined by planting when a person interacts with the forest. The first is the moveable space, which is the space where they can walk. The second is the area that becomes their territory when occupied. The third is the perceived space, which extends past the two previous zones, up to the canopy and, in places, shared between people.

Lingerer

Mover
Movable Zone

Perceived Zone

Movable Zone

1.

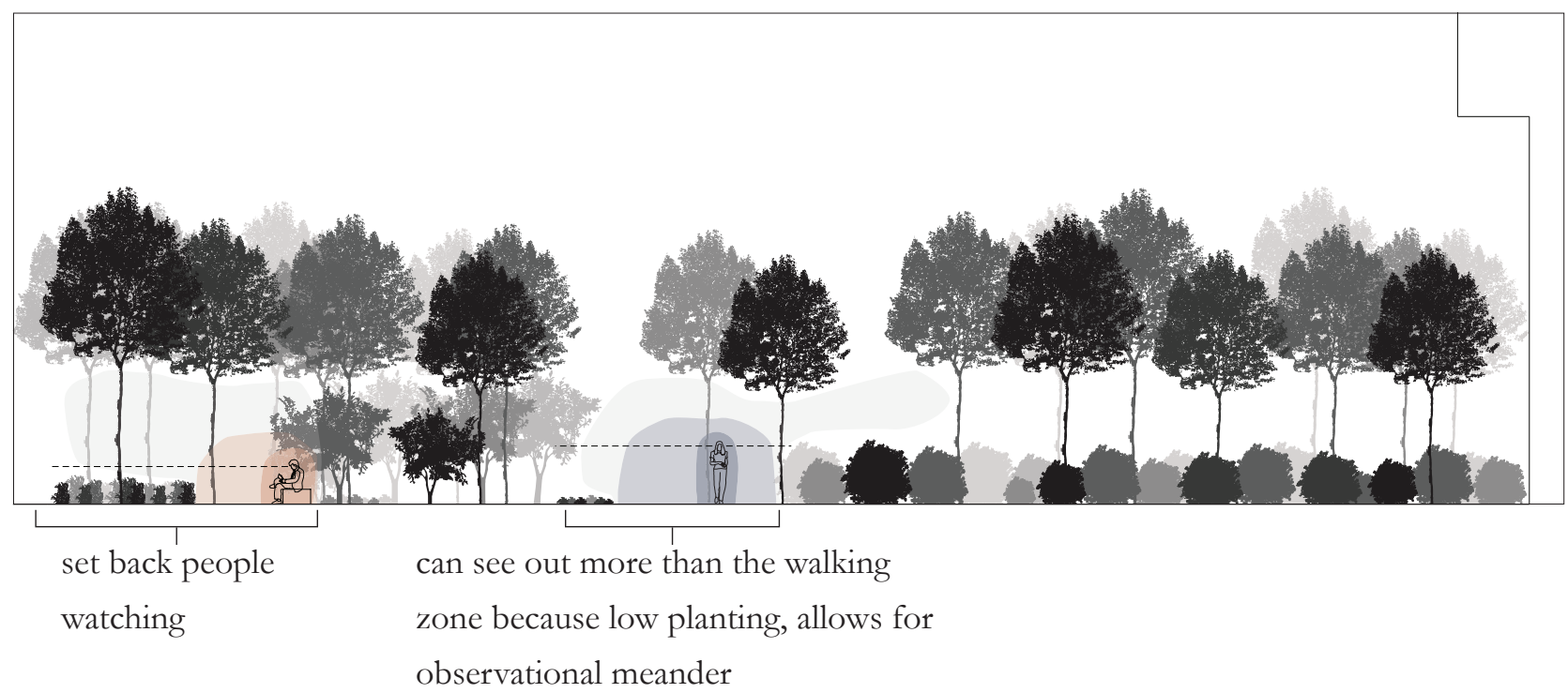

2.

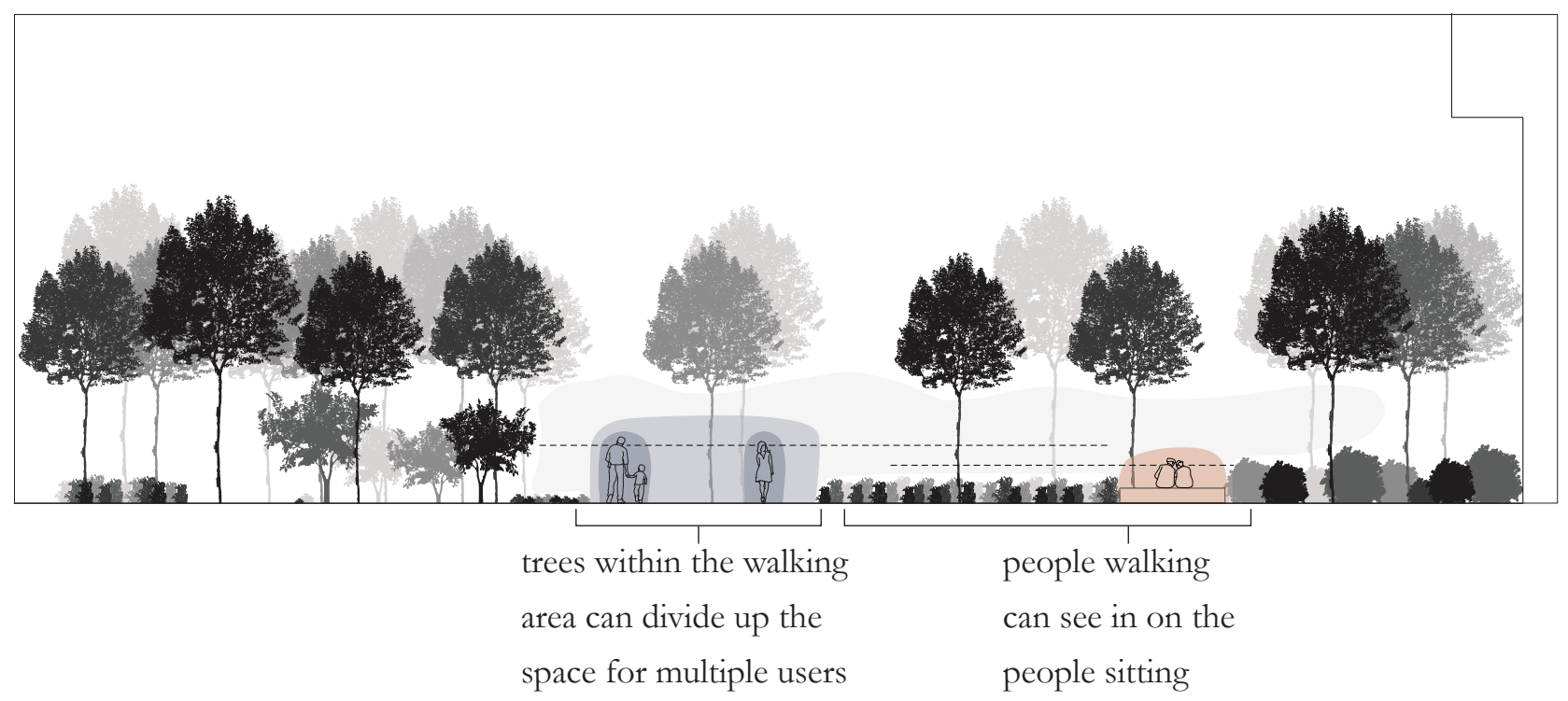



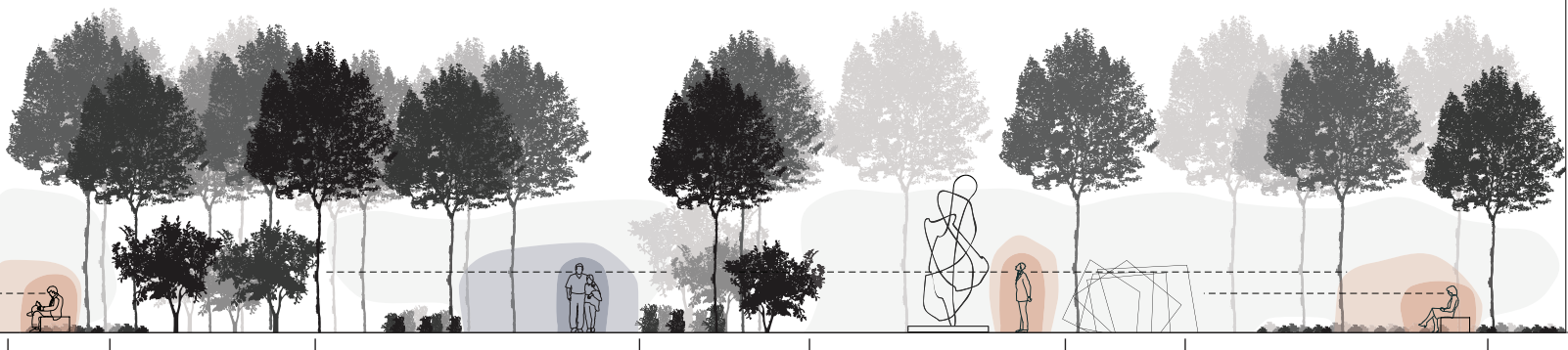


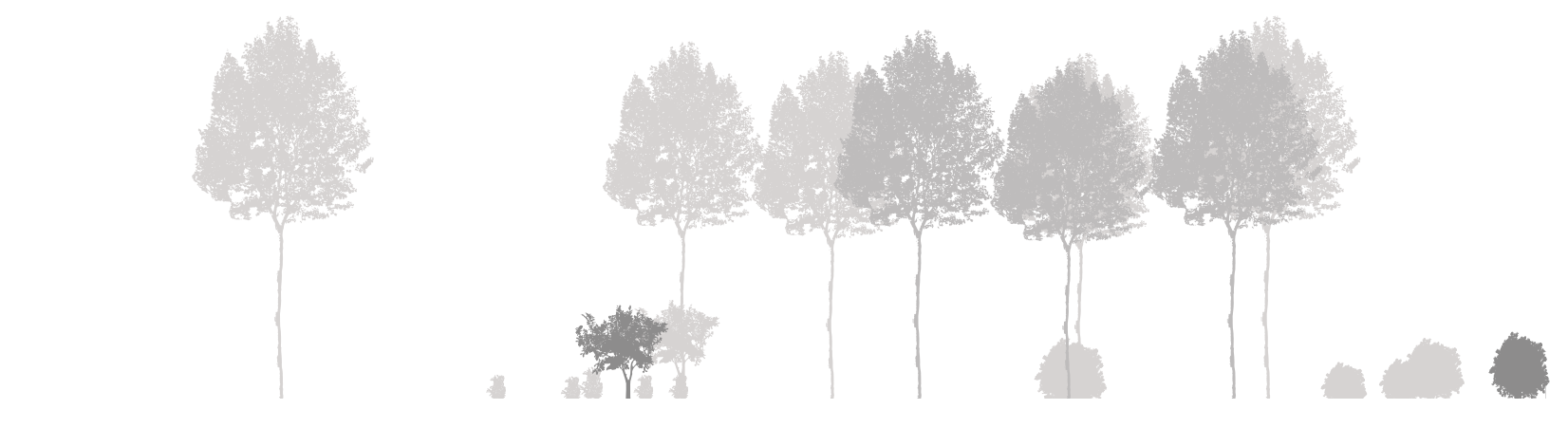



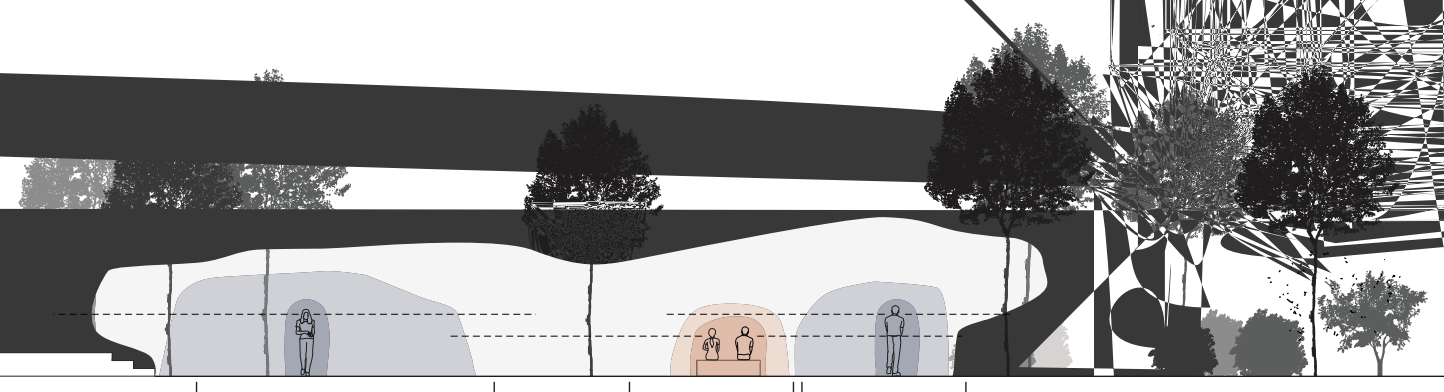
3D Visualisation of Planting Configuration
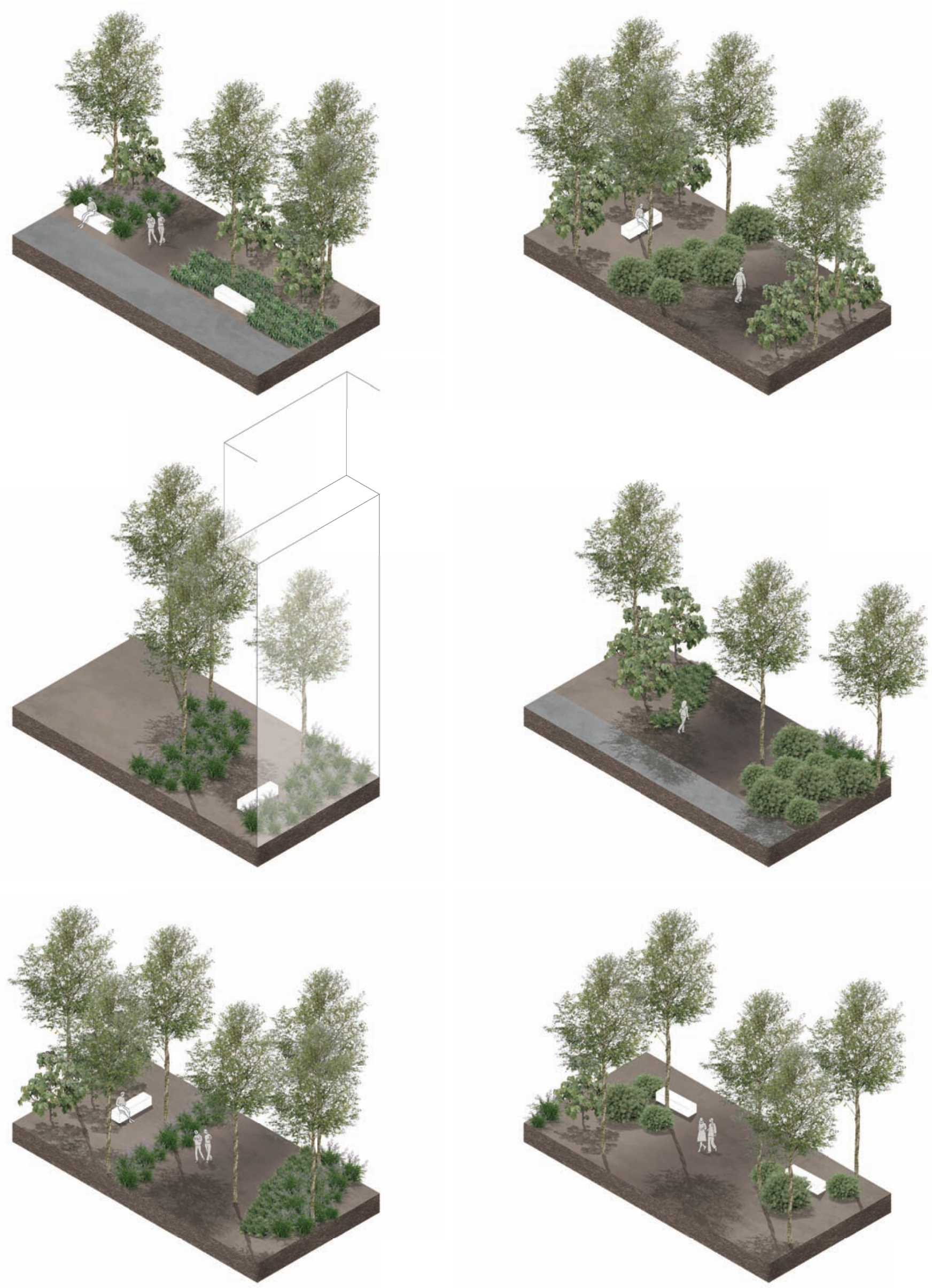

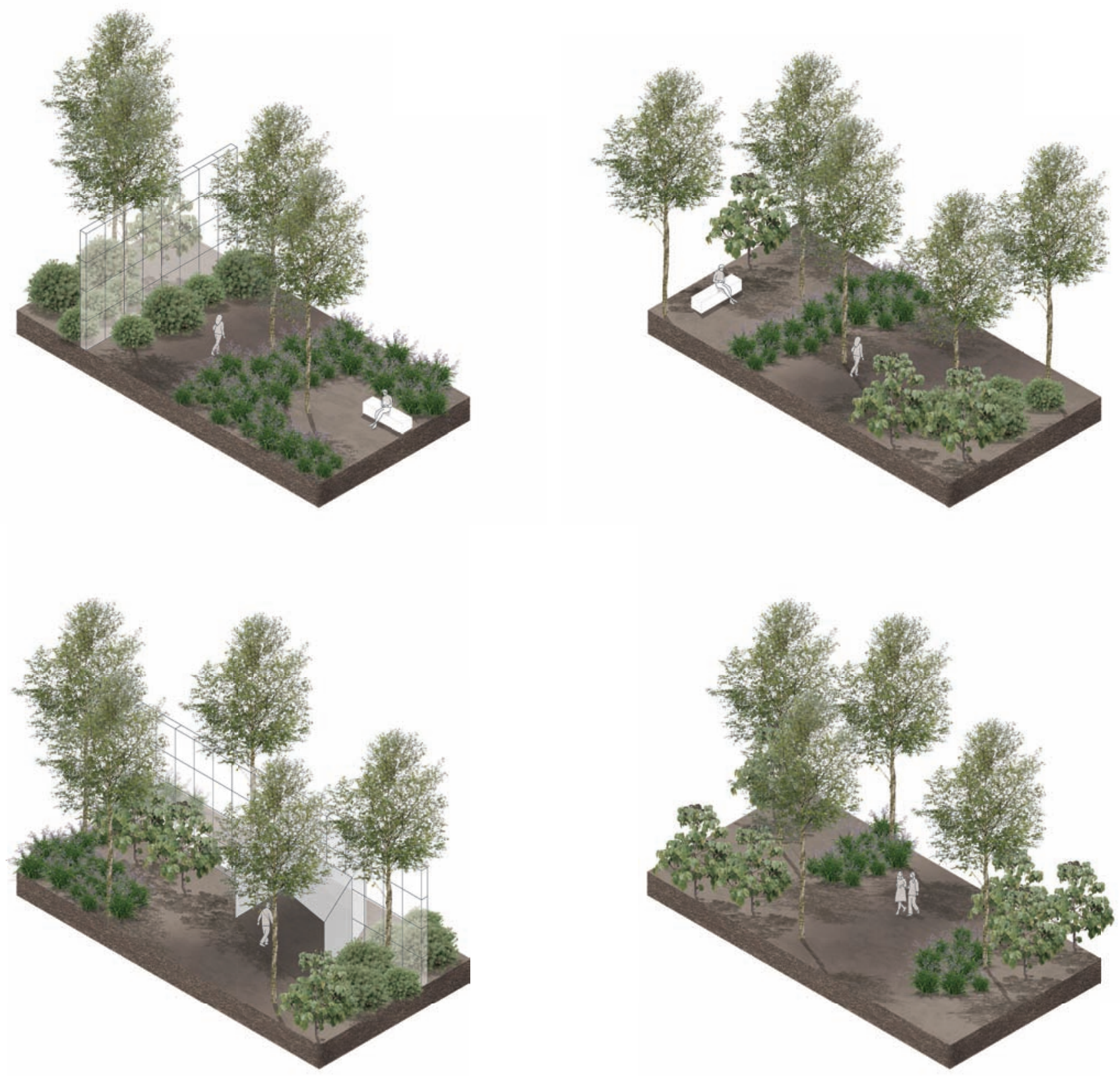

These small snippets taken from different areas within the forest show the interaction that exists between someone who is walking through and the surrounding spaces. 


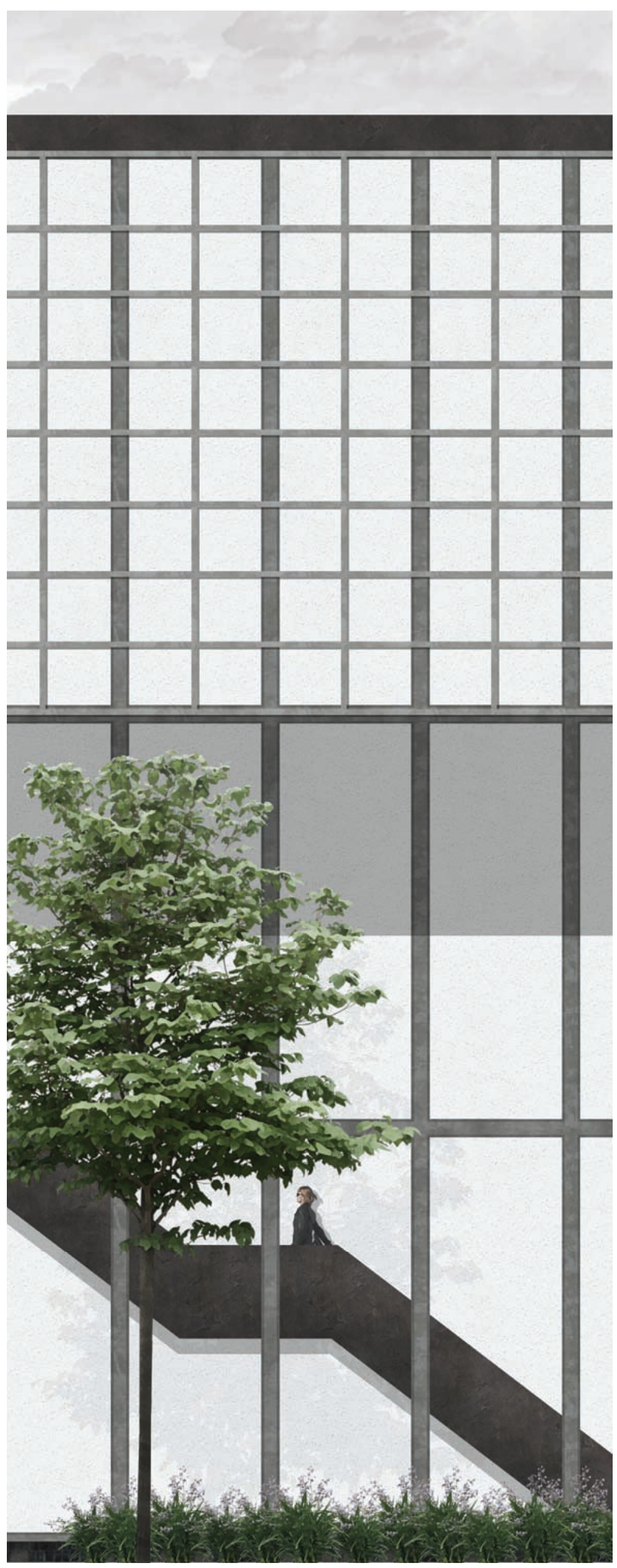

Fig. 7.3.2 Floor plan for exbibition spaces and circulation 1:1000

Fig. 7.3.3 Section 1:400 showing gallery's connection with forest 


\section{ART GALLERY}

The art gallery has a strong connection with the external landscape due to the circulation that exists around the edge of the building: it pushes the exhibition spaces to the centre to ensure their protection from external elements. The primary area of circulation is a large staircase that runs along a massive glass façade, which creates visual connections between the landscape and interior spaces. The limited height of the putaputaweta makes the staircase appear as though people move up into the canopy, and at every point up the staircase, their interaction with the forest will be different depending on how much or little they can see. Along the east wall on the top floor, the connection to the landscape becomes a long strip of windows that let light pour in while maintaining the microclimate necessary for an art gallery. The section below shows how the sculpture garden is located in relation to the art gallery; access to this garden is through the ground floor of the gallery or by walking through the forest.

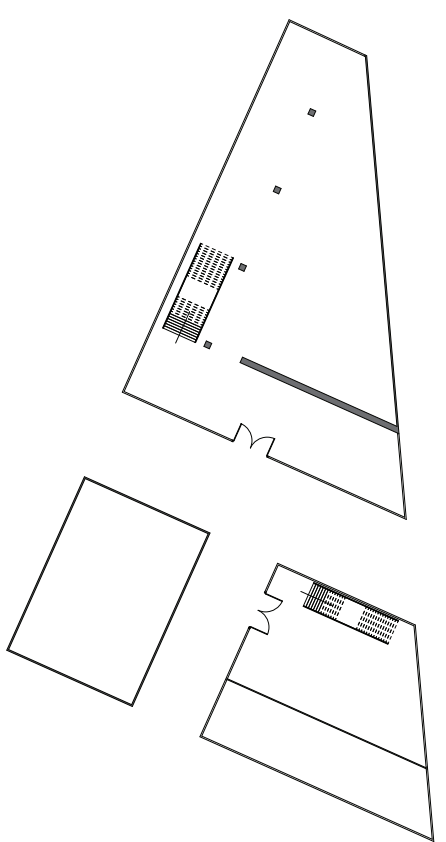

Ground Floor

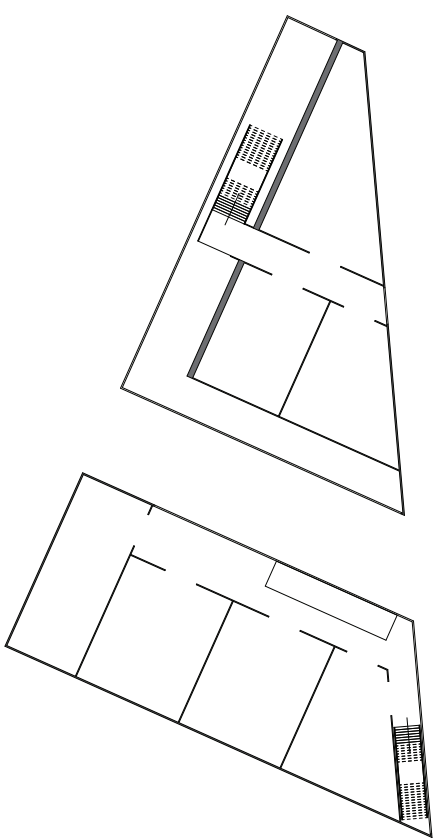

First Floor
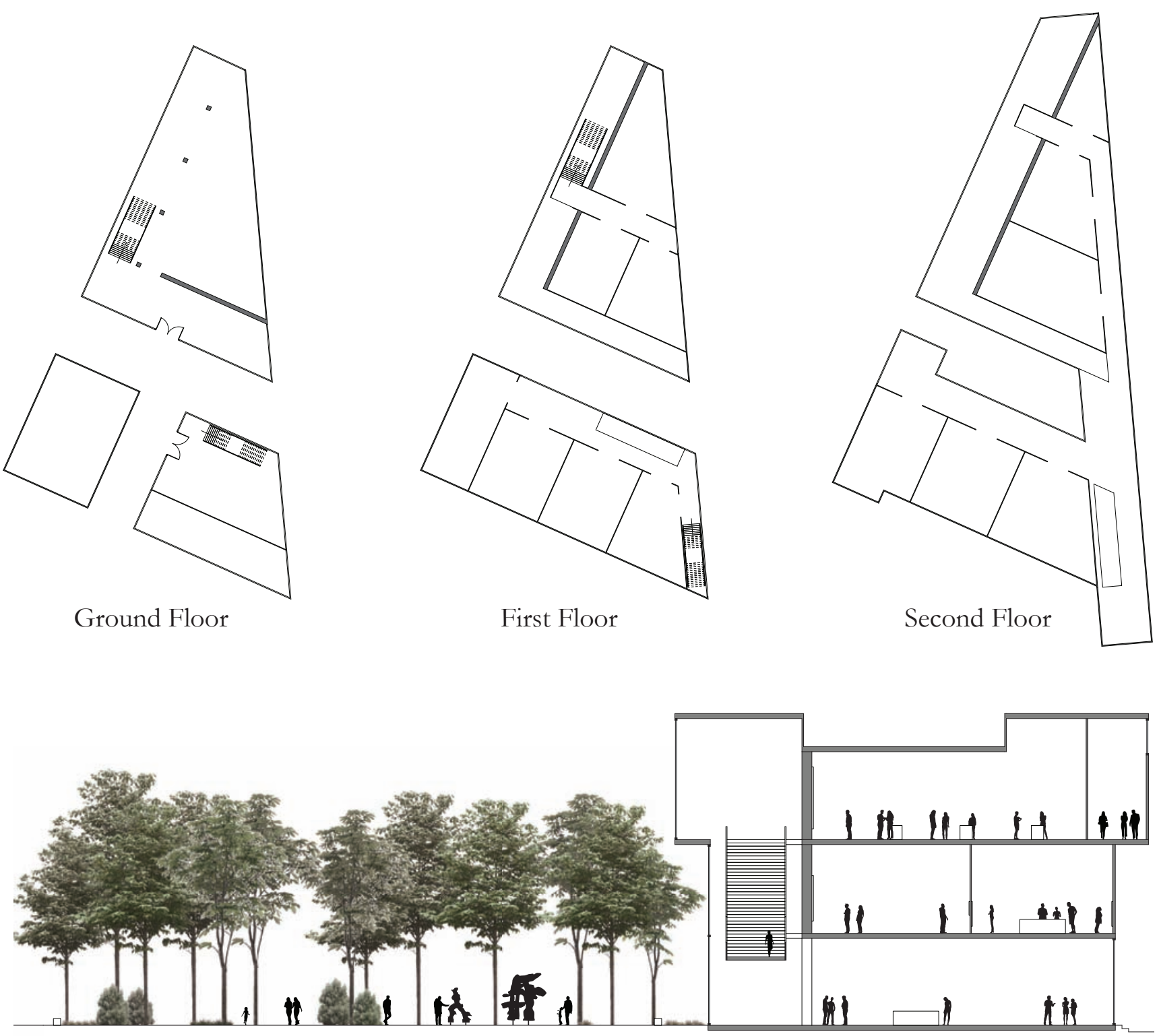


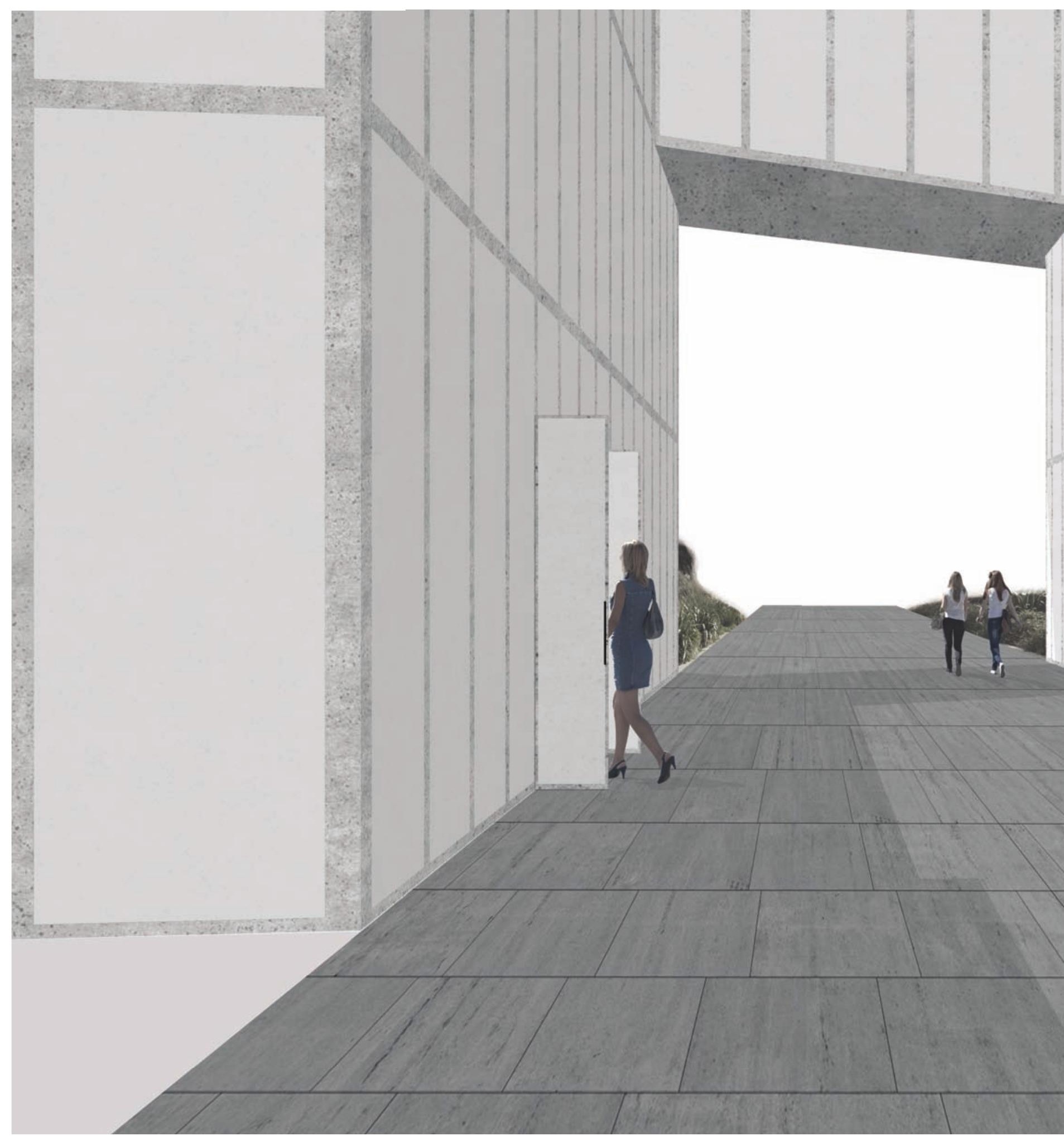

Fig. 7.3.4 Render of connection between the building that allows pedestrians to move freely around the waterfront and city 


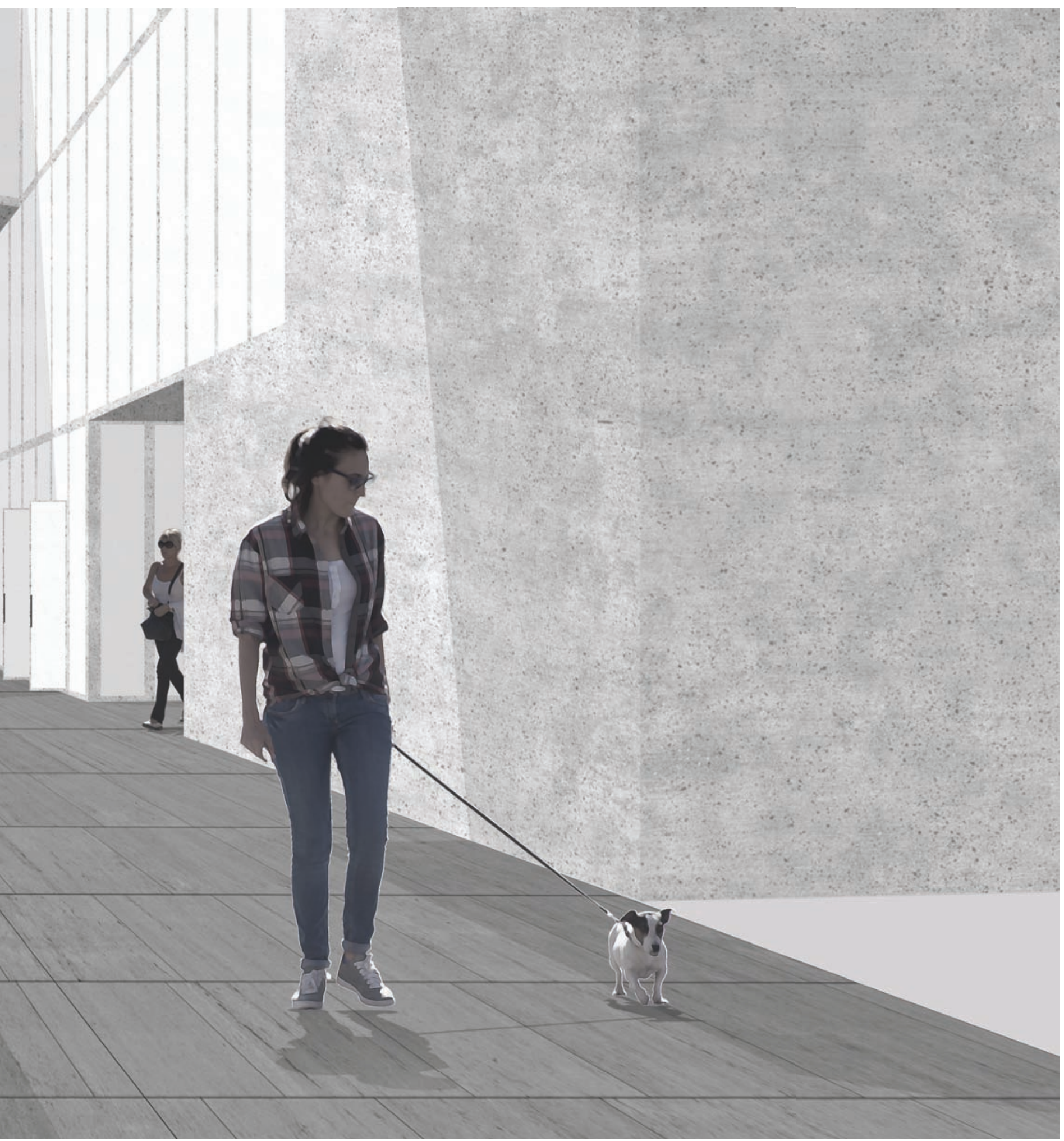

An essential feature of this art gallery design is the connections it creates and maintains within the landscape due to walkway created between two wings of the gallery that remains open except for a third-floor bridge. The T-shape of this walkway connects the new public space to Waitangi Park and an existing minor entrance to the waterfront via Chaffers Street. The glass façade facilitates an interaction between the potential movement through this area, the interior space of the art gallery, and the people inside. 


\section{SHOPS AND SOUTHERN FOREST AREA}

A series of retail/hospitality opportunities creates the potential for a connection between the civic space and the edge of Te Papa, removing the back-of-house feel that the initial lack of connection to these provided. The first approach is a series of stores that blend in with the façade by making use of the covered void that exists on the ground floor; it matches the edges of the façade and pillars, but sets the entrances back into these spaces and connects the inside with the outside through materiality. This approach celebrates the façade above by allowing people to occupy a small strip of space that exists between the store interior and the civic space, which is defined by Te Papa's edge. The second approach to the design is a combination of covered seating areas and permanent food stalls placed against the façade. This approach creates an informal and casual atmosphere that invites people to occupy the space even if they do not utilise the food stalls.

Section 1

Fig. 7.4.1 Zoom plan 1:300 of shops and civic space, and where they connect to the forest

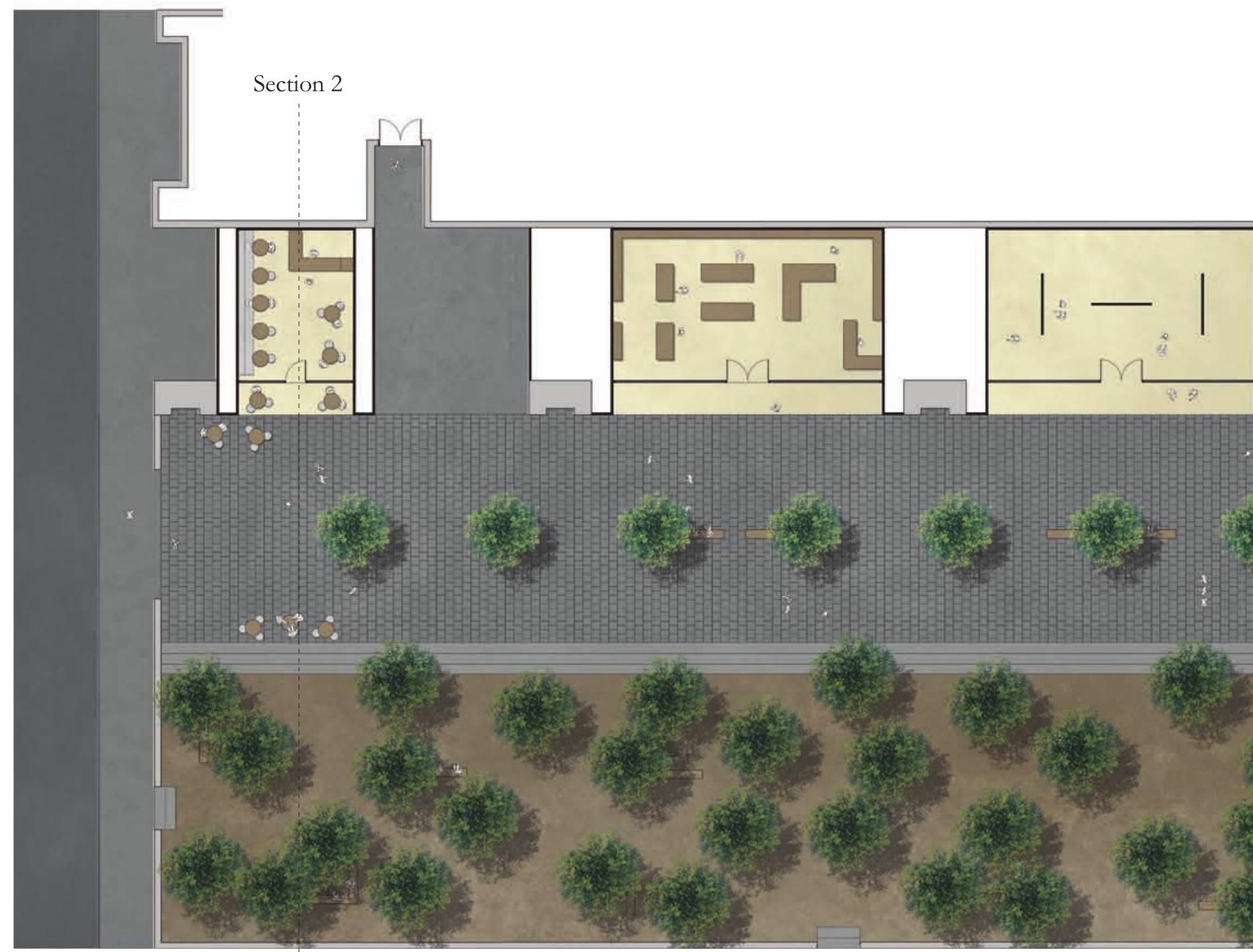




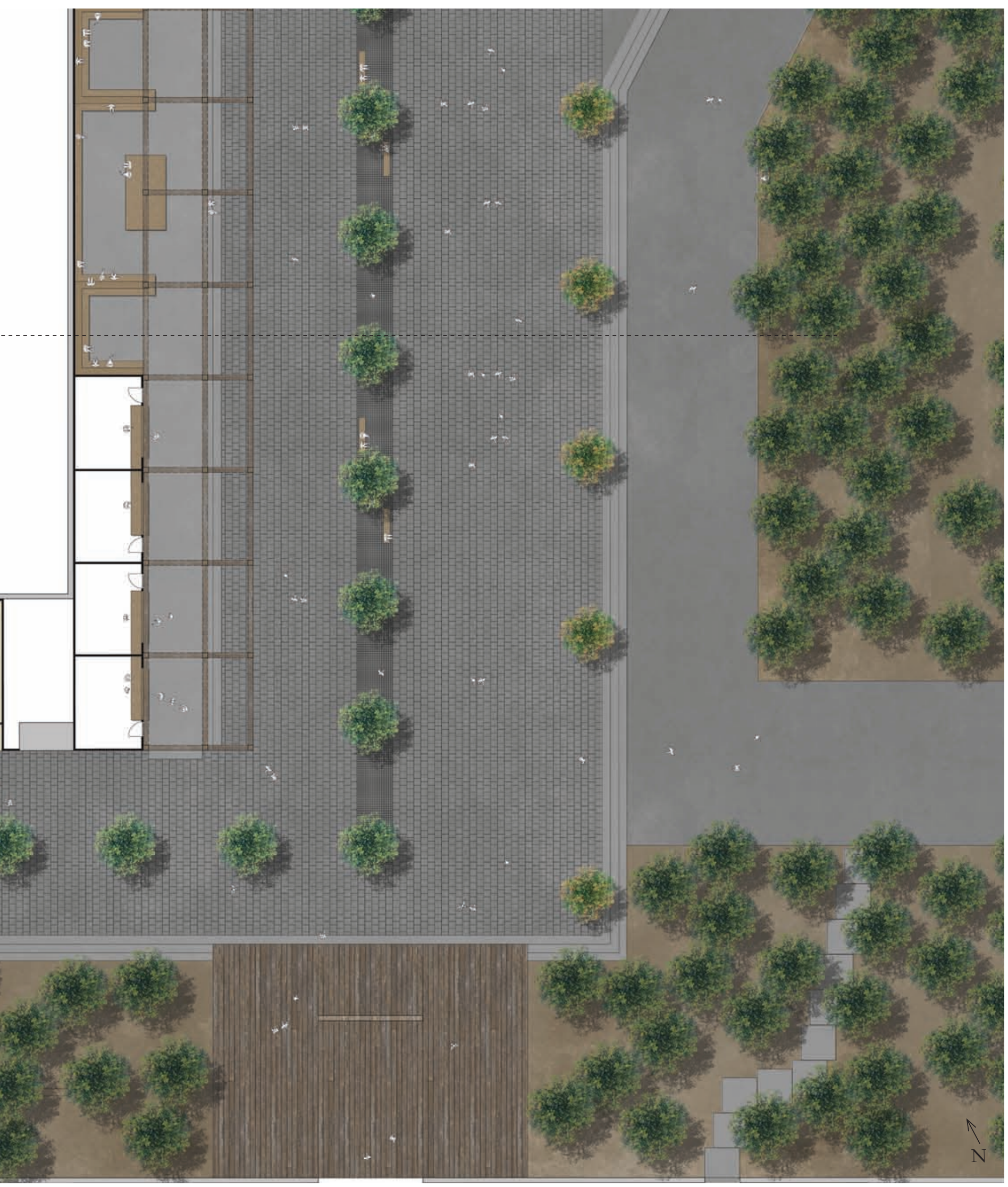


Design Approaches
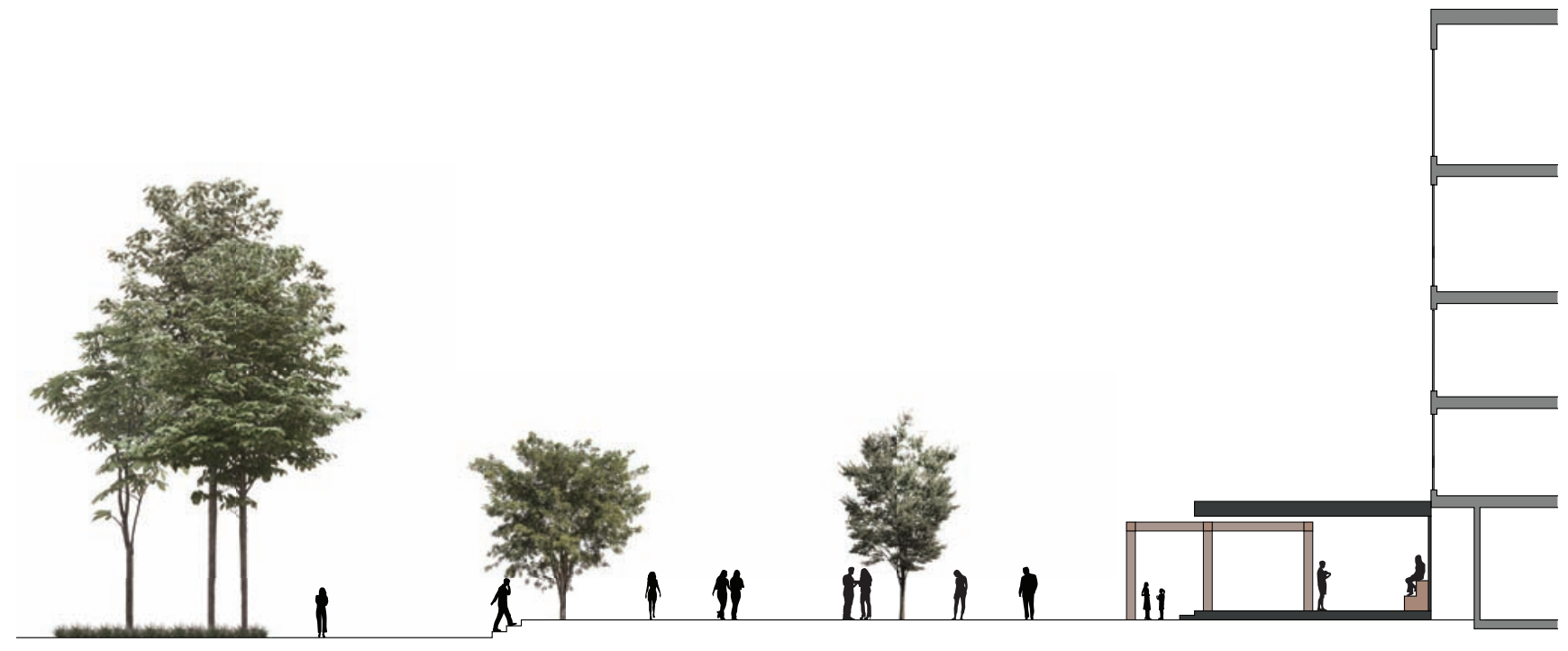

Section 1

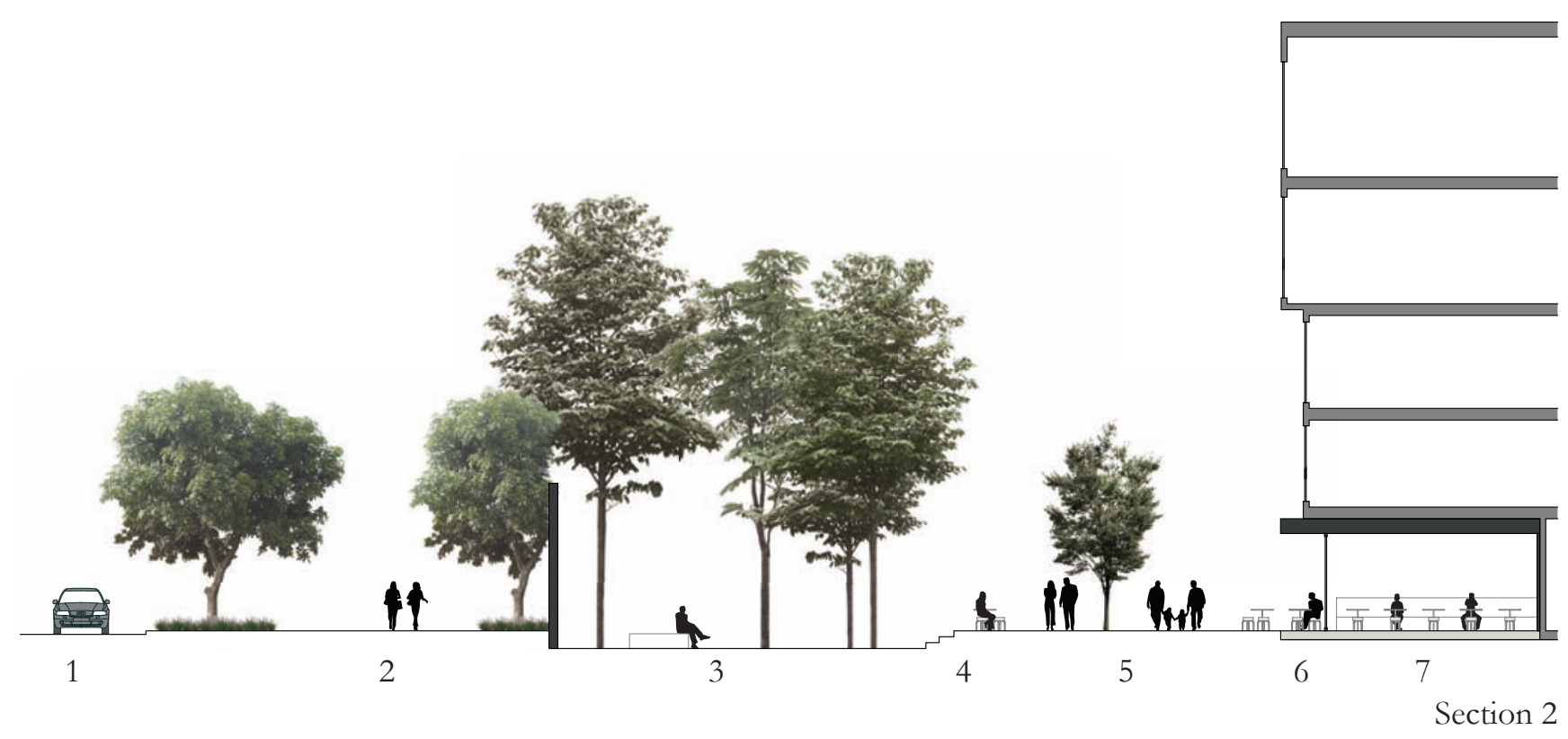




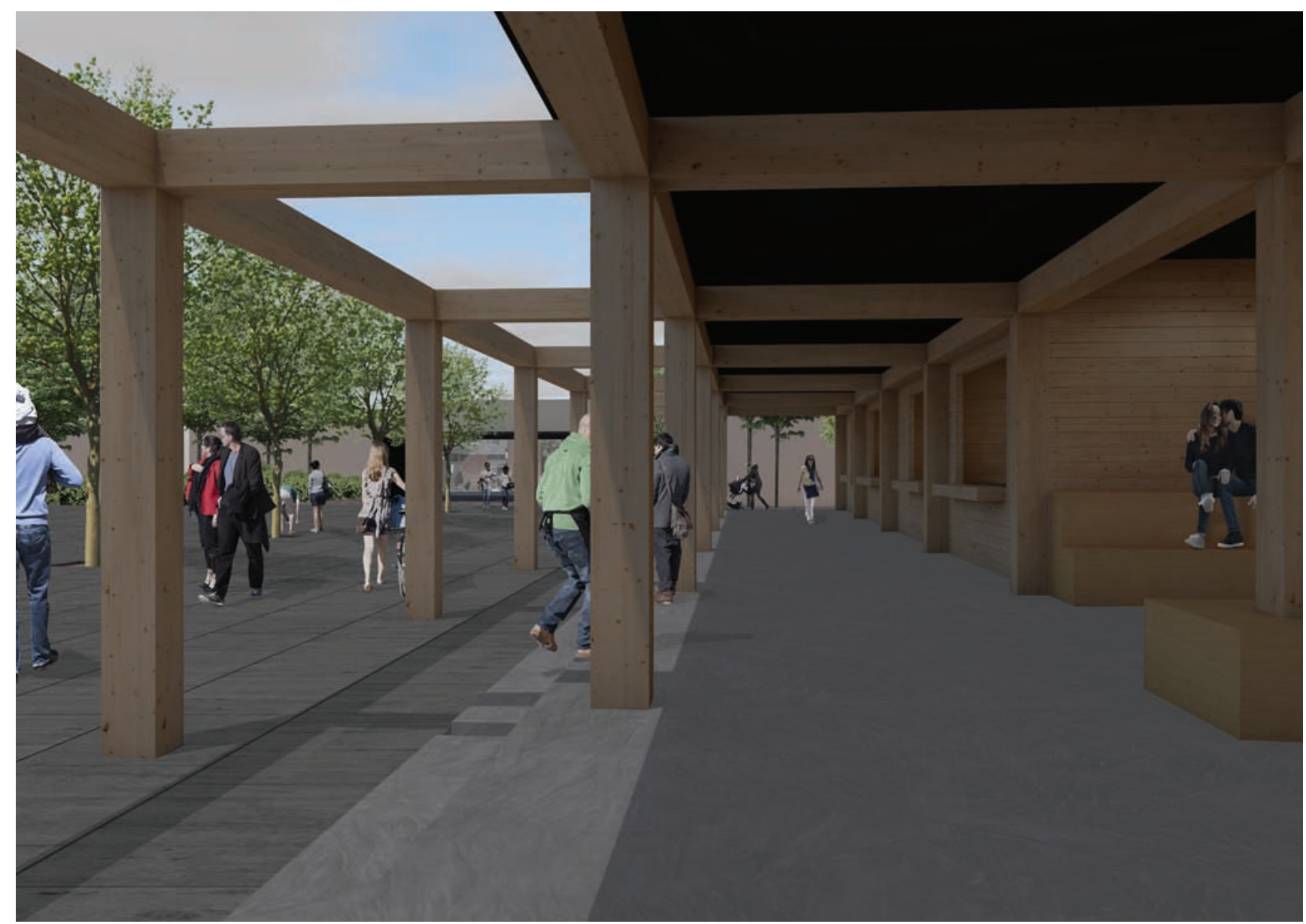

Fig. 7.4.3 shows the connection the internal space has with the landscape and people in it, and it shows how a sliver of this design creates different zones in which a variety of activities can occur. Ngaio trees and herbaceous planting provides the footpath (2) with a sheltered area for pedestrians to walk along without the busy road (1) affecting the experience. Additional planting reduces the dominance of the wind wall and separates the footpath from the new public space. Several more zones exist within the enclosed public space; the first is a lowered area (3) with sheltering canopy planting carried on from the forest that provides places for people to pause, to be part of both the moving civic space and peaceful planting area. People that occupy this lowered area are not fully committed to exploring the large forest area and want to remain in an area where they can observe activity. The level change (4) provides a place for a variety of lingering to occur, in this case, the café has set up some extra tables to integrate their customers with the landscape, seating for the café is also provided inside (7) and against the façade (6). The walking zone (5) is in the middle of all of this activity, and itself is divided in some places with planting. A similar division of zones is seen in Fig. 7.4.2

Fig. 7.4.4 Render taken within the 'popup style' design approach showing its connection to the movement, with the entrance into the space in the background 


\section{SUNLIT BUSH ENCLAVE}

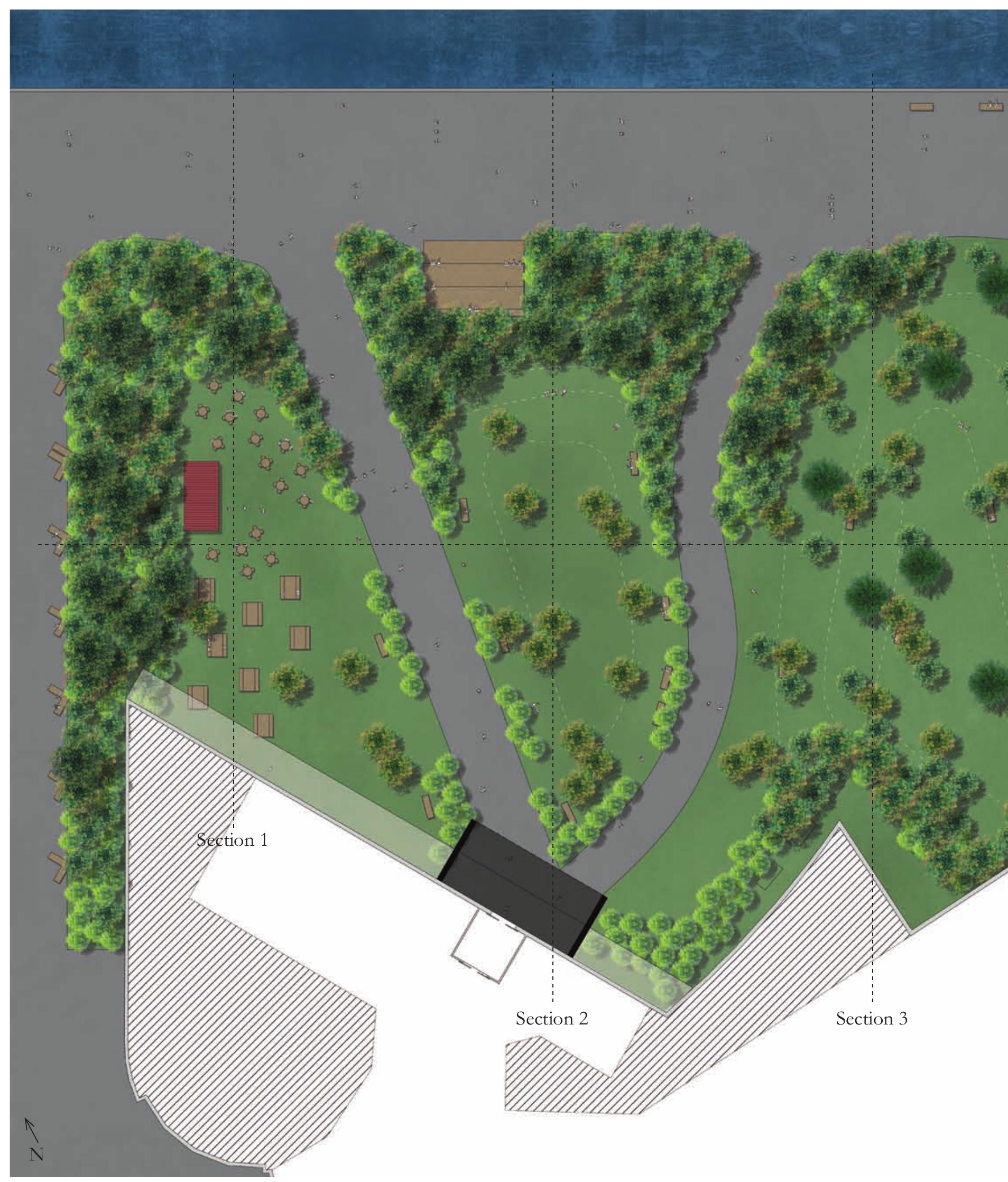




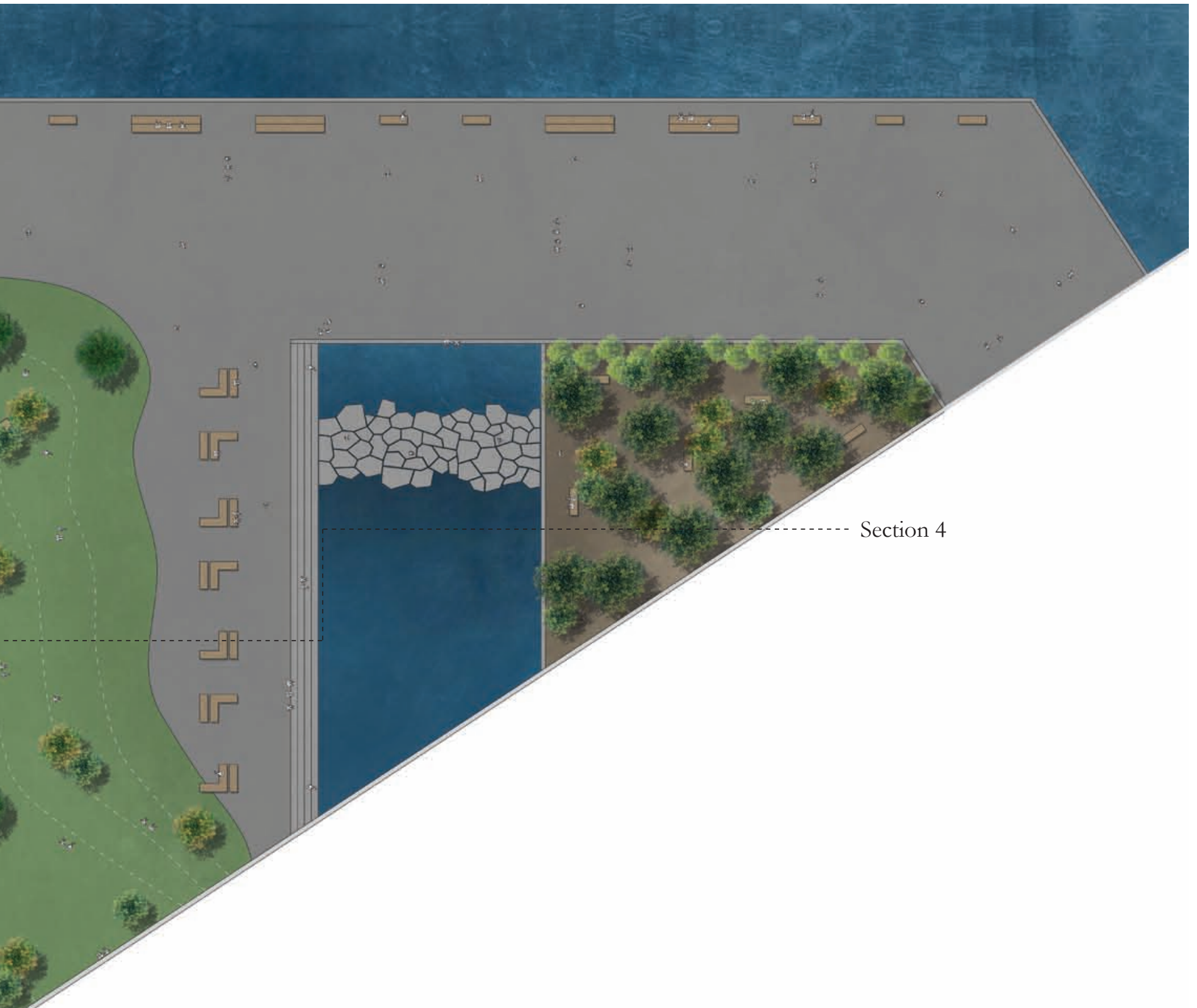

Fig. 7.5.1 Zoom plan 1:500 of the bush enclave public space 
Variety of Spaces
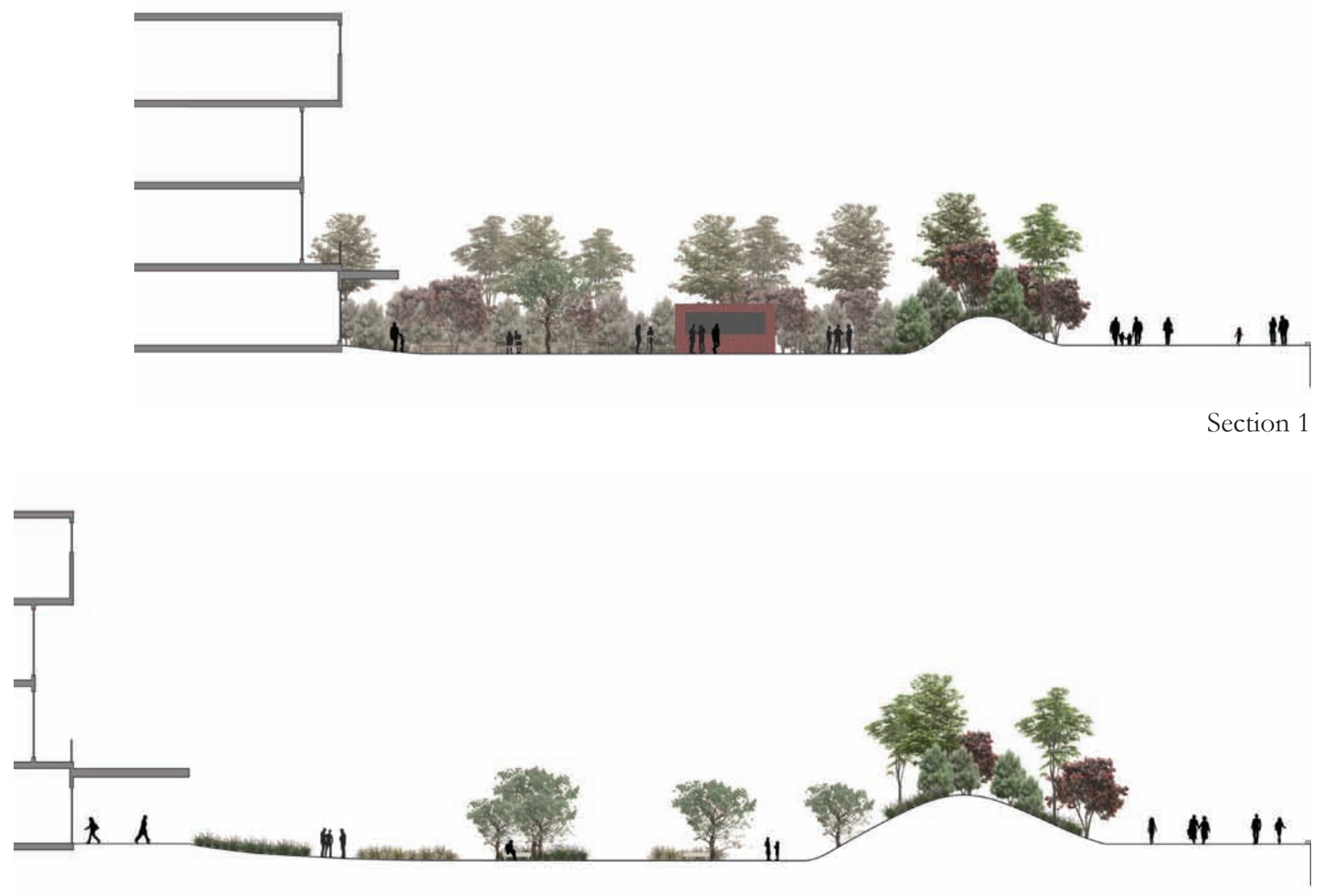

Section 2

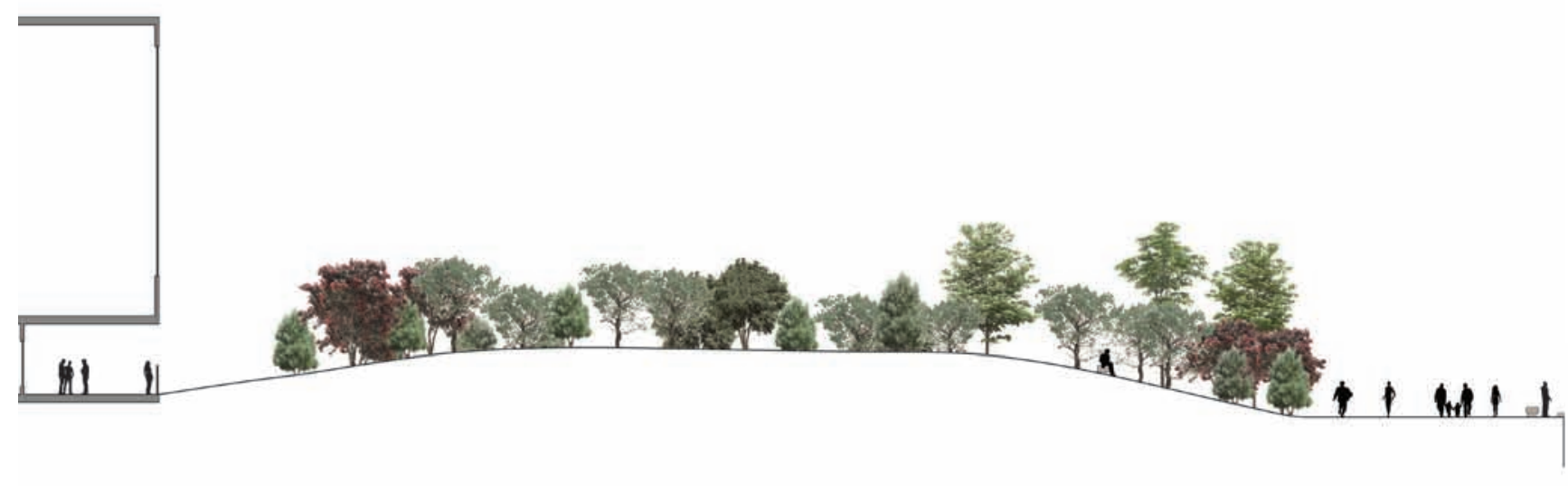

Section 3

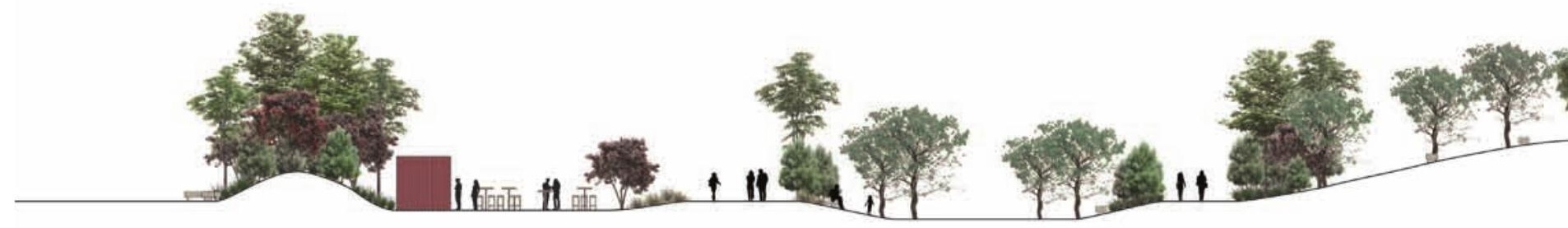


There are several ways to potentially interact with the natural environment in these spaces; they are inspired by a natural New Zealand landscape, which increases people's connection with the landscape of the site. The first potential opportunity for engagement is a bar/café within a shipping container where its seating is surrounded by dense bush, the design provides a sheltered space for customers to enjoy a drink with friends in a unique setting.

On the other side of the main path is a space lowered from surrounding areas where people can sit under kowhai trees or against a slope where they can enjoy the sun streaming into the space.

The third space is a large grassy hill that rises above 4 metres, and it provides shelter for the spaces within the enclave and creates many vantage points for people to view the harbour. The entire hill is easy to climb which creates a traversable barrier that has different limitations depending on who the person is.

Over the hill is an area that connects to both the natural bush enclave and the concrete promenade, and provides additional seating for people to occupy depending on their desired use of the space. A set of steps leads down to a pond that creates places for people to have a connection with the water visually, and physically by allowing them to touch the water or cross over the water.

The space across the water, only accessible via stepping-stones, is a sheltered and secluded microclimate that draws its design from the forest on the other side of Te Papa and provides a place of escape and intrigue.

Fig. 7.5.2 Section of the bar space that is surrounded by dense bush planting 1:500

Fig. 7.5.3 Section of the grassy area beneath kowhai trees, with the large hill to provide shelter from the wind 1:500

Fig. 7.5.4 Section of the hill that provides shelter and lookout areas 1:500

Fig. 7.5.5 Long section through the length of the space shows how all the different spaces are both connected and separated 1:500 


\section{Sun Angle Study}

A significant part of the design of this space is the sun that is able to stream into this site, and the following sections display the affect the planting has on the amount of sun coming in, it will hit the space at different angles and stream through gaps in the plants.

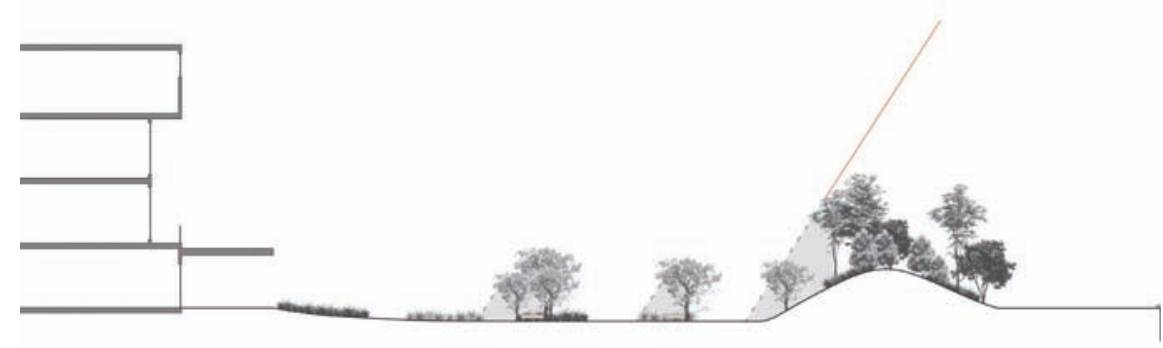

Spring

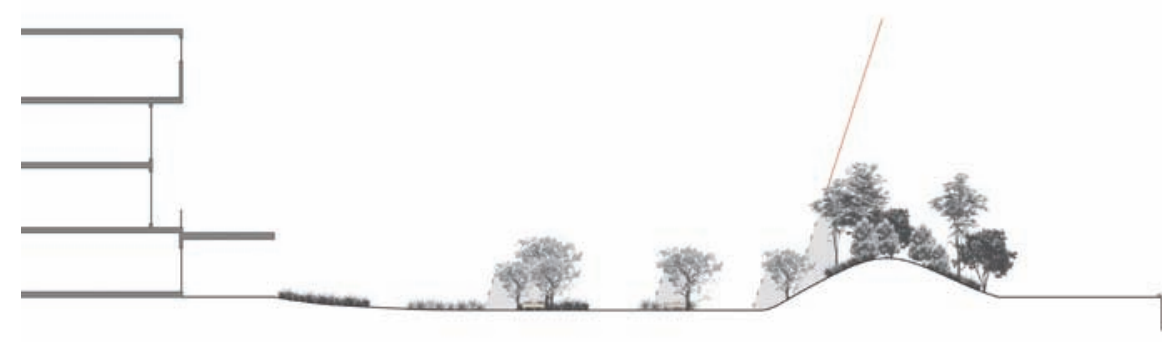

Summer

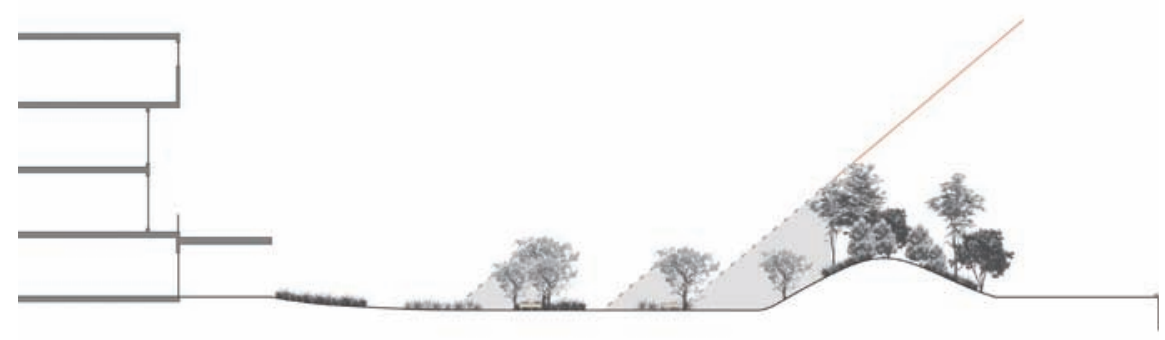

Autumn

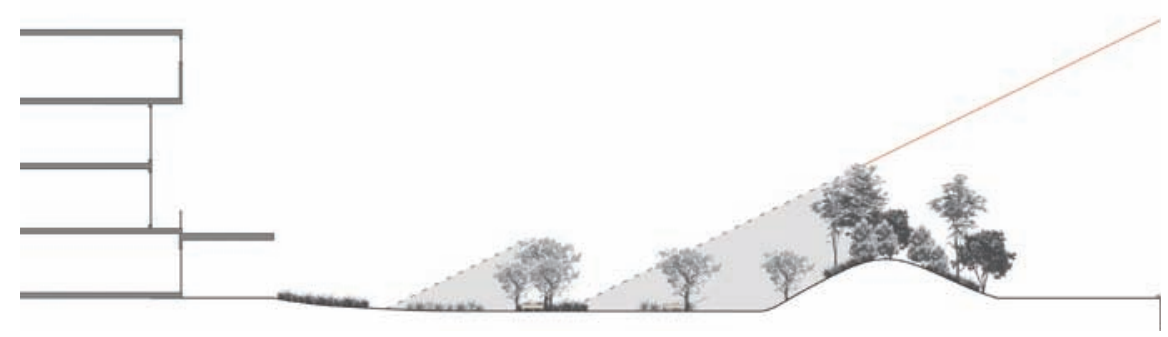

Winter 


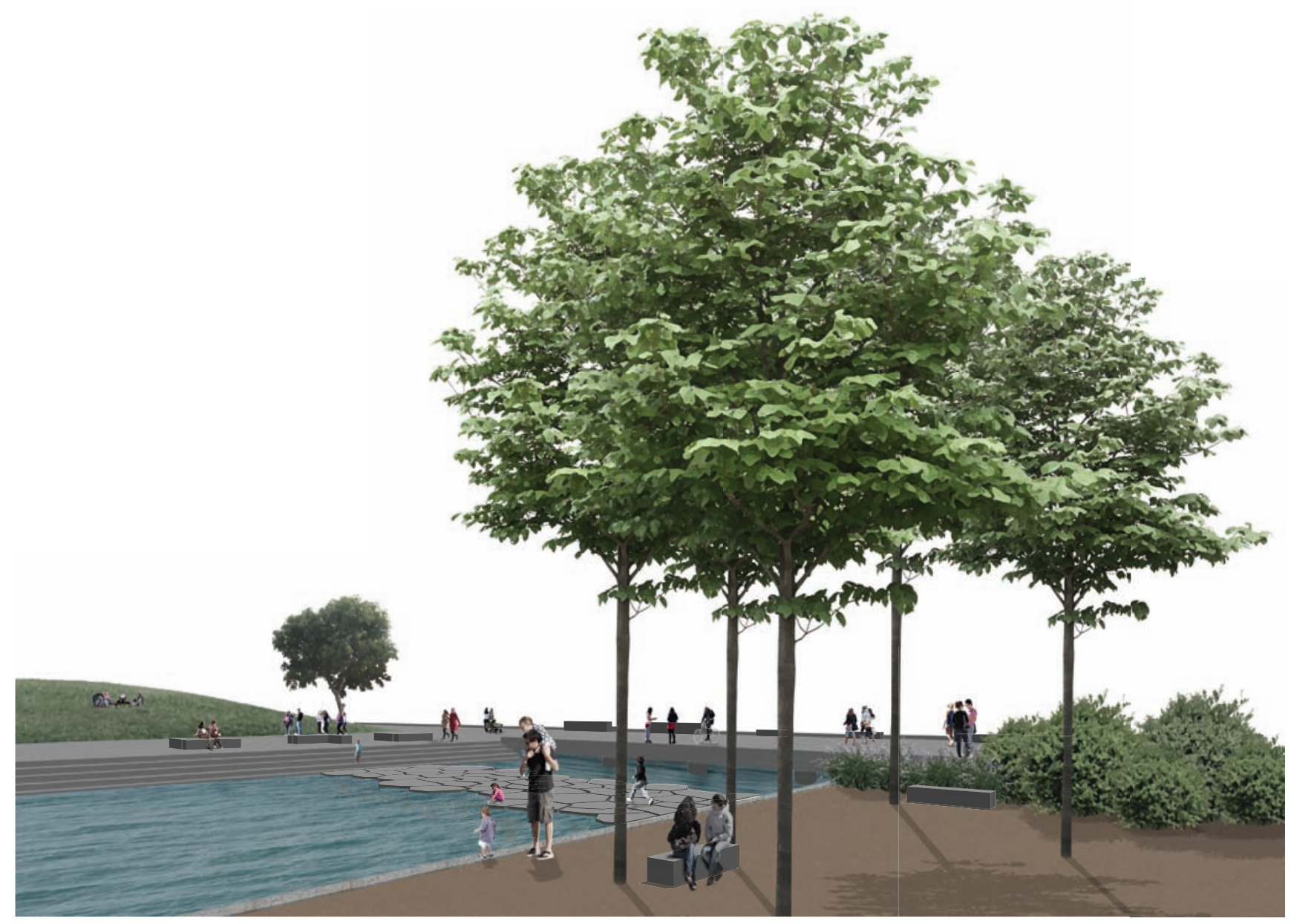

Fig. 7.5.6 Sun studies of the four seasons demonstrate the shade created in the space for each of them

Fig. 7.5.7 Render taken from within the secluded area of this space, looking back out over the pond to the promenade and bill 


\section{PLAYFUL ENTRANCE}

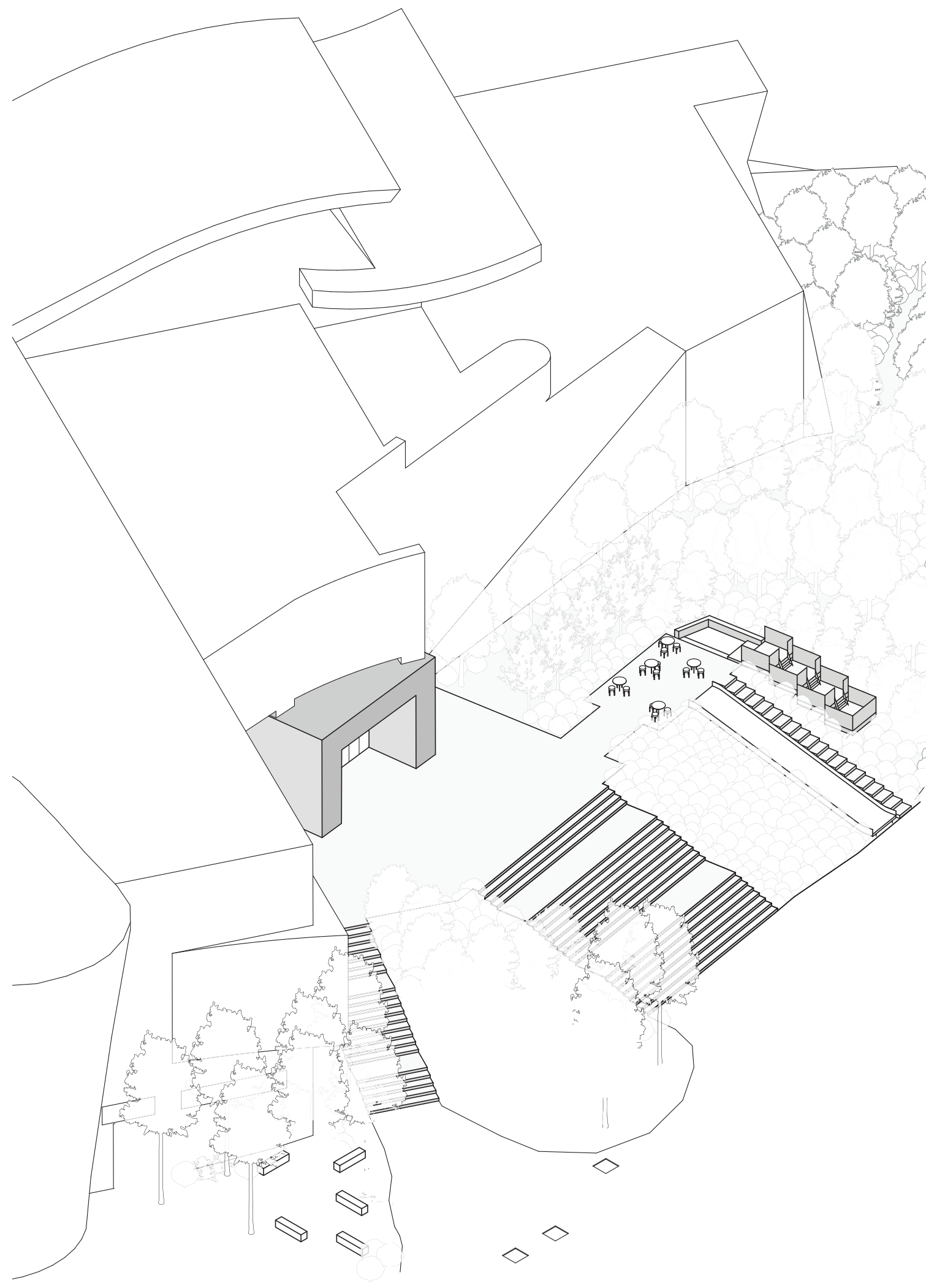




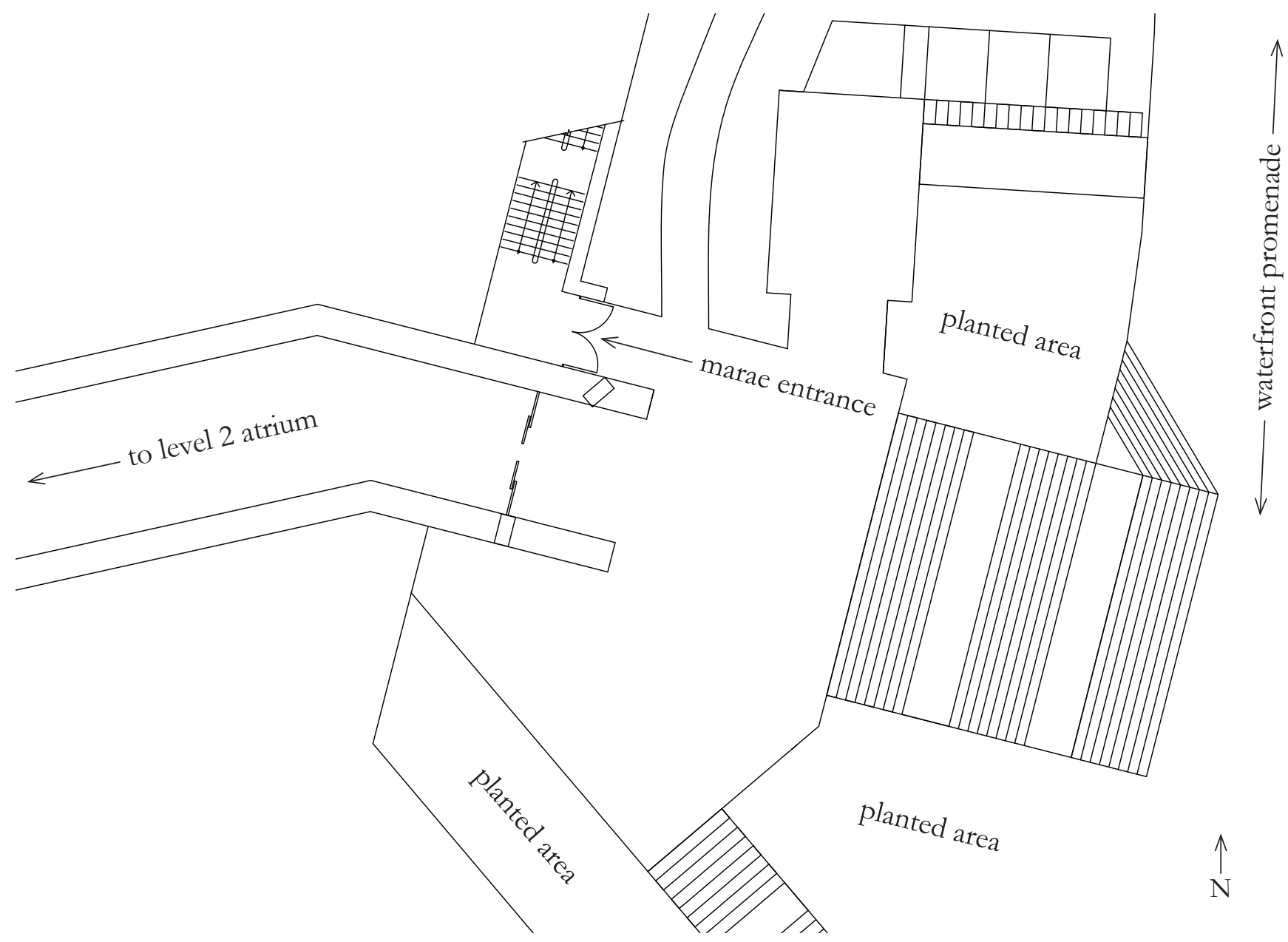

This new entrance creates the opportunity to welcome people through to the atrium space on level two, which is the most important space within the museum in terms of circulation and anchoring the movement. The block design for the entrance appears, to the public, as a separate architectural element that has broken through the building, rather than blending in. The entrance design is a continuous space through to the atrium, through which different exhibitions suitable for this type of display could be installed, creating a journey as people move from landscape to interior, piercing the facade of Te Papa. Two different types of stairs are offered as a way to reach he entrance, one grand staircase and one smaller one surrounded by a variety of planting where someone must weave through putaputaweta trees to reach it.

Fig. 7.8.1 (opposite) Isometric of the new entrance into Te Papa and the playful public space around it

Fig. 7.8.2 Plan 1:300 shows bow the entrance cuts into the existing building 


\section{WIND SHELTER}

The wind wall and wind gates provide the space with as much shelter as possible while still accommodating for the range of movement that will be found in the site. The roadside wind wall remains opaque to allow the new civic space to be fully enclosed. The wind wall found between the civic space and the waterfront is designed with glass to allow the visual connections toward the harbour, and to ensure the space is integrated within the waterfront.

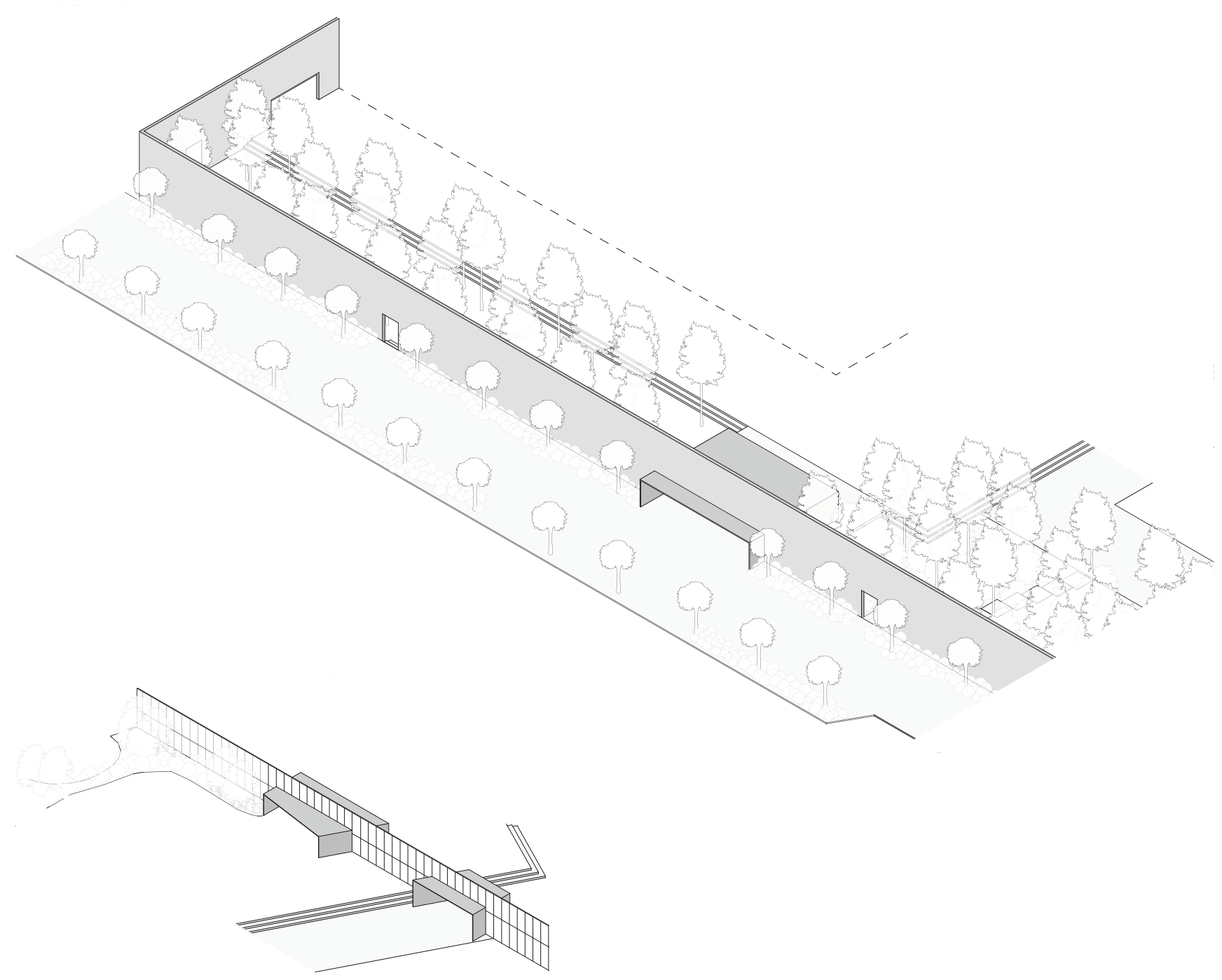

Fig. 6.11.1 Scan of sketches documenting the initial exploration of paving configuration 


\section{WHARF EDGE}

The following is an example of the range of edges that the new design provides, a variety that will add interest to the journey of the walker but also create new opportunities for them to detour off the movement.

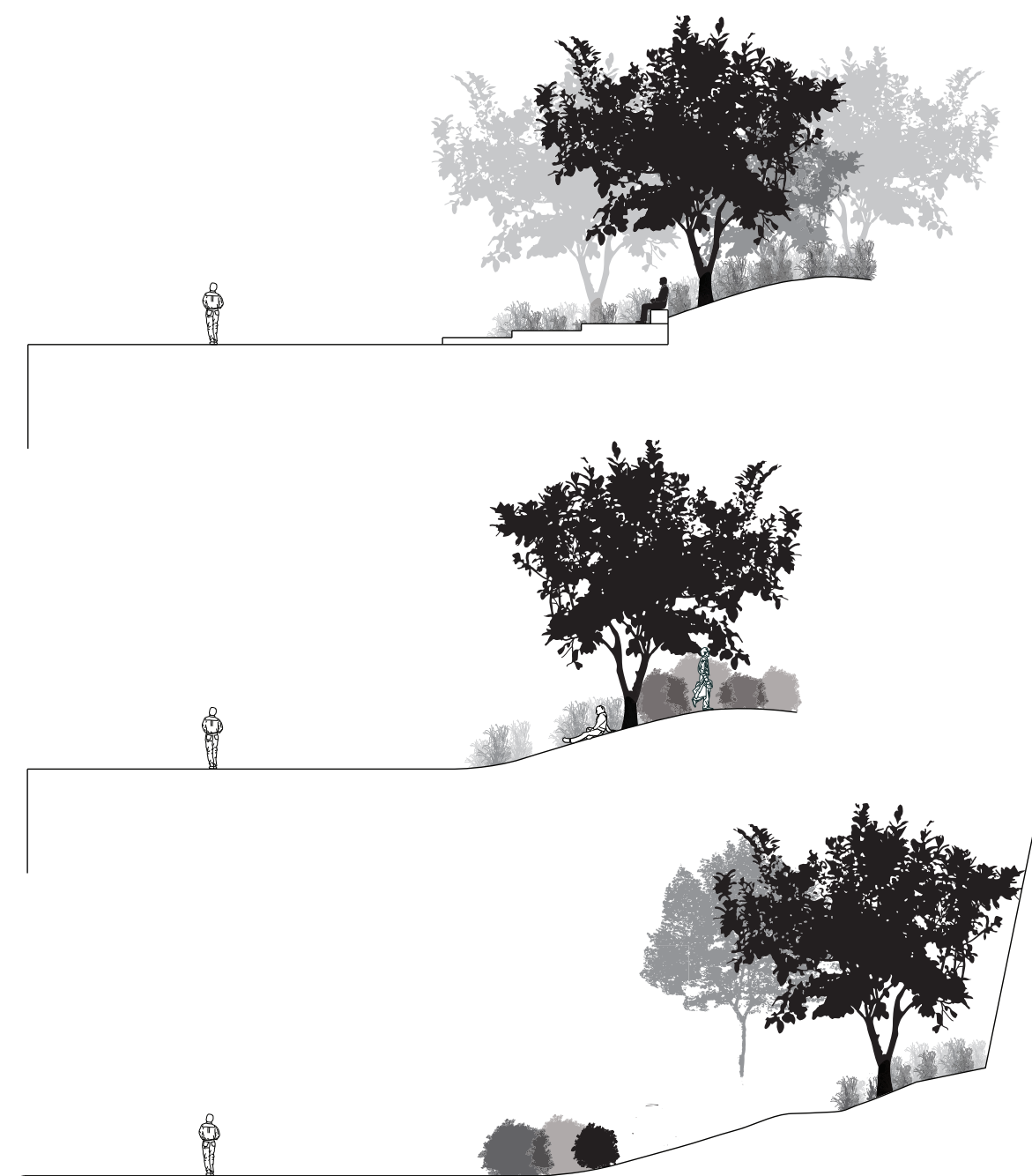




\section{CHANGES IN PUBLIC LIFE}

Comparing the following drawings demonstrates the vast amount of public opportunities that the new design creates. The previous research has provided the knowledge and design outcomes that allowed a successful design such as this to be achieved. Every one of the public life categories (found on opposite page) were enhanced in this waterfront location. The dominant flows that exist in the before analysis are still seen clearly in the new design, and the areas that lacked a focus for the movement have the potential to coordinate and behave in similar ways.

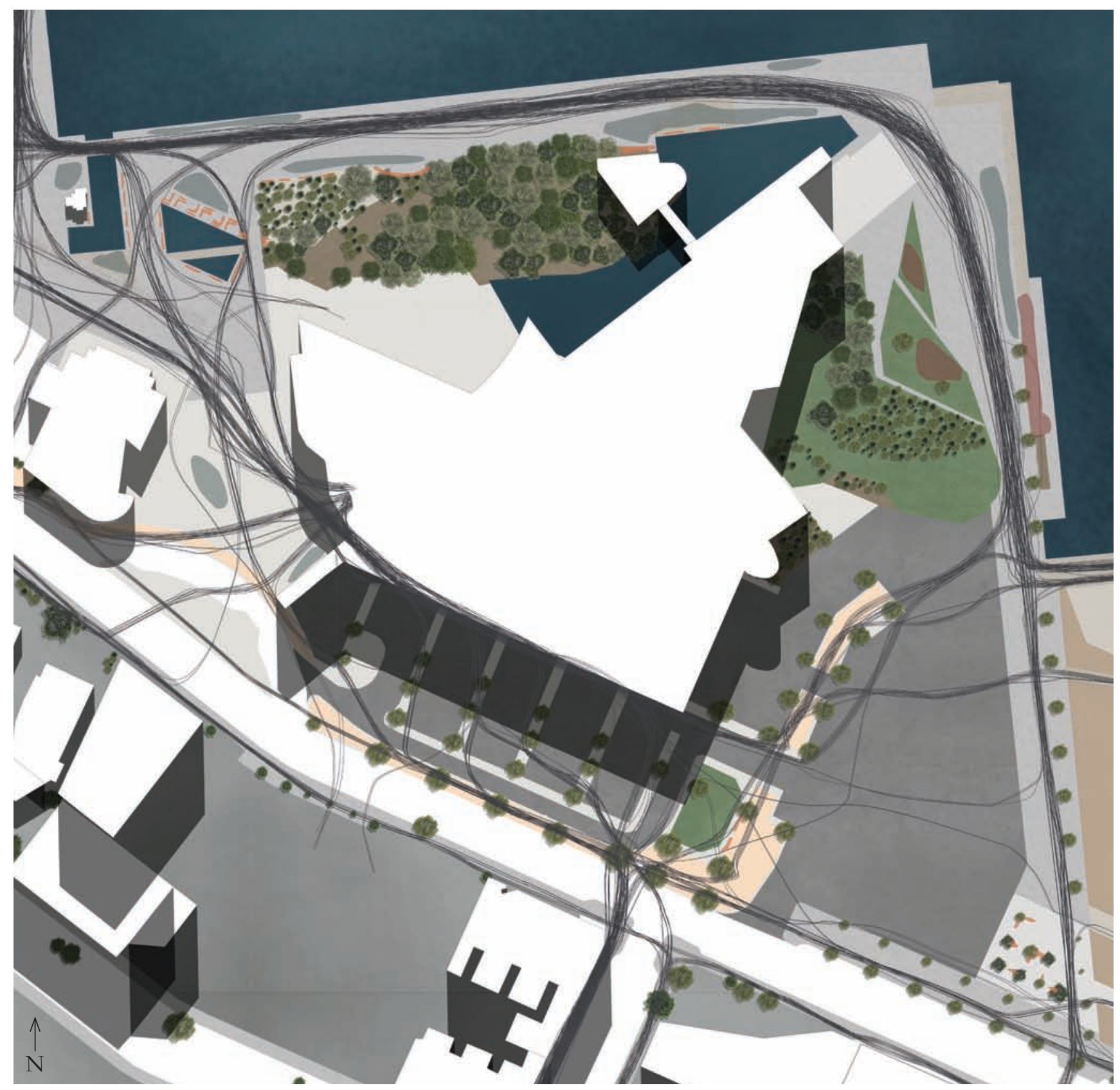

Fig. 6.11.1 Scan of sketches documenting the initial exploration of paving configuration 


\section{Physical Seats}

Physical seats are bench seats, picnic tables, and bar tables that are placed there directly for people to sit on

\section{Occupiable Landscape}

Occupiable landscape are elements within the landscape that may invite people to engage with them. These can be staircases, grassy hills and raised edges.

\section{Brief + Spontaneous Linger Space}

These are spaces where the movement has been coordinated in a way that leaves a clear zone where people can temporarily stop without being in the way of others.

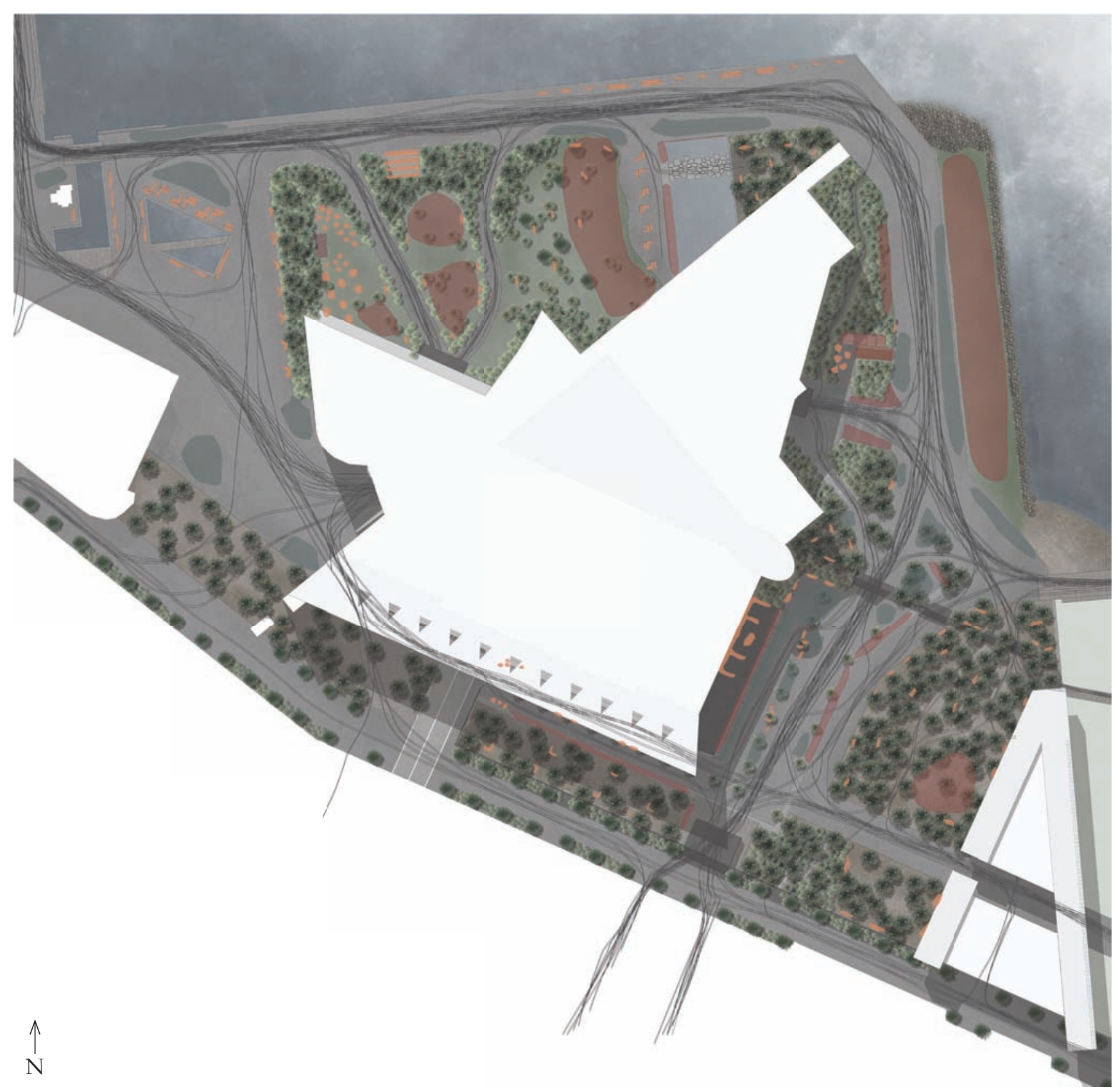

Fig. 6.11.2 Further research lead to this layout of paving, which creates edges within a larger public space to create various lingering opportunities 


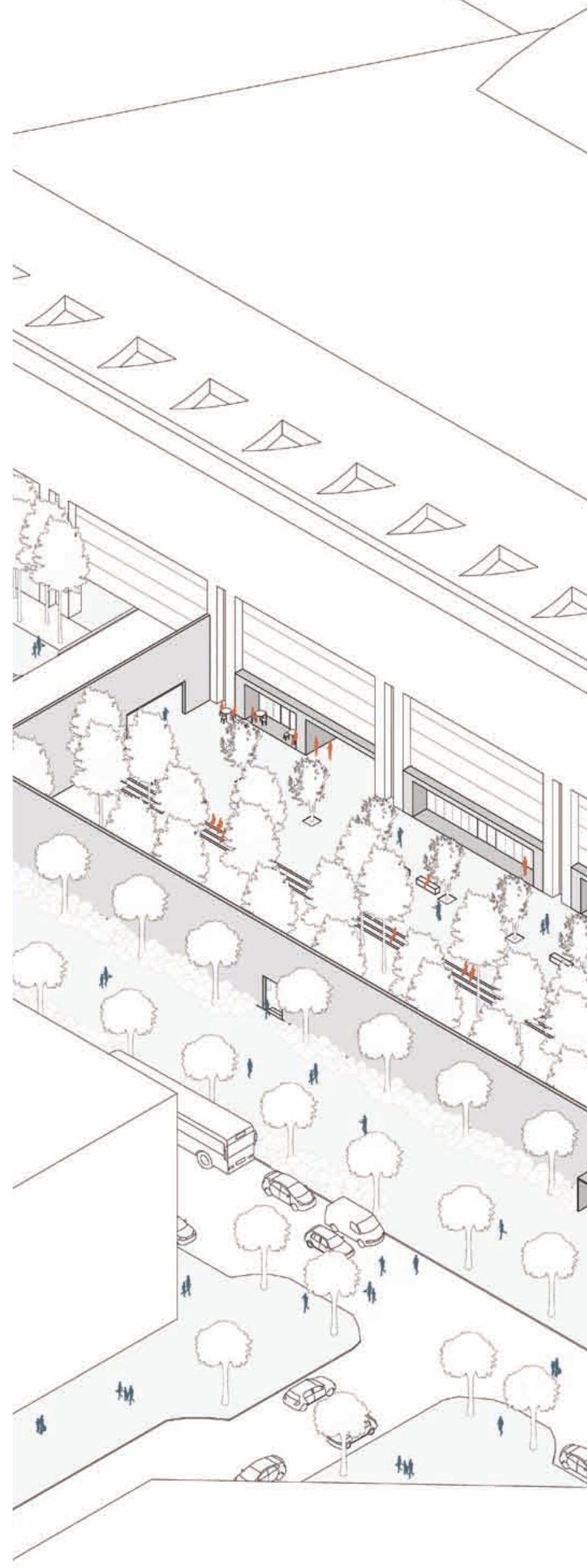



This chapter analysed the final design in terms of what it would bring to Te Papa, Wellington City, the waterfront, and the public life that exists within it. This analysis is able to be made because of the intensive site observations and analysis that was established at the beginning of this research. It shows the potential for the creation of new public life and the opportunities provided for the existing public life.

The before and after comparison demonstrate how public life is likely to have been changed because of the design. It showed all the places that were once neglected along the edges of the building are now places that should facilitate layers of activity and uninterrupted movement.

A range of drawings are used when it is best suited to show various aspects of the public spaces created. Renders are used to show the depth of the space and the atmosphere that exists within it, something that is unable to be displayed through any means of 2D drawing; plans give a technical, top-down view on the configuration of spaces; sections provide an understanding of how the adjacent spaces may or may not interact with each other.

The final stage of this chapter was to visualise the entire space and all the layers of activity that could occur with the creation of a large isometric drawing. This drawing shows how many of these designed spaces have been linked and demonstrates the consideration given to level changes and planting as a way to define the edges of the movement and create opportunities for people to linger. 


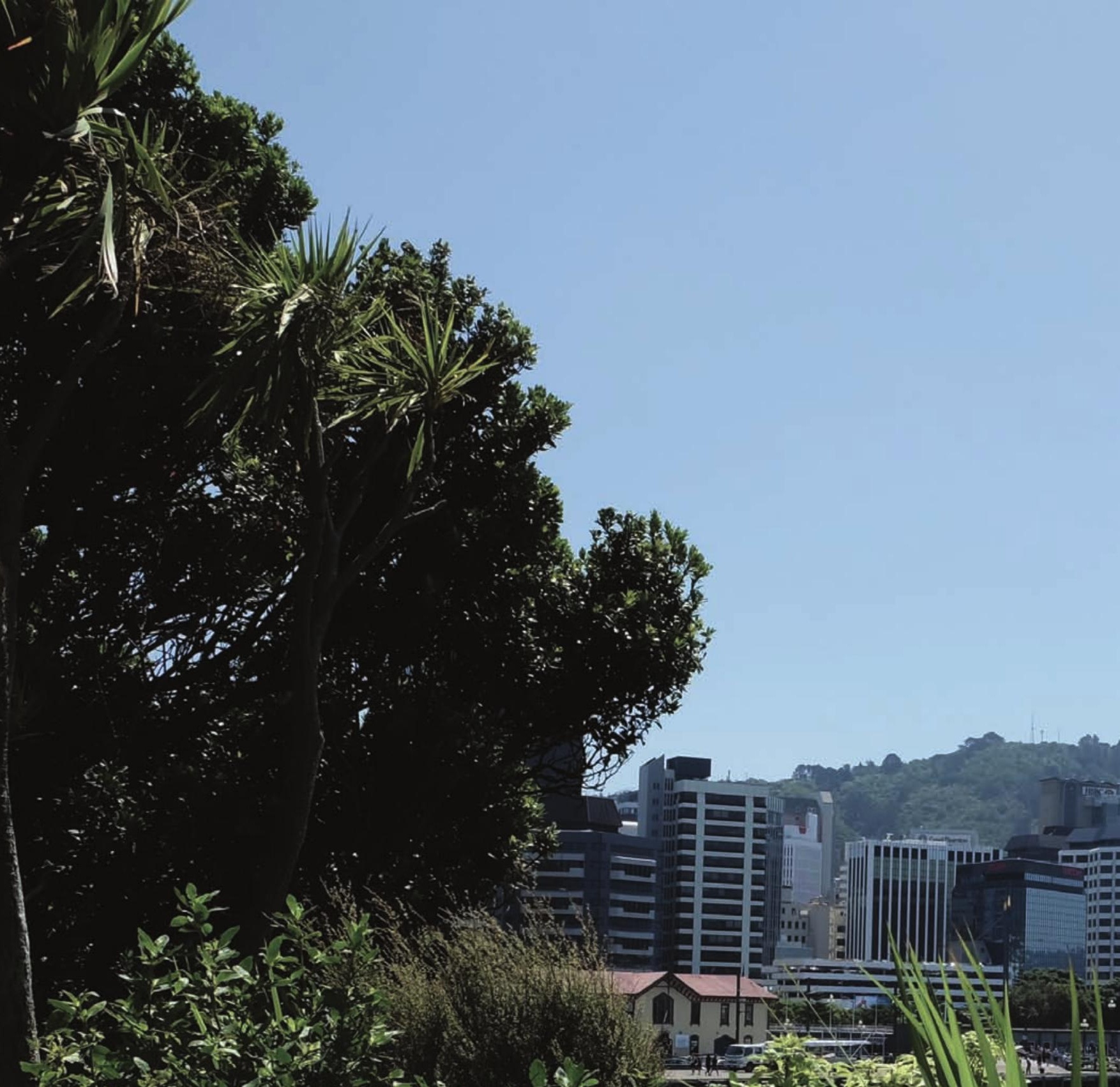

$t^{2}+10$ L. (1)

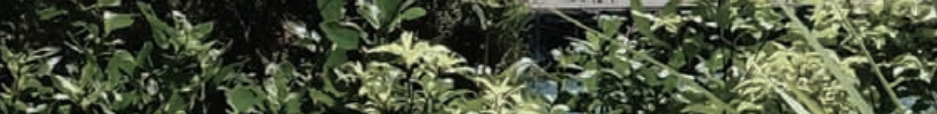
1.5.

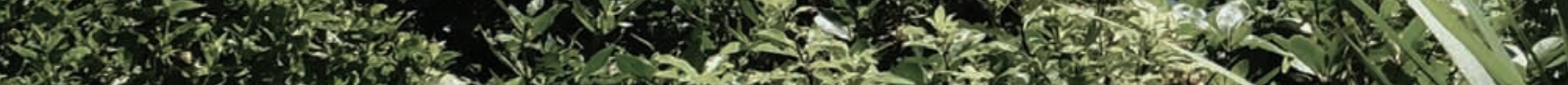

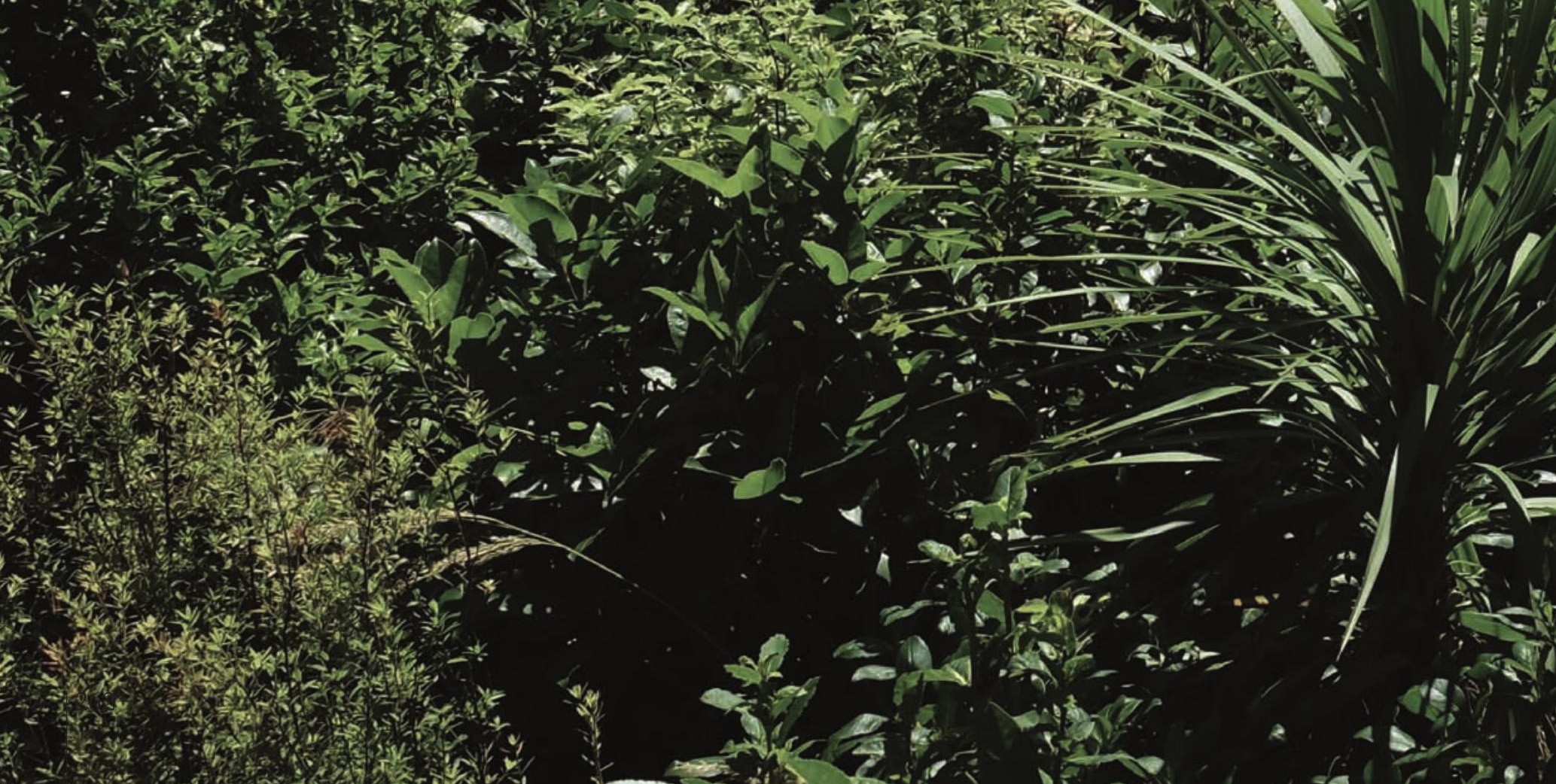

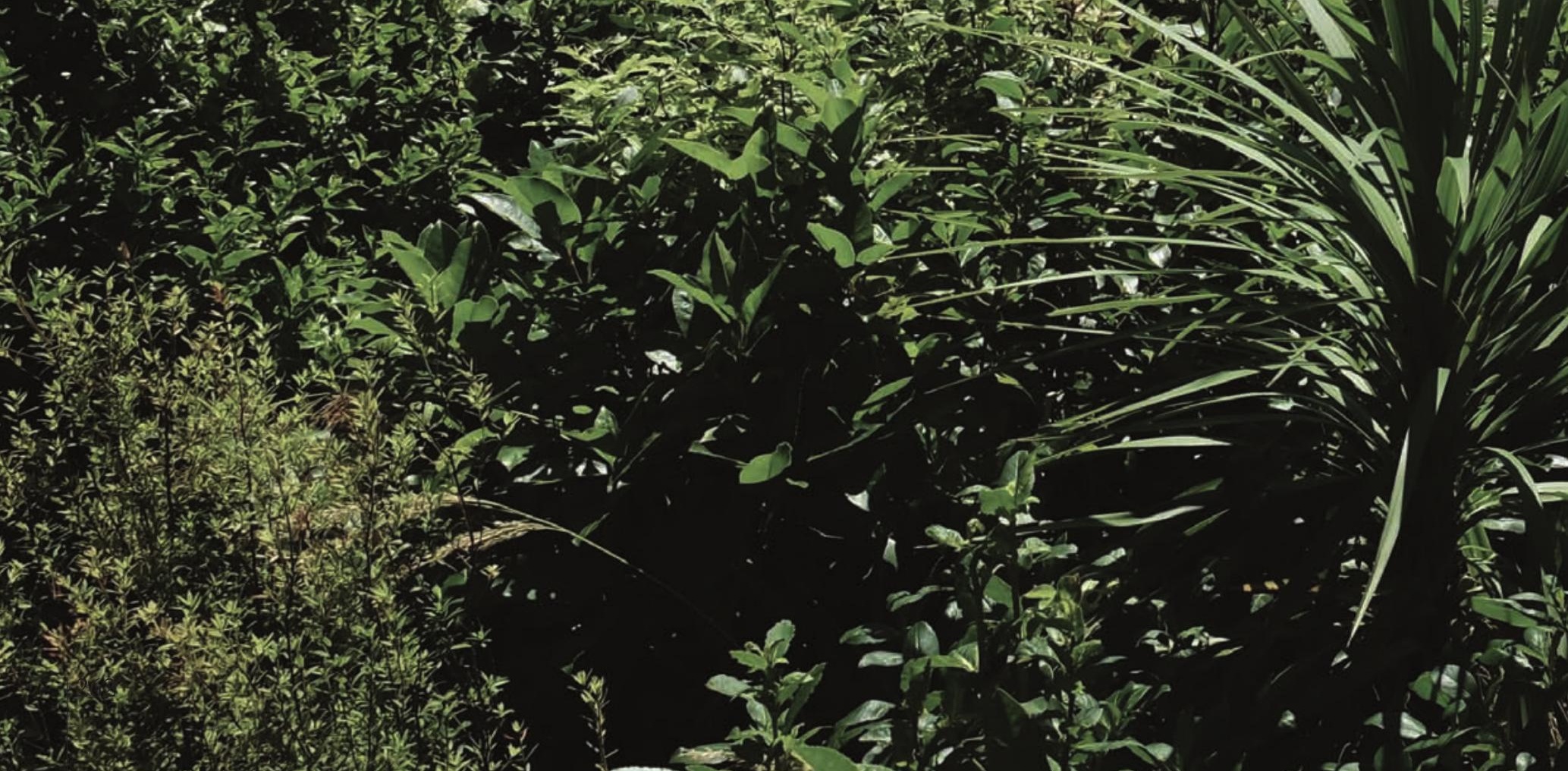




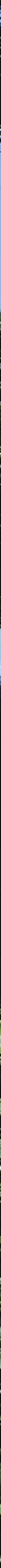


${ }^{204}$ 
In an increasingly urban world, the only interaction many people get with the natural environment is through the open spaces within the city. People rely on their city council to ensure that there are places like this around the city that are consistently maintained and upgraded to stay relevant with what the city and its inhabitants need. The lack of open spaces that respond to the current city life is evident in Wellington City, where there has been a lull in the development of open public spaces that create new opportunities for public life to generate. The location of this research, associated with Te Papa, is an area that has suffered from this lack of development, the extent of which has been thoroughly explored and demonstrated throughout this thesis.

The original disruption in the landscape was caused by the design and placement of Te Papa that was the result of a lack of foresight from the Council and the innovative approach to ensure that the interior remained a controlled microclimate. What was originally conceptualised to be a connector of waterfront and city did more to disconnect them and, even more so, create areas of disconnect within the waterfront.

The first of these elements of disconnection was the distance, both visual and physical, that $\mathrm{Te}$ Papa placed between itself and the water's edge. The combination of both the need to accommodate the annual streetcar race, The Wellington 500, and the architects' decision to include a fully contained native bush environment for knowledge discovery purposes ensured that there was no chance for the original design to create a connection with the water that the design initially set out to do.

The next element of disconnection was the architectural peninsula that extended from the main form of Te Papa out towards the city that was intended as a gesture of the connection the building 'provided' with the city. The true result of this peninsula is seen in disruption created in the landscape, as it creates a huge disconnection with Te Papa's forecourt and any part of the landscape south of Te Papa, and cuts off any spontaneous exploration that visitors to Te Papa could have with that side of the city. Because of this disconnect, the southern area of Te Papa is considered to be back-of-house and people perceive it as neither part of the waterfront nor part of the city, but instead use it solely as a thoroughfare between the two. The physical design of Te Papa is also an element of disconnection, caused by the neglect of the ground floor to respond to the people moving and lingering around the site, and the floors above to provide visual connections with the unique environment that Te Papa is situated in. 
The surrounding landscape must adapt to create new opportunities of engagement with the building and resolve areas where there is a lack of public life due to the disconnections created. Landscape architecture has the ability to reconstruct the landscape, not only physically and visually but also perceptually, due to the significant focus it gives to the singularity of the landscape and its context.. In this research, the design of the landscape is used to:

- signify this area as a valuable public space,

- create a coherent threshold between city and waterfront that provides connection to both,

- coordinate movement in a way that enhances the potential that the public spaces provide for new public life,

- connect Te Papa with its context and create new areas where people can connect with Te Papa.

\section{How can landscape architecture counter the negative affects a large building has on public life?}

Discovering ways that landscape architecture can activate building edges was initiated by a precedent study of buildings that engaged their context and provided links between the interior and the landscape. The influence of precedents can be seen throughout the design testing that led up to the final outcome for the design gallery. Ground floor movement links and desire to connect the interior spaces and landscape with each other were always the subject of the design research and were iterated upon until an acceptable solution for the architectural form was reached.

All of the ways that this design-led research attempts to activate edges was in response to the aims, designing for a vast range of edge activities ensured that there would be a way to engage with the landscape and Te Papa for the majority of people, if not all people, in some way. The redesign of creates engagement with Te Papa's edge by an entirely landscape approach, which provides numerous opportunities for the public life of the space including a physical interaction with the building's facade. Because the new design relies on a combination of the built form and landscape to define these spaces, the new public space pulls the characteristics of the building into it and creates a landscape that connects to the building it surrounds.

An essential part of this design-led research was understanding how specific movement facilitates different public life. It focused on:

- overall movement patterns,

- specific paths taken,

- specific people's movement,

- lingering that occurred in direct relation to movement.

Gaining an in-depth understanding of movement and the public life generated because of it provided the research with the tools necessary to analyse new designs with regards to how potential movement would be coordinated and identifying the locations where different types of public life would have opportunities to occur. Movement was determined to be the biggest influencer in terms of the potential for new public life, if people can move to or see into a space, whether they go there or not, it creates a huge opportunity for the public realm to be interactive and engaging. Coordinating movement, and the lingering that occurs because 
of it, has been the focus of this thesis from the beginning and is a significant design tool when dealing with existing public spaces. and working with movement will be essential for any project that relates to a similar scenario as this, where a building has disrupted the landscape.

During this design-led research, I have learnt so much about both myself and the discipline of landscape architecture. Starting off my education with three years of interior architecture, and then only two of landscape architecture before beginning this thesis gave me a unique approach to designing and observing spaces, and during many stages of the research I was also learning as I went along. One area that I paid close attention to during the research was planting, and the spaces that can be created when the size and shape of a plant is considered in relation to the human body and their potential interaction. This area of research took up a large duration of my research, due to the fact that previously to this I knew very little about different types of planting, so to have such a large focus on planting in both the research and design was something I strived for. I learnt the value of intensive iteration processes in order to achieve an outcome that was well explored to ensure that the desired response from the public will be produced This is something that I have often not been able to accomplish previously due to time constraints.

\section{Limitations}

Whilst the project produced in-depth results it would have furthered the scope of the research if there had been discussions with Te Papa in order to bring their aspirations and plans into consideration. The research may have been limited by my own perception of the site, having lived in Wellington for several years and occupied many spaces in and around the building. Individual design strategies from the Design Direction chapter can be applied to a vast range of architecture and landscape architecture projects, though they will produce stronger designs when they are used together. Aspects of this research could be employed at other locations where a building has disrupted the landscape. In regards to further research around Te Papa, onsite testing of new temporary destinations with the south-east carpark would provide further evidence to analyse and advance the understanding this research had of potential movement and lingering by observing the changes in real time. 


\section{BIBLIOGRAPHY}

A coastal forest garden. (n.d.). Retrieved July, 2018, from http://www.temotukairangi.co.nz/planting/best-plantchoices-for/coastal-forest-garden

Alexander, C. (1980). The timeless way of building. New York: Oxford University Press.

Ashihara, Y. (1981). Exterior design in arcbitecture. New York: Van Nostrand Reinhold.

Bagneres, L. (2015, August 28). Triangulation \& Public Space: Bringing citizens together. Retrieved March, 2018, from https:/ /ecourbanismworldwide.wordpress.com/2015/08/18/triangulation-public-space-bringing-citizenstogether/comment-page-1/

Berrizbeitia, A., \& Pollak, L. (2003). Inside outside: Between arcbitecture and landscape. Massachusetts: Rockport.

Capital spaces: Draft open space strategy. (1998). Wellington, N.Z.: Wellington City Council.

Carmona, M., \& Tiesdell, S. (2015). Urban design reader. London: Routledge.

Carr, S., Francis, M., Rivlin, L. G., \& Stone, A. M. (2009). Public space. Cambridge: Cambridge University Press.

De Arruda Campos, Maria Beatriz Mattei De, M. B. (2000). Urban public spaces: A study of the relation between spatial configuration and use patterns(Unpublished master's thesis). University of London. Retrieved May, 2018, from http://discovery.ucl.ac.uk/1318055/1/321909.pdf

Elenio, P. (2014). The Dominion Post: 150 years of news. Wellington: The Dominion Post/Fairfax Media.

Fowler, M. (1981). Wellington, Wellington ... a bistory. Mallinson Rendel: Wellington, N.Z.

Frank Gehry and the Lost Vision for Te Papa. (2011, June 28). Retrieved May, 2018, from http://werewolf. co.nz/2011/06/frank-gehry-and-the-lost-vision-for-te-papa/

Frank Kitts Park. (n.d.). Retrieved May, 2018, from https://www.eventfinda.co.nz/venue/frank-kitts-parkwellington

Frank Kitts Park | WĀ. (2007). Retrieved May, 2018, from http://www.waal.co.nz/our-projects/urban/frank-kittspark/

Gehl, J., Kaefer, L. J., \& Reigstad, S. (2006). Close encounters with buildings. URBAN DESIGN International,11(1), 29-47. doi:10.1057/palgrave.udi.9000162

Gehl, J., \& Koch, J. (2011). Life between buildings: Using public space. Washington, DC: Island Press.

Hillier, B., \& Hanson, J. (2005). The social logic of space. Cambridge: Cambridge Univ. Press.

Krupat, E. (1964). People in cities: The urban environment and its effects. London: British Road Federation. 
Lynch, K. (1982). The Image of the City. CAMBRIDGE, MASS. (U.A.): M.I.T. PR.

Madanipour, A. (2014). Public and Private Spaces of the City. Abingdon, Oxon: Taylor and Francis.

Map of Te Papa. (n.d.). Retrieved March, 2018, from https:/ /www.tepapa.govt.nz/visit/plan-your-visit/map-tepapa

Michelson, W. M., Marans, R. W., \& Bechtel, R. B. (1990). Methods in environmental and behavioral research. Malabar, FL: R.E. Krieger Pub.

Museum of New Zealand Te Papa Tongarewa Annual Report 2016/17(Rep.). (2017). Retrieved August, 2018, from https://www.tepapa.govt.nz/sites/default/files/te_papa_annual_report_2016-17_online.pdf

Museum of New Zealand Te Papa Tongarewa Statement of Performance Expectations 2017/18(Rep.). (2017). Retrieved August, 2018, from https://www.tepapa.govt.nz/sites/default/files/statement_of_performance_ expectations_2017_18_002.pdf

Newshub. (2018, August 14). Peter Jackson's Wellington movie museum plans scrapped. Retrieved August, 2018, from https://www.newshub.co.nz/home/entertainment/2018/08/peter-jackson-s-wellington-movie-museumplans-scrapped.html

Niven, S. (1992, September/October). Bicultural condition at museum's heart. Architecture New Zealand.

Niven, S. (1998, February). Peninsular and Square. Architecture New Zealand.

OByrne, C. (2016). Evaluating the Influence of Governance on the Built form: The Redevelopment of Wellington, New Zealands Waterfront Precinct: A thesis submitted to the Victoria University of Wellington in fulfilment of the requirements for the degree of Doctor of Philosophy(Unpublished master's thesis). Victoria University of Wellington.

New Zealand. (n.d.). Our capital spaces: An open spaces and recreation framework for Wellington, 2013-23. Wellington: Wellington City Council. Retrieved August, 2018, from https://wellington.govt.nz/ /media/your-council/ projects/files/our-capital-spaces.pdf

Places for People: Establishing a platform of evidence to shape Melbourne's future(Rep.). (2016). Melbourne: The City of Melbourne.

Project for Public Spaces. (2015, October 18). A Street You Go To, Not Just Through: Principles for Fostering Streets as Places. Retrieved July, 2018, from https://www.pps.org/article/8-principles-streets-as-places

Proshansky, H. M. (1974). Environmental psychology: Man and his physical setting. New York: Holt, Rinehart and Winston.

Reid, G. (1998, February). Museo-logic. Architecture New Zealand.

Semmens, S., Perrin, N. D., Dellow, G., \& Van Dissen, R. (2011). NZS 1170.5:2004 site subsoil classification of Wellington City. In Ninth Pacific Conference on Earthquake Engineering Building an Earthquake-Resilient Society. Auckland. Retrieved May, 2018, from http://nzsee.org.nz/db/2011/007.pdf

T.E.R:R.A.I.N - Taranaki Educational Resource: Research, Analysis and Information Network. (n.d.). Retrieved June, 2018, from http:/ /www.terrain.net.nz/friends-of-te-henui-group/table-1/marble-leaf-putuputuweta.html 
Te Papa Museum. (2015). Retrieved March, 2018, from https://www.unstudio.com/en/page/3229/te-papamuseum

Te Papa overcomes controversy to mark 20 years 'for the people, by the people'. (n.d.). Retrieved July, 2018, from https://www.stuff.co.nz/entertainment/arts/101060826/te-papa-to-mark-20-years-of-being-a-museum-forthe-people-by-the-people

Dalsgaard, A. M. (Director). (2012). The Human Scale[Motion picture on DVD]. Australia: Madman Entertainment Pty Ltd.

The Wellington Waterfront Framework(Rep.). (2001). Retrieved May, 2018, from https://wellington.govt.nz/ /media/ your-council/plans-policies-and-bylaws/plans-and-policies/a-to-z/waterfrontframewk/files/framework.pdf

Triangulation. (2011, January 17). Retrieved March, 2018, from https://spacesforpeople.wordpress. com/2011/01/16/triangulation/

Tz17’s Motorsport Videos. (2014, May 25). 1996 V8Supercars | Auckland Sprints | Round 2 | Wellington. Retrieved July, 2018, from https://www.youtube.com/watch?v=NT9bUi9uSRY

Viljoen, A., \& Bohn, K. (2014). Second nature urban agriculture: Designing productive cities. Abingdon, Oxon: Routledge.

Waitangi Park. (2016, October). Retrieved July, 2018, from http://www.landezine.com/index.php/2016/10/ waitangi2/

Watson, D., Plattus, A. J., \& Shibley, R. G. (2003). Time-saver standards for urban design. New York: McGraw-Hill.

Welcome to Wellington City population forecasts. (n.d.). Retrieved August, 2018, from https://forecast.idnz.co.nz/ wellington

Wellington Central. (n.d.). Retrieved August, 2018, from https://profile.idnz.co.nz/wellington/population?EndYear $=2006 \&$ WebID $=460$

Wellington (N.Z.)., City Council. (2000). Wellington City district plan: Te kaupapa whenua o Poneke. Wellington, (N.Z.): Wellington City Council. Retrieved July, 2018.

New Zealand. (2011). Wellington towards 2040: Smart capital. Wellington: Wellington City Council. Retrieved August, 2018, from https://wellington.govt.nz/ /media/your-council/plans-policies-and-bylaws/plans-and-policies/ato-z/wellington2040/files/wgtn2040-brochure.pdf

Whyte, W. H. (2018). The social life of small urban spaces. New York: Project for Public Spaces.

William H. Whyte. (2010, January 3). Retrieved March, 2018, from https://www.pps.org/article/wwhyte

Woolley, H. (2003). Urban open spaces. London: Spon Press.

Yska, R. (2006). Wellington. Auckland: Reed.

Zeisel, J. (2009). Inquiry by design: Environment, behavior, neuroscience in architecture, interiors, landscape, and planning. New York, NY: Norton. 


\section{LIST OF FIGURES}

\section{All figures not attributed are author's own.}

Fig. 2.1.1 Price, Neil. (1998). Quene savers at Te Papa opening [Photograph]. Retrieved from https://blog.tepapa. govt.nz/2018/02/14/remembering-te-papas-opening-day/

Fig. 2.1.2 Nancy \& Barry. (2012). Te Papa Museum [Photograph]. Retrieved from http://www.adventurephiles. com/2012/10/25/its-all-on-at-te-papa-museum-wellington/

Fig. 2.2.9 Niven, Stuart (1998). Harbour Park [Sketch]. In Architecture New Zealand. New Zealand: AGM Publishing.

Fig. 2.2.10 UN Studio. (2015). Te Papa Museum [Render]. Retrieved from https://www.unstudio.com/en/ page/3229/te-papa-museum

Fig. 2.2.11 Unknown. (2018). Artist's impressio of Frank Kitts Park revitalistion [Render]. Retrieved from https:// wellington.govt.nz/your-council/news/2018/04/franks-kitts-park-upgrade-approved

Fig. 2.2.12 WCC. (2016). The aluminium-clad design as seen from Cable Street [Render]. Retrieved from https://www. radionz.co.nz/news/national/310868/film-museum-plans-scale-up-with-fishy-design

Fig. 2.2.14 Peter Jackson's Wellington movie museum plans scrapped. (15/08/2018). Newshub. Retrieved from https://www.newshub.co.nz/home.html. [Screenshot]

Fig. 2.3.1 (1990). Jasmax Group model [Photograph]. In Architecture New Zealand. New Zealand: AGM Publishing.

Fig. 2.3.2 (1990). Boon Philip Cox Group model [Photograph]. In Architecture New Zealand. New Zealand: AGM Publishing.

Fig. 2.3.3 (1990). Warren and Mahoney model [Photograph]. In Architecture New Zealand. New Zealand: AGM Publishing.

Fig. 2.3.4 (1990). Architecti model [Photograph]. In Architecture New Zealand. New Zealand: AGM Publishing.

Fig. 2.3.5 (1990). Cardinal-TSE model [Photograph]. In Architecture New Zealand. New Zealand: AGM Publishing.

Fig. 2.4.1 (1992). Harbour Park [Render]. In Arcbitecture New Zealand. New Zealand: AGM Publishing.

Fig. 2.5.1 (1998). Exhibtion Conceptial Plan [Sketch]. In Architecture New Zealand. New Zealand: AGM Publishing.

Fig. 2.5.2 (1998). Artist's impression of atrium space [Sketch]. In Architecture New Zealand. New Zealand: AGM Publishing.

Fig. 4.1.2.1-3 Philips, Christian. (2016). Chicago Riverwalk Expansion [Photograph]. Retrieved from http://www. landezine.com/index.php/2016/07/chicago-riverwalk-expansion-by-sasaki/Winston, Anna. (2014).

Fig. 4.1.3.1-3 The High Line public park [Photograph]. Retrieved from https://www.dezeen.com/2014/11/03/ elizabeth-diller-ricardo-scofidio-interview-high-line-new-york/ 
Fig. 4.1.4.1-3 Davila, Rodrigo. (2014). University of Los Andes Public Space and Integrated Care Centre [Photograph]. Retrieved from https://www.archdaily.com/571585/university-of-los-andes-public-space-andintegrated-care-center-daniel-bonilla-arquitectos

Fig. 4.1.5.1-3 Poli,Filippo. (2015). Undurraga Devés Arquitects[Photograph]. Retrieved from https://worldarchitecture. org/architecture-news/cceeh/undurraga-devs-arquitects-designed-a-fully-structural-framework-forchilean-pavilion-expo-milano-.html

Fig. 4.1.6.1-3 Hill, Dan. (2008). State Library of Queensland [Photograph]. Retrieved from https://www.flickr.com/ photos/cityofsound/sets/72157603541698538/

Fig. 4.1.7.1-3 BIG. (2015). BIGproposes a new high-riseforFrankfurt [Render]. Retrieved from https://worldarchitecture. org/architecture-news/cccpc/big-proposes-a-new-high-rise-for-frankfurt-city-center.html

Fig. 4.1.8.1-3 Larsen, Signe Find. (2014). Floating structure by White Arckitekter [Photograph]. Retrieved from https:// www.dezeen.com/2014/07/29/hasle-harbour-bath-swimming-white-arkitetker-denmark/

Fig. 4.1.9.1-3 Groehn, Florian. (2015). The Goods Line [Photograph]. Retrieved from http://www.landezine.com/ index.php/2015/10/the-goods-line-by-aspect-studios/

Fig. 4.1.10.1-3 Zahry Architects. (2012). Netanya City Hall Proposal [Render]. Retrieved from https://www.archdaily. com/214246/netanya-city-hall-proposal-zarhy-architects

Fig. 4.4.2.1 Busch, Jason. (Unknown). Native Approach [Photograph]. Retrieved from https://www. peterfudgegardens.com.au/blog/native-approach

Fig. 4.4.2.2 Busch, Jason. (Unknown). Urban Bush Setting [Photograph]. Retrieved from https://www. peterfudgegardens.com.au/our-gardens/urban-bush-setting

Fig. 4.4.2.3 Fastenaekens, Gilbert. (2013). New wing of the Charleroi Museum of Photography [Photograph]. Retrieved from https://www.yellowtrace.com.au/trees-in-interior-design/

Fig. 4.4.2.4 Urban Petranovic. (2014). University Building BGG, Zagreb competition entry [Render]. Retrived from http://bevkperovic.com/?id=1,0,125,1912

Fig. 4.4.2.5 Gollings, John. (2011). Searle $x$ Waldron Architecture's first built project [Photograph]. Retrieved from https://architectureau.com/articles/Risk-2015-More-risk-please/\#img=1

Fig. 4.4.2.6 Elliot + Elliot Architecture. (2018). Spa in a Quarry [Photograph]. Retrieved from https:// mainehomes.com/2018-maine-homes-design-awards/

Fig. 4.4.2.7 Saudargaite, Ieva. (2015). Seikh Nahyan Centre for Arabic Studies [Photograph]. Retrieved from https://www.archdaily.com/878278/sheikh-nahyan-centre-for-arabic-studies-andintercultural-dialogue-fouad-samara-architects

Fig. 4.4.4.1 Van Valkenburgh, Michael. (2002). Allegheny Riverfront Park. [Photograph]. Retrieved from http:// www.mvvainc.com/project.php?id=5

Fig. 4.4.4.2 Basic, Nikola. (2005). Sea Organ [Photograph]. Retrieved from https://www.inspirock.com/croatia/ zadar/sea-organ-morske-orgulje-a887176067

Fig. 4.4.4.3 [Screenshot from Google Maps]. (2018). Retrieved from https://www.google.com/maps/@41.287684,174.7794142,3a,75y,356.05h,92.62t/data=!3m6!1e1!3m4!1s4tTeO4RIlamBAgEqT59L7Q !2e0!7i13312!8i6656 
Fig. 4.4.4.4 Forrec. (2018). Playground \& Interpretive Supergraphic [Render]. Retrieved from https://

d3fpllf1m7bbt3.cloudfront.net/sites/default/files/media/browser/2017-08-22/design-proposalforrec-design.pdf

Fig. 4.4.4.5 LINK Landskap. (2015). Aker Brygge - the city floor [Photograph]. Retrieved from https://landezineaward.com/aker-brygge-the-city-floor/

Fig. 4.4.6.1 Frearson, Amy. (2014). High-altitude viewpoint [Photograph]. Retrieved from https://www.dezeen. com/2014/12/11/observation-deck-viewpoint-quilotoa-volcanic-crater-lake-ecuador-javier-merajorge-andrade-daniel-moreno/

Fig. 4.4.6.2 Julien De Smedt Architects. (Unknown). Faaborg Harbour Bath [Photograph]. Retrieved from https://julienlanoo.com/filter/sea/Faaborg-Harbour-Bathby-Julien-de-SmedtArchitectsFaaborg-Denmark

Fig. 4.4.6.3 Frearson, Amy. (2014). Wooden viewing platform [Photograph]. Retrieved from https://www.dezeen. com/2014/04/14/wooden-viewing-platform-latvia-river-daugava-didzis-jaunzems-jaunromansabele/

Fig. 4.4.6.4 Landezine. (2009). Marina Park [Photograph]. Retrieved from http://www.landezine.com/index. php/2009/10/marina-park-in-viladecans/

Fig. 4.4.8.1 Pegenaute, Pedro. (2009). New Headquarters for Environment Services [Photograph]. Retrieved from https://www.archdaily.com/62939/headquarters-of-the-environment-and-public-spacesmagen-arquitectos

Fig. 4.4.8.2 Spitz, Katherine. (Unknown). Formosa Park [Photograph]. Retrieved from https://www. gardendesign.com/pictures/katherine-spitz_243/\#6237

Fig. 4.4.8.3 Roth, Eric. (2005). Court Square Press Building [Photograph]. Retrieved from https://oliveryaphe. com/architecture/1848/landscaping-set-the-tone

Fig. 4.4.8.4 MTA Flickr. (2014). Pocket Park Oasis [Photograph]. Retrieved from https://inhabitat.com/nyc/ new-yorkers-can-now-enjoy-a-new-pocket-park-oasis-with-waterfall-in-midtown/

Fig. 4.4.10.1 Groehn, Florian. (2014). Pirrama Park [Photograph]. Retrieved from https://land8.com/howpirrama-park-saved-sydneys-harbor-from-residential-development/

Fig. 4.4.10.2 Grant Associates. (2017). Wulugul Walk [Render]. Retrieved from https://theurbandeveloper.com/ articles/barangaroo-south-public-space-urban-renewal-project

Fig. 4.4.12.1 New York City AIDS Memorial. (2012). AIDS Memorial Design [Render]. Retrieved from https:// worldlandscapearchitect.com/new-york-aids-memorial-update/\#.XHOunc8zZQI

Fig. 4.4.12.2 Turenscape. (2010). The Red Folding Paper in the Greenway [Photograph]. Retrieved from https://www. turenscape.com/en/project/detail/4554.html

Fig. 4.4.12.3 (2014). The Swiss touch in landscape architecture [Photograph]. Retrieved from https://www.mask9. com/node/151936

Fig. 4.4.12.4 (Unknown). Kitchen21 [Photograph]. Retrieved from https://www.archdaily.com/794566/the-beststudent-design-build-projects-worldwide-2016

Fig. 4.4.12.5 Bo, Shen. (2015). Flexible Landscape [Photograph]. Retrieved from https://www.archdaily. 
com/775968/flexible-landscape-goa-architects

Fig. 4.4.14.1 Kasugai, Kai. (2014). Bahnhoplats Aachen [Photograph]. Retrieved from https://www.archdaily. com/488779/reshaping-of-the-station-square-hh-f-architekten-hentrup-heyes-fuhrmann

Fig. 4.4.14.2 CMT. (2012). Signature Streetscape Gives Pedestrian Priority [Photograph]. Retrieved from http://www. cmtengr.com/project/georgia-street-improvements/

Fig. 4.4.14.3 Min Lim, Jae. (2013). Ergonomics Crosswalk [Render]. Retrieved from https://www.designboom. com/project/ergo-crosswalkergonomics/

Fig. 4.4.16.1 PWL Partnership. (2014). Glen Park [Photograph]. Retrieved from http://www.pwlpartnership. com/our-portfolio/parks-plazas/glen-park

Fig. 4.4.16.2 RSAK. (2018). Vitula Boulevards [Photograph]. Retrieved from http://www.landezine.com/index. php/2018/02/vistula-boulevards-by-rs-architektura-krajobrazu/

Fig. 4.4.16.3 Jones, Christopher Frederick. (2014). Fitrgibbon Chase's Chibur park [Photograph]. Retrieved from https://architectureau.com/articles/north-lakes-and-fitzgibbon-chase/\#img=5

Fig. 4.4.16.4 Turenscape. (2013). The Bridge Gardens [Photograph]. Retrieved from https://www.trendhunter. $\mathrm{com} /$ trends/bridge-gardens-by-turenscape

Fig. 4.4.18.1 Shengliang, Su. (2013). Huaxin Business Centre [Photograph]. Retrieved from https://visuall. net/2013/12/21/huaxin-business-center-by-scenic-architecture-office/

Fig. 4.4.18.2 Shengliang, Su. (2013). Vector Architects concieve Vamke Centre as an ocean-viewing platform [Photograph]. Retrieved from https://www.designboom.com/architecture/bayuquan-vanke-exhibition-centrevector-architects-12-28-2014/

Fig. 4.4.18.3 Franz Reschke Landschaftsarchitektur. (2015). Space Manufaktur 2nd phase competition entry [Render]. Retrieved from http://afasiaarchzine.com/2015/10/raummanufaktur/

Fig. 4.4.18.4 Siplane, Martin. (2012). Baltic Film and Media School [Photograph]. Retrieved from https://salto.ee/ projects/baltic-film-and-media-school/

Fig. 4.4.18.5 Foster + Partners. (2017). Apple Park Visitor Centre [Photograph]. Retrieved from https://www. fosterandpartners.com/news/archive/2017/11/apple-park-visitor-center-opens-to-the-public/

Fig. 4.4.18.6 Ministry of Design. (2011). Vanke Triple V Gallery [Photograph]. Retrieved from https://archello. $\mathrm{com} /$ project/vanke-triple-v-gallery

Fig. 4.4.18.7 Kim, Chang Kyun. (2012). White Block Gallery [Photograph]. Retrieved from https://wwwarchdaily. com/204928/white-block-gallery-ssd

Fig. 4.4.20.1 Brenner, Marion. (2011). Peninsula Residence [Photograph]. Retrieved from https://www.asla. org/2011awards/018.html

Fig. 4.4.20.2 Yeung, Mike. (2016). M+ Pavilion [Photograph]. Retrieved from https://www.archdaily. com/876399/m-plus-pavilion-vpang

Fig. 4.4.20.3 Rojkind Arquitectos. (2013). Nestle Chocolate Museum [Photograph]. Retrieved from https://www. architravel.com/architravel/building/nestle-chocolate-museum/

Fig. 4.4.20.4 Page Duke. (2014). Crater Hill [Photograph]. Retrieved from https://www.pageduke.com/ 
portfolio/crater-hill/

Fig. 4.4.20.5 Surroca, Jordi. (2012). Extension of the Than School [Photograph]. Retrieved from http://www. batlleiroig.com/es/building/ampliacio-de-lescola-thau-sant-cugat/

Fig. 4.4.20.6 Edward, Bruce. (2013). Memorial Drive Landscape of Memory [Photograph]. Retrieved from http:// www.landezine.com/index.php/2015/04/memorial-drive-landscape-memory-poppy-plaza-marcboutin-landscape-architecture/

Fig. 4.4.20.7 Brenner, Marion. (2012). Geyserville Residence [Photograph]. Retrieved from http://acochran.com/ geyserville-residence/xpnkf9gyfhh6n3vmnrt5j3326qzt7y

Fig. 4.4.22.1 (Unknown). Roof Garden Ideas [Photograph]. Retrieved from https://greenestway.com/roofgardens-ideas/

Fig. 4.4.21.2 (Unknown). Reinterpreting Nature in Design [Photograph]. Retrieved from https:/ /www.designrulz. com/urban-benches-smart-city/

Fig. 4.4.21.3 Urbicus. (2014). Mont-Evrin Park [Photograph]. Retrieved from http://www.landezine.com/index. php/2014/07/mont-evrin-park-by-urbicus/

Fig. 4.4.21.4 Wiener, R. (2015). Fair Carree Nord [Photograph]. Retrieved from https://www.dnd.at/index.php?in $\mathrm{c}=$ projectSelection\&id=15:2076\&slide-1

Fig. 5.3.6.1 Rehwaldt.(2008). ULAP-Platz [Photograph]. Retrieved from https://www.rehwaldt.de/projektegalerie.php?lang $=$ en

Fig. 5.3.6.3 Wernsing, Franziska. (2018). The Dirty Boar [Photograph]. Retrieved from https://us.ritcheylogic. com/us_en/blog/eight-great-gravel-bike-events-in-europe/

Fig. 5.3.6.5 Turtle, Michael. (2017). Skogskyrkogarden [Photograph]. Retrieved from https://www.timetravelturtle. com/skogskyrkogarden-woodland-cemetery-stockholm-sweden/

Fig. 5.3.6.6 Kok, Pedro. (2006). House of Dr. Jung [Photograph]. Retrieved from https://www.archdaily. com/81472/house-of-dr-jung-at-the-kroller-muller-sculpture-garden

Fig. 6.2.8.1 jacqui-nz. (2016). Puriri moth/weta high-rise apartments [Photograph]. Retrieved from https:// inaturalist.nz/observations/3237473

Fig. 6.2.8.2 Sullivan, Jon. (2012). Putaputaweta [Photograph]. Retrieved from https://inaturalist.nz/ observations $/ 946317$

Fig. 6.11.3.1 tunesm1th. (2019). ITAP of a beach in Washington [Photograph]. Retrieved from https://www.reddit. $\mathrm{com} / \mathrm{r} /$ itookapicture/comments/aookxq/itap_of_a_beach_in_washington/

Fig. 6.11.3.2 jacqui-nz. (2016). Puriri moth/weta high-rise apartments [Photograph]. Retrieved from https:// inaturalist.nz/observations/3237473

Fig. 6.11.3.3 (Unknown). Putaputaweta [Photograph]. Retrieved from https://inaturalist.nz/taxa/341690Carpodetus-serratus/browse_photos

Fig. 6.11.3.4 Te Papa. (2008). Mountain five-finger [Photograph]. Retrieved from https:// collections.tepapa.govt. $\mathrm{nz} /$ object/904510

Fig. 6.11.3.5 Kauri Park. (Unknown). Hebe stricta [Photograph]. Retrieved from https://www.kauriparknurseries. 
co.nz/plants/hebe-stricta-koromiko/

Fig. 6.11.4.1-4 (Texture downloaded from textures.com)

Fig. 6.11.4.5 Te Papa. (2010). Kowhai [Photograph]. Retrieved from https://collections.tepapa.govt.nz/ object $/ 1448390$ 